
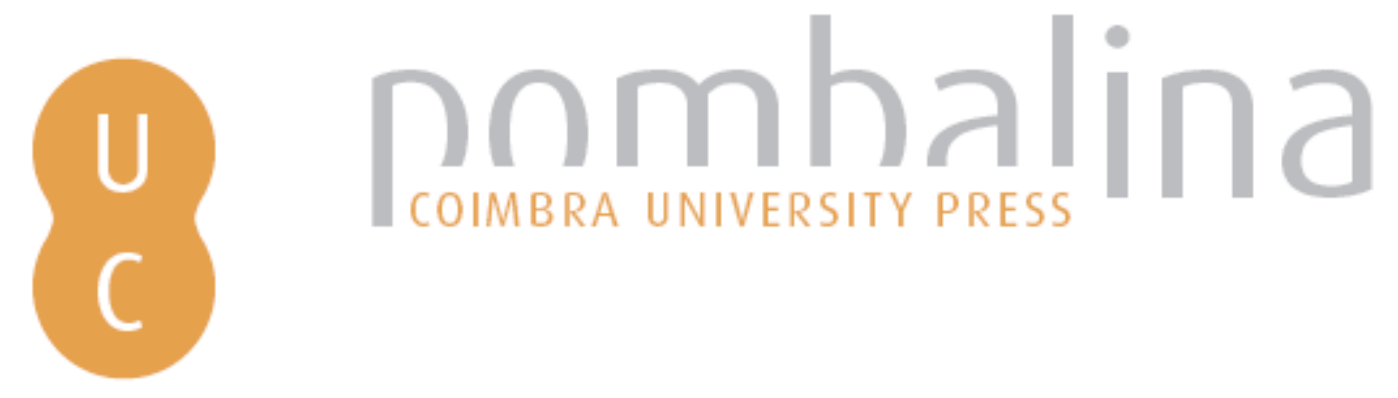

\title{
Proceedings of Maintenance Performance Measurement and Management (MPMM) Conference 2014
}
Autor(es):
Farinha, José Torres; Galar, Diego
Publicado por:
Faculdade de Ciências e Tecnologia da Universidade de Coimbra,
Departamento de Engenharia Mecânica; Imprensa da Universidade de Coimbra

URL persistente:

URI:http://hdl.handle.net/10316.2/33309

DOI:

DOI:http://dx.doi.org/10.14195/978-972-8954-42-0

Accessed : $\quad$ 26-Apr-2023 13:04:49

A navegação consulta e descarregamento dos títulos inseridos nas Bibliotecas Digitais UC Digitalis, UC Pombalina e UC Impactum, pressupõem a aceitação plena e sem reservas dos Termos e Condições de Uso destas Bibliotecas Digitais, disponíveis em https://digitalis.uc.pt/pt-pt/termos.

Conforme exposto nos referidos Termos e Condições de Uso, o descarregamento de títulos de acesso restrito requer uma licença válida de autorização devendo o utilizador aceder ao(s) documento(s) a partir de um endereço de IP da instituição detentora da supramencionada licença.

Ao utilizador é apenas permitido o descarregamento para uso pessoal, pelo que o emprego do(s) título(s) descarregado(s) para outro fim, designadamente comercial, carece de autorização do respetivo autor ou editor da obra.

Na medida em que todas as obras da UC Digitalis se encontram protegidas pelo Código do Direito de Autor e Direitos Conexos e demais legislação aplicável, toda a cópia, parcial ou total, deste documento, nos casos em que é legalmente admitida, deverá conter ou fazer-se acompanhar por este aviso.

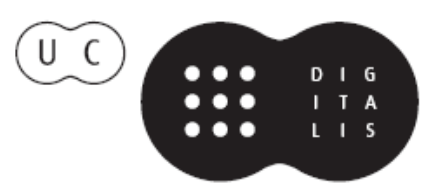




\section{FICHA TÉCNICA}

Title Proceedings of Maintenance Performance Measurement and Management (MPMM) Conference 2014

Authors José Torres Farinha; Diego Galar

Edition FCTUC-DEM

Design MPMM 2014

ISBN 978-972-8954-42-0

DOI http://dx.doi.org/10.14195/978-972-8954-42-0 
The Maintenance Performance Measurement and Management Conference 2014 represents a forum where the academics and professionals converge to discuss the state-of-the-art of the conference topics and the future trends for those topics that are the following ones: Maintenance performance and measurement (Efficiency, effectiveness, productivity; Life Cycle Cost optimization; Quality, risk and maintenance services; International Standards and Certification); Maintenance technology and management (Maintenance management systems; Condition monitoring and prediction; E-maintenance; Maintenance tools and innovations; Performance measurement); Maintenance trends (New Technologies; Re-engineering maintenance process; Maintenance logistics; Maintenance around the world).

University of Coimbra together with Lulea University, Sunderland, Lapperanta and Oulu constitute a network of research centers actively involved in maintenance research and developing MPM methodologies and technologies in close cooperation with international organizations like EFNMS and SMRP. Moreover the dissemination of maintenance research in doctoral thesis, education programs, conference and journals is a relevant contribution from universities and research centers. These activities are needful in order to place maintenance in the position that deserves in the international arena due to its huge importance and impact on the industrial economy.

The competitiveness of the organizations is each time more and more dependent on the optimization of Life Cycle Cost (LCC) of its physical assets. The maintenance costs of these represent, in industry: 5 to $20 \%$ of value added; 5 to $12 \%$ of capital invested; 1 to $15 \%$ of gross sales; 3 to $10 \%$ of production costs. In hospitals they represent, in average, $10 \%$ of the initial investment.
These are strong reasons to emphasize the importance of maintenance, in particular, and the LCC in general.

Maintenance field per si, and all its strands represent very difficult fields to manage and, probably, because of this, it corresponds to the last target variable managed that increase competitive advantages for the organizations. Approaches like on-condition maintenance, predictive maintenance, reliability, virtual reality, holography, certification, Key Performance Indicators, among others are only some of the many maintenance fields or, by other words, LCC fields that potentiate organizations to work better and win more money.

In fact, the most part of organizational areas have been rationalized and or optimized along time, but the maintenance had been left behind, because it is difficult to manage due involving many variables to conjugate simultaneously. Having as objective the unstoppable organization competitiveness, the maintenance sector, finally, is the target of attention of industrial managers, giving more and more importance to the Maintenance Engineering.

The Maintenance Performance Measurement and Management Conference 2014 represents an academic and professional place to discuss all those aspects, in which all experts see on MPMM2014 the privileged forum to upgrade their knowledge and share their research and experience with other colleagues. Additionally, it is a forum that permits to construct a referential repository of all subjects discussed in this Conference for all interested to add value for its future developments in their activities.

The committees in general, chairpersons, scientific, and local committee thank to all participants, speakers, keynote speakers, sponsors, and partners the efforts and commitment for the success of MPMM2014.

José Torres Farinha, Chairman International Scientific Committee

Diego Galar, Chairman International Scientific Committee

Luís Andrade Ferreira, Chairman Local Organizing Committee

Inácio Fonseca, Chairman Local Organizing Committee 


\section{COMMITTEES}

\section{CHAIRPERSONS}

- José Torres Farinha, Chairman International Scientific Committee;

- Diego Galar, Chairman International Scientific Committee;

- Luís Andrade Ferreira, Chairman Local Organizing Committee;

- Inácio Fonseca, Chairman Local Organizing Committee.

\section{INTERNATIONAL SCIENTIFIC COMMITTEE}

- Aditya Parida, Luleå University of Technology, Sweden;

- Altino Loureiro, CEMUC, Portugal;

- Andrew Jardine, University of Toronto, Canada;

- Benoit Iung, University Henri Poincaré-Nancy, France;

- Carlos Cabrita, UBI, Portugal;

- Carlos Gonçalves, Grupo Portucel Soporcel, Portugal;

- Carlos Guedes Soares, Technical University of Lisbon, Portugal;

- Christer Olsson, Chairman, European Maintenance Assessment Committee, Sweden;

- Cristóvão Silva, CEMUC, Portugal;

- David Baglee, University of Sunderland, UK;

- Diego Galar, Luleå University of Technology, Sweden;

- Fernando Pimentel Lopes, ISEC, Portugal;

- Filipe Didelet Pereira, IPS, Portugal;

- Gopinath Chattopadhyay, Central Queensland University, Australia;

- Inácio Fonseca, CEMUC, Portugal;

- Jan Frånlund, Chairman of the Swedish Maintenance Society, UTEK, Sweden;

- Jay Lee, University of Cincinnati, USA;

- Jero Ahola, LUT Energy, Lappeenranta University of Technology, Finland;

- Joaquim Norberto Pires, CEMUC, Portugal;

- Jorge da Silva André, FCTUC, Portugal;

- José Lopes dos Santos, chairman of APMI, Portugal;

- José Sobral, ISEL, Portugal;

- José Torres Farinha, CEMUC, Portugal;

- JP Liyanage, Stavanger University, Norway;

- Juhani Ukko, Lahti School of Innovation, Lappeenranta University of Technology, Finland;

- Lourival Tavares, Unión Panamericana de Asociaciones de Ingenieros;

- Luís Andrade Ferreira, Oporto Engineering Faculty, Portugal;

- Luis Berges, Director of Manufacturing Engineering department, Zaragoza, Spain;

- Marco Garetti, Politecnico di Milano, Italy;

- Pedro Coelho, Grupo Portucel Soporcel, Portugal;

- P-O Larsson Kråik, Trafikverket, Luleå University of Technology, Sweden;

- Raj BKN Rao, Editor-in-Chief, COMADEM International, UK;

- Salih O. Duffuaa, King Fahd University of Petroleum and Minerals, Saudi Arabia;

- Timo Kärri, Industrial Engineering and Management, Lappeenranta University of Technology, Finland;

- Tuomo Kässi, Industrial Engineering and Management, Lappeenranta University of Technology, Finland;

- Uday Kumar, Luleå University of Technology, Sweden;

- Ville Ojanen, Industrial Engineering and Management, Lappeenranta University of Technology, Finland;

- Viriato Marques, ISEC, Portugal.

\section{LOCAL ORGANIZING COMMITTEE}

- Hugo Raposo, CEMUC, Portugal;

- Rúben Oliveira, CEMUC, Portugal;

- Pedro Neves, Portugal 


\section{SUPPORTING}

\section{INSTITUTIONAL PARTNERS}

- Centro de Engenharia Mecânica da Universidade de Coimbra - CEMUC

- Assosiação Portuguesa de Manutenção Industrial - APMI

\section{SPONSORS}

- SEW Eurodrive

- Primavera BSS

\section{PARTNERS}

- Revista Manutenção

- Tecno Hospital

- Câmara Municipal de Coimbra

- Hotel Quinta das Lágrimas

- Hotel Tivoli - Coimbra

- Notícias de Coimbra

- Coimbra 2 Margens

- Novotecna

- Fablab Coimbra

- NE2000 


\section{INDEX}

1

Keynote sessions

\section{CONDITION MONITORING AND PREDICTION}

3 Maintenance conceptual models and their relevance in the development of maintenance auditing tools for school buildings' assets - an overview Ana C. V. Vieira; A. J. Marques Cardoso

11 Real Time Data Collection and Processing For Aircraft Maintenance Enhancement (REACT) Joel Ferreira; Luís Oliveira; Rúben Oliveira

15 Selection of instances in Condition Based Monitoring: The case of aircraft engines Leonor Fernandes; Roberto Henriques; Victor Lobo

21 FMECA Analysis for the Assessing of Maintenance Activity for Power Transformers Mohamed Khalil; Loredana Cristaldi; Marco Faifer

27 Exploring the condition-based maintenance opportunities for production-critical assets Nii Nortey Lokko; Jawad Raza; Tore Markeset; Sukhvir Singh Panesar

35 Predictive Maintenance! To do or let Die

Pedro Dias, José Torres Farinha, Inácio Fonseca, Jorge Cunha

\section{LIFE CYCLE COST OPTIMIZATION}

41 Time Replacement Optimization Models for Urban Transportation Buses with Indexation to Fleet Reserve

Hugo Raposo; José Torres Farinha; Rúben Oliveira; Luís Andrade Ferreira; Jorge André

49 Life Cycle Cost Optimization through an Asset Management based on Risk Principles João Santos; Hugo Barata; Hélio Cordeiro; Cristina Mendonça; José Sobral

57 Better maintenance decision making in business networks with a LCC model Tiina Sinkkonen; Antti Ylä-Kujala; Salla Marttonen; Timo Kärri

\section{MAINTENANCE TOOLS AND INNOVATIONS}

65 A Control System Approach to Optimal Maintenance Planning for Building Retrofitting Project Bo Wang; Xiaohua Xia

73 Advanced 3D Scan Data Analysis for performant Reengineering Maintenance Processes Hendrik Grosser; Rainer Stark

81 Augmented Reality and the Future of Maintenance

Rúben Oliveira; José Torres Farinha; Hugo Raposo; Noberto Pires

\section{E-MAINTENANCE}

89 Maintenance Support Wireless System for Ram of Forming Presses Diego Salazar; Gerardo Glorioso; Markus Wabner; Martin Riedel

95 Maintenance Management in Web ASP.NET MVC Applications Francisco Rodrigues; Inácio Fonseca; Rúben Oliveira; José Torres Farinha

103 Mobile Applications and its Potential to Maintenance Hugo Santos; António Simões; Inácio Fonseca; José Torres Farinha 


\section{PERFORMANCE MEASUREMENT}

111 Maintenance Strategies to Reduce Downtime Due to Machine Positional Errors Abubaker Shagluf; A. P. Longstaff; S. Fletcher

119 Replacement time of mining drilling rigs Hussan Hamodi; Jan Lundberg

125 Maintenance Continuous Performance Assessment of a Hospital Operating Room AVAC System Rui Assis

131 Lean Maintenance

Bruno Inácio

\section{MAINTENANCE MANAGEMENT SYSTEMS}

137 CMMS - An integrated view from maintenance management to on-line condition monitoring José Torres Farinha; Inácio Fonseca; Rúben Oliveira; Hugo Raposo

143 Practical challenges in determining periodic maintenance intervals on the Norwegian Continental Shelf (NCS): Some expert views and opinions

Nii Nortey Lokko; Jawad Raza; Tore Markeset; Sukhvir Singh Panesar

149 Hoshin kanri: a strategic approach to maintenance performance management Peter Chemweno; Liliane Pintelon; Peter Muchiri

\section{INTERNATIONAL STANDARDS AND CERTIFICATION}

157 Aggregation of electric current consumption features for extraction of maintenance KPIs Carl-Anders Johansson; Victor Simon; Diego Galar

163 (Legal) Maintenance Plan for building's energy performance Marimba da Costa; José Torres Farinha; Inácio Fonseca; António Simões

171 Bottom to top approach for railway KPI generation Roberto Villarejo; Carl-Anders Johansson; Urko Leturiondo; Victor Simon; Diego Galar

\section{QUALITY, RISK AND MAINTENANCE SERVICES}

179 Creating an open-books -supported implementation framework for inter-organizational decision-making models in the industrial maintenance context Antti Ylä-Kujala; Salla Marttonen; Tiina Sinkkonen; Timo Kärri

189 Improving risk matrices using the MACBETH approach for multicriteria value measurement Carlos A. Bana e Costa; Diana F. Lopes; Mónica D. Oliveira

197 Risk-based Maintenance: Relationship between the risk and the environment of operation J. F. D. Santos; J. M. F. Calado; A. A. Roque

205 Risk Management based on the Assessment of Safety Barriers José Sobral; Carlos Guedes Soares

213 Incorporating Carbon Penalties into Supplier Selection in the Supply Chain Kanika Gandhi; Diego Galar; P. C. Jha

221 Reliability Analysis on Crucial Subsystems of a Wind Turbine through FTA Approach S. Katsavounis; N. Patsianis; E.I. Konstantinidis; P.N. Botsaris 
(Página deixada propositadamente em branco) 


\section{KEYNOTE SESSIONS}

Big data and MPM: A new maintenance era powered by ISO 55000 Diego Galar

Value Driven Maintenance - Discover the Hidden Value in Your Maintenance Organization Mark Haarman

Some challenges in the mathematical and empirical research of the interdisciplinary dimensions of the maintenance function

Kari Komonen

What is the next "Big Bang" opportunity for maintenance management?

David Baglee

The Maintenance Strategies as essential tools for Risk Management António Costa Gonçalves

O\&M - Added value to Facility Management: A case study from KSA Shauquat Alam

Six Sigma Maintenance Scorecard Methodology and Case Study Carlos Cabrita 
(Página deixada propositadamente em branco) 


\title{
Maintenance conceptual models and their relevance in the development of maintenance auditing tools for school buildings' assets - an overview
}

\author{
Ana C. V. Vieira ${ }^{1}$; A. J. Marques Cardoso ${ }^{2}$ \\ avieira@ipt.pt; ${ }^{2}$ ajmcardoso@ieee.org \\ ${ }^{1}$ Polytechnic Institute of Tomar, Technological Superior School of Tomar \\ Tomar, Portugal \\ ${ }^{2}$ University of Beira Interior/ Faculty of Engineering/ Department of Electromechanical Engineering \\ Covilhã, Portugal
}

\begin{abstract}
Despite the importance of building and infrastructure maintenance and its role in cost control, savings in materials and life cycle enlargement of equipment and facilities, maintenance is often still regarded only as a disturbing factor which causes Public school infrastructures to often suffer from the negative effects of this philosophy.

It is important for managers to improve maintenance performance of school organizations, focusing on areas such as maintenance, building systems, safety improvements and technology, if possible anticipating problems and opportunities in time. To accomplish all of those goals, these organizations must be determined to manage their available resources effectively and to seek improvements for increasing efficiency.
\end{abstract}

In this context, and with the aim of characterizing the Portuguese situation concerning the age and preservation of both installations and fixed equipment of Educational Institutions, as well as their maintenance strategies and politics, maintenance auditing tools for school building assets were developed.

This paper presents an overview of maintenance conceptual models as well as a proposal for a maintenance conceptual model aimed at the Portuguese Educational Institutions.

The full version of this paper discusses the relevant role of maintenance conceptual models in the development of maintenance auditing tools and contains some results of a study regarding the Portuguese Educational Buildings.

Keywords - Maintenance management; Educational organizations, Maintenance strategies in asset management; Maintenance modelling and optimization; Maintenance audits.

\section{INTRODUCTION}

The resources dedicated to maintenance and operation of school building infrastructures come mainly from the state budget. Since education is one of the sectors that most absorb resources, it is becoming more and more important to improve its efficiency $[1,2]$. In fact, financial constraints usually result in reduced maintenance and operation budgets and Public schools' infrastructures often suffer from the negative effects of this philosophy, presenting in some cases early signs of disrepair and neglect generally as the result of the priority on allocating funds to items that directly affect education [3].

Equipment that is in poor condition may interfere not only directly in the economics of the organizations, but also in the reduction of the overall availability of buildings while simultaneously interfering with the occupants' safety. This is why both installations and equipment associated with the operation of school organizations must be kept in good conditions $[3,4]$.

It is important for managers to improve maintenance performance of educational facilities, focusing on areas such as maintenance, building systems, safety improvements and technology, if possible anticipating problems and opportunities in time. To accomplish all of these goals, educational and teaching organizations must be determined to manage their available resources effectively, and to seek improvements for increased efficiency. At the same time it's vital that they implement a regularly scheduled detailed maintenance plan for all assets [5].

In this context, a study was developed regarding the Portuguese Educational Institutions' maintenance management and organization. This paper contains some results of the study mentioned above. It identifies some areas needing improvements, as well as the suggestions made to improve maintenance efficiency, regarding management decision making and strategies employed in maintenance management.

With the aim of characterizing the Portuguese situation concerning the age and preservation of both installations and fixed equipment of Educational Institutions, human and material resources management, as well as their maintenance strategies and politics, maintenance auditing tools for school buildings assets were developed, with the purpose of collecting all the aforementioned information. Some results of the analysis carried out to the gathered global data are described. In addition to the outcomes of the global analysis performed to the collected data, the results of more specific analysis are also mentioned, according to the different levels of education. 
Considering the complexity of the Educational System, there is an obvious need to review management and administration models, applying the principles of the Educational System Foundation Law published in 1986, in particular the principle of institutional autonomy [2, 3, 6-11].

Considering the relevant role of maintenance conceptual models in the development of maintenance auditing tools, this paper presents also an overview of maintenance conceptual models as well as a proposal for a maintenance conceptual model for Portuguese Educational Institutions and a school model that had supported the maintenance auditing tools' development.

\section{REFERENCES TO PORTUGUESE EDUCATIONAL FACILITIES MAINTENANCE}

Within organizations, maintenance strategies must result from the consensus and from a clear coordination between those responsible for managing the organization and those responsible for its assets' maintenance management and organization. Despite this, in teaching establishments the options concerning maintenance have been independent from the organization management within the educational system [3, 7-13].

The Portuguese Educational System Foundation Law, published in 1986, states that the dimensions of educational facilities must provide the possibility of receiving a reasonable number of students, in order to guaranty the necessary conditions for a good pedagogical practice and to promote a true school community. Simultaneously, the management of spaces, installations and equipment, human and material resources, as well as financial and administrative management, should contribute to the educational and academic success of each student [7]

The Portuguese Educational System Foundation Law also states that the construction and maintenance of buildings and equipment of the public school network, across the country, should be based on a policy that clearly defines the competencies for every stakeholder and that guarantees the availability of the necessary resources $[7,9,12,13]$.

In addition, the Portuguese Educational System Foundation Law stipulates that Governmental Bodies should develop " $a$ contingency plan for construction and rehabilitation of school buildings and their equipment, in the sense that the needs of the school system are met, giving priority to basic education" [7, 9].

As regards the Educational System, the legislation published in Portugal is vast, but the reference to issues related to maintenance management and organization of school buildings is vague and sometimes even non-existent. The exceptions that could be found were exclusively oriented towards the assets assigned to preschool, elementary and secondary levels of education [3, 7-17].

Several studies concerning the Educational System have been carried out in Portugal. However, by the end of the twentieth century, the developed and published studies were almost exclusively dedicated to Primary, Preparatory and Secondary schools, and until 2006 they were focused on areas such as pedagogy, politics and administration $[3,14]$. In fact, the importance of the buildings' structure and equipment maintenance management and organization was far from being effectively recognized as a key element in the mission statements of the Portuguese school boards.

Until the beginning of the twenty first century, among the publications of the Portuguese Board of Education, a few consider the operational area of educational organizations and hardly any were found focusing on the importance of maintenance in educational facilities. As an exception the "Schools Operation, Maintenance and Safety Handbook" (MUMSE) may be emphasized, it is a 2003 reissue of the "Schools Maintenance and Utilization Handbook" earlier published in 2000 [12, 13].

Those publications were presented as informative documents, suggesting that "(...) each school board should develop its own operation, maintenance and security manual (...)" considering each building constructive characteristics as well as the installed equipment. They intended to raise awareness among school boards, and users in general, to the importance of preventing accidents, planning for safety and security. They also called the attention to the preservation of health conditions of buildings and equipment, as well as to the protection and preservation of their technical installations, and furniture [12-14]. The MUMSE suggests that when commissioning and at the acceptance of assets, namely of buildings and equipment, the management bodies of educational or teaching establishments"(...) should be handed over a set of elements that constitute an authentic operation, maintenance and safety handbook" [12-15].

Since the early years of this century, the market of building maintenance and rehabilitation has been experiencing a significant evolution and the growing importance of that market led to a significant number of national publications, as well as to a vast legislation regulating such activity. For example, the new regulation on energy efficiency of indoor airconditioning systems in buildings, transposed into the Portuguese Legislation in 2006, also requires regular monitoring of maintenance practices over HVAC systems, not only as a condition of energy efficiency, but also to ensure the indoor air quality in buildings [16].

Although some parallels may be established, the specificity of the Educational System does not always allow documentation to be suitable to the reality of educational facilities. The educational establishments' maintenance policy reflects the general scenario described for buildings' maintenance, it is also the result of the evolution of the Portuguese Educational system over the last four decades, since the objectives defined for the educational system development have direct implications in the school assets preservation [3, 7-15]

The involvement of the central political authorities allowed the change of the described scenario up until 2006. Over recent years, it has been possible to find more publications, whether directly or indirectly related to the maintenance of educational 
facilities, even though almost all of them were still devoted to non- higher education establishments.

In 2006, the political power recognized "the progressive deterioration that over the past decades has been observed in the state of preservation of secondary schools, despite of all the initiatives that casuistically have been implemented in terms of facilities maintenance". It was also acknowledged that those casuistic initiatives "have always been implemented sporadically, consubstantiating forms of superficial approach and only to meet specific needs felt in each educational establishment" $[3,11]$

Established in 2007, the "Parque Escolar, E.P.E." provides technical documentation in the form of accounting reports, reports of service quality, sustainability reports and several manuals. These documents make reference to the maintenance of educational facilities and equipment and it is stated that the "solutions presented during the design phase should always consider three factors: initial cost, maintenance cost and operational cost" [17].

It is acknowledged that the "balance of those three vectors preconizes the best solution for design and execution". The school buildings operating costs are referred to be dependent on the installed equipment, reason why it is stated that the installed equipment must be "not only robust in its operation but also in its use resistance, to the environment and in some situations, vandalism, without unreasonable increasing of the installation costs" [18] .

The Portuguese Court of Auditors has been publishing multiple reports with observations and data about the planning, management, development and execution of the Parque Escolar, E.P.E. modernization plan for the public network of secondary schools and other educational establishments under the responsibility of the Ministry of Education. Despite the references to facilities, systems and equipment maintenance, referred to in legislation and other publications that have just been mentioned, the Court of Auditors' reports identify the need to devote more attention to issues directly related to the maintenance management and organization of school assets.

\section{MAINTENANCE CONCEPTUAL MODELS}

As new maintenance techniques have become available, and the economic implications of maintenance actions have been perceived, it would be expected a direct reflection on planning policies for maintenance activities and on maintenance strategies selection by organizations [19].

As a result of the developments in the area, maintenance management is no longer considered as a pure technical function, it has started to incorporate considerations of costbenefit. Business context issues related to the institutions, and their functional requirements also play an important role. Maintenance management should therefore cover operational issues (such as the planning of maintenance work), tactics (such as decisions relating to the maintenance policy to be adopted in the long-term) and strategic procedures (such as the acquisition of new facilities, design decisions and policies of human resource management) [19-21].

Such development in maintenance management incurs a sharp need for various techniques that would facilitate decision making in the context of assets maintenance management and organization, such as [19]:

- Statistical analysis tools for predicting equipment's failure behavior,

- Mathematical models to optimize the maintenance policy parameters (e.g. predetermined preventive maintenance frequency), decision criteria concerning e-maintenance decision aids for outsourcing decisions, etc.,

- Conceptual models and decision schemes for determining the more suitable maintenance concept.

In the sixties of the twentieth century, most of the publications in the area of maintenance were mathematically oriented and mostly focused on reliability. In the following decade and early eighties publications were more focused on maintenance policies optimization, including the optimization of preventive maintenance intervals, planning of group replacements and inspection modelling. Despite this evolution, the models presented at this stage were still often more focused on mathematical tools than on realistic assumptions and hypotheses. This caused an unfortunate gap between academics and practitioners in the area of maintenance, with practitioners considering the published models to be excessively theoretical $[19,20,22-24]$.

More recently, in addition to traditional maintenance models, there is an increasing number of publications devoted to the study of specific objects and the growing exploration of a more diverse range of models and concepts, such as maintenance strategy design models, concepts of remote maintenance, service parts supply policies and maintenance conceptual models. Simultaneously, there has been a greater acceptance of the scientific work performed by the practitioners in the field of maintenance [19, 20, 22-27].

\section{A. Overview of maintenance conceptual models}

Apart from the generic reference to conceptual models of asset management, publications can be found addressing the particular case of maintenance management models and others on the development and application of conceptual models, both in the business sector and in public institutions [23, 27-44].

Among the various proposals found, the conceptual models released by the Global Forum on Maintenance and Asset Management (GFMAM) and the European Federation of National Maintenance Societies (EFNMS) may be mentioned. Fig. 1 shows the conceptual model for assets management proposed by the EFNMS.

Maintenance conceptual models are based on the assets' life cycle, regardless of whether they are structures or fixed 
equipment, over several stages, from conception to the disposal of the asset, as shown in Table $1[3,21,43,45-47]$.

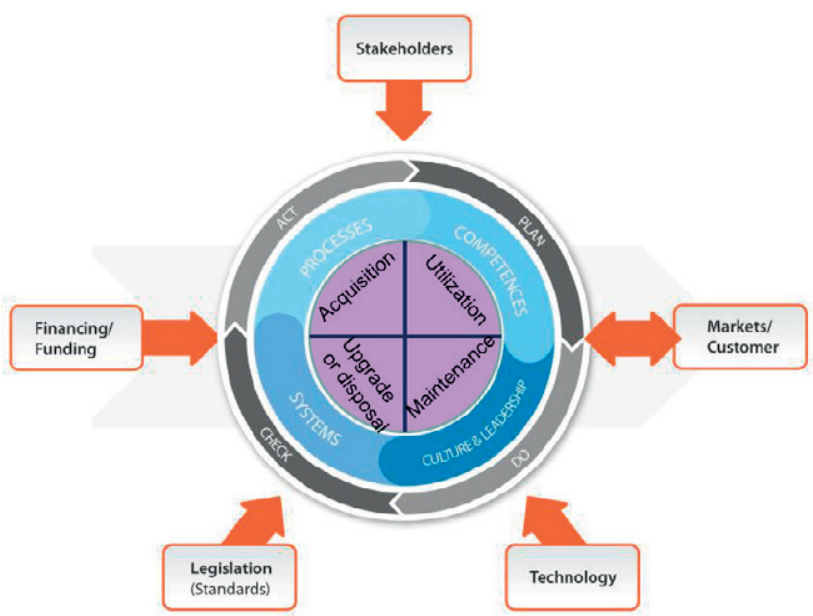

Fig. 1. EFNMS Conceptual model of asset management [42, 43].

TABLE I. StAGES IN THE LIFE CYCLE OF AN ASSET [3, 21, 43, 45-47].

\begin{tabular}{|l|l|}
\hline Life cycle Stages & \\
\hline Preparatory & $\begin{array}{l}\text { Conception and Designing } \\
\text { Manufacturing and Assembly } \\
\text { Procurement and Installation } \\
\text { Accepting and Commissioning }\end{array}$ \\
\hline Operational & Service \\
& Maintenance \\
& Promotion \\
& Planning \\
& Disposal \\
\hline
\end{tabular}

Generically, the investment associated with the acquisition of an asset is expected to be compensated for by the return generated by it. In the particular case of public institutions, such as public schools, the focus is not on the maximum possible profit, but in the optimization of the costs associated with the assets, although their performance should also be considered here as a way to ensure that the asset is able to meet the required functions [46]. On these assumptions, Mollentze presented a holistic model that is summarized in Fig. 2.

When modeling maintenance activities it should be considered its relationship with other areas that the organization considers relevant. This allows efficient solutions, with the possibility of cost control. In this scenario, it becomes important to define structured communication channels that allow sharing relevant information [36]. Based on a holistic view of maintenance, the model of Fig. 3 presents a proposal for a conceptual model regarding the information relevant for maintenance, also considering other activities and typical areas of business entities.

Several models have been developed with the aim of improving and optimizing the maintenance service. As a result of this, it has become clear that the definition of policies and strategies and the understanding of the efficiency and effectiveness of the maintenance department continues to present opportunities for improvement [19]. An effective and efficient Maintenance Management Model must place users and their needs at the center of the organization, abandoning the traditional options for using corrective or preventive strategies merely based on the assets condition analysis and on the available resources $[3,23,39]$.

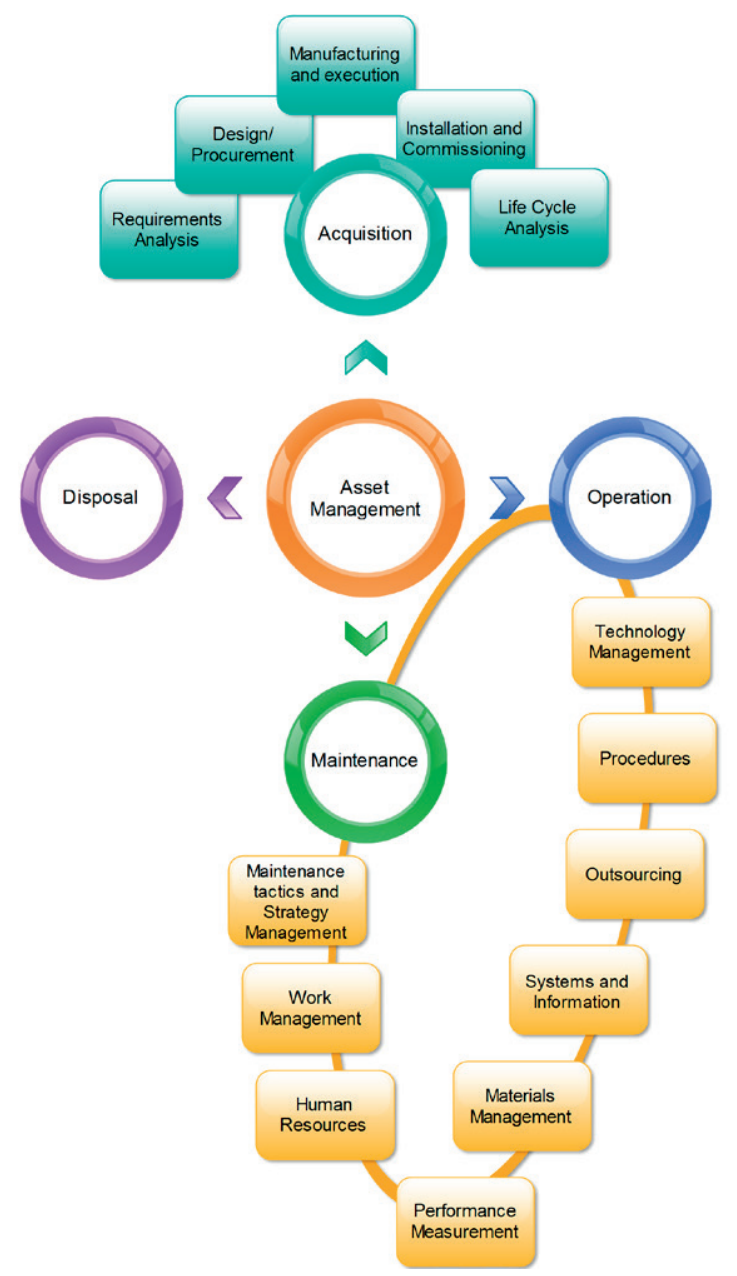

Fig. 2. High-level model for asset management and models/framework for Acquisition and Assets Operation and Maintenance [46]

\section{B. Proposal for a maintenance conceptual model for Portuguese Educational Institutions}

As mentioned before, the approach to maintenance management and organization in Portuguese Educational Institutions has been heavily dependent on financial constraints and on the buildings' state of disrepair. Maintenance management and organization decisions heavily dependent on these two factors tend to be not only damaging to the structures of the buildings, technical installations, engineering services and fixed equipment, but also to the establishment itself and to the assets. These scenarios are more expensive, and also lead to user dissatisfaction [39]. 


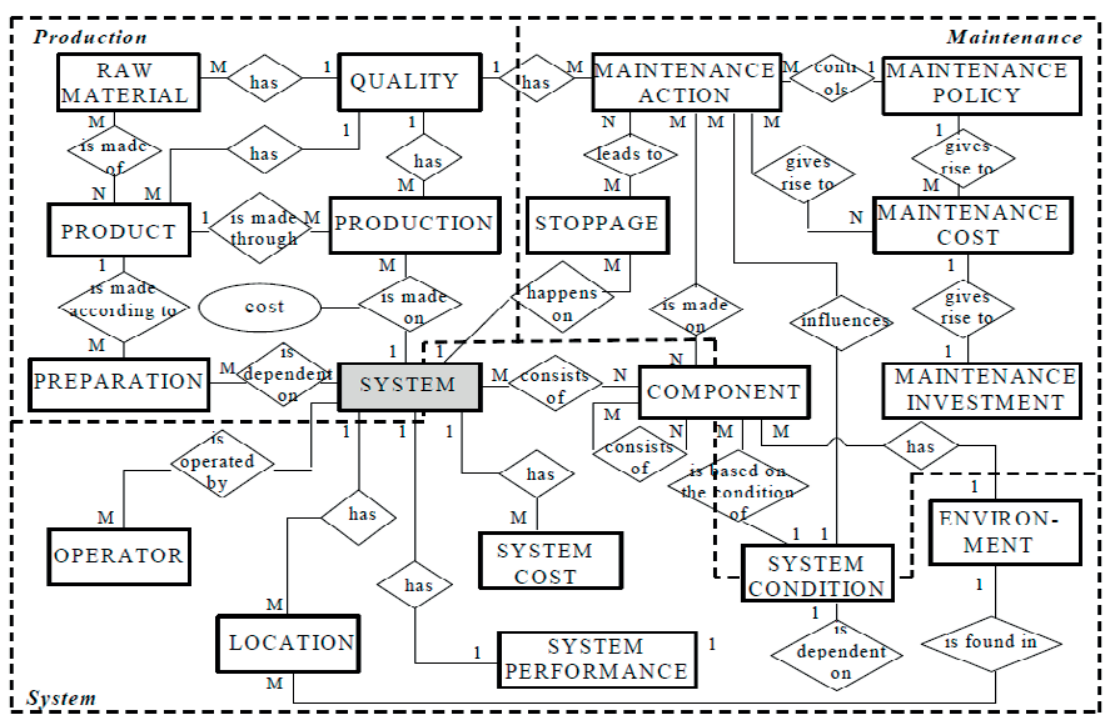

Fig. 3. Conceptual information model showing a holistic representation of maintenance [36].

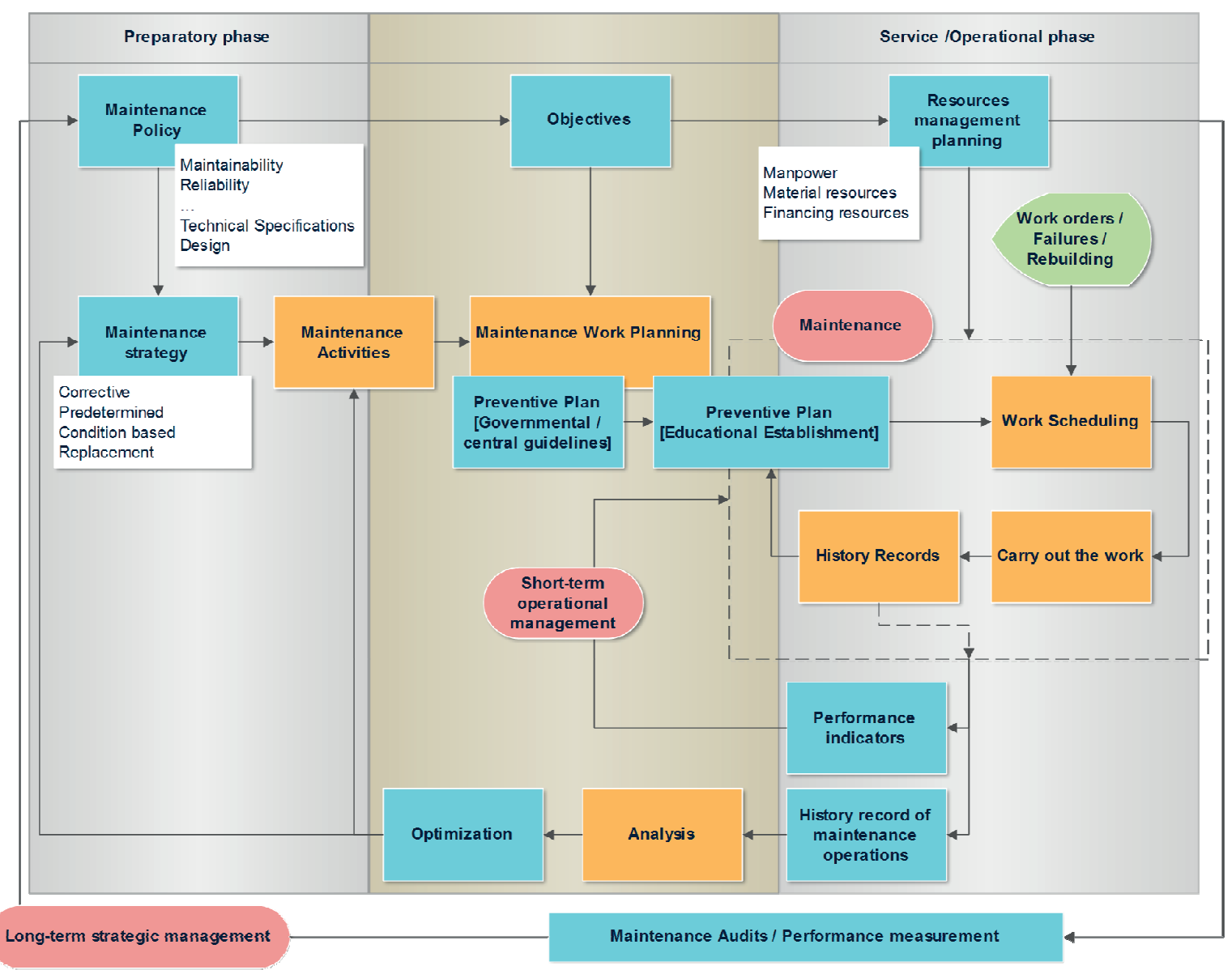

Fig. 4. Conceptual Maintenance Model sugested [3]. 


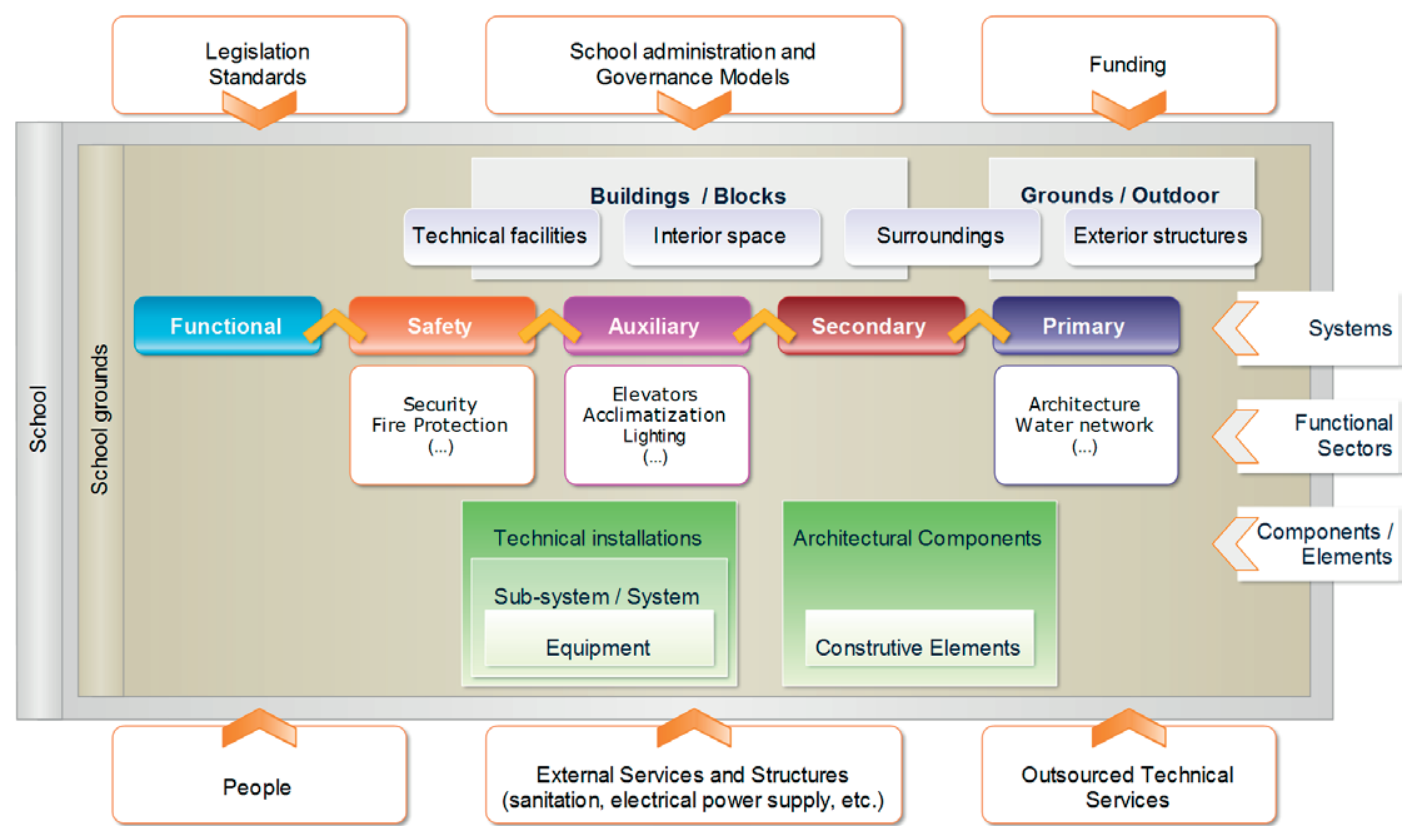

Fig. 5. School Model supporting the development of maintenance auditing tools for data collection [3].

Even though the Portuguese Educational System Foundation Law states that the school buildings need to ensure "conditions of a good pedagogical practice and the promotion of a true school community", the existence of an integrative maintenance management model for Portuguese school building assets is, however, unknown.

Based on the literature review, the framework and structure of the Educational System and on the successive Portuguese governance models, considering the related legislation and also publications in the area of maintenance management and organization, the conceptual maintenance model in Fig. 4 was developed. This conceptual model guided the methodology followed in the study mentioned here and also served as the basis for the development of suitable maintenance audit tools.

The conceptual model proposed in Fig. 4 reflects the concept that the compliance with operational requirements of the maintenance system (such as the maintenance planning) are dependent on tactical and strategic issues. Indeed, the preparatory phase involves the development of strategies for the acquisition of new facilities and fixed equipment in addition to the consideration of tactical issues, such as the definition of maintenance strategies, which naturally affect the identification of the maintenance work. It is important to note that each school is unique, so it is particularly important to adapt any central guidelines to each situation. Inevitably, the planning and scheduling of maintenance are also dependent on strategic decisions related to resources management policies, during the operational phase.

Work planning and scheduling are essential in any attempt to improve the process, since they allow the reduction of corrective work creating the possibility of implementing new practices which should be preventive in nature. Efficient structures allow the achievement of ratios of $80 \%$ for preventive maintenance work to $20 \%$ or less corrective maintenance, which allows one to explore new approaches and to implement more efficient practices [48].

The information concerning the operational phase will be essential for retrofitting decisions related to procedures or systems, both with regard to the short-term operational management and to the long-term strategy and underlying tactics.

\section{DEVELOPMENT OF MAINTENANCE AUDITING TOOLS}

Maintenance conceptual models explore the concept that improvements in maintenance management efficiency depend on a first evaluation phase, based on maintenance audits [46].

The specificity of the Portuguese several levels of education refers not only to pedagogical practices but also to spaces, installations and equipment policies management, human and material resources management, as well as financial and administrative management. It was decided to evaluate the situation for each level of education separately, not only in terms of maintenance management, but also regarding building characteristics, building systems, safety improvements and technology [3].

Since no survey of the Portuguese Educational System, referring to those areas in particular was available, several questionnaires have been developed, to be answered by each school board or institution responsible, with the aim of collecting information for later analysis. The developed questionnaires, were modelled according to the abovementioned specificity [3-5, 14, 15] 
It should be mentioned that the conceptual model followed in the development of auditing tools for data collection is based on the need to collect information about all the schools' assets according to the school model used to support the development of auditing tools for data collection displayed in Fig. 5. Simultaneously, it is focused on the framework of Maintenance and its relationship with resource planning associated with the operational phase, as indicated in Fig. 4.

\section{SOME RESULTS AND CONCLUSIONS}

As several models have been developed with the aim of improving and optimizing the maintenance service, it has become clear that the definition of policies and strategies and the understanding of the efficiency and effectiveness of the maintenance department continue to present opportunities for improvement. The process of improving maintenance in organizations heavily dependent on preventive maintenance strategies leads to improvements that are rarely immediate. In most cases, the transition does not present significant technical difficulties, but nonetheless the improvement due to choosing preventive maintenance strategies managed proactively can take from three to five years [48]. Indeed, it becomes necessary to change the organization's culture, namely the way according to which the same organization faces the maintenance function, which must be assumed as a central process [48].

An effective and efficient Maintenance management model must place users and their needs at the center of the organization, abandoning the traditional options for using corrective or preventive strategies merely based on the assets condition analysis and on the available resources.

In order to manage the available resources in an effective way, it is extremely important that educational organizations may have updated, detailed and accurate information about the buildings, their systems and equipment, and the way they are managed. In this scenario, maintenance audits provide a framework for organizations to systematically review, analyse and recommend improvements in maintenance management performance.

The results of the case study regarding the Portuguese secondary school buildings emphasise the need to develop periodic asset inspections, not only to verify their condition, but also as a support to establish retrofitting maintenance programs.

Not only school board administrations but also the authorities responsible for educational system management must be aware of the importance of school buildings' assets maintenance management and so training must be considered. On the one hand areas such as maintenance management and organization provide the indispensable technical support for planning and scheduling maintenance activities of the educational institutions. On the other hand the former provide the backing for inspection activities, reporting and analysis of the collected data. Additionally, team management, leadership and motivation are a valuable support for school managers to deal better with maintenance personnel.
Unquestionably, school buildings have special management needs but they also present unique development challenges in terms of new studies and applications. Simultaneously, school organizations may have a privileged influence both in individuals and in institutions.

\section{REFERENCES}

[1] Mateus, A.; "Economy - from Structural Adjustment to Growth Rethrowing" Cap. 1 in "To Reform Portugal - 17 Strategies to Change" (in Portuguese); edited by Tavares, L. V.; Mateus, A. and Cabral; F. S., Oficina do Livro; Portugal, 2003.

[2] Tavares; L. V.: "Education - From Growth to Development", Cap. 2 in "To Reform Portugal - 17 Strategies to Change" (in Portuguese); edited by Tavares, L. V.; Mateus, A. and Cabral; F. S., Oficina do Livro; Lisbon, 2003.

[3] Ana C. V. Vieira; "Maintenance Management and Organization in Educational Institutions" (in Portugese); PhD Theses; FCTUC, 2013.

[4] Vieira, A. C. V.; Cardoso, A. J. M.: "Maintenance Audit and Some Maintenance Management Improvements - A School Building Case Study"; International Journal of COMADEM, Vol. 16, No 3, pp. 47-57; July, 2013.

[5] Vieira, A. C. V.; Cardoso, A. J. M.; "The role of information logistics and data warehousing in educational facilities asset management"; International Journal of System Assurance Engineering and Management; Volume 1, Issue 3 - "eMaintenance Solutions and Technologies"; pp. 229-238; 2010; DOI: 10.1007/s13198-011-0042-0.

[6] Delgado, J. M.; Martins, E.; "Autonomy, Administration and Management of Portuguese Schools - 1974-1999" (in Portuguese); Prospective Evaluation and Planning Department of the Board of Education; Portugal, 2002.

[7] Law n. ${ }^{\circ} 46 / 86$ of October $14^{\text {th }}$; "Educational System Foundation Law" (in Portuguese); Diary of the Republic - I Series, n. ${ }^{\circ}$ 237, pp. 30683081; Portugal, 1986

[8] Law n. ${ }^{\circ} 108 / 88$ of September 24 $4^{\text {th }}$; "Universities Autonomy" (in Portuguese); Diary of the Republic - I Series, n. . 222, pp. 3914-3919; Portugal, 1988.

[9] Law n. ${ }^{\circ} 49 / 2005$ of August $30^{\text {th }}$; "Second amendment to the Educational System Foundation Law and the first amendment to the Law on the Financing of Higher Education" (in Portuguese); Diary of the Republic I Series A, n. ${ }^{\circ}$ 166, pp. 5122-5138; Portugal, 2005.

[10] Decree-law $\mathrm{n}^{\circ} 137 / 2012$ of July $2^{\text {nd }}$; "Second amendment to the Autonomy, Administration and Management Regimen for Public Establishments of Preschool education and Basic and Secondary Education" (in Portuguese); Diary of the Republic - I Series, n. ${ }^{\circ}$ 126, pp 3340-3364; Portugal , 2012.

[11] Ministerial Dispatch $n .^{\circ} 7503 / 2006$ of Abril $4^{\text {th }}$ (in Portuguese); Diary of the Republic - II Series, n. ${ }^{\circ}$ 67, pp. 5049-5050; Portugal ,2006.

[12] General Board for Educational Administration, Office Board for Educational Equipments Quality; "Schools Maintenance and Utilization Handbook" (in Portuguese); Board of Education; Portugal, 2000.

[13] General Board for Educational Administration, Office Board for Educational Equipments Quality; "Schools Operation, Maintenance and Safety Handbook" (in Portuguese); Board of Education; Portugal, 2003.

[14] Vieira, A. C. V.; Cardoso, A. J. M.; "Asset Management Characterization of the Portuguese Secondary School Buildings", in: Joseph Mathew, Jim Kennedy, Lin Ma, Andy Tan and Deryk Anderson (Eds.); Engineering Asset Management, pp. 659-669; Springer, London, UK, 2006; DOI: 10.1007/978-1-84628-814-2_71, ISBN 978-1-84628$814-2$.

[15] Vieira, A. C. V.; Cardoso, A. J. M.; "Asset Management of Portuguese Educational Facilities"; in: Amadi-Echendu, J.E.; Brown, K.; Willet, R.; Mathew, J. (Eds.); Definitions, Concepts and Scope of Engineering Asset Management -1st Edition; [EAMR - Engineering Asset Management Review, Volume 1, Part V], pp. 277- 295; SpringerVerlag, 2010; DOI: 10.1007/978-1-84996-178-3_14, ISBN 978-184996-177-6. 
[16] Law n..$^{\text {7 } 79 / 2006 ~ o f ~ A p r i l ~ 4 " ~ ; ~ " R e g u l a t i o n s ~ o f ~ B u i l d i n g s ~ E n e r g y ~ S y s t e m s ~}$ for Heating and Cooling" (in Portuguese); Ministry of Economy and Innovation; Diary of the Republic - IA Series, n. ${ }^{\circ} 67$, pp. 2416-2468; Portugal, 2006.

[17] Decree-Law n. ${ }^{\circ} 41 / 2007$ of February 21" ; "Creation of the Parque Escolar, E.P.E." (in Portuguese); Ministry of Education; Diary of the Republic - I Series, n. ${ }^{\circ}$ 37, pp. 1287-1294; Portugal, 2007

[18] "Design Handbook: Technical facilities"; Secondary School Network Modernization Program; Parque Escolar, E.P.E.; Portugal, 2009.

[19] Pintelon, Liliane; Parodi-Herz, Alejandro; "Maintenance: An Evolutionary Perspective"; Cap. 2 in: K. A. H. Kobbacy and D. N. P. Murthy (Eds.); Complex Systems Maintenance Handbook; pp. 21-48; Springer; 2008; ISBN 978-1-84800-010-0.

[20] Barberá, Luis; Crespo, Adolfo; Viveros, Pablo; Stegmaier, Raúl "Advanced model for maintenance management in a continuous improvement cycle: integration into the business strategy"; International Journal of System Assurance Engineering and Management; Volume 3, Issue 1; pp 47-63; Springer-Verlag; 2012; DOI:10.1007/s13198-0120092-y.

[21] NP EN 13306:2007 (Ed.1); "Maintenance Terminology" (in Portuguese); Portugal, 2007

[22] Akasah, Zainal Abidin; Amirudin, Roslan; "Maintenance Management Process Model For School Buildings: An Application of Idef $_{0}$ Modelling Methodology"; International Conference on Construction Industry 2006: Toward Innovative Approach in Construction and Property Development; June 2006.

[23] Campos, Mónica López; Márquez, Adolfo Crespo; "Review, Classification and Comparative Analysis of Maintenance Managemen Models"; Journal of Automation, Mobile Robotics \& Intelligent Systems; Volume 3, No. 3; pp110-115; 2009.

[24] Akasah, A Z. A; Alias, B. M; "Analysis and Development of the Generic Maintenance Management Process Modeling for the Preservation of Heritage School Buildings"; International Journal of Integrated Engineering; Volume 1, Issue 2; pp. 43-52; 2011.

[25] Imtihan, Muhammad Rofi; Ngadiman, Mohd. Salihin; Haron, Habibollah; "An Alternative Model of ERP Maintenance Strategy", Proceedings of the 2008 Ninth ACIS International Conference on Software Engineering, Artificial Intelligence, Networking, and Parallel/Distributed Computing; pp. 785-793; Phuket, Thailand; August 6-8; 2008; ISBN 978-0-7695-3263-9.

[26] Baglee, David; Knowles, Michael; "Maintenance strategy development within SMEs: the development of an integrated approach"; Control and Cybernetics; Volume 39, No. 1; pp 275-303; 2010.

[27] Olanrewaju, A.; Khamidi, M. F.; Idrus, A.; "Validation of Building Maintenance Performance Model for Malaysian Universities"; World Academy of Science, Engineering and Technology; Issue 56; pp. 726730; 2011.

[28] Kobbacy, K. A. H.; Fawzi, B. B.; Percy, D. F.; Ascher, H. E.; “A Full History Proportional Hazards Model for Preventive Maintenance Scheduling"; Quality and Reliability Engineering International; Volume 13; pp. 187-198; John Wiley \& Sons; 1997.

[29] Kumar, Dhananjay; Westberg, Ulf; "Maintenance scheduling under age replacement policy using proportional hazards model and TTT-plotting"; European Journal of Operational Research; 99; pp. 507-515; 1997.

[30] Tsang, Albert H.C.; Jardine, Andrew K.S.; Kolodny, Harvey; "Measuring maintenance performance: a holistic approach", International Journal of Operations \& Production Management; Volume 19, Issue 7; pp. $691-715 ; 1999$.

[31] Hassanain, M. A.; Froese, T. M.; Vanier, D.J.; "Development of a Maintenance Management Model Based on IAI Standards"; Artificial Intelligence in Engineering; No. 15; pp. 177-193; Elsevier Ltd.; 2001.
[32] Chan, Ling-Yau; "Design of Inspection and Maintenance Models Based on the CCC-chart"; Proceedings of the Symposium on Reliability and Maintainability; pp. 74-81; 2003.

[33] Gomes, Eduardo Alberto Almeida Espinheira; "SIMEH - Integrated System for Maintenance of House Buildings at the Institute of Construction" (in Portuguese); Curricular Training Report; FEUP; Portugal, 2003.

[34] Cassady, C. R.; Iyoob, I. M.; Schneider, K.; Pohl, E. A.; "A generic model of equipment availability under imperfect maintenance"; IEEE Transactions on Reliability; Volume 54, Issue 4; pp. 564- 571; 2005.

[35] Jones, Keith; Sharp, Mark; "A new performance-based process model for built asset Maintenance"; Facilities; Volume 25, No. 13/14; pp. 525535; Emerald Group Publishing Limited; 2007; DOI: 10.1108/02632770710822616

[36] Kans, Mirka; "Achieving Profitable Maintenance by the Utilisation of Data and Information Technology"; in: Ana C. V. Vieira, A. J. Marques Cardoso and Raj B. K. N. Rao (Eds.); "COMADEM 2007 - Machinery \& Process Health Monitoring - Future Trends and Prospects"; Proceedings of the 20th International Congress on Condition Monitoring and Diagnostic Engineering Management; pp. 105-114; Faro, Portugal; June 13-15; 2007; ISBN 978-989-8109-02-6.

[37] Jongen, Rogier; Gulsky, Eduard; Smith, Johan; "Statistical Analysis of Diagnostic and Life Time Data of High Voltage Components"; in: The $8^{\text {th }}$ International Power Engineering Conference (IPEC 2007); pp. 355$359 ; 2007$.

[38] Mathew, Avin D.; Ma, Lin; Hargreaves, Douglas J.; “A conceptual data modeling methodology for asset management data warehousing"; in: Gao, Jinji; Lee, Jay; Ni, Jun; Ma, Lin; Mathew, Joseph, (Eds.); Proceedings of the 3rd World Congress for Engineering Asset Management; pp. 1086-1095; Beijing, China; October 27-30; 2008.

[39] Khamidi, M.F.; Olanrewaju, A.L.A; Idrus, A.; "Development of a Value Maintenance Management Model for Malaysian University Campuses"; W070 Facilities Management and Maintenance - Selected papers from the Proceedings of the 18th CIB World Building Congress; pp. 150-157; The Lowry, Salford Quays, United kingdom; May10-13; 2010.

[40] Campos, M. A. López; Fernández, J. F. Gómez; Díaz, V. González; Márquez, A. Crespo; "A new maintenance management model expressed in UML"; in: Soares, Guedes and Martorell (Eds.); Reliability, Risk and Safety: Theory and Applications; Taylor \& Francis Group; London; 2010; ISBN 978-0-415-55509-8; 2010.

[41] NP 4483:2009; "Standard guide for the implementation of maintenance management systems" (in Portuguese); Portugal, 2009.

[42] Global Forum on Maintenance Asset Management (GFMAM); "The Asset Management Landscape"; ISBN 978-0-9871799-1-3; 2011.

[43] European Asset Management Committee (EAMC); "How organizations manage their physical assets in practice"; European Federation of National Maintenance Societies (EFNMS); 2011.

[44] Ortiz, Alexis; Izquierdo, Henry; Rodríguez Monroy, Carlos; "Maintenance Management Model for Industrial Smes";6th International Conference on Industrial Engineering and Industrial Management ; pp. 276-283; Vigo; 2012

[45] Flores, I.S.; "Maintenance Strategies -Current Building's Envelope" (in Portuguese); Thesis (MSc), IST; Portugal, 2002.

[46] Mollentze, Frederik Jacobus; “Asset Management Auditing - The roadmap to asset management excellence"; Thesis (MSc), FEBEIT; Pretoria, 2005.

[47] NP EN 13460:2009; "Maintenance - Documentation for maintenance" (in Portuguese); Portugal, 2009.

[48] Wireman, Terry; "Benchmarking Best Practices in Maintenance Management"; Industrial Press; 2004; ISBN 0-8311-3168-3. 


\title{
REAL TIME DATA COLLECTION AND PROCESSING FOR AIRERAFT MAINTENANCE ENHANCEMENT (REACT)
}

\author{
Joel Ferreira ${ }^{1}$; Luís Oliveira ${ }^{2}$; Rúben Oliveira ${ }^{3}$ \\ 1.jtferreira@tap.pt; ${ }^{2}$ lmoliveira@tap.pt; ${ }^{3}$ ruben.oliveira@dem.uc.pt \\ 1,2 TAP Manutenção e Engenharia - TAPME \\ Lisboa, Portugal \\ ${ }^{3}$ CEMUC - Centro de Engenharia Mecânica da Universidade de Coimbra \\ Coimbra, Portugal
}

\begin{abstract}
REACT aims to develop an innovative real-time Aircraft/Ground framework to collect, transmit and concentrate aircraft and ground data. This data will be processed to offer maintenance services information for predicting, planning-ahead and supporting aircraft maintenance execution. In the scope of REACT, features of new mobile tools will be also researched with the objective of enhancing the efficiency of maintenance execution.
\end{abstract}

Keywords - Real-time data transmission; Predictive maintenance; Aircraft Maintenance.

\section{INTRODUCTION}

In general, all physical assets are becoming more and more complex and aircrafts are not the exception. Nowadays it is necessary to have an easy and friendly access to the condition of physical assets through its monitoring. However, when dealing with disperse physical assets it is necessary to have robust and secure communication systems to access the data. It is even more difficult if such physical assets are not geographically static.

Managing an aircraft fleet, in terms of its maintenance, is a huge challenge since, it is mandatory to guarantee that the aircraft is on condition to complete the next flight without risks, for the equipment itself, but more importantly, to its occupants (high risk sensitive sector).

Typically, a Reliability Centred Maintenance (RCM) process applies when planning maintenance interventions based upon the condition of the equipment, having as main objective the preservation of the equipment's inherent reliability levels. Setting up a repetitive scheduled plan to periodically remove components from an aircraft regardless its condition, can prove to be a burdensome and very expensive process. Failures however, must be avoided to prevent human catastrophes. Thus, the challenge from a maintenance perspective is to secure the highest safety levels of an aircraft, at the minimum possible cost.

In order to extend the length of the complete life cycle of such physical assets and minimise its maintenance costs they can be monitored to optimise the time of their replacement or even their planned maintenance surveys according to their condition. This still is a RCM approach but controlled by Condition-Based Maintenance (CBM).

Every time a fault is detected it should be determined if the aircraft requires immediate maintenance actions or if those actions can be deferred, in accordance with approved applicable rules. The second option points towards a set of further questions:

- For how long is the aircraft able to fly without unacceptable risks?

- Where and when must the aircraft land to be subject to a maintenance intervention?

Aircrafts are on the move all the time. Finding the best moment to ground an aircraft to perform maintenance actions at the best suitable location, is key to minimise costs.

To manage all the information coming from monitored assets a centralised system must collect and process all the data and support maintenance management under an eMaintenance concept [1].

Today's aircrafts produce a large array of parameters which can be used to infer the state-of-health of some systems or components, so that maintenance actions can be deployed based upon the actual condition of the component rather than waiting for it to fail or relying on accumulated experience.

Current paper addresses the purposes of REACT project that is currently being implemented. REACT aims at develop and integrate technology to:

- Regularly collect, transmit to ground stations and process aircraft data in real-time, in an effective, reliable and affordable way at any given flight stage;

- Predict maintenance needs and reduce the extension of damages on key removed parts;

- Provide maintenance technicians with enhanced mobile access to contextualised documentation, decisionmaking support methods, and effective communication with other departments and the aircraft.

Unlike the existing systems, some of which are provided as services by aircraft Original Equipment Manufacturers (OEMs) and Maintenance Repair and Overhaul Organisations (MROs), that are currently used by the airlines to support the improvement of resources' maintenance management, the system envisioned in REACT will not be based on failures (reactive maintenance). Instead, REACT will be a CBM system aiming to avoid unpredicted failures by monitoring the condition of physical assets and estimating the probability of degradation ending up in a failure, within a certain period of time (predictive maintenance).

The step of implementing a maintenance methodology that makes extensive use of the condition monitoring of the aircraft 
has not yet been taken, mainly because current data transmission technologies from aircraft to ground, do not offer a good balance between the performance in the amount of data and affordability for permanent data transmission at any given flight phase and in all regions of the globe. This stage of things doesn't give the aviation authorities enough confidence to support the gradual replacement of the conventional scheduled maintenance by a CBM methodology.

The novel concept which underpins REACT is to propose an upgrade of the legacy aircraft architecture in terms of data collection, concentration and transmission by integrating reliable and affordable technology. The solution envisioned in REACT will enable a continuous transmission of large amount of data from aircraft to ground stations, supported by its processing, to assess the condition of selected components. As such, timely insights will be provided to the relevant maintenance departments which will support a pre-emptive schedule of maintenance actions and effectively mitigate unplanned downtime of the aircraft.

The enhancement of the maintenance value chain will be fully completed by developing new applications for mobile tools targeted to maintenance technicians, featuring a more intuitive access to information that will allow efficiency gains, shorter turnaround times, better knowledge of the actual aircraft's health condition and fewer operational disruptions.

The remaining of the paper is organised as follows:

- Chapter II presents the concept and approach of REACT system;

- Chapter III presents the REACT architecture;

- The final chapter presents the conclusions.

\section{CONCEPT AND APPROACH}

In order to carry out the proof of concept, REACT envisages that for some selected systems and components, a standard sampling of observable parameters will be defined to describe the expected behaviour of a system when in normal operation. Conditions are created in the aircraft to collect all the necessary data to observe the performance of the established parameters at any flight phase, taking the maximum advantage of the existing aircraft systems.

Whenever the parameters show significant deviation from the previous sampling, data is sent in real-time to a ground station. The ground station records the output of the aircraft's sensors and electronics, processes the transferred information and determines the aircraft's systems that are in risk of failure.

Based on collected data, the centralised system in the ground station, through the use of big data technologies, will analyse the fault conditions and propose a set of tasks and a time frame to those scheduling the maintenance. This will allow the maintenance planners to accommodate those tasks in the regular scheduled inspections of the aircraft, without jeopardising the aircraft's availability. There are several published results from CBM approaches that can be transposed to the aviation world, like in [2] where a solution for wind generators is presented, that accesses monitoring measurements data online and processes these data in realtime using prediction models to prevent failures. In [3] a Hidden Markov Model (HMM) is applied on diesel engines to estimate their condition. The advantage of HMM is that it is a memoryless model.

Trying to find the best compromise between the next aircraft's missions, available resources and skills and the most suitable destination to perform maintenance works, the maintenance planners will distribute the tasks among the appropriate technicians who receive it through a mobile device.

In their mobile device technicians will have access to:

- Assigned job cards;

- Contextualised documentation;

- Bidirectional communication with other departments and the aircraft;

- Selected procedures in augmented and virtual reality.

Apart from the capacity of REACT to transmit aircraft's condition details, even during a flight when deviations pointing to faults are detected, also an interface for on-ground works will be available. Thus, if an anomaly is detected by the technicians, when performing maintenance in the aircraft, they have just to use a mobile device to describe the fault they are facing. Then, an expert system will analyse the report and suggest maintenance procedures to solve the anomaly. If no immediate action is required, the centralised system keeps the information introduced by the technician for later planning of appropriate actions.

Augmented Reality is a powerful technology tested on several projects, some of them in the aviation sector in which the final assembly cabling routes are superimposed in realtime on a video sequence of the aircraft fuselage to avoid mistakes [4] using a tablet or even by projecting on components instructions to complete a task [5]. The major constraint of using augmented reality in industrial environments is to identify the targets without the use of artificial markers; a possible workaround solution could be the use of texture-based techniques, which implementation is however also problematic due to light changes sensibility. A useful edge-based approach that uses CAD model details to detect and track objects in the scene, tends to be more reliable on such environments because the object's contours are not significantly affected by light changes, [6].

Conventional paper-based instructions are becoming inadequate, mainly when changes are applied. Digital instructions tend to be easily accessed, are easier to update and such updates may be available to all maintenance infrastructure in real-time. This has been verified during the assembly of the Airbus A400M [5] reaching significant time savings on creating, consulting and maintaining up to date digital working orders. This problematic is not new; in 2001 a paper has been presented about a project that attempted to replace paper-based documentation by augmented reality instructions on maintenance of nuclear power plants, [7]. There is also a report from 2012 that addresses the expected 
benefits and what must a mobile device contain, to support military aircraft maintenance management at Saab Aeronautics, [8].

Those publications attest the validation of the mobile interface of REACT. However some other constraints must be overcome such as the communication between REACT and the remaining maintenance management systems, namely the proprietary systems.

In REACT the centralised system will preserve data from several aircrafts, over many flights and years, and mine this information with sophisticated algorithms to identify the signs of recurring problems for long-term maintenance needs anticipation. This feature may become an important resource to estimate accurately the behaviour of aircraft's physical assets in the future.

In the project, real life airline operational oriented demonstrations will be defined with the aim of verifying compliance with the objectives. The implementation of the solutions will be evaluated within operational context making use of an end-user's maintenance infrastructure to measure the expected impact in the aviation industry, specifically in what concerns the reduction of maintenance costs and operational disruptions. In Fig. 1, REACT's general concept is illustrated.

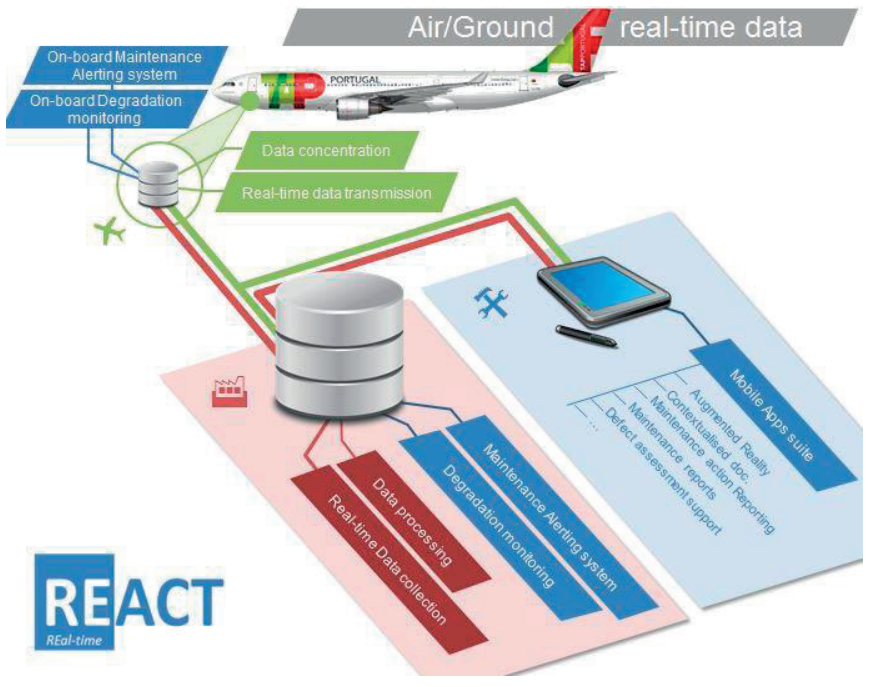

Fig. 1. REACT's concept

\section{ARCHITECTURE}

REACT comprehends tree main sub-systems: the ground platform, which is the central core; the on-board monitoring system; and the mobile devices. The global architecture is presented in Fig. 2.

The Aircraft/Ground maintenance platform is based on the integration of mature aircraft and ground technological bricks to host the real-time maintenance functions within aircraft legacy architecture:

- Aircraft infrastructure segment: Integrated within the aircraft "open world", it would offer a flexible but secured environment to communicate with the legacy
"Aircraft Control Domain" (ACD i.e. Avionics world). It would acquire and concentrate aircraft, maintenance and operational data such as Aircraft Condition Monitoring System/Virtual Quick Access Recorder (ACMS/VQAR), maintenance reports, eLogbook database, etc. and transmit them in real-time, and when appropriate, by making use of available avionics, cabin or open world (i.e. Wi-Fi, 3/4G) connectivity.

- Ground infrastructure segment: This would collect the overall real-time fleet and ground data such as information provided by the Maintenance Information System (MIS) and distribute it to other maintenance functions.

This platform is the backbone to support the aircraft maintenance operations and to host the maintenance functions using the centralised database:

- Maintenance anticipation: It would be a real-time degradation monitoring function split into aircraft segment to provide a quick degradation pattern and ground segment.

- Maintenance preparation: It would be a maintenance alerting system to warn the Maintenance and Engineering (M\&E) back office, or the field operator directly, about degradation of monitored parameters and failures.

- Maintenance execution: It would be an application suite belonging to an on-field maintenance technician to support maintenance execution tasks such as degradation and failure analysis and recovery, maintenance actions reporting, etc.

\section{CONCLUSIONS}

The transmission of data from aircraft to ground in realtime, once the aircraft is airborne, is a burdensome and expensive process with significant limitations. Currently, some reports are transmitted from aircraft to ground when the aircraft is flying. These reports are only transmitted under very specific trigger conditions and are set to minimise transmission costs and make the minimum use of satellite bandwidths.

Aircraft produce plenty of parameters which can be used to infer the state-of-health of some systems or components. Also, due to the lack of effective data processing tools for aircraft maintenance, non-mandatory recorded aircraft data currently produced is often lost or not used by the maintenance services on a systematic and regular basis.

REACT aims at proposing an effective, reliable and affordable solution for making permanent aircraft-ground data transmission in real-time possible. This aircraft-ground data link can be triggered based on the deviation of selected health parameters from normal behaviour or whenever demanded either by the flight crew or by the ground maintenance services, at any flight phase and over any region of the globe.

Innovative data transmission technologies will use artificial intelligence capabilities to make smart decisions on 


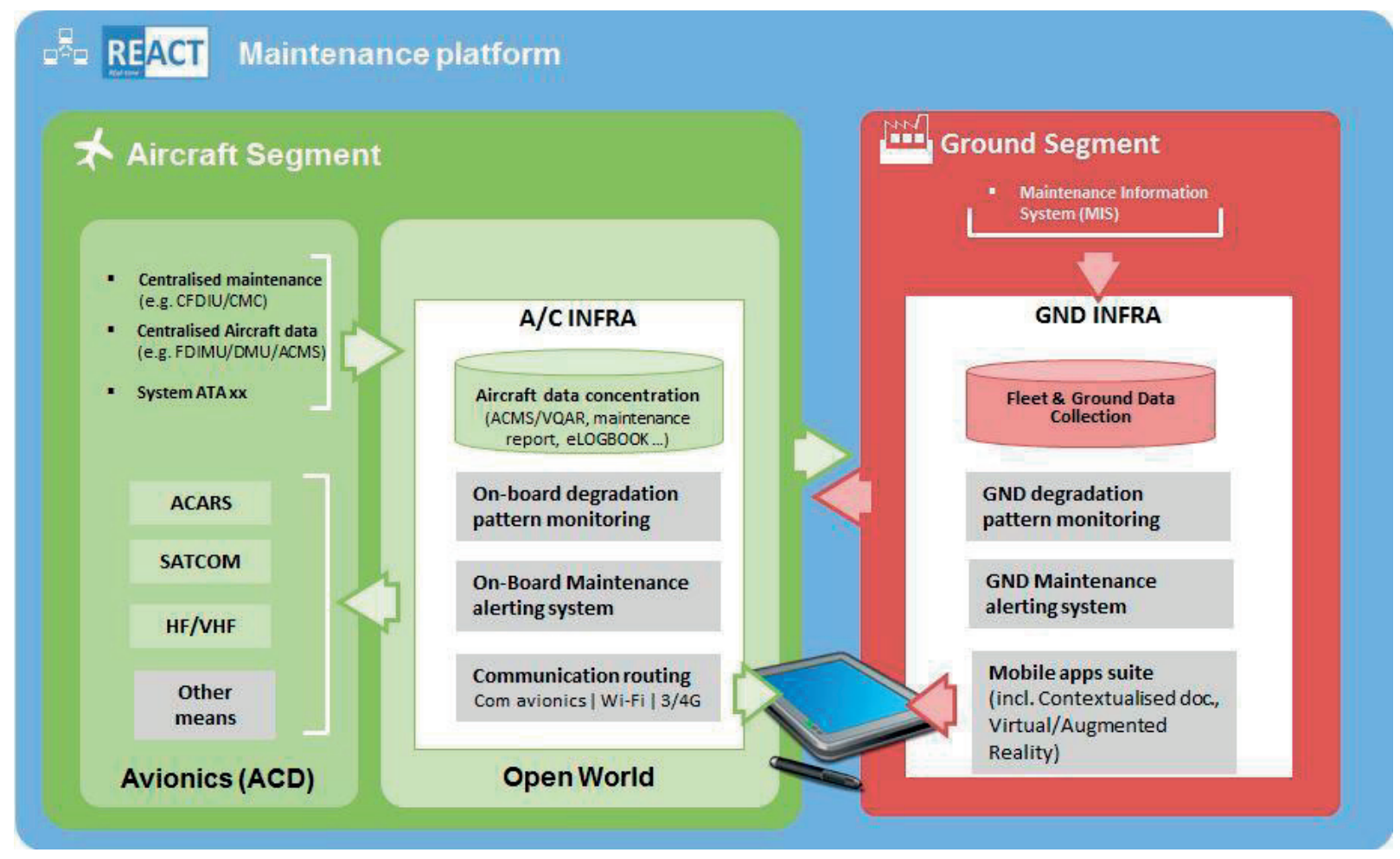

Fig. 2. REACT's generic architecture

data to be transmitted either in real-time or via gate link. This, together with the cutting-edge architecture proposed by REACT, represents a great leap beyond the state-of-the-art.

Through the extensive use of big data technologies, abnormal performance output data of selected aircraft systems and components will be recorded, processed and turned into maintenance relevant information to set up appropriate maintenance actions.

This will not only allow a better management of the maintenance resources, but also a better management of the manpower and airline's resources, like the aircrafts, the maintenance facilities and the spare components needed in the inventory to help preventing operational disruptions due to maintenance.

\section{REFERENCES}

[1] A. Muller, A. C. Marquez, and B. Iung, "On the concept of emaintenance: Review and current research," Reliability Engineering \& System Safety, vol. 93, no. 8, pp. 1165 - 1187, 2008. [Online]. Available: S0951832007002189

[2] I. Fonseca, J. T. Farinha, and F. M. Barbosa, "On-condition maintenance of wind generators - from prediction algorithms to hardware for data acquisition and transmission," WSEAS Transactions on Circuits and Systems, vol. 7, no. 9, pp. 630-647, September 2008.

[3] A. Simões, I. Fonseca, J. T. Farinha, and V. Marques, "On-condition maintenance of diesel engines modelled by a hidden markov model," in NEW ASPECTS of APPLIED INFORMATICS, BIOMEDICAL ELECTRONICS \& INFORMATICS and COMMUNICATIONS, 2010, pp. 258-263.

[4] EADS, "EADS 2011 Coporate Responsability \& Sustainability Report," EADS, Tech. Rep., 2011.

[5] J. Serván, F. Mas, J. L. Menéndez, and J. Ríos, "Using augmented reality in airbus a400m shop floor assembly work instructions," AIP Conference Proceedings, vol. 1431, no. 1, pp. 633-640, 2012. [Online]. Available: http://scitation.aip.org/content/aip/proceeding/aipcp/$10.1063 / 1.4707618$

[6] R. Oliveira, T. Farinha, S. Singh, and D. Galar, "An augmented reality application to support maintenance - is it possible?" in Proc. Maintenance Performance Measurement and Management (MPMM) 2013, 2013, pp. 260-271. [Online]. Available: https://online.unileoben.ac.at/mu_online/voe main2.getVollText?pDocument $\mathrm{Nr}=142932 \& \mathrm{pCurrPk}=32372$

[7] G. Klinker, O. Creighton, A. H. Dutoit, R. Kobylinski, C. Vilsmeier, and B. Brugge, "Augmented maintenance of powerplants: a prototyping case study of a mobile ar system," in Augmented Reality, 2001. Proceedings. IEEE and ACM International Symposium on, 2001, pp. 124-133.

[8] T. Fransson and O. Candell, "A handheld maintenance workstation: Information fusion in the aircraft - ground systems gap," in The 2nd international workshop and congress on eMaintenance, 2012, pp. 33-36. 


\title{
Selection of instances in Condition Based Monitoring The case of aircraft engines
}

\author{
Leonor Fernandes ${ }^{1}$; Roberto Henriques ${ }^{2}$; Victor Lobo $^{3}$ \\ 1'mlfernandes@euroatlantic.pt; ${ }^{2}$ roberto@isegi.unl.pt; ${ }^{3}$ vlobo@isegi.unl.pt \\ 1,2,3 ISEGI - NOVA School of Statistics and Information Management of the Universidade Nova de Lisboa \\ Lisbon, Portugal \\ ${ }^{3}$ CINAV- PRT Navy Research Center \\ Almada Portugal
}

\begin{abstract}
Condition based maintenance (CBM) is based on analysis and data collection monitored by sensors on the aircraft. The knowledge discovery, about the performance of different parameters, by using these data will provide new ways of diagnosing and predicting the state of aircraft engines. However, a single flight produces a huge amount of data that characterize aircraft engine behaviour. The use of algorithms for the simultaneous processing of these data is a difficult and sometimes impossible task. The objective of this work is to choose the best way to select instances for a sample. There should be no loss of relevant information in the sample to identify the state of the engine. We use five methods to select the sample and through clustering techniques and sensibility analysis we choose the best way to select the sample.
\end{abstract}

Keywords - Condition based maintenance (CBM), aircraft engines, instance selection, knowledge discovery in databases, Self Organizing Maps (SOM).

\section{INTRODUCTION}

The parameters characterizing aircraft engine behaviour, and operational conditions of the flight, are the types of information that allow changing the usual decision making procedures concerning the removal of engines for maintenance.

Currently, there is much information, gathered over time, about aircraft engines parameters. This information is abundant, so the techniques of Knowledge Discovery in Databases (KDD) are appropriate to describe and characterize the performance of the engines.

But huge amounts of data may be a problem for the use of the algorithms in the data exploratory phase, so different methods of instance selection need to be studied.

This work's objective is to choose the best way to select instances as a sample. We use five methods to select the sample and, through clustering techniques and sensibility analysis, choose the best, i.e. the sample with the smallest dimension, in such a way that the parameters have the same behaviour as the original data.

We use a dataset of engine's parameters for one commercial B767-300 aircraft passenger model, concerning different flights carried out between 2009 and 2013. We also analyze other types of data about the flights' conditions.
The paper is structured as follows: Section II gives a brief description of the maintenance problem; Section III presents a review of KDD. The description of the data and methodology used are in Section IV. Results are presented in Section V. Section VI gives the conclusions of the study.

\section{Aircraft Engine Maintenance Problem}

Maintenance activities of aircraft, particularly the engines, are a possible way to solve aviation companies' trade-off: keeping the aircraft at high security and operability levels versus low costs. The decision to remove an engine to repair usually depends on regular visual inspections, monitoring aircraft engines' parameters and experts' knowledge. The monitoring of an engine's performance parameters is done by comparing the values recorded during the flight with the manufacturer's thresholds. When flight data are close to these thresholds, maintenance actions are taken. Due to the inherent risks of unexpected failure, engine removal is usually done before the optimal time.

One way of modifying this procedure is through extracting more knowledge of engine behaviour parameters and their interactions, as well as the development of designs which are able to predict the future values of these parameters. Thus it is possible to classify the state of an engine and predict the occurrence of the next failure. This engine health management is based on the concept of condition based maintenance (CBM), now a major concern of aviation companies' maintenance departments. [1].

CBM aims, through fault diagnostics and prognostics activities, to assess an engine's current condition and future state. Prognostics deal with tasks that allow the prediction of failure.

Aviation companies currently have a register of a huge amount of data that enables the development of new forms of diagnosis and prognosis of faults. The application of Knowledge Discovery in Databases (KDD) and techniques of Data Mining (DM) to these data of aircraft engines allows the implementation of new CBM policies.

Hundreds of works, theoretical and applied, appear every year in journals and at conferences ([2], [3], [4], [5], [6]) about $\mathrm{CBM}$ activities. But the area of diagnosis is the one which is most developed. Prognosis is a relatively new research area [7]. 
At the end of the last decade three important works about prognostic activity in the industry have appeared [7], [9] and [10]. In the aviation industry, in 2011, [11] prepared a study on operational management in the industry which refers to concerns about prognostic activities.

The followings works shows different approaches to aircraft engines: [8] in 1993 refers to the advantages of the application of neural networks in monitoring an aircraft engine's condition; [9] in 2005 describes a model which would be able as to predict the residual life of an aircraft engine, using the Principal Components Analyses (PCA) technique in oil data; in 2007 two works distinguished themselves - one about the diagnosis of engine failures [10], the other about advanced estimation in engines [11]; in 2009 more studies appeared about the parameters of aircraft engines and their extreme values [12] as well as forms of classifying their faults from the perspective of diagnosis [13]; the following year [14] studied one important aircraft engine parameter, Exhaust Gas Temperature (EGT). They used three different tools: Self Organizing Map, Vector Machine Experts and Genetic Algorithm. In the same year (2010), [15] proposed a new methodology to find the optimal time of replacement safety for critical aircraft parts, using as base a comparison of two models to try to find the best time at which to change important aircraft engine parts; also in 2010 [16] published a work in which they introduced the concept of health management in aircraft engines. They also proposed a new way to predict optimal preventive maintenance interval decision making using a proportional intensity model. Over the last three years a set of works about fault prediction and aircraft engine health monitoring, using Self Organizing Maps, have been presented by [17], [18] and [19].

\section{KNOWLEDGE DISCOVERY IN DATABASES (KDD) AND DATAMINING}

KDD allows some tasks' performance improvement based on past experience: patterns are identified from historic data. DM includes very important phases: data selection, preprocessing, interpretation and evaluation [20].

During one flight, the amount of available data that allows determining the engine's state is abundant. Different performance and operation parameters of the engines are recorded every second. It is possible to recognize abnormal data in order to identify possible crashes/failures in the engine, but during a flight not all data are relevant.

To select significant data is an important task in the phase of preprocessing of data in KDD [21], but is time-consuming although its tasks contribute to the success of the process [22]. Means for selecting instances are to create a set of training $\mathrm{S}$ that belongs to the original data set $\mathrm{T}$. There should be no loss of relevant information in the subset $S$. S should be able to represent $\mathrm{T}$. The goal is to obtain a sample, with smaller dimensions, in such a way that the variables have the same behavior as the original data [23].

The literature about the instance selection of supervised learning problems is abundant, highlights are provided in [24] which presents a detailed summary of the most commonly used algorithms with their features and also compares their performances.

However, very little literature (after 2000) was found about instance selection to non-supervised learning. The works of [25], [20], [26] refer to the usual sampling procedures for the selection of the sample (i.e. simple random sampling, sampling uniform, stratified). But instance selection to non-supervised learning, is important. The amount of information, in the data exploratory phase, makes this very analysis complex and ineffective, due to the execution time of some algorithms and the non- implementation of other algorithms [20]. So it is important to develop new ways of instance selection to build the training set $\mathrm{S}$ at non-supervised learning.

\section{DATA AND METHODOLOGY}

\section{A. Data description}

We have 229 flights made by one commercial B767-300 between 2009 and 2013. On each flight were recorded, second by second, the data of 31 performance parameters of the two engines and the flight conditions. The final database is large; there are 4,232,008 instances generating typical DM problems. One of them is instance redundancy in the same flight, so in each flight we want to select only the different instances that are interesting.

Table I describes the parameters of the database, $1 / 2$ are the parameters of engines 1 and 2 .

TABLE I - Description of Parameters

\begin{tabular}{|c|c|}
\hline & Parameters \\
\hline \multirow{6}{*}{$\begin{array}{l}\text { Flight } \\
\text { Conditions }\end{array}$} & Altitude \\
\hline & Gross Weight \\
\hline & Mach Number \\
\hline & Static Air Temperature \\
\hline & Total Air Temperature \\
\hline & Pressure Total \\
\hline \multirow{13}{*}{$\begin{array}{c}\text { Engine } \\
\text { Performance }\end{array}$} & Bleed Duct Press Engine 1/2 \\
\hline & Temperature Engine 1/2 \\
\hline & Vibration Engine 1/2 \\
\hline & Engine $1 / 2$ Pressure Ratio \\
\hline & Request EPR 1/2 \\
\hline & Max Limit EPR1/2 \\
\hline & Fuel Flow Engine 1/2 \\
\hline & Fan Speed-Speed Low Pressure Engine 1/2 \\
\hline & $\begin{array}{l}\text { Core Speed-Speed High Pressure Engine } \\
\qquad 1 / 2\end{array}$ \\
\hline & Oil Pressure Engine 1/2 \\
\hline & Oil Quantity Engine 1/2 \\
\hline & Oil Temperature Engine 1/2 \\
\hline & Throttle Resolver Angle \\
\hline
\end{tabular}


The number of observations per flight varies widely because it depends on the duration of each flight. Figure 1 describes the number of instances per flight.

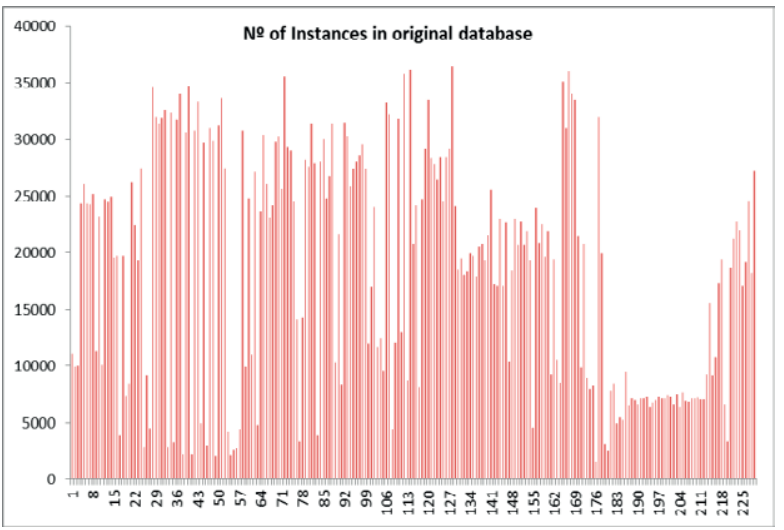

Fig. 1. Distribution of the instances per flight

\section{B. Methodology}

We applied five methods to select the sample. Each method is applied by flight. They are:

1. Uniform over time with constant intervals (Systematic Sampling) - original file records, which are ordered per flight, an instance is selected for the sample with a sampling interval of $\mathrm{k}=\mathrm{n} / \mathrm{N}$, where $\mathrm{n}$ is the sample size and $\mathrm{N}$ the original dataset size.

2. Uniform over time with averages of sets with $\mathrm{k}$ instances - systematically select $\mathrm{k}$ instances and the value selected for the sample is the average of each of the variables of the $\mathrm{k}$ instances.

3. Last Neighbour - the first instance of the original dataset is selected. The Euclidian Distance is calculated between the next instance from the original dataset and the last instance selected to the sample. If this distance exceeds the threshold established, then the instance is selected to the sample and so on.

The threshold has been established through the analysis of the Euclidian Distance between instance i and instance i-1 for several flights.

The usual behaviour of the Euclidian Distance on a flight is shown in figure 2. In this flight $17 \%$ of the instances have a Euclidian Distance equal to zero.

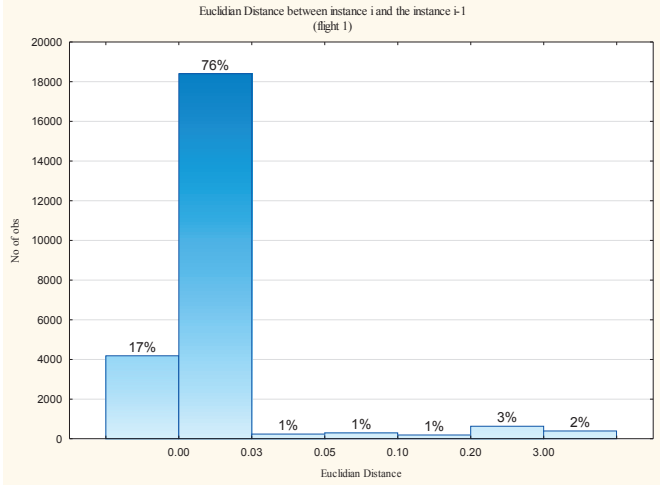

Fig. 2. Distribution of the Euclidian Distance between instance $i$ and instance $\mathrm{i}-1$ in one flight.

Table II shows descriptive statistics for three flights.

TABLE II - Descriptive Statistics of the Euclidian Distance between instance $i$ and the instance $\mathrm{i}-1$

\begin{tabular}{|c|c|c|c|c|c|}
\hline Flight & Valid $N$ & Mean & Median & Min & Max \\
\hline 1 & 24329 & 0.691 & 0.00 & 0.00 & 1213.6 \\
\hline 2 & 26141 & 0.524 & 0.00 & 0.00 & 1728.5 \\
\hline 3 & 24309 & 0.608 & 0.00 & 0.00 & 1358.6 \\
\hline Flight & $\begin{array}{c}\text { Lower } \\
\text { Quartile }\end{array}$ & $\begin{array}{c}\text { Upper } \\
\text { Quartile }\end{array}$ & $\begin{array}{c}\text { Percentile } \\
\mathbf{1 0}\end{array}$ & $\begin{array}{c}\text { Percent } \\
\text { ile } 90\end{array}$ & Coef.Var. \\
\hline 1 & 0.000 & 0.001 & 0.000 & 0.014 & 2240.576 \\
\hline 2 & 0.000 & 0.001 & 0.000 & 0.007 & 2990.828 \\
\hline 3 & 0.000 & 0.001 & 0.000 & 0.006 & 2680.983 \\
\hline
\end{tabular}

We want instances with big differences so we studied thresholds between 0.03 and 3 .

4. All Neighbours - the first instance of the original dataset is selected. The Euclidean's distances are calculated between the next instance of the original dataset and all the instances selected to the sample. If all these distances exceed the threshold established, then the instance is selected to the sample and so on. The threshold has been established the same way as the previous method.

5. Self-organizing maps (SOM) - Create as many clusters as desired for the sample size. For each cluster compute centroids. These centroids will be the instances of the sample. We process one SOM for each flight.

Several scenarios were made for each method varying their parameters. The analysis undertaken in several flights about the Euclidean Distance between instance $\mathrm{i}$ and instance $i-1$, after the data standardisation, is used to establish the starting threshold to methods 3 and 4 . It is 0.03 . The parameters of the other methods were adjusted in order to obtain samples of nearby dimensions, so that the results can be compared.

The method $\mathrm{V}$ is very time-consuming, because that is only applied at last scenario in this work. 
To assess the quality of the samples, we use the technique of clustering. In the samples an original database was created for each flight, ten clusters. After this, a Euclidian Distance between the centroids clusters of the samples and the original database was calculated. The total distance of the flight was compared.

We applied the K-means algorithm for the formation of the clusters and chose ten clusters because during the flight there are six natural clusters, the principal phases of flight [25], but in abnormal situations it is possible to have more phases.

\section{RESULTS}

Each method has different parameters and we simulated several values of these parameters. Table III describes the parameters used and the sample size for the first 4 methods.

TABLE III - Description Methods of Sampling for the first 4 methods

\begin{tabular}{|c|c|c|c|c|c|}
\hline \multicolumn{3}{|c|}{ I-Uniform } & \multicolumn{3}{|c|}{ II-Average Uniform } \\
\hline parameters & $\begin{array}{c}n=\text { sample } \\
\text { size }\end{array}$ & $\begin{array}{c}\% \\
\text { total }\end{array}$ & parameters & $\begin{array}{c}n=\text { sample } \\
\text { size }\end{array}$ & $\begin{array}{c}\% \\
\text { total }\end{array}$ \\
\hline 4 & 1058002 & 25 & 4 & 1058002 & 25 \\
\hline 5 & 846492 & 20 & 5 & 846311 & 20 \\
\hline 8 & 529057 & 12.5 & 8 & 528945 & 12.5 \\
\hline 13 & 325649 & 7.7 & 13 & 325433 & 7.7 \\
\hline 100 & 42438 & 1 & 100 & 42215 & 1 \\
\hline \multicolumn{3}{|c|}{ III-Last Neighbour } & \multicolumn{3}{|c|}{ IV-All Neighbours } \\
\hline parameters & $\begin{array}{c}n=\text { sample } \\
\text { size }\end{array}$ & $\begin{array}{c}\% \\
\text { total }\end{array}$ & parameters & $\begin{array}{c}n=\text { sample } \\
\text { size }\end{array}$ & $\begin{array}{c}\% \\
\text { total }\end{array}$ \\
\hline 0.03 & 1128388 & 26.7 & 0.03 & 1061178 & 25.1 \\
\hline 0.05 & 775620 & 18.3 & 0.05 & 735957 & 17.4 \\
\hline 0.1 & 520821 & 12.3 & 0.1 & 487474 & 11.5 \\
\hline 0.2 & 327614 & 7.7 & 0.2 & 303666 & 7.2 \\
\hline 3 & 50851 & 1.2 & 3 & 31127 & 0.7 \\
\hline
\end{tabular}

Table IV gives the time consumed for each simulation to the first 4 methods.

TABLE IV - Time-consuming, seconds

\begin{tabular}{|c|c|c|c|c|c|}
\hline parameters & Uniform & $\begin{array}{c}\text { Average } \\
\text { Uniform }\end{array}$ & parameters & $\begin{array}{c}\text { Last } \\
\text { Neighbour }\end{array}$ & $\begin{array}{c}\text { All } \\
\text { Neighbours }\end{array}$ \\
\hline 4 & 17.08 & 41.60 & 0.03 & 711.24 & 7150.39 \\
\hline 5 & 14.40 & 34.21 & 0.05 & 363.62 & 3921.23 \\
\hline 8 & 9.88 & 22.22 & 0.1 & 210.39 & 2153.00 \\
\hline 13 & 7.06 & 15.05 & 0.2 & 181.41 & 1608.91 \\
\hline 100 & 3.10 & 5.10 & 3 & 201.46 & 562.63 \\
\hline
\end{tabular}

Low values of the parameters are not of interest because lead to samples of high dimension and are a lot time consuming. So we analyzed the last scenario, which represents
$1 \%$ of the instances of the original database. For this scenario we used more $\mathrm{V}$ method.

Table $\mathrm{V}$ shows dimension and the parameters used at $\mathrm{V}$ method for the last scenario.

TABLE V - Description Methods of Sampling for the first 4 methods

\begin{tabular}{|c|c|c|c|c|c|}
\hline$\alpha$ & $\sigma$ & Size of matrix & $\begin{array}{c}\text { Number } \\
\text { of } \\
\text { iterations }\end{array}$ & $\begin{array}{c}\text { Neighborhood } \\
\text { Function }\end{array}$ & $\begin{array}{c}n=\text { sample } \\
\text { size }\end{array}$ \\
\hline $0.7-$ & $8-3$ & $\begin{array}{c}229 \text { matrix, } \\
\text { the size } \\
\text { ranged } \\
\text { between [4 5] } \\
\text { and [1920] }\end{array}$ & $20 / 30$ & Gaussian & 42254 \\
\hline
\end{tabular}

The time consuming by V method was 30264 seconds.

The descriptive statistics of the total distance between the centroids clusters of the samples and the centroids clusters of the original database are in Table VI.

TABLE VI - Descriptive Statistics Total Distance between centroids clusters

\begin{tabular}{|l|c|c|c|c|c|c|}
\hline \multicolumn{1}{|c|}{ Method } & $\mathrm{N}$ & Mean & Min & Max & $\begin{array}{c}\text { Std. } \\
\text { Dev. }\end{array}$ & $\begin{array}{c}\text { Coef. } \\
\text { Var. }\end{array}$ \\
\hline Uniform & 229 & 616.30 & 13.81 & 3482.98 & 704.93 & 114.38 \\
\hline $\begin{array}{l}\text { Average } \\
\text { Uniform }\end{array}$ & 229 & 146.94 & 13.83 & 678.32 & 138.25 & 94.08 \\
\hline Last Neighbour & 229 & 202.32 & 68.95 & 734.49 & 91.21 & 45.08 \\
\hline All Neighbours & 229 & 199.23 & 39.27 & 989.22 & 119.14 & 59.80 \\
\hline SOM & 229 & 76.94 & 20.794 & 424.96 & 75.72 & 98.41 \\
\hline
\end{tabular}

The Uniform method is the less time consuming but gives the worst values of the descriptive statistics and presents a wide dispersion of total distance. This sample is different from the original database, with the total distance mean being 616.30 because there are some flights with long distances.

The values of average are only representative in the case of Last Neighbour method, where the coefficient of variation is 45.08 .

In figure 3 we compare the distance variability per flight in different methods. When all methods are compared we see the predominance of I method and the distance is between 0 and 3500. At second graph cut this method and the distance is between 0 and 1000 , there was a significant decrease in the range of the distance. If we compare only the methods carried out with distances between instances the range is the same, and there seems to be no many changes. At last graph we compare only II method and IV method. The distance is less than 700. These two methods have smaller distances, and among them the $\mathrm{V}$ method is better. 

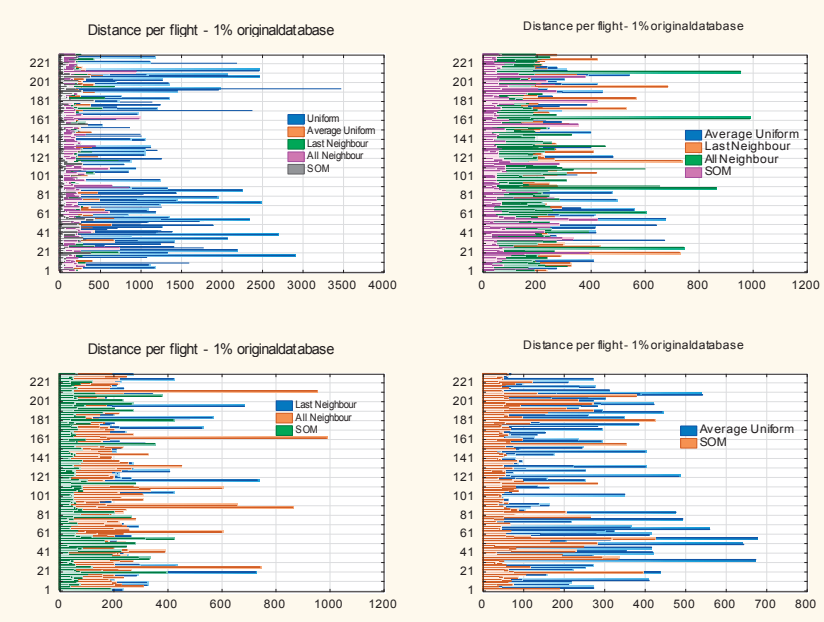

Fig. 3. Comparison of distance variability per flight of the different methods

The figure 4 shows the high dispersion of the total distances of the five methods. The All Neighbour and SOM methods have a low inter-quartile range. The All Neighbour has many extreme values, i.e. this has several flights with the biggest distance between the sample and the original dataset. The SOM, although the extreme values, these don't represent large distances.

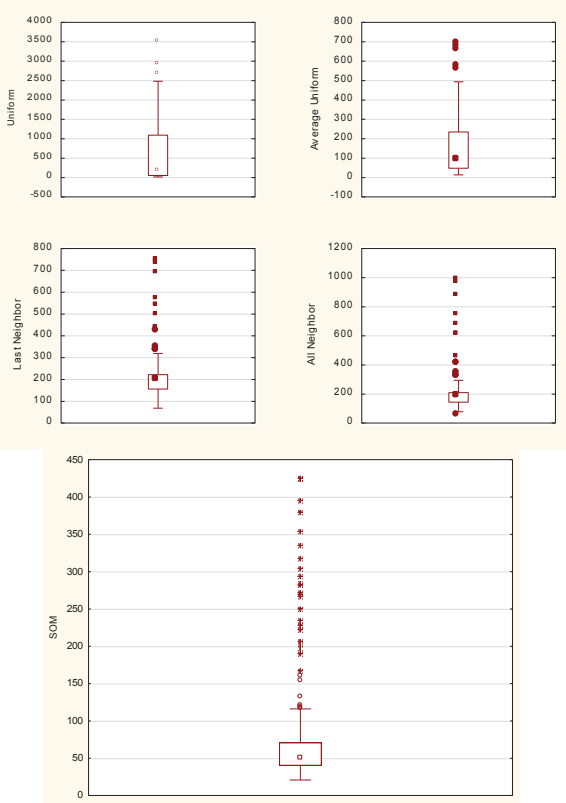

Fig. 4. Distribution of Total distance

The SOM method has the most flights with low distances between the sample and the original dataset as is shows by figure 5 .

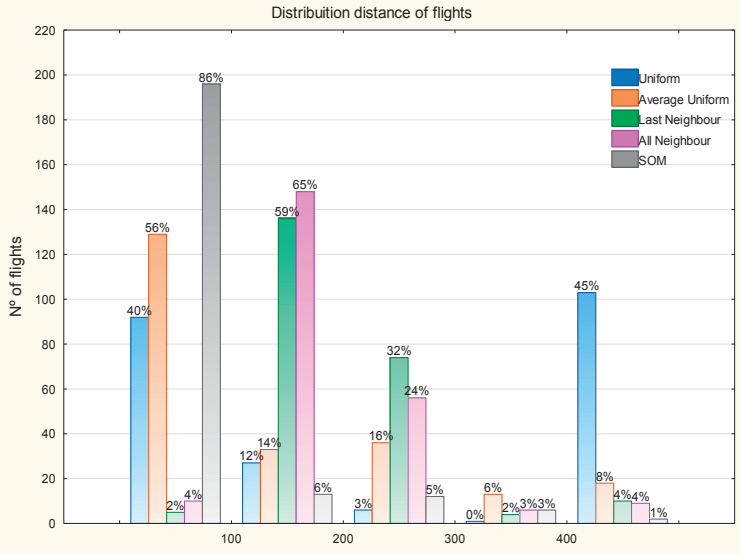

Fig. 5. Distribution distance of flights

The V method is also what has the low total distance (the sum of the distances of all the flights of the sample to the original data set); its distance is half of observed for the II method, figure 6 .

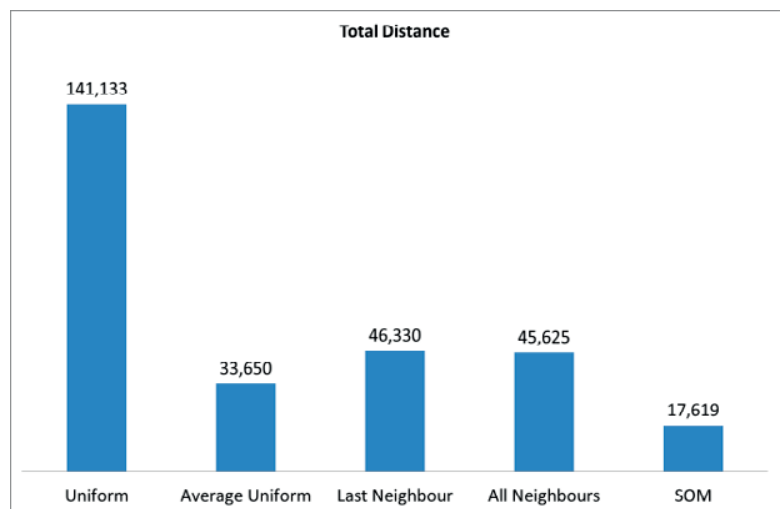

Fig. 6. Total Distance for all flights

\section{CONCLUSIONS}

Different methods are used to select the sample close the original dataset but without redundancy instances. The results are analyzed in order of decreasing sample size, time consuming and similarity of original dataset.

In future works, where we intend to apply new procedures to study the engine behaviour parameters and their interactions, we need the sample with these characteristics.

The last three methods used are based on the distance between instances, so they present good values of the dispersion distances. They have a low dispersion for the set of flights.

The method that shows the best performance is the SOM, but it is the most time-consuming. We need use other options for training this neural network to decrease the time consuming. 
An alternative method is the Average Uniform. It shows a worse performance than SOM but is the easy implementation and has a good time-consuming.

\section{REFERENCES}

[1] Babbar A.;Syrmos V.L.;Ortiz E.M.;Arita M.M., "Advanced Diagnostics and Prognostics for Engine Health Monitoring," presented at the Aerospace conference, 2009 IEEE, Big Sky, MT 2009.

[2] Pandian A.; Ali A., "A review of recent trends in machine diagnostics and prognosis algorithms," in World Congress on Nature \& Biologically Inspired Computing, 2009, pp. 1731-1736.

[3] Jardine A.K.S.; Lin D.; Banjevic D. (2006) A review on machinery diagnostics and prognostics implementing condition-based maintenance. Mechanical Systems and Signal Processing. 1483-1510.

[4] Thurston M.G., "An open standard for Web-based condition-based maintenance systems," in AUTOTESTCON Proceedings, 2001. IEEE Systems Readiness Technology Conference, Valley Forge, 2001, pp. 401-415.

[5] Ly C.;Tom K.;Byington C. S.;Patrick R.;Vachtsevanos G. J., "Fault diagnosis and failure prognosis for engineering systems: A global perspective," in Automation Science and Engineering, 2009. CASE 2009. IEEE International Conference on, 2009, pp. 108-115.

[6] Kipersztok O.;Dildy G. A., "Evidence-based Bayesian networks approach to airplane maintenance," in Neural Networks, 2002. IJCNN '02. Proceedings of the 2002 International Joint Conference on, 2002, pp. 2887-2891.

[7] Heng A.; Zhang S.;Tan A.;Mathew J., "Rotating machinery prognostics: State of the art, challenges and opportunities," Mechanical Systems and Signal Processing, vol. 23, pp. 724-739, 2009.

[8] Cumming S., "Neural networks for monitoring of engine condition data," Neural Computing \& Applications, vol. 1, pp. 96-102, 1993.

[9] Wang W.; Zhang W. (2005, February 11) A Model To predit The residual Life of Aircraft Engines Based Upon Oil Analysis Data. Wiley Periodicals, Inc. 276 284.

[10] Yedavalli R.K., "Robust Estimation and Fault Diagnostics for Aircraft Engines with uncertain model data," in American Control Confere, New York, 2007, pp. 2822-2827.

[11] Viassolo D.E.; Adibhatla S.; Brunell B.J.; Down J.H.; Gibson N.S.; Kumar A.; Mathews H.K.; Holcomb L.D, "Advanced Estimation for Aircraft Engines," in American Control Conference, New York, 2007, pp. 2807-2820.

[12] Babbar A.;Ortiz E.; V. L.Syrmos, "Extreme Value Theory for engine health monitoring and diagnosis," in Control Applications, (CCA) \& Intelligent Control, (ISIC), 2009 IEEE, 2009, pp. 1069-1074.

[13] Babbar A.; Ortiz E.M.;Syrmos V.L., "Fuzzy clustering based fault diagnosis for aircraft engine health management," in 17th Mediterranean Conference on Control and Automation, Thessaloniki, Greece 2009, pp. 199-204.

[14] Yukitomo A. R.; Syrmos V. L., "Forecasting gas turbine Exhaust Gas Temperatures using Support Vector Machine Experts and Genetic Algorithm," in 18th Mediterranean Conference on Control \& Automation Marocco, 2010, pp. 345-350.

[15] Wang P.; Jin T., "Optimal Replacement of SafetyCritical aircraft parts with utilization uncertainties," in IIE Transaction on Reliability, 2010.

[16] Rong X.;Zuo H.;Chen Z., "Civil aero-engine health management integrating with life prediction and maintenance decision-making," in Prognostics and Health Management Conference, 2010. PHM '10., 2010, pp. 1-6.

[17] Cottrell M.; Gaubert P.; Eloy C.; François D.; Hallaux G.; Lacaille J.; Verleysen M., "Fault prediction in aircraft engines using Self-Organizing Maps," Advances in Self-Organizing Maps, pp. 37-44, 2009.

[18] Côme E.;Cottrell M.;Verleysen M.;Lacaille J., "Aircraft engine health monitoring using selforganizing maps," presented at the Proceedings of the 10th industrial conference on Advances in data mining: applications and theoretical aspects, Berlin, Germany, 2010.

[19] Côme E.;Cottrell M.;Verleysen M.;Lacaille J., "Aircraft engine fleet monitoring using selforganizing maps and edit distance," presented at the Proceedings of the 8 th international conference on Advances in self-organizing maps, Espoo, Finland, 2011.

[20] Liu H.; Motoda H., "On Issues of Instance Selection," Data Mining and Knowledge Discovery, vol. 6, pp. 115-130, 2002/04/01 2002.

[21] Fernández A.; Duarte A.; Hernández R.; Sánchez Á., "GRASP for Instance Selection in Medical Data Sets," in Advances in Bioinformatics. vol. 74, M. Rocha, et al., Eds., ed: Springer Berlin Heidelberg, 2010, pp. 53-60.

[22] Reinartz T., "A Unifying View on Instance Selection," Data Mining and Knowledge Discovery, vol. 6, pp. 191-210, 2002/04/01 2002.

[23] Gama J.; Carvalho A.;Faceli K.; Lorena A.; Oliveira M., Extração de Conhecimento de Dados $1^{\mathrm{a}}$ edição ed. Lisboa, 2012.

[24] Olvera-López J. A.; Carrasco-Ochoa J. A.; MartínezTrinidad J. F.; Kittler J., "A review of instance selection methods," Artificial Intelligence Review, vol. 34, pp. 133-143, 2010/08/01 2010.

[25] C. Common Taxonomy Team. (2012) Phase Of Flight - Definitions And Usage Notes. 


\title{
FMECA Analysis for the Assessing of Maintenance Activity for Power Transformers
}

\author{
Mohamed Mahmoud Abdel Fattah Khali1 ${ }^{1}$; Loredana Cristaldi ${ }^{2}$; Marco Faifer ${ }^{3}$ \\ 1․mohamedmahmoud.khalil@polimi.it; ${ }^{2}$ loredana.cristaldi@polimi.it; ${ }^{3} \underline{\text { marco.faifer@polimi.it }}$ \\ 1,2,3 DEIB -Politecnico di Milano \\ Milano, Italy
}

\begin{abstract}
A serious failure of a large power transformer can generate substantial costs for the transport to factory, repair and financial losses resulting from power interruption. Therefore, utilities have a clear incentive to assess the actual condition of high voltage transformers, with the aim to minimize the risk of failures and avoid forced unexpected outages. Special attention in this respect is given to large transformers. In this paper, a general FMECA for outage causes of $220 \mathrm{kV}$ power transformers is presented, including the local and final effects, and recommended actions to avoid these outages. Assignment of risk priority numbers to the various outage causes, which might occur at this voltage level, are carefully considered.
\end{abstract}

\section{Keywords-Transformer Failures, FMECA.}

\section{INTRODUCTION}

According to ANSI/IEEE C57.117-1986 [1], a transformer is a static electric device consisting of a winding or two, or more coupled windings, with a magnetic core for introducing mutual coupling between electric circuits through electromagnetic induction.

The transformer includes all transformer-related components, such as bushings, load tap changers, fans, temperature gauges, etc., and excludes all system-related components (e.g. surge arresters, grounding resistors, highvoltage switches, low-voltage switches and house service equipment).

Transformers can be classified into many types such as power transformers, autotransformers, regulating transformers, etc. Based on their application, transformers are classified into substation transformers, transmission tie transformers, unit transformers, etc. The study reported in this paper considers 220 $\mathrm{kV}$ power transformers for utility applications.

Transformers have a key role in power systems and their reliability directly affects the reliability of the whole network. Outage of transformers is considered a failure, since it is an event that determines a fault state (the transformer cannot perform its specified function) [1].

Generally, transformer outages are either forced or scheduled, and both are done by means of switching operations. Forced outages of transformers are mainly due to automatic switching operations performed by protection systems [2], [3], [4]. They are caused by either external (such as transmission line faults) or internal causes (such as core failure and winding failure). In [3] and [4] more details about failure statistics of transformer subassemblies are given. For the purpose of abbreviation in this paper, the term 'outage' will refer to 'forced outage'.

Transformers outages are classified according to their operating voltage level in the network. In this paper the $220 \mathrm{kV}$ voltage level was selected, because it is considered one of the oldest transmission networks in many European countries[5], [6]. For instance, the generation plants in Germany are linked to the unified Grid through $220 \mathrm{kV}$ level [7]. In both Romania and Switzerland, the $220 \mathrm{kV}$ system is considered the backbone of transmission network [8],[9].

Since large groups of transformers operating in the world have already exceeded 30-year exploitation period [25], in the literature several surveys highlighting the outage causes of transformers can be found. A ten years survey by a CIGRÉ working group, on internal failures in large substation utility transformers [2] pointed out that about $41 \%$ of failures were due to on-load tap changers (OLTC) and about $19 \%$ were due to the windings. The number of transformers, under investigation, with on load tap changer was 15786 unityears and voltage level ranges from $100 \mathrm{kV}$ to $300 \mathrm{kV}$. The total numbers of failures were 370 during the study period 1968-1978. Fig. 1 shows the percentage failure distribution for power transformers with onload tap changers [2].

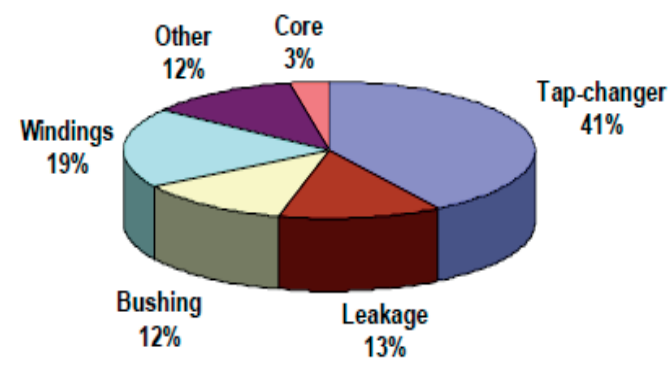

Fig. 1. Percentage failure of power transformers (CIGRE survey).

Transformer internal failure data analysis in South Africa in the period 1985-1995 is presented in [3]. The failure analysis was based on 188 outages of transformers with a rated voltage ranging from $88 \mathrm{kV}$ to $765 \mathrm{kV}$ and rated power from 20 to 800 MVA. Considering 100-400MVA transformers, the total number of failures for general ageing, core problems, lighting/switching, others, short circuit, and tap changers were $15,8,2,15,1$, and 5 respectively. In 2006 this investigation was extended for units failing in the period 1996 to 2006, and was based on failure study of step-up generator, transmission and 
distribution transformer failures. Bushings, tap changers and windings represent about $79 \%$ of outage causes during this study period. The contribution of core related failures was $2 \%$ only [4].

Another study was done on 50 outages of 500 transformers with rated power ranging from 14MVA to 175 MVA [19]. Tap changer and bushing failure were the dominant causes of outage for transformers having a rated voltage ranging from 110 to 150 $\mathrm{kV}$. In [20] the failure statistics of transformers in Thailand was studied by considering the scattering of history data. The data were collected from 44 transformers with rated voltage of 230/115/22 kV with total 68 minor failures. The failure statistical analysis shows that other failure was the highest, $41.3 \%$, followed by bushing, $31.7 \%$, tap changer, $17.5 \%$, leakage $7.9 \%$ and winding $1.6 \%$. Outage data analysis for power transformers in Egypt over the period 2002-2009 is presented in [21], [22], [23], [9].

TABLE I. TRANSFORMERS OUTAGE CAUSES

\begin{tabular}{|c|c|c|}
\hline Failure & \multicolumn{2}{|c|}{ Outage Cause } \\
\hline \multirow{5}{*}{$\stackrel{\grave{g}}{\dot{\Xi}}$} & Outage category & \\
\hline & Electrical outage & $\begin{array}{ll}\text { - } & \text { Buchholz \& Pressure relief } \\
\text { (B\&P) } \\
\text { - } & \text { Over current (OC) } \\
\text { - } & \text { Earth fault protection (EFP) } \\
\text { - } & \text { Differential protection (DP) } \\
\text { - } & \text { Outage of incomers (OI) } \\
\text { - } & \text { Bus bar protection (BBP) }\end{array}$ \\
\hline & Mechanical outage & $\begin{array}{ll}\text { - } & \text { Breakdown \& Damage } \\
\text { (B\&D)* } \\
\text { - } & \text { Fire Fighting System (FFS) } \\
\text { - } & \text { Hot spots (HS) } \\
\text { - } & \text { Oil, Air or SF6 leakage } \\
\end{array}$ \\
\hline & $\begin{array}{l}\text { Environmental } \\
\text { outage }\end{array}$ & $\begin{array}{ll}- & \text { Bad weather (BW) } \\
\text { - } & \text { Animal \& birds (A\&B) } \\
\end{array}$ \\
\hline & Others outage & $\begin{array}{ll}- & \text { No Flags }(\mathrm{NF}) \\
& \text { Others } \\
\end{array}$ \\
\hline$\cdot \frac{\grave{a}}{\sum^{\pi}}$ & $\begin{array}{ll}\text { - } & \text { Tap changer } \\
\text { - } & \text { Winding } \\
\text { - } & \text { Core } \\
\text { - } & \text { Bushing } \\
\text { - } & \text { Tank and Conse } \\
\text { - } & \text { Insulation deteri }\end{array}$ & $\begin{array}{l} \\
\text { tor } \\
\text { tion }\end{array}$ \\
\hline
\end{tabular}

* B\&D include external equipment failures in transformer circuit (current $\&$ potential transformer, surge arrestor, etc.)

Surveys and reports put in evidence two main kinds of failure sources of transformer outages. Major failures, those that are severe and require the removal of transformer to be reprocessed under factory conditions or its replacement. Minor failures can be repair on site. An overall view on general outage causes of transformers, according to previous surveys, is shown in Table 1. The others outage causes are related to over flux tripping, circuit breaker failure, low oil level, etc.

This paper is organized as follows, in section II the qualitative and quantitative failure modes and effect analysis (FMEA and FMECA) is discussed, while in section III FMEA on power transformers is reported.

\section{FMECA}

IEC-60182 [10] defines FMEA as a systematic procedure for the analysis of a system which target is the identification of the potential failure modes, their causes and effects on system performance. It is a bottom up failure analysis method that highlights common failure causes of the system and provide a rank for each failure mode related to element importance. Additionally, it focuses on system parts and/or functions that are most likely to fail. MIL-Std-1629A [11] consideres the usefulness of the FMEA as a reliability tool during design phase for decision making process upon the effectiveness of system functional failures and problems information. On other hand, TM 5-698-4 standard [12] and ANSI/IEEE std. 352 [13] depict the importance of FMEA for safety analysis, maintainability plan analysis and failure detection.

FMEA should include a list of equipment failure modes, like that shown in table 1 , reasons of these failures, local effects that refer to the consequences of each possible failure on the system element, final effects that describe the impact of that possible failures on the whole system, an alternative provision or recommended corrective actions to avoid these failures [10], [11], [12], [13]. Finally, a critically analysis (CA) allowing to assign a Risk Priority Number (RPN) to each failure mode must be done:

$$
\mathrm{RPN}=S \times O \times D
$$

where $S$ (Severity) represents the severity on the base of the assessment of the worst potential consequences resulting from an item failure, $O$ (Occurrence) denotes the probability of failure mode occurrence and $D$ (Detection) represents the chance to identify and eliminate the failure before the system or customer is affected. Fig. 2 shows a schematic diagram of the necessary steps to carry out both FMEA and CA.

In this way the definition of RPN allows to introduce the criticality of outages (FMECA). The criteria for selecting severity, occurrence, and detection values depends on standards [10], [11], [12]. In this paper, an analysis based on IEC-60182 evaluation criteria, as shown in TABLE II. is applied to power transformers.

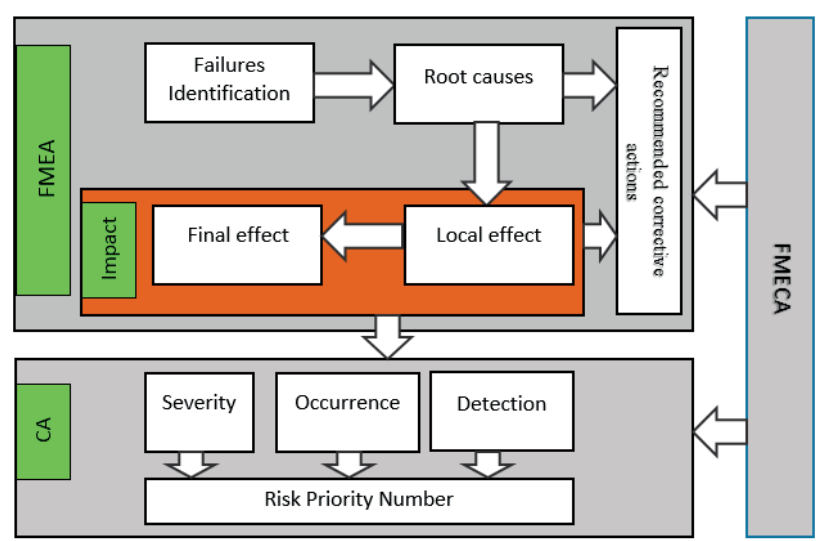

Fig. 2 Schematic Diagram of FMECA 


\begin{tabular}{|c|c|c|c|}
\hline Occurrence $(O)$ & Severity $(S)$ & Detection $(D)$ & Ranking \\
\hline Failure is unlikely & No discernible effect & Almost certain & 1 \\
\hline \multirow{2}{*}{$\begin{array}{c}\text { Low: } \\
\text { Relatively few failures }\end{array}$} & Very minor & Very high & 2 \\
\hline & Minor & High & 3 \\
\hline \multirow{3}{*}{$\begin{array}{c}\text { Moderate: } \\
\text { Occasional failures }\end{array}$} & Very low & Moderately high & 4 \\
\hline & Low & Moderate & 5 \\
\hline & Moderate & Low & 6 \\
\hline \multirow{2}{*}{$\begin{array}{c}\text { High: } \\
\text { Repeated Failures }\end{array}$} & High & Very low & 7 \\
\hline & Very high & Remote & 8 \\
\hline \multirow{2}{*}{$\begin{array}{l}\text { Very high: } \\
\text { Failure is almost unavoidable }\end{array}$} & Hazardous with warning & Very remote & 9 \\
\hline & Hazardous without warning & Absolutely uncertain & 10 \\
\hline
\end{tabular}

\section{FMECA FOR $220 \mathrm{KV}$ TRANSFORMERS}

The FMECA of functional/components minor and major failures of in-service transformers are estimated in Table III and Table IV respectively. In these tables attention is given to all possible major and minor failures that might result in interruption of transformer service. The impact of minor failures are not significant on transformer life. Therefore, the final effects of minor failures are interpreted in terms of transformer repair time duration. However, the frequent over current outages in the long run, resulting from overloading, lead to insulation degradation over time [14]. Also operation of Buchholz and pressure relief gives a strong indication to high percentage of combustion gases that are considered the catalyst agent for transformer ageing [15].

As reported in Table III overcurrent outages scores the highest RPN. Nowadays, the goal for the majority of transmission dispatch centers is the operation of transformers within IEC-60354 loading limit [16]. However, their ultimate challenge is the rapid growth of loads. Consequently, transformers are tripped frequently by overcurrent protection.

On other hand, earth fault and differential protection have the same high RPN. Their occurrence represent a hazard for the transformer operation. Generally, the low voltage side of $220 \mathrm{kV}$ transformers feed medium level transformers, $132 \mathrm{kV}$, $66 \mathrm{kV}$, or 33 $\mathrm{kV}$, and they are quite far from the unbalance in the distribution system. Therefore, the activation of earth fault protection in $220 \mathrm{kV}$ requires more attention and investigation for recognizing the fault nature. The differential protection operates if there is a disturbance in the protection zone, its operation gives a strong indication to utilities for a serious hazard within this zone. This will require site tests for the transformer including gas analysis. Buchholz and pressure relief are utterly similar to differential protection, its protective zone is limited to the transformer body.

Outage of incomers is a source of disturbance for utilities network operation, these outages occur frequently in transmission networks that have limited generation capabilities. It is associated with the disappearance of voltage from the $220 \mathrm{kV}$ busbar. This will force the transmission utility to disconnect the transformer from both sides and reconnect it again.

Table IV assigned the highest RPN in transformer major failures to insulation deterioration and on-load tap changer respectively. Insulation deterioration is an irreversible phenomena associated with transformers in service that results from oxygen, moisture and temperature. Moreover, it is considered the major reason of transformer failures before reaching their designed expected life [17]. Tap changer is the only moveable element in the transformer, and had been prone to a range of failures associated with the switching contacts and drive mechanism. Therefore, the condition of the tap changer oil and its contacts resistance are the most encountered problems to power utilities [18]. Nowadays, large number of utilities mount filter units externally on the tap changer compartment. However, these units reduce the filtration periods of the oil but don't give a clear view on the state of the switching contacts. Thus, the contacts degradation and mechanical defects can remain undetected.

Core and windings failures are the most catastrophic scenarios of transformers outages, they require an immediate replacement of the transformer and, in case a spare transformer is not directly available, additional costs for not delivered power and penalty costs should also be considered. The frequency of their occurrence is very low but their impact on the network operation is extremely high. 
TABLE III. MINOR FAILURES FMECA OF TRANSFORMERS

\begin{tabular}{|c|c|c|c|c|c|c|c|c|c|}
\hline Failure & $\begin{array}{c}\text { Outage } \\
\text { mode }\end{array}$ & Possible outage cause & Local effect & Final effect & $\begin{array}{c}\text { Compensating provision } \\
\text { against failure } \\
\end{array}$ & $\mathbf{S}$ & O & D & RPN \\
\hline \multirow{16}{*}{$\dot{\bar{g}}$} & B \& P & Internal arcs & $\begin{array}{c}\text { Excessive pressure and } \\
\text { combustion gases }\end{array}$ & $\begin{array}{l}\text { Long repair time \& long } \\
\text { term transformer ageing } \\
\end{array}$ & $\begin{array}{l}\text { Dissolved gas analysis } \\
\text { Condition monitoring }\end{array}$ & 5 & 5 & 2 & 50 \\
\hline & $\mathrm{OC}$ & $\begin{array}{l}\text { Overloading / External } \\
\text { faults }\end{array}$ & Thermal ageing & $\begin{array}{c}\text { Intermediate repair time } \\
\& \text { long term transformer } \\
\text { ageing }\end{array}$ & System monitoring & 6 & 6 & 2 & 72 \\
\hline & EFP & $\begin{array}{l}\text { Winding inter turn / core/ } \\
\text { external faults }\end{array}$ & Loss of power & Short repair time & System monitoring & 5 & 4 & 3 & 60 \\
\hline & DP & $\begin{array}{l}\text { Internal fault within the } \\
\text { protected region }\end{array}$ & Loss of power & Intermediate repair time & $\begin{array}{c}\text { Preventive maintenance of } \\
\text { transformer } \\
\text { switchgear/accessories }\end{array}$ & 5 & 4 & 3 & 60 \\
\hline & OI & $\begin{array}{l}\text { Voltage of HV bus bar } \\
\text { disappeared as a result of } \\
\text { power generation outages/ } \\
\text { faults at BB incomers }\end{array}$ & $\begin{array}{l}\text { Immediate shutdown of } \\
\text { transformer and loss of } \\
\text { power }\end{array}$ & Short repair time & System monitoring & 6 & 4 & 2 & 48 \\
\hline & $\mathrm{BBP}$ & $\begin{array}{l}\text { Internal fault within the } \\
\text { protected region }\end{array}$ & Power interruption & Short repair time & $\begin{array}{l}\text { Protection design and proper } \\
\text { setting of protection relays }\end{array}$ & 7 & 3 & 2 & 42 \\
\hline & B \& D & $\begin{array}{c}\text { Breakdown \& damage of } \\
\text { transformer/main circuit } \\
\text { HV equipment }\end{array}$ & $\begin{array}{c}\text { Power Interruption during } \\
\text { the replacement of } \\
\text { damaged equipment }\end{array}$ & Long repair time & $\begin{array}{c}\text { Preventive maintenance } \\
\text { through electrical tests to } \\
\text { check up insulation condition }\end{array}$ & 7 & 3 & 2 & 42 \\
\hline & FFS & $\begin{array}{c}\text { A real hazard or } \\
\text { malfunction in Firefighting } \\
\text { sensors/valves }\end{array}$ & $\begin{array}{l}\text { Power interruption for } \\
\text { real hazard, immediate } \\
\text { shut down of FFS for } \\
\text { malfunction }\end{array}$ & $\begin{array}{c}\text { Short repair time } \\
\text { ( FFS malfunctioning) }\end{array}$ & $\begin{array}{l}\text { Scheduled maintenance } \\
\text { program to check the valves } \\
\text { and sensor conditions, } \\
\text { pressure of air and water of } \\
\text { FF system }\end{array}$ & 2 & 3 & 3 & 18 \\
\hline & HS & Loose connections & $\begin{array}{l}\text { Overheating and power } \\
\text { losses }\end{array}$ & Short repair time & Thermal Image & 2 & 4 & 4 & 32 \\
\hline & Leakage & $\begin{array}{c}\text { Leakage of oil from main } \\
\text { tank/SF6 gas from GIS } \\
\text { compartment/ air from } \\
\text { Circuit breaker }\end{array}$ & $\begin{array}{c}\text { Low level of oil operates } \\
\text { buchholz relay/ circuit } \\
\text { breaker will be in blocked } \\
\text { state for Sf6 or air } \\
\text { leakage }\end{array}$ & Long repair time & $\begin{array}{l}\text { Periodic visual inspection of } \\
\text { pressure gauges }\end{array}$ & 2 & 4 & 3 & 24 \\
\hline & FO & Deposit of dirt on bushings & $\begin{array}{l}\text { Arcing and tracking } \\
\text { Of bushings }\end{array}$ & Intermediate repair time & $\begin{array}{c}\text { Periodic cleaning of } \\
\text { transformer tank and } \\
\text { bushings }\end{array}$ & 2 & 4 & 4 & 32 \\
\hline & BW & Wind and rains & $\begin{array}{c}\begin{array}{c}\text { Slippage of transformer } \\
\text { accessories and protection } \\
\text { devices }\end{array} \\
\end{array}$ & Intermediate repair time & $\begin{array}{c}\text { Checking the outdoor } \\
\text { protection wires /cables and } \\
\text { clearance distances }\end{array}$ & 4 & 3 & 2 & 24 \\
\hline & $\mathrm{A} \& \mathrm{~B}$ & $\begin{array}{c}\text { Crossing the magnetic field } \\
\text { of the transformer }\end{array}$ & $\begin{array}{l}\text { Phase to phase or phase } \\
\text { to ground faults }\end{array}$ & Intermediate repair time & $\begin{array}{l}\text { Caging outdoor visible } \\
\text { connections }\end{array}$ & 4 & 3 & 2 & 24 \\
\hline & $\mathrm{HM}$ & $\begin{array}{l}\text { Wrong switching, } \\
\text { intervening actions within } \\
\text { transformer magnetic field }\end{array}$ & $\begin{array}{c}\text { Human injury risk, loss of } \\
\text { power }\end{array}$ & Short repair time & $\begin{array}{l}\text { Following up a firmly safety } \\
\text { rules }\end{array}$ & 7 & 3 & 2 & 42 \\
\hline & NF & $\begin{array}{l}\text { No alarm or indication to } \\
\text { transformer outage }\end{array}$ & $\begin{array}{l}\text { Overloading risk on } \\
\text { nearby parallel } \\
\text { transformer }\end{array}$ & $\begin{array}{c}\text { Intermediate repair time } \\
\text { for investigating the } \\
\text { exact outage reason }\end{array}$ & $\begin{array}{l}\text { Considering the design of } \\
\text { protection \& alarm system }\end{array}$ & 3 & 3 & 4 & 36 \\
\hline & Others & $\begin{array}{l}\text { Malfunction of circuit } \\
\text { breakers, over flux } \\
\text { protection, abnormal } \\
\text { sounds of operation, tap } \\
\text { changer control, etc. }\end{array}$ & Loss of power & High repair time & $\begin{array}{c}\text { Preventive maintenance of } \\
\text { transformer } \\
\text { switchgear/accessories }\end{array}$ & 3 & 5 & 3 & 45 \\
\hline
\end{tabular}


TABLE IV. MAJOR FAILURES FMECA OF TRANSFORMERS

\begin{tabular}{|c|c|c|c|c|c|c|c|c|c|}
\hline Failure & $\begin{array}{l}\text { Outage } \\
\text { mode }\end{array}$ & $\begin{array}{c}\text { Possible outage } \\
\text { cause }\end{array}$ & Local effect & Final effect & $\begin{array}{c}\text { Compensating provision } \\
\text { against failure }\end{array}$ & $\mathbf{S}$ & $\mathbf{O}$ & D & RPN \\
\hline \multirow{6}{*}{$\stackrel{\bar{a}}{\frac{\operatorname{ag}}{2}}$} & $\begin{array}{c}\text { On-load } \\
\text { tap changer }\end{array}$ & $\begin{array}{l}\text { Wearing out of } \\
\text { selector contact, } \\
\text { loose base, loose } \\
\text { spring, low } \\
\text { insulation of oil }\end{array}$ & $\begin{array}{l}\text { Arcs and partial } \\
\text { discharges inside } \\
\text { tap. Overheating } \\
\text { and excessive } \\
\text { pressure }\end{array}$ & $\begin{array}{l}\text { Replacement of } \\
\text { tap changer and } \\
\text { loss of power }\end{array}$ & $\begin{array}{l}\text { Preventive maintenance } \\
\text { based on regular periods or } \\
\text { number of tap changer } \\
\text { operations. } \\
\text { Online oil filtration. }\end{array}$ & 7 & 4 & 7 & 196 \\
\hline & Winding & $\begin{array}{l}\text { Continuous } \\
\text { Overloading, } \\
\text { moisture } \\
\text { contents, sludge, } \\
\text { oxidation }\end{array}$ & $\begin{array}{l}\text { Thermal and } \\
\text { mechanical } \\
\text { ageing of } \\
\text { winding. } \\
\text { Incapability to } \\
\text { stand future short } \\
\text { circuits }\end{array}$ & $\begin{array}{l}\text { Transformer } \\
\text { ageing, and } \\
\text { replacement of } \\
\text { transformer }\end{array}$ & $\begin{array}{c}\text { Mechanical and Electrical } \\
\text { condition assessment } \\
\text { (SFRA, DC resistance of } \\
\text { winding, turns ratio, } \\
\text { Meggar) }\end{array}$ & 9 & 2 & 9 & 162 \\
\hline & Core & $\begin{array}{l}\text { Rust deposits, } \\
\text { excessive heating } \\
\text { or burning of the } \\
\text { laminations } \\
\text { insulation }\end{array}$ & $\begin{array}{l}\text { Hot spot, high } \\
\text { losses as a result } \\
\text { of eddy current } \\
\text { and flux } \\
\text { distortion }\end{array}$ & $\begin{array}{l}\text { Transformer } \\
\text { ageing. } \\
\text { Replacement of } \\
\text { transformer }\end{array}$ & $\begin{array}{l}\text { Condition monitoring } \\
\text { through Dissolved gas } \\
\text { analysis, oil and furan } \\
\text { analysis. }\end{array}$ & 9 & 2 & 9 & 162 \\
\hline & $\begin{array}{l}\text { Oil-Filled } \\
\text { Bushings }\end{array}$ & $\begin{array}{l}\text { Moisture from } \\
\text { leaky gaskets. } \\
\text { Gas bubbles } \\
\text { from prolonged } \\
\text { exposure to } \\
\text { extreme } \\
\text { electrical, } \\
\text { mechanical and } \\
\text { environmental } \\
\text { conditions. }\end{array}$ & $\begin{array}{l}\text { Conducting } \\
\text { tracks that can } \\
\text { short out one or } \\
\text { more layers of } \\
\text { the bushing. }\end{array}$ & $\begin{array}{l}\text { Bushing/ } \\
\text { gasket } \\
\text { replacement }\end{array}$ & $\begin{array}{l}\text { Thermal image and } \\
\text { bushing tan delta, } \\
\text { capacitance monitoring. } \\
\text { Periodic inspection of oil } \\
\text { level of the busing window }\end{array}$ & 6 & 2 & 7 & 84 \\
\hline & Tank & $\begin{array}{l}\text { Tank rupture as a } \\
\text { result of severe } \\
\text { short circuit and } \\
\text { malfunction in } \\
\text { protection system }\end{array}$ & $\begin{array}{l}\text { Transformer } \\
\text { replacement }\end{array}$ & Loss of power & $\begin{array}{l}\text { Regular testing of } \\
\text { protection systems }\end{array}$ & 9 & 2 & 3 & 54 \\
\hline & $\begin{array}{c}\text { Insulation } \\
\text { deterioration }\end{array}$ & $\begin{array}{l}\text { Oxidation, high } \\
\text { acidity, low } \\
\text { breakdown of oil, } \\
\text { moisture of } \\
\text { windings paper }\end{array}$ & $\begin{array}{c}\text { High arcing, } \\
\text { corona, and } \\
\text { partial discharge }\end{array}$ & $\begin{array}{l}\text { Oil filtration / } \\
\text { oil replacement } \\
\text { in site, or } \\
\text { reprocessing of } \\
\text { insulation } \\
\text { condition in } \\
\text { factory }\end{array}$ & $\begin{array}{c}\text { Dissolved gas analysis } \\
\text { monitoring, Furan test, tan } \\
\text { delta of oil, and chemical } \\
\text { analysis of oil } \\
\text { characteristics }\end{array}$ & 8 & 4 & 8 & 256 \\
\hline
\end{tabular}

\section{CONCLUSIONS}

The aim of presenting a FMECA on utility transformers is to provide power utilities a guide of feasible hazards that could interrupt transformers operation and result in financial losses. FMECA risk priority number depends on many factors and varies according to the operating and environmental condition of power utilities. We tried to generalize the severity, occurrence and detection of the $220 \mathrm{kV}$ transformer failures for a better performance in the transmission network.

\section{REFERENCES}

[1] IEEE Guide for Reporting Failure Data for Power Transformers and Shunt Reactors on Electric Utility Power Systems. 1986.

[2] An international survey on failures in large power transformers in service, Final Report of Working Group 05 of Study Committee 12, Electra, 88, May 1983.

[3] MSA Minhas, JP Reynders, and PJ de klerk, "Failure in power system transformers and appropriate monitoring techniques," presented at the 11th International Symposium on High Voltage Engineering, London, U.K., 1999

[4] J.N. Jagers, J. Khosa, P.J. De Klerk, and C.T. Gaunt," Transformer Reliability and Condition Assessment in a South African Utility, "presented in XV International Symposium on High Voltage Engineering, Ljubljana, Slovenia, August 2007.

[5] Dietermann T, Balzer G, Neumann C. The development in electricity exchanges and their impact on the German transmission system. In: Proceedings of the power tech, Lausanne, Switzerland; 2007. p. 12-6

[6] European Network of Transmission System of Electricity, TEN-YEAR NETWORK DEVELOPMENT PLAN 2010-2020, final report 2010. Available on www.entsoe.eu

[7] J. Jansen, "EHV lines in the Federal Republic of Germany," IEEE Spectrum, 7 (4) (2009), pp. 33-40

[8] Mateescu, E.; Marginean, D.; Florea, G.; Gal, S.I.A.; Matea, C., "Reconductoring using HTLS conductors. Case study for a $220 \mathrm{kV}$ double circuit transmission LINE in Romania," Transmission and Distribution Construction, Operation and Live-Line Maintenance (ESMO), 2011 IEEE PES 12th International Conference, pp.1-7, May 2011.

[9] M. Abdelfatah, M. EL-Shimy, and H. M. Ismail, "Reliability and maintainability analysis of medium voltage transformers in Egypt," in 8th 
International Conference on Electrical Engineering ICEENG-8, Cairo, Egypt, 2012

[10] IEC-60182, Analysis techniques for system reliability- Procedure for failure mode and effects analysis (FMEA), 2006.

[11] MIL-STD-1629A, Procedures for Performing a Failure Mode, Effects and Criticality Analysis, Nov. 1980.

[12] Department of the Army, TM 5-698-4, Failure Modes, Effects and Criticality Analyses (FMECA) for Command, Control, Communications, Computer, Intelligence, Surveillance, and Reconnaissance (C4ISR) Facilities, 29 September 2006.

[13] IEEE guide for general principles of reliability analysis of nuclear power generating station protection systems, ANSI/IEEE std. 352, 1987.

[14] Sen, P.K.; Sarunpong Pansuwan, "Overloading and loss-of-life assessment guidelines of oil-cooled transformers," Rural Electric Power Conference, 2001, pp.B4/1-B4/8, 2001

[15] IEEE Guide for the Interpretation of Gases Generated in Oil-Immersed Transformers," IEEE Std. C57.104-2008 (Revision of IEEE Std. C57.104-1991), pp.1-36, 2009.

[16] IEC-60354, loading guide for oil-immersed power transformers, 2nd edition, 1991.

[17] Arshad, M.; Islam, S.M., "Significance of cellulose power transformer condition assessment," Dielectrics and Electrical Insulation, vol.18, no.5, pp.1591-1598, October 2011

[18] Jauch, E.T., "How Tapchanger Controls Contribute to Premature Transformer Failures," Power Engineering Society General Meeting, pp.1-5, June 2007.
[19] R. Jongen, Peter Morshuis, E. Gulski, and J. Smit, "Statistical analysis of power transformer component life time, " in Proc. 8th International Power Eng. Conf. (IPEC 2007), Singapore, 2007, pp. 1273-1277.

[20] Thanapong Suwanasri, Ekkachai Chaidee, and Cattareeya Adsoongnoen, "Failure statistics and power transformer condition evaluation by dissolved gas analysis technique," in international Conference on Condition Monitoring and Diagnosis, Beijing, China, 2008.

[21] M. Abdelfatah, M. EL-Shimy, and H. M. Ismail, "Outage data analysis of utility power transformers based on outage reports during 2002-2009," in International Journal of Electrical Power \& Energy Systems, Volume 47, pp. 41-51, May 2013.

[22] M. EL-Shimy, M. Abdelfatah, and H. M. Ismail, "Reliability, Availability, and Maintainability (RAM) Analysis of Utility Power Transformers," in ELEKTRIKA- UTM Journal of Electrical Engineering, Vol. 14, No 1 (2012).

[23] M. Abdelfatah, M. EL-Shimy, and H. M. Ismail, "Performance analysis of protective devices for power transformers in Egypt," in 8th International Conference on Electrical Engineering ICEENG-8, Cairo, Egypt, 2012.

[24] Renaud, F., "220 kV gas-insulated transmission line-Palexpo Geneva Switzerland," Power Engineering Society General Meeting, 2003, IEEE, vol.4, no., pp.,2479 Vol. 4, 13-17 July 2003.

[25] Borucki, S.; Boczar, T.; Fracz, P.; Zmarzly, D., "Diagnostics of power transformers cores using a modified vibroacoustic method," Electrical Insulation (ISEI), Conference Record of the 2012 IEEE International Symposium, pp.179-183, 10-13 June 2012 


\title{
Exploring the condition-based maintenance opportunities for production-critical assets
}

\author{
Nii Nortey Basil Lokko'; Jawad Raza ${ }^{2}$; Tore Markeset ${ }^{1}$; Sukhvir Singh Panesar ${ }^{1}$

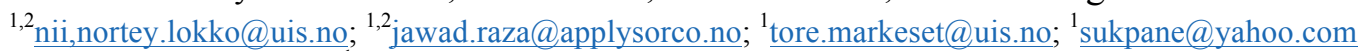 \\ ${ }^{1}$ University of Stavanger, N4012 Stavanger, Norway \\ ${ }^{2}$ Apply Sørco AS, N4012 Stavanger, Norway
}

\begin{abstract}
The optimum maintenance strategies for an installation on the Norwegian Continental Shelf (NCS) are seen as a combination of Condition-Based Maintenance (CBM), predetermined periodic Preventive Maintenance (PM) and runto-failure. CBM strategies are traditionally reserved for high safety-critical and high production-critical equipment. In recent years, however, there has been an increasing demand to maximize the use of CBM strategies on offshore installations.
\end{abstract}

Arguments are presented in this paper to explore the opportunities where CBM strategies can be justifiable for other production-critical equipment. The justification presented is thus related to the cost-effectiveness of establishing a Condition Monitoring (CM) system, which would primarily be based on the use of process and equipment performance measures.

The paper presents an intuitive explanation for the costeffective justification of CBM and also summarizes some general issues that influence the decision process for the different equipment criticality classes. A graphical representation is then presented. On the basis of analysis, a scenario is presented where CBM strategies and activities are justifiable for other production-critical equipment.

Keywords-Condition monitoring, maintenance, maintenance cost-effectiveness

condition-based

\section{INTRODUCTION}

The initial method that formed the basis for which the concept of Condition-Based Maintenance (CBM) was first introduced in the late 1940s was the trending of process parameters in the Rio Grande Railway Company [1]. The company attained some level of success in detecting leaks within its engines by trending pressure and temperature readings. This provided early evidence that trending of process parameters has the potential to yield positive results. It is such early works that inform our current definition of CBM as a maintenance program where interventions are based on information obtained by monitoring the condition of equipment [2].

Research and developments in technology since then have shown that other methods can also result in the reduction of unexpected system failures. Subsequently, the use of vibration measurements, oil particle analysis, process parameters, acoustic emission, etc., has become relatively common within mission-critical and capital-intensive industries such as process, manufacturing, railway and aviation. CBM is essential within such industries because of the high consequences of failure with respect to safety and cost. The Oil and Gas (O\&G) industry is also a mission-critical and capital-intensive industry where there are severe consequences of failure and high downtime costs. CBM is therefore considered essential to O\&G operations.

The optimum maintenance strategy for an installation on the Norwegian continental shelf (NCS) is a combination of $\mathrm{CBM}$, predetermined periodic maintenance and run-to-failure, with $\mathrm{CBM}$ as the preferred strategy wherever cost-effective. However, due to limited capital and human resources with the right competence, CBM is often reserved for some of the most critical (safety and production) systems. Medium or low critical equipment may sometimes either have predetermined periodic maintenance programs or simply be run-to-failure [3]. Veldman et al. [4] support the assertion that CBM is not yet a dominant maintenance concept. However, their matrix of CBM types (typology) suggests that a Type 1 analysis (i.e. statistical models applied to analyze pressure and temperature data) was used by the Rio Grande Railway Company when the concept of CBM was first introduced. Such analysis, supported with recent advancements in technology and analysis techniques, can be replicated for equipment that has existing predetermined periodic maintenance programs.

Increasing maintenance costs and decreasing production profile drive companies to find more efficient maintenance strategies. CBM is an example of an efficient maintenance strategy, if practical and cost-effective to implement. To minimize the effect of increasing maintenance costs and decreasing production profile, the current scope of CBM needs to be extended. The purpose of the paper is to investigate and establish the feasibility of employing condition monitoring techniques based on process parameters and performance degradation measures to implement CBM. Some principles of CBM, existing CM techniques and data-processing methods are presented in this paper. A summary of issues relating to the cost-effectiveness of CM systems on the NCS is also presented, which is followed by a discussion on opportunities to widen the scope for CBM implementation on production-critical equipment.

\section{DIAGNOSTICS VERSUS PROGNOSTICS}

Tsang [5] suggests that no matter what the CBM method, two conditions must be satisfied. Firstly, there must be a strong correlation between the data collected and the onset of failure. 
Secondly, a clear threshold value must be identified that suggests an intervention is necessary. Thus Jardine et al.'s [2] suggestion that diagnosis and prognosis are the main tasks within CBM is in support of Tsang's suggestions. The objective of diagnosis is the detection of component failure or abnormal conditions [6]. Prognosis, on the other hand, entails the prediction of remaining useful life and/or component reliability (i.e. time to failure) [2].

Some research indicates that both diagnosis and prognosis may be industrially applied [2] [3] [7] [8]. However, Garg and Deshmukh [9] suggest that most real industrial applications are more diagnostic than prognostic. Veldman et al. [4] tested this postulate and concluded from case studies that there is some evidence in support of this assertion. Though the evidence was limited, there was enough to suggest that the industrial application of CBM is for decision support and often viewed by engineers in three stages: early warning/detection of incidents, failure definition and decision-making.

\section{SOME CONDITION MONITORING (CM) TECHNIQUES}

Only after accurate and reliable data has been collected can the data then be processed for decision-making. The following are some of the most common CM techniques employed as the source for collecting equipment condition data for analysis and decision-making:

TABLE I. COMMON CM TECHNIQUES

\begin{tabular}{|l|l|}
\hline Technique & Comments and references \\
\hline $\begin{array}{l}\text { Vibration Analysis } \\
\text { VA) }\end{array}$ & $\begin{array}{l}\text { The most common CM technique [10], but it is also } \\
\text { accompanied by considerable cost implications. } \\
\text { Most commonly used in detecting defects in roll } \\
\text { element bearing [11] and wind turbines [12]. }\end{array}$ \\
\hline Oil Analysis (OA) & $\begin{array}{l}\text { OA is another common CM technique. Some defects } \\
\text { are detectible in oil samples much earlier than they } \\
\text { manifest in vibration readings [13] [14]. Despite the } \\
\text { availability of the technology of online [15], offline } \\
\text { oil sample taking is a preferred method [14]. }\end{array}$ \\
\hline $\begin{array}{l}\text { Process Parameter \& } \\
\text { Performance } \\
\text { Monitoring }\end{array}$ & $\begin{array}{l}\text { García Márquez et al. [12]suggest that maintenance } \\
\text { based on process parameters is still common } \\
\text { practice (at least in the case of wind turbines). Some } \\
\text { to as thermodynamic } \\
\text { parameter } \\
\text { monitoring) }\end{array}$ \\
$\begin{array}{l}\text { relationship between measured performance } \\
\text { parameters such as speed, power, efficiency, etc., } \\
\text { can be used for failure diagnosis. Complex } \\
\text { techniques are not employed in the analysis [14]. }\end{array}$ \\
\hline
\end{tabular}

Other techniques such as acoustic emission, thermography, strain measurement, shock pulse method, stator current harmonic measurements, etc., have been known to deliver some level of success in failure diagnosis and (to some extent) the prognosis of dynamic systems. A CM method selection chart showing a list of 18 equipment groups and $28 \mathrm{CM}$ techniques has been compiled by the British Institute of NonDestructive Testing (NDT) as a guide for selective application [18].

\section{CM DATA/SIGNAL PROCESSING METHODS}

Condition monitoring does not end at simply collecting the data obtained. A diagnosis and/or prognosis in support of decision-making must be the ultimate purpose of any $\mathrm{CM}$ activity. Two main basic elements within any CM system are: the number and type of sensors, and the corresponding signal processing and simplification methods used to convert the signals into information that can then be employed for decision-making [12].

Some of the data (signal) processing methods currently being employed include statistical methods, time-domain analysis, trend analysis (TA), filtering methods, hidden Markov models (HMM), cepstrum analysis, artificial neural networks, fuzzy logic, expert systems, time-synchronous averaging (TSA), fast Fourier transform (FFT), amplitude demodulation, order analysis and wavelet transforms.

\section{COST-EFFECTIVENESS OF CONDITION MONITORING ON THE NCS}

The unexpected failures of safety- and production-critical equipment on the NCS can be safety- and environment-critical and capital-intensive, which therefore makes them candidates for $\mathrm{CM}$ and eventually for the implementation of CBM. Increased demand for unmanned production facilities and/or personnel reduction of manned offshore installations increases the requirement for real-time, online condition assessment of equipment. Despite the increased requirement for CM, there are many challenges in implementing CBM. Some of the challenges that affect the cost-effectiveness of CBM include:

- Integrating multiple CM techniques

- High volume of sensors and related challenges

- Availability of technical CM expertise and interdisciplinary know-how

\section{A. Integrating multiple CM techniques}

Some maintenance experts on the NCS are of the opinion that a single $\mathrm{CM}$ technique is most often insufficient for equipment diagnostic and prognostic purposes. Hence, it is often quite common to have combinations of different techniques applied on one equipment unit [19]. The main conclusion is that only an integrated approach could provide the comprehensive and reliable solutions needed (see [20]).

This need for integrating multiple techniques for proper failure diagnosis and/or operational prognosis is one of the major reasons why $\mathrm{CBM}$ is not the dominant maintenance strategy on the NCS. To procure, install, operate and maintain a complete $\mathrm{CM}$ system would often require a cost build-up which is a function of the number of techniques to be integrated. After the initial capital expenditures (CAPEX) (procurement, installation, etc.), the cost of the CM system operation and maintenance expenditures (OPEX) accumulate over time. The accrued benefits of using such an integrated system of techniques must outweigh the combined CAPEX and OPEX. This life cycle cost-benefit evaluation must also include the resulting maintenance cost (increase/decrease) of the production equipment itself in the analysis. 


\section{B. High volume of sensors and related challenges}

Accurate and reliable data is necessary for effective condition monitoring and its related activities. García Márquez et al. [12] suggest that the number and type of sensors is fundamental to the accuracy and reliability of the data collected. The more quality sensors are installed, the more accurate and reliable data is collected. The numbers of reliable sensors that are needed for a single technique can become costly to install (procurement, installation and systems integration costs), operate (data collection, storage and analysis costs) and maintain (repair and replacement costs).

An example is provided by a maintenance engineer on the NCS, who stated that they have expensive vibration sensors installed on some of their equipment. However, the vibration sensors are installed in such a way that they cannot be removed without compromising their accuracy and effectiveness. Therefore, after every major maintenance activity, new vibration sensors need to be obtained and installed.

In addition, the costs related to sensor failures and unwanted stoppages with high downtime cost may increase with more sensors.

Hence, the cost of integration of CM techniques is likely to increase with respect to the number of techniques being integrated. Subsequently, justifying the expenses required for an integrated condition monitoring solution is more practicable on equipment that is highly production-critical. It may not be cost-efficient to run CBM on less critical offshore production assets. Experienced-based periodic maintenance strategies may be more cost-effective and hence a preferred maintenance strategy.

\section{Availability of technical CM expertise and interdisciplinary know-how}

Processing and analyzing data seems to be another major practical application challenge that needs to be overcome. Some maintenance engineers on the NCS are also of the opinion that several of the CM techniques are quite specialized fields of study and may be monitoring one of the many failure modes of critical equipment. Consequently, the competences required to effectively operate and manage $\mathrm{CM}$ are not readily available internally within the maintenance departments. They suggest that this is the reason why the monitoring of equipment is often wholly/partly subcontracted to specialized service providers with the required expertise.

Schlechtingen et al. [21]support the notion that the application of the $\mathrm{CM}$ techniques often requires extensive knowledge about the system to be monitored. In the absence of such knowledge, building physical models that have the desired level of accuracy becomes an even more daunting task (especially of dynamic systems with high system complexities). The absence of such know-how, compounded by a seeming lack of an interdisciplinary team approach, often manifests in the establishment of CM systems without a clearly defined framework/process to move from data/information to decision-making/intervention (CBM). Furthermore, the companies need to have organization in place that integrates the information available from CM techniques into decisionmaking processes to hinder the performance/condition degradation of monitored equipment.

Thus, if the necessary expertise is not already available within the O\&G operating company, and the cost of obtaining such expert analysis is unjustifiably high, CBM will likely be unavailable for the less production-critical equipment (and even for some highly production-critical equipment).

\section{UNDERSTANDING THE COST-EFFECTIVENESS BASELINE AND CURVE}

These issues, which have been shown to influence the costeffectiveness (and efficiency) of CBM, have become defining factors for the successful implementation of CM systems.

A CM system generally comprises: 1) the sensors and probes, 2) the local system control unit, 3) a data storage unit, and 4) a monitoring unit (which often comprises computers, screens and analysis software and applications). Each unit is often connected to the other via wireless or cable/wire connections. Figure 1 shows an overview of the lifecycle cost build-up for CM systems.

\section{Condition monitoring system cost build-up}

(A general overview)

\begin{tabular}{|c|c|c|}
\hline $\begin{array}{l}\mathrm{CM} \text { system acquistion } \\
\& \text { installation expenses }\end{array}$ & $\begin{array}{c}\text { CM system } \\
\text { operation expenses }\end{array}$ & $\begin{array}{c}\mathrm{CM} \text { system } \\
\text { maintenance expenses }\end{array}$ \\
\hline & 15 & $\mathrm{~N}_{\mathrm{N}}$ \\
\hline $\begin{array}{l}\text { - Sensors } \\
\text { - System control unit } \\
\text { - Cables \& wires (wireless routers) } \\
\text { - Installation \& systems integration } \\
\text { - Personnel training }\end{array}$ & $\begin{array}{l}\text { - Software/package licenses } \\
\text { - Data transfer \& storage } \\
\text { - Equipment monitoring \& } \\
\text { health assessment } \\
\text { - Reporting services }\end{array}$ & $\begin{array}{l}\text { - Routine CM system } \\
\text { maintenance checks } \\
\text { - Component repair/replacement } \\
\text { - CM system overhaul }\end{array}$ \\
\hline
\end{tabular}

Fig. 1. An overview of CM system cost build-up 
This life cycle cost build-up is a major factor in deciding the cost-effectiveness of the CM systems under evaluation. Any justifications for CBM implementation need to be costeffective. The cost-benefit analysis includes the added cost or cost savings that are a direct result of the condition-based activities and interventions performed on the equipment being monitored (over time). Moreover, the integration costs to integrate $\mathrm{CM}$ techniques on existing installations can further increase CAPEX.

It makes economic sense to spend more resources on safeguarding higher valued equipment than on lower valued equipment (where the resources themselves are limited). Subsequently, the limit to the amount of resources dedicated to failure prevention and/or prediction should be proportional to the equipment criticality (consequence) classification. It therefore follows that the economic threshold for CBM on high critical equipment will be greater than medium critical equipment and low critical equipment (respectively and in that order of ranking). Figure 2a, therefore, provides an intuitive reasoning for why less production-critical equipment often falls outside the cost-effective scope for CBM strategies.

Figure $2 \mathrm{a}$ shows that at a certain cost level of CBM, the level of justification required to establish the cost-effectiveness of implementing CBM is lowest for high critical equipment, and highest for low critical equipment. In other words, establishing the economic benefits of CBM is comparatively simpler for high critical equipment than for less critical equipment at the same CBM cost level. This is depicted in the slopes for each (high critical, medium critical and low critical) line. There is a minimum cost-effectiveness level (baseline) that any CM system must meet, irrespective of the equipment criticality class. This cost-effectiveness baseline will be dependent on available resources (human and capital), operational philosophy and statutory regulations. The age of the installations, business goals, organization, etc., are additional factors, which may influence the baseline and affect the implementation of CBM. The economic threshold for lower critical production equipment often falls below this minimum level. Hence CBM strategies are usually not an option for such equipment. As the CBM cost increases, the level of justification required to establish the cost-effectiveness increases accordingly. Most often, however, slight increases in $\mathrm{CBM}$ costs may push the cost-effectiveness level beyond the economic threshold for even medium critical equipment. Consequently, several of these items of critical production equipment are also not selected for CBM strategies. Hence, within the bounds of limited available resources, some items of critical equipment are the prime candidates for CM and CBM.

A curve drawn from the baseline through the points of the respective line intersections produces a CBM costeffectiveness curve, as depicted in Figure 2a.
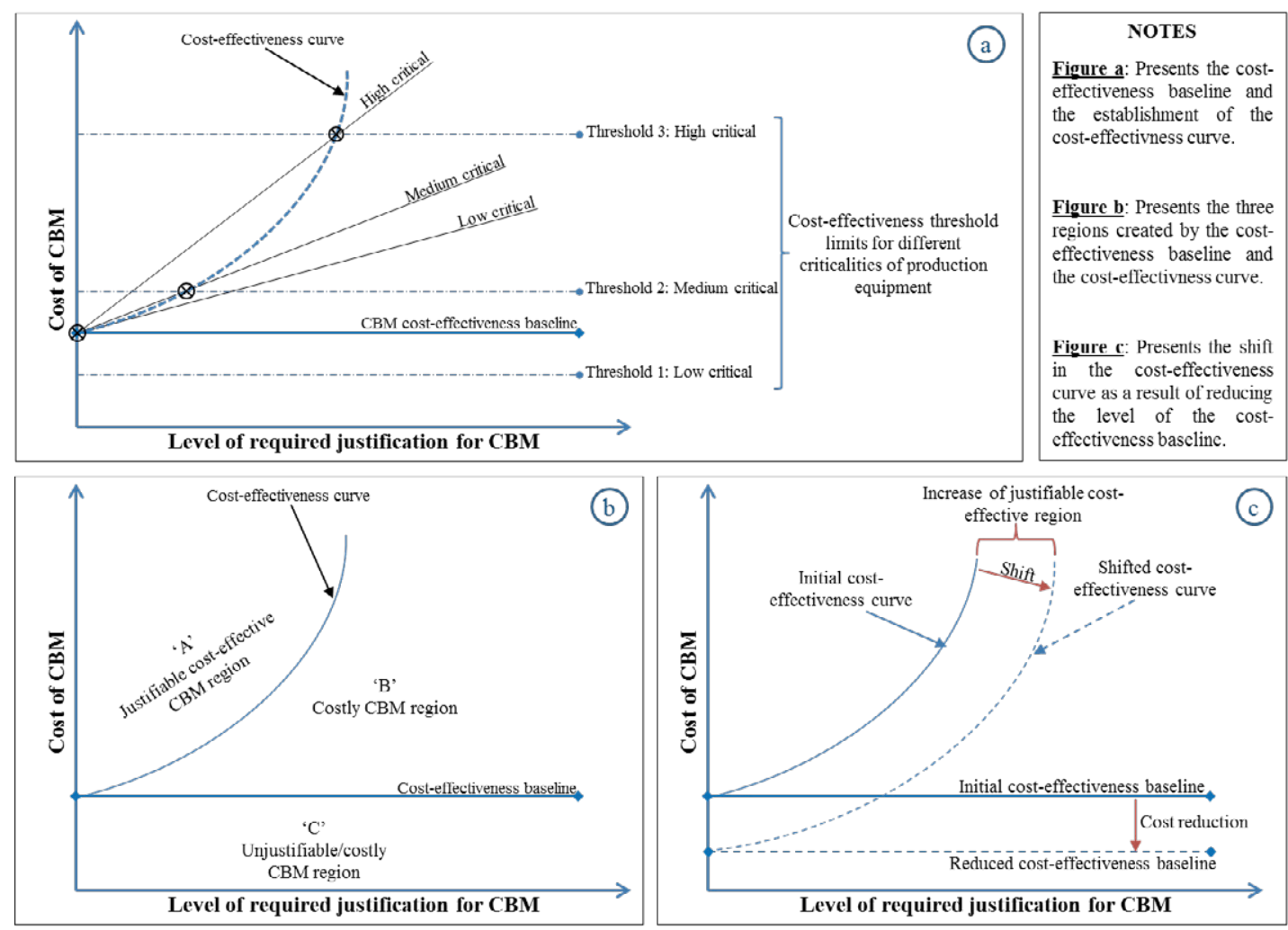

Fig. 2. The cost-effectiveness baseline \& curve, and the CBM justifiable regions 
The cost-effectiveness curve provides the boundary beyond which CBM is no longer cost-effective. Three distinct regions are created as a result of the cost-effectiveness baseline and curve. This is shown in Figure 2b. Region " $A$ " represents a zone where CBM cost-effectiveness is justifiable. In region "B", cost-effectiveness may be economically unjustifiable, but CBM strategies may still be employed for other overriding reasons (such as regulations or company policies). For region "C", CBM is not cost-effective, and no other factor can be used to justify its implementation. Thus with limited resources, only equipment that falls into region " $\mathrm{A}$ " and a selected few that fall into region " $\mathrm{B}$ " will be eligible for CBM.

If the level of CBM is to increase on the NCS, the size of region "A" will have to be increased. One way this can be achieved is by lowering the CBM cost-effectiveness baseline.

\section{INCREASING THE CBM COST-EFFECTIVENESS}

A possible remedy to the cost and expertise-related challenges is to use data that is already available. Process and/or performance data are constantly being collected and stored for operation/production purposes. Subsequently, there may be no need for the additional cost of installing, operating and maintaining specialized sensors for an integrated multitechnique CM system.

A list of $18 \mathrm{CM}$ techniques was used to compile the $\mathrm{CM}$ selection chart by the British Institute of NDT [18]. This list can be further grouped into broad categories as follows: process parameters \& performance monitoring, thermography \& thermal imaging, vibration \& noise analysis, oil \& wear analysis (tribology), and other CM techniques. An analysis of this CM selection chart suggests that performance monitoring is an appropriate $\mathrm{CM}$ technique for a majority (25 out of the 28) of the identified equipment groups. The monitoring of process parameters such as temperature and pressure (and flow) is also appropriate for a significant proportion of equipment groups (17 out of 28). A CBM strategy may, therefore, be feasible on the basis of a comparative assessment of measured performance indicators and process parameters, provided a strong and clear relationship between the parameters and possible failures is observable.

Process parameters \& performance monitoring, therefore, provide the highest opportunity for implementing CBM on various equipment types. Schlechtingen et al. [21], Müller et al. [16] and Sorensen et al. [17] support this assertion with their respective research works.

The above deduction is also supplemented with the following practical information:

- Supervisory control and data acquisition (SCADA) systems on offshore facilities are constantly collecting and recording process data (and to some extent performance data).

- Data historians (such as OSIsoft's PI System and Honeywell's Uniformance Process History Database (PHD)) are the systems backbone of O\&G production and platform operations and are therefore present for onshore support of offshore operations.
- New, improved, robust, accurate and precision sensor technologies are being developed and installed for all purposes (i.e. both for condition and process/performance monitoring). In certain cases, equipment is designed to have built-in sensors that effectively eliminate the additional sensor acquisition and related installation expenses.

- Advancements in computing and information technology (IT) provide the platform for cheaper, robust and more powerful IT infrastructure and computer hardware. Larger volumes of data can now be collected, processed and stored faster and more cheaply than previously [22]

- Wireless sensor technology is becoming more available for use.

- Improvements in advanced analysis technology such as neural networks, genetic algorithms, etc., are being used [23].

Consequently, the cost-effectiveness justification for CBM based on process and performance monitoring seems less daunting as compared to other $\mathrm{CM}$ techniques. The same process and/or performance data will be employed by maintenance personnel and process/operations personnel for analysis. Hence, the issue of a lack of collaborative, interdisciplinary approach to CBM is also tacitly addressed.

In relation to the cost-effectiveness baseline, cost reduction (across the board) is attainable if the CBM strategy is based on process and performance parameter monitoring (as shown in Figure 3). The cost-effectiveness baseline is subsequently lowered, and the cost-effectiveness curve is consequently shifted to the right (as shown in Figure 2c). Thus, this creates the opportunity for more justifiable cost-effective CBM strategies on all production equipment (irrespective of criticality classification). What remains challenging and the driving factor to this approach is obtaining the appropriate process/methodology for transforming data into diagnostic and prognostic information for decision-making.

According to Schlechtingen et al. [21], equipment behavior models can be made available to the maintenance engineer, provided that advanced analysis techniques such as neural networks and fuzzy logic can be utilized. They suggest that the use of signal (process and performance) behavior models is advantageous in the sense that prior knowledge of signal behavior is not a requirement. However, there is an intrinsic property of normal behavior models that suggests the possibility of monitoring a signal can be independent of the operational mode. Zaher et al. [24] and Sanz-Bobi et al. [25] also suggest that changes in signal behavior can be observed as early as days, weeks, and even months before failure occurs. These arguments advocate the dynamic CM capability of behavior models that are based on performance and process data. Adaptive neuro-fuzzy interference systems utilized on wind turbines is a demonstration of the potential behavioral models for CM [21]. Hence it can be concluded that there is a high possibility for utilizing cost-effective CBM strategies, even on lesser production-critical equipment on the NCS. 
CBM based on process and performance monitoring alone may not provide the complete diagnostic and/or prognostic capabilities for all equipment failure modes, but some level of $\mathrm{CM}$ on production-critical equipment is better than none at all.

\section{CONCLUDING REMARKS}

Despite the current scenario, where CBM is often justifiable on a few items of production-critical equipment on the NCS, the analysis presented in this paper suggests that CBM strategies may also be feasibly extended to other production-critical offshore assets. A limiting factor to justifying the cost-effectiveness of condition monitoring systems, on this production equipment, is identified as the lowering of the cost-effectiveness baseline. The issues identified as factors influencing the cost-effectiveness of CM systems can be successfully circumvented if the appropriate process/methodology is developed to effectively use the already available process and performance data. It is, therefore, necessary to focus on extending theoretical research works in the area of utilizing process and performance parameters for more equipment diagnostics and prognosis.

On the whole, even if technology provides the possibilities of CM, companies need to strategically evaluate and decide on the opportunities that need to be realized for complete or partial implementation of condition based maintenance. The age of the installation, business goals, operational philosophy, organization, human resources and competence, etc., are some of the additional factors that influence CBM implementation.

Condition monitoring system cost build-up

(Primarily based on process \& performance parameter monitoring)

\begin{tabular}{|c|c|c|}
\hline $\begin{array}{l}\text { CM system acquistion } \\
\& \text { installation expenses }\end{array}$ & $\begin{array}{l}\text { CM system } \\
\text { operation expenses }\end{array}$ & $\begin{array}{c}\mathrm{CM} \text { system } \\
\text { maintenance expenses }\end{array}$ \\
\hline $\begin{array}{l}\text { - Sensors } \\
\text { - System control unit } \\
\text { - Cables \& wires (wireless routers) } \\
\text { - Installation \& systems integration } \\
\text { Personnel training }\end{array}$ & $\begin{array}{l}\text { - Software/package licenses } \\
\text { - Data transfer \& storage } \\
\text { - Equipment monitoring \& } \\
\text { health assessment } \\
\text { - Reporting services }\end{array}$ & \multirow[t]{2}{*}{$\begin{array}{l}\text { - Routine CM system } \\
\text { maintenance checks } \\
\text { - Component repair/replacement } \\
\text { - CM system overhaul }\end{array}$} \\
\hline $\begin{array}{l}\text { Reduced CM system } \\
\text { acquisiton \& } \\
\text { installation costs }\end{array}$ & $\begin{array}{l}\text { Reduced CM system } \\
\text { operating expenses }\end{array}$ & \\
\hline $\begin{array}{l}\text { Almost no extra sensor } \\
\text { acquisition costs } \\
\text { - No additional system control unit } \\
\text { expenses } \\
\text { - No extra cables \& wires (wireless } \\
\text { routers) cxpenses } \\
\text { - Some installation \& systems } \\
\text { integration expenses } \\
\text { - Some personnel training costs }\end{array}$ & $\begin{array}{l}\text { Marginal-to-no extra charges } \\
\text { for data transfer \& storagc } \\
\text { - Little/no reporting service } \\
\text { charges }\end{array}$ & $\begin{array}{l}\text { Marginal-to-no additional cost } \\
\text { of routine CM system checks } \\
\text { - Marginal-to-no additional } \\
\text { component repair/replacement } \\
\text { costs } \\
\text { - Marginal-to-no additional } \\
\text { system overhaul costs }\end{array}$ \\
\hline
\end{tabular}

Fig. 3. Influences of the use of process and performance parameters on CM system cost build-up

\section{ACKNOWLEDGMENT}

We would like to acknowledge all asset managers and maintenance engineers from the NCS who contributed to this study.

\section{REFERENCES}

[1] Prajapati, A., Bechtel, J. and Ganesan, S., (2012), Condition-based maintenance: a survey, Journal of Quality Maintenance Engineering: 18 , pp. 384-400

[2] Jardine, A., Lin, D. and Banjevic, D., (2006), A review on machinery diagnostics and prognostics implementing condition-based maintenance, Mechanical Systems and Signal Processing: 20 (7), pp. 1483-510

[3] NORSOK Z-008, (2011), Risk based maintenance and consequence classification

[4] Veldman, J., Klingenberg, W. and Wortmann, H., (2011), Managing condition-based maintenance technology: A multiple case study in the process industry, Journal of Quality Maintenance Engineering: 17, pp. $40-62$
[5] Tsang, A., (1995), Condition-based maintenance: tools and decisionmaking, Journal of Quality in Maintenance Engineering: 1 (3), pp. 3-17

[6] Venkatasubramanian, V., Rengaswamy, R. and Kavuri, S.N., (2003), A review of process fault detection and diagnosis part II: qualitative models and search strategies, Computers and Chemical Engineering: 27 (3), pp. 313-26

[7] Heng, A., Zhang, S., Tan, A. and Mathew, J., (2009), Rotating machinery prognostics: state of the art, challenges and opportunities, Mechanical Systems and Signal Processing: 23 (3), pp. 724-39

[8] Venkatasubramanian, V. (2005), Prognostic and diagnostic monitoring of complex systems for product lifecycle management: challenges and opportunities, Computers and Chemical Engineering: 29 (6), pp. $1253-$ 63

[9] Garg, A. and Deshmukh, S.G., (2006), Maintenance management: literature review and directions, Journal of Quality in Maintenance Engineering: 12 (3), pp. 205-238

[10] Randall, R.B., (2011), Vibration-based Condition Monitoring, Wiley, Chichester, West Sussex, UK, ISBN 9780470747858

[11] Tandon, N., Yadava, G.S. and Ramakrishna, K.M., (2007), A comparison of some condition monitoring techniques for the detection of 
defect in induction motor ball bearings, Mechanical Systems and Signal Processing: 21(1), pp. 244-256.

[12] García Márquez, F.P., Tobias, A.M., Perez, J.M.P. and Papaelias, M., (2012), Condition monitoring of wind turbines: techniques and methods, Renewable Energy: 42, pp. 169-178

[13] Leske, S. and Kitaljevich, D., (2006), Managing gearbox failure, Dewek, Dewi Magazine: N. 29

[14] Verbruggen, T.W., (2003), Wind turbine operation \& maintenance based on condition monitoring, WT-O. Final report, ECN-C-03-047; April

[15] Hameed, Z., Hong, Y.S., Choa, Y.M., Ahn, S.H. and Song C.K., (2009), Condition monitoring and fault detection of wind turbines and related algorithms: a review, Renewable and Sustainable Energy Reviews: 13, pp. 1-39

[16] Müller, H., Pöller, M., Basteck, A., Tilscher, M. and Pfister, J., (2006), Grid compatibility of variable speed wind turbines with directly coupled synchronous generator and hydro-dynamically controlled gearbox. In: Sixth International Workshop on Large-Scale Integration of Wind Power and Transmission Networks for Offshore Wind Farms, Delft, NL; pp. 307-315.

[17] Rao, B.K.N., (1996), Handbook of Condition Monitoring, Elsevier Advanced Technology, Kidlington, Oxford, UK

[18] Sheng, S., (2011), Investigation of various condition monitoring techniques based on a damaged wind turbine gearbox, presented at, 8th International Workshop on Structural Health Monitoring: September 1315
[19] Kumar, R., Panesar, S.S. and Markeset, T. (2009), Development of technical integrity management services - A concept, Journal of Quality in Maintenance Engineering: 15 (3), pp. 271-284

[20] Schlechtingen, M., Santos, I.F. and Achiche, S., (2013), Wind turbine condition monitoring based on SCADA data using normal behavior models Part 1, System description, Applied Soft Computing: 13, pp. 259-270

[21] Sorensen, B.F., Lading, L., Sendrup, P., McGugan, M., Debel, C.P., Kristensen, O.J.D., et al., (2002), Fundamentals for remote structural health monitoring of wind turbines blades - A pre-project, Riso-R-1336 (EN)

[22] Lee, J., Ni, J., Djurdjanovic, D., Qiu, H. and Liao, H., (2006), Intelligent prognostics tools and e-maintenance, Computers in Industry: 57 (6), pp. 476-489

[23] Lee, J., Wu, F., Zhao, W., Ghaffari, M., Liao, L. and Siegel, D., (2014), Prognostics and health management design for rotary machinery systems - Reviews, methodology and applications, Mechanical Systems and Signal Processing: 42, pp. 314-334

[24] Zaher, A., McArthur, S.D.J., Infield, D.G., and Patel, Y., (2009), Online wind turbine fault detection through automated SCADA data analysis, Wind Energy: 12, pp. 574-593

[25] Sanz-Bobi, M.A., del Pico, J. and Garcia, M.C., (2006), SIMAP: Intelligent system for predictive maintenance application to the health condition monitoring of a wind turbine gearbox, Computers in Industry: 57, pp. 552-568 
(Página deixada propositadamente em branco) 


\title{
Predictive Maintenance! To do or let Die
}

\author{
Pedro Dias ${ }^{1}$, José Torres Farinha ${ }^{2}$, Inácio Fonseca ${ }^{3}$, Jorge Cunha ${ }^{4}$ \\ pedro.dias@skf.com1; torres.farinha@dem.uc.pt2; inacio.fonseca@dem.uc.pt3; jorge.cunha@skf.com4 \\ SKF Portugal1,4; CEMUC2,3 \\ PORTUGAL1,2,3,4
}

\begin{abstract}
In a competitive world all equipment must maximize its availability. The predictive maintenance objective is to follow the evolution of its use and the tear that results from the dynamics of components.

Nowadays, with the evolution of technology it is possible to check and detect almost every problem. In critical organizations, like paper industry, chemical industry, oil industry, and so on, it is necessary to follow the "health" of the most part of equipment in general, and the vital ones in particular, because even small errors can cause a lot of monetary damages.
\end{abstract}

This type of companies need to check every detail of their assets. The majority of the companies use a lot of technology to evaluate the condition of each critical component. They want to know the value of on-condition variables like vibration monitoring offline, vibration monitoring online, thermograph, oil analysis, and so on.

However, having lot of offers of equipment for diagnosis and a lot of offers of maintenance services by specialized companies, the factories didn't increase the predictive maintenance level because they aren't sensitive enough to do that. The pressure that the international economic market has in companies causes factories to work every minute they can before equipment and components break. Companies try to delay the time of each maintenance intervention, but this delay, when it is done without on-condition accompaniment increases the total maintenance costs, which increases the total value of equipment maintenance, both direct and indirect. In this case, the predictive maintenance can have an important role to increase the production time.

These are the main topics that will be handled in the paper industry, with focus on vibration monitoring applied in a paper factory, including maintenance analysis versus cost analysis.

Keywords - on-condition maintenance; predictive maintenance; vibration analysis; paper industry.

\section{INTRODUCTION}

The pulp and paper mills work with top market machine. A lot of brands are specialized in a part of the process. For example, the pumps of the pulp and paper plant have the same features as the fluid in its movement, corresponds a real situation where some manufacturers have gained a lot of expertise in it.

For this work, the manufacturers design the machine components to work $24 \mathrm{~h}$ a day, during a specific time where the reliability is maintained high enough. This time, also called safety time, corresponds to which the manufacturer indicates to begin the maintenance schedule; in other words, to start the process of changing some components of the machine according to a relation working time/scheduled maintenance this maintenance type is also called Preventive Maintenance.

Preventive Maintenance gives an important contribution to safety. The company follows up every advice of the manufacturer and changes every component of the machine according to the work times stabilized by the manufacturer. In this type of maintenance there are a lot of pieces that are changed after they work a well defined number manufacturing hours. If we put these pieces in the scrap, we lose a lot of money.

In the ambit of the precedent context this paper deals with a tool that SKF has developed to solve that type of problems and also improve the maintenance tasks in the factory, helping to increase the operation of all equipments and, by consequence, to increase the production.

\section{THE COMPANY}

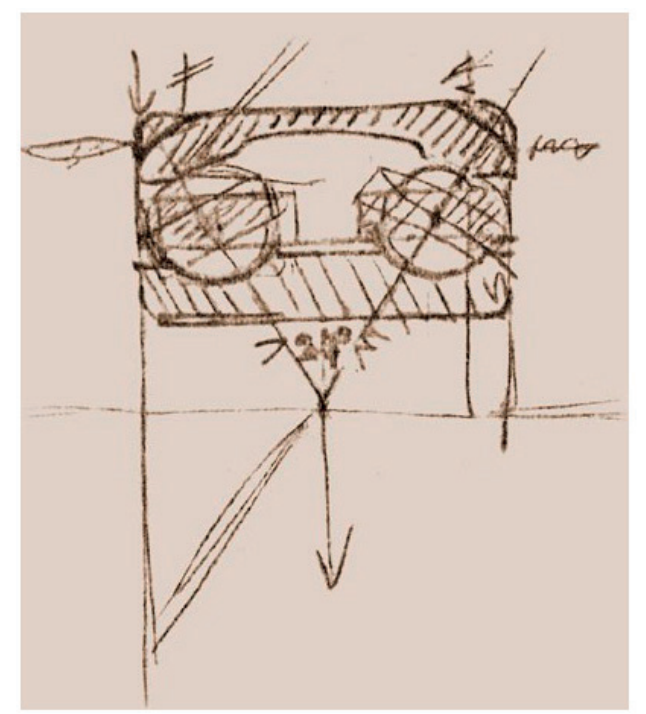

Fig. 1 - Drawing of multi-row self-aligning radial ball bearing

SKF is a company more than 100 years old. The company has been a leading global technology provider since 1907. It began with the production of bearings leaded by Mr. Sven Wingqvist who, in that year, registered the patent $\mathrm{n}^{\circ} 25406$, for a multi-row self-aligning radial ball bearing (Figure 1). With 
this discovery, this man found the solution for rigid ball bearing, [1-2].

Since this date, the company has been growing, opening their business in other areas like condition monitoring, seals, lubrication, etc.

Nowadays, SKF is based in five platforms, figure 2. These platforms we going talk in the platform "Services". In this platform they are included all systems and technology to monitor and manage the maintenance.

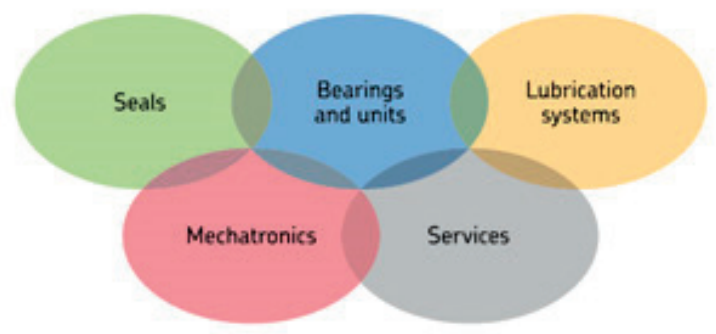

Fig. 2 - The 5 platforms which is based of the SKF business

\section{TECHNOLOGIES APPLIED TO PREVENTIVE MAINTENANCE OF PULP AND PAPER MACHINE}

At the beginning of the industrial paper era, when a lot of paper companies bought their first machines, they also acquired equipment to measure the vibration online. Due to the hard condition to work in the drier, this is the only way to analyze the bearings and the other components condition.

By the other hand, some pulp and paper plants strategy is to have outsourcing specialize partnerships to provide this specified service. To follow up both condition systems, the online and the offline measurement, there are partners specialize in the failures beginning detection as SKF. But this technology isn't the only one; there are complimentary variables to increase the diagnosis security like oil analysis among others.

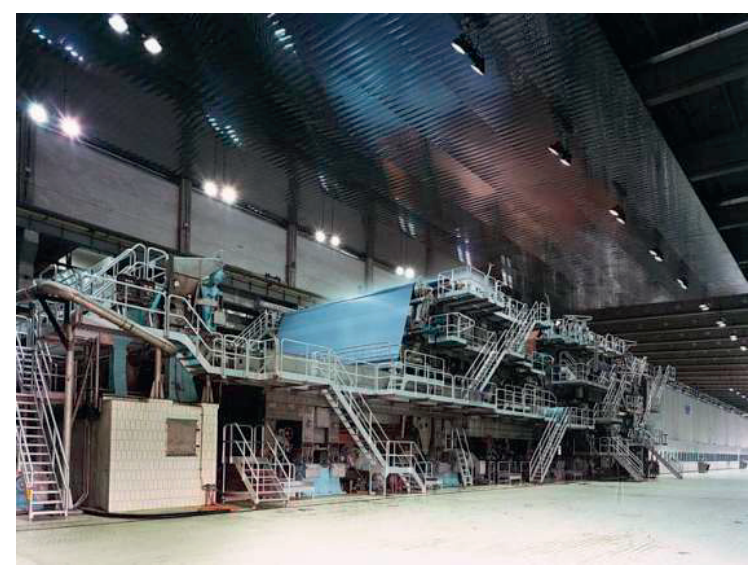

Fig. 3 - Paper Machine

In Figure 3, it can be seen a paper machine. The system online for vibration measurement collects the information about the several rolls bearing condition. In Figure 4 it can be seen the SKF system to follow up the status of dynamic components. This system is IMx-S of 32 channels that can measure 32 points of the paper machine or equipment that are considered critical.

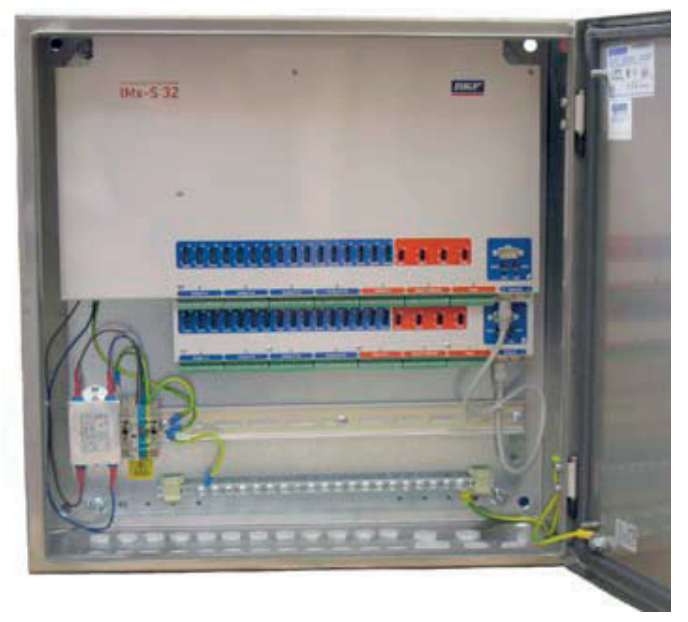

Fig. 4 - System SKF IMx'S

IMx-S is part of the SKF Multilog On-line System product range; it is designed to be used for a variety of condition monitoring applications. In conjunction with SKF@ptitude Observer or Analyst software, IMx-S provides a complete system for early fault detection and prevention, automatic advice for correcting existing or impending conditions and advanced condition-based maintenance to improve machine reliability, availability and performance, [2].

This system doesn't replace the old system of maintenance managing strategy. In other words, this technology doesn't replace the first level preventive maintenance. But it is a huge help in the work preparation, because it is possible to detect the flaws since the beginning.

The standard preventive maintenance is done by operators. It is necessary to approach the operators with the equipment. When the operator does this type of maintenance, he only looks for any visual problems (for example, an oil leakage), abnormal noise, etc. Every point that the operator sees is registered in a document that constitutes an historic concerning the problems throughout the time.

Every week the operators have a new route to do. Throughout the time, the company creates a historic of machine problems, and with this information it is possible to create a data base with critical value for some points of measurement, for example, the temperature.

\section{OPERATOR DRIVEN RELIABILITY (ODR) CONCEPT}

With new maintenance methodologies like TPM (Total Productive Maintenance), RCM (Reliability Centered Maintenance), LEAN Maintenance) each time more present in factories, the SKF company developed a system that can change the old preventive of on-condition maintenance 
techniques and increase the participation of operator in maintenance interventions, [3-4].

The term Operator Driven Reliability (ODR) relates to maintenance practices that are owned, managed, and performed by operators. Process operators usually have at least some interface with maintenance in so far as they will typically request maintenance support to investigate and correct suspect conditions that they have detected (usually by subjective way). Operators also become involved in maintenance through their participation in reliability-related activities namely the ones that are the Root Cause Failure Analysis (RCFA) or maintenance strategy review processes. A prime objective of the operator involvement in maintenance is the improvement of equipment support strategy. Their involvement ensures that operations staff understands and fulfill their role ensuring plant-wide reliability.

Accomplishing the complexity of modern production machinery, it is necessary that every department of factory works as a team. Only in this way it is possible to solve the problems and find the best solutions so that the faults don't happen again. Only with this condition, the company can reduce the production cost and increase the competitive edge.

To implement the ODR, it is necessary that the operator knows what to do and what he can do to improve. First, it is necessary to find the venue of the factory to implement this approach and then choose the best person to start. know:

The operators involved in this maintenance activity need to

- What constitutes a problem through equipment knowledge and performance standards;

- What to do when each problem is observed;

- What not to do when each problem is observed;

- What tasks fall within the limits of personal competence;

- What tasks are outside the limits of personal competence.

It can be given responsibility to the operator to help that each machine works according to the best performance and the condition from which it was designed.

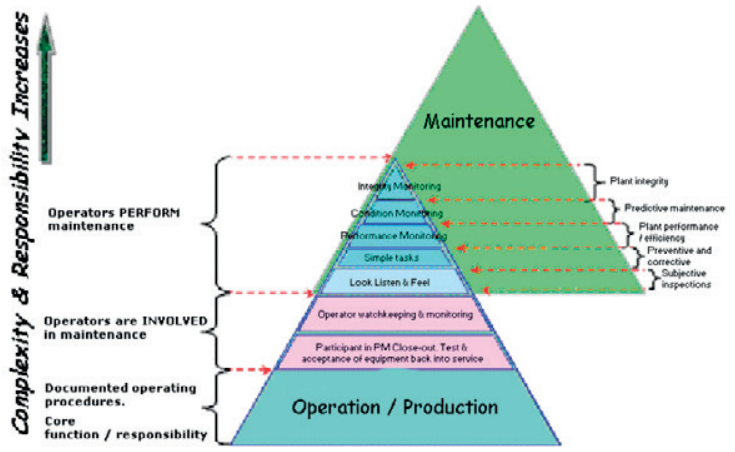

Fig. 5 - The increase of competence of the operator

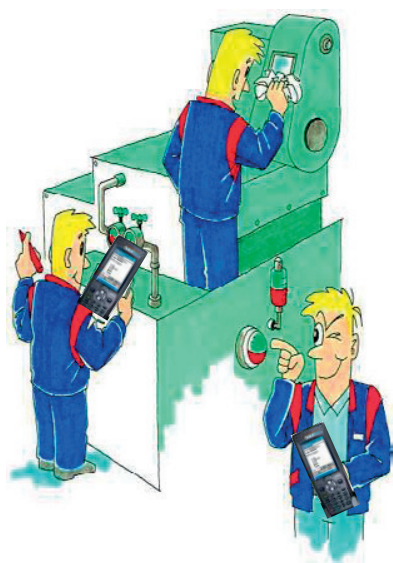

Fig. 6 - Operator check machine

In Figure 5, it is possible to see where the operator fits in the maintenance structure for this process.

The operator role is to go to the machine, follow the check list (this check list is prepared by maintenance and production) and put $\mathrm{OK}$ or not OK. To do that, the operator takes a portable PDA (Personal Digital Assistant) to register the status of the machine. In Figure 6, it is possible to observe this example. The operator checks the level of oil and cleans the glass and checks the valves.

\section{ODR PRINCIPLE OF FUNCTIONING}

Operator Driven Reliability (ODR) is a process pioneered by SKF that empowers operators to contribute proactively to a company-wide maintenance strategy. The process is built on a simple realization: equipment operators are usually the first to detect even the smallest changes in machine conditions. SKF operator involvement starts from the first ODR project facilitation meeting where operators participate in criticality and FMEA analysis. The shared asset knowledge is the basis for correct operator activities.

In first place, it is necessary to define the equipments that will be checked by ODR. With this list, it will do the routes (it is necessary to take attention to track, for the operator to make a circuit). At the next step, the points to check are defined and, if it is the case, the vibration points to measure. With every point characterized, it only needs to upload the routes in PDA software. When operator starts route, he switches on PDA and follows the instructions applied to each equipment registering all values. When one measurement is out of the normal value, the operator asks for help to solve the problem, [5].

Why did choose ODR to help improving this maintenance practice?

- Because this system can measure more points, can change the check list from paper to PDA (the problem with the paper is the risk of loss and the time necessary to insert data into system) what makes easier uploading data and quicker analyses about faults and so on. 


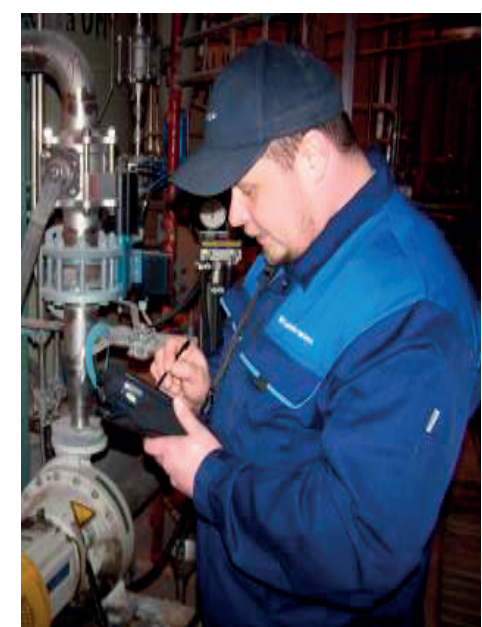

Fig. 7 - The operators makes an ODR route

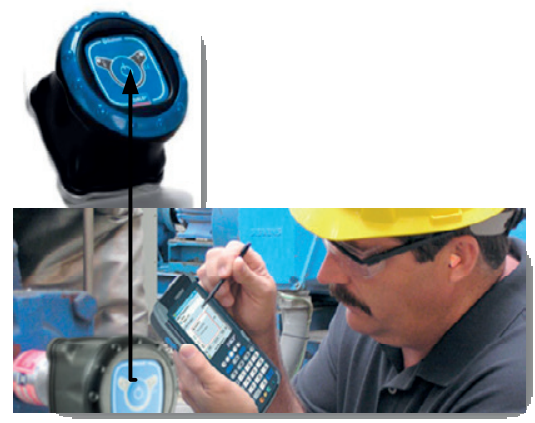

Fig. 8 - The operators makes an ODR route

In Figure 7 it is possible to see an operator analyzing and registering data on a PDA - in this case the operator only checks the level. However, for example, in the Figure 8, another operator is measuring a vibration in a machine. This is a great evolution by preventive maintenance versus maintenance through ODR. With this analysis, it is possible to detect a problem, and call the responsible of maintenance or the vibration technician to analyze in more detail the equipment and to detect the element damaged or what is inducing the increase of vibration values.

\section{ODR VALUE-ADDED}

As can be seen in Figure 9, through ODR it is possible to join the preventive maintenance with a first analysis of vibrations. It is also possible to upload the data to program and analyze the trends of all inspections. In the case of increasing of the value in one trend, the operator will solve the problem (for example, during a process fault) or may ask for help to a SKF technician or find the solution together in a team perspective. With this, the operator contributes with:

- Operator inspections provide increased opportunities for failure detection;
- Trending the inspection results that identifies small incremental changes;

- Sharing the results improves teamwork and proactive decision making.

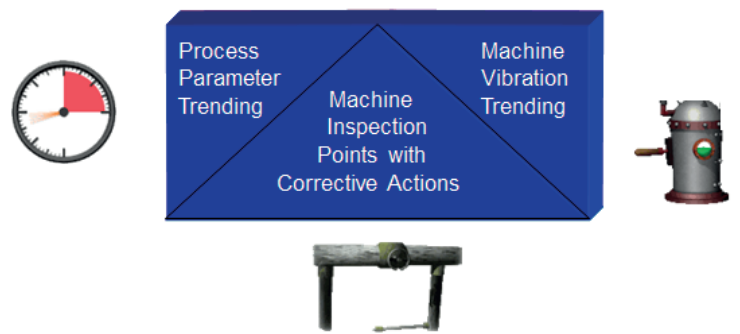

Fig. 9 - The Best Solution by SKF

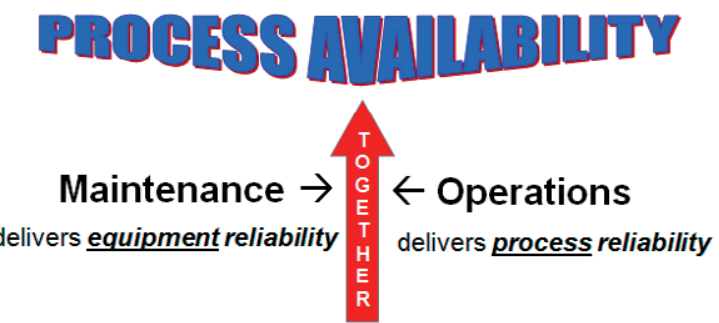

Fig. 10 - The Combination between Maintenance and Operation

The ODR makes the Maintenance and Operation work together and, as showed in Figure 10, when these two departments of the factory work together, it is possible to increase the workability of equipment and return all the potential of each equipment.

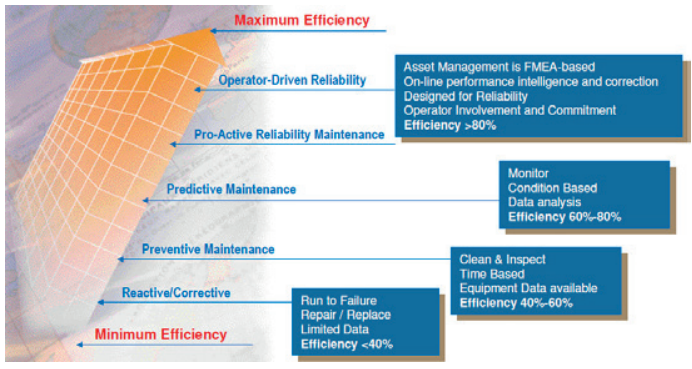

Fig. 11 - The Efficiency of ODR

This maximum efficiency, as we can see in Figure 11, is possible by the work of both partners. With the insertion of operators in maintenance work and decision, it will become a better environment to all the operators and essentially an easier communication between these two departments.

\section{CONCLUSIONS}

At the outset of this discussion, ODR was described as a logical extension of operator involvement in maintenance and the performance by operations staff of basic maintenance activities. It is difficult to imagine any production or processing plant without some element of operator involvement in maintenance. They invariably request maintenance work, and 
(though sometimes reluctantly) make equipment available for required maintenance. However, too often, this dialogue is unidirectional - this is the classic syndrome "we run it, you fix it".

However, experience shows that ODR is beneficial in terms of its cost effectiveness and development of an enlightened and productive dialogue between maintenance and production functions. Embracing an ODR approach diminishes maintenance time allowing to implement new monitoring and diagnostic technologies, without taking the risk of neglecting basic maintenance tasks.

\section{REFERENCES}

[1] SKF (2014): WWW.SKF.COM. 2014.06.21.

[2] SKF (2014): http://investors.skf.com/annual2010en/1-about-skf/SKFsplatforms.php auth. SKF. 20.06.2014.

[3] SKF Reliability Systems (2011): SKF Multilog On-line System IMx-S User Manual. Lulea.

[4] McKenna, T.; Oliverson, R. (1997): Glossary of reliability and maintenance terms. Houston: Gulf Publishing Company.

[5] SKF Reliability Systems @ptitudeXchange (2004): Operator Driven Reliability (ODR). The Definition, Scope, Limitations, Benefits, \& Positioning of ODR in the Maintenance World. - San Diego. 
(Página deixada propositadamente em branco) 


\title{
Time Replacement Optimization Models for Urban Transportation Buses with Indexation to Fleet Reserve
}

\author{
Hugo Raposo ${ }^{1}$, José Torres Farinha ${ }^{2}$, Rúben Oliveira ${ }^{3}$, Luís Andrade Ferreira ${ }^{4}$, Jorge André ${ }^{5}$ \\ hugrap@gmail.com ${ }^{1}$, torres.farinha@dem.uc.pt ${ }^{2}$, ruben.oliveira@dem.uc.pt ${ }^{3}$, lferreir@fe.up.pt ${ }^{4}$,jorge.andre@dem.uc.pt ${ }^{5}$ \\ $\mathrm{CEMUC}^{1,2,3}, \mathrm{FEUP}^{4}, \mathrm{UC}^{5}$ \\ Coimbra $^{1,2,3,5}$, Porto $^{4}$, Portugal $1^{1,2,3,4,5}$
}

\begin{abstract}
An efficient management of physical assets in general and the urban transportation buses in particular, has as objective the optimization of its Life Cycle Cost (LCC), being the optimization of its maintenance and the determination of the right moment of its withdrawal or its renewal, essential elements for optimization of the capital investments.
\end{abstract}

These aspects are related to the determination of the optimal dimension of the fleet reserve, aiming the maximization of its availability and the investment minimization. This can be reached through several algorithms that ought to be in consideration aspects like the maintenance costs, reseller cost, and inflation, among others.

This is reached trough the adequate maintenance policies, being these scheduled and or on-condition predictive or any kind of planned ones. This type of decisions are determinant to maximize the LCC and, by consequence, the dimension of reserve fleet.

It is through this perspective that the identification of the right moment of replacement or total renewal of an asset can be a strategic element in the competitiveness of the organizations by reducing the costs that can come from there.

The validation of the management models to be implemented will be done in the road transports sector of passengers' transportation and the models and the results have the potential to help this strategic sector in the global economy.

Keyword: Equipment Removal; LCC; Fleet reserve; On-Condition Maintenance; Scheduled Maintenance; Predictive Maintenance.

\section{INTRODUCTION}

The present article refers the replacement of buses, with indexation to the fleet reserve in companies of urban transportation buses.

In the present globalized economy, the companies' survival or, in a more generalized way, of the organizations depends on its ability to innovate. For that, they endlessly search new tools that may contribute for its continuous improvement.

The maintenance management or physical assets corresponds to a fundamental side for that goal. To guarantee the maximum availability of the equipment is a main goal of any maintenance section and this fact is determinant so that the companies are able to respond to the competitive challenges in which they are involved. A maintenance program that focus on the assets' management will only be successful if it stops to have an error management routine to the management of the life cycle of the assets.

The passenger transportation buses' management is an essential activity for the guarantee of the optimal compliance of its life cycle, which implies the combination of actions of management, technical and economical, in the sense of obtaining higher availability at rational costs, [1-5].

The cost of an asset's life cycle corresponds to the sum of all the spent capitals on the support of that asset since its conception and manufacturing, going through the operation until the end of its useful life [2]. It is understood that the useful lifetime goes until the deactivation of the equipment and that this could be different from the effective lifetime of the item, like it is the case of the equipment with fast technologic obsolescence.

The LCC of an asset can be significantly superior to the value of the initial investment and, in many cases, it's defined right on the project phase. [3]

The analysis of the cost of the life cycle it's a foreseeing and, therefore generally different methods are used in cost estimate, [7] and others like the Activity-Based Costing (ABC) [8]. The simulation method of Monte Carlo is another tool to deal with uncertainty.

To support the analysis of the cost of the life cycle there are rules as the referred in [9-10]. The rule about the assets management [11] is a good source of guidelines to the assets management that can be applied to any sector.

Though, the systematized study in this area remains underdeveloped, having the need of applying and creating new models of equipment management that can bring more benefits to the companies, in order to improve its productivity and quality of service, having in consideration the side of the environmental sustainability, including the rules of quality management, environment, safety, maintenance and energy [12], although it is known that many companies maintain equipment in function, even when its operation is no longer viable because they do not accompany its economic cycle , which has exogenous implications, in the case of passengers transportation, in the size of the fleet reserve.

According to [14], the traditional production systems are built over the scale economy principle. This author even 
illustrates a problem of equipment replacement, in a Lean Thinking context. [15] Says that the technological transformation as the motivation for replacement of the equipment. In scientific references is commonly assumed that technology continuously develops according to a well-defined function.

[16] Shows that combining continuous and discrete time models, the time to replace equipment is lower when the technology applied is superior.

According to [17], "the assessment of an profit is established by future benefits expected by cash flows referred to the present value by a discount rate that reflects the risk of the decision." Consequently, methods that consider the time value of money are the most suitable.

According to [18], the method of Equivalent Uniform Annual Cost CAUE is appropriate in the analysis of the company's operational activities, with investments that may repeat. Furthermore, the standardization of investment results equivalent to annual values makes the analysis of these results will easy the decision making. The use of this method is to determine what is the year with the lowest equivalent annual cost, which indicates the best time to replace the technical active [19].

The calculation of the equivalent annual cost is due to the use of the Capital Recovery Factor and it is through it that we can compare two or more investment opportunities and determining which ideal replacement of equipment time, taking into account information such as: value of the investment or acquisition; resale value or residual value at the end of each year; operating costs and cost of capital or minimum attractive rate [19].

The problem of determining the economic life of equipment for the purpose of replacing could be identified in four types of situation [20]:

1. When the good is already inadequate for the activity;

2. When the good has reached its limit of life;

3. When the good is already obsolete due to technological advances;

4. When more efficient methods show to be more economic.

In a certain point in the life cycle of a profit it is important to assess if keep it running or replaced. For this purpose, you must satisfy the following [12]:

i. Availability of new technologies;

ii. Fulfillment of safety standards or other mandatory;

iii. Availability of spare parts;

iv. Obsolescence that may limit its use.

After the listed aspects of the last point of the life cycle of the equipment, it is important to charactherize some calculation methods for determining the appropriate time to replace it. For this purpose it is necessary to take into account several variables:

- acquisition value

- Value of expiration

- operating costs

\section{- Inflation rate}

- Maintenance costs

O Operating Costs

- Capitalization rate

The majority of previous values of the variables are obtained by history, with the exception of the value expiration. In this case, to get the market value for each particular equipment, that can be not easy for many goods. An alternative it can simulate several types of devaluation such as the following [21]:

- Linear method of depreciation - the decline of the value of the equipment is constant over the years.

- Method of the sum of digits - the annual depreciation is not linear.

- Exponential method - The annual depreciation charge is decreasing over the life of the equipment.

Another method commonly used is the "lifetime" that defines that ends when the maintenance costs exceed the costs of maintenance plus the amortization of the capital of equivalent new equipment. According to [12] there are several methods for determining the economic cycle equipment replacement. The most common are:

- Method of Uniform Annual Rent (MUAR);

- $\quad$ Method of Minimizing Total Average Cost (MCMT);

- MCMT method with the reduction of the present value (MCMT-PVR);

In [22], illustrates the effective use of fixed assets as a major objective in the management of companies in the urban passenger transport sector.

Companies in the urban transport sector, the efficient use of profits is linked to a well-structured policy assessment and fleet replacement. Some cases of fleet replacement applied to the city bus segment are reported in [22-25].

The adoption of a single decision criteria is restrictive, given that costs, efficiency and level of service should be evaluated simultaneously. Methods such as Multi Attribute Utility Theory (MAUT), Analytical Hierarchy Process (AHP) and Quality Function Deployment (Quality Function Deployment - QFD) have been used to accommodate multiple decision makers and multiple decision criteria. However, were not found in the literature approaches consolidated using these methods in the replacement of public transport vehicles. It is also referred the use of stochastic models in conjunction with neural networks to model the creation of a replacement vehicle.

[26] Presents a proposal of a generic stochastic process model based on neural networks called Stochastic Neural Process (NSP) that can be applied in problems involving stochastic phenomena or periodic behavior and characteristics. Through neuronal networks of the PEN models the behavior of the time series of these phenomena without requiring a priori information about the series, by generating synthetic time series equally adaptable to the historical series. Some cases of using neural networks and stochastic models are reported in the literature [27-33]. 


\section{BUSES REPLACEMENT MODELS}

The replacement of equipment is an umbrella concept that embraces selection of similar profits, but new ones, to replace the existing ones, to evaluate the profits that act in ways completely different performance of the same function. This is the case of obsolete buses may be replaced by new models that operate in a similar manner.

Replacement decisions are critical for the company, because they are generally irreversible, ie, have no cash and require large amounts of money.

There are several reasons to make economic action to do the replacement of equipment. The deterioration is one of the causes, and is manifested by excessive operating costs and by the increasing of the maintenance costs. There are situations here the replacement of a standard operation conduce to the loss of the device ability to operate efficiently, ie, it becomes inappropriate.

Importa fazer a caracterização de métodos de cálculo adequados para determinação da altura adequada à substituição dos autocarros de transporte urbano de passageiros. Para o efeito, é necessário ter em consideração diversas variáveis:

So it is important perform a characterization of the appropriate methods of calculation for determining the proper time of replacement of buses for urban passenger transport. Indeed it is necessary to take in account several variables:

- Cost of acquisition (CA)

- Value of expiration (VC)

- The operating costs (EC)

- Maintenance costs $(\mathrm{CM})$

- Operating costs $(\mathrm{CO})$

- inflation rate $(\Theta)$

- capitalization rate (i)

The majority of previous values of the variables are obtained by history, with the exception of the value expiration. In this case, to get the market value for each particular equipment, that can be not easy for many goods. As an alternative it can simulate several types of devaluation such as the following: [21]

- Linear depreciation method- that lies on the assumption that the decline of the value of the equipment is constant over the years.

- Method of the sum of the digits - the annual depreciation is not linear.

- The Exponential method - The annual depreciation charge is decreasing over the life of the equipment.

\section{A. Linear Depreciation Method}

This method assumes that the decrease in the value of the device is constant over the years and is calculated by the following formula:

$$
d_{j}=\frac{C A-V C_{n}}{N}
$$

$\mathbf{d}_{\mathbf{j}} \quad$ Annual depreciation quota

CA Acquisition cost of equipment
$\mathbf{V C}_{\mathbf{n}}$ Residual value of the equipment at the end of $\mathrm{N}$ periods

N Lifetime corresponds to

j $\quad \mathrm{j}=1,2,3 \ldots \mathrm{n}$

$\mathbf{V}_{\mathbf{n}} \quad$ Value of the equipment over a period $\mathrm{n}=1,2,3 \ldots \mathrm{n}$. by:

The value of the equipment $\mathrm{V}_{\mathrm{n}}$, in a period $\mathrm{n}$ lower $\mathrm{N}$ is given

$$
V_{j}=C A-j * d
$$

\section{B. Method of Sum of Digits}

In this method, the annual depreciation is not linear and is calculated the following way:

$$
\begin{gathered}
d_{j}=2 * \frac{N-(j-1)}{N+1} * \frac{C A-V C_{n}}{N} \\
V_{n}=C A-d_{j}
\end{gathered}
$$

\section{Exponential Method}

The exponential method emphasizes an annual depreciation that decreases over the life of the equipment. The calculation formula is as follows:

$$
\begin{gathered}
d_{j}=V C_{j-1} *\left(1-\sqrt[N]{\frac{V C_{n}}{C A}}\right) \\
V_{n}=C A-d_{j}
\end{gathered}
$$

According to [12] the equipment can be replaced by various criteria. The financial aspect, a usual criterion is the "economic cycle" which determines the optimal period which minimizes the average total costs of operation, maintenance and capital immobilization.

Another method commonly used is the "lifetime" that defines that the equipment ends when their maintenance costs exceed the costs of maintenance plus the amortization of the capital of equivalent new equipment.

However, despite being possible from the depreciation values of market power pass to the analysis of equipment replacement, should be taken into account two other variables, which are:

- The capitalization rate, called for $\mathrm{i}$

- The inflation rate, called by $\theta$

These rates are related as follows:

$$
i_{A}=i+i+\theta \times \theta
$$

According to [12] there are several methods for determining the economic cycle equipment replacement. The most common are:

- Method of Uniform Annual Income (MRAU)

- Method of Minimizing Total Average Cost (MCMT) 
- MCMT method with the reduction of the present value (MCMT-PVR)

This article will use the Uniform Method of Annual Income (MRAU), this makes use of the following data:

- Acquisition cost of equipment

- $\quad$ expiration values (calculated according to the methods exposed ago)

- Maintenance Costs and Exploration over the years

- Apparent rate

D. Net present value in year $n$ (VPLn)

$$
V P L_{n}=C A+\sum_{j=0}^{n} \frac{C M_{j}+C O_{j}}{\left(1+i_{A}\right)^{j}}-\frac{V_{n}}{\left(1+i_{A}\right)^{j}}
$$

With,

CA Acquisition cost of equipment

$\mathbf{C M}_{\mathbf{j}} \quad$ Maintenance costs in year $\mathrm{j}=1,2,3 \ldots . \mathrm{n}$

$\mathbf{C O}_{\mathbf{j}} \quad$ Operating costs in year $\mathbf{j}=1,2,3 \ldots . n$

$\mathbf{i}_{\mathbf{A}} \quad$ Apparent rate

$\mathbf{V}_{\mathbf{n}} \quad$ Value of the equipment over a period $\mathrm{n}=1,2,3 \ldots \mathrm{n}$.

E. Uniform Annual Rent (RAUn)

$R A U_{n}=\frac{i_{A}\left(1+i_{A}\right)^{j}}{\left(1+i_{A}\right)^{j}-1} *\left(C A+\sum_{j=0}^{n} \frac{C M_{j}+C O_{j}}{\left(1+i_{A}\right)^{j}}-\frac{V_{n}}{\left(1+i_{A}\right)^{j}}\right)$

$$
R A U_{n}=\frac{i_{A}\left(1+i_{A}\right)^{j}}{\left(1+i_{A}\right)^{j}-1} * V P L_{n}
$$

With,

$\mathbf{V P L}_{\mathbf{n}} \quad$ Net present value $\mathrm{n}=1,2,3 \ldots \mathrm{n}$

The minor RAU calculated value indicates the respective period (multi-year), in which the equipment must be replaced. This value is equivalent to a minimum income that the equipment would cost annually.

The MCMT determines the lowest average cost of ownership of the equipment and the respective it occurs that corresponds to the optimal time of replacement. They are not considered capital costs and the rate of inflation. The calculation procedure is as follows:

$C_{n}^{\prime}=\frac{\sum_{j=0}^{n} C M_{j}+C O_{j}}{n} \quad C_{n}=\frac{C A-V_{n}}{n} \quad C_{n}=C_{n}^{\prime}+C_{n}^{\prime \prime}$

With,

n Number of years $n=1,2,3 \ldots \mathrm{n}$

$\mathbf{C}_{\mathbf{n}} \quad$ Average total cost

The MCMT - RVP the calculation procedure is identical to the previous one, with the exception that are considered capital costs and the inflation rate. The various values of maintenance and disposal, over the years, are reduced to present value, according to the following procedure:

$C_{n}^{\prime}=\frac{1}{n} \sum_{j=1}^{n} \frac{C M_{j}+C O_{j}}{\left(1+i_{A}\right)^{j}} C_{n}^{\prime \prime}=\frac{C A-\frac{V_{n}}{\left(1+i_{A}\right)^{j}}}{n} C_{n}=C_{n}^{\prime}+C_{n}^{\prime \prime}$

\section{APPLICATION OF THE MODEL IN THE TRANSPORT SECTOR}

The demonstrational application of the equipment replacement model will be made then in the road transport sector, with an emphasis on passenger, which corresponds to a strategic sector of the national and global economy. Application of the Model in the Transport Sector

The aim of this paper to present a model replacement bus passenger transport leading to the rationalization of the reserve fleet in a global perspective, to create integrated models that allow:

- Optimizing the management of their lifecycle;

- Optimizing the time of replacement;

- Optimizing the fleet reserve.

To develop this study and the fulfillment of the objectives listed in the previous paragraph, should be taken into consideration variables related aspects such as the technological aspects, the duly itemized direct operating costs, downtime costs, as well as indicators economic applicable, such as inflation and interest rates, among others.

In the first phase of the data collection operation for preparation of LCC is made, a road transport company. Based on these data is initiated the development of simulation models from a small number of buses, taken as a pilot to validate the replacement model.

\section{A. Characterization of buses}

In this phase the variables relevant to the purpose have been defined such as: Operation, maintenance, service user and the environment. Further characterize aspects that significantly affect the operating performance of the buses (existence and type of air-conditioning, engine power, etc.).

In the preparation of the models the following variables were used: the year of manufacture of the buses; starting year of operation; trademark; model; type of vehicle; maintenance costs; cost of operation; etc.

10 cars divided into two brands and five different models of buses, as shown in Table 1 were selected.

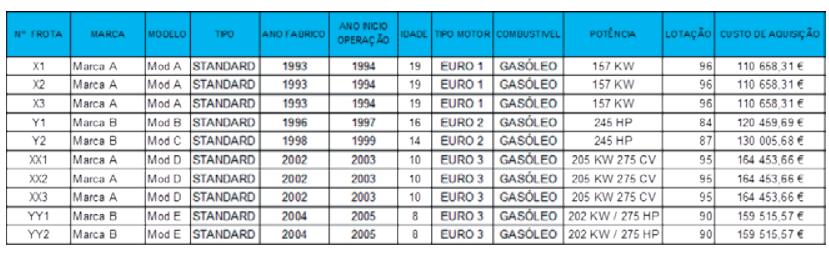

Fig. 1. Table Characteristics of Buses

\section{B. Background data of Buses}

At this stage, the focus corresponds to the identification and collection of primary data that are the basis for the analysis. The data should be relevant to the description of fleet costs and related activities, and should support the understanding of strategic economic and business information. Should be given priority to the information concerning procedures of operation, maintenance and planning. In this context, the historical data 
for each vehicle target of the study were collected, as can be seen below in Tables 2-6.

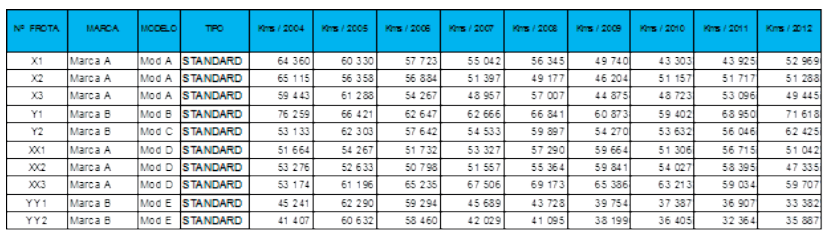

Fig. 2. Table Kms / year traveled by bus

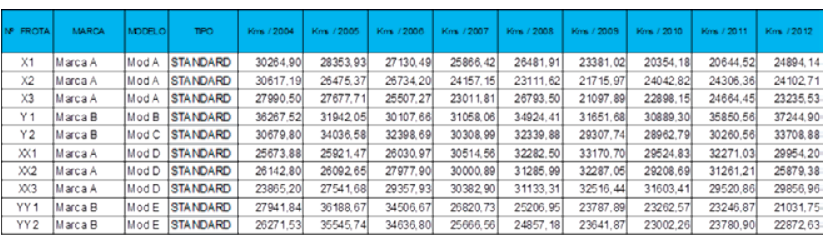

Fig. 3. Table of Litres of Fuel consumed / year by bus

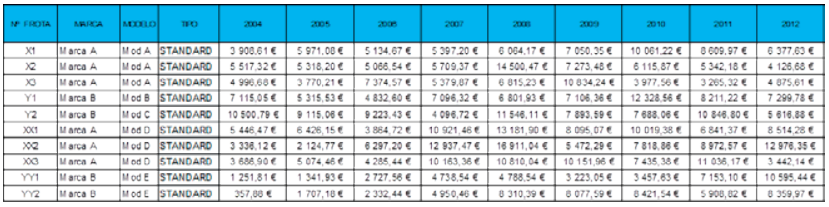

Fig. 4. Table of Operating Costs

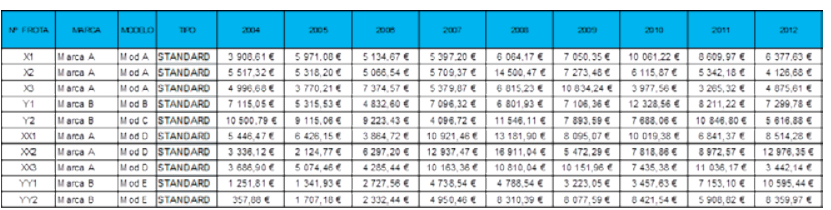

Fig. 5. Table of Maitenance Costs

\begin{tabular}{|c|c|c|c|c|c|c|c|}
\hline N FROTA & MARCA & MOOEE & neO & 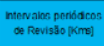 & 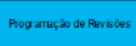 & 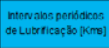 & 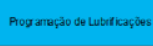 \\
\hline $\mathrm{x} 1$ & Marca A & Mod A & STANDARD & 30000 & $A 1, A 2, A 1, A 3, A 1, A 2$ & 25000 & L2.L4.L2.L4 \\
\hline$x_{2}$ & MarraA & Mod A & STANDARD & 30000 & $\mathrm{~A} 1 \mathrm{~A} 2 \mathrm{~A} 1 \mathrm{~A}, \mathrm{~A}, \mathrm{~A} 1 \mathrm{~A} 2$ & 25000 & L2,L4L2LA \\
\hline$\times 3$ & Marca A & ModA & STANDARD & 30000 & A1,A2,A1,A3,A1,A2. & 25000 & L2.L4.L2.L4 \\
\hline $\mathrm{Y} 1_{1}$ & Mara B & Mod B & STANDARD & 20000 & $A 1, A 2, A 1, A 3, A 1, A 2$ & 15000 & L2.L3.L2.L4 \\
\hline $\mathrm{Y} 2$ & Marca B & Mod C & STANDARD & 20000 & A1,A2,A1,A3,A1,A2. & 15000 & L2,L3.12,L4 \\
\hline$x \times 1$ & Marra $\mathrm{A}$ & Mod D & STANDARD & 50000 & $A 1, A 2, A 3, A 1, A 2, A 3$ & 50000 & $2, L 3, L 2, L 4$ \\
\hline 202 & Marca A & Mod D & STANDARD & 50000 & $A 1, A 2, A 3, A 1, A 2, A 3$ & 50000 & L2.L3.L2.L4. \\
\hline$\times \times 3$ & Marra A & Mod D & STANDARD & 50000 & $A 1, A 2, A 3, A 1, A 2, A 3$. & 50000 & $\angle 2, L 3 . L 2, L 4$ \\
\hline$w_{1}$ & Marca $B$ & Mod E & STANDARD & 25000 & A1,A2,A3,A1,A2,A3. & 15000 & L2.L3.L2.L3.L2.L4. \\
\hline $\mathrm{Y} 2$ & Marca B & Mod E & STANDARD & 25000 & $A 1, A 2, A 3, A 1, A 2, A 3$. & 15000 & L2.L3,L2.L3,L2.L4 \\
\hline
\end{tabular}

Fig. 6. Intervals and systematic preventive maintenance schedule

In the next section will be analyze the method of Uniform Annual Rent (RAU) for determining the economic cycle of buses replacement, we are analyzing a company in the sector of urban transport. Table 7 presents the values related to Linear Depreciation Method, Table 8 the method of Sum of Digits, and Table 9 the Exponential Method.

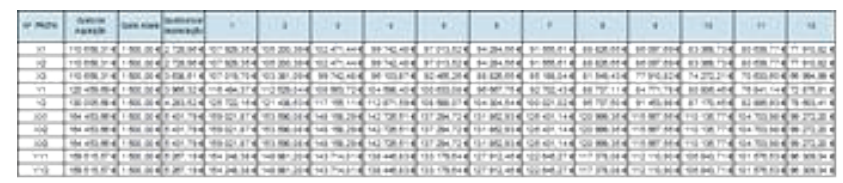

Fig. 7. Linear depreciation method Styling

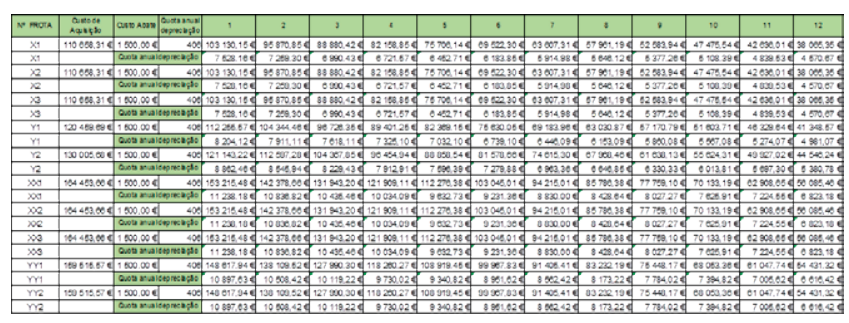

Fig. 8. Method of Sum of Digits

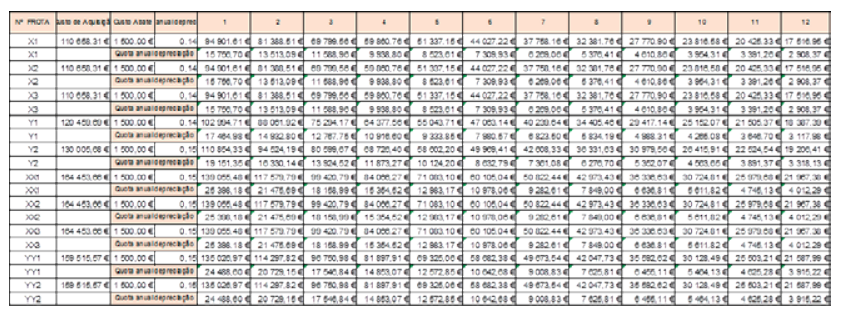

Fig. 9. Exponential Method

\section{The application the Method of Uniform Annual Rent (RAU)}

For the application of UARM we used historical data for a group of vehicles. These were grouped into homogeneous groups, in a period between 1993 to 2012 it were studied the vehicles with 19,16,14,10 and 9 years were studied. Table 10 shows the calculation of Annual Income Uniforms for homogeneous group: Brand A, Model A, with three cars of 19 years. We also analyzed data of buses designated as X2 and $\mathrm{X} 3$, the results are shown in Figures 11 to 13.

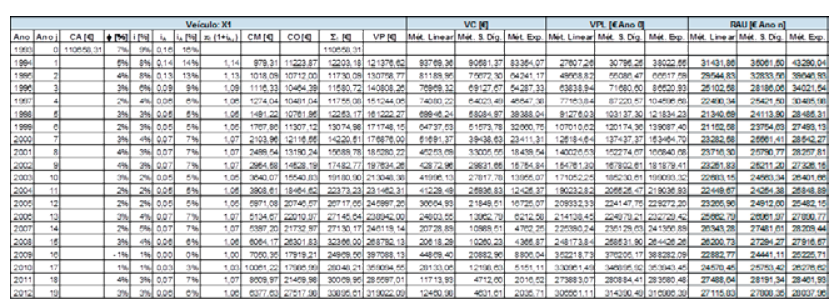

Fig. 10. Tablet RAU - Bus X1

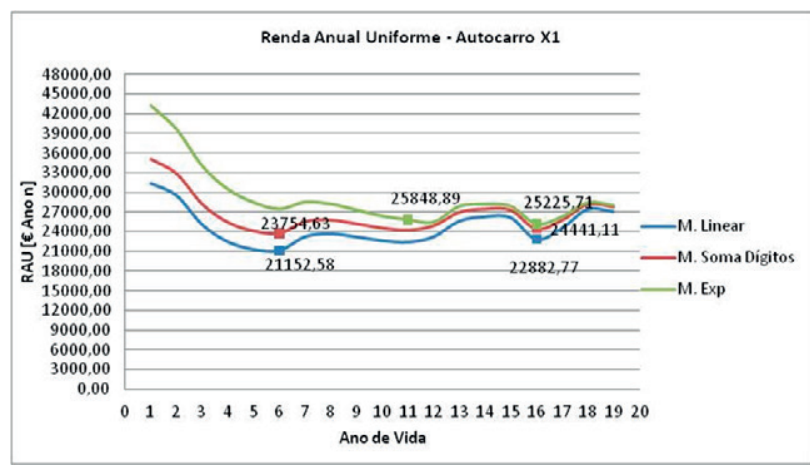

Fig. 11. Grafic RAU - Bus X1 


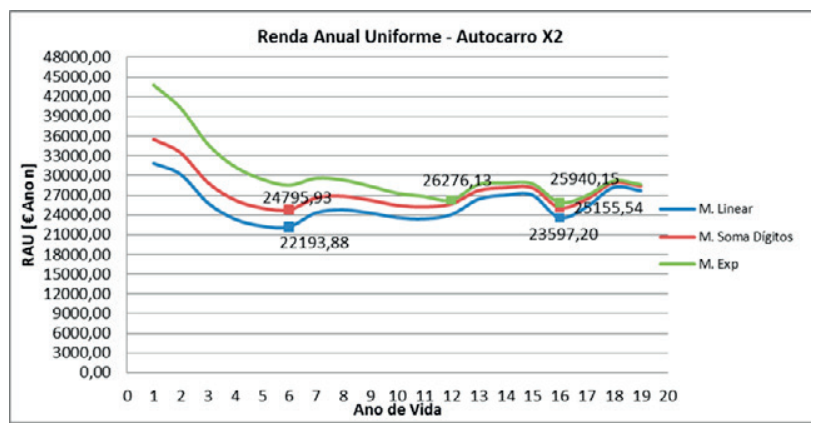

Fig. 12. Grafic RAU - Bus X2

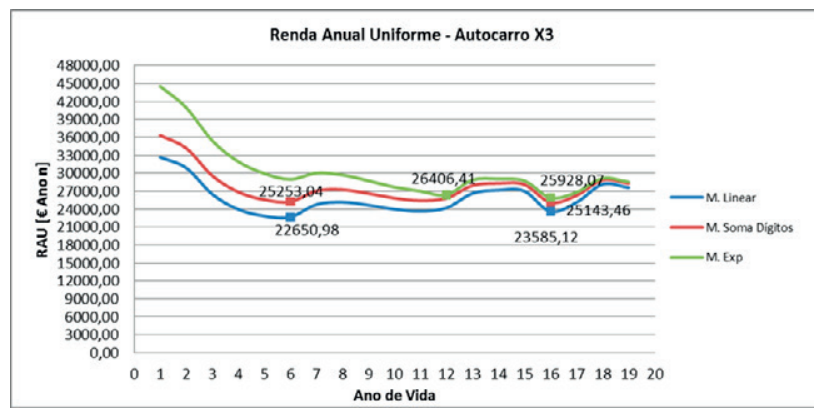

Fig. 13. Grafic RAU - Bus X3

Through the analysis of previous data can be seen that the values of rents vehicles are very similar. On Table 10 and the Depreciation Method Exponential it appears that the Uniform Annual Cost is minimal between the twelfth and the sixteenth year (economic life), with an approximate value of $€ 25,000 /$ year.

The minor RAU calculated value indicates the respective period (multi-year) in which the equipment must be replaced. This value is equivalent to a minimum income that the equipment would cost annually. It can be concluded that this period corresponds to the ideal time to proceed to the replacement of buses based on the Exponential Method for depreciation. If the methods of depreciation are used and the Linear Sum of Digits it appears that the RAU values decrising; however there is an increase in the period where the value of RAU is minimal, that is between the sixth and the sixteenth, that creat problems to the decision of the ideal moment to replace the equipment.

We can then verify the calculation of Uniform Annual Rent for homogeneous group: B Brand, Model B and C, consisting of two cars of 16 and 14 years (Table 14 and 15).

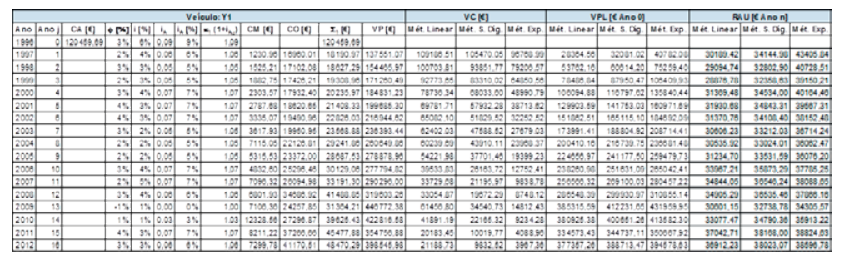

Fig. 14. Tablet RAU - Bus Y1

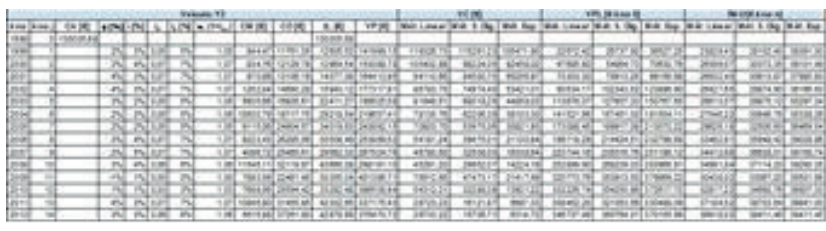

Fig. 15. Tablet RAU - Bus Y2

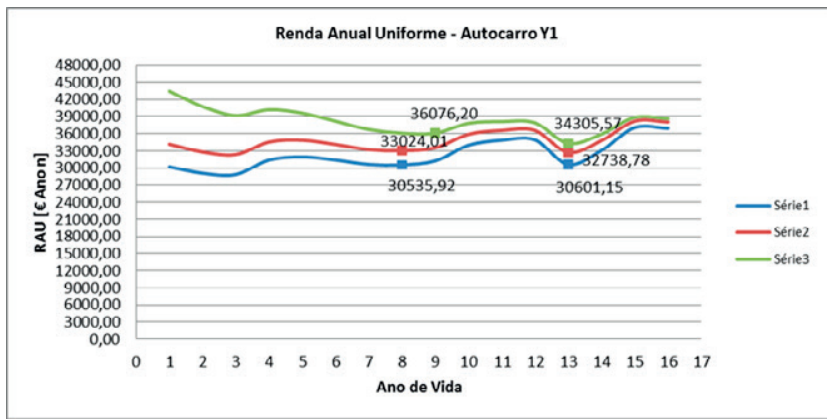

Fig. 16. Grafic RAU - Bus Y1

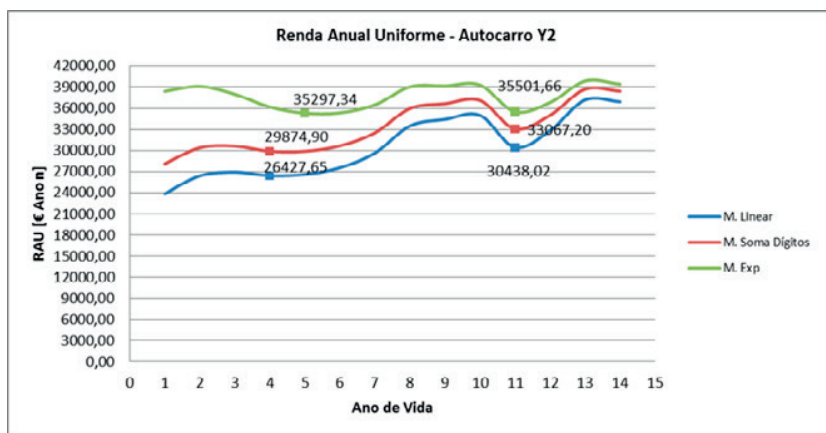

Fig. 17. Grafic RAU - Bus Y2

Through the analysis of charts of RAU of the buses Y1 and Y2 can be seen that the values of rents vehicles are not identical.

In relation to vehicle $\mathrm{Y} 2$ is verified that the RAU will be minimal between the fourth and eleventh years (economic life), with an approximate value of $€ 35,000$ / year.

If the methods of depreciation and Linear Sum of Digits are used can be seen that the RAU values decrease, but occurs an increase of one year in the period where the value of RAU is minimal, which produce problems in the taking of decision of the best time to proceed to the replacement of the equipment.

The Table 18 illustrates the calculation of the RAU to the bus XX1 of the homogeneous group: Brand A, Model B, composed of three vehicles of 10 years; Figures 19 to 20 illustrate the evolution of RAU for XX1, XX2 and XX3.

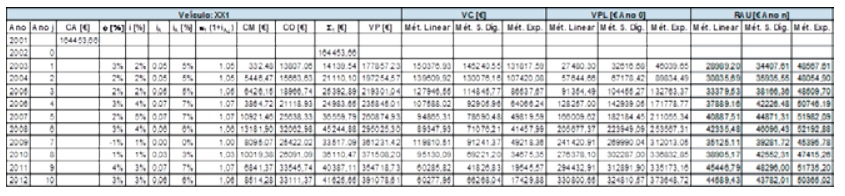

Fig. 18. Tablet RAU - Bus XX1 


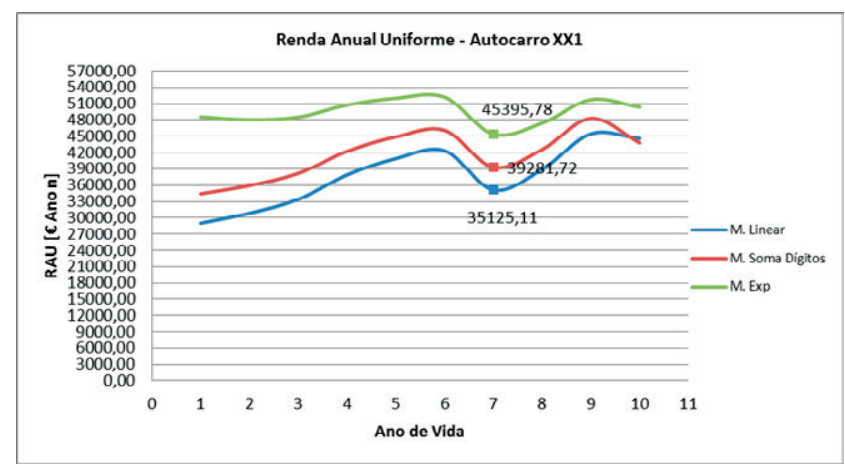

Fig. 19. Grafic RAU - Bus XX1

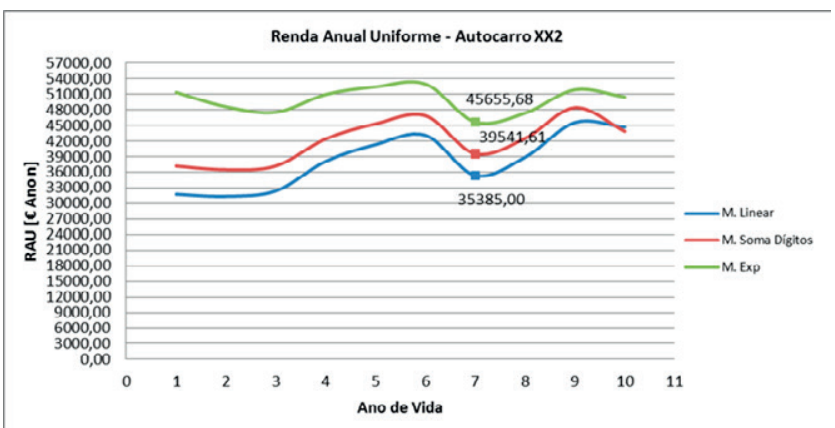

Fig. 20. Grafic RAU - Bus XX2

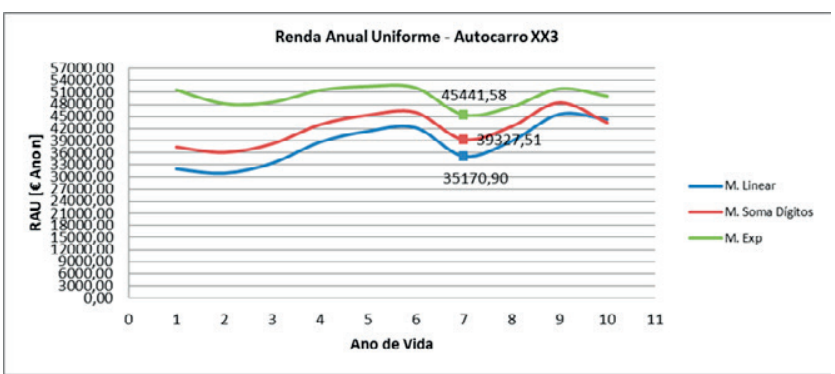

Fig. 21. Grafic RAU - Bus XX3

By the data showed it appears that the replacement period varies from homogenous group to homogeneous group of vehicles and there are several variables that can influence the outcome and the final decision of the manager, such as the apparent rate of each year as well as the depreciation model used. Another very important variable that can significantly influence the results is the maintenance cost. This, in turn, depends heavily on the policies and management of maintenance that is performed at public transport companies.

\section{CONTRIBUTIONS TO THE FLEET RESERVE}

The urban transport companies always have a given rate of buses reservation, which varies from company to company. A low reserve ratio is a synonym of high reliability, relying essentially on implementation of an efficient planned maintenance, which results in the application of new methods and maintenance techniques that lead to the assessment of the state of the equipment and the decision of replacing or renewing the equipment's.
There is a common set of factors that affect the optimal size of the number of vehicles in a reserve fleet, that are:

- Composition of the bus fleet;

- Brands and models;

- Age of the fleet;

- Annual rolling of the buses;

- Commercial speed that buses are subject;

- Surrounding and the operating environment;

- Daily fluctuations in the demand for transport;

- Policies and maintenance plans;

- Ratio of vehicles per mechanic;

- Planes maintenance training;

- Number of interventions picket;

- Tunings introduced the routes;

- Tunings introduced in services;

- Inventory management;

- Administration and Finance

To assess the management practices in transport companies the FTA (Federal Transit Administration - USA) conducted a survey of the 36 North American and Canadian companies, which included eight small companies with fleets of between 33 and 199 buses eight medium enterprises with fleets between 225 and 472 bus, 12 large companies with fleets ranging between 537 and 963 buses and eight very large companies with fleets between 1009 and 3664 buses. A synthesis of indicators of activity distributed by classes can be analyzed in Table 22.

\begin{tabular}{|c|c|c|c|c|c|}
\hline Classe & Nimerer de & 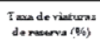 & 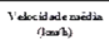 & 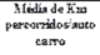 & 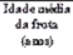 \\
\hline Syonese & $\varepsilon$ & 19 & 260 & $\$ 4765$ & $\%$ \\
\hline 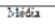 & 8 & 22 & 30,6 & 59:5!! & 81 \\
\hline Gavit & 12 & 21 & 26,9 & $6 \mathrm{KCDC}$ & ${ }^{3}$ \\
\hline 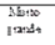 & s & 17 & 19,3 & 6271 & 2,3 \\
\hline 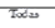 & 36 & 20 & 20,3 & 6124 & 5,3 \\
\hline
\end{tabular}

Fig. 22. Indicators of operating fleets, according to their size

The measurement and monitoring of reserve rates continue to be an important management tool in the urban transport sector. The inquire results highlight that transport managers are aware of their responsibility in the management of fleets within reasonable constraints of rolling materials reserve.

Survey responses indicate that efforts are being made in the sector to find ways to reduce the number of units vehicles spares. Many maintenance managers not only follow the guidelines of the FTA regarding the target of $20 \%$ of vehicle spares, as they have adopted the philosophy of "the smaller the better" in the managing of their fleets.

Ten percent of the buses are in daily standard repairs. On average, each bus of external service uses the pickets intervention nine times a year. The combined effects of the restrictive legislation of pollution in California, the dedicated maintenance, the high demand of transports and a skewed distribution on age and type of the impact of bus effects have led to an increased rate of reserve vehicles.

As a corollary, it may be noted that the definitions of the indicators of management of urban passenger transport shift 
from company to company. It also appears that the technologies used, the accuracy and frequency of collection of values of operating variables and indicators of buses network, the methodology and handle of the data vary significantly from operator to operator.

. In urban transport companies there is a great diversity of reserve rates of vehicles, which seems to show empiricism in its determination. It is therefore important to study this discrepancy in terms of optimizing an integrated model of replacement that necessarily implies a rationalization in the reserve fleet. Intends to implemented mathematical modeling of final decision support for replacement of buses of a fleet indexed to the reserve buses fleet. This model will be validated in all is extension in an enterprise of collective to transports not only with the aim of the validation, but also to incorporate the goods of the contributions of the managers who will use it.

\section{V.CONCLUSIONS}

This article presents a new approach to the economic models to the determination of the most adequate time for a replacement of buses in a urban fleet of an enterprise. The economic aspects were defined in concordance with the pertinent indicators and the cash flow, driven by the cost associated to the acquisitions, maintenance, and operation, among others.

The study presented allows the equipment's life cycle assessment by the managers and obviously it is a decision support tool.

It was demonstrated in the study that exist a variation of ideal moment for as replacement of a vehicle of a fleet, given by the analyses performed by the model of the annual uniform lease. Despite this still to be an anchor point and a useful tool to be used in future models that support the better take of decision. This new models should take in account not only the economics criteria but also non-economics as strategic and management assessed by the multy-dicision tools.

The new model should allow a detailed assessment of the present buses performance against the potential substitutes that turn viable a constant motorization of the goods of the enterprise and keeping high levels of quality and satisfaction of the customer service.

\section{REFERENCES}

[1] Aoudia, M.; Belmokhtar, O., (2008): Economic impact of maintenance management ineffectiveness of na oil gas company. Journal of Quality in Maintenance Engineering, Vol. 14, nº 3, pp. 237-261.

[2] Assis, R., (2010): Apoio à decisão em manutenção na gestão de activos fisicos. Lisboa: $1^{\text {a }}$ Edição, Lidel - Edições técnicas, Lda.

[3] Assis R.; Julião, J. (2009): Gestão da Manutenção ou Gestão de Activos? (custos ao longo do Ciclo de Vida). Comunicação $10^{\circ}$ Congresso Nacional Manutenção, APMI, Figueira da Foz, Portugal.

[4] Bescherer, F (2005): established Life Cycle Concepts in the Business Environment - Introductionand terminology, Laboratory of Industrial Management Report Series, report 1/2005, Helsinki University.

[5] Lindholm, A. and Suomala, P (2004): "The possibilities of Life Cycle Costing in Outsourcing Decision Making”. Frontiers of E-Business Research 2004.

[6] Korpi, E. and Ala-Risku, T. (2008), Life cycle costing: a review of public case studies. Managerial Auditing Journal, Vol. 23, N. 3, pp. 240-61.

[7] Durairaj, S.K., et al. (2002), Evaluation of life cycle cost analysis methodologies, corporate Environment Strategy, Vol. 9 N. 1, pp. 30-9.

[8] Emblemsvag, J. (2001), Activity-based life-cycle costing. Managerial Auditing Journal, Vol. 16, N. 1, pp. 17-27.

[9] International Electrotechical Commissioning (2004), IEC 60300-3-3: Dependability management - Part 3-3: life cycle cost analysis - Application Guide, Chicago, II.

[10] ASTM International (2002), Standard practice for measuring life-cycle costs of buildings and buildingsystem. Annual Book of ASTM Standards: 2002, Vol. 4, ASTM International West Conshohocken,PA, E 917, No. 11.

[11] BAS PAS 55 (2008), Asset Management: PAS 55-1, Part 1: Specification for the optimized managementof physical assets | PAS 55-2, Part 2: Guidelines for the application of PAS 55-1. British Standards, UK.

[12] Farinha, J. M. T. (2011): Manutenção - A Terologia e as Novas Ferramentas de Gestão. Lisboa: $1^{\text {a }}$ Edição, Monitor - Projecto e Edições, Lda.

[13] Oliveira, J. A. N. (1982), Engenharia Económica - Uma abordagem às Decisões de Investimento, São Paulo: McGraw-Hill do Brasil.

[14] William, G. S.; Thomas, N. M.; Eileen M. V. A. (2002): Equipment replacement decisions and lean manufacturing. ELSEVIER.

[15] Jennifer, L. R. and Joseph C. H. (2005): Equipment replacement under continuous and discontinuous technological change. IMA Journal of Management Mathematics; Volume 16, Issue 1.

[16] Natali, H.; Yuri Y. (2007): Optimal equipment replacement without paradoxes: A continuous analysis. Operations Research Letters. ELSEVIER. Volume 35, Issue 2, March, Pages 245-250

[17] Assaf Neto, A. (2005): Finanças corporativas e valor. São Paulo: Atlas.

[18] Casarotto Filho, N. (2000): Análise de investimentos - matemática financeira, engenharia económica, tomada de decisão, estratégia empresarial. \&ndash; 9.ed. \&mdash; São Paulo: Atlas.

[19] Vey, I. H.; Rosa, R. M. (2004): Substituição de frota em empresa de transporte municipal de passageiros: um estudo de caso. Universidade Federal de Santa Maria.

[20] Motta, R. R.; Calôba, G. M. (2002): Análise de investimentos: tomada de decisão em projetos industriais. São Paulo: Atlas.

[21] Oliveira,J. A. N. (1982), Engenharia Económica - Uma abordagem às Decisões de Investimento, São Paulo: McGraw-Hill do Brasil.

[22] Feldens, A. G.; Muller, C. J.; Filomena, T. P.; Neto, F. J. K.; Castro, A. S.; Anzanello, M. J. (2010): Política para Avaliação e Substituição de Frota por Meio da Adoção de Modelo Multicritério. Porto Alegre, Brazil, ISSN 1980-4814.

[23] Pinar, K.; Hartman, J. (2004), Case Study: Bus Fleet Replacement. The Engineering Economist, 49(3): 253-278.

[24] Khasnabis, S.; Alsaidi, E.; Ellis, R. (2002),Optimal allocation of resources to meet transit fleet requirements. Journal of Transportation Engineering, 128(6): 509-518.

[25] Di, J.; Hauke, L. (2000), Optimal fleet utilization and replacement. Transportation Research Part E, 36E(1): 3 .

[26] Campos, L. C. D.; Vellasco, M. M. B. R.; Lazo, J. G. L. (2010): Um modelo estocástico baseado em redes neurais. UFJF, Juiz de Fora, Brazil.

[27] Amaya, E. J.; Tonaco, R.;Souza, R. Q.; Álvares, A. J. (2007): Sistema Inteligente de Manutenção Baseada em Condição para Usina Hidrelética de Balbina. Universidade de Brasília, Departamento de Engenharia Mecânica e Mecatrônica, Grupo de Inovação em Automação Industrial (GIAI), CEP 70910-900, Brasília, DF, Brasil.

[28] Figueiredo, L. M. J. (2009): Modelo multicritério de apoio à substituição de equipamentos médicos hospitalares, IST, Lisboa, Portugal.

[29] Zhao, H. (2009). A chaotic time series prediction based on neural network: Evidence from the shanghai composite index in china. In Test and Measurement, 2009. ICTM 09. International Conference on, volume 2, pages $382-385$.

[30] Luna, I., Ballini, R., and Soares, S. (2006). Técnica de identificacão de modelos lineares e não-lineares de séries temporais. Revista Controle e Automacão, 17(3):245-256.

[31] Múller, D. (2007). Processos Estocásticos e Aplicacões, volume Coleccão Económicas -

2. ${ }^{\text {a }}$ Série of Direito Financeiro E Tributário. Almedina.

[32] Marco, A. R.; Angelo, A. D.; Leizer, S.; Silvio, A. B. V. (2010): A utilização de redes Bayesianas no processo decisório de de intervenções em equipamentos. Programa de Engenharia Industrial, Universidade Federal da Bahia, Escola Politécnica, Federação, 40.210-630, Salvador, Brasil.

[33] Araujo, M. S.; Bezerra, C. A.(2004): Desenvolvimento de componentes para sistemas estocásticos de apoio à decisão. PUCPR, Congresso Brasileiro de Computação, Engenharia Software, Brasil. 


\title{
Life Cycle Cost Optimization
}

\section{through an Asset Management based on Risk Principles}

\author{
João Santos ${ }^{1}$; Hugo Barata ${ }^{2}$; Hélio Cordeiro ${ }^{3}$; Cristina Mendonça ${ }^{4}$; José Sobral ${ }^{5}$ \\ 1joaosantos8@hotmail.com; ${ }^{2}$ h.reibarata@gmail.com; ${ }^{3}$ heliodmcordeiro@gmail.com ; \\ ${ }^{4}$ mclvmendonca@gmail.com; ${ }^{5}$ jsobral@dem.isel.ipl.pt \\ 1,2,3,5 Mechanical Engineering Department, ISEL - Instituto Superior de Engenharia de Lisboa \\ Lisboa, Portugal \\ ${ }^{4}$ SOCIUS - Research Centre in Economic and Organizational Sociology, ISEG \\ Lisboa, Portugal \\ ${ }^{5}$ CENTEC - Center for Marine Technology and Engineering, IST - Instituto Superior Técnico \\ Lisboa, Portugal
}

\begin{abstract}
When someone talks about assets life cycle optimization, the objective is mainly related with the reduction of operational and maintenance costs. However, regarding the newly asset management concept based on PAS 55 and the recent ISO 55000 standards family, this optimization should take into account and consider other issues like the risk associated with those decisions. Risk can be identified for each potential failure mode using a simplified FMEA (Failure Modes and Effects Analysis) and ranked or included into categories upon a determined and assumed criteria. Based on the previous risk level the decision making process aims to identify which hard time maintenance activities can be delayed in time in order to reduce maintenance costs and thus optimize the asset life cycle cost. The present paper presents a case study of equipment installed on a war vessel (diesel generators) and tries to assess if some relative hard time maintenance can be delayed without compromising safety. The amount of money to keep risk under the acceptable limits is then compared with the earning value related to the delay of maintenance activities. This work is supported by effective data gathered along the years for this specific equipment, which permits to have a realistic approach of the proposed decision. The chosen system operates on a maritime environment, has its last overhaul on 2010 and has been operating worldwide since then.
\end{abstract}

Keywords - FMEA, diesel generator, cost, risk.

\section{INTRODUCTION}

One of the main concerns of engineers and technicians with responsibilities on asset management is to keep risk under acceptable limits and at the same time promote an optimised life cycle cost.

Usually the problem is to combine these two areas of conflict in a way to achieve the best compromise. Frequently there is some difficulty to identify the probability of occurrence of undesired events and the severity of such situations and thus calculate the risk associated to the potential failure modes, although the several methodologies and tools available to reach such objective.
In almost industrial fields maintenance activities follow the manufacturer instructions and recommendations and so hard time maintenance programmes are followed and accomplished. Sometimes the frequency established for those activities is not the appropriate considering the working conditions of the assets. The decision to modify maintenance intervals is not so simple and must be based on trusted and proven information.

In the Portuguese Navy this concept is also applied and mostly systems installed in war vessels fulfil the requirements of hard time maintenance (HTM). This complies with some activities of condition based maintenance (CBM) and sometimes the necessarily corrective maintenance.

This paper intends to analyse specific equipment that exists in a vessel and verify if some hard time maintenance activities can be delayed in time taking into account the maximum risk acceptable once it is critical equipment. The objective is to compare the amount of money saved with this decision with the cost to keep risk under a pre-defined level.

To accomplish this work a Failure Mode and Effects Analysis (FMEA) was applied, including some additional studies. The paper is structured in four sections. Section II refers the Failure Mode and Effects Analysis (FMEA) methodology, its characteristics, benefits and drawbacks and Section III presents diesel generators as the equipment under study describing the use of such equipment on a war vessel and on maritime environment. Section $\mathrm{V}$ corresponds to the development of the case study and section VI points out some conclusions and future works that can be done on the sequence of the present study.

\section{FAILURE Mode AND EFFECTS ANALYSIS (FMEA)}

A Failure Mode and Effect Analysis (FMEA) is an engineering technique used to define, identify and eliminate known and potential failures, problems, errors, design process and/or service. It is a systematic approach and a mental discipline that an engineer normally goes through in any manufacturing process [1]. A FMEA is a living document based on experience, past concerns and key performance 
indicators. Most of times FMEA is an inductive approach to support risk assessment studies.

This methodology was first proposed by NASA in the $1960 \mathrm{~s}$ in order to fulfil reliability requirements. From then, it has been extensively applied as a powerful technique for system safety and reliability analysis of products and processes [2].

Several studies applying FMEA can be observed in a huge variety of subjects, since automotive, aeronautical, military and nuclear, among others. For example, Arabian-Hoseynabadi [3] applies this methodology to study the reliability of a wind turbine system and compares the results to reliability field data from real wind turbines systems and their assemblies.

Medicine is also a potential field for the application of FMEA. Recently many papers and studies use this tool as a guide to identify failure modes in this area. Chiozza and Ponzetti [4] used a FMEA to identify medical errors in order to prevent and reduce them and thus improve patient safety. In other work [5] the FMEA was applied to intraoperative radiation therapy just to prevent accidental exposures to the patient.

Cicek and Celik [6] applied the method to prevent crankcase explosion failure on a ship engine. The impact of such event can be catastrophic with damage on ship structure or on the crew members.

Feili et al [7] made a risk analysis of geothermal power plants using the FMEA technique to identify and analyse common cause failures (CCF) that could affect this type of installation.

In other cases FMEA is used in early stages of design in order to systematically improve processes and reduce project cost [2]. Usually, in a FMEA there are three measures under consideration: the probability of occurrence $(\mathrm{O})$, the severity of the consequences $(\mathrm{S})$ and the detectability of the failure before it occurs (D). The product of these three factors gives a parameter called risk priority number (RPN).

$$
R P N=(O) \times(S) \times(D)
$$

The team should be focused on failure modes with higher RPN once this means higher risk. So, using a risk matrix, RPN is used to identify acceptable and non-acceptable failure modes, providing a hierarchy of failures in accordance to the RPN achieved.

A criticism of FMEA is usually related to the possibility of failure modes with lower RPN could have some factors (like severity) with high values and sometimes it is not observed when someone only looks to the RPN value. After determining RPN some recommendations or corrective actions should be performed with the objective:

- To reduce or eliminate the probability of occurrence of the causes;

- To reduce the severity of the effects of the consequences;
- To increase the detectability of the failure before its occurrence.

When the analysis of failure modes is developed on a system, people can go into a desired level of detail just to identify potential failure modes before they occur and may cause undesirable events. So, the risk of failure is minimised by proposing design or operational changes.

A FMEA is a team work including experienced engineers and people familiar with project as well as experts who have a deep understanding of the product or process. The expertise team can vary according to the scope and complexity of the focused problem.

The FMEA process covers the following steps:

- Analysis of the process, product or system;

- Description of each function;

- List of the identified potential failures (functional failures);

- Evaluation of their frequency, severity and detection technique;

- Global evaluation (includes RPN analysis);

- Identification of corrective actions or recommendations

\section{DIESEL GENERATORS IN A VESSEL}

The physical assets analysed in the present work are diesel generators consisting in diesel engines coupled to alternators. These systems are installed in a vessel and mainly work in a maritime environment. This type of generator is prepared to work in a maritime condition, due to utilization of seawater for refrigeration purposes.

At the present study, it was considered the example of diesel generators from a modern Portuguese Navy vessel (frigate). The frigate platform has four diesel generators, each one with $655 \mathrm{~kW}$, in a total power of $2620 \mathrm{~kW}$. The generators provide $440 \mathrm{~V} / 60 \mathrm{~Hz}$ to two main switchboards that distributes energy for the entire platform. The vessel in a sailing situation requires two generators in permanent function and, when alongside, only one is required. Figure 1 shows a view of the diesel engine analysed in the present work.

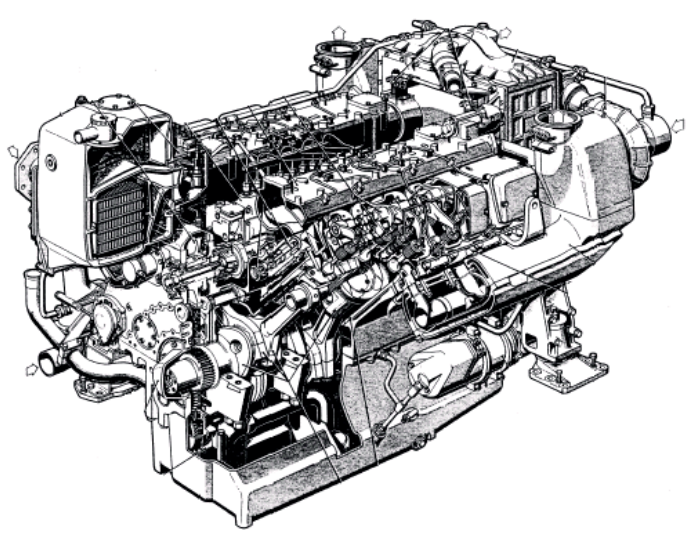

Figure 1. Diesel Generator MTU 8V 396 TB53 
The studied equipment is a MTU V8 Diesel generator, adapted to maritime applications. These generators are in use since 1991 and have been maintained according to the MTU maintenance program. The MTU maintenance program foresees the follow maintenance activities [8]:

- W1: This is a daily maintenance task which previews the verification of well-functioning parameters.

- W2, W3 and W4: These maintenance tasks are made by the operators during the generator stoppage period. The tasks are done in the function local and with the follow periodicity:

\section{- W2: 250 hours or 6 months \\ - W3: 1000 hours or 1 year \\ - W4: 2000 hours or 2 years}

- W5: This maintenance task is a partial overhaul. It requires the partial dismantling of the engine. This maintenance has a periodicity of 6000 hours or 6 years.

- W6: This maintenance task is an overhaul to the engine. It requires the entire dismantling of the engine and has a periodicity of 24000 hours or 12 years.

In the scope of this paper, the engine was decomposed in its subsystems in a way to perform a FMEA.

The diesel generator was decomposed in: (1) Cylinder Head; (2) Engine block; (3) Sump; (4) Alternator; (5) Rotor; (6) Stator; (7) Shaft; (8) Bearing shaft; (9) Ventilator; (10) Auxiliary equipment; (11) Cooled exhaust manifold; (12) Charge air cooler; (13) Housing cooler; (14) Alternator cooler; (15) Coupling; (16) Regulator and speed limiter; (17) Fuel feed pump; (18) Injection pump; (19) Lubrication oil pump; (20)
Coupled refrigeration water pump; (21) Coupled seawater pump; (22) Diesel engine turbocharger; (23) Pre-refrigeration water heater; (23.1) Heater; (23.2) Circulation water pump [9].

In accordance to the data available concerning the failures occurred in the several subsystems there were selected three of them to build the FMEA and serve as an example. The chosen systems were:

- The lubrication system (oil);

- The refrigeration system (water)

- The fuel oil system.

These subsystems were chosen because almost the failures registered on generators occurred on them.

\section{DEVELOPMENT OF A CASE STUDY}

The purpose of the present study is to quantify the risk associated to the rescheduling of the overhaul (W5), how to keep it under acceptable limits and how it costs. It is took into account all historical data from this diesel generator.

The first step of the present case study was to identify all the subsystems inside each pre-selected system. Then, for each of these subsystems were defined the inherent functions and all possible failure modes, assuming a failure mode when the function is not accomplished.

After that, it was studied the possible causes associated to each failure and the link to the specific maintenance programme (W's) that should be performed on the respective subsystem.

For the allocation of probability of occurrence $(\mathrm{O})$, severity (S) and detectability (D) were used matrices based on MILSTD 1629A [10]. The referred matrices were adapted to the present study. These matrices are shown on Table I, II and III, respectively.

TABLE I. PROBABILITY OF OCCURRENCE MATRIX

\begin{tabular}{|c|c|c|}
\hline \multirow{2}{*}{$\begin{array}{c}\text { Probability } \\
\text { level }\end{array}$} & \multicolumn{2}{|l|}{ Occurrence Matrix } \\
\hline & Description & Classification \\
\hline Frequent & $\begin{array}{l}\text { A high probability of occurrence during the item operation time interval. High probability } \\
\text { may be defined as a single failure mode. Probability greater than } 0.20 \text { of the overall } \\
\text { probability of failure during the item operating time interval. }\end{array}$ & 5 \\
\hline $\begin{array}{l}\text { Reasonably } \\
\text { Probable }\end{array}$ & $\begin{array}{l}\text { A moderate probability of occurrence during the item operating time interval. Probable } \\
\text { may be defined as a single failure mode probability of occurrence which is more than } 0.10 \\
\text { but less than } 0.20 \text { of the overall probability of failure during the item operating time. }\end{array}$ & 4 \\
\hline Occasional & $\begin{array}{l}\text { An occasional probability of occurrence during item operating time interval. May be } \\
\text { defined as a single failure mode probability of occurrence which is more than } 0.01 \text { but less } \\
\text { than } 0.10 \text { of the overall probability of failure during the item operating time. }\end{array}$ & 3 \\
\hline Remote & $\begin{array}{l}\text { An unlikely probability of occurrence during item operating time interval. May be defined } \\
\text { as a single failure mode probability of occurrence which is more than } 0.001 \text { but less than } \\
0.01 \text { of the overall probability of failure during the item operating time. }\end{array}$ & 2 \\
\hline $\begin{array}{l}\text { Extremely } \\
\text { unlikely }\end{array}$ & $\begin{array}{l}\text { A failure whose probability of occurrence is essentially zero during item operating time } \\
\text { interval. May be defined as a single failure mode probability of occurrence which is less } \\
\text { than } 0.001 \text { of the overall probability of failure during the item operating time. }\end{array}$ & 1 \\
\hline
\end{tabular}


TABLE II. SEVERITY MATRIX

\begin{tabular}{|c|c|c|c|c|c|}
\hline \multirow[b]{2}{*}{ Category } & \multicolumn{5}{|c|}{ Severity Matrix } \\
\hline & Causes & Safety & $\begin{array}{c}\text { Unavailability } \\
\text { period }\end{array}$ & Power loss & Classification \\
\hline Catastrophic & $\begin{array}{l}\text { A failure which may cause death. Loss } \\
\text { of power for more than } 30 \text { min. Power } \\
\text { output for less than } 60 \% \text {. }\end{array}$ & Death & $>30 \mathrm{~min}$ & $<60 \%$ & 4 \\
\hline Critical & $\begin{array}{l}\text { A failure which may cause severe } \\
\text { injury. Loss of power until } 30 \mathrm{~min} \text {. } \\
\text { Power output between } 60 \text { to } 80 \% \text {. }\end{array}$ & $\begin{array}{l}\text { Serious } \\
\text { injuries }\end{array}$ & $\leq 30 \mathrm{~min}$ & $60 \%<\mathrm{P} \leq 80 \%$ & 3 \\
\hline Marginal & $\begin{array}{l}\text { A failure which may cause minor injury. } \\
\text { Power output between } 80 \% \text { and } 100 \% \text {. }\end{array}$ & $\begin{array}{l}\text { Minor } \\
\text { injuries }\end{array}$ & 0 & $80 \%<\mathrm{P} \leq 100 \%$ & 2 \\
\hline Minor & $\begin{array}{l}\text { A failure not serious enough to cause } \\
\text { injury. System damage, but which will } \\
\text { result in unscheduled maintenance or } \\
\text { repair. }\end{array}$ & $\begin{array}{l}\text { No } \\
\text { injuries }\end{array}$ & - & - & 1 \\
\hline
\end{tabular}

TABLE III. DETECTABILITY MATRIX

\begin{tabular}{|l|l|c|}
\hline \multicolumn{1}{|c|}{ Detectability Grade } & \multicolumn{1}{c|}{ Detectability Matrix } & Description \\
\cline { 2 - 4 } Easily detectable & Automatic detection of the fault before occurs. & 1 \\
\hline Moderately detectable & Fault detection through inspection, before the effects are produced. & 2 \\
\hline Hardly detectable & Failure detection before their effects are felt through advanced diagnostics. & 3 \\
\hline Unable to detect & Failure cannot be detected before the effects are produced & 4 \\
\hline
\end{tabular}

Based on the classification used to categorize each failure mode a risk priority number (RPN) was achieved. This number represents the risk associated to each identified potential failure.

The probabilities of occurrence were determined upon the available historic data referred to the last three years. Based on that, it was analysed the number of occurrences registered and the inherent value for probability.

The severity was analysed taking into account the impact on the health of the crew, the system unavailability period and the generator power loss.
The detectability grade measure how difficult is the identification of the failure before it happens.

The risk acceptance criteria are based on the following rule:

- Acceptable-RPN from 1 to 10;

- Acceptable with remarks - RPN from 11 to 20;

- Unacceptable - RPN from 21 to 80.

So, after determining the RPN for each failure mode the result shows that three of them were in the "unacceptable" zone, as presented in Table IV.

TABLE IV. INITIAL UNACCEPTABLE RPN's

\begin{tabular}{|c|l|l|l|l|l|l|c|c|}
\hline \multirow{2}{*}{ FM \# } & \multicolumn{1}{|c|}{ System } & \multicolumn{1}{|c|}{ Sub system } & \multicolumn{1}{c|}{ Function } & \multicolumn{1}{c|}{ Failure Mode } & $\boldsymbol{O}$ & $\boldsymbol{S}$ & $\boldsymbol{D}$ & $\boldsymbol{R} \boldsymbol{P} \boldsymbol{N}$ \\
\cline { 2 - 9 } & $\begin{array}{l}\text { Lubrication oil } \\
\text { system }\end{array}$ & $\begin{array}{l}\text { Lubrication oil } \\
\text { cooler }\end{array}$ & $\begin{array}{l}\text { Keep the oil at the right } \\
\text { temperature conditions }\end{array}$ & The oil is not cooled & 5 & 3 & 2 & 30 \\
\hline B & Fuel system & $\begin{array}{l}\text { Diesel injection } \\
\text { pump }\end{array}$ & $\begin{array}{l}\text { Compresses the fuel with } \\
\text { the right sequence and } \\
\text { injection pressure }\end{array}$ & $\begin{array}{l}\text { There are no fuel } \\
\text { compression }\end{array}$ & 2 & 2 & 4 & 32 \\
\hline C & Cooling system & $\begin{array}{l}\text { Saltwater circuit } \\
\text { accessories }\end{array}$ & $\begin{array}{l}\text { Ensure the water flow rate, } \\
\text { pressure and containment } \\
\text { along the circuit }\end{array}$ & $\begin{array}{l}\text { Saltwater circulation } \\
\text { interruption }\end{array}$ & 2 & 3 & 4 & 24 \\
\hline
\end{tabular}

For these failure modes some recommendations were suggested just to reduce the RPN at least to the "acceptable with remarks" range of results. These recommendations are related to some modifications in the monitoring process that may cause some changes in the classifications of $\mathrm{O}, \mathrm{S}$ and $\mathrm{D}$ :
FM \#A - Control pressure changes along the circuit or evaluate the thermal gradient provided by the cooler. Clean or repair the oil cooler during downtime. With this, pressure problems are detected, reducing the probability of occurrence and increasing its detectability. 
FM \#B - Condition monitoring using vibration analysis, enhancing detectability.

FM \#C - Control pressure changes in the circuit and draw a graphic which represents the pressure loss trend, enhancing detectability.

The implementing costs are:

- $\mathrm{FM} \# \mathrm{~A}=400$ euros
- $\quad \mathrm{FM} \# \mathrm{~B}=150$ euros

- $\mathrm{FM} \# \mathrm{C}=$ without cost (only internal human resources are used. Cost not considered)

Now, assuming the successful implementation of recommendations, all RPN related to the analysed failure modes (now called $\mathrm{RPN}^{1}$ ) are positioned in an acceptable level as shown on Table $\mathrm{V}$.

TABLE V. RPN ${ }^{1}$ VALUES AFTER IMPLEMENTING RECOMMENDATIONS

\begin{tabular}{|c|c|c|c|c|c|c|}
\hline \multirow{2}{*}{ FM \# } & \multicolumn{7}{|c|}{ FMEA - Diesel Generator } \\
\cline { 2 - 7 } & $\boldsymbol{R P N}$ & $\boldsymbol{O}^{\boldsymbol{I}}$ & $\boldsymbol{S}^{\boldsymbol{I}}$ & $\boldsymbol{D}^{\boldsymbol{I}}$ & $\boldsymbol{R P}^{\boldsymbol{I}}$ & Modification Cost \\
\hline A & 30 & $\mathbf{4}$ & 3 & $\mathbf{1}$ & 12 & 400 euros \\
\hline B & 32 & 2 & 4 & $\mathbf{2}$ & 16 & 150 euros \\
\hline C & 24 & 2 & 3 & $\mathbf{2}$ & 12 & 0 euros \\
\hline \multicolumn{8}{|c|}{ Total Cost } \\
\hline
\end{tabular}

The next step was taking the decision to delay one year the W5 maintenance programme and analyse the impact of such decision on risk (RPN).

In the absence of coherent information about such scenario it was assumed that the announced delay of W5 maintenance activities will produce an increase of one level on the probability of occurrence of each failure mode related with W5 programme.

Based on this believed assumption new RPN's were determined (now called $\mathrm{RPN}^{2}$ ). Five new situations of unacceptable $\mathrm{RPN}^{2}$ values were achieved, as presented in Table VI.

TABLE VI. NEW RPN VALUES AFTER ONE YEAR OF DELAY (W5)

\begin{tabular}{|c|c|c|c|c|c|c|c|c|}
\hline \multirow{2}{*}{ FM \# } & \multicolumn{8}{|c|}{ FMEA - Diesel Generator } \\
\hline & System & Sub system & Function & Failure Mode & $\mathrm{O}^{2}$ & $S^{I}$ & $D^{1}$ & $R P N^{2}$ \\
\hline $\mathrm{B}$ & Fuel system & $\begin{array}{l}\text { Diesel injection } \\
\text { pump }\end{array}$ & $\begin{array}{l}\text { Compresses the fuel with the right } \\
\text { sequence and injection pressure }\end{array}$ & $\begin{array}{l}\text { There are no fuel } \\
\text { compression }\end{array}$ & 3 & 4 & 2 & 24 \\
\hline $\mathrm{D}$ & Fuel system & $\begin{array}{l}\text { Fuel system } \\
\text { accessories }\end{array}$ & $\begin{array}{l}\text { Ensure correct fuel flow along the } \\
\text { circuit, pressure and correct containment }\end{array}$ & Disrupted circuit & 2 & 3 & 4 & 24 \\
\hline $\mathrm{E}$ & Fuel system & Leakage tank & Hold fuel leaks & Tank rupture & 2 & 3 & 4 & 24 \\
\hline $\mathrm{F}$ & Fuel system & Fuel pump & $\begin{array}{l}\text { Pressurizes the fuel in the service tank } \\
\text { and sends it in the injection pump }\end{array}$ & $\begin{array}{l}\text { Does not } \\
\text { compress fuel }\end{array}$ & 2 & 4 & 3 & 24 \\
\hline G & $\begin{array}{l}\text { Cooling } \\
\text { system }\end{array}$ & Refrigeration & $\begin{array}{l}\text { Accessories of refrigeration water } \\
\text { circuit }\end{array}$ & $\begin{array}{l}\text { There is no } \\
\text { refrigeration water } \\
\text { circulation }\end{array}$ & 2 & 3 & 4 & 24 \\
\hline
\end{tabular}

Once again were suggested some recommendations in a way to decrease unacceptable RPN situations (again at least to the "acceptable with remarks" level).

FM \#B - Condition monitoring using vibration analysis, enhancing detectability.

FM \#D - Control pressure changes in the circuit and draw a graphic which represents the pressure loss trend, enhancing detectability.

FM \#E - Periodic inspections of tank thickness. This action increases detectability.

FM \#F - Condition monitoring using vibration analysis, enhancing detectability.

FM \#G - Control pressure changes along the circuit using pressure sensors strategically mounted in a few points of the circuit. Than anticipate a reactive action before the effects are produced. Enhance the detectability.
This set of measures implies the following costs:

- $\quad \mathrm{FM} \# \mathrm{~B}=150$ euros

- $\mathrm{FM} \# \mathrm{D}=$ without cost (only internal human resources are used. Cost not considered)

- $\quad \mathrm{FM} \# \mathrm{E}=150$ euros

- $\quad \mathrm{FM} \# \mathrm{~F}=150$ euros

- $\quad \mathrm{FM} \# \mathrm{G}=400$ euros

If the implementation of these proposals is considered, the impact on $\mathrm{RPN}^{2}$ can be assessed and new values for this indicator achieved (called final RPN or $\mathrm{RPN}^{3}$ ) resulting on the Table VII. 
TABLE VII. FINAL RPN $\left(\mathrm{RPN}^{3}\right)$

\begin{tabular}{|c|c|c|c|c|c|c|}
\hline \multirow{2}{*}{ FM \# } & \multicolumn{7}{|c|}{ FMEA - Diesel Generator } \\
\cline { 2 - 7 } & $\boldsymbol{R} \boldsymbol{P} \boldsymbol{N}^{2}$ & $\boldsymbol{O}^{3}$ & $\boldsymbol{S}^{3}$ & $\boldsymbol{D}^{3}$ & $\boldsymbol{R P N}^{3}$ & Modification Cost \\
\hline B & 24 & $\mathbf{2}$ & 4 & 2 & 16 & 150 euros \\
\hline D & 24 & 2 & 3 & $\mathbf{3}$ & 18 & 0 euros \\
\hline E & 24 & 2 & 3 & $\mathbf{3}$ & 18 & 150 euros \\
\hline F & 24 & 2 & 4 & $\mathbf{2}$ & 16 & 150 euros \\
\hline G & 24 & 2 & 3 & $\mathbf{3}$ & 18 & 400 euros \\
\hline \multicolumn{7}{|c|}{ Total Cost } \\
\hline
\end{tabular}

As it can be seen, the total cost related to the implementation of the measures is about 1.400 euros. However for the present study only 850 euros will be considered once the cost to reduce RPN to RPN ${ }^{1}$ is always necessary in the present moment if one wants to keep risk under the acceptable limits.

This value is assumed to be spent in every sixth years after the partial overhaul corresponding to W5 (revised).

Now, is time to determine the profit of delaying the W5 maintenance programming for one year, changing from 6 to 7 years the scheduled activities.

According to the registered historic values concerning the cost of a W5 task, including an outsourcing contract, spare parts and material necessary to perform it, results in a global value of approximately 71.000 euros each 6 years.

For a more realistic observation about the impact of this simple (but complex) decision it was analysed the behaviour of cumulative costs along the years in a temporal distance of 30 years, as shown in Figure 2.

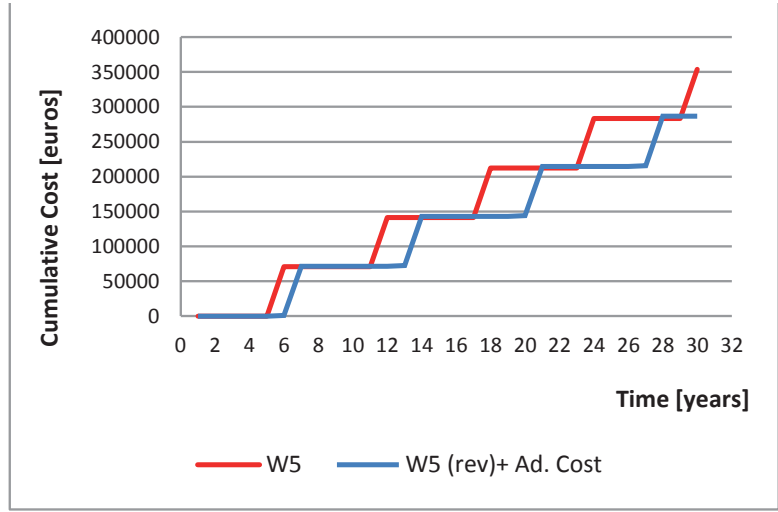

Figure 2. Comparison of the evolution of cumulative costs

As it can be seen costs vary on time. For the actual W5 partial overhaul (red line) cost increase earlier than for the proposed W5 (W5 revised) added the cost related to the implementation of risk reduction measures (blue line). With the passing time this gap has more significance.

\section{CONCLUSIONS AND FUTURE WORKS}

This work deals with maintenance and tries to demonstrate the relationship between cost and risk. In the present study a FMEA was applied to a specific equipment (diesel generator) installed in a war vessel just to identify its failure modes and determine the risk level associated. Based on historic failures some subsystems were identified and selected for the present case study.

Then it was proposed a change on the frequency of a hard time maintenance programme, delaying the inherent activities for a year. The amount of money earned with this decision is then compared with the estimated cost for keeping risk under acceptable limits referred in a pre-defined risk matrix.

Based on the present study it was shown that it is worth to make that decision, resulting on a profit once the cumulative cost appear in a later moment. All of this is achieved without compromising safety.

As future works, one may say that is necessary a validation of the values concerning the proposed measures in the present study as well as a more accurate study on the probabilistic data related to the failures registered along the years. It is also necessary to extend the FMEA to other subsystems covering the entire parts of the diesel generator. Later, it is also necessary to observe the impact of such decision as a whole, once a vessel has four diesel generators. This step is important for safety and operational purposes.

The present work shows in a clearly way that is possible to manage and optimise the life cycle cost of an asset taking into account risk principles.

\section{ACKNOWLEDGMENT}

The authors want to give a special acknowledgment to the Propulsion and Energy Department of NRP Álvares Cabral (Portuguese Navy) for providing technical information and historic maintenance data for the present case study. 


\section{REFERENCES}

[1] Ahire, C. and Relkar, A., "Correlating Failure Mode Effect Analysis (FMEA) \& Overall Equipment Effectiveness (OEE)", Procedia Engineering, vol. 38, pp. 3482-3486, 2012.

[2] Bahrami, M., Bazzaz, D. and Sajjadi, S., "Innovation and Improvements in Project Implementation and Management; Using FMEA Technique", Procedia Social and Behavioral Sciences, vol. 41, pp. 418-425, 2012.

[3] Arabian-Hoseynabadi, H., Oraee, H. and Tavner, P., "Failure Modes and Effects Analysis (FMEA) for wind turbines", Electrical Power and Energy Systems, vol. 32, pp. 817-824, 2010.

[4] Ciozza, M. and Ponzetti, C., "FMEA: A model for reducing medical errors", Clinica Chimica Acta, vol. 404, pp. 75-78, 2009.

[5] Ciocca, M., Cantone, M., Veronese, I., Cattani, F., Pedroli, G., Molinelli, S., Vitolo, V. and Orecchia, R., "Application of failure mode and effects analysis to intraoperative radiation therapy using mobile electron linear accelerators, International Journal Radiation Oncology Biol. Phys., vol. 82, pp. 305-311, 2012.

[6] Cicek, K. and Cleik, M., "Application of failure modes and effects analysis to main engine crankwise explosion failure on-board ship", Safety Science, vol. 51, pp. 6-10, 2013.

[7] Feili, H., Akar, N., Lotfizadeh, H., Bairampour, M. and Nasiri, S., "Risk analysis of geothermal power plants using Failure Modes and Effects Analysis (FMEA) technique", Energy Conversion and Management, vol. 72, pp. 69-76, 2013.

[8] MTU “Diesel Engine V 396 T.3 - Maintenance Manual”, Germany 1995

[9] MTU "Diesel Engine 8V 396 TB 53 - Description and Operation Manual", Germany 1989.

[10] DoD, "MIL-STD 1629 A - Procedures for Performing a Failure Mode Effects and Criticality Analysis - Revision A“, Department of Defense of USA, 1980 
(Página deixada propositadamente em branco) 


\title{
Better maintenance decision making in business networks with a LCC model
}

\author{
Tiina Sinkkonen ${ }^{1}$; Antti Ylä-Kujala ${ }^{2}$; Salla Marttonen ${ }^{3}$; Timo Kärri ${ }^{4}$ \\ 1tiina.sinkkonen@lut.fi; ${ }^{2}$ antti.yla-kujala@lut.fi; ${ }^{3}$ salla.marttonen@1ut.fi; ${ }^{4}$ timo.karri@lut.fi \\ 1,2,3,4 School of Industrial Engineering and Management, Lappeenranta University of Technology, \\ Lappeenranta, Finland
}

\begin{abstract}
Outsourcing of maintenance operations has created new kind of decision-making situations. These situations require above all increased cost-awareness. Our industrial research partners have noticed in several occasions that there is a need for a common network-level tool which would enable the planning of maintenance operations. Most planning is even today made by each partner's own simple calculations or is based on the empirical knowledge of maintenance experts. Co-operation between the customer and the service provider is still rather uncommon.

This article presents a life-cycle model that helps in planning maintenance operations better than previous models. Most models are very case-specific, suitable only for the item or the purpose of use in question. In many cases the models are quite theoretical and include complicated mathematical solutions, requiring special skills from the user. Usually the models have also been constructed for the needs of asingle company without a network perspective. Our general item level life-cycle model takes into account the point of view of all maintenance network members, it makes planning the future scenarios of maintenance operations together possible, and it provides a practical tool for daily use to reach cost and time savings in the whole network.
\end{abstract}

Keywords-life-cycle model, maintenance, customer, network, service provider, net present value, benefit-cost ratio

\section{INTRODUCTION}

Industrial maintenance outsourcings have changed the basis of maintenance decision making in many companies. When multiple different organizations (e.g. a customer, a service provider and an equipment provider) must collaborate to ensure the availability of production equipment, the decisions cannot be based on the tacit knowledge of individual maintenance experts, as has often been the case in in-house maintenance. Instead, a new kind of transparency is required from the companies operating in maintenance networks, not to mention cost-awareness, which is an essential part of service pricing, contract formulation and maintenance performance measurement.

Maintenance decision making often has to do with the future, especially as regards proactive maintenance: resources are sacrificed to improve the functioning of the items, not just at the moment but also in times to come. Thus maintenance should be approached from the perspective of investment appraisal, and the impacts of the decisions on the whole life cycle of the item should be considered.
A number of life-cycle cost (LCC) models for different kind of products, equipment, machines or systems can be found in the literature [1]-[8]. Although the demand for LCC models is commonly admitted, these models are still often very case-specific, suitable only for the item or the purpose of use in question. There cannot be found a single LCC model that has been widely used and accepted as a standard [4].

Hochchorner and Noring [9] carried out an interview study in 2005-2006 and 2010 among Swedish companies regarding the use of LCC. They noticed that "even though many interviewees believed that LCC can be important for decision making, it was not always performed or used." The reason for this was that LCC was experienced as difficult and complicated to use, and a time-consuming and expensive method to carry out. This result supports the argument of Korpi and Ala-Risku [10], according to whom there is no evidence that LCC models are commonly used. They have also observed that the LCC analysis is often affected by a lack of adequate information. Kayrbekova et al. [6] note that it may be impossible to perform a complete LCC model due to the enormous need of data and information.

The interviewees in the study of Hochchorner and Noring [9] pointed out that there was a real need for a common and easy-to-use LCC model as a decision-making tool. Our industrial research partners, operating either as maintenance service buyers or providers, have noticed also in several occasions that there is a need for a common network-level tool which would enable the planning of maintenance operations. We have created an LCC model to support maintenance decision making in business networks.

The research questions of the paper are the following:

- How does the created life-cycle model differ from or is better than the existing models?

- What are the possible limitations of the model?

This paper contributes to the previous discussion through pointing out the general shortcomings of the existing LCC models in maintenance. We also describe the design and costing principles used in constructing our general item-level LCC tool for network-level maintenance decision making, and finally explicate the limitations and challenges that still remain unsettled and should thus evoke further research.

After this introduction section, section II concentrates on the comparison between the existing models and our model by 
using the five-step method of LCC. Next, section III introduces the mathematical structure of our LCC model for an industrial maintenance network. In section IV the limitations and challenges of our LCC model are discussed. The article finishes with conclusions in section $\mathrm{V}$.

\section{LIFE-CYCLE COSTING PROCESS}

Originally, the LCC has been seen as a tool for estimating the acquisition cost of a product from design to disposal. Nowadays the LCC can be used in various situations, like managing the costs, planning the future or organizing the actions in the long run [11].

Life-cycle costs mean typically the costs which arise from owning, utilization, maintenance and disposal of a product, item, project or system [12], [13]. As the main focus in analysing different kinds of LCC methods is usually on costs, when speaking of comprehensive LCCs, the profits must also be included. The life-cycle profits (LCP) are the profits the company gains during the whole life-cycle period of the product, item or service [14]. Indounas [15] has pointed out that the price is the only way to get profit. This is true when we think of the equipment provider or service provider, but the customer on the other hand gets profit for example through rationalization or better reliability [16].

Many models and methods for describing the LCC have been developed. For example the standards for life-cycle costs present calculation processes including four to seven main stages [17], [18]. Several alternatives for designing the LCC process can be found in the literature [19] - [21]. Figure 1 shows a five-step method for the LCC, adapted from Woodward [19] and Kawauchi \& Rausand [21].

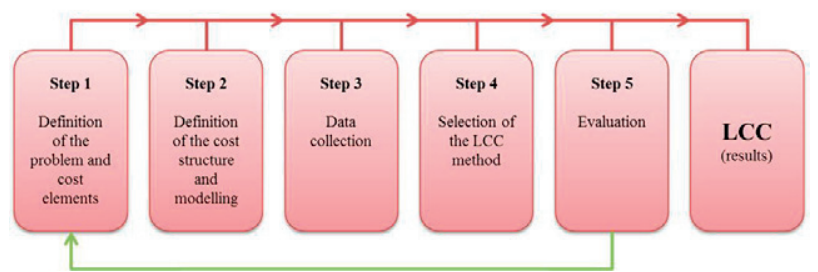

Fig. 1. Five steps of LCC (adapted from Woodward [19] and Kawauchi \& Rausand [21])

The following chapters concentrate on comparing the existing models with our model by using the five-step method of LCC presented in figure 1.

\section{A. Step 1: Definition of the problem and cost elements}

Step 1 defines the problem and the cost elements needed. This means specifying the wideness and target of the model. It also includes a description of the cash flow along the life cycle. This step is important for the success of the final accounting process, although it may be very challenging to identify the cash flow in many cases [19], [21].

Seven recent academic studies from years 2006 - 2012 presenting LCC models including maintenance, have been mainly constructed to contain costs along the whole life cycle, designed only for the item in question and from the perspective of one company [1] - [7]. Our general item-level life-cycle model takes account of the point of view of all maintenance network members, i.e. the customer, service provider and equipment provider.

Our model focuses on the life cycle of the item based on the maintenance contracts. This life cycle can vary depending on the role of the network member. The length of the life-cycle period of the item for the equipment provider may be for example ten years, but at the same time the customer company may have two to three different contracts with the maintenance service provider. During the life cycle of the item, the cash flows to be included in the model include e.g. the network members' maintenance costs, revenues from equipment and service sales, and performance-related bonuses and penalties.

\section{B. Step 2: Definition of the cost structure and modelling}

Step 2 is definition of the structure of the model and the cost categories to be used. There are many ways to classify the costs, but it must be done so that the company can make a comparison between the selected products or services on a sufficient level. The costs can be categorized for example by design, research and development, production, implementation, and utilization [19], [21].

Jun and Kim [2] have only three main cost categories in their LCC model; investment, annual operation and maintenance, and disposal costs. Waghmode and Sahasrabudhe [4] have included 25 different cost elements in their LCC model, whereas Lapašinskaite and Boguslauskas [3] have paid most attention only to operational and maintenance costs.

There are six cost categories in our model; operational maintenance, quality, outsourcing and logistics, environmental, asset management, and other costs. These main cost categories (e.g. operational maintenance costs) are then further divided to subcategories like labour, material or energy. The original cost structure was developed together with companies working in the forest industry and it was then specified in co-operation with maintenance experts [22] - [24]. Although our model contains a number of subcategories for costs, using them is optional in order to increase the generalization of the tool. If the accumulated cost data is not specific enough, or if the company feels that breaking down the costs will not bring any specific additional value to them, they are free to use even one single cost category.

All recent LCC models [1] - [7] consider the costs only from the point of view of the user. Our model is made for a maintenance network. It is a tool for planning the operations together with a customer (buyer of maintenance services), a maintenance service provider and an equipment provider, who supplies the equipment and maybe also equipment-related services to the customer.

\section{Step 3: Data collection}

Step 3 is collecting all the data required. This step has the great impact on the final results. The initial data must be reliable and as relevant as possible [19], [21]. This has been a very challenging stage for us as well, because it is very difficult to acquire adequate maintenance cost data at the item or operational level. There are a lot of cost data in companies' cost systems, but the information is not detailed enough. Production-related information such as capacity, operating time, production speed etc. is well known, and also 
maintenance-related information like maintenance hours and the share of corrective or preventive maintenance can be found easily. However, product-related information can be problematic, because the item in question may not produce finished products but semi-finished products or parts of the finished product. In these situations it is challenging to define for example the unit production cost or profit margin. This problem will disappear when the perspective is expanded to the production line or even larger entities.

The network-level view is beneficial also from the perspective of data collection. The life-cycle data of the item can be fragmented between different network partners, and pooling the data with a joint decision-making tool can result in valuable information for each company.

\section{Step 4: Selection of the LCC method}

The method for life-cycle accounting is chosen in step 4 . The model must be suitable for analysing the costs of the product or service in question. This stage includes also the actual calculation.

In life-cycle cost analysis, the cost elements will occur at different times throughout the life of the item. Thus, it is essential to calculate the present value of the life-cycle costs. The future costs can be discounted to the present value by using a specific discount rate [19]. The present value can be seen as a good evaluating method when discounted cash flows are concerned [25] - [27]. For example Jun and Kim [2], Waghmode and Sahasrabudhe [4], Lapašinskaitè and Boguslauskas [3], and Lad and Kulkarni [1] use the present value to calculate the LCC.

Kayrbekova et al. [6] introduce activity-based LCCs in their research. This technique observes the overhead costs and allocates them more accurately than conventional cash flow oriented costing. It also highlights the cause-and-effectrelationships of the costs. Korpi and Ala-Risku [10] remind that using the activity-based method requires an extensive activity-cost database.

We have developed our model based on the conventional cash flow -oriented model by using the present value to calculate the LCC. These choices make it possible to keep the model simple to implement and easy to use. The decision of not to apply the activity-based LCC is justified in terms of model generalization, as a vast majority of companies do not have the needed activity-related data available.

\section{E. Step 5: Evaluation}

Step 5 is for analysing the LCC results, estimating the whole calculation process and sensitivity analyses. It is possible to analyse the changes of the important factors and their impact for the final results. It is also possible to move back to step 1 and change the initial data if necessary [19], [21]. Jun and Kim [2] emphasise the importance of sensitivity analysis when there are uncertainties in the input data.

Our LCC model results in the cumulative net present value of maintenance as well as in the maintenance benefit-cost ratio for each network member. For years now the academic discussion on maintenance has emphasized the fact that in order to convince the decision makers, the results of maintenance analysis should be translated into economic aspects. This is what we have done, trying to offer maintenance managers a tool for validating their decisions to the managers at the top levels of organizational hierarchy. In addition, the results of our model enable network-level performance measurement and management. However, sharing the economic results outside the company borders requires a considerable amount of trust and work from the partners, and is thus not often put into practice.

\section{OUR NETWORK LEVEL LCC MODEL}

In this section, the structure of our life-cycle cost model as a planning tool for an industrial maintenance network is presented. The developed model focuses on the maintenance operations and their costs and effects at the network level. The objective has been to create a common tool for planning to gain benefit for each member by increasing the value of the whole network.

The life-cycle model is defined as the summation of three cost components; maintenance costs, maintenance cost savings and maintenance profit loss or gain. In addition, the maintenance profit loss or gain, closely connected to the maintenance of the equipment itself, is substituted with certain profit categories, such as contract-based profits, in the case of the service provider or equipment provider, as the equipment is owned by the customer.

The model focuses on maintenance, because its costs, savings and profits dominate along the whole life-cycle of the item in many cases [3], [4].

Figure 2 illustrates the design and costing principles of our model. The input data is on the left of the figure, the costing principles in the middle and the results on the right. 


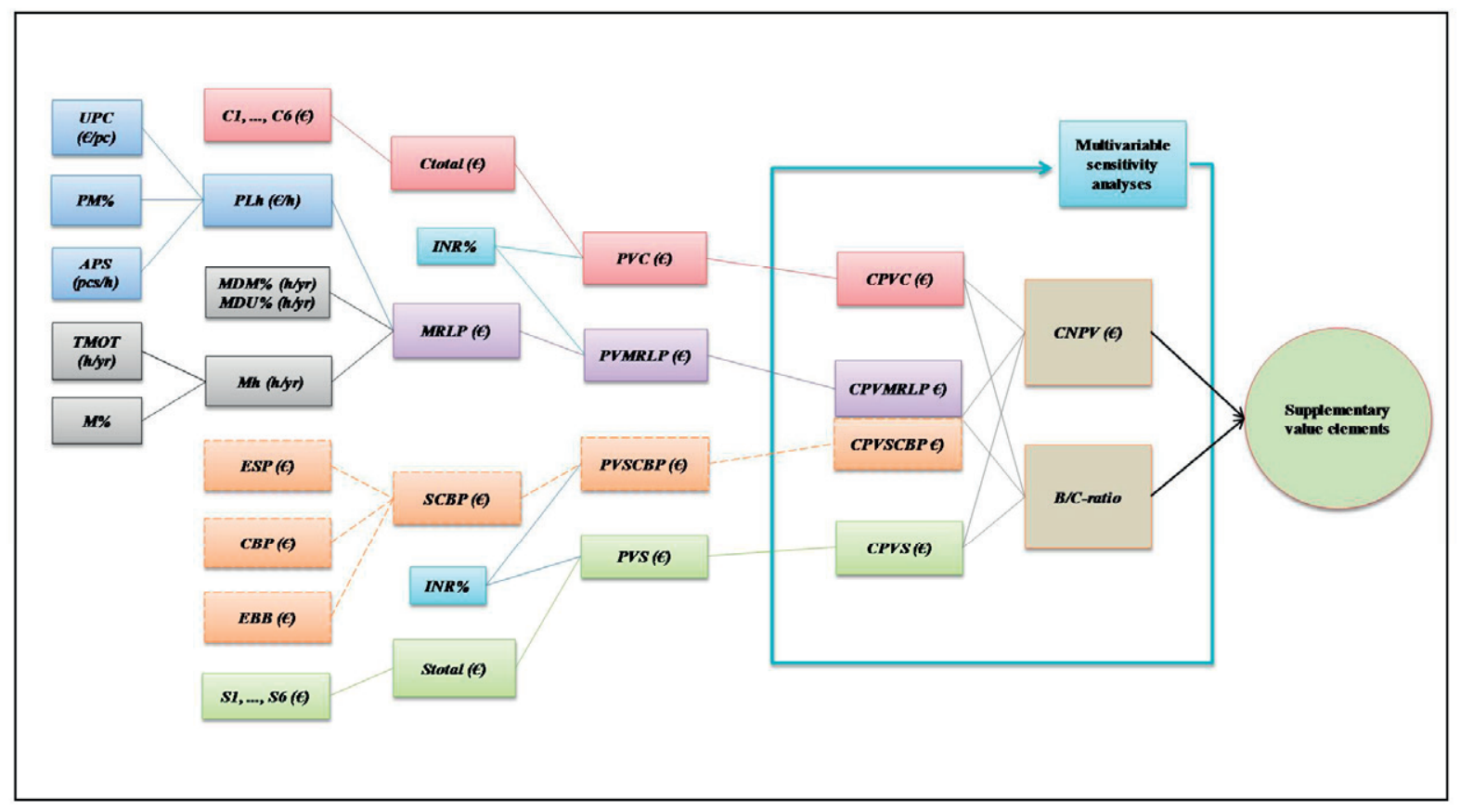

Fig. 2 LCC model for a maintenance network (the abbreviations are explained in the sections below)

\section{A. Annual Maintenance Costs}

The annual maintenance costs in total, $C_{\text {total }}$, can be calculated by summing up the six subcategories of the costs (1).

$$
C_{\text {total }}=C_{1}+C_{2}+C_{3}+C_{4}+C_{5}+C_{6}
$$

where

$$
\begin{aligned}
& C_{1}=\text { operational maintenance costs } \\
& C_{2}=\text { quality costs } \\
& C_{3}=\text { costs of outsourcing and logistics } \\
& C_{4}=\text { environmental costs } \\
& C_{5}=\text { asset management costs } \\
& C_{6}=\text { other costs }
\end{aligned}
$$

These six subcomponents of the costs are based on the definition of the cost structure for maintenance services made by the researcher [22]. Some of the original cost categories have been left out during the development of the model due to the reserved feedback of maintenance experts.

The operational maintenance costs, $C_{l}$, consist of labour, energy and material costs. The quality costs, $C_{2}$, include quality control costs and disposal and processing costs of low-grade products. The costs related to outsourcing and logistics are marked as $C_{3}$. The environmental costs, $C_{4}$, are the sum of cleaning, processing and supervision costs. The costs of current assets and the costs of fixed assets form asset management costs, $C_{5}$. The other costs, $C_{6}$, are composed of costs like tools and instruments, research and development, training and negotiation, as well as the costs of occupational safety and accidents. There is, however, a couple of exceptions to this categorization. First of all, the quality costs include warranty costs instead of the abovementioned ones for the service providers and equipment providers in the model. Also research and development form a separate cost category to these two actors, including both designing costs and data acquisition costs.

\section{B. Annual Maintenance Cost Savings}

Annual maintenance cost savings, $S_{\text {total }}$, consist of six sub components (2) which are based directly on cost information entered by the user. For example $S_{l}$ is the operational cost savings.

$$
S_{\text {total }}=S_{1}+S_{2}+S_{3}+S_{4}+S_{5}+S_{6}
$$

Modelling the annual cost savings is based on the comparison of the average costs of the life-cycle so far to the annual costs of the present year. Thus occasional large variation in yearly costs can be eliminated and they do not have too much influence on planning the future operations. Equation (3) presents the annual subcomponent of maintenance cost saving.

$$
S_{1}=\left(\sum_{n=1}^{k} C_{1_{n}}\right) / k-C_{1_{k}}
$$


where

$S_{I}=$ operational maintenance cost savings based on input data of operational costs

$k=$ length of the planning period, including both history and future years

The other five cost saving subcategories from $S_{2}$ to $S_{6}$ are calculated the same way as $S_{l}$ above.

\section{Annual Maintenance Profit Loss or Gain}

Maintenance-related profits and losses illustrate the financial effects of maintenance changes. This can be calculated by the profit losses due to one hour stoppage in production, $P L h$, and maintenance hour, $M h$. Profit losses caused by one hour stoppage in production, $P L h$, is calculated by multiplying the production costs per unit, $U P C$, profit margin ratio, $P M \%$, and production speed on average, $A P S$ (4).

$$
P L h=U P C \cdot P M \% \cdot A P S
$$

The annual maintenance hours, $M h$, consist of maintenance stoppages, maintenance performed during on-going manufacturing and maintenance executed during other production stoppages. This means stoppages during which no actions are done with the machine. However, underutilization is not included in the number. Mh.

Equation (5) represents the annual maintenance hours,

$$
M h=T M O T \cdot M \%
$$

where

$T M O T=$ theoretical maximum operating time

$M \%=$ share of maintenance of maximum operating time

The theoretical maximum operating time, TMOT, is the absolute maximal number of hours in a year that the equipment could be run in an ideal situation. For example, when the equipment is continuously in use, the theoretical maximum operating time is $24 \mathrm{~h} \cdot 365=8760 \mathrm{~h}$. The share of total maintenance of maximum operating time, $M \%$, is the percentage of different maintenance operations in relation to the annual operating time maximum. This percentage includes both corrective and preventive maintenance.

The lost profits caused by maintenance operations are constructed in a way that only maintenance-related stoppages are taken into the calculations. Maintenance operations executed during manufacturing without a stoppage and maintenance carried out during other stoppages than maintenance-related ones, are not included either, because they do not add to losses from maintenance.

The annual maintenance profit loss or gain in relation to the life-cycle average, $M R P L$ is

$$
M R P L=[M h-(M D M \% \cdot M h+M D U \% \cdot M h)] \cdot P L h
$$

where

$$
\begin{gathered}
M D M \%=\text { share of maintenance performed during } \\
\text { manufacturing } \\
M D U \%=\begin{array}{c}
\text { share of maintenance performed during } \\
\text { underutilization }
\end{array}
\end{gathered}
$$

$M R P L$ is for the customer. The profit of the service provider or equipment provider is called $S C B P . S C B P$ is a sum of contract-based profits, $C B P$, equipment-based bonuses, $E B B$, and equipment sales-based profits, $E B P(7)$.

$$
S C B P=C B P+E B B+E B P
$$

The contract-based profits, $C B P$, are understood here widely, as all those payments/profits that belong to the service provider are based on maintenance contracts. The equipment-based bonuses, $E B B$, are extra profits/incentives that the service provider or equipment provider gets only under certain circumstances, such as meeting key indicators. For example, a bonus is granted when the utilization rate goes over 90 percent. This potential bonus can also be dependent on certain steps $(90$ percent $=$ bonus amount, 95 percent $=2 \mathrm{x}$ bonus amount) in order to give extra motivation to the one taking care of maintaining the equipment. The equipment sales-based profits, ESP, include only those profits that originate directly from equipment sales to the customer. Thus, this category is only available for the equipment provider. The contract-based profits should not be entered here.

\section{Cumulative Net Present Value of Maintenance Profits}

The first key figure of the life-cycle model is the cumulative net present value. The cumulative net present value of maintenance profits, $C N P V$, is a sum of the cumulative present value of maintenance costs, $C P V_{C}$, cost savings, $C P V_{S}$, and profit loss or gain, $C P V_{M R P L}$.

Equation (8) presents the cumulative net present value of maintenance profits, $C P N V$

$$
C N P V=\left(C P V_{S}+C P V_{M R P L}\right)-C P V_{C}
$$

The first part of the equation of the $C N P V$ is a sum of the present values of the annual cost savings, $C P V_{S}$, throughout the planning period (9).

$$
C P V S=\sum_{n=1}^{k}\left(\frac{1}{(1+i)^{n}} \cdot S_{\text {total }_{n}}\right)
$$

The second part of the equation of the $C P N V$ is a sum of the present values of the annual profit loss or gain, $C P V_{M R P L}$, along the planning period (10).

$$
C P V_{M R L P}=\sum_{n=1}^{k}\left(\frac{1}{(1+i)^{n}} \cdot M R L P_{\text {total }_{n}}\right)
$$


The third factor of the equation of the $C P N V$ is a sum of the present value of the annual maintenance costs, $C P V_{C}$, throughout the planning period.

$$
C P V_{C}=\sum_{n=1}^{k}\left(\frac{1}{(1+i)^{n}} \cdot C_{\text {total }_{n}}\right)
$$

It is possible to estimate the maintenance profits of the whole planning period by the cumulative net present value with a specific discount rate.

The cumulative net present value expresses the maintenance surplus, or alternatively the maintenance deficit over the chosen planning period in the model. Therefore, the $C N P V$ is an excellent indicator that ultimately clarifies the point where the profits exceed the costs within the item's life-cycle. Naturally, it is possible that this kind of a "breaking point" does not exist and thus the $C N P V$ can also be used to find an acceptable level for the deficit and maintain it.

\section{E. Benefit-Cost Ratio}

The second key figure of the life-cycle model is the benefit-cost ratio (12). It can be seen annually what the proportion of maintenance profits is in the maintenance costs. The figure benefit-cost ratio describes in practice what the multiple maintenance profits are in comparison with the maintenance costs. The benefit-cost ratio should always get the value of over 1 , because then the profits overrun the costs.

$$
B / C-\text { ratio }=\frac{\left(C P V_{S}+C P V_{M R P L}\right)}{C P V_{C}}
$$

The benefit-cost ratio is a suitable indicator for analysing the balance between costs and profits. It is important to find the optimal balance between the maintenance costs and maintenance losses, but it is also important not to focus too much on optimizing the maintenance actions, because it may lead to a situation where the costs of item maintenance are bigger than the received profits.

\section{F. Sensitivity analyses}

In our model it is possible to analyse the changes of the important factors and their impact on the final results (cumulative net present value and benefit-cost ratio) by using sensitivity analysis. The user can decide which input factor share of maintenance of maximum operating time, cost element, production speed on average or interest-rate, is critical and what are the effects to the calculation if this factor changes for example $\pm 10 \%$ from the planned.

\section{G. Value-elements}

The user can choose one to five important value elements and weight the elements based on his perspective and thoughts in this particular maintenance service case. The model gives numerical values to the value elements, which can be then used as a basis for contracts and bonus systems between the network members.

\section{LIMITATIONS OF OUR LCC MODEL}

The model has been developed in close cooperation with maintenance experts from eight different companies representing a customer, service provider and equipment provider. These experts have tested the model and given us useful information and feedback to improve the model so far, but there are still some shortcomings in the model. Some of these weaknesses, limitations and targets for further development are listed below.

- Existing market conditions should be acknowledged in relation to the theoretically lost production that causes lost profits in the model. At the moment all stoppages are treated as a lost profit although the production cannot be sold. This can be eliminated in the model by decreasing the theoretical maximum operating time.

- Eliminating the present correlation of the increased production speed and the increased profit losses by taking gained revenues into account. The model works like that at the moment.

- Taking alternative or reduplicate production options and buffer stocks into account when determining the maintenance costs in the model. The model does not take into account the effect of the sale on the maintenance. The errors of maintenance lead to lost production, but improved maintenance does not raise the profits. This is already an option in the model, but it is not linked to the components of lost production.

- Enabling the entering of start-up and shutdown times of an item to the model, as the production speed may be reduced in these cases. At the moment these are left out, because the idea was to develop a generallevel model, and considering the costs along the whole life cycle, these are trivialities.

- Protecting confidential information throughout the worksheets of the value-based life-cycle model should be rigorously considered. At the moment all input data is shown to all network members.

- The entire value-thinking should be altered. At the moment we have decided to speak only for increased total value of the network (equals CNPV). Value distribution into the single elements will be left out of our LCC model, because the current division of the value by weighted value elements is quite artificial. However, the value elements are still useful for negotiations and contracts between the members of the maintenance network.

The first three improvements on the list, related to the calculation of the maintenance-related profit losses will most likely be included in the third version of the model, as these aspects have somewhat substantial influence on the main results. The aim is to develop the general-level and simple model, and therefore some facts for special lines of business must be left out. 
There are still some limitations in applying our model in different industries and contexts. The network perspective brings additional challenges related to information confidentiality. In addition, the results of the model should be integrated better to comprehensive maintenance performance measurement, taking intangible value elements into account. These limitations represent logical topics for further research.

The value elements and the distribution of value will be realised with an additional model called value analyser, which will probably be connected to the LCC model. These two models together complement each other in such a way that LCC model presents the hard side of the value thinking, and the value analyser the soft side.

\section{CONCLUSIONS}

In this paper we have shed light on the construction process of a general LCC model for maintenance planning at the network level. Compared to the existing LCC models in maintenance, we have made the improvements described in Table I.

Table 1. Comparison of the characteristic of previous LCC models and the created model.

\begin{tabular}{|c|c|}
\hline $\begin{array}{c}\text { Characteristics of previous } \\
\text { models }\end{array}$ & $\begin{array}{c}\text { Characteristics of the created } \\
\text { model }\end{array}$ \\
\hline Case-specific & Pursuing generalization \\
\hline The perspective of one company & $\begin{array}{c}\text { The perspective of a company } \\
\text { network or one company }\end{array}$ \\
\hline $\begin{array}{c}\text { Life-cycle profits are not always } \\
\text { included }\end{array}$ & $\begin{array}{c}\text { Life-cycle profits are included and } \\
\text { customized for each network } \\
\text { member }\end{array}$ \\
\hline $\begin{array}{c}\text { Various different sets of cost } \\
\text { categories, depending on the case } \\
\text { and on the model }\end{array}$ & $\begin{array}{c}\text { Various cost categories in the same } \\
\text { model, the user can decide on how } \\
\text { to apply them }\end{array}$ \\
\hline $\begin{array}{c}\text { Data collection poses challenges } \\
\text { for each user individually }\end{array}$ & $\begin{array}{c}\text { Collaboration in data collection is } \\
\text { enabled through a joint tool }\end{array}$ \\
\hline $\begin{array}{c}\text { LCC methods depend on the case; } \\
\text { some could be generalized, some } \\
\text { not }\end{array}$ & $\begin{array}{c}\text { Conventional cash flow and present } \\
\text { value chosen as LCC methods to } \\
\text { increase applicability }\end{array}$ \\
\hline $\begin{array}{c}\text { Sensitivity analyses and } \\
\text { economically justified results are } \\
\text { often used }\end{array}$ & $\begin{array}{c}\text { Sensitivity analyses, economically } \\
\text { justified results and the possibility } \\
\text { for network-level performance } \\
\text { management }\end{array}$ \\
\hline
\end{tabular}

The theoretical contribution of the paper includes pointing out the limitations of previous research on LCC modelling in maintenance. We have suggested a model to overcome a number of these limitations, and we have presented the design and costing principles of our model in a transparent way to enable feedback, discussion and iteration. Our model still has a number of shortcomings, which indicate possible research gaps for the academia. Our managerial implications include discussion on the process and mathematics of constructing a general model to support decision making in maintenance. Hopefully this paper will challenge companies to use LCC modelling in maintenance planning, both at the company and network level.

\section{REFERENCES}

1] B. K. Lad and M. S. Kulkarni, "Optimal maintenance schedule decisions for machine tools considering the user's cost structure", International Journal of Production Research, Vol. 50, No. 20, pp. 5859-5871, 2012.
[2] H.K. Jun, and J.H. Kim, J.H., "Life Cycle Cost Modeling for Railway Vehicle", International Conference on Electrical Machines and Systems, October, 8-11, 2007, Seoul, Korea.

[3] R. Lapašinskaitè, and V. Boguslauskas, "Non-Linear Time-Cost Break Even Research in Product Lifecycle", Engineering Economics. nro 1, pp. 7-12, 2006

[4] L.Y. Waghmode, and A.D. Sahasrabudhe, "Modelling maintenance and repair costs using stochastic point processes for life cycle costing of repairable systems", International Journal of Computer Integrated Manufacturing, Vol. 25, No. 4-5, pp. 353-367, 2012.

[5] Z. Wang, and X. Xu, "SVLC: Service value life cycle model", IEEE International Conference on Cloud Computing. September 21-25, Bangalore, pp. 159-166, 2009.

[6] D. Kayrbekoya, T. Markeset, and B. Ghodrati, "Activity-based life cycle cost analysis as an alternative to conventional LCC in engineering design", International Journal of Systems Assurance Engineering and Management, Vol. 2, No. 3, pp. 218-225, 2011

[7] A. Navarro-Galera, and R.I. Ortúzar Maturana, "Innovating in defence policy through spending efficiency: The Life Cycle Costing Model", Journal of Policy Modeling, Vol. 33, No. 3, pp. 407-425, 2011.

[8] L. A. Ferreira, J. Sobral, and J. T. Farinha, "LCC - Life Cycle Cost, its relevance to Physical Asset Management", EuroMaintenance 2014, Congress proceedings, May 5-7, Helsinki, Finland, 2014.

[9] E. Hochschorner, and M. Noring, "Practitioners'use of life cycle costing with environmental costs - a Swedish study", International Journal of Life Cycle Assessment, Vol. 16, No. 8, pp. 897-902, 2011.

[10] E. Korpi, and T. Ala-Risku, "Life cycle costing: a review of published case studies", Manag Audit J 23(3):240-261, 2008

[11] A. Lindholm, and P. Suomala, "Learning by costing - Sharpening cost image through life cycle costing?", International Journal of Productivity and Performance Management, Vol. 56, No. 8, pp. 651$672,2007$.

[12] H.P. Barringer, A Life Cycle Cost Summary, International Conference of Maintenance Societies. May, 20-23, 2003, Perth, Australia, 2003

[13] Y. Asiedu, and P. Gu, "Product life cycle cost analysis: state of the art review", International Journal of Production Research, Vol. 36, no. 4, pp. 883-908, 1998

[14] L. Hagberg, S. Hautanen, T. Henriksson, H.S. Laine, E. Löppönen, and E. Riikonen, Käynnissäpidon johtaminen ja talous, Rajamäki, KP-Tieto, p. 224, ISBN 951-97101-2-4, 1996.

[15] K. Indounas, "Successful industrial service pricing", The Journal of Business \& Industrial Marketing. Vol. 24, no. 2, pp. 86-97, 2009.

[16] S. Huber, and S. Spinler, "Pricing of full-service repair contracts", European Journal of Operational Research, Vol. 222, no. 1, pp. 113 $121,2012$.

[17] NORSOK O-CR-002, Life Cycle Cost for Production Facility, Norwegian Technology Standards Institution, p. 35, 1996.

[18] EN ISO 15663-1, Petroleum and natural gas industries - Life cycle costing - Part 1: Methodology, 1st edition, Brussels, European Committee for Standardization, p. 17, 2000.

[19] D.G. Woodward, "Life cycle costing - theory, information acquisition and application", International Journal of Project Management. Vol.15, No. 6, pp. 335-344, 1997.

[20] H.P. Barringer, and D.P. Weber, Life Cycle Cost Tutorial. The 5th International Conference on Process Plant Reliability. October 2-4, Houston, Texas, p. 58, 1996

[21] Y. Kawauchi, and M. Rausand, "Life Cycle Cost (LCC) analysis in oil and chemical process industries", Norwegian University of Science and Technology, Trondheim, Norway, 1999

[22] T. Sinkkonen, S. Marttonen, L. Tynninen, and T. Kärri, "Modelling costs in maintenance networks", Journal of Quality in Maintenance Engineering, Vol. 19, No. 3, pp. 330-344, 2013

[23] T. Sinkkonen, H. Kivimäki, S. Marttonen, and T. Kärri, "A valuebased life-cycle framework for networks of industrial maintenance service", The 26th International Conference on Competitiveness 
Through Maintenance and Asset Management, June, 11-13, 2013, Helsinki, Finland.

[24] H. Kivimäki, T. Sinkkonen, S. Marttonen, and T. Kärri, "Creating a life-cycle model for industrial maintenance networks", Proceedings of the Maintenance Performance Measurement and Management, Conference 12th - 13th September, 2013, Lappeenranta, Finland, ISBN 978-952-265-443-4, 2013

[25] P. Baily, D. Farmer, D. Jessop, and D. Jones, Purchasing Principles and Management. 9th edition. Harlow. Financial Times Prentice Hall. p. 427 ISBN 0-273-64689-3, 2005.

[26] C.T. Horngren, S.M. Datar, and G. Foster, Cost Accounting: A Managerial Emphasis, 12th edition, Upper Saddle River, New Jersey. Prentice Hall, p. 868, ISBN 0-13-149538-0, 2006.

[27] J.F. Oehmke, "Anomalies in net present value calculations", Economics Letters. Vol. 67, no. 3, pp. 349-351, 2000. 


\title{
A Control System Approach to Optimal Maintenance Planning for Building Retrofitting Project
}

\author{
Bo Wang ${ }^{1}$; Xiaohua Xia ${ }^{2}$ \\ ${ }^{1,2}$ Center of New Energy Systems of the University of Pretoria \\ Pretoria, South Africa
}

\begin{abstract}
Existing studies paid most attentions to the strategic planning of building retrofitting project. During the actual operation, the overall energy performance of the retrofitting project deteriorates over time owing to the usage and failures of the retrofitted facilities. For the sustainability of energy efficiency, the maintenance plan optimization for the retrofitted facilities must be considered, which suggests the possibility to sustain the building energy efficiency during operating. However, the overall energy performance reveals strong time dynamics subject to the failures and maintenance actions, which make the maintenance plan optimization a complicated problem. This paper characterizes the dynamics of the totality of the retrofitted facilities by the multi-state system models governed by a discrete-time Markov process. The impacts of both preventive and corrective maintenance actions on the over energy efficiency of the plant are then quantified by the present model. The optimization problem is thus casted into a stochastic optimal control problem which aims at maximizing the long-term energy efficiency and financial payback. An MPC based approach is employed to solve the present control problem. Finally, a case study is conducted to demonstrate the effectiveness of the present approach.
\end{abstract}

Keywords-Building retrofitting, Facilities maintenance policy, Energy efficiency, Multi-state system, Control system

\section{INTRODUCTION}

Existing studies on improving building energy efficiency mainly focus on two aspects: the strategic planning of the building retrofitting [1], [2], [3], [4], and the optimal operating of a certain kind of facilities in the building [5], [6], [7]. However, after the implementation of an energy efficiency option or a retrofitting plan, the energy efficiency of the retrofitted facilities can not escape from deterioration due to the usage and the failures. From the management perspective, the overall energy efficiency of the plant degrades over time, as facilities can contribute less energy savings than people expected due to the age or usage, and breakdowns can take place which completely stop items from contributing energy saving. For the sustainability of building energy efficiency, maintenance as an important aspect of the facilities management, deserves more attention from the energy efficiency community.

However, the optimal maintenance plan for a building retrofitting project is not easy to achieve. The totality of the retrofitted facilities can demonstrate significant time dynamics under the impacts of both failures and maintenance actions on the management level. The energy efficiencies of the retrofitted facilities can either degrade due to the usage and failures or be restored by the maintenance actions, and the overall energy performance of the retrofitted plant over a period of time can be influenced by various maintenance actions on different facilities at different time instants. The maintenance decision can be difficult due to this complexity. Furthermore, economy must be taken into account by the maintenance planner as well. The maintenance budgets are often limited in practice, and the cost-effectiveness of the maintenance actions, as a part of the economy of retrofitting project, should not be ignored.

The control system approach can be a good perspective to address the complexity of the maintenance planning optimization. Control system approaches have been used to obtain the optimal maintenance strategies of single-unit or multicomponents machines from the manufacturing industry [8], [9]. In these literatures, the studied machines are assumed to have multiple working states and a failure state. The productivity of the machine differs under different working modes and the failure mode, i.e., the different system states. The state transition of the machine is governed by a continuous-time Markov process, and the influence of maintenance actions, including Preventive Maintenance (PM) and Corrective Maintenance (CM) are represented by the jump rates from deteriorated of failure states to better working states. The multi-state systems are also popular among the reliability community. Literatures [10], [11] focused on the modeling of deteriorating systems using the multi-state system approach. The corresponding reliability optimization under realistic conditions are also investigated in these literatures. However, none of these studies, either from the control science community or from the reliability engineering community, has ever considered a plant that can not be modeled by one single multi-state system.

In this paper, the totality of retrofitted facilities in the building energy efficiency context, instead of individual items, is considered as our plant. Multiple categories of heterogeneous facilities are involved in the retrofitting project, each corresponds to a multi-state system model. The possible working modes and jump rates can be different between the categories. The maintenance actions are planned on the management level, i.e., for a group of homogenous facilities rather than for a single item. As a consequence, the numbers of items under different working modes, rather than the probabilities 
of one single item being under different modes, are the main concerns of the present approach. The dynamics of number of items under different states is governed by a discretetime Markov process, due to the limitation of inspection capability in practice. The maintenance actions over each sampling period are also represented by the jump rates of the Markov process, which allow the growth of the item population under better working mode and the decrease of the item population under worse working mode or failure mode. By the employment of multi-state system models in the present model, the impact of the PM and CM actions on the overall energy efficiency of the plant can be quantified. The maintenance plan optimization is thus transformed into a stochastic optimal control problem taking into account several different multi-state system models and the dynamics of item populations under respective system states. Two objectives are introduced for the optimal control problem: the maximum of overall energy saving and the maximum of payback ratio of the retrofitting project over a pre-decided time period. A Model Predictive Control (MPC) based approach is employed to solve the present optimal control problem. A simple practical retrofitting project is adopted as the case study to test and verify the feasibility of the present approach.

The remainder of the paper consists of four sections. Section 2 gives the modelling of the multi-state systems and the stochastic optimal control problem formulation. Section 3 introduces the MPC based approach. Section 4 provides the simulation results and analysis of the case study. Section 5 draws conclusion and discusses future research.

\section{Control Problem Modeling}

\section{A. Problem statement}

There are generally two types of facilities involved in the context of the building energy retrofitting project. Type-I facilities are generally considered as single-unit systems and do not undertake any preventive maintenance over the lifecycle. After the breakdown of an item from type-I facilities, corrective replacement take place and the failed item is scrapped. Globes, motion sensors, desktop PC monitors are typical type-I facilities. Type-II facilities are more complicated than type-I facilities, which are often considered as multicomponent systems. Preventive maintenance can sustain the energy performance of type-II facilities. Failures that are repairable by corrective maintenance can take place during the operation of the item from type-II facilities before the scrap of the item. Air-conditioner and heat pumps are typical typeII facilities. As the lifespan of type-II facilities are usually as long as over ten years, the preventive/corrective replacement for type-II facilities is not taken into account in the present study.

The energy performances of type-I facilities are considered constant over the life-cycle in the present study. For type-II facilities, the energy performance will degrade as usage over life-cycle. By the implementation of preventive and corrective maintenance actions, the breakdowns and the performance degradation of the items are removed, i.e., the deterioration of the facilities has been controlled. The models which characterize the controlled deterioration of the two types of facilities are given in the following section:

\section{B. Controlled process of type-I and type-II retrofitted facilities deterioration}

Let $N_{I}$ denote the total number of a group of type-I facilities. Type-I facilities have two modes denoted by $S_{I}=\{1,2\}$. Mode 2 means the item is not available. Items under mode 2 do not contribute to the energy saving of the retrofitting project. Mode 1 denotes the normal working status of the item. The energy saving of the item is constant value under mode 1 . During practical operation, an item has a possibility to change from one mode to another. According to [8], the transition between the modes of the item can be governed by a discretetime Markov process $\left\{r\left(t_{k}\right), k \geq 0\right\}$, where $t_{k}$ denotes the sampling instants. The transition matrix taking value in $S_{I}$ can be obtained:

$$
Q_{I}\left(t_{k}\right)=\left(\begin{array}{ll}
q_{11}^{I}\left(t_{k}\right) & q_{21}^{I}\left(t_{k}\right) \\
q_{12}^{I}\left(t_{k}\right) & q_{22}^{I}\left(t_{k}\right)
\end{array}\right)
$$

where $q_{i j}^{I}\left(t_{k}\right) \geq 0, j \neq i, q_{i i}^{I}\left(t_{k}\right)=1-\sum_{j \neq i} q_{i j}^{I}\left(t_{k}\right)$. Jump rate $q_{21}^{I}\left(t_{k}\right)$ represents the influence of corrective replacement denoted by $\omega_{r}^{I}\left(t_{k}\right)$, i.e., the control rate. $q_{12}^{I}\left(t_{k}\right)$ represents the deterioration rate of the population of items under mode 1. The transition matrix of the controlled Markov process can be rewritten as:

$$
Q_{I}\left(t_{k}, \omega_{r}^{I}\left(t_{k}\right)\right)=\left(\begin{array}{cc}
1-q_{12}^{I}\left(t_{k}\right) & \omega_{r}^{I}\left(t_{k}\right) \\
q_{12}^{I}\left(t_{k}\right) & 1-\omega_{r}^{I}\left(t_{k}\right)
\end{array}\right)
$$

Let $x^{I}\left(t_{k}\right)=\left[\begin{array}{lll}x_{1}^{I}\left(t_{k}\right) & x_{2}^{I}\left(t_{k}\right)\end{array}\right]^{T}$ denote the number of items under mode 1 and 2 at instant $t_{k}$, where $x_{1}^{I}\left(t_{k}\right)+x_{2}^{I}\left(t_{k}\right)=N_{I}$, the states of the group of type-I facilities at next sampling instant can be obtained:

$$
x^{I}\left(t_{k+1}\right)=Q_{I}\left(t_{k}, \omega_{r}^{I}\left(t_{k}\right)\right) x^{I}\left(t_{k}\right) .
$$

Type-II facilities have four modes denoted by $S_{I I}=$ $\{1,2,3,4\}$, where mode 4 means the item is under repair and not available, mode 1,2,3 denote there working modes of the item: good, average and bad. Item under mode 1 has the best energy performance, i.e., provides largest energy saving. Item under mode 2 and 3 only provides discounted energy savings compared with Item under mode 1 . For the simplicity, the energy performances from mode 1,2 and 3 are considered constant. The transition matrix taking value in $S_{I I}$ can be obtained:

$$
Q_{I I}\left(t_{k}\right)=\left(\begin{array}{cccc}
q_{11}^{I I}\left(t_{k}\right) & q_{21}^{I I}\left(t_{k}\right) & q_{31}^{I I}\left(t_{k}\right) & q_{41}^{I I}\left(t_{k}\right) \\
q_{12}^{I I}\left(t_{k}\right) & q_{22}^{I I}\left(t_{k}\right) & 0 & 0 \\
0 & q_{23}^{I I}\left(t_{k}\right) & q_{33}^{I I}\left(t_{k}\right) & 0 \\
q_{14}^{I I}\left(t_{k}\right) & q_{24}^{I I}\left(t_{k}\right) & q_{34}^{I I}\left(t_{k}\right) & q_{44}^{I I}\left(t_{k}\right)
\end{array}\right)
$$

where $q_{i j}^{I I}\left(t_{k}\right) \geq 0, j \neq i, q_{i i}^{I I}\left(t_{k}\right)=1-\sum_{j \neq i} q_{i j}^{I I}\left(t_{k}\right)$. Jump rates $q_{21}^{I I}\left(t_{k}\right)$ and $q_{31}^{I I}\left(t_{k}\right)$ are the preventive maintenance rates denoted by $\omega_{p a}^{I I}\left(t_{k}\right)$ and $\omega_{p b}^{I I}\left(t_{k}\right)$. Jump rate $q_{41}^{I I}\left(t_{k}\right)$ is the corrective maintenance rate denoted by $\omega_{r}^{I I}\left(t_{k}\right) . \omega_{p a}^{I I}\left(t_{k}\right)$, $\omega_{p b}^{I I}\left(t_{k}\right)$ and $\omega_{r}^{I I}\left(t_{k}\right)$ are the control rates. Let $\omega_{I I}\left(t_{k}\right)=$ 
$\left[\omega_{p a}^{I I}\left(t_{k}\right) \omega_{p b}^{I I}\left(t_{k}\right) \omega_{r}^{I I}\left(t_{k}\right)\right]$. Similarly, the transition matrix of the controlled Markov process can be rewritten as:

$Q_{I I}\left(t_{k}, u_{I I}\left(t_{k}\right)\right)=\left(\begin{array}{cccc}q_{11}^{I I}\left(t_{k}\right) & \omega_{p a}^{I I}\left(t_{k}\right) & \omega_{p b}^{I I}\left(t_{k}\right) & \omega_{r}^{I I}\left(t_{k}\right) \\ q_{12}^{I I}\left(t_{k}\right) & q_{22}^{I I}\left(t_{k}\right) & 0 & 0 \\ 0 & q_{23}^{I I}\left(t_{k}\right) & q_{33}^{I I}\left(t_{k}\right) & 0 \\ q_{14}^{I I}\left(t_{k}\right) & q_{24}^{I I}\left(t_{k}\right) & q_{34}^{I I}\left(t_{k}\right) & 1-\omega_{r}^{I I}\left(t_{k}\right)\end{array}\right)$

where $q_{12}^{I I}\left(t_{k}\right)$ and $q_{23}^{I I}\left(t_{k}\right)$ represent the degradation of the energy performance, $q_{14}^{I I}\left(t_{k}\right), q_{24}^{I I}\left(t_{k}\right)$ and $q_{34}^{I I}\left(t_{k}\right)$ represent the deterioration of the population of working items. Let $N_{I I}$ denote the total number of the type-II items, $x^{I I}\left(t_{k}\right)=$ $\left[\begin{array}{llll}x_{1}^{I I}\left(t_{k}\right) & x_{2}^{I I}\left(t_{k}\right) & x_{3}^{I I}\left(t_{k}\right) & x_{4}^{I I}\left(t_{k}\right)\end{array}\right]^{T}$ denote the number of items working under mode 1,2,3 and 4 respectively at instant $t_{k}, \sum_{i=1}^{4} x_{i}^{I I}\left(t_{k}\right)=N_{I I}$. The states of the group of type-II items at next sampling instant can be obtained:

$$
x^{I I}\left(t_{k+1}\right)=Q_{I I}\left(t_{k}, \omega_{I I}\left(t_{k}\right)\right) x^{I I}\left(t_{k}\right) .
$$

The jump rates in $Q_{I}\left(t_{k}\right)$ and $Q_{I I}\left(t_{k}\right)$ can be characterized by different deterioration models from reliability engineering [12]. In the present models, due to the lack of extensive studies on the retrofitted facilities, several assumptions are made to figure out the jump rates:

1) The jump rates are considered constant over time;

2) The failure rate of the items is independent of the working modes, i.e., $q_{i 4}^{I I}\left(t_{k}\right)$ with $i=1,2,3$ are the same values decided only by the Mean Time Between Failures (MTBF);

3) For type-II facilities, the average running times from mode good to average and from average to bad are prior known, denoted by $t 1$ and $t 2$. Deterioration rates $q_{12}^{I I}\left(t_{k}\right)$ and $q_{23}^{I I}\left(t_{k}\right)$ are thus characterized by $t 1$ and $t 2$;

4) The maintenance actions take place prior to the deterioration of item populations. Over the sampling period when maintenance actions are applied, only the items that are not maintained can deteriorate.

An exponential decay model from [12] is thus adopted to decide the jump rates. Let $\theta$ denote the MTBF of a facility and $k=\theta^{-1}$, the failure rate is $1-e^{-k}$, i.e., the value of jump rate $q_{12}^{I}\left(t_{k}\right)$ for type-I facilities and jump rates $q_{i 4}^{I I}\left(t_{k}\right)$ with $i=1,2,3$ for type-II facilities. Similarly, $q_{12}^{I I}\left(t_{k}\right)=1-e^{-t 1^{-1}}$ and $q_{23}^{I I}\left(t_{k}\right)=1-e^{-t 2^{-1}}$.

\section{Characterization of energy and financial performances}

In the present model, the energy and financial performance characteristics are required to evaluate the energy efficiency and cost effectiveness of a maintenance plan. Let $T$ denote the length of time period that the planning covers, namely evaluation period. The total energy saving and the payback ratio over the evaluation period $[0, T]$ are the main required characteristics, subject to a series of constraints, including the targeted energy saving limits, the budget limits and nonnegative NPV limits.

Given $n_{I}$ groups of type-I facilities and $n_{I I}$ groups of type-II facilities with respective rated lifespan and deterioration characteristics. Let $x\left(t_{k}\right)=\left[x_{I}\left(t_{k}\right) x_{I I}\left(t_{k}\right)\right]^{T}$ denote the system states inspected at instant $t_{k}$, where $x_{I}\left(t_{k}\right)=$ $\left[\left.x_{i}\right|_{n} ^{I}\right]^{T}, n \in\{1,2\}, i \in\left[1, n_{I}\right] ; x_{I I}\left(t_{k}\right)=\left[\left.x_{i}\right|_{n} ^{I I}\right]^{T}$, $n \in\{1,2,3,4\}, i \in\left[1, n_{I I}\right]$. For the energy conservatism, $x\left(t_{k}\right)$ is considered to be the system states over sampling period $\left[t_{k-1}, t_{k}\right]$. The control variables, i.e., the maintenance actions, are thus represented by $u\left(t_{k}\right)=\left[u_{I}\left(t_{k}\right) u_{I I}\left(t_{k}\right)\right]^{T}$, where $u_{I}\left(t_{k}\right)=\left[\left.\left.\omega_{i}\right|_{r} ^{I}\left(t_{k}\right) x_{i}\right|_{2} ^{I}\left(t_{k}\right)\right]^{T}, i \in\left[1, n_{I}\right] ; u_{I I}\left(t_{k}\right)=$ $\left[\left.\left.\left.\left.\left.\left.\omega_{i}\right|_{p a} ^{I I}\left(t_{k}\right) x_{i}\right|_{2} ^{I I}\left(t_{k}\right) \quad \omega_{i}\right|_{p b} ^{I I}\left(t_{k}\right) x_{i}\right|_{3} ^{I I}\left(t_{k}\right) \quad \omega_{i}\right|_{r} ^{I I}\left(t_{k}\right) x_{i}\right|_{4} ^{I I}\left(t_{k}\right)\right]^{T}$, $i \in\left[1, n_{I I}\right]$. The control actions are considered to be implemented over the next sampling period $\left[t_{k}, t_{k+1}\right]$.

The performance characteristics are formulated as following: let $a_{i}^{I}\left(t_{k}\right)=\left[\left.a_{i}^{I}\right|_{n}\left(t_{k}\right)\right], n \in\{1,2\}, i \in\left[1, n_{I}\right]$; $a_{i}^{I I}\left(t_{k}\right)=\left[\left.a_{i}^{I I}\right|_{n}\left(t_{k}\right)\right], n \in\{1,2,3,4\}, i \in\left[1, n_{I I}\right] . a_{i}^{I}\left(t_{k}\right)$ and $a_{i}^{I I}\left(t_{k}\right)$ denote the average energy savings that an item contributed under different working modes over the sampling period $\left[t_{k}, t_{k+1}\right]$. Similarly, $b_{i}^{I}\left(t_{k}\right)$ and $b_{i}^{I I}\left(t_{k}\right)$ denote the average cost savings. Apparently, $\left.a_{i}^{I}\right|_{2}\left(t_{k}\right),\left.b_{i}^{I}\right|_{2}\left(t_{k}\right),\left.a_{i}^{I I}\right|_{4}\left(t_{k}\right)$ and $\left.b_{i}^{I I}\right|_{4}\left(t_{k}\right)$ are constantly 0 . Let $C_{i}^{I}=\left[\left.C_{i}^{I}\right|_{r}\right], i \in$ $\left[1, n_{I}\right], C_{i}^{I I}=\left[\left.C_{i}^{I I}\right|_{p a},\left.C_{i}^{I I}\right|_{p b},\left.C_{i}^{I I}\right|_{r}\right], i \in\left[1, n_{I I}\right]$, where $\left.C_{i}^{I}\right|_{r},\left.C_{i}^{I I}\right|_{p a},\left.C_{i}^{I I}\right|_{p b},\left.C_{i}^{I I}\right|_{r}$ denote the respective maintenance costs. The energy saving at each instant $t_{k}$ and the overall energy saving over $[0, T)$ are thus obtained:

$$
\left\{\begin{array}{c}
E S\left(t_{k}\right)=\sum_{i=1}^{n_{I}} a_{i}^{I}\left(t_{k}\right) x_{i}^{I}\left(t_{k}\right)+\sum_{i=1}^{n_{I I}} a_{i}^{I I}\left(t_{k}\right) x_{i}^{I I}\left(t_{k}\right), \\
\left.E S\right|_{\text {all }}=\sum_{k=0}^{K_{T}} E S\left(t_{k}\right),
\end{array}\right.
$$

and the accordingly cost savings are obtained:

$$
\left\{\begin{array}{c}
B\left(t_{k}\right)=\sum_{i=1}^{n_{I}} b_{i}^{I}\left(t_{k}\right) x_{i}^{I}\left(t_{k}\right)+\sum_{i=1}^{n_{I I}} b_{i}^{I I}\left(t_{k}\right) x_{i}^{I I}\left(t_{k}\right), \\
\left.B\right|_{\text {all }}=\sum_{k=0}^{K_{T}} B\left(t_{k}\right),
\end{array}\right.
$$

the maintenance cost at each time instant is obtained:

$$
\begin{aligned}
h\left(t_{k}\right)= & \left.\left.\sum_{i=1}^{n_{I}} C_{i}^{I}\right|_{r} u_{i}\right|_{r} ^{I}\left(t_{k}\right)+\left.\left.\sum_{i=1}^{n_{I I}} C_{i}^{I I}\right|_{p a} u_{i}\right|_{p a} ^{I I}\left(t_{k}\right)+ \\
& \left.\left.\sum_{i=1}^{n_{I I}} C_{i}^{I I}\right|_{p b} u_{i}\right|_{p b} ^{I I}\left(t_{k}\right)+\left.\left.\sum_{i=1}^{n_{I I}} C_{i}^{I I}\right|_{r} u_{i}\right|_{r} ^{I I}\left(t_{k}\right),
\end{aligned}
$$

and the overall investment of the retrofitting project:

$$
\left.h\right|_{\text {all }}=h_{0}+\sum_{k=1}^{K_{T}} h\left(t_{k}\right)
$$

where $h_{0}$ denotes the initial investment of the retrofitting project, $K_{T}$ denote the number of sampling instants over $[0, T]$.

The profit of the project is then obtained by $P=\left.B\right|_{\text {all }}-$ $\left.h\right|_{\text {all }}$. However, the more usual method to evaluate the economy of a project is NPV. The NPV over $[0, T]$ is:

$$
N P V=\sum_{k=1}^{K_{T}} \frac{B\left(t_{k}\right)-h\left(t_{k}\right)}{(1+d)^{k}}-h_{0},
$$

where $d$ denotes the discount rate for NPV calculation.

\section{Control Problem Formulation}

Based on the equations obtained in the previous sections, the population dynamics of a retrofitting project is characterized 
by the following equation:

$$
\begin{aligned}
x\left(t_{k+1}\right) & =f\left(x\left(t_{k}\right), u\left(t_{k}\right)\right) \\
& =\left[Q_{I}\left(t_{k}, \omega_{r}^{I}\left(t_{k}\right)\right) x^{I}\left(t_{k}\right), Q_{I I}\left(t_{k}, \omega_{I I}\left(t_{k}\right)\right) x^{I I}\left(t_{k}\right)\right]^{T},
\end{aligned}
$$

where $x\left(t_{0}\right)=x_{0}$.

The control objective is to find a control law $\mathbf{u}(\cdot)=\left\{\left(u\left(t_{k}\right), \omega\left(t_{k}\right), k \in\left[0, K_{T}\right]\right\}\right.$ with $\omega\left(t_{k}\right)=\left\{\omega_{r}^{I}\left(t_{k}\right), \omega_{p a}^{I I}\left(t_{k}\right), \omega_{p b}^{I I}\left(t_{k}\right), \omega_{r}^{I I}\left(t_{k}\right)\right\}$, which minimize the following performance index:

$$
J\left(x_{0}, \mathbf{u}(\cdot)\right)=E\left[-\left.\lambda_{1} E S\right|_{\text {all }}+\lambda_{2} \frac{\left.h\right|_{\text {all }}}{\left.B\right|_{\text {all }}}\right],
$$

subject to

$$
\left\{\begin{array}{c}
\left.E S\right|_{\text {all }} \geq \alpha, \\
\sum_{k=i * M+1}^{(i+1) * M} h\left(t_{k}\right) \leq \beta, i=0,1,2,3, \ldots \\
N P V \geq 0, \\
\omega_{p a}^{I I}\left(t_{k}\right), \omega_{p b}^{I I}\left(t_{k}\right)=0, \quad k \notin P, \\
\omega_{r}^{I}\left(t_{k}\right), \omega_{r}^{I I}\left(t_{k}\right)=0, k \notin Q,
\end{array}\right.
$$

where $\lambda_{1}$ and $\lambda_{1}$ denote the weighting factors. $\alpha$ denotes the target energy saving amount, $\beta$ denotes the maintenance budget limit over a series of fixed time periods $\left[t_{i * M+1}, t_{(i+1) * M}\right]$, $i=0,1,2,3, \ldots$, with constant number of sample instants $M$. $P$ denotes a set of time instants, indicating when the preventive maintenance actions are scheduled to take place. Similarly, $Q$ includes the time when the corrective maintenance actions are scheduled to take place.

\section{MPC APPROACH}

To solve the optimal control problem represented by equations (9) and (10), an MPC based approach is adopted. In MPC approaches, an open loop optimal control problem is repeatedly solved over a finite horizon according to the plant model prediction. The obtained optimal open loop control is then used to generate the optimal control input for the problem to be solved, with which the state variables executed over the next finite horizon are obtained. As the optimal controller over the next finite horizon is actually a function of the system state from the previous control step, a closed-loop feedback is thus obtained. Consider a horizon with length $N$, a mathematical transformation of the optimal control problem is applied, and the open loop optimal control problem over $\left[t_{m}, t_{m+N}\right]$ is accordingly defined as the following minimization problem:

$$
\min J^{\prime}\left(x\left(t_{m}\right),\left.\mathbf{u}^{\prime}\right|_{m}(\cdot)\right)=E\left[-\left.\lambda_{1} E S^{\prime}\right|_{m}+\lambda_{2} \frac{\left.h^{\prime}\right|_{m}}{\left.B^{\prime}\right|_{m}}\right],
$$

subject to

$$
\left\{\begin{array}{c}
\left.E S^{\prime}\right|_{m} \geq \alpha^{\prime}, \\
\left.h^{\prime}\right|_{m} \leq \beta^{\prime}, m \in R \\
\left.N P V^{\prime}\right|_{m} \geq h_{0}^{\prime}, \\
\omega_{p a}^{I I}\left(t_{k}\right), \omega_{p b}^{I I}\left(t_{k}\right)=0, k \notin P, \\
\omega_{r}^{I}\left(t_{k}\right), \omega_{r}^{I I}\left(t_{k}\right)=0, k \notin Q,
\end{array}\right.
$$

where

$$
\left.E S^{\prime}\right|_{m}=\sum_{k=m+1}^{m+N} E S\left(t_{k}\right),
$$

$$
\begin{gathered}
\left.h^{\prime}\right|_{m}=\sum_{k=m+1}^{m+N} h\left(t_{k}\right), \\
\left.B^{\prime}\right|_{m}=\sum_{k=m+1}^{m+N} B\left(t_{k}\right), \\
\left.N P V^{\prime}\right|_{m}=\sum_{k=m+1}^{m+N} \frac{B\left(t_{k}\right)-h\left(t_{k}\right)}{(1+d)^{k}},
\end{gathered}
$$

$\alpha^{\prime}, \beta^{\prime}$ denote the proportional targeted energy saving amount and maintenance budget over $\left[t_{m}, t_{m+N}\right], h_{0}^{\prime}$ denotes a proportion of initial investment $h_{0}$ that is expected to be covered by the cash flow over $\left[t_{m}, t_{m+N}\right]$.

This problem is solved over the interval $\left[t_{m}, t_{m+N}\right]$ when $m \in P$ or $m \in Q$, and a series of optimal control rates are obtained, represented by $\left.\boldsymbol{\omega}^{\prime}\right|_{m}=\left\{\left.\omega^{\prime}\right|_{m}\left(t_{k}\right): k=\right.$ $m, m+1, \ldots, m+N-1\}$. For the sake of easy implementation, a DE based approach is thus applied to solve problem (11) [13]. Only the optimal solution in the first sampling period $\left[t_{m}, t_{m+1}\right]$ is applied, represented by $\left.\overline{\boldsymbol{\omega}}\right|_{m}=$ $\left\{\left.\omega^{\prime}\right|_{m}\left(t_{m}\right)\right\}=\left\{\left.\bar{\omega}\right|_{m}\left(x\left(t_{m}\right)\right)\right\}$, where the last equation is to emphasize the functional dependence of the optimal control on the initial state $x\left(t_{m}\right)$ of the MPC formulation in equations (11)-(16). According to equation (8), $\left.\overline{\boldsymbol{\omega}}\right|_{m}$ is applied, $u\left(t_{m}\right)$ and $x\left(t_{m+1}\right)$ are thus obtained. $x\left(t_{m+1}\right)$ then becomes the initial condition of the MPC formulation over the time horizon $\left[t_{m+1}, t_{m+N+1}\right]$. When $m \notin P$ and $m \notin Q$, the control rates $\boldsymbol{\omega}\left(t_{m}\right)=0$ is implemented as a solution. These are taking place consecutively over the control period to obtain the optimal control rates $\overline{\boldsymbol{\omega}} \cdot x\left(t_{k}\right)$ is then applied as the initial state for the open loop optimal control problem over the next finite horizon. In summary, the following MPC algorithm can thus be formulated [14]:

\section{A. MPC Algorithm}

Initialization: Let initial state $x\left(t_{0}\right)=x_{0}$ and $m=0$.

(i) Compute the open loop optimal solution $\left\{\left.\omega^{\prime}\right|_{m}\left(t_{k}\right)\right\}$ of the problem formulation (11)-(16), where $k=m, m+1, \ldots, m+$ $N-1$.

(ii) The MPC controller $\left.\overline{\boldsymbol{\omega}}\right|_{m}=\left\{\left.\omega^{\prime}\right|_{m}\left(t_{m}\right)\right\}$ is applied to the plant in the sampling interval $[m, m+1]$. The remains of the open loop optimal solution $\left\{\left.\omega^{\prime}\right|_{m}\left(t_{k}\right): k=m+1, \ldots, m+\right.$ $N-1\}$ are discarded. $x\left(t_{m+1}\right)$ are then obtained according to:

$$
\begin{aligned}
x\left(t_{m+1}\right) & =f\left(x\left(t_{m}\right), u\left(t_{m}\right)\right) \\
& =\left[Q_{I}\left(t_{m}, \omega_{r}^{I}\left(t_{m}\right)\right) x^{I}\left(t_{m}\right), Q_{I I}\left(t_{m}, \omega_{I I}\left(t_{m}\right)\right) x^{I I}\left(t_{m}\right)\right]^{T}
\end{aligned}
$$

and executed over the period $\left[t_{m}, t_{m+1}\right]$.

(iii) Let $m:=m+1$ and go back to step (i).

Due to the constraint $\omega\left(t_{m}\right)=0, m \notin P$ and $m \notin Q$, it is not necessary to solve the open loop optimal control problem over $\left[t_{m}, t_{m+N}\right]$, and $x\left(t_{m+1}\right)$ is obtained by $x\left(t_{m+1}\right)=f\left(x\left(t_{m}\right), 0\right)$. The above MPC algorithm will go over the control period to solve out the optimal control strategy. 


\section{Simulation And Verification}

\section{A. Case study}

A small retrofitting project for a government office building is presented as our case study to verify the effectiveness of the present model. The retrofitting plan is decided prior to the maintenance planning, thus the objective of our case study is to obtain the optimal maintenance plan over a pre-decided implementation period. There are 5 types of facilities involved in the retrofitting, listed in Table I. In this table, the quantities represent the number of retrofitted facilities from each category. At the initial stage, all facilities are in good condition. The unit prices represent the initial investment taking into account all the purchase and installation. The unit energy savings and cost savings are the average measure over one year. During the implementation period, the unit savings are considered constant. The corrective cost, preventiveA cost and preventiveB cost represent the average costs of implementing the respective maintenance actions, where preventiveA refers to the preventive maintenance action that restores the system state from average to good, and preventiveA refers to the one that restores the system from bad to good. Preventive maintenance does not work on the type-I facilities. The MTBF, the mean time from good to average and the mean time from average to bad are given in Table II.

The maintenance plan is scheduled to be implemented over 120 months. From the auditing, the energy baseline of this retrofitting project is known as $2,249,500 \mathrm{kWh}$ per year. The targeted energy saving amount is $10 \%$ of the energy baseline over the maintenance plan implementation period, which is $2,249,500 \mathrm{kWh}$. The yearly maintenance budget is $\$ 15,000$. The discount rate for NPV calculation taking into account the interests and inflation is $1.77 \%$ per year. An inspection will be applied at the end of each month to monitor the status of the retrofitted facilities, i.e., the sampling instants and sampling periods. The maintenance schedule is thus pre-decided as the following: the preventive maintenance actions take place at the end of every year, i.e., the end of month $12,24,36, \ldots$, the corrective maintenance take place at the end of every seasons, i.e., the end of month $3,6,9, \ldots$ Therefore, in our case study, $P=\{12,24,36,48, \ldots, 120\}, Q=\{3,6,9,12, \ldots, 120\}$ and $M=12$.

\section{B. illustrative results and analysis}

Table III illustrates the performance characteristics in three different maintenance contexts: without maintenance, full

TABLE II

Mean times of involved retrofitted facilities

\begin{tabular}{lcccc}
\hline Facilities & Type & MTBF & $\begin{array}{c}\text { t1 (good } \\
\text { to average) }\end{array}$ & $\begin{array}{c}\text { t2 (average } \\
\text { to bad) }\end{array}$ \\
\hline Motion sensor & I & 33.5 & N/A & N/A \\
35W retrofit ECG & I & 27.2 & N/A & N/A \\
180W new projector & I & 32.8 & N/A & N/A \\
3kW heat-pumps & II & 52 & 25.2 & 100 \\
Latest airconditioner & II & 43.8 & 21.6 & 86.4 \\
\hline
\end{tabular}

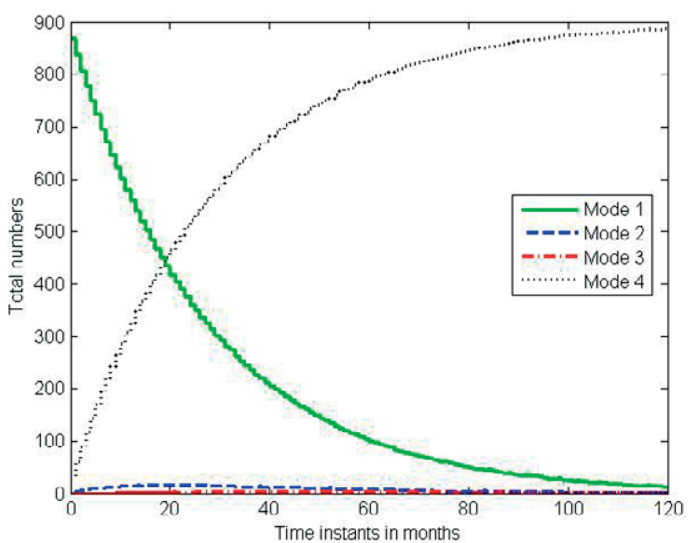

Fig. 1. Time dynamics of the totality of retrofitted facilities in the No Maintenance context

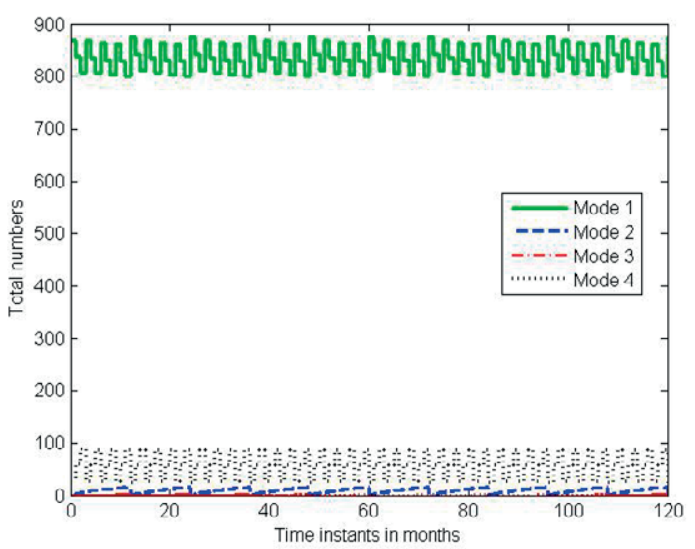

Fig. 2. Time dynamics of the totality of retrofitted facilities in the Full Maintenance context

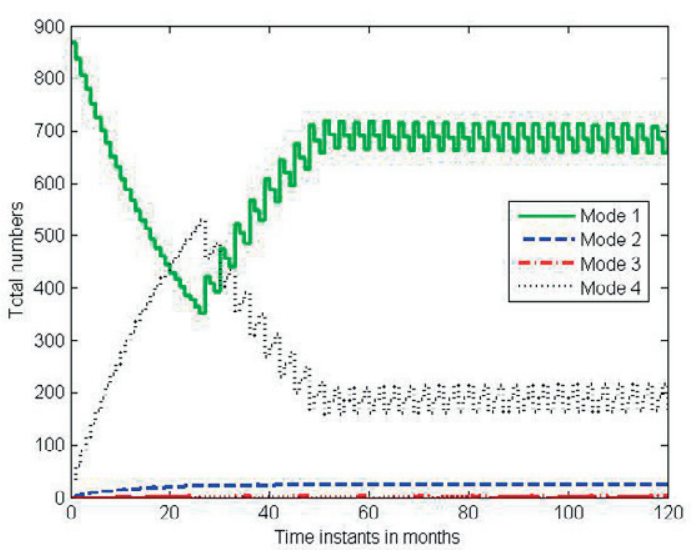

Fig. 3. Time dynamics of the totality of retrofitted facilities in the Optimal Maintenance 1 context 
TABLE I

Characteristics of involved retrofitted facilities

\begin{tabular}{lcccccccc}
\hline Facilities & Type & Quantities & $\begin{array}{c}\text { Unit Price } \\
(\$)\end{array}$ & $\begin{array}{c}\text { Unit Energy } \\
\text { Saving }(\mathrm{kWh})\end{array}$ & $\begin{array}{c}\text { Unit Cost } \\
\text { Saving }(\$)\end{array}$ & $\begin{array}{c}\text { Corrective } \\
\text { Cost }(\$)\end{array}$ & $\begin{array}{c}\text { PreventiveA } \\
\text { Cost }(\$)\end{array}$ & $\begin{array}{c}\text { PreventiveB } \\
\text { Cost }(\$)\end{array}$ \\
\hline Motion sensor & I & 125 & 196 & 1141 & 135.1 & 196 & N/A & N/A \\
35W retrofit ECG & I & 682 & 14.19 & 102 & 10.91 & 14.19 & N/A & N/A \\
180W new projector & I & 48 & 490.8 & 230.4 & 25.95 & 263.28 & N/A & N/A \\
3kW heat-pumps & II & 11 & 1250 & 8640 & 973.3 & 201 & 47 & 65 \\
Latest airconditioner & II & 36 & 989 & 1782 & 195.65 & 175 & 26 \\
\hline
\end{tabular}

TABLE III

Performance characteristics of obtained maintenance plan in different contexts

\begin{tabular}{|c|c|c|c|c|c|c|c|}
\hline Contexts & $\begin{array}{c}\text { Energy Saving } \\
(\mathrm{kWh})\end{array}$ & Ratio & $\begin{array}{c}\text { NPV } \\
(\$)\end{array}$ & $\begin{array}{l}\text { PaybackPeriod } \\
\text { (months) }\end{array}$ & $\begin{array}{c}\text { Investment } \\
(\$)\end{array}$ & $\begin{array}{l}\text { Maintenance } \\
\text { Cost }(\$)\end{array}$ & $\begin{array}{l}\text { Profit } \\
(\$)\end{array}$ \\
\hline No Maintenance & 1093608 & $4.78 \%$ & 29346.88 & 48.69 & 107090 & 0 & 34395.83 \\
\hline Full Maintenance & 3653566 & $15.98 \%$ & 125981.1 & 52.81 & 293923.6 & 186833.6 & 144914.3 \\
\hline Optimal Maintenance 1 & 2580266 & $11.28 \%$ & 153002.4 & 40.86 & 178613.4 & 71523.37 & 172466.3 \\
\hline Optimal Maintenance 2 & 3563632 & $15.58 \%$ & 188545.3 & 41.35 & 243243.1 & 136153.2 & 212668.4 \\
\hline Optimal Maintenance 3 & 2559074 & $11.19 \%$ & 161228.9 & 38.89 & 164281.5 & 57191.47 & 181392.5 \\
\hline
\end{tabular}

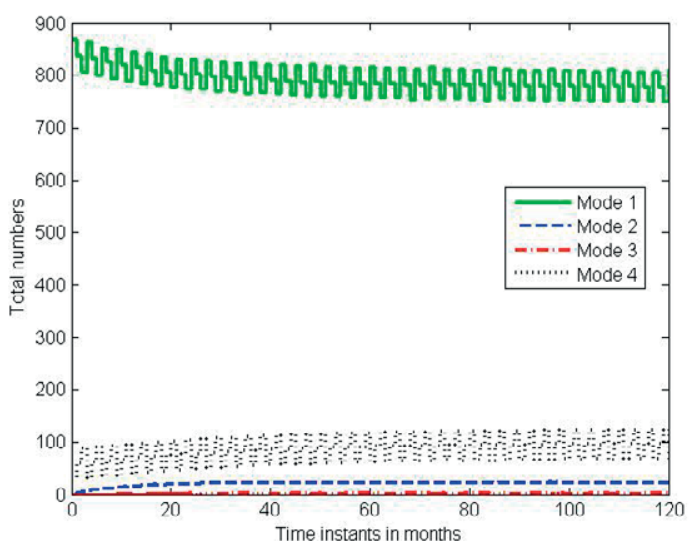

Fig. 4. Time dynamics of the totality of retrofitted facilities in the Optimal Maintenance 2 context

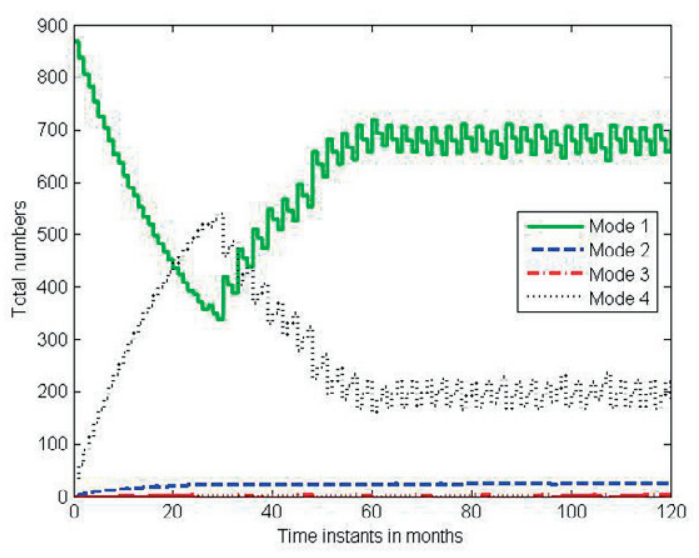

Fig. 5. Time dynamics of the totality of retrofitted facilities in the Optimal Maintenance 3 context maintenance and optimal maintenance. The performance characteristics without maintenance illustrates the impact of deterioration to the plant. The full maintenance policy allows all the degraded or failed items to be restored to good states without taking budget into account. The optimal maintenance context applies optimal maintenance plan obtained by the present approach. In Table III, it can be observed that without maintenance, the energy efficiency of the plant can not sustain against the deterioration. The economy of the retrofitting project is seriously damaged as well. This reveals the importance of maintenance for a retrofitting project from both energy efficiency and cost-effectiveness perspectives. The full maintenance plan obtains the maximum energy saving amount among all the contexts, but the corresponding financial performance appears unacceptable, due to the longest payback period and the lowest profit and NPV. Furthermore, the maintenance expenditure of the full maintenance plan considerably exceeds the maintenance budget, which is $\$ 150,000$ in ten years. The performance of full maintenance plan reveals the necessity of maintenance plan optimization.

The following three rows illustrate the performance of the optimal maintenance plan obtained by the present approach. Different combination of weighting factors are employed in these contexts: for optimal maintenance $1, \lambda_{1}=0.5$ and $\lambda_{2}=$ 0.5 , for optimal maintenance $2, \lambda_{1}=0.75$ and $\lambda_{2}=0.25$, for optimal maintenance $3, \lambda_{1}=0.25$ and $\lambda_{2}=0.75$. These different combinations show different emphasis on the multiple objectives: optimal maintenance 1 considers the balance between two objectives, optimal maintenance 2 reveals stronger need for the energy efficiency and optimal maintenance 3 emphasizes the financial payback of the retrofitting project. This allow the decision makers to use the present approach to obtain maintenance plan subject to their specific requirements.

Figs. 1 - 5 demonstrate the time dynamics of the totality of retrofitted facilities in respective contexts. In all these figures, the solid curves illustrates the dynamics of the totality of items under working mode 1, i.e., the good state. The dashed 
curve illustrates the dynamics of the total number of the items that are not available, comprising the items under mode 2 from type-I facilities and mode 4 from type-II facilities. The dashdoted curve and dotted curves show the dynamics of the totality of items from type-II facilities that are under working mode 2 and 3 , respectively.

\section{CONCLUSiON}

This paper employs a multi-state system model that is governed by a discrete-time Markov process to characterize the deterioration of the totality of retrofitted facilities from a building retrofitting project in the energy efficiency context. Different from the existing multi-state system approaches in literatures, the present model takes into account heterogeneous categories of retrofitted facilities. Each category is modeled by a multi-state system, and the involved multi-state systems have different states and jump rates. The totality of the groups of heterogeneous facilities instead of individual items is adopted as our plant and the main concern of maintenance plan optimization. The employment of multi-state system in the present model allows the quantified evaluation of the impact of preventive and corrective maintenance actions over a long period of time on the overall energy efficiency of the plant. The optimization problem is accordingly casted into a stochastic optimal control problem, by which the significant time dynamics of the totality of the retrofitted facilities can be address by a control system approach. An MPC based approach is thus presented to solve the stochastic control problem. A simple practical retrofitting project adopted as the case study is investigated to verify the effectiveness of the present approach. From simulation results, the effectiveness of the present approach can be observed. Furthermore, the present approach allows the decision makers to obtain optimal maintenance plan taking into account their specific requirements.

The present work calls for further studies on the following topics: the introduction of maintenance polices subject to more realistic conditions; the employment of more practical multistate system models and deterioration models; the further studies on control system approaches to solve the proposed stochastic optimal control problem.

\section{REFERENCES}

[1] C. Diakaki, E. Grigoroudis, and D. Kolokotsa, "Towards a multiobjective optimization approach for improving energy efficiency in buildings," Energy and Buildings, vol. 40, no. 9, pp. 1747-1754, 2008.

[2] E. Asadi, M. G. da Silva, C. H. Antunes, and L. Dias, "Multi-objective optimization for building retrofit strategies: A model and an application," Energy and Buildings, vol. 44, pp. 81-87, 2012.

[3] E. M. Malatji, J. Zhang, and X. Xia, "A multiple objective optimisation model for building energy efficiency investment decision," Energy and Buildings, vol. 61, pp. 81-87, 2013

[4] B. Wang, X. Xia, and J. Zhang, "A multi-objective optimization model for the life-cycle cost analysis and retrofitting planning of buildings," Energy and Buildings, vol. 77, pp. 227-235, 2014.

[5] E. Mathews, C. Botha, D. Arndt, and A. Malan, "Hvac control strategies to enhance comfort and minimise energy usage," Energy and Buildings, vol. 33, no. 8, pp. 853-863, 2001.

[6] V. L. Erickson, Y. Lin, A. Kamthe, R. Brahme, A. Surana, A. E. Cerpa, M. D. Sohn, and S. Narayanan, "Energy efficient building environment control strategies using real-time occupancy measurements," in Proceedings of the First ACM Workshop on Embedded Sensing Systems for Energy-Efficiency in Buildings. ACM, 2009, pp. 19-24.

[7] T. Salsbury, P. Mhaskar, and S. J. Qin, "Predictive control methods to improve energy efficiency and reduce demand in buildings," Computers \& Chemical Engineering, vol. 51, pp. 77-85, 2013.

[8] E. Boukas and Z. Liu, "Production and maintenance control for manufacturing systems," IEEE Transactions on Automatic Control, vol. 46, no. 9, pp. 1455-1460, 2001.

[9] A. Gharbi and J.-P. Kenné, "Maintenance scheduling and production control of multiple-machine manufacturing systems," Computers \& industrial engineering, vol. 48, no. 4, pp. 693-707, 2005.

[10] C. Ming Tan and N. Raghavan, "A framework to practical predictive maintenance modeling for multi-state systems," Reliability Engineering \& System Safety, vol. 93, no. 8, pp. 1138-1150, 2008

[11] M. D. Le and C. M. Tan, "Optimal maintenance strategy of deteriorating system under imperfect maintenance and inspection using mixed inspection scheduling," Reliability Engineering \& System Safety, vol. 113, pp. 21-29, 2013.

[12] P. O'Connor and A. Kleyner, Practical Reliability Engineering. Wiley, Chichester, UK, 2011.

[13] J. Zhang and A. C. Sanderson, "Jade: adaptive differential evolution with optional external archive," IEEE Transactions on Evolutionary Computation, vol. 13, no. 5, pp. 945-958, 2009.

[14] X. Xia, J. Zhang, and A. Elaiw, "An application of model predictive control to the dynamic economic dispatch of power generation," Control Engineering Practice, vol. 19, no. 6, pp. 638-648, 2011. 
(Página deixada propositadamente em branco) 


\title{
Advanced 3D Scan Data Analysis for performant Reengineering Maintenance Processes
}

\author{
Hendrik Grosser ${ }^{1}$; Rainer Stark ${ }^{1,2}$ \\ ${ }^{1}$ hendrik.grosser@ipk.fraunhofer.de; ${ }^{2}$ rainer.stark@ipk.fraunhofer.de \\ ${ }^{1,2}$ Division of Virtual Product Creation, Fraunhofer IPK Berlin \\ Berlin, Germany \\ ${ }^{2}$ Chair of Industrial Information Technology, TU Berlin \\ Berlin, Germany
}

\begin{abstract}
Overhaul processes of long-living, cost-intensive machines and facilities are time-consuming tasks. They aim either at full recovery of the original product condition through repair or spare part exchange or at modernization for performance enhancement. However, decision for an overhaul should be carefully considered, because realization may be difficult und time-critical. Every overhaul process is unique and based on a thoroughly diagnosis of product condition. This makes it a risky and hard to plan project. In this context speed of overhaul operation is essential for avoiding costs due to machine down times. Obsolescence of components and modernization goals demand for an efficient reengineering to design geometric models for production. Modern 3D scanning technologies deliver 3D models of actual product geometry and allow deviation and tolerance analyses in case of available reference models. However, optical limitations and difficult part disassembly make 3D digitization still a laborious task and is additionally followed by a high effort in data post-processing. This paper depicts a new approach to facilitate reengineering processes through advanced methods in 3D scan data analysis of non-disassembled products. Implementations allow parts identification in 3D assembly scans through shape recognition and database search for provision of needed $\mathrm{CAD}^{1}$ data.
\end{abstract}

Keywords-Maintenance; overhaul; inspection; reengineering; $3 D$ scan; shape retrieval.

\section{INTRODUCTION}

Reengineering in general means to revise or rework something with the aim of performance enhancement or adaptation $[1,2]$. This can be related to products or processes like mechanical, electrical or software designs as well as business, design or lifecycle processes. This paper focusses on reengineering of long-living products with high investment costs, e. g. steam turbines, jet engines, turbo chargers, means of transportation (air crafts, trains, ships), factory plants, machine tools and engines. Operating times are between twenty and fifty years. These types of products are predominantly custommade items that are adapted to customer's needs. In case of steam turbines an adaptation to customer's factory design with specific parts, piping and placement next to related machines and facilities has to be realized. Individualization is a big problem for maintenance tasks, because maintenance companies are not able to develop standardized processes of inspection, meaning functionality checking and error search as well as spare part selection. Basis of the inspection process is the identification of build in parts which can be a timeconsuming task. Parts have to be disassembled and labels and geometries have to be compared with part data bases manually. Maintenance companies struggle with wear-induced difficult disassembly and label reading and the diversity of variants. In most difficult maintenance tasks technical documents like bill of material and design drawings or data as well as maintenance protocols are not available. This issue happens if the maintenance company is not the original equipment manufacturer (OEM). An additional issue occurs if spare parts are no longer available, because suppliers quit production or their business due to economic reasons. In this case parts have become obsolete and machine owners have to reengineer and remanufacture equivalent or similar parts in order to continue machine operation. The worst case appears if functionality of a whole obsolete system (e. g. a control station) cannot be understood sufficiently for maintenance purposes. In this case the complete system has to be reengineered. Another need for reengineering appears if aging machines cannot keep up with state of the art machines in terms of performance or efficiency and an overhaul is the most economical solution to stay competitive. However, costs of overhaul processes which are always unique projects are hard to determine. In addition they are time critical, because machine downtimes are linked with high financial loss for the owner. Overhaul processes comprise all mentioned reengineering issues of parts design, system design and modernized design so that these processes will be analyzed in more detail in the following. Automation of reengineering processes is a challenge of the future. Therefore $3 \mathrm{D}$ product data of existing products to be overhauled is needed and has to be acquired by a reverse engineering process. In this case it means the process from acquisition of $3 \mathrm{D}$ scan data to modifiable CAD models.

${ }^{1} \mathrm{CAD}$ - Computer Aided Design 


\section{OVERHAUL PROCESS ANALYSIS}

Overhaul processes are being performed in the service phase of the product life cycle. They are unplanned and will be necessary after several years of product use and maintenance (e. g. after 10 to 30 years). Fig. 1 shows the generic overhaul process. The first step after machine decommissioning is preinspection with the goal to determine product condition without disassembly. If technical documentation is available all documents are worked through and the product will be visually checked. In case of turbines boroscopes are being used to inspect inner components. In order to proceed with inspection parts have to be disassembled, cleaned and identified by manual search in data bases or parts catalogues as mentioned above. In the inspection phase optical, electrical and tactile measurement principles deliver precise data and allow a deviation analysis with nominal or desired condition. 3D scanning sensors are used for acquisition of geometric data. Additionally, functional principles of the product are clearly described and components or systems for substitution or modernization have been identified. Operation scheduling aims for planning of resources like staff, IT usage or working times. Reengineering is based on 3D scan data of the current product's parts, components and installation space as well as on original CAD data from the $\mathrm{OEM}^{2}$. However, as reasoned above the latter is hardly available. The digitization process is based on 3D point coordinates measured by a 3D sensor. These point clouds are post processed to a polygon model and afterwards to a constructed solid geometry (CSG) which can be modified with CAD systems. After design engineers have developed new parts and components resources have to be determined for the production schedule. Due to production tolerances remanufactured products have to go through a quality check which means to apply again the mentioned measurement equipment. Especially 3D scanning allows a fast process for geometrical deviation analysis because reference data from the reengineering phase does already exist. Then, all parts and components can be reassembled to proof machine performance by test runs. Finally, machine is handed out to the owner for recommissioning. The whole process is supported by product data management and document management systems.

From the beginning of the overhaul process information and data is compiled or created. This sub-process is individual to every machine and there is no standardized practice which allows determining exact effort and costs of this sub-process. If retrieval of information about parts concerning their original design intend (e. g. tolerances or system functionality) was not successful reengineering becomes more difficult. In this case engineers have to reinvent parts and components that realize the original purpose of the machine and additionally achieve higher efficiency. Preparation of simulation models and even prototypes for testing might be necessary. This kind of reengineering process with subsequent production and testing equals the engineering process of life cycle's design stage. Consequently, on this part of the overhaul process there is no specific optimization potential. Improvement concerns work on methodologies, collaboration and concurrent engineering, product data management (PDM), CAD performance and IT system interoperability which covers a large field of research activities that are already running. Hence, this paper focusses on the inspection and digitization issues which aim for part information and data retrieval with the goal of better preparation of the reengineering stage through an automation approach. Conclusion: time reduction in the data retrieval phase leads to time reduction of reengineering und thus has the highest potential for improvement of overhaul processes.

\section{SOLUTION APPROACH}

The reengineering stage needs as an input $3 \mathrm{D}$ product models in the form of constructive solid geometry (CSG). This comprises single parts, components and assemblies as well as the whole product with its installation spaces. Two types of 3D geometry models are needed: geometry of the real product (as-is condition) and of the original design (as-designed condition). Due to wear both conditions can be crucially different. Furthermore, information in the form of a bill of material (BOM) and an inspection report is needed including

- Part or component name

- $\quad$ ID code

- Part quantity

- Materials

- As-is condition compared to as-designed condition.

The earlier this information and geometric data is retrieved in the overhaul process the faster the reengineering stage can be started. Thus, research aims to get more information and data out of the pre-inspection stage. This information shall be used by engineers for subsequent understanding of whole system functionality, single operating principles and necessary tolerances for production.

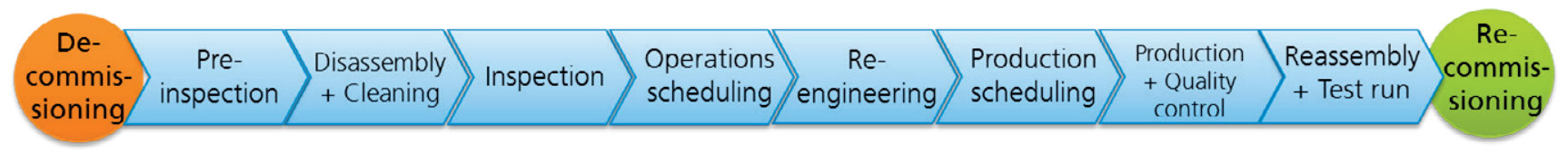

Product data management + Document management

Fig. 1. Generic overhaul process.

${ }^{2}$ OEM - Original Equipment Manufacturer 


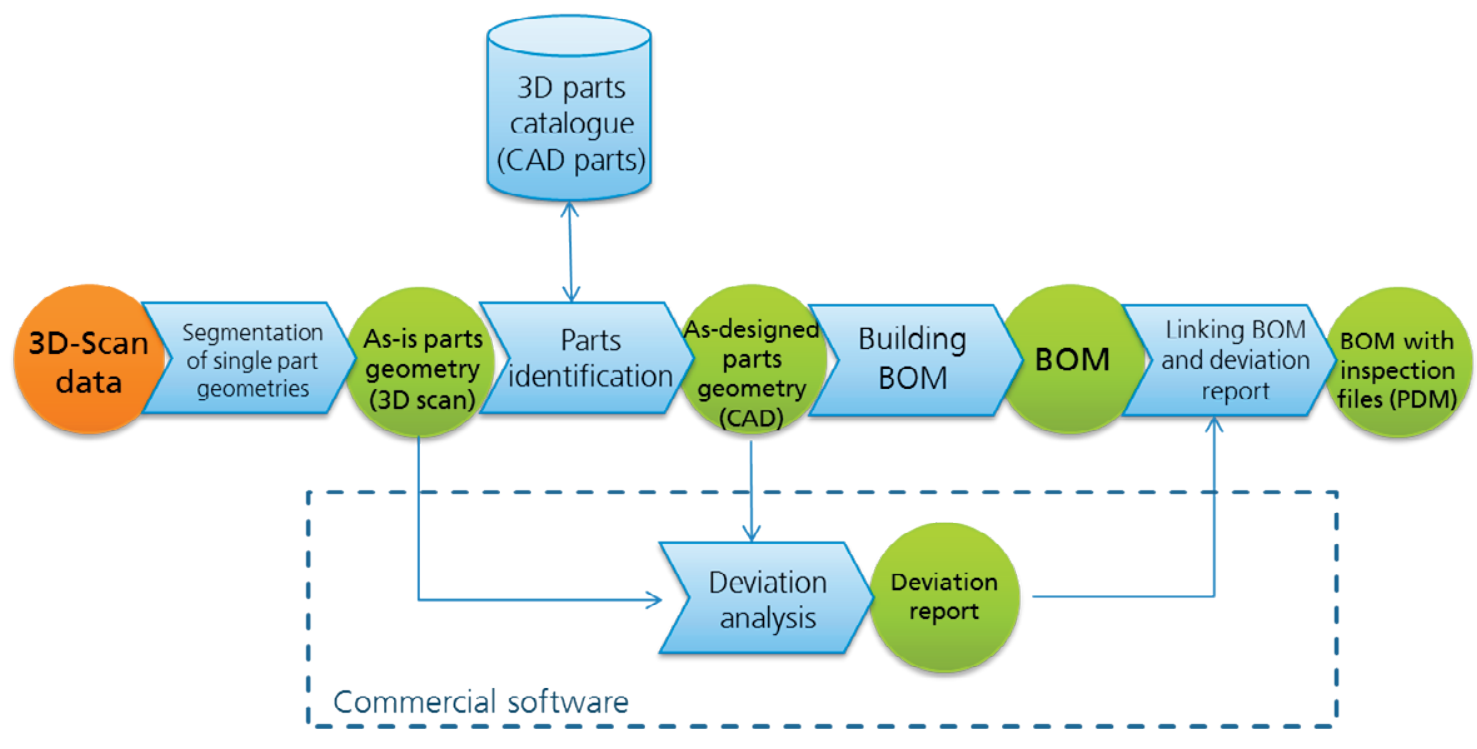

Fig. 2. Process to be realized with the reengineering cokpit.

With the goal to achieve a high degree of automation a 3D scanning and post-processing process will be invented and a test implementations has to be done. Fig. 2 shows how 3D scan data shall be processed with the new process to automate generation of product BOM and to add a damage report. Since this process is part of the pre-inspection stage of the overhaul process products will be digitized without disassembly. Future 3D scanning, X-ray and boroscope solutions may allow digitizing not only of the outer surface but also of inner and hidden structures. The process of Fig. 2 may also be beneficial with acquisition of only outer surface geometry. Once the digital geometry model has been created by standard reverse engineering methods as a polygon model (e. g. in the common STL format) it will be imported in a shape retrieval application to be developed. This application provides intelligent algorithms that are able to detect geometry of single parts and to separate them from each other. In case only 3D scanning was used to digitize outer surface this sub-process delivers single part geometries which are incomplete. However, the more complete the surface the easier will be the next step of parts identification which shall be automatically performed by a geometrical similarity search. This shape search is based on self-defined footprints or so called descriptors. A mathematical calculation delivers such a descriptor for any part geometry. Then, part geometries can be compared to other part geometries in a data base by comparing their descriptors provided that the data base allowed it to calculate such descriptors. Shape search delivers a priority list of similar geometries respectively parts and calculates a percentage that indicates their matching rate. Found parts will be extracted from the data base and saved separately together with data base information about parts name, ID and materials if available.

Parts from open source online data bases or commercial parts catalogues are representing as-designed CAD geometry (CSG files) whereas 3D scans deliver the as-is geometry. In the next step matching part files can now be compared by a deviation analysis with commercial software. The result will be a graphical report which shows deviations of part's surfaces with a color scale. Colors can indicate e. g. if as-is part's geometry runs out of tolerance. Thus, for maintenance purposes it can be used as a damage report.

In the next step information about product's BOM will be stored in an $\mathrm{XML}^{3}$ file and linked with damage reports and 3D data files. Finally, the XML file can be imported in a $\mathrm{PDM}^{4}$ system that allows robust data management. This allows engineers to understand product condition and gives hint about operational principles. Finally, engineers can start with their creative process of designing for the overhaul processes. It may be necessary to transform the polygon data by the $3 \mathrm{D}$ scans into $\mathrm{CAD}$ files (CSG files) with commercial reverse engineering tools.

\section{SHAPE RETRIEVAL SYSTEM}

Recent work dealt with approaches of mesh segmentation as well as with gray scale segmentation in voxel data $[3,4]$. In addition this paper focuses on the identification of single parts presenting a new approach. This approach aims for a geometrical similarity search of 3D scanned parts with parts of a data base.

\section{A. Related research work and applications}

Main components of a shape retrieval system are a mathematical descriptor for geometry and a data base with reference models. In addition an evaluation principle for performance evaluation of descriptors can be used. A very famous evaluation principle is offered by the Princeton Shape Benchmark (PSB) [5]. However, it was not used because the according data base does not include mechanical parts. This is

\footnotetext{
${ }^{3}$ XML - Extensible Markup Language

${ }^{4} \mathrm{PDM}$ - Product Data Management
} 
important, because for test series geometry of data base parts should be very similar to 3D scanned parts. More suitable is the Engineering Shape Benchmark (ESB) which consists of mechanical parts [6].

Demo shape retrieval systems are available on the websites of Princeton University [7] and the Informatics \& Telematics Institute [8]. Part search is possible through input of 2D or 3D sketches and text. The companies TurboSquid, GrabCAD and CADENAS offer free online data bases for 3D geometry parts search. CADENAS PARTsolutions is the most interesting due to mechanical parts catalogues [9]. This data base has been designed to search for CAD parts. Research has shown that it is also suitable for 3D scan data, but with some limitations [4]. No retrieval system could be found that allowed a partial matching meaning search for incomplete $3 \mathrm{D}$ scanned geometry of parts.

\section{B. Procedure of part identification}

A shape retrieval system was designed through adaptation of the system of Funkhouser et. al. [10] by combining shape variant and invariant descriptors (Fig. 3). Size invariant descriptors are favored to size variant (respectively geometric) descriptors due to better matching rates and faster processing times. However, in this case shape variant descriptors enable a preselection by sorting according to dimensions, focal point, volume and surface.

The adapted shape retrieval procedure starts with a $3 \mathrm{D}$ model of a single part that was segmented out of a point cloud (query object). Firstly, a size variant descriptor is calculated for this object and the reference objects of a data base. Then, size of the query object is compared with reference objects by using bounding boxes or convex hulls which enables calculating distances of the descriptors. After sortation $\mathrm{n}$ best data base models are shown to the user whereas $2 \mathrm{n}$ descriptors are used for further processing. The second step is comparison between calculated size invariant descriptors of query objects and data base objects. Resulting distances will be sorted again and finally $n$ best data base models are shown to the user.

\section{Definition of a feature descriptor}

Query objects coming from 3D mesh segmentation have no closed surface and thus are hard to compare with CAD data models of a data base. For comparison it is necessary to normalize their size, position and rotation. Analyses of existing descriptors showed that no existing descriptor alone was able to deliver satisfying results. Hence, different descriptors were combined respectively correlated. Thereunder were geometrical descriptors as well as scaling invariant descriptors (TABLE 2 and TABLE 3). The following restrictions were considered when analyzing and selecting descriptors for test series:

- Information about object sizes had to be included

- No precise description of surface which would hinder partial matching

- Standard PCA (Principal Component Analysis) algorithm by Vranic et. al. [11] is deficient for normalization of rotation

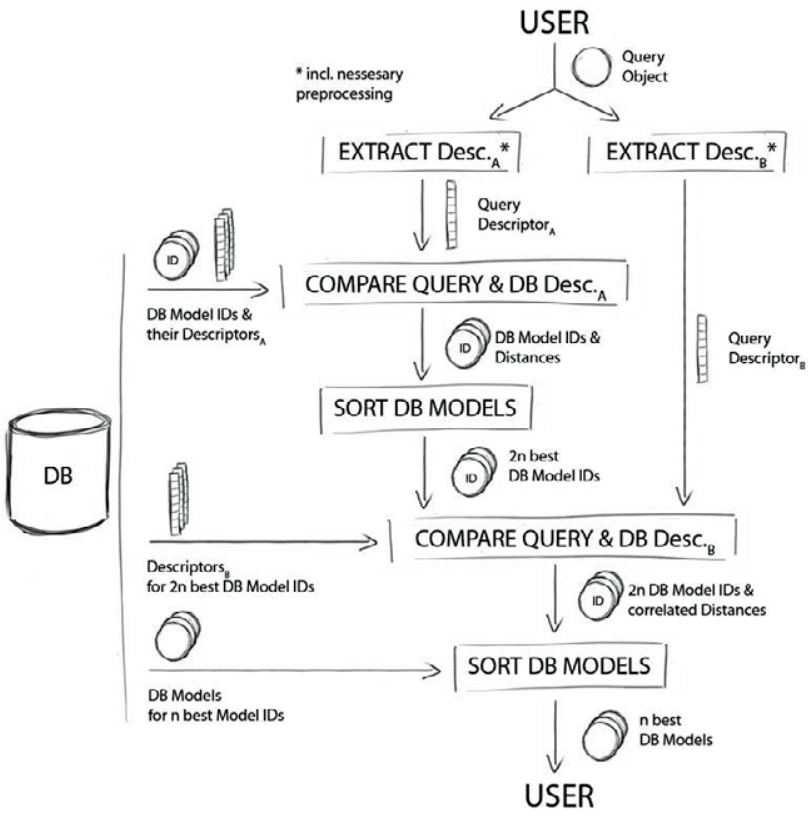

Fig. 3. Procedure of part identification. Descriptor A is size variant whereas descriptor B is size invariant.

\section{Set up of test data base and query objects}

A test data base was set up with parts from Engineering Shape Benchmark (ESB), CADENAS PARTsolutions and with own 3D scanned parts of a car generator which were segmented with own segmentation principles in previous work [4]. TABLE 1 shows all reference parts and numbers of subjectively assessed similar objects. For some query objects variants have been used (Fig. 4).

TABLE 1. DATA BASE MODELS AND QUERY OBJECTS

\begin{tabular}{|c|c|c|}
\hline $\begin{array}{l}\text { Reference models } \\
\text { in data base (CAD) }\end{array}$ & $\begin{array}{l}\text { Variants of } \\
\text { corresponding } \\
\text { query object (3D } \\
\text { scan) }\end{array}$ & $\begin{array}{c}\text { similar objects } \\
\text { (subjectively } \\
\text { assessed) }\end{array}$ \\
\hline Generator housing & 4 & 15 \\
\hline Bearing Bracket & 4 & 5 \\
\hline Fan & 4 & 13 \\
\hline Pulley & 4 & 13 \\
\hline Slip ring & 1 & 15 \\
\hline Stator & 3 & 16 \\
\hline Blade & 1 & 2 \\
\hline Block & 1 & 8 \\
\hline Gearbox plate & 1 & 8 \\
\hline Impeller 1 & 1 & 14 \\
\hline Impeller 2 & 1 & 12 \\
\hline $\begin{array}{l}\text { Impeller } 3 \\
\text { (ceramic) }\end{array}$ & 1 & 18 \\
\hline Piston & 1 & 13 \\
\hline Turbine & 1 & 7 \\
\hline$=14$ & $=28$ & $=159$ \\
\hline
\end{tabular}




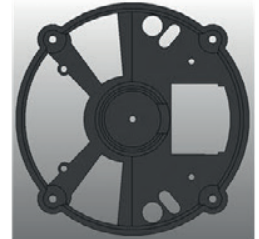

(a) CAD model (reference)

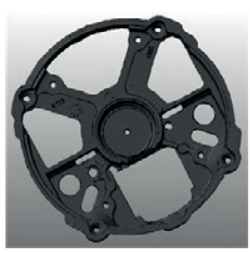

(b) 3D scan

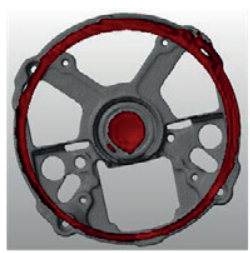

(c) Manually segmented CT

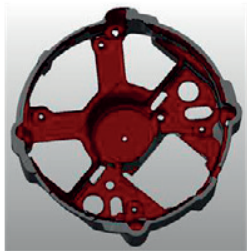

(c) Manually segmented 3D scan

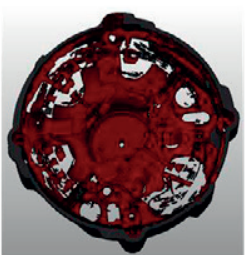

(d) Automated 3D scan segmentation
Fig. 4. Variants of generator housing.

\section{E. Test series}

Separate test series for geometric and scaling invariant descriptors as well as correlated descriptors from both groups were performed. Comparison was made through calculation of average precision (AP) respectively ranks:

$$
A P=\frac{1}{m} \sum_{k=1}^{m} \operatorname{Precision}\left(R_{k}\right)=\operatorname{Precision}\left(R_{1}\right)=\frac{1}{\text { Rank }_{1}}
$$

$\mathrm{m}=$ number of relevant results

$\mathrm{R}_{\mathrm{k}}=$ set of ranked retrieval results till the $\mathrm{k}^{\text {th }}$ relevant result

The mean for APs of all query objects is

$$
m A P=\frac{1}{Q} \sum_{j=1}^{Q} A P_{j}
$$

Due to the fact that there is only one fitting reference object in the data base equation (2) can be simplified and resolved to mean Rank $(\mathrm{mR})$ which allows quantitative comparison of queries:

$$
m R=\frac{1}{Q} \sum_{j=1}^{Q} \operatorname{Rank}_{j}
$$

TABLE 2TABLE 2, TABLE 3TABLE 3 and Fig. 5 show mean Ranks for all query objects for the popular L1 and L2 metrics:

$$
\begin{array}{ll}
\text { L1-Metric: } & d(x, y)=\sum_{i=1}^{n}\left|x_{i}-y_{i}\right| \\
\text { L2-Metric: } & d(x, y)=\sqrt{\sum_{i=1}^{n}\left(x_{i}-y_{i}\right)^{2}}
\end{array}
$$

These metrics calculate distances for $3 \mathrm{D}$ vectors pointing to objects points and thus allow comparison of descriptors by calculation of point distances.

Test series for geometric descriptors showed that the descriptor for the surface obtained the best results followed by descriptors for dimension and Bounding Box. Metrics L1 and L2 were close together so that it makes no big difference which one has been chosen for comparison. Down sampling of voxel grid caused only for the barycenter descriptor a slightly better result whereas all other values were slightly worse (TABLE 2).

TABLE 2. MEAN RANKS FOR GEOMETRIC DESCRIPTORS.

\begin{tabular}{|l|c|c|c|c|}
\hline \multirow{2}{*}{ Descriptor } & \multicolumn{2}{|c|}{ Original } & \multicolumn{2}{c|}{ After downsampling } \\
\hline $\begin{array}{l}\text { Bounding } \\
\text { Box }\end{array}$ & 8,39 & 9,54 & 8,46 & 9,79 \\
\hline Dimension & 6,29 & 6,96 & 6,89 & 7,11 \\
\hline $\begin{array}{l}\text { Dimension } \\
\text { sorted }\end{array}$ & 6,75 & 7,29 & 7,25 & 7,71 \\
\hline $\begin{array}{l}\text { Barycenter } \\
\text { Volume }\end{array}$ & 11,89 & 12,00 & 11,14 & 12,18 \\
\hline Surface & 9,54 & 9,54 & - & - \\
\hline $\begin{array}{l}\text { Volume/ } \\
\text { surface }\end{array}$ & $\mathbf{5 , 8 9}$ & $\mathbf{5 , 8 9}$ & - & - \\
\hline
\end{tabular}

Test series for scaling invariant descriptors for different voxel sizes $(8,16,32$ and 64) showed that the Spherical Harmonics Descriptors (SHD) delivers best results (but was only applicable for a voxel size of 64) followed by Point Distance Distribution (PDD). PDD delivered best results for voxel size 16 and the Vector Descriptor (VD) for size 32 (TABLE 3). 
TABLE 3. MEAN RANKS FOR SCALING INVARIANT DESCRIPTORS.

\begin{tabular}{|c|c|c|c|c|c|c|c|c|}
\hline \multirow{2}{*}{ Descriptor } & \multicolumn{2}{|c|}{$8 \times 8 \times 8$} & \multicolumn{2}{|c|}{$16 \times 16 \times 16$} & \multicolumn{2}{|c|}{$32 \times 32 \times 32$} & \multicolumn{2}{|c|}{$64 \times 64 \times 64$} \\
\hline & L1 & L2 & L1 & L2 & L1 & L2 & L1 & L2 \\
\hline $\begin{array}{l}\text { Spherical } \\
\text { Harmonics } \\
\text { Descriptor } \\
\text { (SHD) }\end{array}$ & - & - & - & - & - & - & - & 7,00 \\
\hline $\begin{array}{l}\text { Point } \\
\text { Distance } \\
\text { Distribution } \\
\text { (PDD) }\end{array}$ & 20,10 & 19,18 & 18,61 & 18,64 & 29,58 & 30,2 & - & - \\
\hline $\begin{array}{l}\text { Voxel } \\
\text { Descriptor } \\
\text { (VD) }\end{array}$ & 26,71 & 26,61 & 19,21 & 19,25 & 16,04 & 16,82 & 16,86 & - \\
\hline
\end{tabular}

When combining geometrical descriptors with scaling invariant descriptors mean Rank values could be lowered to 2.46. This result was achieved by experimental setting of weights for the six chosen descriptors depicted in Fig. 5.

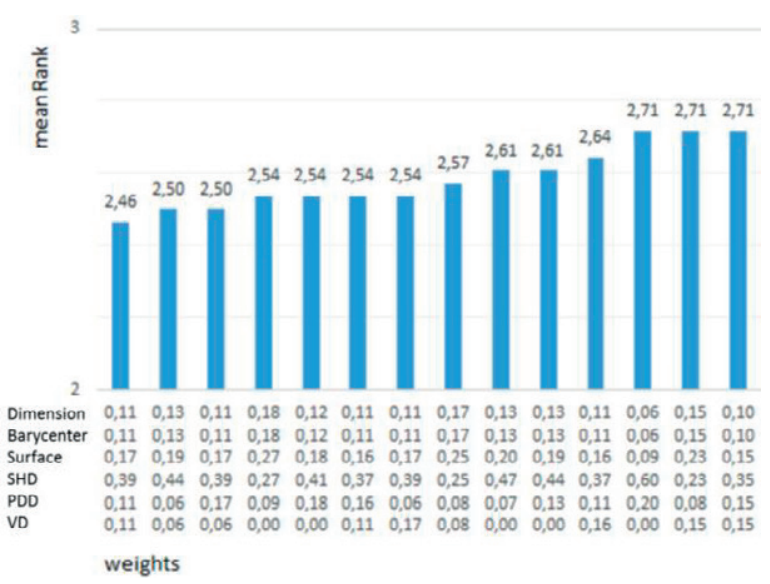

Fig. 5. Mean Ranks of weighted combinations of six chosen descriptors.

\section{GRAPHICAL USER INTERFACE (GUI)}

The Point Cloud Library (PCL) [12] was used as the framework for implementation of the shape retrieval system and Qt [13] enabled the realization of the Graphical User Interface (GUI).

The implemented GUI (Fig. 6) allows to load query objects (e. g. 3D scanned parts) (A) and to visualize them $(\mathrm{G})$. The maximum number of found priorities can be set with toolbar (C). Toolbar (F) enables configuration of descriptors. Six descriptors can be chosen, combined and weighted. Metrics can be defined for evaluation with (E). Button (D) starts the identification procedure.

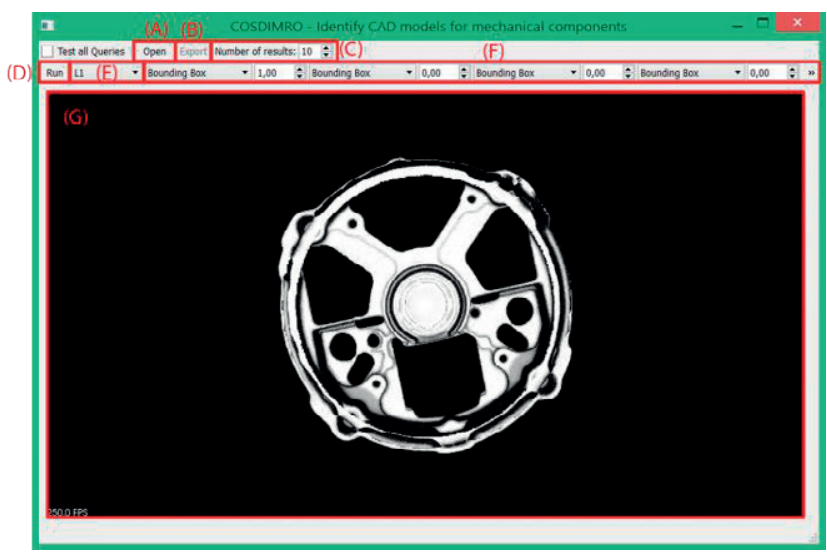

Fig. 6. GUI with loaded query object and parameters for configuration.

When the comparison of the query object with the data base parts is finished a priority list shows best matches with a percentage (I) (Fig. 7). Similarity is defined as:

Similarity $=1-$ Distance

Similarity in $\%=$ Similarity $* 100$

For combined and weighted descriptors diagram $(\mathrm{H})$ shows deviations of each single descriptor of the query object to its corresponding reference descriptor. Status bar $(\mathrm{J})$ names the rank of the selected parts and button (B) provides an export function.

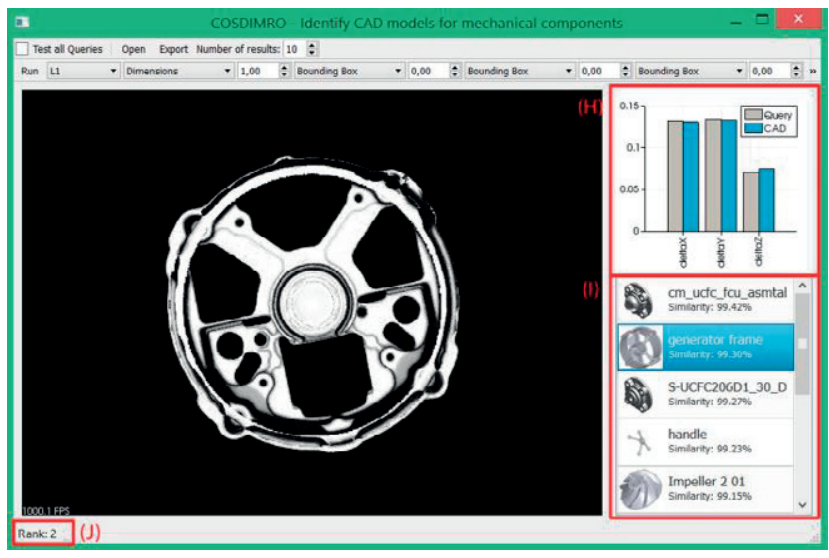

Fig. 7. Identification result with priority parts list and similarity value.

The user can open another screen (Fig. 8) for additional analysis of rank distribution (K). Query objects can be selected with drop down box (L). Bar chart (M) shows calculated ranks of each single query object with an own color. Status bar (N) depicts the mean Rank. This analysis tool enables calculation of mean Ranks for individual compositions of descriptors and weights. 


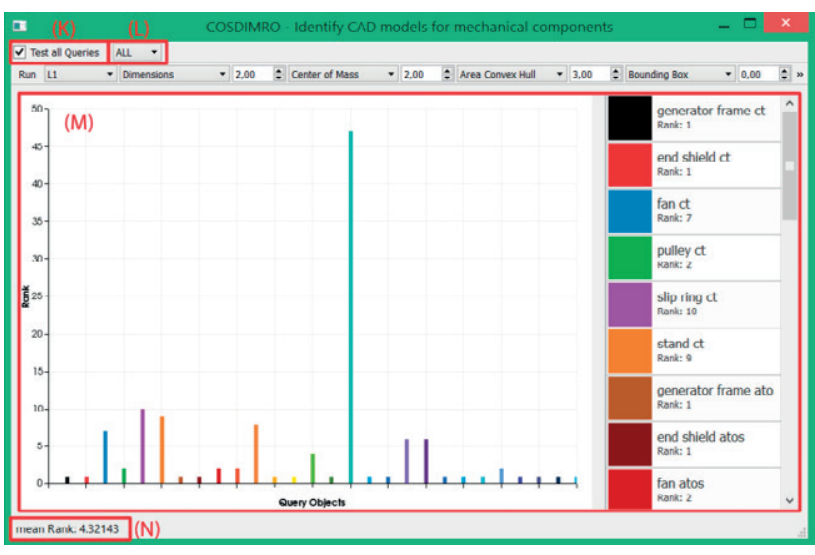

Fig. 8. Analysis tool for calculation of individual mean Ranks.

\section{CONCLUSION AND OUTLOOK}

Results for test data set were very promising. Every query object could be identified. Only some difficulties appeared when comparing a manually designed and simplified CAD model (electric stator) with a 3D scan (Fig. 9).
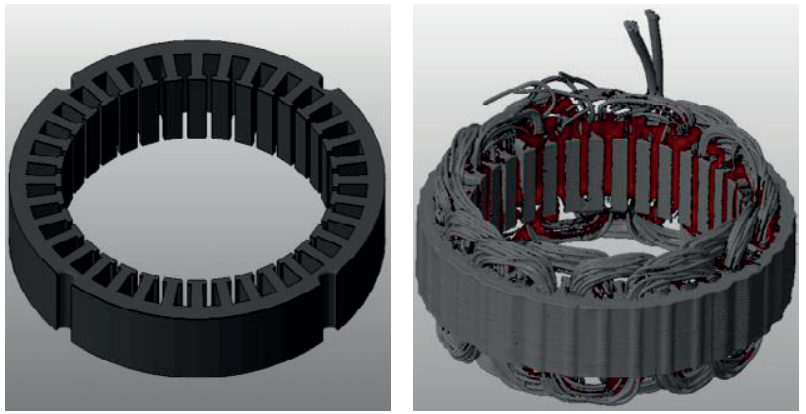

Fig. 9. CAD model (left) and 3D scan of an electric stator (right).

Further test series with a bigger data base and more test objects have to be made to quantify industrial relevance for the presented shape retrieval application. In addition, analysis of common geometrical differences between as-designed CAD objects and as-is scan objects could improve definition of descriptor selection and weighting. The manual combination and weighting of descriptors is time-consuming and needs experience. Classification of geometric features could enable automated pre-selection of appropriate descriptors and their correlation. Furthermore, identification results are dependent on alignment of query and CAD object. Thus, improvement of alignment or overlay method could be very beneficial. For object comparison distances of single 3D coordinates were calculated by a time-consuming brute force method so that a more intelligent calculation can improve processing time and would enable efficient search in large data bases.

Future research aims to realize automated generation of BOMs with linking to damage reports as depicted in Fig. 2. This principle shall afterwards be integrated in the more comprehensive concept that was presented in [4]. Work will also comprise approaches for integration of part segmentation in $3 \mathrm{D}$ scanned assembly models and identification. Therefore, CAD parts from a data base shall be directly fitted into assembly point clouds through a pattern matching algorithm. A 3D scan of a used helicopter gas-turbine (Klimov GTD-350) will be used as test object (Fig. 10).

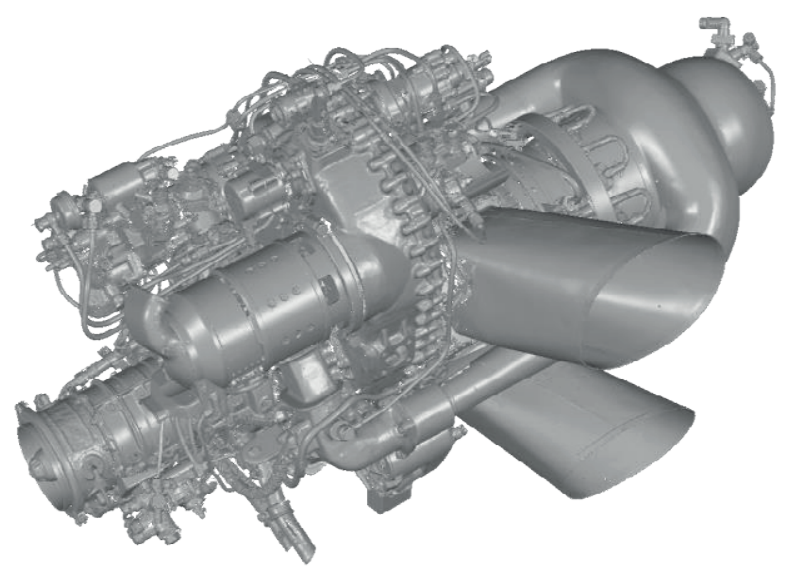

Fig. 10. 3D scan (polygon model) of the helicopter gas-turbine Klimov GTD350 .

\section{ACKNOWLEDGEMENT}

This research was facilitated by the work of Anja Sonnenberg and Kai-Uwe Barthel of the Beuth Hochschule für Technik Berlin. Furthermore it was supported by the senate administration of Berlin (Senatsverwaltung für Bildung, Wissenschaft und Forschung) and funded by the European Union with EFRE means.

\section{REFERENCES}

[1] Meriam Webster Online Dictionary. Available: http://www.merriamwebster.com/dictionary/reengineering (8th June 2014).

[2] The Free Dictionary. Available:

http://www.thefreedictionary.com/reengineering (6th June 2014).

[3] H. Grosser, B. Beckmann-Dobrev, F. Politz, and R. Stark, "Computer Vision Analysis of 3D Scanned Circuit Boards for Functional Testing and Redesign," Procedia CIRP, vol. 11, pp. 229-233, 2013.

[4] R. Stark, H. Grosser, and P. Müller, "Product analysis automation for digital MRO based on intelligent 3D data acquisition," CIRP Annals Manufacturing Technology, vol. 62, no. 1, pp. 123-126, 2013.

[5] P. Shilane, P. Min, M. Kazhdan, and T. Funkhouser, "The princeton shape benchmark," in Proceedings Shape Modeling Applications, 2004, pp. 167-388.

[6] S. Jayanti, Y. Kalyanaraman, N. Iyer, and K. Ramani, "Developing an engineering shape benchmark for CAD models," Computer-Aided Design, vol. 38, no. 9, pp. 939-953, 2006.

[7] Princeton Shape Retrieval \& Analysis Group, 3D Model Search Engine. Available: http://shape.cs.princeton.edu/search.html (12th June 2014).

[8] Informatics \& Telematics Institute, 3D Search. Available: http://3dsearch.iti.gr/3DSearch (12th June 2014).

[9] CADENAS Konstruktions-, Softwareentwicklungs- und Vertriebs GmbH, 2D and 3D CAD Models: Manufacturer Catalogs. Available: http://b2b.partcommunity.com/community/ (12th June 2014).

[10] T. Funkhouser, P. Min, M. Kazhdan, J. Chen, A. Halderman, D. Dobkin, and D. Jacobs, "A search engine for 3D models," ACM Trans. Graph, vol. 22, no. 1, pp. 83-105, 2003. 
[11] D. V. Vranic, D. Saupe, and J. Richter, "Tools for 3D-object retrieval: Karhunen-Loeve transform and spherical harmonics," in 2001 IEEE Fourth Workshop on Multimedia Signal Processing, pp. 293-298.

[12] Point Cloud Library (PCL). V1.6. Available: http://pointclouds.org/ (12th June 2014).

[13] Qt. V4.8. Available: http://qt-project.org/ (12th June 2014). 


\title{
Augmented Reality and the Future of Maintenance
}

\author{
Rúben Oliveira ${ }^{1}$; Torres Farinha ${ }^{2}$; Hugo Raposo ${ }^{3}$; Noberto Pires ${ }^{4}$ \\ ${ }^{1}$ ruben.oliveira@dem.uc.pt; ${ }^{2}$ torres.farinha@dem.uc.pt; ${ }^{3}$ hugrap@gmail.com; ${ }^{4}$ norberto@uc.pt \\ 1,2,3,4 Centre for Mechanical Engineering of the University of Coimbra - CEMUC \\ Coimbra, Portugal
}

\begin{abstract}
This paper addresses the use of Augmented Reality (AR) systems to improve maintenance technicians' performance from training stage to daily interventions. The concept of AR born in industry and since then has being developed by scientists to fulfill the real demands of operational teams. It will be presented the most relevant industrial AR projects and their results, as well as others that significantly contributed for the development of $A R$ and their implementation on industrial environments, namely the progress from marker-based systems to model-based systems. Nowadays, industrial AR systems are not a faraway utopia.
\end{abstract}

To expand the benefits of AR systems for the maintenance sector, it must be combined with other tools, such as real-time monitoring, fault-diagnosis and prevention systems in order to enhance the capabilities of technicians and thus improve maintenance interventions performance.

A technician centered AR system to support maintenance interventions should recognize partially the real environment in order to represent the appropriate virtual data. The most natural procedure is to use different technologies and methodologies based on environment specifications. For this reason a modular system is proposed instead a non-customizable.

The use of markers represents a huge restriction in industrial environments for $A R$, the target objects must be found based on their natural characteristics, like textures or edges. For daily use the AR system's hardware must be portable; one of the AR challenges is to process all the data in tablets or smartphones because these devices have all the required components and, at the same time, are small enough to be carried naturally by technicians and user-friendly interfaces - however are less powerful than dedicated machines.

A timeline with most relevant projects of $A R$ applied to maintenance and assembly sector is presented, being these projects developed in industrial facilities and real work environment to make that the achieved results are close to reality.

Keywords-Industrial Augmented Reality; Maintenance trends; e-Maintenance.

\section{INTRODUCTION}

Whilst physical assets are becoming more and more complex, and consequently their maintenance more demanding, what represents an increasing complexity of maintenance operations, new methods are being developed to support technicians on their duties and to ensure a high level of overall maintenance effectiveness. These methods involve not only on condition maintenance analysis, layouts and or sequence of operations but also technological solutions to give support from the technicians on the field up to the maintenance manager. Augmented Reality (AR) is a trendy and powerful technology that may be used to improve the operability of technicians on the field.

AR is a technology that born on industrial environment [1] aiming to provide digital intuitive instructions at the same time as technicians were working on their tasks minimizing the time spent on looking for instructions manuals. In fact these objectives remain the main purpose of $\mathrm{AR}$ for industrial maintenance today. There is not a unique solution to all environments - each scenario must be carefully analyzed to choose the most suitable equipment to be used and each Working Order (WO) must be virtually prepared.

A well-documented maintenance WO is critical for a good maintenance performance, because it contains procedures and resources to complete the required tasks, and also the warnings about critical steps to avoid errors and dangerous situations. Commonly, the WO have drawings for technicians easily prepare and complete the tasks without errors but, often changes are applied on physical assets during their lifecycle, being original drawings far representations from the real scene. To overcome this problem WO must be available virtually, and ought be completed with 3D models and kept updated, [2]. Two industrial projects carried on military aeronautic industry, [3-4], attests that using updated 3D models the WO are easily created and maintained with a huge time savings.

AR is a technology that enrich real environment by superimposing virtual data on it, Fig. 1. There are a lot of variations of AR systems, starting by hardware: the virtual contents displayed, which may be 2D data or 3D models; the human-machine interaction (HMI); or even the way in which target locations are identified on a scene.

AR applied to industrial environments may looks like a utopia, but results from several projects, from different activity sectors like aerospace, automotive, defence and health show that $\mathrm{AR}$ achieves promising results and is a powerful technology to support technicians. Nevertheless, further developments on this subject will enhance its benefits.

About the equipment, while the first prototypes were limited in a major part by bulky and heavy systems a natural evolution occurs being available nowadays lightweight and portable devices. Developments keep going on hardware aiming to achieve fully wearable equipment suitable for AR systems. 


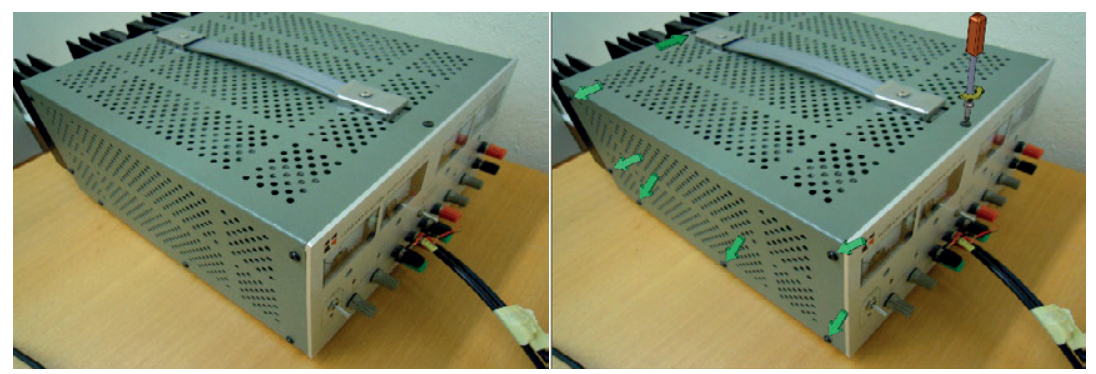

Fig. 1. (left) real environment; (right) AR environment in which instructions are superimposed and aligned with real environment

Similarly to the reutilization of $3 \mathrm{D}$ models to enhance the potential of AR on industrial maintenance sector, the AR system should be also connected to the Computer Maintenance Management System (CMMS), but at this point a huge restriction is the proprietary CMMS. Commonly, each manufacturer has their own CMMS being the communication with CMMS encrypted. However, it becomes to be common that CMMS make available the main fields of the main tables in an interface module, through Excel or similar, to share data with other systems.

But, the same is not yet possible at the level of on-condition modules, because there isn't available standard communication protocols. It is because of this that the protocols proposed by MIMOSA [5] are relevant.

The AR system ought to be connected to the general CMMS in all modules enlarging the application range of its potential.

Apart from integration with other systems, it will be noted on the projects review that physical assets' detection and tracking on non-laboratory environments is a challenging task, that's why whenever is allowed, the identification of parts is done based on AR markers. On the other hand, markers represent a restrictive and non-practical solution. For this reason the tracking subject is one of the most active subjects in terms of applied research on AR.

There are other publications that also address to a review of AR state of the art:

- The first one was published in 1997 [6] giving a definition of AR and summarizing works up to that time.

- More recently Zhou et al. [7] present an overview of papers submitted to ISMAR conference in a period of ten years. It is a scientific research oriented publication that resumes the most common techniques that were applied and most active research topics up to that date.

- Other survey, [8], is more focused on AR systems Human-Machine Interface (HMI) namely by differentiating display technologies and related equipment, like user interfaces; it also resumes several methods to track user movement and some applications of AR on different activity sectors.

- [9] besides the review being focused on construction engineering and architecture AR applications it presents AR software regularly used;
- $[10]$ conducted a survey on industrial AR - the author identified several AR projects that are related or may be applicable on industrial environments, distinguished by activity areas and evaluating if the projects have industrial applicability and their implementations stage (prototypes or final product).

It can be concluded that most projects were not user tested and industrial AR was not fully developed at that date.

The present paper presents a review of the most significant AR projects, mainly those that are related to manufacturing and maintenance environments, but besides being focused on HMI we focus on interfaces between the AR system with the maintenance network because it is expectable larger benefits as will be demonstrate.

Apart from introduction the paper is organized in four more sections:

- The following one describe the most relevant industrially-related AR projects supported by a timeline to easily compare the solutions used on each projects with the time they were developed;

- In section III is presented the main steps of an AR system and the solutions and methods available to each one;

- The up-coming solutions are presented in section IV for the reader get to know which alternatives are more probable to be available in a future;

- The final section is about conclusions of the paper.

\section{AR PROJECTS}

$\mathrm{AR}$ involves distinguished scientific topics like computer vision, HMI, 3D modelling, rendering, among others. The most active AR subjects in the terms of research were tracking, interaction and calibration, [7]. Nowadays, interaction remains to be one of the most active subjects motivated by introduction of tablets and smartphones as a single AR system user device. Additionally recognition and tracking subjects are also on top due the progress on 3D vision, namely depth sensors, and because it stills be a challenging task to identify the targets on real environments without engineering the scene.

Besides the first AR projects didn't came out of the lab, the results reached by them pointed to promising results and marked $\mathrm{AR}$ as a beneficial technology even for industrial 


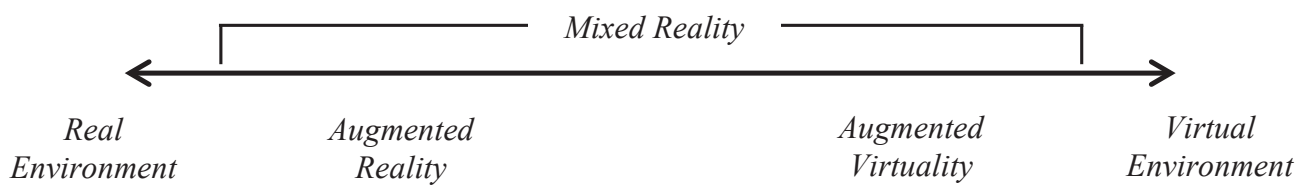

Fig. 2. Milgram's Virtuality Continuum [12]

environments if some technological constraints were suppressed. Those projects were and still being relevant to identify gaps and prospective directions for AR developments.

The KARMA project [11] was the first project conducted for maintenance applications using a see-through head mounted display to display instructions about how to perform a task on a printer. Markers were place on key components to determine in which pose instructions must be visually displayed.

In 1994 Milgram and Kishino [12] presented the "virtuality continuum" in which AR is part of Mixed Reality (MR) and is positioned on a diagram in comparison to real environment and virtual environments as exemplified on Fig. 2. Few years later Azuma [6] completed the definition of AR referring that a system to be considered as AR should:

- Combine real and virtual scenarios;

- Be interactive in real-time;

- $\quad$ And registered in 3D.

In automotive industry, a paper about a car door lock assembly using CAD data is presented in [13]; it reports to a specific task that require some preparation because the space to maneuver the door lock was very limited and hidden from the user. Additionally particular procedures must be done to complete the assembly process. To track the target part magnetic trackers were not used because their incompatibility with metal parts, that is the case of real car door. Because of that a visual tracking system with local markers were used to determine the pose of the door. Since a see-through Head Mounted Display (HMD) was used to display the augmented scenario the same markers used to track the car door were used to calibrate the HMD. The prototype was showed at an industrial fair and had attracted industrial partners to start planning a project to exploit industrial AR.

Klinker et al proposed a step-by-step maintenance interactive guide for nuclear power plant technicians to replace paper-based instructions, [14]. The same authors also referred other AR projects of industrial application, like a system to assist a skilled mechanic in disassembly procedures [15] and another two to support assembly task, [16, 17].

The year of 1999 is considered by the authors as a big start of AR developments. At that year it was published the first work [18] about what becomes to be the most popular open-source library for AR, the ARToolKit [19], which uses black and white markers (Fig. 3) to be easily detected on a scene and to determine the full pose of the target in order to present virtual data correctly aligned with the scene. In the same year had begun a succession of German funded projects, the ARVIKA project, [20,21] was the first one; from July 1999 to July 2003, it congregated relevant partners from automotive and aerospace industries and also technological centers aiming to develop AR solutions for industry, namely for maintenance and assembly tasks. The main topics of ARVIKA were improve:

- Systems interaction with speech recognition;

- The use of HMD as output devices;

- The development of a browser user interface framework;

- And the use of markers to identify target parts on real environments and to determine their pose in order to align virtual contents in the augmented scenario.

Besides several limitations, most of them related to technological developments and bulky hardware limited the portability of designed systems; a prototype named Intelligent Welding Gun was applied on real industrial environment; it uses reflective markers to estimate the pose of components on the scene, [22].

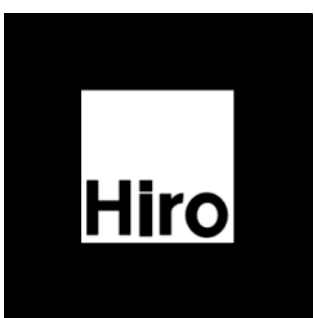

Fig. 3. Example of an ARToolkit marker

In February 2004 starts the Advanced Augmented Reality Technologies for Industrial Service Applications (ARTESAS) project with the main purpose of solving problems identified on ARVIKA, [23]. The AVILUS [24] and the AVILUSplus [25] were other two German funded projects descendant from ARTESAS that was developed almost in parallel. The main difference between those two projects was while the AVILUS was focused on industrial solutions the AVILUSplus was about researching and developing technologies that may be applied in industry some years later.

Meanwhile, other consortiums across Europe developed the industrial maintenance AR projects STARMATE and ULTRA; this project [26] was focused on development of an AR markerless maintenance guide system suitable to run on pocket 


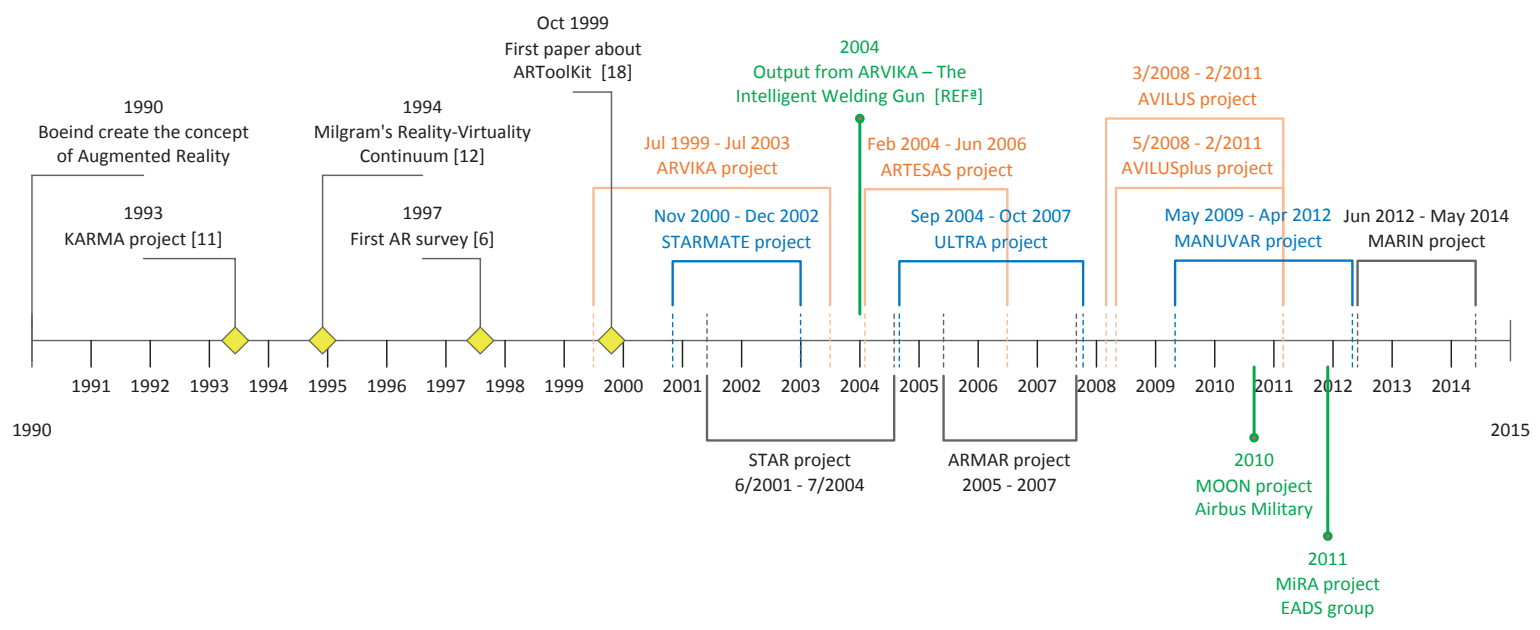

Fig. 4. Timeline of industrial AR projects

devices; in this case on a PDA. The STARMATE [27] achieved good results but was only validated on laboratorial environment. The system was prepared to rain complex maintenance tasks using two cameras and retro-reflective markers to track the targets. Despite the limitations ofSTARMATE system results were positive and AR was identified as a technology with a future potential for maintenance.

A transatlantic project name STAR (Service and Training through Augmented Reality) occurred from July 2001 to June 2004 congregated partners from Europe and USA to develop a system for online remote training and planning, according to [28]. The project aimed to evaluate the potential of the system for commercialization, [29].

To support maintenance interventions or assembly tasks on military/defence equipment two projects are known that explored such sectors. The ARMAR project [30] was about a maintenance system to assist technicians on repair sequences inside of and armored vehicle turret; it is a tracking system with ten cameras applied to track the user's head in order to indicate the location of target components using different AR output methods to evaluate the time spent on each method, [31]. Because the use of devices like a keyboard is limitative to the human interaction with AR system, ARMAR was managed through gestures recognition using a separate camera. In this project it was also evaluated the functionality of a specific Graphical User Interface (GUI) and the performance of gesture recognition algorithm for a vertical layout of virtual buttons

The second military project, named MOON [32], was conducted by AIRBUS Military in 2010 using data provided from the industrial Digital Mock-Up (iDMU) [3]. The system was designed to assist assembly operations by giving detailed instructions about procedures and rules. The results attested the capacity of AR to replace conventional paper based documentation and the benefit of a wireless system being possible to access information in the local where tasks must be done. At the same time it was verified the savings of reusing 3D information generated on previous stages; this point was already expected by other authors in [33].
The MiRA project was also conducted in EADS (European Aeronautic Defence and Space Company) group, but at this time the target were the civil airplanes A350 XWB and A380 in production lines. Even using markers MiRA was used to verify secondary structural brackets and pipes on airplanes fuselage. This system was extremely benefic allowing a minimization from 300 hours to 60 hours spent on checking those attributes and a reduction by $40 \%$ late discoveries of noncompliance; such results were published in [34].

The project ManuVAR begun in May 2009 - Manual Work Support throughout System Lifecycle by Exploiting Virtual and Augmented Reality focused on maintenance of railway sector. A consortium of 18 partners from eight European countries identified expert manual work as an expensive component of maintenance services, namely when an unpredicted failure state of a physical asset is identified and the most appropriate expert technician is not available on-site [35]; in this case it is necessary to wait until an expert reach the physical asset or contract extraordinary maintenance services nearby; both solutions increase the costs. The scope of ManuVAR was to develop an AR system to enhance the communication between remote experts and on-site workers [36]. Markers were also used on this project to identify target components once this solution is identified as a limitation being a markerless tracking system pointed as critical for introduction of AR in industrial scenarios.

Addressed to the shipbuilding industry, the MARIN (Mobile Augmented Reality Tool for Marine Industry) project purpose is to replace blueprint papers, which are often hard to handle and must be protected from rain and dust, by a mobile AR system that can store and display all the required information. The target applications for MARIN had as objective to show which equipment and where it should be installed and how to support surveys, providing intuitive information to easily check if installations are as planned, [37]. Tracking objects on such environment is a demanding task because interferences from illumination and dust are frequent. Another constraint comes when only steel walls are captured by the camera, because the lack of texture keypoints extraction and matching methodologies cannot be applied. 
Apart from these projects and referenced papers there are two other relevant marks for recent and future developments in AR that are the Kinect sale on November 2010 and the official SDK released on June 2011. Until these dates 3D Vision from depth sensors wasn't common because the high cost of required equipment. Kinect caused an extra enforce on developments based on point cloud, the use of depth data, and implicitly in 3D vision in general, being such technological solutions more affordable.

Significant developments are being made to approach AR and industrial environments; a proof is that in 2006, D. Willers from Airbus, presented several reasons about why AR failed in aircraft building industry [38] and few years later, in 2010 and 2011, two AR projects from EADS group were classified as a success, MOON and MiRA projects respectively.

Most relevant projects about maintenance and assembly operations are considered in this paper due the similarity of basic tasks of AR system, which are identifying target objects on the scene, tracking and determining their pose and present virtual instructions showing how to perform a task. On figure 6 it is presented a timeline with the same information of figure 4 but completed with papers considered relevant marks for the topic. There are additional papers addressing AR for industrial applications such as:

- $\quad$ Factory planning [39];

- An AR system for static scenes [40], with a huge potential for showrooms allowing a user to customize a product, being possible not only to change the color of the object but also to reproduce the light's shine on the augmented scenario in real time; or a training platform mainly for less skilled operators [41];

- $\quad$ Tang et al present a study comparing the effectiveness of performing the same with and without the support of an AR system, [42].

\section{AR's EQUIPMENT}

A critical specification of AR systems is the hardware, because it may happen that solutions stills being bulky, heavier and or have a few processing power for certain requirements, like faced on ARVIKA project [20]

Until a few time ago, a significant percentage of research were allocated to development of HMD [7], [9]. Nowadays, smartphones and tablets are leading the output device used because it is a mobile solution all-in-one; this kind of devices usually has integrated the following resources:

- Wireless connections;

- A camera;

- A touchscreen, that is simultaneously an input component and the output of visual data;

- A microphone and speaker;

- A reasonable processing power;

- Are lightweight and portable.
HMD may become again the most attractive output solution when wearable computing becomes competitive against tablets or smartphones.

The AR equipment will depend on environment and target object's characteristics; Fig. 5 represents the general process of an AR system with input and output hardware typically used. The calibration is mandatory step, followed by scene acquisition to get input data. Here the presence of texture, natural characteristics of target objects and illumination conditions will have a strong impact on decision about which hardware must be used. IMU and magnetic or electromagnetic sensors are a complement of the precedent ones to provide measurements with improved accuracy or to be combined with a single camera to reconstruct the scene. The reconstruction into a point cloud is an optional step that is mandatory if the use of depth data is chosen; a multi-camera approach also is applied for stereo vision purpose.

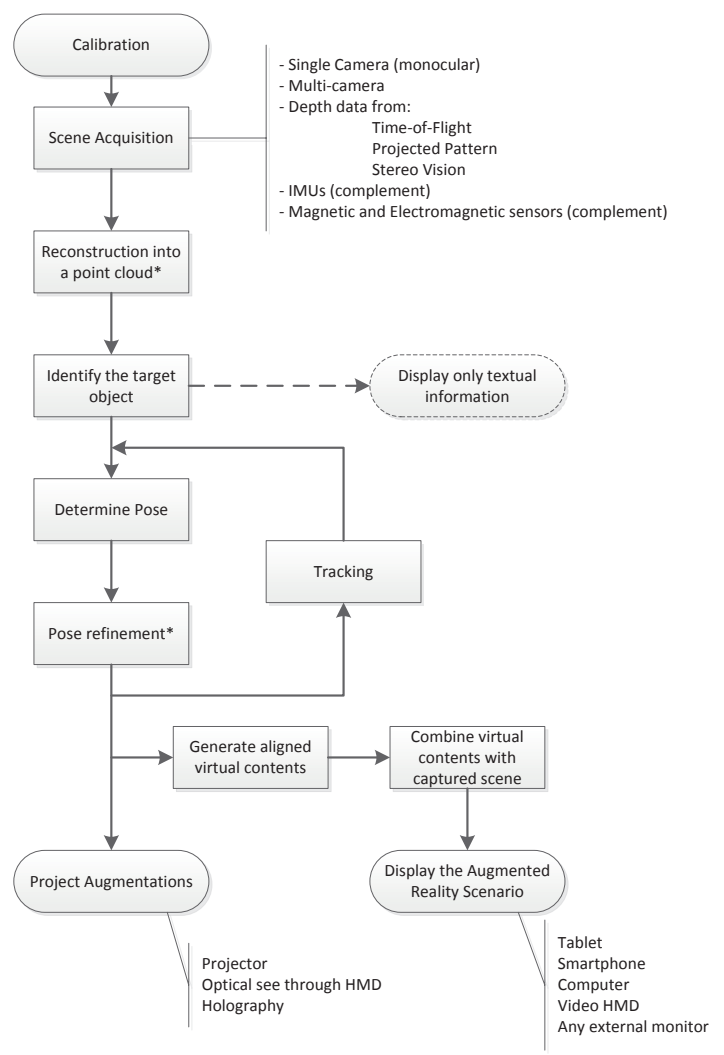

Fig. 5. AR General process

If the goal is just to present textual information, what is rare, a simple identification of the target object in the scene is sufficient; However, the full benefits from an AR system comes from displaying $3 \mathrm{D}$ animations indicating how to perform a task. In those cases it is necessary to determine the pose of the target, which is often refined by iterative methods, followed by tracking methods on sequenced images. The most delicate issue about tracking methods is the initialization, in which input measurements should be as close as possible to the real state. 


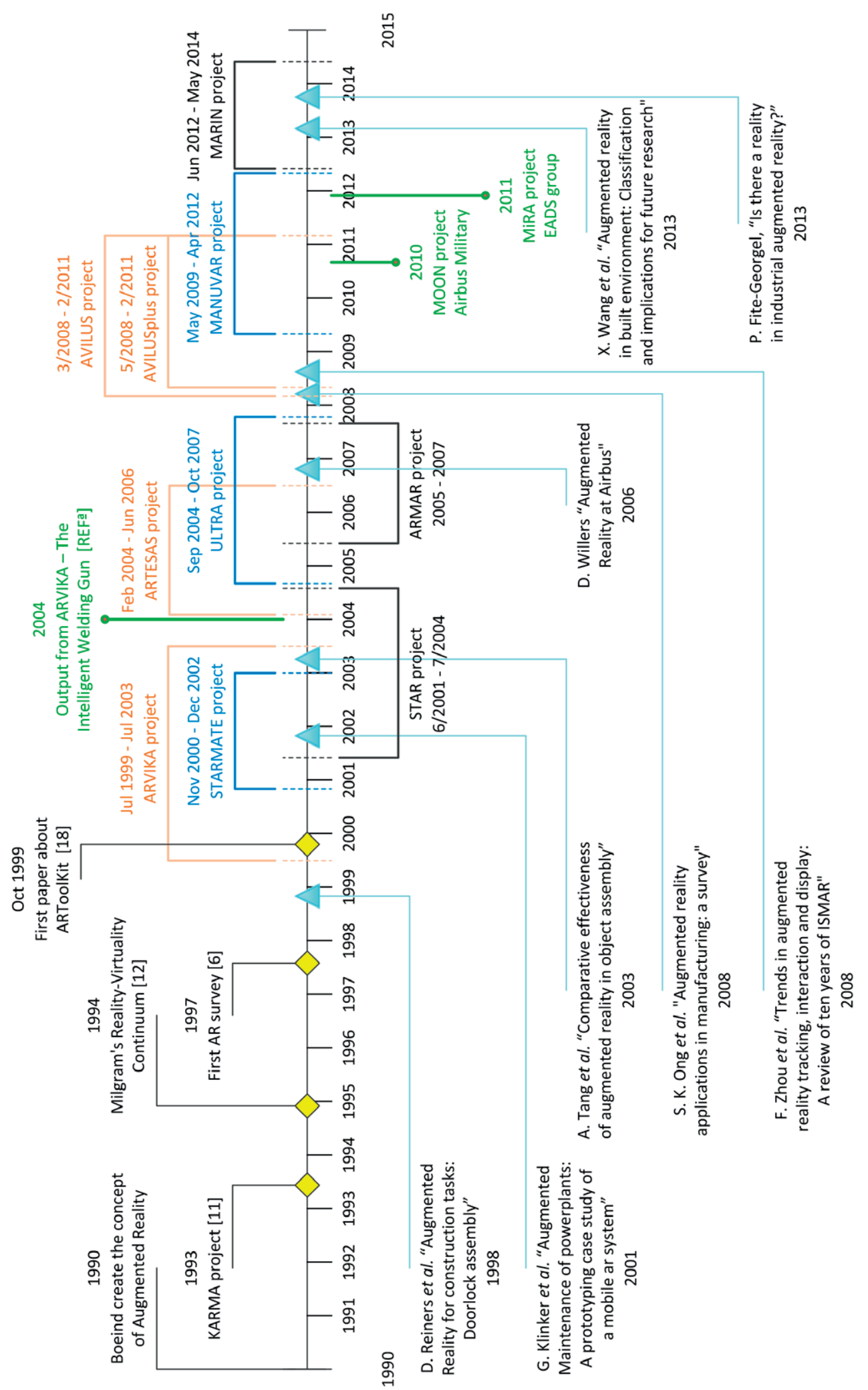

Fig. 6. Timeline of industrial AR projects with relevant papers published 
The final process of showing the virtual data superimposed in real scene is here divided in two groups:

- The first one named "Project Augmentations" where are represented technologies that only project the virtual information and don't need project the real environment. In such cases a calibration of output device is obligatory. Holography isn't yet available for this kind of applications but the authors consider that it will be accessible on future and thus holography is already classified.

- The other group present an image of the real scene combined with virtual data on a screen.

Doing a quick brief, the most suitable equipment for specific AR applications is chosen based on the following items:

- Budget;

- Scene characteristics;

- System's portability;

- On measurement's precision and reliability.

\section{UP-COMING SOLUTIONS}

It is difficult to describe very accurately what will the next AR solution or which equipment will be the most reliable for AR purposes; but, in general, it was identified an actual trend to 3D vision, namely the use of depth sensors and thus further improvements on point cloud works. A very interesting work on $3 \mathrm{D}$ reconstruction of scenes is presented by Whelan et al in [43]. GPU processing also represents one trend method with vast benefits for computer vision area and consequently for AR too.

About mobile devices it is a little bit harder to point which will be the next most used device; both smartphones and tablets are becoming more powerful in term of processing capacity and graphics. At the same time a new generation of laptops are already available which are the convertible laptops (all-in-one) that may be transformed on a tablet, being an alternative to these. Nevertheless, wearable computer with a HMD is an active research topic for a mid and long-term solutions.

So far, the AR systems implemented on industrial facilities are a unique solution for specific tasks and don't communicate with the remaining maintenance infrastructure. This is a very sensitive topic that, for sure, will enlarge the applicability of AR, using a mobile device not only to receive instructions about how to perform a task but also to report the conclusion of a task or even to report faults.

The identification of target parts stills be a high priority concern since the global effectiveness of the AR system depends directly on it. Currently, the authors are working on this topic in order to develop a system to detect and track robustly the targets based on their natural features, like shape and texture.

\section{CONCLUSIONS}

There are several AR solutions available and adequate for training environments but to a generic markerless solution to be applied on open environments is not yet available, mainly because the interferences on computer vision sub-system which is, nowadays, the most critical part of an AR system.

Nevertheless, for pre-defined operations, it was proved that the use of AR is benefic because, in general, the same task is done in less time, are committed less errors and the quality is improved. For small companies AR isn't affordable yet, but for the bigger ones where the same tasks are performed many times it is profitable. Additionally, for critical services, like aeronautic sector or in nuclear power plants, in which safety is a major concern and all the work is done using drawings and checklists, AR have potential to improve the results.

Industrial AR is a long journey that is only in the beginning but new methods must be tested to verify their benefits and gaps that must be solved by future solutions.

The objective of the survey presented in the paper is to have a state-of-the-art that can be used to briefly identify previous projects, their results, technologies available at the time and to find the most relevant publications on industrial AR related to the subjects of maintenance in order to find practical examples to support the evaluation of using AR, and also to easily identify gaps to be overcome with new research projects.

\section{ACKNOWLEDGMENT}

This work was supported by a grant from Fundação para a Ciência e a Tecnologia - FCT by contract SFRH/BD/86816/2012.

\section{REFERENCES}

[1] D. Sims, "New realities in aircraft design and manufacture," Computer Graphics and Applications, IEEE, vol. 14, no. 2, pp. 91-, March 1994

[2] R. Oliveira, T. Farinha, S. Singh, and D. Galar, "An augmented reality application to support maintenance - is it possible?" in Proc. Maintenance Performance Measurement and Management (MPMM) 2013 2013, pp. 260-271. [Online]. Available: https://online.unileoben.ac.at/mu_online/voe_main2.getVollText?pDocumentNr=142932\&pCurrPk=32372

[3] F. Mas, J. L. Menéndez, J. Serván, A. Gómez, and J. Ríos, "Aerospace industrial digital mock-up exploitation to generate assembly shop floor documentation," in 29th Intl. Manufacturing Conference (IMC29), Belfast, 2012.

[4] J. Serván, J. M. Rubio, F. Mas, A. Gómez, and J. Ríos, “Augmented reality using laser projection for the airbus a400m wing assembly," in 29th Intl. Manufacturing Conference (IMC29), 2012, pp. 154-162.

[5] Mimosa - an operations and maintenance information open system alliance. [Online]. Available: http://www.mimosa.org/

[6] R. T. Azuma, "A survey of augmented reality," Presence: Teleoperators and Virtual Environments, vol. 6, no. 4, pp. 355-385, Aug. 1997.

[7] F. Zhou, H.-L. Duh, and M. Billinghurst, "Trends in augmented reality tracking, interaction and display: A review of ten years of ismar," in Mixed and Augmented Reality, 2008. ISMAR 2008. 7th IEEE/ACM International Symposium on, Sept 2008, pp. 193-202.

[8] D. W. F. van Krevelen and R. Poelman, "A Survey of Augmented Reality Technologies, Applications and Limitations," The International Journal of Virtual Reality, vol. 9, no. 2, pp. 1-20, Jun. 2010.

[9] X. Wang, M. J. Kim, P. E. Love, and S.-C. Kang, "Augmented reality in built environment: Classification and implications for future research," Automation in Construction, vol. 32, no. 0, pp. $1-13,2013$. [Online]. Available: http://www.sciencedirect.com/science/article/pii/S0926580512002166

[10] P. Fite-Georgel, "Is there a reality in industrial augmented reality?" in Mixed and Augmented Reality (ISMAR), 2011 10th IEEE International Symposium on, Oct 2011, pp. 201-210. 
[11] S. Feiner, B. Macintyre, and D. Seligmann, "Knowledge-based augmented reality," Commun. ACM, vol. 36, no. 7, pp. 53-62, Jul. 1993. [Online]. Available: http://doi.acm.org/10.1145/159544.159587

[12] P. Milgram and F. Kishino, "A Taxonomy of Mixed Reality Visual Displays," IEICE Transactions on Information Systems, vol. E77-D, no. 12, pp 1321-1329, Dec. 1994.

[13] D. Reiners, D. Stricker, G. Klinker, and S. Müller, "Augmented reality for construction tasks: Doorlock assembly," in Proceedings of the International Workshop on Augmented Reality : Placing Artificial Objects in Real Scenes: Placing Artificial Objects in Real Scenes, ser. IWAR '98. Natick, MA, USA: A. K. Peters, Ltd., 1999, pp. 31-46. [Online]. Available: http://dl.acm.org/citation.cfm?id=322690.322694

[14] G. Klinker, O. Creighton, A. H. Dutoit, R. Kobylinski, C. Vilsmeier, and B. Brugge, "Augmented maintenance of powerplants: a prototyping case study of a mobile ar system," in Augmented Reality, 2001. Proceedings. IEEE and ACM International Symposium on, 2001, pp. 124-133.

[15] D. Curtis, C. Esposito, P. Gruenbaum, A. Janin, and D. Mizell, "The boeing portable maintenance aide," in Demonstration at the 1st International Symposium on Augmented Reality (ISAR'00), Munich, Oct 2000.

[16] D. Curtis, D. Mizell, P. Gruenbaum, and A. Janin, "Several devils in the details: Making an ar app work in the airplane factory," in Augmented Reality-Placing Artificial Objects in a Real Scene, R. Behringer, G. Klinker, and D. Mizell, Eds. A.K. Peters, 1999, pp. 47-60.

[17] J. Molineros, V. Raghavan, and R. Sharma, "AREAS: Augmented Reality for Evaluating Assembly Sequences," in Augmented Reality-Placing Artificial Objects in a Real Scene, R. Behringer, G. Klinker, and D. Mizell, Eds. A.K. Peters, 1999, pp. 91-99.

[18] H. Kato and M. Billinghurst, "Marker tracking and hmd calibration for a video-based augmented reality conferencing system," in Augmented Reality, 1999. (IWAR '99) Proceedings. 2nd IEEE and ACM International Workshop on, 1999, pp. 85-94.

[19] ARToolKit. [Online]. Available: http://www.hitl.washington.edu/artoolkit/

[20] J. Weidenhausen, C. Knoepfle, and D. Stricker, "Lessons learned on the way to industrial augmented reality applications, a retrospective on ARVIKA," Computers and Graphics, vol. 27, no. 6, pp. 887-889, December 2003.

[21] W. Friedrich, "Arvika - augmented reality for development, production and service," in 1st International Symposium on Mixed and Augmented Reality (ISMAR '02), I. C. Society, Ed., 2002, pp. 3-4.

[22] F. Echtler, F. Sturm, K. Kindermann, G. Klinker, J. Stilla, J. Trilk, and H. Najafi, "EnglishThe intelligent welding gun: Augmented reality for experimental vehicle construction," in EnglishVirtual and Augmented Reality Applications in Manufacturing, S. Ong and A. Nee, Eds. Springer London, 2004, pp. 333-360.

[23] Artesas - advanced augmented reality technologies for industrial service applications. [Online]. Available: http://edok01.tib.uni-hannover.de/edoks/e01 fb07/551471905.pdf

[24] Avilus - angewandte virtuelle technologien im produkt-und produktionsmittel-lebenszyklus. [Online]. Available: http://www.vdtc.de/content/dam/iff/vdtc/de/dokumente/avilus-vr-fuer-

produktmittellebenszyklus.pdf

[25] Avilusplus - angewandte virtuelle technologien mit langfristfokus auf den produkt- und produktionsmittel-lebenszyklus. [Online]. Available: http://www.avilusplus.de/

[26] P. Riess, D. Sticker, G. Voss, and W. Mueller-Witting, "ULTRA Ultra Portable Augmented Reality for Industrial Maintenance Applications," CG Topics, vol. 6, pp. 16-18, 2006. [Online]. Available: http://portal.hsweingarten.de/c/document_library/get_file?uuid=fd9b2146-ea78-4467-b96e5 eb14dc8ed08\&groupId $=26000$

[27] B. Schwald and B. de Laval, "An augmented reality system for training and assistance to maintenance in the industrial context," WSCG, vol. 11, no. 1, pp. 3-7, 2003.
[28] S. K. Ong, M. L. Yuan, and A. Y. C. Nee, "Augmented reality applications in manufacturing: a survey," International Journal of Production Research, vol. 46, no. 10, pp. 2707-2742, 2008. [Online]. Available: http://dx.doi.org/10.1080/00207540601064773

[29] A. Raczynski and P. Gussmann, "Services and training through augmented reality," in Visual Media Production, 2004. (CVMP). 1st European Conference on, March 2004, pp. 263-271.

[30] (2013) Armar project webpage. [Online]. Available: http://graphics.cs.columbia.edu/projects/armar/index.htm

[31] S. Henderson and S. Feiner, "Exploring the benefits of augmented reality documentation for maintenance and repair,"Visualization and Computer Graphics, IEEE Transactions on, vol. 17, no. 10, pp. 1355-1368, Oct 2011.

[32] J. Serván, F. Mas, J. L. Menéndez, and J. Ríos, "Using augmented reality in airbus a $400 \mathrm{~m}$ shop floor assembly work instructions," AIP Conference Proceedings, vol. 1431, no. 1, pp. 633-640, 2012. [Online]. Available: http://scitation.aip.org/content/aip/proceeding/aipcp/10.1063/1.4707618

[33] J. T. Farinha, R. Oliveira, I. Fonseca, and L. A. Ferreira, "Technical asset management beyond tomorrow," in Electronic Proceedinds of The 2nd World Maintenance Forum, Lugano, Switzerland, Sept. 2013.

[34] EADS, "EADS 2011 Coporate Responsability \& Sustainability Report,” EADS, Tech. Rep., 2011.

[35] M. Leva, A. M. Kay, T. Smith, A. Diez, J. Azpiazu, P. Liston, and S. Cromie, "The use of augmented reality to support maintenance: Human factors issues and advantages," in Irish Ergonomics Society Annual Conference 2011, L. W. O’Sullivan and C. Leva, Eds., 2011, pp. 37 - 47.

[36] J. Azpiazu, S. Siltanen, P. Multanen, A. Mäkiranta, N. Barrena, A. Díez, J. Agirre, and T. Smith, "Remote support for maintenance tasks by the use of Augmented Reality: the ManuVAR," in CARVI 2011: IX Congress on virtual reality applications, Spain, Nov 2011.

[37] J.-P. Arimaa, R. Suominen, A. Euranto, O. Lahdenoja, T. Knuutila, and T. Lehtonen, "Tracking and integration aspects of a mobile augmented reality tool for shipbuilding," in EEE ISMAR 2013 Joint Workshop on Tracking Methods \& Applications and TrakMark, Adelaide, Australia, Oct 2013.

[38] D. Willers, "Augmented reality at airbus," in International Symposium on Mixed \& Augmented Reality 2006, 2006. [Online]. Available: http://ismar2006.vgtc.org/images/3a-airbus.pdf

[39] K. Pentenrieder, C. Bade, F. Doil, and P. Meier, "Augmented reality-based factory planning - an application tailored to industrial needs," in 6th IEEE and ACM International Symposium on Mixed and Augmented Reality, ser. ISMAR '07. Washington, DC, USA: IEEE Computer Society, 2007, pp. 19. [Online]. Available: http://dx.doi.org/10.1109/ISMAR.2007.4538822

[40] G. Gay-Bellile, S. Bourgeois, M. Tamaazousti, S. Naudet-Collette, and S. Knodel, "A mobile markerless augmented reality system for the automotive field," in IEEE ISMAR 2012 Workshop on Tracking Methods and Applications, 2012.

[41] S. Webel, U. Bockholt, T. Engelke, N. Gavish, M. Olbrich, and C. Preusche, "An augmented reality training platform for assembly and maintenance skills," Robotics and Autonomous Systems, vol. 61, no. 4, pp. 398 - 403, 2013, <ce:title>Models and Technologies for Multi-modal Skill Training</ce:title>. [Online]. Available: http:/www.sciencedirect.com/science/article/pii/S0921889012001674

[42] A. Tang, C. Owen, F. Biocca, and W. Mou, "Comparative effectiveness of augmented reality in object assembly," in Proceedings of the SIGCHI Conference on Human Factors in Computing Systems, ser. CHI '03. New York, NY, USA: ACM, 2003, pp. 73-80. [Online]. Available: http://doi.acm.org/10.1145/642611.642626

[43] T. Whelan, M. Kaess, J. Leonard, and J. McDonald, "Deformationbased loop closure for large scale dense rgb-d slam," in Intelligent Robots and Systems (IROS), 2013 IEEE/RSJ International Conference on, Nov 2013, pp. $548-555$. 


\title{
Maintenance Support Wireless System for Ram of Forming Presses
}

\author{
Diego Salazar ${ }^{1}$; Gerardo Glorioso ${ }^{2}$; Markus Wabner ${ }^{3}$; Martin Riedel $^{4}$ \\ 1. \\ ${ }^{4}$ martin.riedel@imc-berlin.de \\ 1,2 Advantic Sistemas y Servicios SL \\ Madrid, Spain \\ ${ }^{3}$ Fraunhofer Institute for Machine Tools and Forming Technology \\ Chemnitz, Germany \\ ${ }^{4}$ imc Meßsysteme GmbH \\ Berlin, Germany
}

\begin{abstract}
In the paper, an innovative wireless system for press ram stress monitoring will be presented as component of a decision support system for predictive maintenance. This system involves low power consumption wireless nodes and energy harvesting techniques to gain autonomy for the whole solution. The monitoring systems output signals serve to extract and generate "virtual sensor" signals. These represent actual load and stress situations on locations that are crucial for machine stability but are inaccessible for real measurement or even buried inside the frame structure. In addition, the monitoring system is embedded into a networked environment of an e-maintenance cloud, linking a variety of information sources like enterprise resource planning.
\end{abstract}

Keywords - condition monitoring, maintenance, forming, fatigue, simulation, wireless.

\section{INTRODUCTION}

Breakages at highly stressed components of forming presses like frame, crown, table, and plunger often cause very high direct and indirect costs for the machine owner. To prevent or minimize this, the monitoring of mechanical stresses is a very important field of research. Although the facility manufacturers are trying to prevent crack formation by oversizing of highly stressed parts, the high number of failure cases high-lights the relevance of this problem. An example of a repaired fatigue breakage of a press crown is shown in Fig. 1.

A promising approach to solve this problem is the monitoring and evaluation of stresses in production presses and its embedment into a preventive maintenance strategy. To reach this goal, three main challenges have to be solved:

- development and integration of embedded in-formation devices with data pre-processing capabilities in order to capture relevant information like loads, strains and stresses

- definition of new algorithms and techniques in order to provide intelligent data processing and knowledge extraction from production equipment
- development of reliability \& maintainability de-sign practices/methods to predict and assess the availability of equipment already at an early de-sign stage

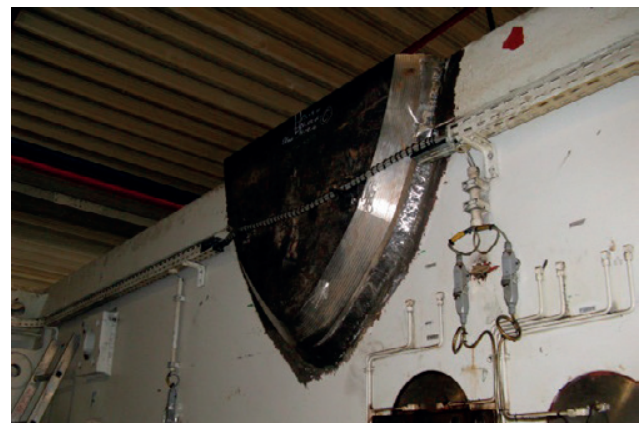

Fig. 1. Repaired fatigue breakage at a press

A basic technology - the monitoring of mechanical stresses - actually is not applied to industrial forming machines, but is well-known from a number of different industries. One important example is the ship building industry, where the strain of ship hulls [1-2] and motor shafts is measured. Also concrete buildings are equipped with strain sensors in order to obtain data concerning their structural health [3]. But the direct measurement of strains or stresses can be done only locally and at the previously identified critical places. The estimation of the stresses in the whole geometry corresponds with the need of a high number of sensors or relatively uniform stress gradients that allow a mathematical description of the nonsensored areas. That's why - on the one hand - it is done mostly on relatively simple geometries like bars, drive shafts or plates.

In conclusion, the stress monitoring in forming presses with its complex mechanical structures like welded parts or ribbed frame components and under varying load conditions is a core challenge of the project. The reasons are the partial inaccessibility of the required measurement locations, the high number of potential fracture critical locations and their dependence on varying load conditions based on the ram stroke or tool geometry. 
On the other hand, mostly fatigue breakages are the reasons for press breakages, while static overloads normally can be avoided by overload protection units.

The common strategy to avoid fatigue breakages is to operate forming machines below the fatigue limits. These limits are estimated by static simulations (e.g. finite element methods) during the design stage, based on pre-defined load scenarios. But in practice the high numbers of breakages show that not every critical load scenario can be considered during design stage, not least because of the unknown future production spectrum and the resulting real loads.

To learn more about real mechanical loadings and the reasons of breakages, and to minimize future failures in forming presses, in the iMAIN project a novel stress and condition monitoring system is in development, embedded into a cloud-based maintenance concept. In chapter 2 this overall concept will be introduced and in the following chapter 3 the Wireless system concept will be explained.

\section{IMAIN SYSTEM CONCEPT}

To address the maintenance challenges listed above, a novel concept has been developed, that is based on intelligent information agents. These agents combine different data and information sources like control-inherent sensors, additional real sensors and model-based virtual sensors, that allow continuous, real time, remote, and distributed monitoring and analyzing of forming machinery. The chosen approach to get knowledge from data and information is planned to be demonstrated on forming machines, but can be applied also to other industries with highly and dynamically loaded systems, e.g. power plants, transportation sectors or aircraft industries.

The prediction of the remaining service life, as one of the core challenges of the project, needs information about the actual deterioration of components (deterioration history) and about future load scenarios. The deterioration is estimated by the monitoring of maxi-mum strain or stress values of every forming cycle under real process loads and its accumulation during the life cycle via cumulative damage hypotheses. For this, a load and deterioration history has to be stored, covering the whole lifecycle of the forming equipment.

Considering the challenges in stress monitoring, a special approach - the so-called "virtual sensor technology" - has been developed (Fig. 2). It extends the information of a limited number of real sensors (especially strain gauges and force sensors) by additional virtual sensor signals that are processed in real-time. These "live" calculations continuously derive how stress on virtual locations is determined by signals from the surrounding real sensors. The respective models that represent these relationships are developed by reduced-order finite elements (FE) models. This allows the observation of all potentially critical points of the press mechanics with minimized effort and even over-coming physical limitations. The crucial calculations are implemented as a part of the embedded condition \& energy monitoring system (ECEM system). Stress monitoring on both real and virtual sensors together with the assessment of a wide variety of additional machine related sensors and data contributes to building an extensive history of machine life. The so-called Smart Service Life Prediction (SSLP) system will then combine data from load and deterioration history as well as actual sensor and production planning information and allow for intelligent and predictive maintenance strategies.

Based on the functionalities described above, such a monitoring and maintenance system consists of a number of distributed components that are networked for close cooperation (Fig. 3). These are:

- press machines to be monitored, which are each

- associated with an ECEM system, including a SSLP system

- multiple machines/ECEM

The ECEM systems are typically installed in close proximity to the associated machine. Such units in turn are distributed over a wide area industrial installation that can extend across a single facility or company and even across multiple sites, industrial entities, companies and even countries. The overarching networking structure of this setup is called the "eMaintenance Cloud". It provides mechanisms and services to allow multiple clients to participate in the condition monitoring process. These clients can be:

- data center providing IT infrastructure, processing services and database information

- monitoring operators

- press manufacturer

- scientific experts

While operators typically control the process and selected machines in an interactive or automated way, manufacturers and scientific experts can also contribute in adding additional information and input in order to optimize the process.

\section{FUNCTIONALITY AND STRUCTURE OF THE WIRELESS SYSTEM}

The wireless network that has been thought for inter-facing with the ECEM system is intended for capturing temperature from the moving slide since this parameter has a direct relation with excessive friction due to its misalignment.

The press operation scenario considered in this case is a press' running mode of 30 cycles per minute with a working period of 16 hours/day during 5 days per week (Monday to Friday). Moreover, a photovoltaic (PV) system was dimensioned in order to supply the wireless sensor nodes.

The system proposed comprises the wireless monitoring system with 4 "sensor nodes" that measure the temperature of each linear guiding rail. For this purpose, each sensor node should be able to measure two temperature points and send the information to the remote network system gateway. Furthermore, each wireless sensor node should be autonomous. 


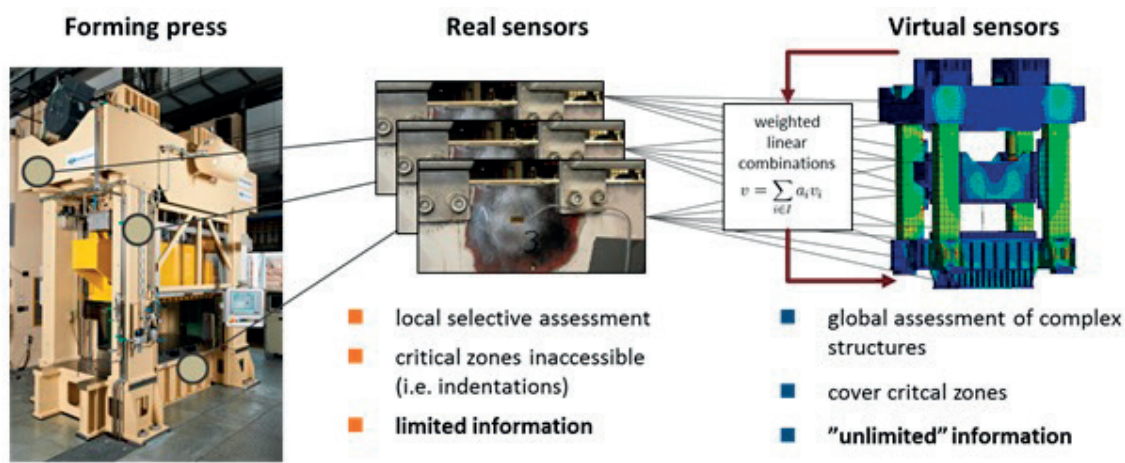

Fig. 2. Principle of using virtual sensor technology

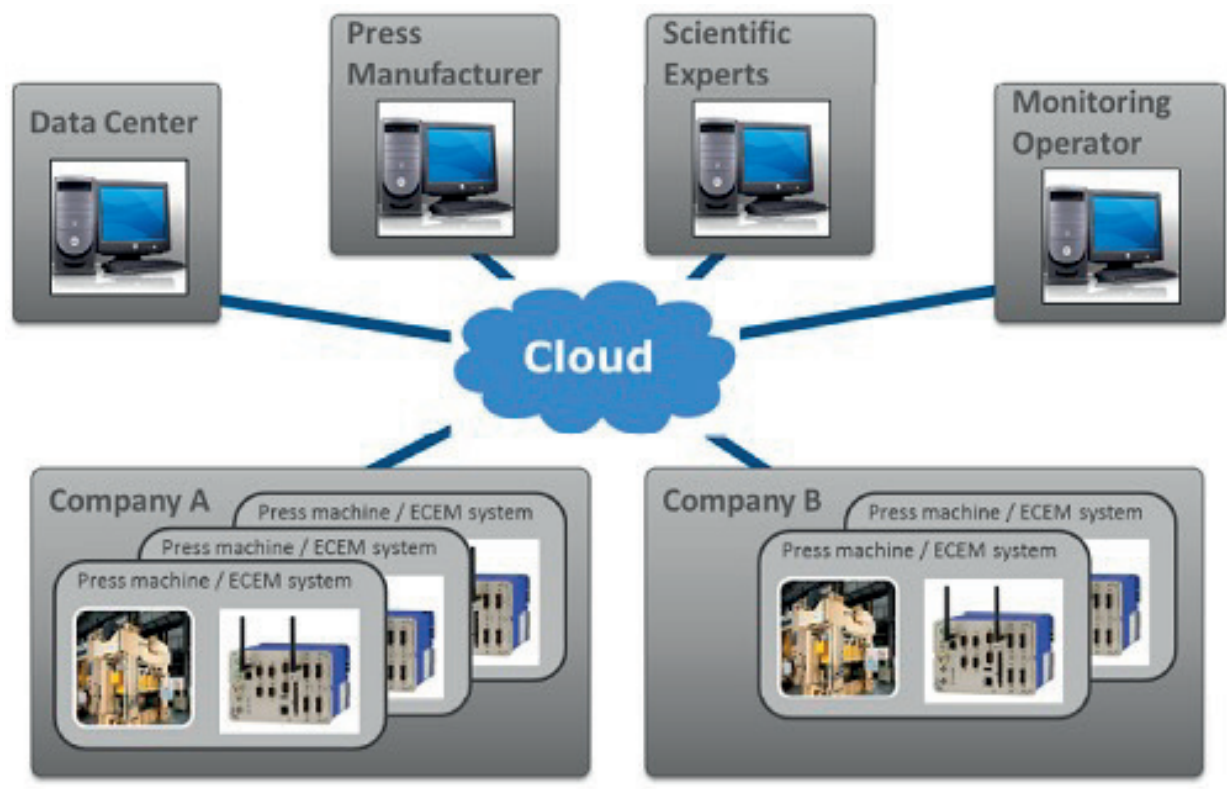

Fig. 3. Distributed condition monitoring environment

Therefore, in order to fulfil this aim, a mixed power supply system based on batteries and energy harvesting technologies is developed. Following the low power requirement, during the "ON mode" the sensor nodes are able to send frames to the data collector upon request. If there are no requests during this mode, the Sleep mode is set up.

Since the sensor node cannot identify when the press operation cycle begins, an automatic start up system by detecting movement in the press is implemented. The movement detection system consists of a high-sensitivity accelerometer that turns on the node when a press movement is detected.

\section{A. System's blocks}

The monitoring system is divided in the following functional blocks (Fig. 4):

- Power system
- Wireless Sensor node

- Wireless communication bridge

- Data collector and communication gateway

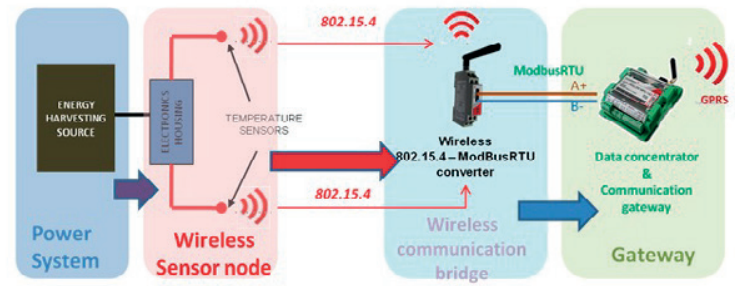

Fig. 4. Wireless system blocks

The power system is composed by an energy harvesting module based on a high-capacity capacitor. It is powered with 
a solar panel that recollects energy from the ambience light. Moreover, for ensuring that the wireless sensor node is able to work in case of insufficient light conditions it was also included a high-capacity battery. Using both energy sources it is possible to ensure a wireless sensor node life cycle up to a year. Moreover as an energy saving task, during the nonoperation period two low consumption modes can be set up in the wireless sensor nodes: low-power mode $(\sim \mathrm{uA})$ and ultra low-power mode $(\sim \mathrm{nA})$.

The Wireless Sensor node is an IEEE 802.15.4 compliant wireless sensor node based on the original open-source "TelosB" platform design developed and published by the University of California, Berkeley ("UC Berkeley"). The node has the following general characteristics:

- IEEE 802.15.4 WSN platform

- $\quad$ TI MSP430F1611 Microcontroller

- $\quad$ TI CC2420 Radio Transceiver

- $\quad$ TinyOS 2.x \& ContikiOS Compatible

- Temperature, Humidity, Light sensors

- User \& Reset Buttons

- $3 x$ Leds

- USB Interface

- 2xAA Battery Holder

In order to transmit the information collected by the wireless sensor nodes to the communication gateway, wireless 802.15.4 to Modbus RTU is used. The selected device is the Advanticsys ${ }^{\circledR}$ DM-124 wireless communication bridge. The main function is to collect all the data sent by the wireless sensor nodes and transmit them automatically to the central gateway, which is in charge of the data and energy saving management, so the mote life cycle is optimized. Moreover, due to the use of the DM124 device it is possible to reduce the amount of cables needed in RS485 installations by bridging devices through IEEE 802.15.4 based wireless networks. This provides legacy industrial installations the versatility and ease of deployment of wireless sensor networks (WSN).

Finally, an Advanticsys ${ }^{\circledR}$ controller MPC product line is used as data collector. It is mainly in charge of managing the information from the wireless sensor nodes and the integration with the iMain platform.

\section{B. Operation}

The temperature reached in the press linear guides must be supported by the wireless sensor node. According to the press documentation, the temperature range of this part of the press is from 0 degrees up to 250 degrees. The response time is also a revelant aspect as this parameter has influence on the "ON" time of the node (if the response time is big we have to power it more time to have a valid measure).

In order to achieve the aim of monitoring the press temperature during working cycles, it has been defined a system prototype according to the measurement requirements (Fig. 5). During the press working cycle the sensor node is switching from the $\mathrm{ON}$ mode to the Low-Power mode alternatively. In the low power mode, when the T Threshold is reached, the node turns to Ultra-Low-Power mode and all the electronics power down except the energy harvesting module and the wake up accelerometer, which is the responsible of switching on the sensor node when motion is detected or several samples without motion are detected (time of inactivity, this is to avoid that the node never wakes up again in case of failure). In the next $\mathrm{ON}$ mode, all the peripheral should be initiated again (microcontroller, RF transceiver, accelerometer, RTC, flash memory, etc.).

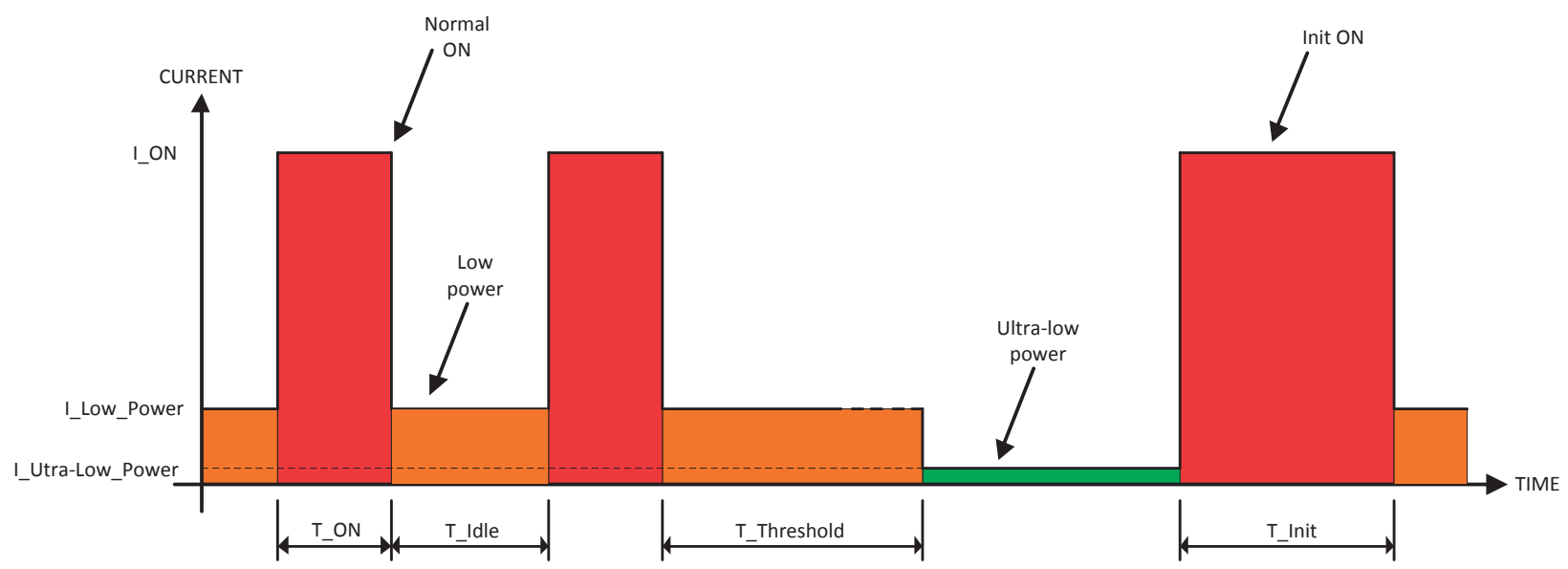

Fig. 5. . Continuous- operation Software/Hardware cycle 


\section{CONCLUSIONS}

Frequent occurrences of fatigue fractures and failures of forming machines have motivated the development of a novel strategy for stress monitoring and predictive maintenance of high-loaded mechanical components. The smart combination of advanced monitoring and knowledge-generation approaches like the virtual sensor technology, life cycle histories or the merging of location independent information sources requires the development of new IT infrastructures. In the paper, the high-level structure of such a system has been presented along with the concept of a wireless system for data acquisition. This structure will be the base of an advanced and modular condition monitoring and maintenance system for forming machines as well as other highly stressed systems from different industries.

\section{ACKNOWLEDGMENT}

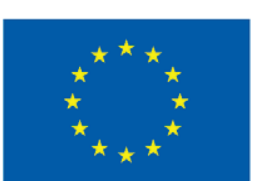

The project has received funding from the European Community's Seventh Framework Programme (FP7/20072013) under grant agreement number 314304 - the iMAIN project.

\section{REFERENCES}

[1] Wang, et al (2001) "Ship hull structure monitoring using fibre optic sensors", in Smart Materials and Structures Vol.10, pp.472-478.

[2] Masterson \& Frederking (1993) "Local contact pressures in ship/ice and structure/ice interactions", in Cold Regions Science and Technology Vol. 21, pp.169-185.

[3] Cumunel et al (2012) "Long-gage optical fiber extensometers for dynamic evaluation of structures", in Sensors and Actuators Vol.184, pp.1-15. 
(Página deixada propositadamente em branco) 


\title{
Maintenance Management in Web ASP.NET MVC Applications
}

\author{
Francisco Rodrigues ${ }^{1}$; Inácio Fonseca ${ }^{2}$; Rúben Oliveira ${ }^{3}$, José Torres Farinha ${ }^{4}$ \\ ${ }^{1}$ franciscocardos0@hotmail.com; ${ }^{2}$ inacio@isec.pt; ${ }^{3}$ ruben.oliveira@dem.uc.pt; ${ }^{4}$ torres.farinha@dem.uc.pt \\ ${ }^{1,2}$ Instituto Superior de Engenharia de Coimbra \\ Coimbra, Portugal \\ ${ }^{3,4}$ Centre for Mechanical Engineering of the University of Coimbra - CEMUC \\ Coimbra, Portugal
}

\begin{abstract}
Maintenance presents itself as one of the key factors for increasing the productivity of companies. Its importance is increasingly recognized due to the need for greater efficiency in the management of physical assets and resources that are associated with it, thus avoiding unnecessary costs.

This article presents a management system to support maintenance management, which is being developed, named GESP, designed with the help of ASP.NET MVC Web program, which transacts the data through a base data developed in SQL. This system intends to perform inventory management, human resources outsourcing (subcontracting) and maintenance of the activity itself. The differentiating feature of this tool stems from its ability to measure in real time variables of control (hours, kilometer...) of physical assets and the ability to automatically schedule working orders, even taking into account the physical structure of the active targeted for intervention.
\end{abstract}

Keywords-Maintenance management; Stocks management; Maintenance resources; Outsourcing; CMMS.

\section{INTRODUCTION}

Maintenance presents itself today as one of the primary factors that contribute to the productivity of enterprises. Its importance is recognized because the aim for greater efficiency in resource management, thus avoiding unnecessary expenditure of funds.

Maintenance management is an arduous task that involves human resource management, physical assets, including stocks, and yet, when applicable, the management of subcontracted services. All of this should be done in harmony with the production sector to minimize the losses caused by the stoppage of production. However, it is impossible to predict all the failures in physical assets, being mandatory some unplanned interventions, forcing sometimes a re-schedule of previously planned maintenance interventions.

Mainly in large organizations, the maintenance cannot be only focus on an expert, existing systems that store and keep updated detailed information about the overall physical assets of an organization. The systems commercially available are differentiated by their ability to share information with different departments of the organization, data collection, data management, including artificial intelligence applied in several processes, giving to the maintenance manager a set of information in order to improve the efficiency of maintenance management.
Considering all the precedent characteristics, this paper presents a tool, which stills under development, to support maintenance management encompassing stock management, human resources outsourcing (subcontracting) and own maintenance activity, scheduling maintenance events and classifying them according to their AFNOR standards, [1]. Current system version is being designed in ASP.NET MVC Web [2] linked to a model database in SQL [3]. This system has the peculiarity to communicate in real time with the physical assets in order to check their variables of control (hours of work, kilometers...), analyze them and so prescheduling its planned maintenance interventions. It is mainly useful for non-periodic / aperiodic interventions.

The paper is structured as follows:

- Chapter two is the approach to programming in ASP.NET MVC C\#;

- Chapter three, maintenance data management, presents a general approach to manage data maintenance, including the following items:

○ The permissions system;

- The technological decomposition;

- The management of planned maintenance;

○ The stock management;

○ The scheduling of working orders (WO);

- Analysis of the history;

- Classification of the maintenance tasks.

- Chapter four presents the GESP application;

- Chapter five defines future development application for GESP;

- The chapter six presents the conclusions and finally;

\section{APPROACH TO PROGRAMMING IN ASP.NET MVC C\#}

The GESP system is developed in ASP.NET [2] which is a Microsoft's platform for developing Web applications. It is a component of IIS (Internet Information Services) that allows, through an integrated programming language in the .NET Framework to create dynamic pages. ASP.NET is based on NET Framework [4], which inherits the features of .NET application. The platform offers advantages such as the development of the following applications: 
- The code is written in several languages, in this case the GESP is developed in $\mathrm{C} \#$ [5] NET that can be developed in Visual Basic NET [6];

- Application development in Visual Studio.NET [7] facilitates the programming work, with visual components to create forms of Web pages. Whilst it is possible to develop ASP.NET applications using only a text editor and compiler. NET;

- It is possible to reuse the code of any other draft written for NET platform, even if the language is different;

- Despite the code of the application is not written in VB.NET [8], this tool allows you to call components written in $\mathrm{C} \#$ and Web Services written in $\mathrm{C}++[9]$;

- The ASP.NET applications are compiled before execution, giving a sensitive performance gain;

- Allows you to run ASP.NET applications on other platforms (Linux [10]) through the module that enables the Apache HTTP Server to work in conjunction with NET Framework and ASP.NET applications running on the , or is, mod_aspdotnet project.

The MVC pattern [2], represents an important role in computing, particularly with regard to the creation of architectural patterns related to the construction of UI (User Interface). A key feature of this pattern is the separation of responsibilities, thus contributing to the code used in a given area is isolated from that used in the construction of graphical interfaces. Thus, the division of responsibilities contributes to simplify development (simplifies the modularization), simplifies testing of the various components and improves the maintenance of the application at the expense of a small increase in complexity. Thus, a single standard lists three elements: model (Model); control (Control); and the view (View) - The model is a class or set of classes that encapsulates the data and business rules that are applied to them; The view is responsible for generating a graphical user interface presented to the user; Control is responsible for managing the interaction between the model and the view.

\section{MaInTENANCE DATA MANAGEMENT}

The management of all information affects the maintenance activity which is a complex process including the influence of some processes against others in a bi-directional way. Often a multi-criteria analysis is performed, but it may be too complex that only with the aid of computer tools is can be solved and thus manage efficiently the overall maintenance sector of an organization [11-12].

\section{A. Sytem permissions}

The proposed maintenance management system has several pre-defined access patterns, manage by the system administrator, depending on individual background and position of each collaborator. People on the same positions but different background may have different access to information, such as a mechanical technician compared with an electrical technician. Although the system has a predefined set of accesses, as schematised in figure 1, the administrator of the system can set new levels of access to different profiles and others background specialties.

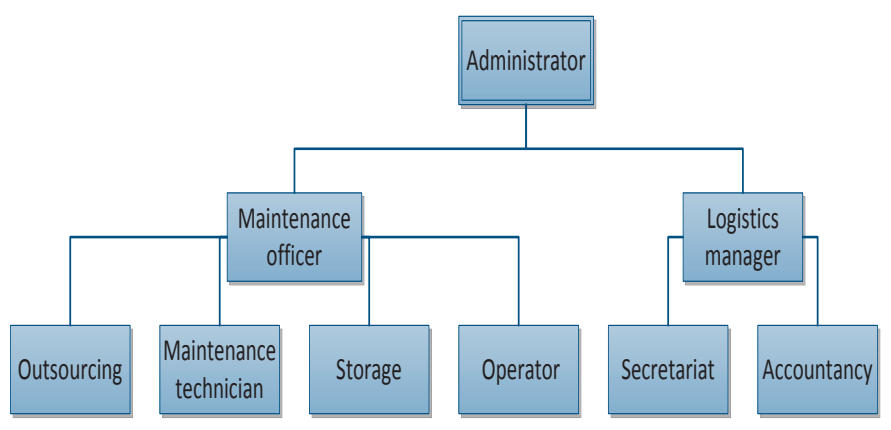

Fig. 1. Permissions of the GESP users

\section{B. Technological decomposition}

Technological decomposition of each physical asset is important and highly relevant to the performance of the proposed system. Each asset is classified according to its condition, family, manufacturer's recommendations as well as their references, especially useful in the selection of replacement parts.

Thus, each asset is classified according to its state of condition such as:

- Operational - meets all requirements of normal operation;

- Out of order - when a failure occurs and the physical asset is under maintenance works;

- Slaughtered - physical assets whose life cycle has ended.

Regarding family, each physical asset is identified as follows:

- Equipment Parent - category of physical assets;

- Integral Part - indicates the main equipment of which the physical asset in question is an integral part;

- Alternative Part - alternative to part.

In the case of a physical asset be a part of a production line (an induction motor for example), that line is the Integral Part and the alternative part a similar production line whit the same characteristics as the Integral Part because in case of an engine failure the whole production line is stopped. If the physical asset is one defibrillator, it is itself the Integral Part being the alternative another defibrillator. Highly important are the recommendations of the manufacturer about regular operational conditions and maintenance plans in order to extend as much as possible the life cycle of each physical asset and not lose the warranty, which is sometimes lost due the improper use of physical assets or for not fulfilling their maintenance plans.

The references, these are used to manage orders and for market analysis and acquisition of physical assets, aiming to achieve better prices and identify alternative parts that allow similar performances. 


\section{Management of planned maintenance}

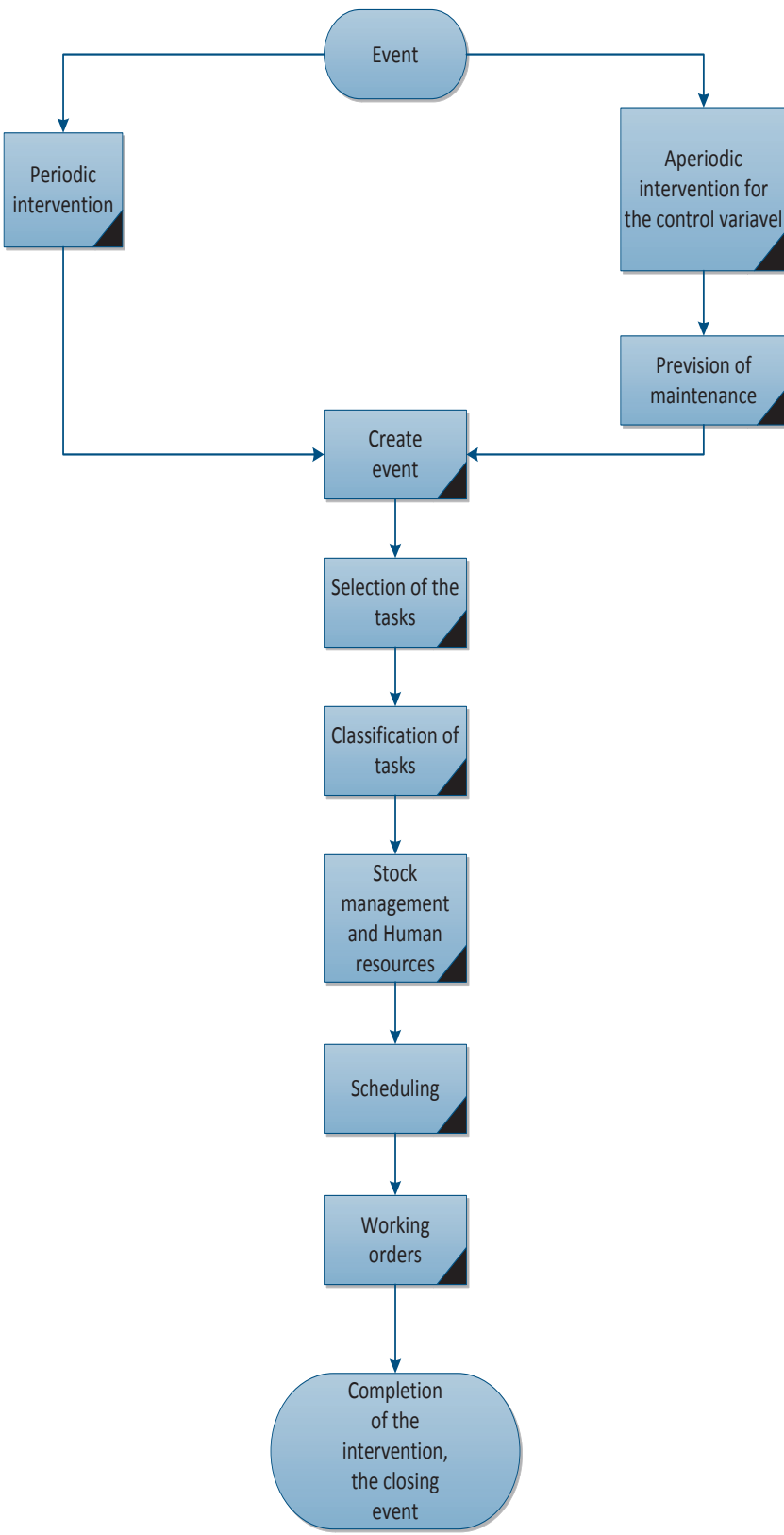

Fig. 2. Processing management from planned maintenance, in GESP application

The management of planned maintenance interventions is performed through the maintenance events following the structure shown in Fig. 2. The order of creation of a new maintenance event is given by temporally periodic or aperiodic maintenance interventions. In the latter case, the creation of a maintenance event depends on a variable of control and a prediction of the event scheduling. This is supported by a communication module, connected to assets, in order to obtain the data from the variable of control and analyze operating periods in order to make the best possible prediction to the planned maintenance intervention that should occur.

Created the event, it is selected the tasks that must be performed, not only based on the specifications from the technological decomposition but also from the analysis of the physical asset's history and or its family, which may result in additional tasks.

Each task is classified according to the AFNOR standards in order to manage efficiently the human resources available for the period in which the maintenance works are performed. The system will be prepared to indicate not only the internal organization's human resources as well as the outsourcing services if applicable or demanded. The availability of parts that need to be replaced in stock is also important for scheduling interventions.

After all this information is gathered, it will be the maintenance manager who will decide the exact moment when the maintenance intervention should occur and identify who is responsible for carrying out each task by issuing working orders (WO).

In spite of what were presented above, it will be able not only for the technician but also the operator to report failures or evidences that will be evaluated by the maintenance manager and, if applicable, create an event with appropriate tasks to ensure adequate operational conditions of physical assets. Given the nature, this is considered a "preventive Event".

All the parameters to schedule interventions are pre-defined in a database. The management system will compare the predefined in the database with the values from the variables of control that are monitored in real-time, being the communications carried out via a PLC, following the structure shown in Fig. 3.

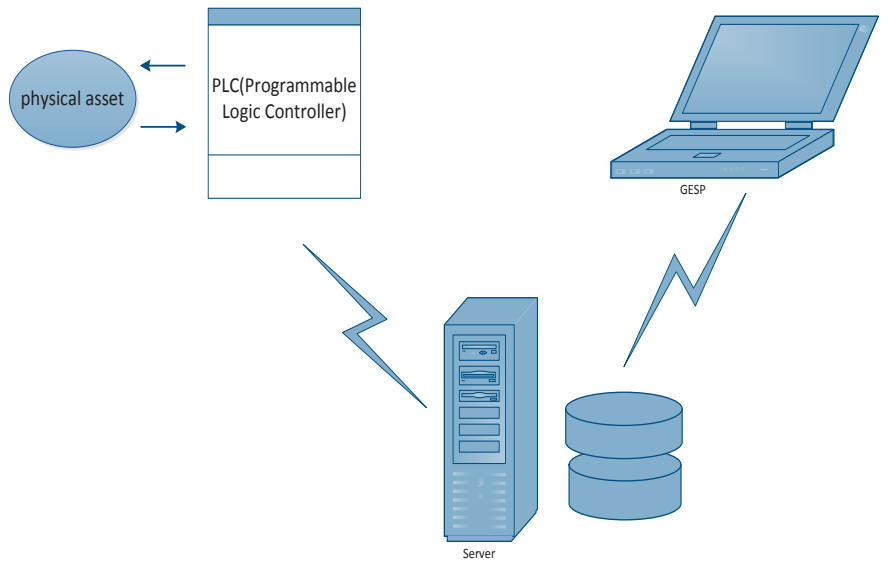

Fig. 3. Communication of the physical asset with the GESP application

\section{The stock management}

A good stock management of reserve parts predicts the required resources for a certain period of time, thus ensuring all necessary parts will be available on time. Throughout the historical analysis, the maintenance manager may provide the 
recommended quantity of parts that should be always available in case of a failure.

An efficient stock's management means having the minimum parts in storage to guarantee the maintainability of physical assets.

It is planned a stock form that gathers all the information regarding the components and materials available for each physical asset, presenting its definition and classification. The classifications are created by the user and consists of assigning a category within a classification and description.

Upon delivery of the goods, the organization creates a record of delivery. In this, the average and actual purchase price is determined on the stock form, being the amount of available parts also updated appropriately.

The states of deliveries and the periods of states are a vital information to predict the physical assets that must be available for a certain maintenance event.

\section{E. Scheduling of working orders (WO)}

The events are related to specific maintenance tasks, which flow through the system and contain the information stored. After the creation of an event, a WO is generated according to the tasks that must be performed.

\section{F. Historical analysis}

The history of the technological decomposition consists in storing information of interventions that have been performed, their description, including the timeline in which they were performed. The data collected from monitoring each physical asset is also part of the historical, being the system in future versions enriched with mathematical tools to analyze patterns in order to identify and detect behaviors that represent a high probability rate of failure. Thus, the maintenance manager will be provided with an additional tool to schedule preventive maintenance events in time.

\section{G. Classification of maintenance tasks}

The maintenance tasks classification is a very important point, it describes the level of importance of maintenance events, allowing to perform optimal resource management (Figure 4). Events are classified according to the levels defined in the AFNOR X60-010 and the type of maintenance to be done (Figure 5).

Maintenance levels defined in the standard AFNOR X60010 are as follows [1]:

Standard 1 - Simple tunings provided by the manufacturer without equipment disassembly or replacement of accessible elements;

Standard 2 - Repairs performed from the replacement of standard elements provided for this purpose or minor repairs preventive maintenance (rounds);

Standard 3 - Identification and diagnosis of faults, repair by replacement of functional components and minor mechanical repairs;

Standard 4 - Important works of curative, preventive or corrective maintenance;
Standard 5 - Work of renovation, construction or major repairs in a central workshop or by subcontracting.

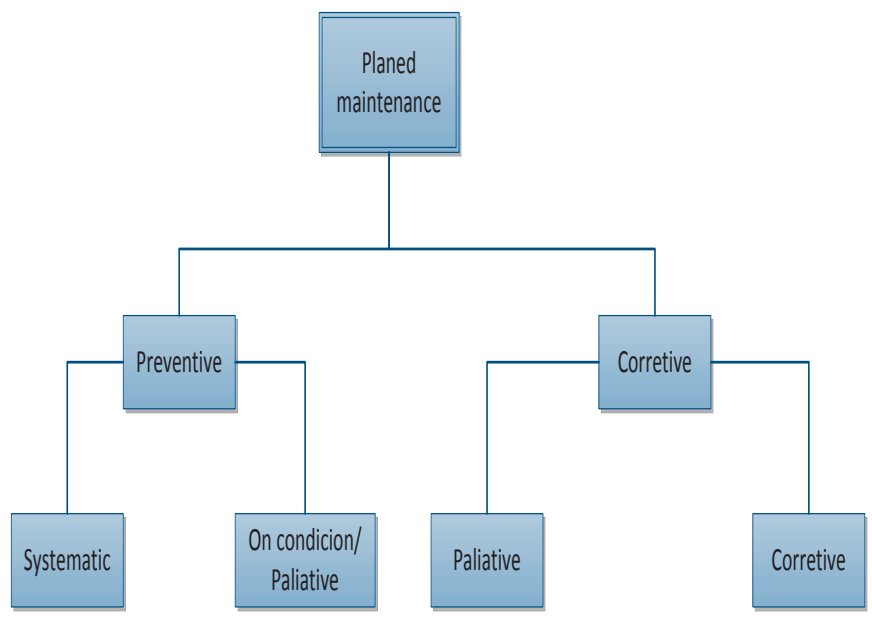

Fig. 4. Classification of planned maintenance in GESP application

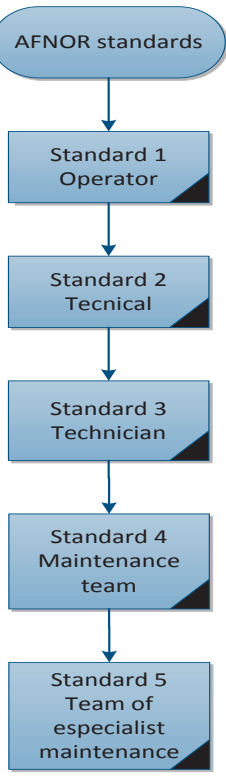

Fig. 5. Classification of specialties of users according to the AFNOR X60-010

\section{GESP APPLICATION}

The GESP system is architected to have a friendly user interface, according to the structure illustrated in Figure 6. The main menu of the application consists of four buttons, which allow access to four major groups that are related to maintenance management. 


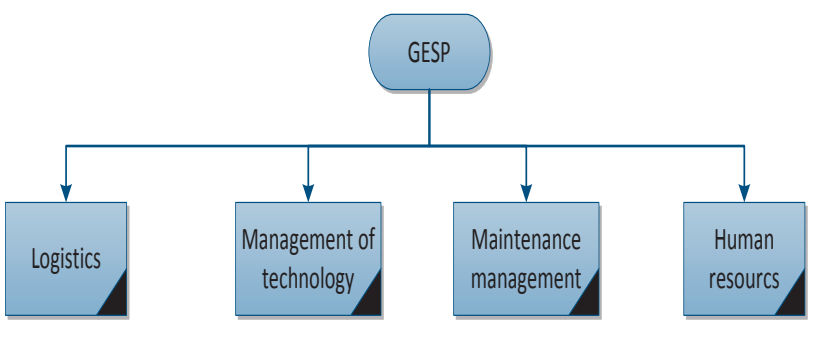

Fig. 6. GESP application main menu

Logistics is a submenu of the main menu which consists of four main buttons, two submenus give access to others two, as seen in Figure 7. The logistics contains the information on the resources and internal and external relationships of the organization, to carry out the maintenance.

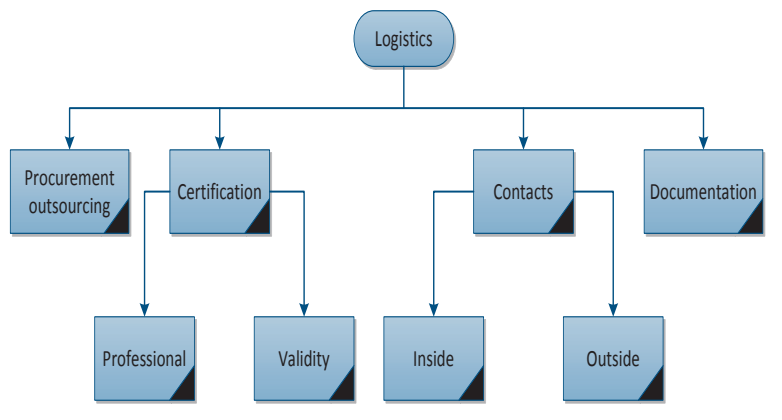

Fig. 7. Logistics submenu of the GESP application main menu

The management of technology comprising a total of six buttons where four of them buttons provide access to relative submenus, such as shown in Figure 8; this submenu contains the data subject to maintenance on physical assets.

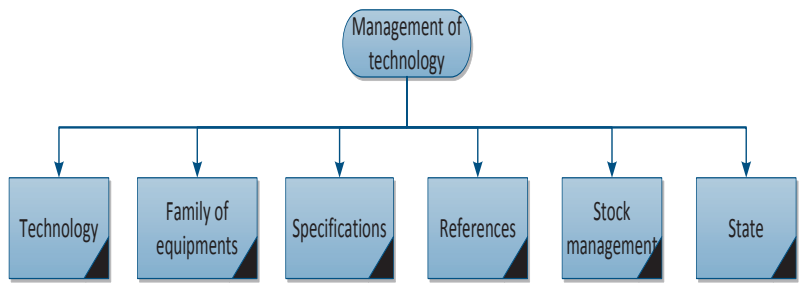

Fig. 8 - Technology management submenu from GESP application main menu

The family of equipment is a submenu of the technology management application that contains information to classify the family of physical asset, according to the structure of Figure 9 .

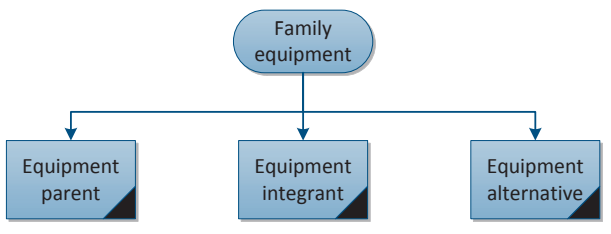

Fig. 9. Family submenu of the equipment submenu of the technology management GESP application

Specifications are accessed through a submenu of the technology management application that contains information to classify the active physical specifications to meet the main menu, following the structure of Figure 10.

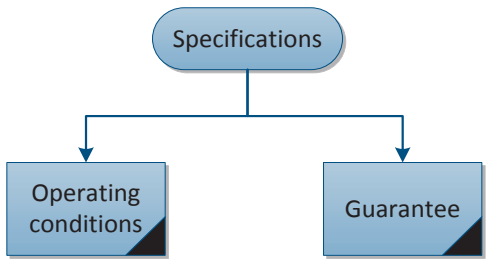

Fig. 10. Submenu of submenu specifications of the technology management GESP application

The references correspond to a submenu of management technology main application menu containing the information of the reference physical asset, according to the structure of Figure 11 .

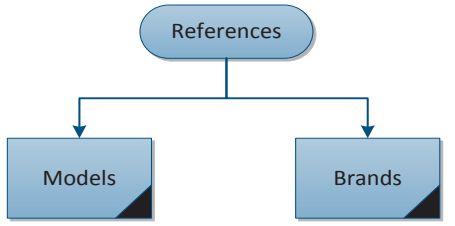

Fig. 11. Submenu of references submenu of the technology management GESP application

The stock management is accessed through a submenu of the technology management application, which contains the necessary information to make the management of stocks of physical assets main menu, according to the structure of Figure 12.

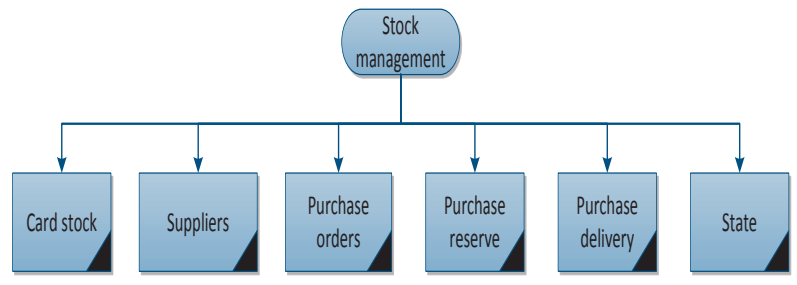

Fig. 12. Submenu of stock management submenu of the technology management GESP application

The management service is accessed through a submenu of the main menu of the system, which is composed of four submenus, according to the structure illustrated in Figure 13; this submenu contains the relevant information of the maintenance management of physical assets where the application will be implemented. 


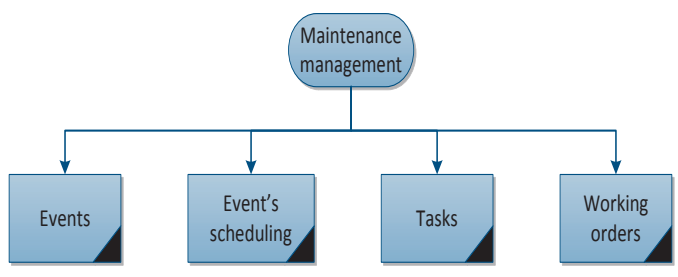

Fig. 13. Submenu of the maintenance management of the GESP application main menu

The events correspond to a submenu of the maintenance management, which follows the structure of Figure 14 containing information about its description, classification and analysis.

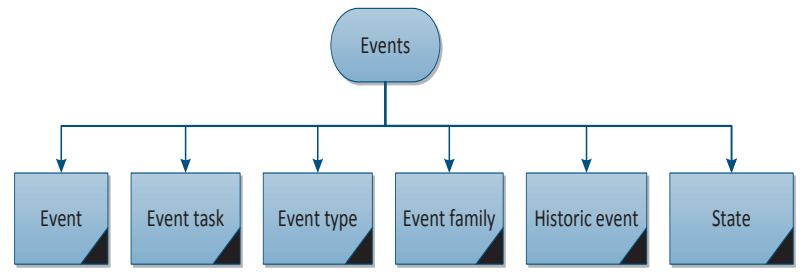

Fig. 14. Submenu of events submenu of the maintenance management GESP application

The event schedule corresponds to a submenu of the application maintenance management, which follows the structure illustrated in Figure 15, which contains information about scheduled periodic maintenance events and variables of control in case of aperiodic planned maintenance events.

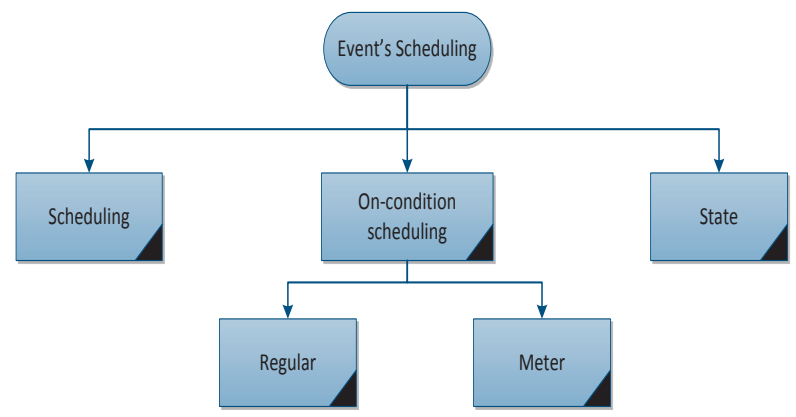

Fig. 15. Submenu of cheduling the events submenu of the maintenance management of the GESP

The tasks corresponding to a submenu of the application maintenance management, which follows the structure of Figure 16, contains information of the maintenance work performed in the organization.

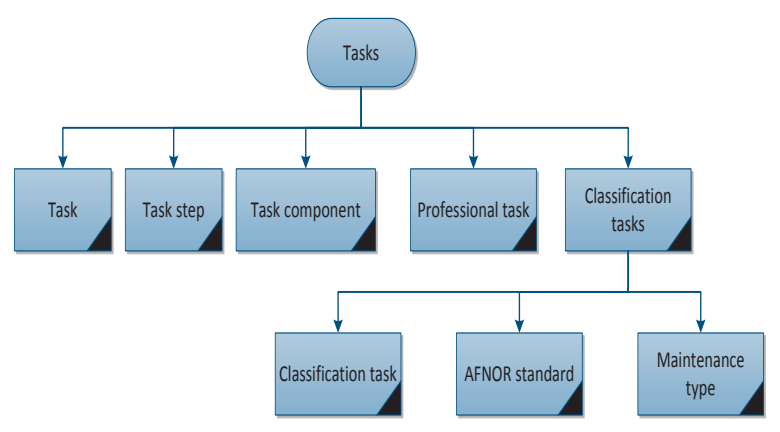

Fig. 16. Submenu of the submenu of the maintenance management of the GESP application tasks

The WO correspond to a submenu of the maintenance management application, which follows the structure illustrated in Figure 17, containing the data of the maintenance work performed in the organization.

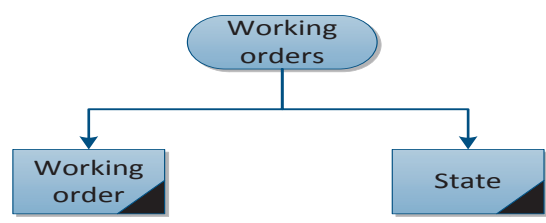

Fig. 17. Submenu of work orders from the submenu of the maintenance management of the GESP application

Human resources represent a submenu of the main menu of the application, consisting of two submenus, according to the structure illustrated in Figure 18, where is traded data of human resources for maintenance.

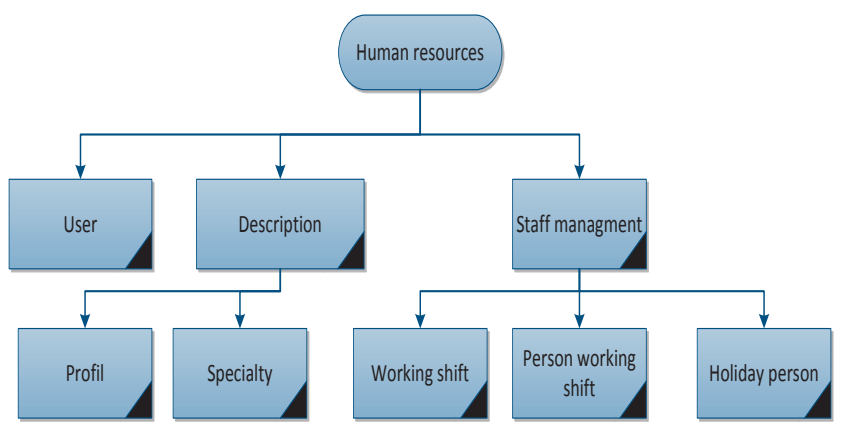

Fig. 18. Submenu of human resources of the GESP application main menu

\section{GESP APPLICATION - FUTURE DEVELOPMENTS}

The next challenge to be reached by the system is the development of a scheduling system in real-time, prospecting an automatic maintenance management, embedded with a failure prediction model based on dynamic modeling, where a historical analysis of the physical assets, the monitoring and the analysis of critical features will be made.

The next version of the proposed system (GESP) aims to manage maintenance operations with greater autonomy and 
robustness, being the tasks selected automatically by the system and evaluated the alternatives with respect to human resources.

It is estimated that the maintenance condition assumes particular relevance in the following years as well as the application of e-Maintenance concept [13]. In maintenance condition sector several studies were performed, one of them highlights a prediction model applied to wind generators based on vibration analysis [14], or a failure prediction by the analysis of diesel engine exhaust gases without being required the historical of physical assets [15]

Due to the high degree of complexity of performing maintenance interventions, paper-based instructions are falling into disuse, being replaced by its equivalent in electronic version to be accessed by tablets or smartphones. The use of these devices opens doors to new horizons as the introduction of augmented reality in industrial environments [16], a technology that consists of superimposing virtual content to the real environment, which allows to display, on intuitive way, the sequence of instructions that technician must perform.

\section{CONCLUSIONS}

The GESP is a CMMS in development, based on the concept of managing multi-events occurring and planned maintenance. The management of the same is done in accordance with available resources, being the priorities of operation established in accordance with the levels of AFNOR X60-010.

The application allows for systematic events of planned maintenance or control variables according to previously established parameters, and perform preventive maintenance events, in order to maximize the lifecycle of the physical assets and reduce maintenance costs.

Besides maintenance management of physical assets, the proposed system also allows the management of resources and outsourcing, from professional certifications to work shifts, as well as holiday periods and pre-established tasks.

\section{REFERENCES}

[1] AFNOR Standard NF X60-010.

[2] Abreu, L. (2012) : ASP.NET MVC. FCA - Editora de Informática, Lda.

[3] SQL Server 2012. http://www.microsoft.com/en-us/servercloud/products/sql-server/ - acedido em 2014.06.30

[4] Framework.NET: http://framework.net/ - acedido em 2014.06.30

[5] Loureiro, H. (2013): C\# 5.5 com Visual Studio 2012. FCA - Editora de Informática, Lda.

[6] Visual Basic: http://msdn.microsoft.com/en-us/vstudio/hh388573.aspx acedido em 2014.06.30

[7] Visual Studio.NET: http://msdn.microsoft.com/enus/vstudio/hh388573.aspx - acedido em 2014.06.30

[8] VB.NET: http://vb.net/ - acedido em 2014.06.30

[9] C++: http://www.cplusplus.com/ - acedido em 2014.06.30

[10] Linux: http://www.linux.com/ - acedido em 2014.06.30

[11] Farinha, J. M. T. (1997): "Manutenção das Instalações e Equipamentos Hospitalares - Uma Abordagem Terológica". ISBN 972-8318-16-2. Livraria Minerva Editora. Coimbra; Portugal.

[12] Farinha, J. M. T. (2011): "Manutenção - A Terologia e as Novas Ferramentas de Gestão". MONITOR, Lisboa, Portugal. ISBN 978-9729413-82-7.

[13] Muller, A. C. Marquez, and B. Iung, "On the concept of e-maintenance: Review and current research," Reliability Engineering \& System Safety, vol. 93, no. 8, pp. 1165 - 1187, 2008. [Online]. Available: http://www.sciencedirect.com/science/article/pii/S0951832007002189

[14] Fonseca, I; Farinha, J. T.; Barbosa, F. M. (2008): "On-condition maintenance of wind generators - from prediction algorithms to hardware for data acquisition and transmission". WSEAS Transactions on Circuits and Systems. Issue 9, Volume 7, September 2008. ISSN 1109-2734, pp909-918.

[15] Simões, A.; Farinha, J. T.; Fonseca, I.; Marques, V. (2010): “Oncondition maintenance of Diesel engines modelled by a Hidden Markov Model". Proceedings NEW ASPECTS of APPLIED INFORMATICS, BIOMEDICAL ELECTRONICS \& INFORMATICS and COMMUNICATIONS. ISSN: 1792-460X ISBN: 978-960-474-216-5. Pp 258-263.

[16] Oliveira, R.; Farinha, J. T.; Singh, S.; Galar, D. (2013): "An Augmented Reality Application to Support Maintenance - Is It Possible?". Publication: Research - peer-review; Article in proceedings. MPMM 2013 (Maintenance Performance Measurement and Management) Maintenance Performance Measurement and Management Conference. Place of publication: Lappeenranta, FINLAND. Publication date: 12 Sep 2013. Pages 260-272. ISBN (print) 978-952-265-443-4. ISBN (electronic) 978-952-265-443-4. 
(Página deixada propositadamente em branco) 


\title{
Mobile Applications and its Potential to Maintenance
}

\author{
${ }^{1}$ Hugo Santos, ${ }^{2,3}$ António Simões, ${ }^{1,3}$ Inácio Fonseca, ${ }^{2,3}$ Torres Farinha \\ hugombsantos@hotmail.com; \\ ${ }^{1}$ Electrical Engineering Department; ${ }^{2}$ Mechanical Engineering Department; ${ }^{3} \mathrm{CEMUC}$ \\ Coimbra, Portugal
}

\begin{abstract}
Mobile technology is constantly evolving, most notably following the advent of Smartphone technology. As this equipment becomes faster, more powerful, and less expensive, it will become an excellent platform for the development of ergonomic and effective maintenance tools.

The present article describes an application that allows for an easy, organized and systematic way of improving the process of recording physical equipment data within the field of maintenance management, thus making the following contribution one of immense value to the field by increasing the accuracy of data storage.

The first, and arguably the most crucial step, necessary to elaborating the equipment dossier is to register its intrinsic data, planning data, and so on. Although, this phase is perceived as the easiest, it is usually one of the weakest points in equipment registering.

Having this issue in mind, an application was developed in order to facilitate equipment registering. The ultimate goal was to increase the efficiency of the registering process and equipment dossier, in addition to the processes involved during maintenance management. The present approach also aims to demonstrate that it is possible to develop effective maintenance via low-cost tools that do not require specialized equipment to function effectively. Mobile applications provide a huge opportunity to improve the working conditions experienced by maintenance teams.

From the initial process of regularly organizing workplace equipment, to operation issues when carrying out work orders, mobile technology can help improve the efficiency of various processes. The application allows effective and systematic way to improve the process of recording equipment, and is designed for mobile devices running Android (Google's system), or industrial equipment like PDAs running windows mobile - for example the Lynx model from Datalogic.
\end{abstract}

Keywords — Mobile applications; Maintence; Equipment dossier

\section{INTRODUCTION}

Mobile applications have a huge opportunity to improve the working conditions of maintenance teams, presently, there exists a void in available applications that use Smartphone devices. However, some companies have already begun to provide some products in this area, like Yardi [5] its mobile solutions allow completion of maintenance and inspection tasks, access to approve invoices and purchase orders, and also companies like RealPage [4] with its OneSite Facilities Mobile Service[9], which automates the whole process of maintenance performed by a technician through an easy management of all maintenance requests and Work Orders
(WO). Thereby, reducing the time spent managing the entire documentation generated by the aforementioned process while also increasing technician productivity, by allowing for new WO to be received on site. In the field of wireless categorization of inventory it is possible to find solutions such as MobileAsset v7 and MobileAsset.EDU from the company Wasp Barcode Technologies [7]. These solutions offer a complete cataloging system that includes servers, an advanced management interface for standard computers, built-in communication with industrial equipment (capable of reading barcodes), and Smartphone applications for Android or iOS devices to access information from a database.

Using some of these ideas and concepts an application was developed to demonstrate various possibilities offered by Smartphone mobile systems in the maintenance field.

\section{VALUE-ADDED TO THE MAINTENANCE FIELD}

The main issue that exists in the maintenance field is that of data loss, following and in between scheduled maintenance completion and WO fulfillment. In order to counteract this loss, data may be more efficiently managed and stored, during and post-maintenance intervention, via the mobile application referred to in the present paper. The ultimate goal of this mobile application, thus, is to store all WO data immediately following each maintenance action as to avoid 'forgotten' data. Other contributions occur during the interventions, namely when these ones are not planned, because the technician can access on-line a fault diagnosis tool, if it exists.

But the interest of the technology under discussion begins at the moment that equipment is purchased, because it permits technicians to register on-site; including bar-code reading and so on. In fact, a correct registration of the equipment dossier in the working database may be one of the main determinants for a correct evaluation of Life Cycle Cost, including: WO, human resources, materials, and so on.

When an intervention request, in particular, urgent requests needing immediate attention, comes about a digital tool, such as a tablet or similar device may facilitate the completion of working orders received by a technician without loss of time. Furthermore, the introduction of new technologies (Augmented Reality, 3D models, Expert Systems, and to name a few) and applications creates synergies in order to minimize intervention time, increase quality, minimize risks, and maximize availability. 


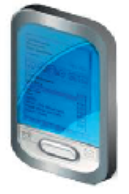

Mobile Side

\section{HTTP Request}

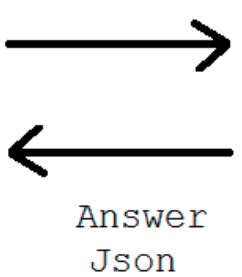

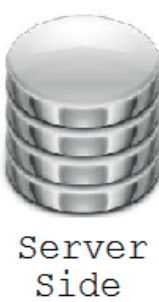

Side
Fig.1. Interaction between the server side and the Mobile side.

\section{GENERIC MOdEl FOR A MoBILE APPLICATION}

This application can be separated in two main categories, which include the server side, where all information is stored and processed, and the mobile side where all information is accessed or entered (Fig.1).

The server component runs a Rest server (Fig. 2) that receives and manages all requests to the server. This Rest server is a PHP script, which is able to receive HTTP requests, either GET or POST requests, and it is able to respond in XML, HTML or JSON. The Rest server is also used as a form of security because it sits between the database and all requests from the outside, not allowing direct access to the main database. The database should be sql type as it allows for easy development and integration with the Rest server.

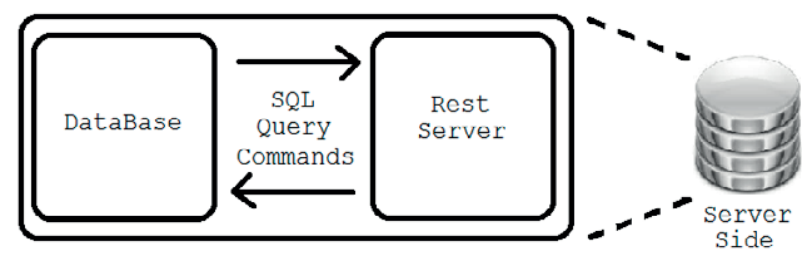

Fig. 2. Server Side Diagram

The mobile side must be able of connecting to the network via Wireless or via GPRS to obtain all the information needed. The device must also be capable of reading barcodes, this can be achieved through image capture or scanning, which requires the mobile to have a camera or a laser scan. The device must also have in his hardware list a touch screen sensitive enough to capture signatures as well as a camera to take photos and store them on the database. In some instances a GPS system may be useful to register the location of the device. In addition to all the listed prerequisites, the mobile device must be able to run an internal database to implement an offline mode. For several years all these features could only be found in expensive industrial devices, such as the PDA Datalogic Lynx, but at present, any Smartphone is capable of fulfilling these requirements. For this reason the author decided to use a PDA and Smartphone for the aforementioned research.

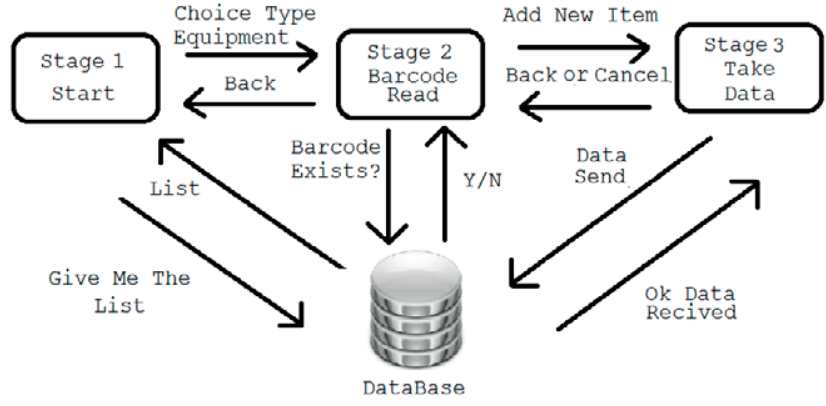

Fig. 3. Basic scheme of functioning of the application.

Once the mobile device is activated the application should check if the device is connected to the network, and that the server is functional. After this initial check, the application should ask the server for a complete list of all perishable equipment. After the list is displayed, the user needs to select the particular item that he wants to catalog.

\section{Stage 1}

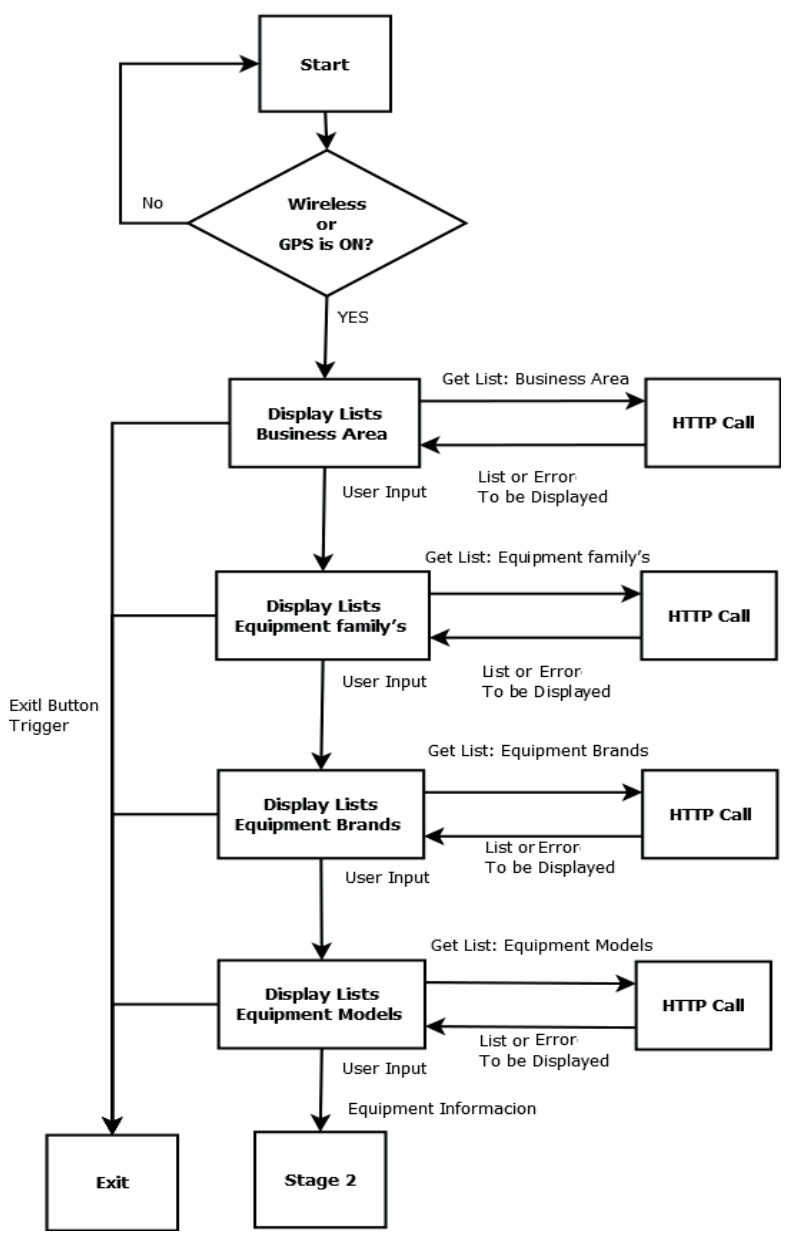

Fig. 4. Flowchart of Stage 1 
In the next stage, the application can be used to scan barcodes, or input them manually, asking the database if the barcode has already been input. If so, the application will ask the user if he intends to overwrite the previous entry. In the event that the user wishes to overwrite the previous entry, or the input is a new entry, the application should jump to its third stage.

\section{Stage 2}

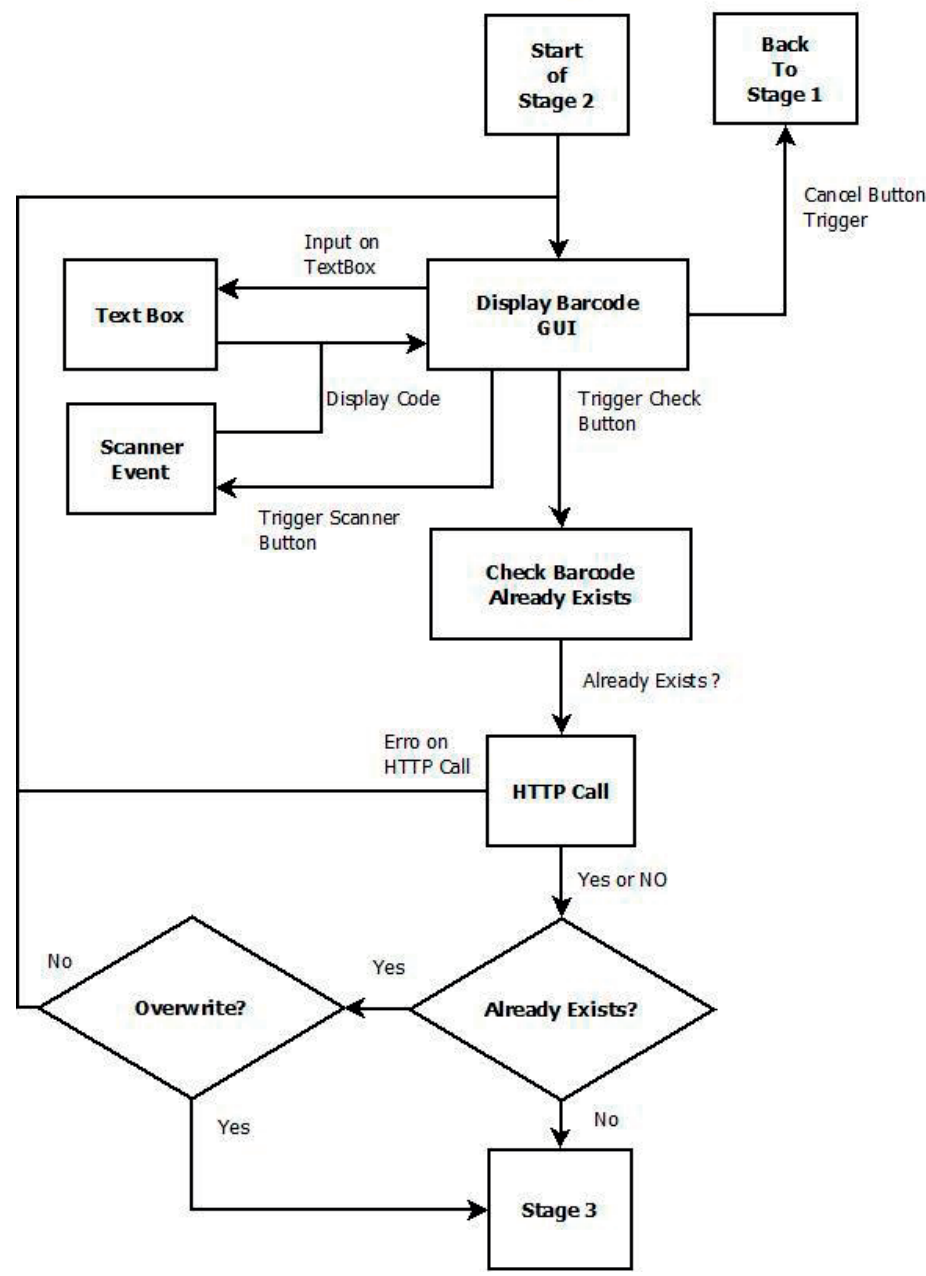

Fig. 5. Flowchart of Stage 2

In the third stage, the user should collect photos, information about the location of equipment, comments regarding the state of the documented equipment, and etcetera, finally obtaining the user's signature. Note that in the case of indoor activity, the GPS function is not the ideal method to determine the device's location. So other means must be found, for example, through the use of a unique ID room system that can be either manually inputted or introduced as a barcode tag.
After all the aforementioned information has been collected, data should be sent to and then processed by the server. Following this action, the application should revert back to stage two - the barcode reading process. This behavior is stated on the following flowcharts (Fig. 3, Fig. 4, Fig. 5 and Fig. 6).

\section{Stage 3}

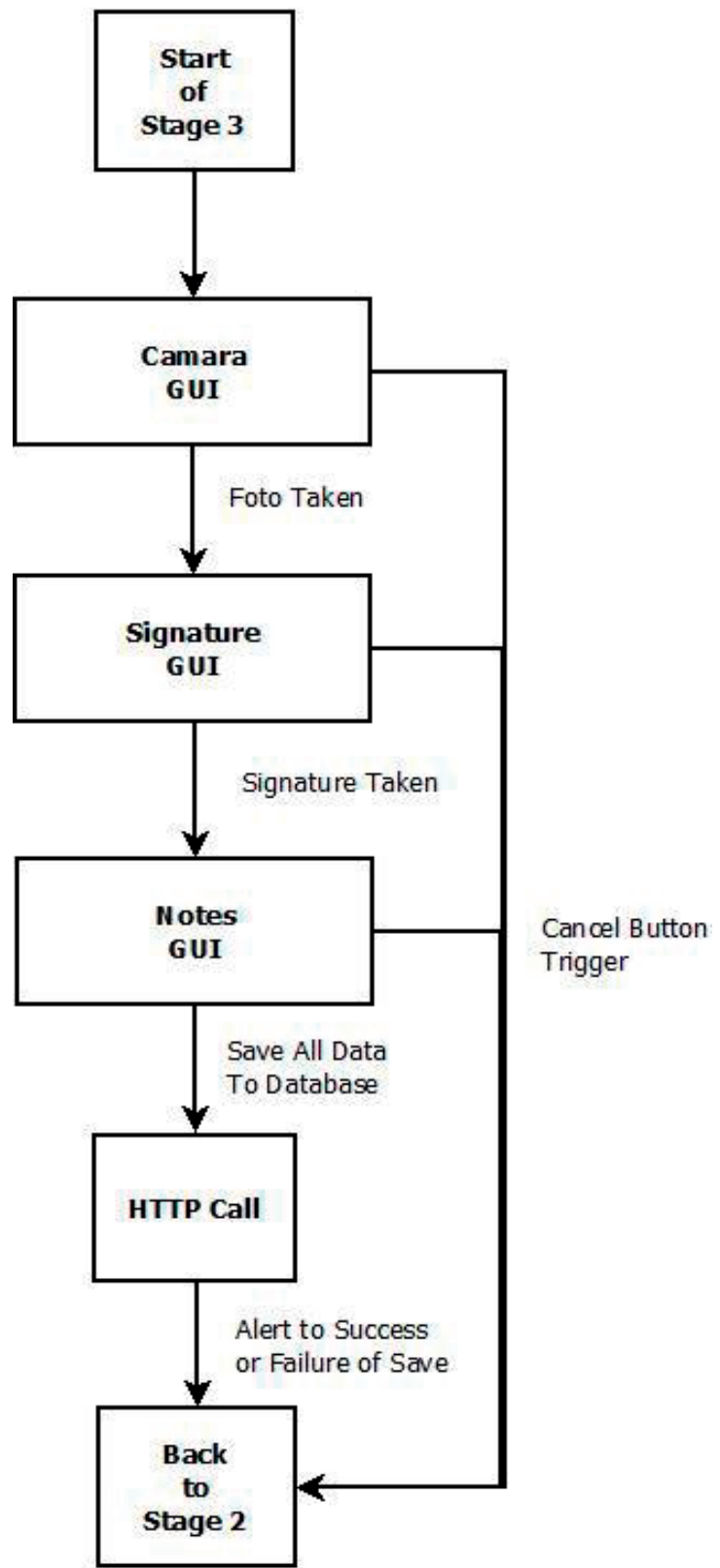

Fig. 6. Flowchart of Stage 3 


\section{PRACTICAL IMPLEMENTATION}

\section{A. Database Implementation}

The database MySQL was integrated with the development environment MySQL WorkBench. By doing so, time was saved, as the whole implementation of the database was developed graphically, a much more intuitive way of database development.

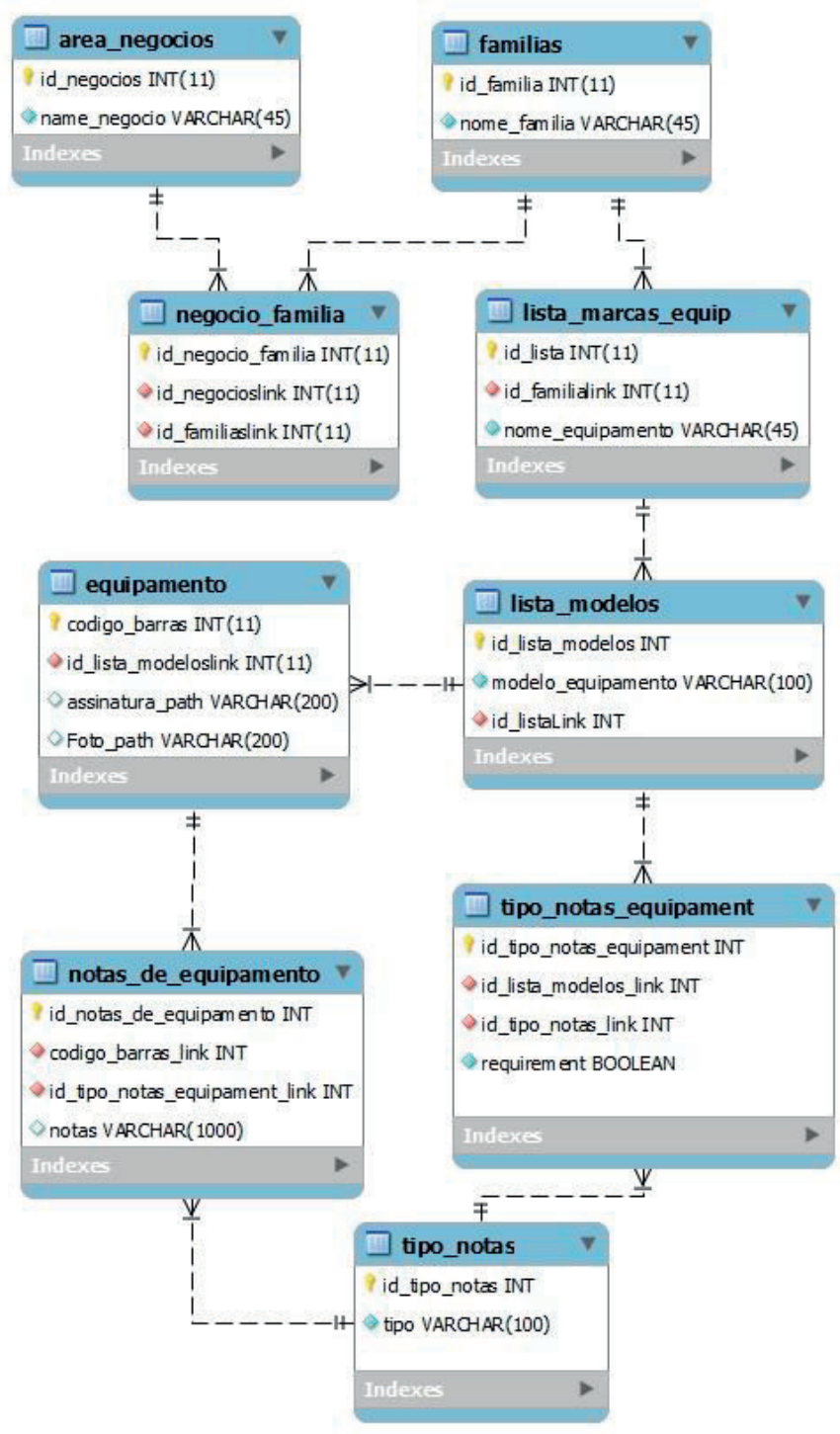

Fig. 7. Database Scheme.

As you can see from Fig. 7, the database is relatively small, containing only nine tables, each one devoted to a specific function.

The database information is organized in the following main areas:
- $\quad$ Business area - table area_negocios;

- Bridge between Business area and Equipment family's - table negocio familia;

- Equipment family's - table familias;

- Equipment brands - table lista_marcas_equip;

- Equipment model - table lista_modeles;

- Bridge between Equipment model and Equipment type notes - table tipo notas equipament;

- Equipment type notes - table tipo_notas;

- Information cataloged - table equipamento;

- Equipment notes taken - table notas_de_ equipamento.

The first seven tables are responsible for the list and sub lists of all the equipment described in the first, initial stage of application. While the two remaining tables are responsible for the storage of all information regarding the cataloged equipment.

\section{B. Rest Server Implementation}

The Representational State Transfer (REST) style is an abstraction of the architectural elements within a distributed hypermedia system [2] [3]. It works by receiving HTTP requests from the mobile device, and acting based on them. Those requests are compose by a web address and the message, they are separated by the character "?" (example: http://192.168.252.207/PDA/rest.v2.php ?accao=autorizacao), as can be seen the message component functions by having a keyword, in this case "accao" and a value "autorizacao", it is also possible to add additional data by adding the character "\&" between messages.

Upon receiving the request, the Rest server should execute the request action. In response, the server should send a message communicating to the device whether the message was a success or failure, in addition to data that was requested by the user. All this information uses the standard RFC 7159 format [1] (this is the JavaScript Object Notation for easy organization and information collection, allowing for friendly handling when receiving data at the mobile application terminal).

\section{Android Implementation}

This mobile application was developed on IDE Eclipse, and debugged on a Samsung GT-S7390, (Fig. 8), with Android version 4.1.2. It was written in Java, the android native language.

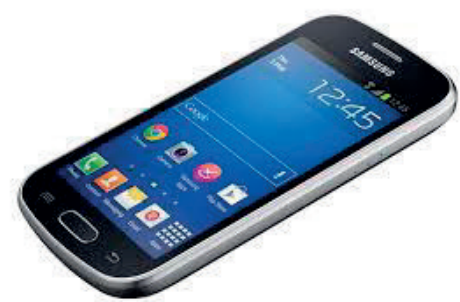

Fig. 8. Samsung GT-S7390 
The aplicacion follows the sequence of information described in Fig. 3, but because the device does not have a laser scanner, it was necessary to find a way to read the barcode via camera. In order to achieve that, a separate application - the Barcode Scanner from Zxing, Fig. 11- was used in combination with the current one to obtain the barcode information. This technique was also recommended by WeiMeng Lee in his book [6].

In Fig. 9 it is possible to see the interface that is available to the user during equipment selection from the catalog (stage 1 of the android application - Choose in sequence: Business Areas, Equipment Family, Marks, and Model). For example: Electronics, Multimeters, AMPROBE, and AM 520 EUR.

\begin{tabular}{|c|c|c|c|}
\hline \multicolumn{2}{|c|}{ '్̂, Rest Call V4 } & \multicolumn{2}{|c|}{ 암 Rest Call V4 } \\
\hline \multicolumn{2}{|c|}{ Business Areas } & \multicolumn{2}{|c|}{ AMPROBE } \\
\hline Computers & (3) Item's & \multirow[t]{2}{*}{ M 520 EUR } & \multirow[t]{2}{*}{ (8) Item's } \\
\hline Electronics & (4) Item's & & \\
\hline Energy & (2) Item's & \multicolumn{2}{|c|}{ You Want To add New Item? } \\
\hline Health & (0) Item's & No & Yes \\
\hline teste1 & (0) Item's & & \\
\hline \multirow[t]{2}{*}{ teste2 } & (0) Item's & & \\
\hline & & \multicolumn{2}{|c|}{ You choice AM 520 EUR } \\
\hline
\end{tabular}

Fig. 9. Display of Equipment List on Android

The display in Fig. 10 and Fig. 11 are where the user can trigger the Barcode Scan activity by pushing the scan button "Start Scan" on the GUI, or manually introduce barcode data in textbox (stage 2).

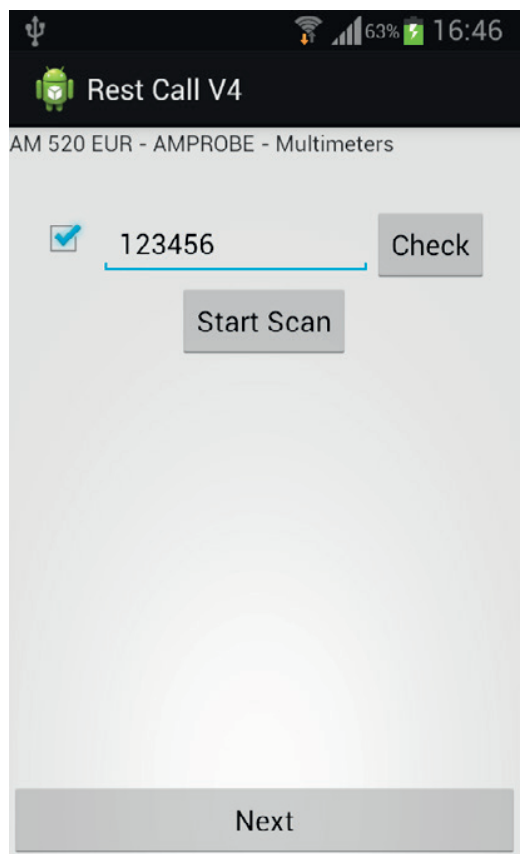

Fig. 10. Display to introduce the barcode on Android

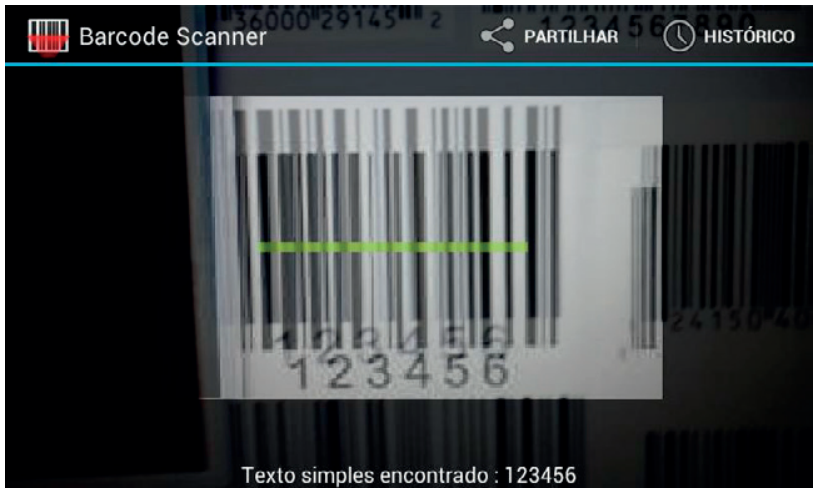

Fig. 11. Barcode Scanner From Zxing.

After the database approves the barcode, and the user presses the "Next" button, the application should begin to gather information about the equipment; first, photos and signature, and then in the tab notes the user can insert other valuable information like location and power supply (see tab interface, Fig. 12 and Fig. 13). 


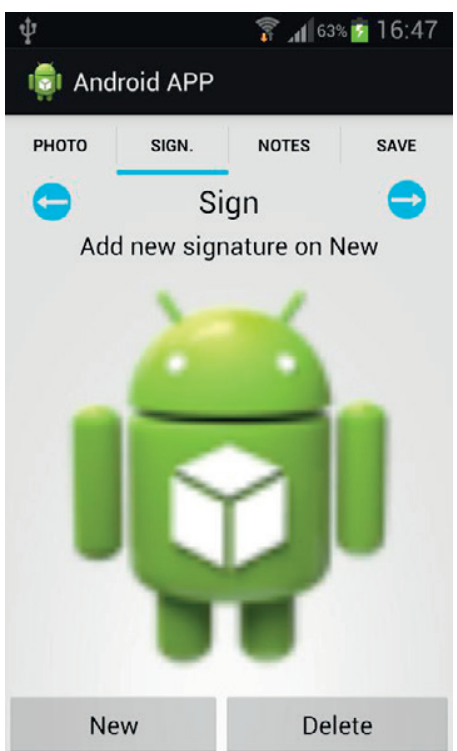

Fig. 12. GUI interface for user take photos and signature.

Here the user can choose to take photos, signatures or take notes about the item, as can be seen in the following pictures. By pressing the button entitled "New", the user should pass to the camera GUI, (default Android camera GUI from the device), or the signatures GUI and the Notes GUI (Fig. 14).

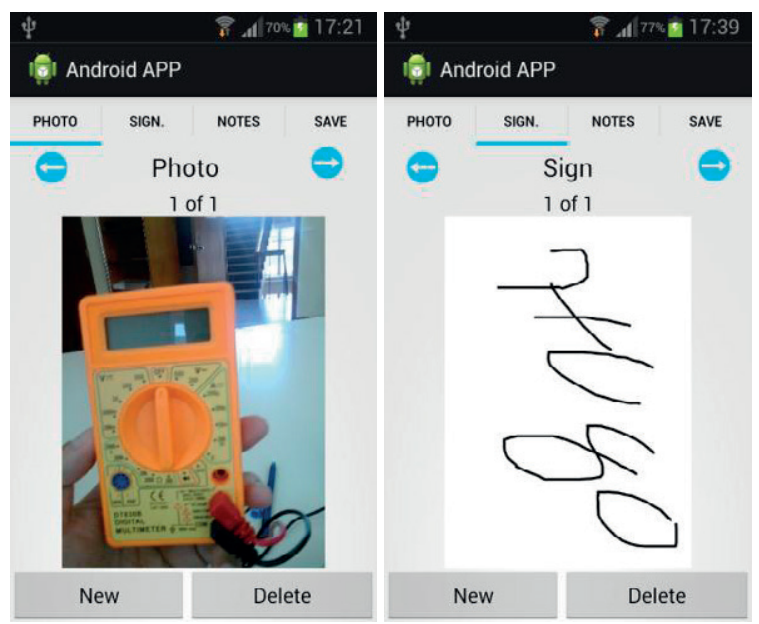

Fig. 13. Camara capture and signature capture GUI on Android.

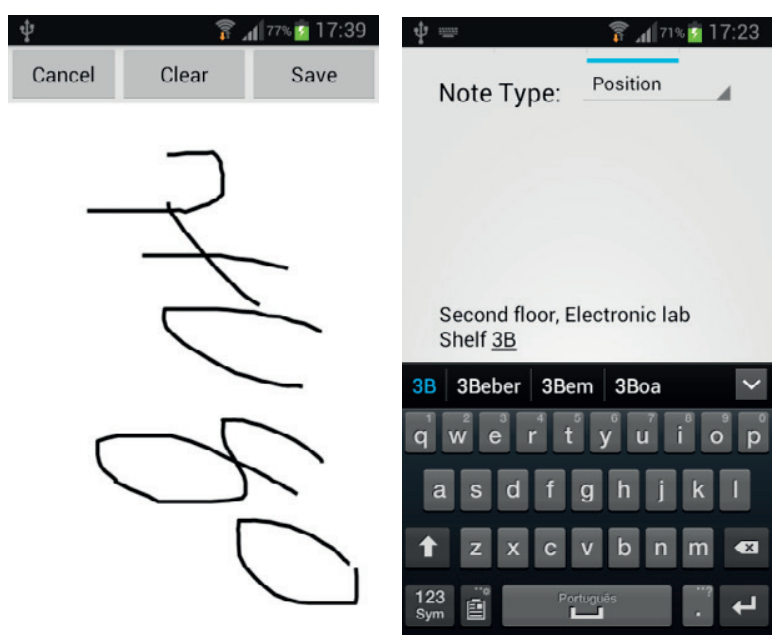

Fig. 14. Signture and Notes GUI

The user should press the "save" tab following data collection. In response, the application should upload all the registered information to the server, notifying the technician of the success or failure of this procedure before returning to stage 2 .

\section{Windows Mobile Implementation}

To implement this application on Windows Mobile it was necessary to use the standard IDE of Microsoft, Microsoft Visual Studio, and all developed code was written in C\#. In order to test and debug, this application used a Datalogic device, more precisely the Datalogic Lynx, (Fig. 15).

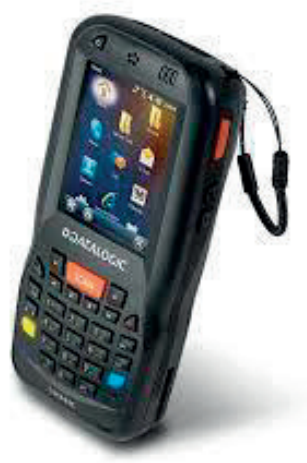

Fig. 15. Datalogic Lynx

The industrial PDA is a mobile device that is capable of withstanding manufacturing environments. Included in the device's hardware is a laser scanner, eliminating the need for a third party software, which is needed for the Android Implementation. Unfortunately, the industrial PDA requires the use of an application programming interface offered by Datalogic to access the scanner and is often much more expensive than conventional Smartphone devices. 
In Fig. 16, it is possible to see the interface that the Windows mobile user would encounter when selecting the equipment catalog; it is similar to that of the Android (stage 1).

\begin{tabular}{|c|c|}
\hline \multicolumn{2}{|l|}{ Call Data Base } \\
\hline - Areas de Negocio & ᄉ \\
\hline † Electrónica & \\
\hline+ Energia & \\
\hline †-Informática & \\
\hline+ Saude & \\
\hline † teste1 & \\
\hline+ teste 2 & \\
\hline+ teste3 & \\
\hline+ teste 4 & \\
\hline t.teste5 & $\checkmark$ \\
\hline Back & Exit \\
\hline
\end{tabular}

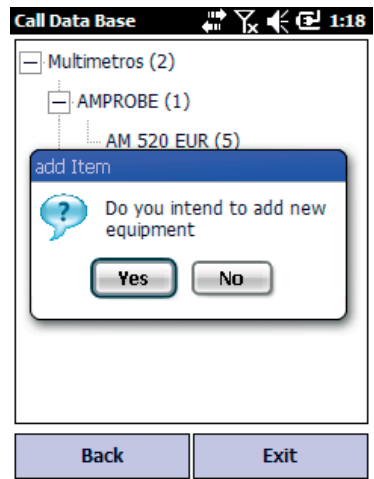

Fig. 16. Display of Equipment List on Lynx

The display Fig. 17 is where the user can trigger the laser scan by pushing the scan button on the device, or manually introducing the commend in the textbox (stage 2).

\section{additem $1: 23$}

Insert Barcode

$\frac{1817767}{\text { check }}$

\section{Next}

Cancel

Fig. 17. Display to introduce the barcode on Lynx

After the database approves the barcode, and the user presses the "Next" button, the application should allow the user to take a photo and capture a signature to authenticate the job; as can be seen in Fig. 18(stage 3).

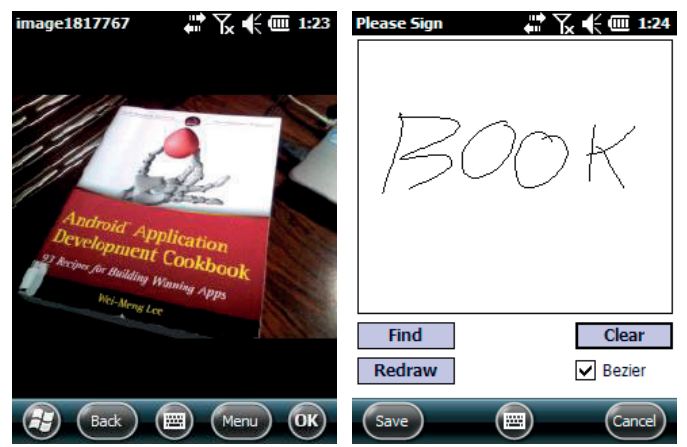

Fig. 18. Camara capture and signature capture GUI on Lynex.

As previously described, the application should upload all data taken to the server and alert whether the upload has been successfully, returning then to stage 2 .

\section{IMPROVEMENTS IN INITIAL MAINTENANCE ORGANIZATION AND LOCALIZATION}

Firstly, the outlined application is intended to improve the cataloging process of stocks and equipment through the automation of this process in an attempt to improve the overall maintenance process.

Secondly, there is the possibility of improving the management of assets since through the database it is possible to obtain several details about assets, conditions, images, location and additional details, ultimately effectively organizing day-to-day maintenance processes.

Finally, the present application demonstrates the endless possibilities of using generic equipment, instead of costly specialized equipment, in the maintenance process by ensuring a substantial reduction in costs.

\section{CONCLUSIONS}

The present research demonstrates the potential and capabilities available through mobile and server applications within the maintenance field by enhancing automation, increasing data accuracy, lowering costs, and simplifying the overall process. The following application demonstrates an ever evolving process as new technological innovation may lead to greater optimization. For example, the GUI interface in both versions may be graphically improved upon to become more user friendly. It is also important to improve the running speed of the application in both the Android and Windows versions. Tests are taking place to interface the tables in the asset management application, and findings demonstrate that Object Maintenance with mobile devices improve the working time of human resources. Future applications may include data collection for hospital Object Maintenance catalogs. 


\section{REFERENCES}

[1] Internet Engineering Task Force (IETF), "The JavaScript Object Notation (JSON) Data Interchange Format," 3 2014. [Online]. Available: http://tools.ietf.org/html/rfc7159. [Acedido em 304 2014].

[2] R. T. Fielding, "CHAPTER 5 - Representational State Transfer (REST)," 2000 [Online]. Available: www.ics.uci.edu/ fielding/pubs/dissertation/rest arch style.htm. [Accessed 25 2014].

[3] R. T. FIELDING and R. N. TAYLOR, "Principled Design of the Modern Web Architecture," $52002 . \quad$ [Online]. Available: www.ics.uci.edu/ taylor/documents/2002-REST-TOIT.pdf. [Accessed 45 2014].

[4] I. RealPage, "RealPage home page," RealPage, Inc, 2014. [Online]. Available: http://www.realpage.com/. [Acedido em 26 2014].

[5] I. Yardi Systems, "Yardi home page," Yardi Systems, Inc, 2014. [Online]. Available: http://www.yardi.com/. [Acedido em 26 2014].
[6] W.-M. Lee, "Android Application Development Cookbook," in Capturing Barcodes, Indianapolis, Indiana, USA, John Wiley \& Sons, Inc., 2013, pp. 319 - 323.

[7] Wasp Barcode Technologies, "Introducing MobileAsset v7," Wasp Barcode Technologies, 2014. [Online]. Available: http://www.waspbarcode.com/asset-tracking/whats-new-v7. [Acedido em $3072014]$.

[8] Wasp Barcode Technologies, "Wasp Barcode Technologies Announces MobileAsset v7, MobileAsset.EDU with iPhone, iPad, Android connectivity," Wasp Barcode Technologies, 2014. [Online]. Available: http://www.waspbarcode.com/about-us/press-release/2014-05-29mobileasset-with-ios-android-connectivity. [Accessed 3007 30].

[9] RealPageMedia, "Keep Your Service Technicians in the Field," RealPage, $12 \quad 4 \quad 2012 . \quad$ [Online]. Available: https://www.youtube.com/watch?v=8m3q0urO6uc. [Acedido em 201407 30]. 


\title{
Maintenance Strategies to Reduce Downtime Due to Machine Positional Errors
}

\author{
Abubaker Shagluf; A. P. Longstaff; S. Fletcher \\ abubaker.shagluf@hud.ac.uk; a.p.longstaff@hud.ac.uk; s.fletcher@hud.ac.uk \\ Centre for Precision Technologies, University of Huddersfield \\ Huddersfield, United Kingdom
}

\begin{abstract}
Manufacturing strives to reduce waste and increase Overall Equipment Effectiveness (OEE). When managing machine tool maintenance a manufacturer must apply an appropriate decision technique in order to reveal hidden costs associated with production losses, reduce equipment downtime competently and similarly identify the machines' performance.
\end{abstract}

Total productive maintenance (TPM) is a maintenance program that involves concepts for maintaining plant and equipment effectively. OEE is a powerful metric of manufacturing performance incorporating measures of the utilisation, yield and efficiency of a given process, machine or manufacturing line. It supports TPM initiatives by accurately tracking progress towards achieving "perfect production."

This paper presents a review of maintenance management methodologies and their application to positional error calibration decision-making. The purpose of this review is to evaluate the contribution of maintenance strategies, in particular TPM, towards improving manufacturing performance, and how they could be applied to reduce downtime due to inaccuracy of the machine. This is to find a balance between predictive calibration, on-machine checking and lost production due to inaccuracy.

This work redefines the role of maintenance management techniques and develops a framework to support the process of implementing a predictive calibration program as a prime method to supporting the change of philosophy for machine tool calibration decision making.

Keywords-maintenance strategies, down time, OEE, TPM, decision making, predictive calibration.

\section{INTRODUCTION}

Effective maintenance management is critical to the operation of the machines. Taking into consideration various concepts of programs, managers may plan and undertake maintenance activities proactively or reactively. A reactive approach initiates maintenance activities after some failure or problem occurs. This approach is typical for traditional manufacturing organisations where maximum throughput is the highest priority or where there is low investment in reconfiguring manufacturing systems. Due to growing pressure on manufacturing companies for improvements on productivity industrial companies' maintenance managers take preventive measures before crises occur in order to maintain machine tool availability. In general maintenance terms, this means ensuring that production continues to run. With respect to the positional accuracy of the machines, tighter tolerance demands from customers, means that maintaining the quality performance of individual machine tools is essential to avoid expensive rework or scrap, with the detrimental impact this has on rate of product output. As the name implies, a proactive maintenance approach uses well-defined preventive measures to prevent failures and shutdowns.

This paper is oriented towards predictive calibration as a proactive approach for eliminating production failure due to machine tool inaccuracy. The problem of the decision-making process is discussed, leading to the importance of making distinctions between reaction to incidents and the need for onmachine checking and preventive and predictive calibration.

The article presents various maintenance management approaches and how these can be applied to achieve competitive advantage by reducing machine tool downtime. It explores, by means of a review, which maintenance management strategies are used and how they are selected. It refers to the authors' previous work $[1,2]$ which proposed a model to help selection of the most cost effective machine tool measurement policy, and how to improve the effectiveness of calibration decision-making. Finally, this paper discusses how to assess the impact of the management strategies on the strategic objective of maintaining positional accuracy without prohibitive impact upon machine availability.

\section{MANAGEMENT OF INDUSTRIAL MAINTENANCE}

Over recent years, maintenance management has changed, possibly more than any other management discipline [3]. The change is a response to increasing competition and higher value demands on manufacturing output. It also includes the growing awareness of the influence of machine breakdown on safety and the environment [3].

Manufacturing development needs to be supported by effective and efficient maintenance. The maintenance function has become more complex, involving technical and management skills and requiring the flexibility to cope within a dynamic business environment. Emphasis should be made on carefully implementing a well-considered maintenance strategy, since simply following the latest trends can lead to significant negative impact in terms of wasted of time, money and morale. The purpose of maintenance management is to reduce the adverse effects of breakdown and to maximise the production system availability at minimum cost [4]. With the 
increasing complexity of modern $\mathrm{CNC}$ machine tools, the correct maintenance policy is ever more critical to the ability of the manufacturing organisations to compete. In this respect, operations management, especially maintenance management, is taking on a wider organisational strategic role [5].

Total maintenance costs for different machine tools or production lines will vary, depending upon the type of work, complexity of the machine and age of the machine, etc. It is therefore critical to evaluate each machine individually as well as the holistic viewpoint to establish an appropriate maintenance policy for each machine and production line. It is important not to perform excessive maintenance activities [4]. As reported by Mather, there still remain many opportunities to bridge the gap between the philosophy and practical application of these strategies [6].

Maintenance management approaches have been studied and presented by different authors with varying perspective. In this paper, maintenance management methodologies and their application are redefined and discussed with respect to decision making for planning calibration of positional errors; the eventual aim is to develop a framework to support the process of implementing a predictive calibration program as a prime method for supporting a change of philosophy for machine tool positional accuracy maintenance.

There are three basic maintenance strategies: Corrective (Run-to failure) unplanned; preventative (time-based); and predictive (condition-based). Predictive Maintenance (PdM) is a strategy that includes feedback of the instantaneous condition of the machine and detects degradation before a fault becomes critical [7].

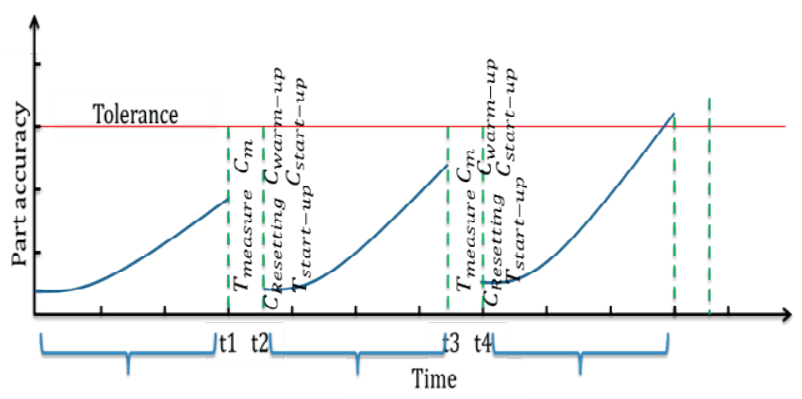

Fig. 1. Preventative calibration and adjustment at fixed rate

In recent years, the tools to enable comprehensive measurement of machine tool accuracy have become more readily available. For this reason, management strategies of preventative calibration and machine tool diagnostic techniques have attracted considerable attention. This approach uses modern metrology and analysis techniques to identify and predict the signs of deterioration or imminent failure. Fig. 1 shows such a time-based schema, where regular measurement and remedial work or compensation can be used to keep the machine within the desired accuracy tolerance. Naturally, it is important that the time between calibration cycles is no longer than the time taken for the machine to exceed the tolerance. A drawback of this strategy is the length of time required to perform the calibration. On large or complex machines, a full calibration can take several days.

Predictive Calibration ( $\mathrm{PdC})$ is a new methodology proposed to be analogous with, or indeed a subset of, a PdM strategy. Correctly implemented, it can achieve the same goal of sustaining the machine accuracy, but reduce the unnecessary downtime required for period calibration. It is intended to be a formalised approach applied to machine tools to measure and monitor any degradation in the mechanical parts to assist with maintaining the key performance indicator (KPI) of positioning accuracy, while having the added-value of revealing other maintenance issues such as wear in ball-screws, guide-ways, impending bearing failure, etc. Degradation of the machine condition over time can be extracted by analysis of the historic data from the machine. Such an inspection history may be provided by "quick check" tools such as artefact probing, double Ballbar or any other appropriate measurement technique. Such measurements take between a few minutes and an hour to run. Downtime cost must be traded-off against richness of data and required trending of daily perturbations in performance.

This can be achieved by establishing relevant secondary KPI's associated with the measurement method that indicate degradation in overall machine accuracy performance. Setting appropriate tolerances then provides a trigger from these checks to instigate further intervention. Unambiguous analysis of the data is the basis of decision making for the machine to be corrected [7].

Although inspired by PdM, accuracy is difficult to monitor "live" with available technology so a periodic approach is required. It is therefore essential to apply the necessary technical knowledge along with management strategies and decision making skills [1]. Fig. 2 shows the periodic cycle of intermittent "quick checks" which eventually lead to a requirement (at time $=\mathrm{t} 5$ ) for more in-depth analysis through a full accuracy calibration.

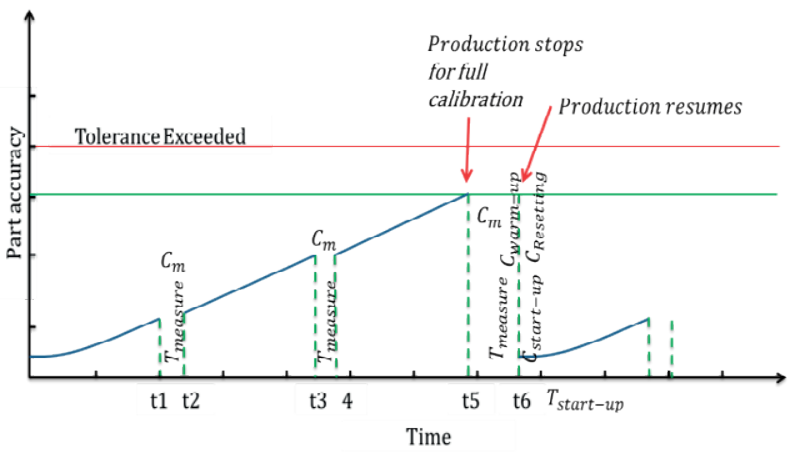

Fig. 2. Predictive calibration

Quality has always been one of the most important factors for achieving competitive advantage [8]. As a result, quality management theory is increasingly adopted in industry for 
improving competiveness and financial results. Total quality management (TQM) has been one of the most dominant methods for several years. Its goal is continuously improving organisations' abilities to deliver high quality products and services to customers, thus meeting their requirements [9]. The evolution of other quality management methods like Lean Enterprise and Six Sigma; have given the manufacturing industry the options for selecting the most suitable strategy to meet their needs. Consequently, the right balance between each of these philosophies, allowing more flexibility to the users and their integration, continues to grow towards improving overall performance [10].

In some cases, Six Sigma could be the most appropriate backbone for maintenance management improvement and the deliverance of better organisation/machine performance and cost reduction. It seeks to eliminate all unnecessary steps from a company's the processes. Six Sigma provides a structured approach to solving problems through the implementation of five phases; Define, Measure, Analyse, Improve and Control (DMAIC). Six Sigma has been described one of the WorldClass processes, [11], meaning that it can be an optimal framework for the maintenance process. This assumes that it is comprehensive and understandable for all contributors in the process, and requires minimal implementation costs. It also implies that it is globally applicable and increases overall equipment effectiveness (OEE) of the technical systems, which ultimately leads to a greater profit for the business [11].

Applying Six Sigma to maintenance follows a standard method for a program: focus on the process and engage workers. Engaging the people who best understand the process includes both the maintenance personnel and the shop-floor operators. Operators who run the machines are a key resource for achieving higher machine uptime and overall effectiveness. It is commonly assumed that such preventive management techniques work better in large companies, especially those engaged in mass production [12]. The philosophy is more difficult to apply in small companies where the investment cost of implementation is difficult to justify, even though it might eventually lead to a reduction in lost revenues and overall downtime costs.

\section{TPM}

One approach to improving the maintenance activity performance is to implement the total productive maintenance (TPM) philosophy. Based on his own observations, Nakajima [13]developed the original approach of total productive maintenance (TPM) and introduced it in Japan in 1971.

A substantial amount of literature is available from various resources on the discussion of TPM (McCall [14]; Wang [15, 16]; McKone [17]; Ahuja and Khamba [18]; etc.). However, the available literature does not explicitly discuss the positional accuracy of the machine tool. There is also a large body of literature on the role of maintenance in measuring and improving maintenance performance. Some key review articles such as: Lofsten [4]; Garg [19]; Parida [20, 21]; Al-Najjar [22]; Alsyouf [23]; Al-Turki [24]; and Simoes [5].
Academics and industry experts have published articles and case studies to raise the profile of this methodology. Consequently, TPM has expanded greatly across the world [19]. According to Pedja and Rall, "One of the concepts which cannot be avoided in reaching World-Class maintenance in a company is the application of Total Productive Maintenance" [11]. While this statement can be challenged since it makes TPM an imperative rather than an option for success, it highlights the case for taking an holistic view of the management of a company's resources.

TPM is an approach that organises all employees from top management to shop-floor workers. Nakajima argues that, "In discussing quality control, people often say that quality depends on process. Now, with increasing robotisation and automation it might be more appropriate to say that quality depends on equipment." [13]. While this is true for highly automated industries, there remains a large proportion of manufacturing industry that relies on manually-serviced or semi-automatic production. Nevertheless, modern CNC machine tools are being given greater complexity that needs to be considered in this context.

The following five critical success elements have been defined for delivering benefits from TPM:

- Maximise equipment effectiveness.

- Establish a thorough system of preventative maintenance for the equipment's entire life span.

- Involve all departments (engineering, operations, and maintenance).

- Involve all employees from top management to workers on shop-floor.

- Promote TPM through motivation management: autonomous small group activities.

These concepts can all be translated to the challenge of maintaining machine tool positional accuracy. There are many examples of TPM effectiveness [12] such as reduction of equipment breakdown of $2 \%$, up to $26 \%$ increase in equipment operation rates, $90 \%$ reduction in process defects and $40-50 \%$ increase in labour productivity [13]. However, it has been reported to take an average of three years from the introduction of TPM to achieve such dramatic results. Some companies fail to reach this stage because they do not support the entire workforce or involve all levels of management [13]. These initiatives failed because they were applied piecemeal and so were rejected by those people who did not have ownership of the integration [12]. Restoring the equipment to its proper condition and educating workers about the equipment are therefore fundamental costs that the company should take into account.

\section{STRIVING FOR OEE - OVERALL EQUIPMENT EFFECTIVENESS}

Setting understandable and quantifiable targets is a fundamental strategy for ensuring that all elements of the workforce can focus on a common goal. Key performance 
indicators (KPIs) are measurable metrics that provide an essential common reference for comparison of achievement against target. The value placed upon a KPI must be sufficiently ambitious to drive change, but must be realistic or will lead to failure and constant "firefighting."

A particular issue around machine tool accuracy is the existence of possibly conflicting KPIs. For example, when a machine is required to produce low volumes of products then the KPI for machine utilization might be low. This would allow plenty of time to carry out measurement tasks to ensure that accuracy levels were maintained at a high value. The converse is true; where high production rates are demanded, then this can affect the ability to meet accuracy maintenance targets. This problem is exacerbated where two independent departments have "ownership" of the conflicting KPIs; the maintenance department is required to ensure accuracy, while the production department is measured against production rate. This is why the company-wide approach is so important.

The result of TPM activities is made evident by measuring the Overall Equipment Effectiveness (OEE). Nakajima [13] identified the input factors as man, machine and material and the outputs comprised of production $(\mathrm{P})$, quality $(\mathrm{Q})$, cost $(\mathrm{C})$, delivery (D), safety, health and environment (S), and morale (M). TPM strives to improve OEE by maximising output while minimising input, i.e. the Life Cycle Cost [13]. More clearly, TPM strives to maximise (PQCDSM) by maintaining ideal operation conditions and running equipment effectively. A machine, equipment or instrument that often breaks down, experiences speed losses, produced rejects or non-conformance parts is not operating effectively.

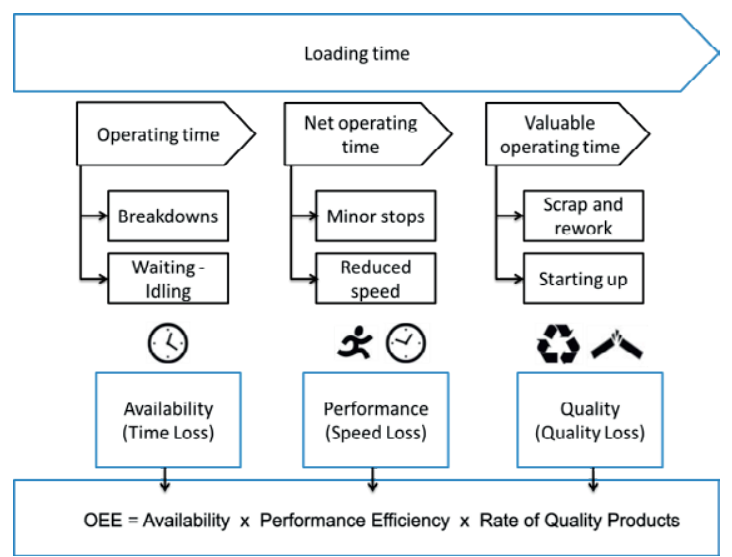

Fig. 3. Overall Equipment Effectiveness

To achieve OEE, TPM focuses on eliminating the six major equipment loss elements "six big losses" $[12,13]$, which are categorized in Fig. 3.: breakdown due to equipment failures; setup and unnecessary adjustments; idling and minor stops; reduced speed; start-up rejects; and production rejects.

The final two "losses" are the quality related waste which can partly derive from the positional inaccuracy of the machine. Once again, a balance must be achieved between addressing these issues and the negative impact that the proactive tasks will have on downtime of the machine. A further conflict, which cannot be ignored, is that maximizing speed of production can have an adverse effect upon the accuracy of the machine.

Calibrating the machine regularly has a time penalty, but aims to produce better overall machine availability by reducing scrap and rework. Therefore, it will increase the effective operating time by eliminating the wasteful bad-production time. The machine availability will have a great influence on having better performance efficiency and as a result a higher quality rate of parts will be produced. In other words, maintaining the machine regularly should increase the OEE.

\section{The EIGHT PILlaRs OF TPM}

The Japan Institute of Plant Maintenance (JIPM) developed an eight pillar approach to TPM, as shown in Fig. 4 that is focused on achieving:

- Zero Accidents

- Zero Break-downs

- Zero Defects

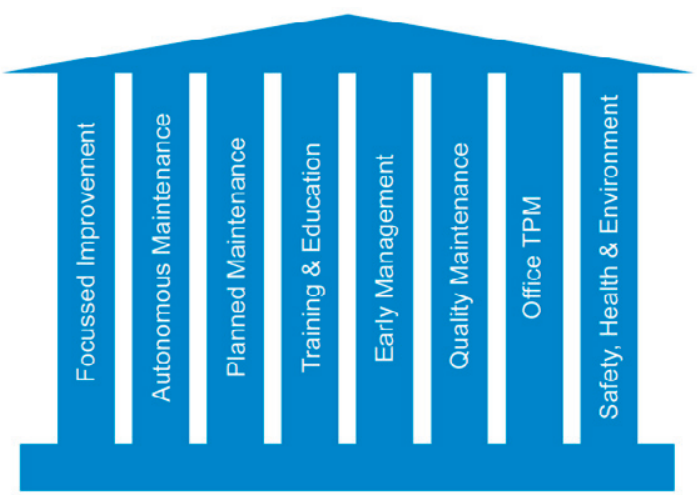

Fig. 4. Eight pillar approach to TPM (source:[25])

The goal for each pillar is to reduce loss with the ultimate aim of elimination of all losses. The overall process is a long term structure to support the cultural change within the industry. These pillars form an organised structure that bridges the gap in a way of managing change to ensure the industry sustains improved results for the future. The way in which these pillars are applied to machine tool calibration is detailed below.

\section{A. Focusssed Improvement}

The first pillar of TPM is focused improvement, which is based on the belief that, "it can always be better." In order for an industry to maintain maximal efficiency and availability of all its machines, it needs a different approach from the traditional concept of maintenance management. This must 
take into account the entire organization as a man-machineenvironment. It must also apply continual measures to prevent all losses, while improving maintenance processes.

This pillar provides a structured, team-based approach in order to eliminate losses in any process [25].

The focused improvement pillar can reduce defects and machine inaccuracy by developing the capabilities of teams to be self-sufficient in applying appropriate problem solving, as well as improving safety performance through to eliminating losses. It also ensures that the approach taken is repeatable and consistent, to assure sustainability [25].

\section{B. Autonomous Maintenance}

The second of the eight pillars of TPM is autonomous maintenance. This pillar aims to increase the skill levels of maintenance personnel so they can better understand, manage and improve their machines and the production process. The objective is to change workers from being reactive to working in a more proactive way [25], to achieve optimal conditions that eliminate stops as well as reducing the production of nonconformance parts, rejects and machine failures.

For instance, a CNC machine tool operator might traditionally react to inaccuracies in a part by making minor adjustment to the machine's set up or an offset in the part program. It is also quite common for an operator to "override" a feed-rate to increase production rates, or override a spindle speed command if the machining process "sounds" wrong. However, such a course of action, when taken in isolation, can have serious ramifications. Although a change in procedure can benefit a particular job, it could make some other jobs worse, or at least could mask an underlying problem. These undocumented reactive measures should be eliminated as part of autonomous maintenance. Instead, the knowledge and experience of the operator should be embraced to inform the maintenance department of potential issues developing on the machine.

\section{Planned maintenance}

The third pillar of TPM is planned maintenance. It provides a structure that follows an approach to establish clear maintenance plans that improves the machine reliability at optimum cost. A highly skilled maintenance team leads the planned maintenance activities and they should be able to provide a clear evaluation of the current maintenance performance and costs to set the focus for the pillar activity [25]. Both autonomous and planned maintenance go hand in hand together to support each other to establish a sustainable standard basic condition and the team focuses on eliminating the causes of the machine positional errors, machine deterioration or imminent failure. The maintenance team identifies the optimum strategy for maintaining the machine, starting with a preventative (Time-based) maintenance strategy then introducing predictive maintenance where appropriate [25].

\section{Training and education}

Training and educating workers is essential in order to change the culture of the company. Good education will alter the way the workers react when changes are proposed. For example, the knowledge and skills of maintenance technicians may be useful to further improve the detail of the maintenance plan [19]. However, this wealth of experience can only be exploited if all parties communicate with a common language and reference frame. This pillar ensures that employees are trained in the skills identified as necessary both for their personal development and for the effective deployment of TPM; without sufficient education, the impact of the other pillars will not be sustainable [25].

Machine tool accuracy is affected by a complex interaction of many factors. Therefore, education in the fundamentals of the issue and training in specific maintenance tasks must precede implementation of changes to maintenance procedures. The maintenance technicians should be given full training in order to eliminate any misinterpreting, false readings and therefore false reaction. Machine operators should be suitably informed of the reasons that maintenance technicians are performing measurement jobs on their machines so that they can provide support evidence for any root cause analysis. Product designers need to understand the true capability of machines so that they can tailor their designs according to available assets, or else specify that new equipment is required to meet their exacting demands.

\section{E. Quality Maintenance}

This pillar stresses that everyone is responsible for maintaining optimal quality conditions and striving for zero defects. Operators and maintenance workers must have the essential capability to sustain the quality of machine conditions so that they can rectify any machine deterioration and eliminate any process problems.

Critical to the success of maintaining machine tool accuracy is the need for the measurement action to be done properly. Measurement tools must be kept protected, clean and tidy to a level that is not always seen with other maintenance tools. For example, some maintenance workers keep dial/digital test indicators, able to measure with ten micron resolution, unprotected in their tool boxes alongside spanners and screw drivers. In this situation, without proper use and storage, no subsequent measurement could be relied upon.

\section{F. Office TPM}

Office TPM is a very important pillar that concentrates on all areas that provide administrative and support functions in the whole industry. This plays an important role in scheduling measurement tasks, collating and safely storing data, etc. This function allows a single measurement to become part of a company-wide investigation, maximising the value of the measurement time. 


\section{G. Safety, Health and Environment}

Safety, health and the environment pillar aims to eliminate the root of causes of incidents and reduce the risk of future potential incidents. It targets workers' behaviour, machine conditions and the management system. It can prevent the recurrence of lost time incidents and reduce the number of minor incidents. The benefit of this is a financial saving in the cost of investigation and compensation as well as reputational impact [25].

Recent trends in distributing the measurement tasks for machine quick checks have led to higher requirement for health and safety. For instance, the double ball bar is a tool that can be used by machine tool operators, but which traditionally required that the machine doors be open to allow the data capture wire to be connected to a PC. In recent years, Renishaw plc developed a wireless version of the device (QC$20 \mathrm{w}$ ) so that it can be operated without the need for safety doors to be open.

Presently, more complicated measurements using, for example, a laser interferometer are more difficult to be achieved with the machine doors closed. They are run under special maintenance modes by expert personnel. However, this could be improved by modifying the machine tool to allow access for the laser without interfering with the safety systems.

\section{PRedictive Calibration ScEnario}

A strong case is required to justify the period of downtime for machine tool calibration if the machine is producing the quantity of parts desired within their nominal tolerance. A new method for maintaining machine tool accuracy that is complimentary to the predictive maintenance paradigm is required. This strategy, called predictive calibration, is a methodology that depends on the prediction of the degradation in machine tool accuracy based upon regular data capture. It is shown in Fig. 5.

Predictive calibration is a methodology that depends on the prediction of the degradation in machine tool accuracy based upon regular data capture. It is a new method of identifying indirect boundaries of machine tool working tolerance. These boundaries reflect the degradation level corresponding to production capacities and the resultant effect on the quality of the part produced. Although introducing such a strategy will introduce a new cost, the aim is to offset this investment by optimising the operational efficiency and reducing the overall downtime cost due to unexpected and unplanned quality issues of the machine. The further benefit is that, being in control of the machine accuracy, it will reduce the overall downtime of a manufacturing facility by being able to eliminate the machine as a root cause of any failure later in the production process.

The main objective is achieved by monitoring the condition of the machine tool by collecting data using quick check measurement techniques or monitoring post-process quality data. Calibration should, therefore, be driven by the data measured from either the machine or the part. Building a database of inspection history by measuring the machine on a regular basis, with relatively non-invasive methods, will make the decision of scheduling extensive calibration a better informed process [1].

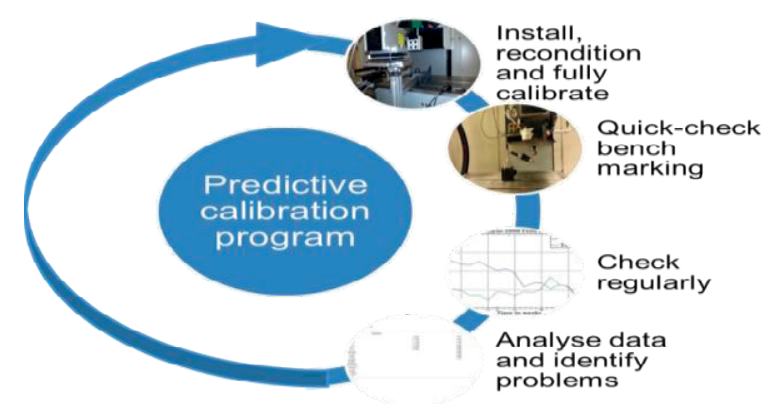

Fig. 5. Predictive calibration process

\section{Maintenance Strategy As Part Of An Holistic PROCESS}

Statistical data describing the frequency of failures can be summarised in what is called a "bathtub curve." illustrated in Fig. 6. The bathtub curve is a well-known theoretical representation of the mean-time-to-failure (MTTF) profile over a product lifecycle. It indicates that a new product (in this case machine tool) has a high likelihood of failure due to design errors and/or installation problems throughout the first few weeks of operation. These failures are referred to as "wear in" failures [26]. After this initial period, the likelihood of failure is relatively low for a relatively extended period of operation. This period of low risk of failure is known as the "normal wear" period that represents most of the life of the machine tool. After this normal period, the machine gradually reaches the end of its designed life and the chance of failure increases with time. This is called "wear-out" failures [26, 27].

Preventative and predictive maintenance (accuracy-based), consists of deciding whether or not to maintain a system according to its state [19]. They are effective proactive counter measures for machine failures. However, there are some machine early design errors and other accidental errors caused primarily by operation errors. All these could be reduced efficiently by the implementation of TPM. The success of TPM in this case depends on the cooperation of all departments by ensuring that the installation, wearing-in and service life of the machine are managed to limit breakdowns and accuracy failures.

The bathtub curve drawn to represent any particular machine tool is dependent upon a number of factors including: how many other machines of that type have been produced by the original equipment manufacturer (OEM); how many have been used by the end-user of the system; what variance there is in production types; complexity of the machine; age of the facility; etc.

Often, the performance, repeatability and precision designed into machine tools is assumed to be guaranteed from the OEM facility to the end-user's factory. However, this is not 
always the case. Furthermore, proper installation, in a manner designed specifically to meet the machine's requirements, is essential to minimize the wear-in accuracy failures. An important aspect is the foundation and subsoil onto which the machine is installed. It is an essential aspect of attaining optimal performance with the machine tools, but is often not considered as a measurable property of the machine. Nevertheless, there are many cases where the main cause for excessive maintenance or scrap at an early stage of the machine's life was due to unmonitored settling of the foundations. Normal accuracy wear also derives from an installation that did not provide satisfactory support or isolation against shock and vibration [28].

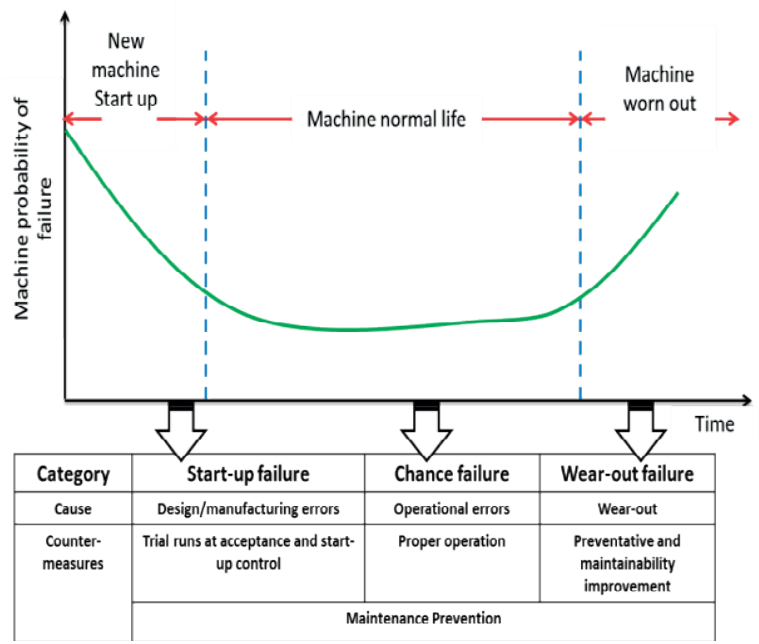

Fig. 6. Typical bathtub curve and machine failure counter measures [13]

Other factors that could affect the early part of the machine's working life include the unexpected effects from nearby manufacturing operations including heavy presses, moving cranes, local transport infrastructure, etc. Not every machine is affected by such perturbations, but without comprehensive accuracy monitoring, a new machine can produce unexpectedly poor performance due to such effects.

Early-life incidents occur dynamically and unpredictably while the machine is being integrated into the production processes. Programming/operator errors due to unfamiliarity can increase the likelihood of collisions. Such events makes the new machine tool have a high likelihood of sudden accuracy change throughout the first few weeks of machine operation and cause operation problems that interrupt the production process introduce delays in the working schedule plan. For instance, a collision problem could damage the machine guideways or the ball-screw. Consequently, the accuracy of the machine tool deviates resulting in manufacturing error. Reactive maintenance would not see this error until after it had occurred. Worse still, since the machine is only being "learned" by the company, it is likely that root cause analysis will focus on other aspects of the production loop, such as programming or fixturing, rather than the new machine. Therefore, this is one of the most critical periods of the machine lifecycle to have a good understanding of the machine accuracy KPI. Benchmarking the machine at the point of installation (or preferably the point of assembly, which might be at the OEM's facility) is an essential factor to enabling the new predictive calibration strategy to handle out-of-ordinary events.

These early problems could be mitigated through designers and operators experience. When installing a similar machine on subsequent occasions, the initial phase of the machine's life should be less arduous.

One of the main contributing factors to the cost of a calibration is the downtime of the machine tool, which is often perceived to be a barrier to implementing predictive calibration [2]. Both economic and performance aspects need to be considered in order to make a decision in support of machine checking and particular positional error handling policies [1]. Financial reductions can be achieved when using preventative and predictive calibration in collaboration with TPM. Such techniques are intended to leading to a better maintenance activity performance that can provide benefits to different volumes and value of manufacturing productivity [2].

\section{Discussion AND CONCLUSION}

Maintenance is a strategic concern in high value manufacturing. To achieve an optimal, cost-effective maintenance approach, the analysis of failures and development and use of applicable mathematical cost algorithms is essential. The performance of a machine tool or group of machine tools depends not only on the design, layout and operation, but also on effective calibration and maintenance of the machines during their operational lifetime.

Advanced manufacturing technologies and modern metrology introduces key factors such as downtime and product quality when measuring maintenance effectiveness. Considerations of safety and environmental sustainability of manufacturing facilities have also become increasingly important. Waste in manufacturing, scrapped raw materials, energy and consumables during re-machining all have a significant cost and negative impact on the environment.

Product inaccuracy can be derived from many factors. One of these is the machine tool on which the part is produced. Errors in the machine can also be caused by many factors. These can be worst during the early life of the machine. Design, installation and operation problems, poor measuring techniques, poor measuring equipment and misinterpretation of measuring data could lead to machine inaccuracy or incorrectly ascribing product inaccuracy to the machine. A scientific approach to measurement is essential for minimising uncertainties and aiming for better decision making.

Performance, repeatability, and precision designed into today's sophisticated machine tools cannot be delivered without proper installation in a manner designed specifically to meet the machine's requirements. Predictive calibration is a technique which helps to facilitate greater control of manufacturing accuracy issues and diagnosis of the cause of out of tolerance parts. In turn, this leads to a reduction in 
machine tool downtime and facilitates traceable inspection on the machine, increasing overall efficiency.

Defining KPI's is a common management tool. Performance metrics provide an essential common platform for comparison, based on which improvements can be sought for any individual indicator. Performance metrics assist in establishing benchmarks that provide guidance to management in decision-making and indicate the success of current facility management practices. Furthermore, authentic, well-defined, and compatible performance indicators should be the backbone of strategies for analysis and decision-making.

It has been accepted over the last sixty years that the total productive maintenance management technique saves a significant amount of money in lost production, reduces waste production and can extend machine lifetime.

The article presented review of maintenance management methodologies, in particular TPM, and their application to positional error calibration decision-making. This paper is oriented to predictive calibration as a proactive approach to addressing machine tool inaccuracy and the problem of the decision making process and therefore the importance to make distinction between incidents and the need for on machine checking, preventive and predictive calibration. This work seeks to redefines the role of maintenance management methods and develops a framework to support the process of implementing a predictive calibration program as a prime method to supporting the change of philosophy for machine tool calibration decision making. This paper discusses some examples of the different TPM pillars for the problem of machine tool position accuracy maintenance.

\section{ACKNOWLEDGMENT}

The authors gratefully acknowledge the UK's Engineering and Physical Sciences Research Council (EPSRC) funding of the EPSRC Centre for Innovative Manufacturing in Advanced Metrology (Grant Ref: EP/I033424/1).

\section{REFERENCES}

[1] A. Shagluf, A. P., Longstaff, S., Fletcher, P., Denton, , "Toward a Downtime Cost Function to Optimise Machine Tool Calibration Schedules," presented at the International Conference on Advanced Manufacturing Engineering and Technologies, KTH Royal Institute of Technology in Stockholm, Sweden, 2013. A. Shagluf, S., Parkinson, A. P., Longstaff, S., Fletcher, , "Towards an Optimization Calculation for Preventative and Reactive Calibration Strategies," presented at the Sustainable Design and Manufacturing 2014, SDM-14., Cardiff, Wales, UK. 2014.

[3] J. Moubray, Reliability-centred maintenance. New York, N.Y: Industrial Press, 1992.

[4] H. Löfsten, "Measuring maintenance performance - in search for a maintenance productivity index," International Journal of Production Economics, vol. 63, pp. 47-58, 2000. of maintenance performance measurement: A conceptual framework and directions for future research," Journal of Quality in Maintenance Engineering, vol. 17, pp. 116-137, 2011.

\& Francis, 2013

A. Shagluf, A. P., Longstaff, S., Fletcher, P., Denton, A., Myers, , "Predictive Calibration-Based Tolerance Boundaries For Arresting Deterioration of Machine Tool Accuracy," presented at the Manufacturing the Future conference 2013, Manufacturing at Cranfield University, 2013.

[8] V. B. Andrea Ionica, Eduard Edelhauser, Sabina Irimie, "TQM and Business Excellence.pdf," Annals of the University of Petrosani, Economics, vol. 10(4), pp. 125-134, 2010.

[9] J. S. Oakland, Total Quality Management, Second ed. Oxford: Butterworth-Heinemann, 1993.

[10] B. Klefsjo and B. Bergquist, "Six Sigma and Total Quality Management Different Day Same Soup," Inernationa Journal for Six Sigma and competitive Advantage, pp. 162-178.

[11] M. Pedja and Klaus Rall, "Six Sigma concept in the maintenance process of technical systems," Mechanical Engineering, vol. 3, pp. 93-108, 2005.

[12] D. McCarthy and N. Rich, Lean TPM: a blueprint for change. Amsterdam; London: Elsevier Butterworth-Heinemann, 2004.

[13] S. Nakajima, Introduction to TPM: total productive maintenance. Cambridge, Mass: Productivity Press, 1988.

[14] J. J. McCall, "Maintenance Policies For Stochastically failing Equipment: A Survey," Management Science, vol. 11, pp. 493$524,1965$.

[15] C. Wang and B. Thomas, "Predictive maintenance and machine tool calibration techniques," vol. 69, ed. Cincinnati: Gardner Business Media Inc, 1997, p. 102.

[16] H. Wang, "A survey of maintenance policies of deteriorating systems," European Journal of Operational Research, vol. 139, pp. 469-489, 2002.

[17] K. E. McKone and R. G. Schroeder, Cua, Kristy O., "The impact of total productive maintenance practices on manufacturing performance," Journal of Operations Management, vol. 19, pp. 39$58,2001$.

[18] I. P. S. Ahuja and J. S. Khamba, "Total productive maintenance: literature review and directions," International Journal of Quality \& Reliability Management, vol. 25, pp. 709-756, 2008.

[19] A. Garg and S. G. Deshmukh, "Maintenance management: literature review and directions," Journal of Quality in Maintenance Engineering, vol. 12, pp. 205-238, 2006.

[20] A. Parida and U. Kumar, "Maintenance performance measurement (MPM): issues and challenges," Journal of Quality in Maintenance Engineering, vol. 12,pp. 239-251, 2006.

[21] A. Parida and G. Chattopadhyay, "Development of a multi-criteria hierarchical framework for maintenance performance measurement (MPM)," Journal of Quality in Maintenance Engineering, vol. 13, pp. 241-258, 2007.

[22] B. Al-Naijar, "The lack of maintenance and not maintenance which costs: A model to describe and quantify the impact of vibrationbased maintenance on company's business," International Journal of Production Economics, vol. 107, pp. 260-273, 2007.

[23] I. Alsyouf, et al., "The role of maintenance in improving companies' productivity and profitability," International Journal of Production Economics, vol. 105, pp. 70-78, 2007.

[24] U. Al-Turki, "Methodology and theory a framework for strategic planning in maintenance," Journal of Quality in Maintenance Engineering, vol. 17, pp. 150-162, 2011.

[25] O. Chris, Industry Forum, Business Excellence Through Inspired People. "Total Productive Maintenance" [Online]. Available: http://www.industryforum.co.uk/wpcontent/uploads/2011/05/Total-Productive-MaintenanceOverview-Low-Res.pdf

[26] C. K. Mechefske, "Machine Condition Monitoring and Fault Diagnostics," in Vibration an d shock Handbook, C. W. d. Silva, Ed., ed. Boca Raton: CRC press, Taylor and Francis Group, 2005, p. 35 .

[27] R. K. Mobley. (2002, June/2013). An introduction to predictive maintenance (second edition ed.).

W. Whittaker, "Preventing Machine Instalation Problems," U. M. I. Systems, Ed., ed. Jackson, MI, USA: Manufacturing Engineering, 1980, pp. 1-4. 


\title{
Replacement time of mining drilling rigs
}

\author{
Hussan Hamodi ${ }^{1}$; Jan Lundberg ${ }^{2}$ \\ 1'hussan.hamodi@1tu.se; ${ }^{2}$ Jan.Lundberg@1tu.se \\ 1,2 Division of Operation, Maintenance and Acoustics - Luleå University of Technology \\ Luleå, Sweden
}

\begin{abstract}
This paper presents a practical model to calculate the optimal replacement time (ORT) of drilling rigs used in underground mining. As a case study, cost data for drilling rig were collected over four years from a Swedish mine. The cost data include acquisition, operating, maintenance and downtime costs when using a redundant rig. A discount rate is used to determine the value of these costs over time. The study develops an optimisation model to identify the ORT of a mining drilling rig which represents a key performance indicator. It uses an artificial neural network (ANN) technique to identify the effect of the various cost factors on the ORT. The absolute ORT in the case study is 87 months, and there is an optimal replacement range within which the company can replace the rig. The results also show that the redundant rig cost has the largest impact on the ORT followed by acquisition, maintenance and operating costs. Regression analysis shows a linear relationship between the cost factors and the ORT of the drilling rig.
\end{abstract}

Keywords: capital equipment, decision support models, life cycle cost, optimal replacement time, optimisation model.

\section{Abbreviations}

\begin{tabular}{|c|c|c|c|}
\hline ORT & $\begin{array}{l}\text { Optimal replacement } \\
\text { time (month) }\end{array}$ & $P_{T_{i}}$ & $\begin{array}{l}\text { Using time of redundant } \\
\text { rig }(\mathrm{h})\end{array}$ \\
\hline$A N N$ & $\begin{array}{l}\text { Artificial neural } \\
\text { network }\end{array}$ & $C_{R_{i}}$ & $\begin{array}{l}\text { Redundant rig cost per } \\
\text { hour }(\mathrm{cu} / \mathrm{h})\end{array}$ \\
\hline$T C$ & Total cost (cu) & $T_{R_{i}}$ & $\begin{array}{l}\text { Logistic time for redundant } \\
\text { rig }(\mathrm{h})\end{array}$ \\
\hline $\mathrm{cu}$ & Currency unit & $T_{F_{i}}$ & $\begin{array}{l}\text { Restoring time of the faulty } \\
\text { rig to operation }(\mathrm{h})\end{array}$ \\
\hline$A C$ & Acquisition cost (cu) & $T_{1 i}$ & $\begin{array}{l}\text { Moving time of redundant } \\
\text { rig from its location to } \\
\text { production point }(\mathrm{h})\end{array}$ \\
\hline$i$ & Time period (month) & $T_{2 i}$ & $\begin{array}{l}\text { Moving time of redundant } \\
\text { rig from production point } \\
\text { to its original location }(\mathrm{h})\end{array}$ \\
\hline$R T$ & $\begin{array}{l}\text { Replacement time } \\
\text { (month) }\end{array}$ & $T_{M_{i}}$ & $\begin{array}{l}\text { Moving time of faulty rig } \\
\text { from production point to } \\
\text { workshop }(\mathrm{h})\end{array}$ \\
\hline$M C_{i}$ & Maintenance cost (cu) & $T_{W_{i}}$ & $\begin{array}{l}\text { Time in workshop of faulty } \\
\text { rig (h) }\end{array}$ \\
\hline$O C_{i}$ & Operating cost $(\mathrm{cu})$ & $T_{L_{i}}$ & $\begin{array}{l}\text { Moving time of repaired } \\
\text { rig from workshop to } \\
\text { production point }(\mathrm{h})\end{array}$ \\
\hline $\mathrm{CO}_{i}$ & $\begin{array}{l}\text { Compensation cost } \\
\text { (cu) }\end{array}$ & $t_{d_{i}}$ & $\begin{array}{l}\text { Delay time in workshop of } \\
\text { faulty rig before repair }(\mathrm{h})\end{array}$ \\
\hline$S_{i}$ & Resale value (cu) & $t_{r}$ & $\begin{array}{l}\text { Actual repair time of faulty } \\
\text { rig }(\mathrm{h})\end{array}$ \\
\hline$r$ & Discount rate $(\%)$ & $t_{L}$ & $\begin{array}{l}\text { Idle time in workshop of } \\
\text { faulty rig after repair }(\mathrm{h})\end{array}$ \\
\hline$T$ & $\begin{array}{l}\text { Planned life time } \\
\text { (month) }\end{array}$ & $B V_{1}$ & $\begin{array}{l}\text { Rig value at the first day of } \\
\text { operation (cu) }\end{array}$ \\
\hline
\end{tabular}

\begin{tabular}{|c|c|c|c|}
\hline$C M_{i}$ & $\begin{array}{l}\text { Corrective } \\
\text { maintenance cost (cu) }\end{array}$ & $D r$ & Depreciation rate \\
\hline$P M_{i}$ & $\begin{array}{l}\text { Preventive } \\
\text { maintenance cost }(\mathrm{cu})\end{array}$ & $S V$ & Scrap value (cu) \\
\hline$S P_{C i}$ & $\begin{array}{l}\text { Spare part cost for } \\
\text { corrective } \\
\text { maintenance (cu) }\end{array}$ & $I A C$ & $\begin{array}{l}\text { Increasing acquisition cost } \\
(\%)\end{array}$ \\
\hline$L C_{C i}$ & $\begin{array}{l}\text { Labour cost for } \\
\text { corrective } \\
\text { maintenance (cu) }\end{array}$ & $R M C$ & $\begin{array}{l}\text { Reduced maintenance cost } \\
(\%)\end{array}$ \\
\hline$S P_{P_{i}}$ & $\begin{array}{l}\text { Spare part cost for } \\
\text { preventive } \\
\text { maintenance (cu) }\end{array}$ & $R O C$ & $\begin{array}{l}\text { Reduced operating cost } \\
(\%)\end{array}$ \\
\hline$L C_{P i}$ & $\begin{array}{l}\text { Labour cost for } \\
\text { preventive } \\
\text { maintenance (cu) }\end{array}$ & $R R C$ & $\begin{array}{l}\text { Reduced redundant rig cost } \\
(\%)\end{array}$ \\
\hline$R C_{i}$ & $\begin{array}{l}\text { Redundant rig cost } \\
(\mathrm{cu})\end{array}$ & $\mathrm{h}$ & Hour \\
\hline
\end{tabular}

\section{INTRODUCTION}

Mines are important sources of minerals and energy resources. An extremely important and very expensive piece of equipment used in mineral extraction is a drilling rig. Drilling rigs are necessary for production, but like all equipment used in underground mining, they are subject to degradation throughout their operating life. Therefore, the operating cost increases as a result of increased operating hours, causing a negative economic effect. In addition, the equipment used in underground mining is subject to a harsh working environment, and this accelerates its degradation. Given all these factors, a key question for mining companies is when to replace equipment to minimise cost. The optimum replacement age of equipment is defined as the time at which the total cost is at its minimum value [1]. In this study, total cost is represented by investment (acquisition or initial), operating and maintenance costs, and compensation cost.

Bellman [2] developed the first optimal asset replacement model for the variable lifetime of assets. Wagner [3] offered dynamic programming formulation for the equipment replacement problem in which the state of the system is the time period and the decision in each replacement is to keep the equipment for $N$ periods. His formulation has been extended by researchers to deal with technological changes [4-7]. These researchers assume a finite horizon in their approach to the problem of equipment replacement under non-stationary costs. A number of researchers have studied the $O R T$ of capital equipment. Some use the theory of dynamic programming considering technological changes under finite and infinite horizons [5; 8; and 9]. Others consider the optimal lifetime of 
capital equipment using economic theories and vintage capital models, represented mathematically by non-linear Volterra integral equations with unknown limits of integration [10-13]. Hartman and Murphy [14] offer a dynamic programming approach to the finite horizon equipment replacement problem with stationary cost. Their model studies the relationship between the infinite horizon solution and the finite-horizon solution. Kärri [15] considers the optimal replacement time of an old machine, using an optimisation model which minimises the machine cost. The model is built to handle capacity expansion and replacement situations using real costs without inflation. Hritonenko and Yatsenko [16] construct a computational algorithm to solve a nonlinear integral equation; the solution is important for finding the optimal policy of equipment replacement under technological advances. Other researchers have considered reliability, maintainability and optimum replacement decisions; readers are referred to, e.g., $[17 ; 18]$ for further information.

Blanchard et al. [19] mention that the costs associated with equipment operation and maintenance can account for more than $75 \%$ of the equipment life cycle cost. Given the importance of operation, maintenance and loss of production costs, industries often use redundant production equipment to prevent loss of production. Another solution is to make a pooling agreement with other companies, whereby they rent a piece of equipment to ensure the failed equipment will be replaced by a serviceable machine. But any of these compensation strategies cost money. Thus, the aim of this paper is to present a practical model for to determine the optimal replacement time of capital equipment, considering the redundant rig cost. The paper also examines the relative importance of the most influential cost factors on the $O R T$ of a drilling rig: acquisition, operating, maintenance and redundant rig costs. Finally, the optimisation model considers the time value of money by using a discount rate.

\section{CASE STUDY AND DATA COLLECTION}

The study tests the ORT model on a case study of equipment used in the mining industry. A typical mining cycle can be represented by the following processes; drilling, charging, blasting, loading, scaling and bolting. Because drilling is the first step in the cycle and the drilling rig has high acquisition and maintenance costs, the drilling rig is selected as a case study. The drilling rigs used in mines are manufactured by different companies and have different technical characteristics, e.g. power and capacity, but all are composed of similar operating units, including cabin, boom, rock drill, hose reeling unit, hydraulic pump, front jacks, feeder, rear jack, electric cabinet, service platform, cable reeling unit, diesel engine, operator panel, oil reservoir and water tank. The cost data in the mine used in this study were collected over four years in the MAXIMO computerised maintenance management system (CMMS). The cost data contain preventive maintenance costs, corrective maintenance costs, and repair time. The preventive and corrective maintenance costs contain labour and spare parts costs. In CMMS, the cost data are recorded based on calendar time. Since drilling is not a continuous process, the operating cost is estimated by considering the utilisation of the rig. The operating costs are administration, fuel, energy, operator's salary, consumables like steel rods, indirect overhead costs, etc. Due to the regulations of the collaborating mining company, all cost data are encoded and expressed as currency units (cu).

\section{MODEL DEVELOPMENT}

The ORT of capital equipment is the age that minimises total cost. In this study, the total cost is represented by investment (acquisition or initial) costs, operating and maintenance costs, and compensation costs. All repairable equipment wears with age, leading to increasing operating and maintenance $(O \& M)$ costs (data collected from MAXIMO in our case study), and decreasing resale value. This study examines the $O R T$ problem over a finite time horizon. The engineers at the collaborating mining company say the company plans to use a drilling rig for ten years (i.e. 120 months). The objective of the optimisation model is to minimise the discounted total cost over this period. In this paper, the ORT of drilling rig is defined as the value of the replacement time $(R T)$ which minimises the total cost, as shown in the following model:

$T C=\left[\left\{\begin{array}{l}\left(A C+\left[\sum_{i=1}^{R T}\left(M C_{i}+O C_{i}+C O_{i}\right)\right]-S_{i}\right) \\ \times \frac{1}{(1+r)^{\frac{i}{12}}}\end{array}\right\} \times \frac{T}{R T}\right]$

where $T C, A C, M C_{i}, O C_{i}, C O_{i}, S, r, T$ represent the total cost, acquisition cost, maintenance cost, operating cost, compensation cost, resale value, discount rate and planned lifetime respectively.

We assume the replacement rig (i.e. anew rig) has the same performance as the existing rig (i.e. identical rigs). The number of replacement cycles during the planned lifetime is equal to the planned lifetime divided by the replacement time. The maintenance cost is a summation of materials and labour expenses required to keep the equipment in suitable working condition. In this paper, the maintenance cost is represented as follows:

$$
M C_{i}=C M_{i}+P M_{i}
$$

where $C M_{i}$ and $P M_{i}$ represent corrective and preventive maintenance cost (cu) respectively.

$$
C M_{i}=S P_{C_{i}}+L C_{C_{i}}
$$

where $S P_{C_{i}}$ and $L C_{C_{i}}$ represent spare part costs and labour costs for corrective maintenance $(\mathrm{cu})$ respectively.

$$
P M_{i}=S P_{P_{i}}+L C_{P_{i}}
$$

where $S P_{P_{i}}$ and $L C_{P_{i}}$ represents spare part costs and labour costs for preventive maintenance $(\mathrm{cu})$ respectively.

In this study we focus on the redundant rig cost as a critical factor affecting the $O R T$ of a drilling rig. The maintenance 
experts at the collaborating mine classify rig failures in three categories as follows:

1. Failures fixed by maintenance team at the workshop.

2. Failures fixed by maintenance team at the production point.

3. Failures fixed by operators at the production point.

Note: we obtained information on the drilling process and maintenance of drilling rigs after discussions with experts in the user company (U) and manufacturing company (M). Detailed information, such as experience in years and work position of the experts, is provided in Table I.

TABLE I. DESCRIPTION OF EXPERTISE OF THE EXPERT GROUP

\begin{tabular}{|l|l|}
\hline \multicolumn{1}{|c|}{$\begin{array}{c}\text { Current position at } \\
\text { companies (U) and (M) }\end{array}$} & \multicolumn{1}{|c|}{$\begin{array}{c}\text { Expert field and experience (\# } \\
\text { years) }\end{array}$} \\
\hline $\begin{array}{l}\text { Maintenance Engineer } \\
\text { (U) }\end{array}$ & $\begin{array}{l}\text { Maintenance of mobile and fixed } \\
\text { equipment's (23) }\end{array}$ \\
\hline $\begin{array}{l}\text { Mine production } \\
\text { Foreman (U) }\end{array}$ & Underground drill machines (30) \\
\hline $\begin{array}{l}\text { Mine production } \\
\text { Manager (U) }\end{array}$ & Mine drilling and production (15) \\
\hline $\begin{array}{l}\text { Mine production } \\
\text { Planner (U) }\end{array}$ & Mine production planning (22) \\
\hline $\begin{array}{l}\text { Maintenance Supervisor } \\
\text { (U) }\end{array}$ & $\begin{array}{l}\text { Maintenance of mobile equipment's } \\
(30)\end{array}$ \\
\hline $\begin{array}{l}\text { Maintenance Manager } \\
\text { (U) }\end{array}$ & $\begin{array}{l}\text { Maintenance of mobile equipment's } \\
(26)\end{array}$ \\
\hline $\begin{array}{l}\text { Mine production } \\
\text { Manager (U) }\end{array}$ & Mine drilling and production (32) \\
\hline $\begin{array}{l}\text { Maintenance Foreman } \\
\text { (U) }\end{array}$ & $\begin{array}{l}\text { Maintenance of mobile equipment's } \\
(25)\end{array}$ \\
\hline $\begin{array}{l}\text { Maintenance Engineer } \\
\text { for fixed equipment (U) }\end{array}$ & $\begin{array}{l}\text { Maintenance of fixed equipment's } \\
(10)\end{array}$ \\
\hline $\begin{array}{l}\text { Global Service } \\
\text { Operations Manager } \\
\text { (M) }\end{array}$ & Maintenance of equipment (20) \\
\hline $\begin{array}{l}\text { Design Engineer- } \\
\text { Underground Drill Rigs } \\
\text { (M) }\end{array}$ & $\begin{array}{l}\text { Designing underground equipment } \\
(10)\end{array}$ \\
\hline $\begin{array}{l}\text { Global Fleet Manager } \\
\text { Vice President Service } \\
\text { Operations (M) }\end{array}$ & $\begin{array}{l}\text { Marketing and business management } \\
\text { management and Maintenance of } \\
\text { mobile equipment (18) }\end{array}$ \\
\hline $\begin{array}{l}\text { Regional business- } \\
\text { marope and product line }\end{array}$ & $\begin{array}{l}\text { Project management and business } \\
\text { management (10) }\end{array}$ \\
\hline
\end{tabular}

\section{A. First category of failures}

In the first category, failures are fixed by the maintenance team at the workshop. In this study, we assume if a rig fails and must be sent to the workshop for maintenance, the company will use a redundant rig which has the same performance as the faulty rig. Since in the mining industry, the downtime in production is almost zero, the compensation cost in this case represents the cost of using the redundant rig. As the drilling rig has failed, the drilling process will stop. The redundant rig must move from its location to the production point; the drilling process will be restarted with the redundant rig. The faulty rig must move from the production point to the workshop for repair. After repair, the faulty rig will return to the production point; the drilling process will continue by using the repaired drilling rig. The redundant rig will move from the production point back to its original location. Therefore, the compensation cost based on the first category of failures is modelled as follows:

$$
C O_{i}=R C_{i}=P_{T_{i}} \times C_{R_{i}}
$$

where $C O_{i}$ represents the compensation cost (cu), $R C_{i}$ represents the redundant rig cost $(\mathrm{cu}), P_{T_{i}}$ represents the using time of the redundant rig (h) and $C_{R_{i}}$ represents the redundant rig cost per hour, in this case study, $3(\mathrm{cu} / \mathrm{h})$.

$$
P_{T_{i}}=T_{R_{i}}+T_{F_{i}}
$$

where $T_{R_{i}}$ represents the logistic time for a redundant rig (h) and $T_{F_{i}}$ represents the time taken to restore the faulty rig to operation (h).

$$
T_{R_{i}}=T_{1_{i}}+T_{2_{i}}
$$

where $T_{1}$ and $T_{2}$, represent the time to move the redundant rig from its location to the production point and the return time after finishing its job from the production point to its original location (h) respectively.

$$
T_{F_{i}}=T_{M_{i}}+T_{W_{i}}+T_{L_{i}}
$$

where $T_{M_{i}}, T_{W_{i}}$ and $T_{L_{i}}$ represent the time to move a faulty rig from the production point to the workshop (h), time in workshop (h) and the moving time for the repaired rig from the workshop to the production point (h) respectively.

$$
T_{W_{i}}=t_{d_{i}}+t_{r_{i}}+t_{I_{i}}
$$

where $t_{d_{i}}, t_{r_{i}}$ and $t_{I_{i}}$ represent delay time in the workshop before repair $(\mathrm{h})$, actual repair time (h) and idle time in the workshop after repair (h) respectively.

\section{B. Second category of failures}

This category includes the failures fixed by the maintenance team at the production point (mining room). Suppose a rig is stopped and can be repaired in its location (i.e. production point). We assume the company will use a redundant rig with the same performance as the faulty rig. The compensation cost in this case represents the cost of using a redundant rig. As the drilling rig has failed, the drilling process will stop. The redundant rig must move from its location to the production point; the drilling process will be restarted using the redundant rig. The maintenance team will move from the workshop to the production point to repair the faulty rig. After repair, the drilling process will continue with the repaired drilling rig. The redundant rig will start to move from the production point back to its original location. Therefore, in the second category of failures, the usage time of the redundant rig when a fault is found in the existing rig is modelled as follows:

$$
P_{T_{i}}=T_{M_{i}}+T_{R_{i}}+t_{r_{i}}
$$


Since the moving speed inside the underground mine is limited to low speed, we assume the moving time of the maintenance team from the workshop to the production point is almost equal to the moving time of the faulty rig from the production point to the same workshop. Table II illustrates the minimum and maximum time values used in the model, following the suggestions of the maintenance expert in the collaborating mine.

TABLE II. MINIMUM AND MAXIMUM TIME VALUES (HOUR) USED IN THE MODEL

\begin{tabular}{|l|l|l|}
\hline \multicolumn{1}{|c|}{ Description } & Minimum & Maximum \\
\hline $\begin{array}{l}\text { Moving time for faulty rig from } \\
\text { production point to workshop }\end{array}$ & 0.5 & 1 \\
\hline Delay time in workshop before repair & 0.5 & 1.5 \\
\hline Idle time in workshop after repair & 0.5 & 1 \\
\hline
\end{tabular}

The time values $t_{d_{i}}, t_{I_{i}}, T_{M_{i}}, T_{L_{i}}, T_{1_{i}}$ and $T_{2_{i}}$ are simulated by using MATLAB code for the use of the redundant rig over four years, since this type of data is not available from the collaborating mine. We assume the moving times of the redundant rig $T_{1_{i}}$ and $T_{2}$ are equal to the moving time of the faulty $\operatorname{rig} T_{M_{i}}$. We use a discount rate of $10 \%$ to consider the time value of money, again following the company's suggestion.

\section{Third category of failures}

In the third category, failures are fixed by operators at the production point (mining room). As these are classified small failures and take little time, the mining company does not use a redundant rig.

\section{Resale value}

A declining balance depreciation model is used to estimate the resale value of our case study drilling rig after each month of operation. The rig resale value is its value if the company wants to sell it at any time during its planned lifetime. The resale value of the machine denoted $S_{i}$, is assumed to be given by the following formula $[20 ; 21]$ :

$$
S_{i}=B V_{1} \times(1-D r)^{i}
$$

where " $i$ " represents time, $i=1,2,3, \ldots, 120$ (months), $B V_{1}$ is the rig's value on the first day of operation and $D r$ represents the depreciation rate. In addition,

$$
B V_{1}=A C \times a
$$

where " $a$ " represents the percentage that is multiplied by the rig acquisition cost to determine the rig value on the first day of use. During discussions with us, company experts agreed that the rig's purchase price decreases by $10 \%$ on the first day of use (i.e. $a=0.9$ ). In this study, the rig purchase price is $6000 \mathrm{cu}$. Hence, the rig's value on the first day of use is 5400 $c u$. The depreciation rate that allows for full depreciation by the end of the planned lifetime of the rig is modelled as follows [20]:

$$
D r=1-\left(\frac{S V}{B V_{1}}\right)^{\frac{1}{T}}
$$

where " $T$ " represents the planned lifetime of the rig, 120 months in this case study. The rig is assumed to reach scrap value $(S V)$ after 120 months of operation.

The declining balance depreciation model is suitable in this case because it assumes that more depreciation occurs at the beginning of the equipment's planned lifetime, less at the end. It also considers the equipment is more productive when it is new, and its productivity declines continuously due to equipment degradation. Therefore, in the early years of its planned lifetime, a rig will generate more revenue than in later years. The scrap value is an estimate of the value of the equipment at the time it is disposed of. In this case study, $50 \mathrm{cu}$ is assumed to be the scrap value of the rig, following the comments of company experts.

\section{RESUTS AND DISCUSSION}

The model for $O R T$ was tested in a case study of a drilling rig. This rig is manufactured by Atlas Copco Company and used by Boliden Mineral AB in Sweden. MATLAB ${ }^{\mathrm{TM}}$ software is used to enable a variation of the replacement time $(R T)$ of (1) which minimises the total cost. The results show that the lowest possible total cost can be achieved by replacing the rig after 87 months of life. A decision to replace the rig before or after its $O R T$ incurs greater costs for the company. Figure 1 shows the total cost versus different replacement time $R T \mathrm{~s}$ of this case study when $C_{R_{i}}$ is equal to $3(\mathrm{cu} / \mathrm{h})$.

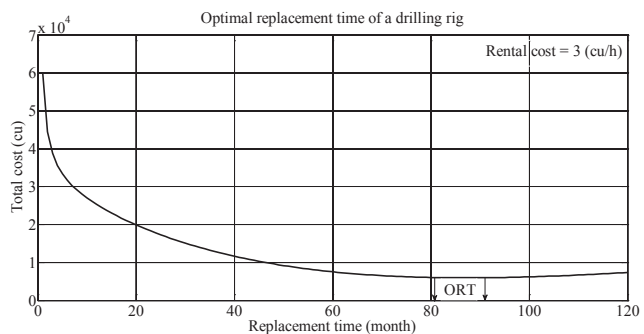

Fig. 1. Optimal replacement time of drilling rig.

Figure 1 also shows a range of 81-92 months when the minimum total cost can be still achieved in practice. In this study, we call it the optimal replacement range.

We perform sensitivity analysis to show the effect of the various cost factors influencing the rig's $O R T$. We look at rig acquisition, operating, maintenance and redundant rig costs using the $A N N$ technique. We use four MATLAB codes to identify the effect of increasing acquisition cost $(I A C)$, reduced maintenance cost $(R M C)$, reduced operating cost $(R O C)$ and reduced redundant rig cost $(R R C)$ on the $O R T$ of a new drilling rig. The resulting $O R T$ from these codes is fed as input to the neural network. The method of partitioning weights, proposed by Garson [22] and adopted by Goh [23], is used to determine the relative importance of these cost factors. Figure 2 illustrates 
their relative importance using a redundant rig cost per hour equal to $3(\mathrm{cu} / \mathrm{h})$

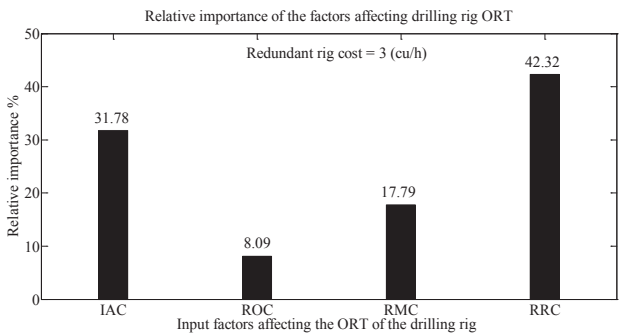

Fig. 2. Relative importance of the factors affecting the drilling rig's $O R T$

As evident in Figure 2, the most important factor influencing the $O R T$ of the drilling rig is $R R C$ followed by $I A C$, $R M C$ and $R O C$. Therefore, a design for reliability and maintainability should be adopted to reduce the downtime and maintenance costs.

To increase our understanding of the correlation between the input and output factors in the $A N N$; we performed a sensitivity analysis to identify the effect of $I A C, R M C, R O C$ and $R R C$ on the drilling rig's $O R T$. In the sensitivity analysis, the acquisition cost increases while the $O \& M$ and redundant rig costs decrease. Figure 3 shows the $O R T$ as a function of $R R C$ with $I A C$ for a given $25 \% R O C$ and $R M C$. Figure 4 shows the $O R T$ as a function of $R R C$ with $R M C$ for a given $25 \% I A C$ and $R O C$. Figure 5 shows the $O R T$ as a function of $R R C$ with $R O C$ for a given $25 \% I A C$ and $R M C$.

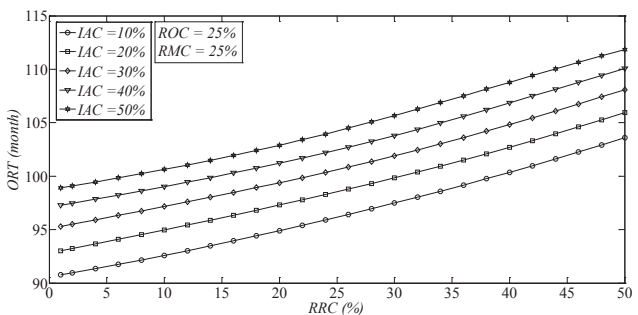

Fig. 3. $O R T$ as a function of $R R C$ with $I A C$ for a given $25 \% R O C$ and $R M C$.

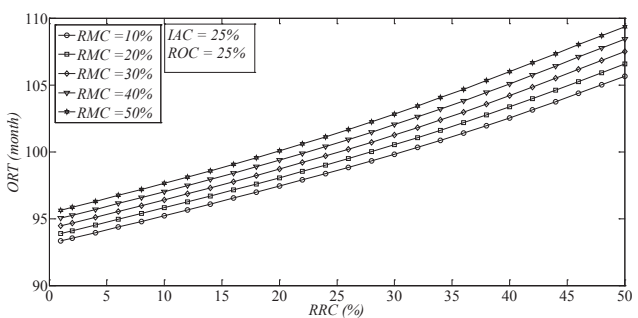

Fig. 4. ORT as a function of $R R C$ with $R M C$ for a given $25 \% I A C$ and $R O C$.

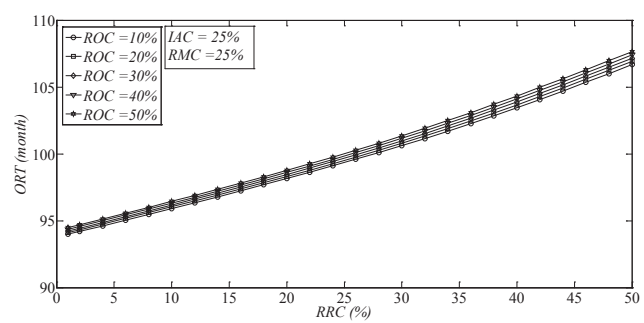

Fig. 5. ORT as a function of $R R C$ with $R O C$ for a given $25 \% I A C$ and $R M C$.

As Figures 3-5 show, $R R C, I A C, R M C$ and $R O C$ have a positive effect on increasing the $O R T$ of a new drilling rig. It is also evident that $R R C$ with $I A C$ has the largest impact followed by $R R C$ with $R M C$ and $R R C$ with $R O C$.

\section{A. Regression analysis}

The regression analysis of the results obtained from the four MATLAB codes uses Minitab software and the least square's method. $O R T$ is modelled as a linear function of $I A C$, $R O C, R M C$ and $R R C$. The regression analysis results in the following mathematical model:

$$
\begin{aligned}
& O R T=85.5+0.21 \times I A C+0.02 \times R O C \\
& +0.07 \times R M C+0.27 \times R R C
\end{aligned}
$$

It is evident from the constants of the regression model (14) for this particular case (i.e. $C_{R_{i}}=3 \mathrm{cu} / \mathrm{h}$ ) that $R R C$ has largest effect on the $O R T$ of the drilling rig followed by $I A C, R M C$ and $R O C$. The R-squared value obtained from regression analysis, $\mathrm{R}^{2}$ (adj.) $=99.1$, indicates that the $O R T$ of the drilling rig depends linearly on the factors of $I A C, R O C, R M C$ and $R R C$. It is obvious from (14) that the regression model confirms the computations and the results of the sensitivity analysis. The mining company can use the obtained regression model to estimate the ORT of a new drilling rig. They also can use it in negotiations with manufacturing company on the purchase price of the new model, since they know the new rig's replacement time and the amount of revenue it will generate.

\section{CONCLUSIONS}

This paper presents a practical model for a finite time horizon equipment replacement problem. It is also shows the relationship between the factors affecting the ORT of a drilling rig in the particular case of using a redundant rig cost per hour equal to $3(\mathrm{cu} / \mathrm{h})$. The model is found to be a good choice for calculating the ORT of a drilling rig used in underground mines. Therefore, it can be extended to other capital assets in other industries.

According to the results of the optimisation curve, the absolute $O R T$ of our case study is 87 months of operation. However, the ORT has a range of 81 to 92 months, during which time the total cost remains almost constant. This means the company has the flexibility to make replacements within the optimum replacement age range of 12 months.

The results of the $A N N$ analysis show that the redundant rig cost has the highest impact on the ORT. This factor affects the 
ORT of our case study by $42 \%$. The sensitivity analysis indicates that increasing the acquisition cost, decreasing the $O \& M$, and decreasing the redundant rig costs have a positive effect on increasing the $O R T$ of a new drilling rig. This proves that improving the reliability and maintainability of rigs is essential to reduce the downtime and maintenance costs. The sensitivity analysis also shows that $R R C$ with $I A C$ has the greatest impact on increasing the $O R T$ of a new drilling rig followed by $R R C$ with $R M C$ and $R R C$ with $R O C$. The regression analysis indicates that the $O R T$ of the new rig depends linearly on its $I A C, R O C, R M C$ and $R R C$. These results confirm the results of the sensitivity analysis.

Finally, our optimisation model can help decision makers in their management to determine when it is best economically to replace old equipment with new machines. They also can use it in negotiations with manufacturing companies on the purchase price of new drilling rigs.

\section{ACKNOWLEDGMENT}

The authors would like to thank Atlas Copco and Boliden Mineral AB for supporting this research. Special appreciation is extended to the experts at Boliden Mineral $\mathrm{AB}$ and Atlas Copco for sharing their valuable knowledge and experience to enhance our paper. The authors would like also to thank Arne Vesterberg at Boliden Mineral AB and Andreas Nordbrandt at Atlas Copco for them supports.

\section{REFERENCES}

[1] A. Jardine, and A. Tsang, Maintenance, Replacement, and Reliability Theory and Application, Taylor \& Francis Group: New York, 2006, pp.135-137.

[2] R. Bellman, "Equipment replacement policy," Journal of Society for Industrial and Applied Mathematics, vol. 3, pp. 133-136, 1955

[3] H.M. Wagner, Principles of Operations Research, Prentice-Hall, Inc., Englewood Cliffs, 1975, pp. 303-337.

[4] R.V. Oakford, J.R. Lohmann, and A. Salazar, "Adynamic replacement economy decision model," IIE Transactions, vol. 16, pp. $65-72,1984$

[5] J.C. Bean, J.R. Lohmann, and R.L. Smith, "A dynamic infinite horizon replacement economy decision model," The Engineering Economist, vol. 30, pp. 99-120, 1985.

[6] J.C. Hartman, and J. Rogers, "Dynamic programming approaches for equipment replacement problems with continuous and discontinuous technological change," IMA Journal of Management Mathematics, vol. 17, pp. 143-158, 2006.
[7] N. Hritonenko, and Y. Yatsenko, "The dynamics of asset lifetime under technological change," Journal of the Operations Research Letters, vol. 36, pp. 565-568, 2008.

[8] E.J. Elton, and M.J. Gruber, "On the Optimality of an Equal Life Policy for Equipment Subject to Technological Improvement," Operational Research Quarterly, vol. 27, pp. 93-99, 1976.

[9] G. Bethuyne, "Optimal Replacement Under Variable Intensity of Utilization and Technological Progress," The Engineering Economist, vol. 43, pp. 85-105, 1998.

[10] R. Boucekkine, M. Germain, and O. Licandro, "Replacement Echoes in the Vintage Capital Growth Model," Journal of economic theory, vol. 74, pp. 333-348, 1997.

[11] T. Cooley, J. Greenwood, and M. Yorukoglu, "The replacement problem," Journal of Monetary Economics, vol. 40, pp. 457-499, 1997.

[12] N. Hritonenko, "Optimization Analysis of a Nonlinear Integral Model with Applications to Economics," Nonlinear Studies, vol. 12, pp. 59-71, 2005.

[13] N. Hritonenko, and Y. Yatsenko, Applied Mathematical Modeling Of Engineering Problems, Kluwer Academic Publishers: New York, 2003, pp 183-232.

[14] J.C. Hartman, and A. Murphy, "Finite-horizon equipment replacement analysis," IIE Transactions, vol. 38, pp. 409-419, 2006.

[15] T. Kärri, Timing of Capacity Change: Models for Capital Intensive Industry, $\mathrm{PhD}$ thesis, Lappeenranta University of Technology, Lappeenranta, 2007.

[16] N. Hritonenko, and Y. Yatsenko, "Integral equation of optimal replacement: Analysis and algorithms," Journal of Applied Mathematical Modelling, vol. 33, pp. 2737-2747, 2009.

[17] A. R. Wijaya, J. Lundberg, and U. Kumar, "Robust-optimum multi-attribute age-based replacement policy," Journal of Quality in Maintenance Engineering, vol. 18, pp. 325 343, 2012.

[18] R. Dandotiya, Decision support models for the maintenance and design of mill liners, PhD thesis, Luleå University of Technology, Luleå, 2012.

[19] B. S. Blanchard, D. Verma, and E. L. Peterson, Maintainability: a key to effective serviceability and maintenance management, John Wiley \& Sons: New York, 1995, pp. 6, 426.

[20] B. Luderer, V. Nollau, and K. Vetters, Mathematical formulas for economists, $4^{\text {th }}$ ed. Springer-verlag Berlin Heidelberg: London New York, 2010, pp.43.

[21] T. Eschenbach, Engineering economy: applying theory to practice, 3rd ed., Oxford University Press: New York, 2010, pp. 173-180.

[22] G. D. Garson, "Interpreting neural network connection weights," Artificial Intelligence, vol. 6, pp. 47-51, 1991.

[23] A. T. C. Goh, "Back-Propagation neural networks for modeling complex systems," Artificial Intelligence in Engineering, vol. 9, pp. 143-151, 1995. 


\title{
Maintenance Continuous Performance Assessment of a Hospital Operating Room AVAC System
}

\author{
Rui Assis \\ rassis@rassis.com; www.rassis.com \\ Instituto de Soldadura e Qualidade - ISQ \\ Tagus Park, Oeiras, Portugal
}

\begin{abstract}
The present paper depicts a method to continuously evaluate the operational performance of resources allocated to the maintenance of an AVAC system, that provides air conditioning to surgery rooms in a public hospital at the lowest possible energy cost. The method combines three other methods: the "Balance Score Card (BSC)", the "Analytical Hierarchy Process (AHP)" and the "Metrics-Merit Conversion (MMC)". The hierarchy is formed by 52 indicators. A sensitivity analysis completes the decision making process by providing guidance to prioritize improvement courses of action.
\end{abstract}

\section{Keywords-AHP, performance assessment, metrics}

\section{INTRODUCTION}

The recently published International Standard ISO 55000 specifies the requirements for the establishment, implementation, maintenance and improvement of a management system for asset management, referred to as an "asset management system". This International Standard can be applied to all types of assets and by all types and sizes of organizations. This International Standard is intended to be used for managing physical assets in particular, but it can also be applied to other asset types. Point 9 of this standard deals with "Performance evaluation" and sub-point 9.1, more specifically, deals with "Monitoring, measurement, analysis and evaluation".

Further below, a method which was developed a few years ago by the author and counting already with a few implementations in the field is proposed to allow the management performance assessment of resources - technical and human - allocated to a major objective here named "overall merit" in a broad sense. The method combines three known management methods: Balanced Scorecard (BSC) [2], Analytic Hierarchy Process (AHP) [3] and Metrics-Merit Conversion (MMC) [4]. The management performance (the overall merit) is designed in such a fashion that it is made dependent on a number of sub-objectives forming a multilevel hierarchy which is designed according to each specific case under evaluation.

This design must obey to two principles: 1) to be permanently in line with the strategic objectives of the Organization and 2) influence behaviours of people in charge (motivate), towards the accomplishment of each sub-objective measured by a specific "metric". Targets of the metrics are negotiated between a management controller ${ }^{1}$ and people in charge and fine-tuned during the course of time as improvements progress.

\section{BACKGROUND}

Most of the historical background of management performance control over the years since the end of the XIX century and the description of the three management methods used in this article can be found in reference [1] Chapter 8 . The author will focus from this point forward on the method that aggregates the three above mentioned methods with a real world case scenario (numerical data are altered for privacy protection purposes).

\section{THE CASE}

The case tackles an $R \& D$ project (that is still under way) promoted by the ISQ group with a partnership comprehending IST $^{2}$ and QUADRANTE. The project focus on the technical and organizational resources allocated to guarantee an appropriate air quality at the minimum energy cost possible in the operating rooms of a Portuguese public hospital. The same approach is expected to be replicated later on to other services.

Adequate air quality is understood to comply with standards and in house regulations, as well as to accommodate temperature and relative humidity set by the head surgeon (dependent on each specific surgery). These two variables, besides the fact of playing an important role with regard to ambient comfort, are also known to influence greatly the size of pathogenic microorganism's colonies.

The project promoter formed a working group (WG) and the author was nominated as technical coordinator.

Given the unique missions in health services providers, metrics cannot be developed alone by outside consultants. Metrics have to be carefully designed by those who know these processes most intimately - the hospital engineering and maintenance staff, from craft to management. Furthermore, people involved will feel more responsible and committed to achieving the goals (measured by metrics) that they have negotiated and accepted beforehand. Metrics also allow professionals to know how well their services are running and whether they conform to requirements they are engaged with. It

\footnotetext{
${ }^{1}$ With appropriate soft skills and experience

2 Instituto Superior Técnico
} 
is the role of the WG to provide guidance to these professionals through the several steps of the method.

\section{Step 1: Hierarchy design}

Having in mind the second perspective of BSC "Business Process", which refers to internal business processes and after a in depth diagnosis, the WG identified three main objectives to be continuously monitored:

1. "Quality" of the air in the rooms and maintenance services provided to the AVAC equipment. In fact, this is the main objective. The diagnosis revealed several spots where parameters were out of standard;

2. "Efficiency"; resources have to be effective (providing good air quality) and efficient simultaneously, that is, provide good air quality at the minimum possible economic cost. A computer simulation revealed a few issues to be corrected or updated in face of the current state of the art;

3. "Availability" of the AVAC equipment. In fact, good air quality is necessary all the time, which means that the "twenty four seven" regimen of service has to be guaranteed. This can be accomplished by increasing reliability in different forms. The diagnosis revealed a poor information system in the Maintenance Department supported on several dispersed Excel Worksheets.

In order to better describe which is meant by each one of these three objectives, the WG, after hours of discussion, identified a number of sub-objectives contributing to those three upper level objectives (depicted through Figures 1 to 3).

In Figures 1, 2 and 3, objectives are highlighted in grey, metrics are bordered and references can be seen in between.

Metrics have to be chosen very carefully in order to measure as effectively and accurately as possible the progress made over time towards the achievement of each negotiated target. Data on metrics originated over the past few months are gathered in a data warehouse and can be accessed at any time.

Some of these data are refreshed automatically on a timely basis (every \# minutes) which is the case of physical variables (temperatures, humidity, pressure,...) governed by the existing $\mathrm{SCADA}^{3}$ while other data are driven by events, which is the case of closing work orders in a CMMS ${ }^{4}$. Some data are originated only when an audit takes place, which is the case of anesthetic gases concentrations, being therefore registered on purpose by hand.

Figure 1 depicts the hierarchy of sub-objectives necessary to pursuit in order to comply with the main objective "Quality". This objective contributes in turn, along with Efficiency and Availability, for the utmost merit (overall performance). A few notes on this particular hierarchy follow:

1. Physical metrics, such as temperature, are obtained in real time and are assessed by three characteristics (or metrics) which are:

\footnotetext{
${ }^{3}$ Supervisory Control And Data Acquisition

4 Computerized Maintenance Management System
}

a. "Frequency" of drifts from the preset values (upper and/or lower limits) which can be measured in drifts per hour (or any other period), and must be as close to zero as possible;

b. "Severity" of drifts which is divided into two parts: "Duration" which can be measured in minutes per drift, and "Magnitude" which can be measured by the percentile 90 of the amplitude frequency distribution of drifts. Both must be as close to zero as possible.

2. Metrics are calculated, or averaged, inside a time frame. In a three shift regimen, a time frame of 8 hours is often the most convenient;

3. With regard to temperature and relative humidity - two variables set by the head surgeon -, a time delay of 15 minutes had to be arranged in order to avoid readings during transient periods which would give rise to a misleading interpretation. Only stationary periods count;

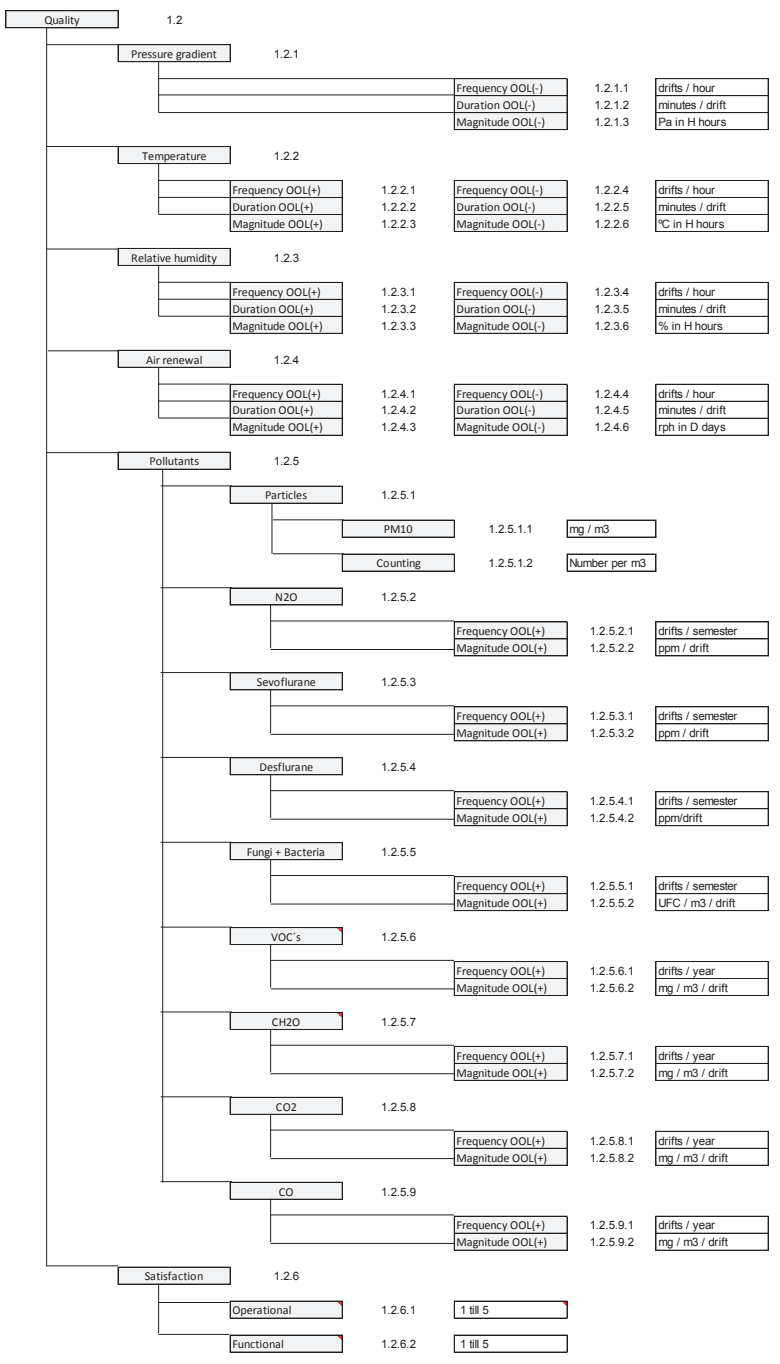

Fig. 1. Hierarchy of sub-objectives aiming to Quality 


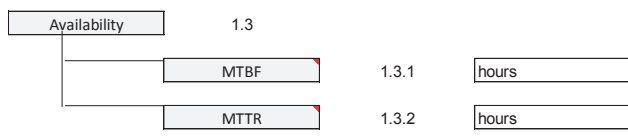

Fig. 2. Hierarchy of sub-objectives aiming to $\underline{\text { Availability }}$

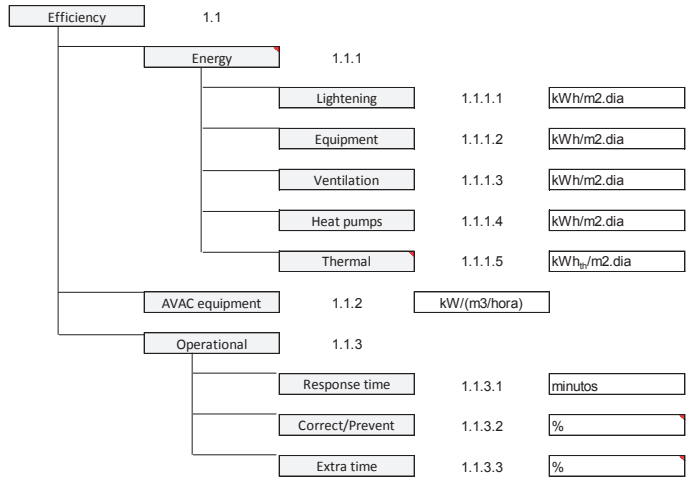

Fig. 3. Hierarchy of sub-objectives aiming to Efficiency

4. Metrics "Pressure gradient" and "Air renewals" (hourly number of) in each room are preferably measured in real time by adequate sensors instead of audits performed arbitrarily;

5. Pollutants have to be measured periodically as a routine or whenever there is a suspicion of a durable drift state. However, as concentrations of a few gases can be currently measured in real time by appropriate sensors, their adoption is highly recommended;

6. The degree of satisfaction is obtained twofold:

a. Through work orders related to AVAC that are being closed, by providing a specific field for the person who requested the work to enter his judgment on how well the work was done, within a scale from 1 to 5 ;

b. Through a questionnaire to be fulfilled every month by the people in charge of Services using also a scale ranging from 1 to 5 .

Figure 2 shows that "Availability" depends on "Reliability" or MTBF (Mean Time Between Failures) measured by the metric "hour" and "Maintainability" or MTTR (Mean Time To Repair) also measured in hours.

Figure 3 shows that "Efficiency" has two dimensions: one is "technical" (Electric energy and thermal energy) and the other is "operational", meaning that the former depends on equipment and the later depends on people (maintainers), that is, depends on how well the Maintenance Service is organized and competences held.

\section{STEP 2: HIERARCHY LEVEL WEIGHING}

Every objective in the hierarchy receives a weight proportional to the importance (preference) attributed by the WG. In this regard, the AHP methodology of pairwise comparison of objectives at each level of the hierarchy was used. The response to each question takes the form of a value from one to nine and its reciprocals. The magnitude of the response indicates the strength of preference of one decision element to another. Saaty [3] suggested numbers to express degrees of preference between elements $\mathrm{x}$ and $\mathrm{y}$ as can be seen in Table I.

TABLE I. SCALE OF PREFERENCES ACCORDING TO AHP

\begin{tabular}{|l|c|}
\hline \multicolumn{1}{|c|}{ If $\boldsymbol{x}$ is ... as (than) $\boldsymbol{y}}$, & $\begin{array}{c}\text {...then the preference } \\
\text { number to assign is: }\end{array}$ \\
\hline . Equally important/prefered & $\mathbf{1}$ \\
. Weakly more important/prefered & $\mathbf{3}$ \\
Strongly more important/prefered & $\mathbf{5}$ \\
. Very strongly more important/prefered & 7 \\
Absolutely more important/prefered & $\mathbf{9}$ \\
\hline
\end{tabular}

The pairwise comparison is quite advantageous when seeking to minimize the subjectivity always present in this type of decision making processes.

Table II depicts the result of the pairwise comparison of the five sub-objectives of the third level objective "Energy (efficiency)" leading to a Consistency Ratio of 0.069 (a threshold of 0.1 is actually considered) and the weights obtained which can be seen in the right extreme column.

TABLE II. PAIRWISE COMPARISON OF OBJECTIVES LOCATED IN LEVEL THREE

\begin{tabular}{|c|c|c|c|c|c|c|}
\hline \multicolumn{7}{|c|}{ Pairwise comparison of objectives } \\
\hline Criteria or Objectives & Lightening & Equipment & Ventilation & Heat pumps & Thermal & Weights \\
\hline Lightening & 1 & 2 & 3 & 1 & & 0,19091033 \\
\hline Equipment & & 1 & 1 & & & 0,09587115 \\
\hline Ventilation & & & 1 & & & 0,11050049 \\
\hline Heat pumps & & 3 & 2 & 1 & & 0,19558466 \\
\hline Thermal & 4 & 3 & 2 & 3 & 1 & 0,40713338 \\
\hline
\end{tabular}

The same approach was extended to all branches of the hierarchy of objectives.

\section{STEP 3: CONVERTING METRICS INTO MERIT SCORES}

Last readings of the elected metrics are depicted in Table III.

TABLE III. MOST RECENT METRIC VALUES OBTAINED

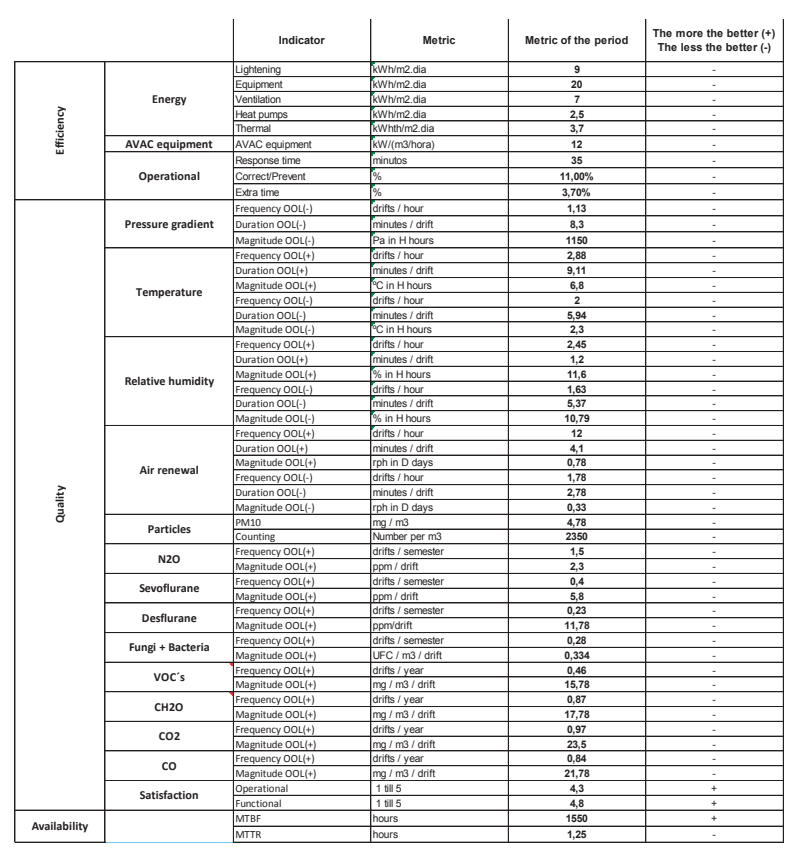


The ultimate goal is to achieve the maximum score of a non -dimensional scale which can be arbitrarily set as ranging from zero to whatever limit. The present case adopted a scale ranging from 0 to 10 . Zero (0) is given to a specific value of a metric which has already been registered in the recent past and has a low probability of being registered again. Ten (10) is attributed to a specific value of a metric which is believed to be attained in the near future (within a few weeks or months ahead), requiring management effort only, and is to be negotiated with the person who is responsible for its pursuit. The negotiation process is very important at this stage, as this is actually the more effective way of clearing doubts and gaining trust and commitment from people in charge.

The negotiation can be carried out by a future management controller acting preferably as a facilitator.

Once the value of a metric reaches the previously agreed upper level limit (equivalent to 10 in the merit scale), a new limit has to be agreed on. This is actually a short term commitment.

The method might be used to reward employees somehow.

Only two more metric values are set during an interactive process of judgment of level of effort needed to progress from 0 to 10 by dividing the metric range into quarters and choosing the $1^{\text {st }}$ quarter and the $3^{\text {rd }}$ quarter. The function that relates metric values to merit values can be linear or diverse. Most often two circumstances occur:

1. The situation is in such a bad state that little effort is required to start improving it. The merit gradient should therefore be small to start with and increase as performance progresses rewarding the augmentation of effort needed (as the situation becomes better, extra improvement becomes more and more difficult);

2. Resistance to change may happen. In these circumstances, the merit gradient is high to start with and diminishes as performance progresses. That is, a great effort is necessary at the beginning of the metric scale and becomes less and less demanding as it approaches the negotiated target. It may happen though the opposite towards the end of the merit scale and extra improvements require more and more effort. An increasing merit gradient is therefore applied.

Intermediate values of the function Merit $=f($ Metric $)$ can be approximated by a third degree polynomial function. Figures 4 and 5 depict an example of both situations.

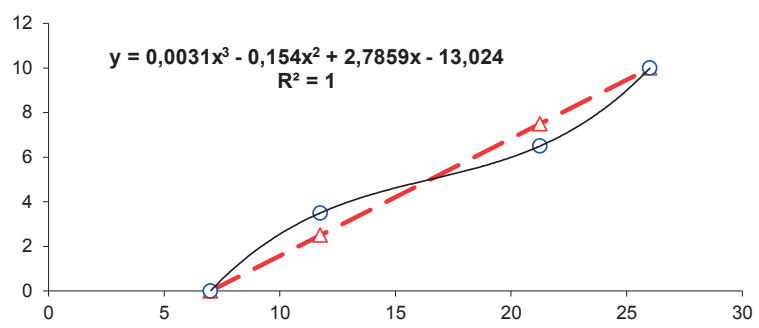

Fig. 4. Metric-Merit function when metric values are desirably ascendent

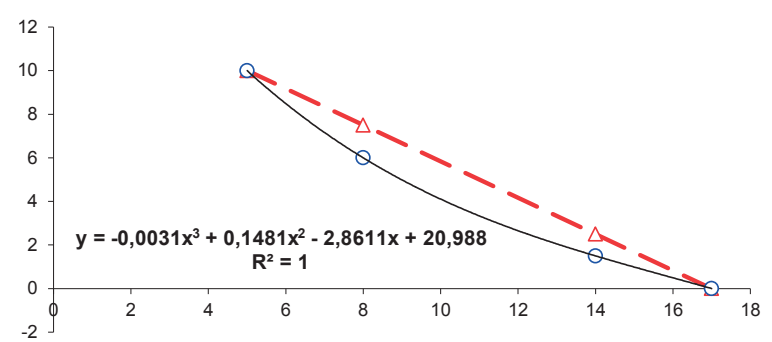

Fig. 5. Metric-Merit function when metric values are desirably descendent

EXCEL or MATLAB deal easily with this situation.

\section{STEP 4: OVERALL PERFORMANCE OR MANAGEMENT MERIT}

By multiplying merits of objectives at each level of the hierarchy by the correspondent weights of all upper levels in ascending order, an overall value of merit (score) is finally obtained. In the present case, a score of 6.57 is achieved within the preset scale ranging from 0 to 1 , which could be classified as "fairly good" if a semantic scale was used instead.

So, now what should be done in order to improve further this overall score (merit)?

\section{STEP 5: SENSITIVITY ANALYSIS}

To answer this question, one should perform a sensitivity analysis. This analysis consists of running a test to find out how much the overall score would increase if a metric is improved by a fixed percentage while keeping all the other metrics constant. The outcome of this process might then be arranged in descendant order and be displayed in a graph. This is the well-known Pareto analysis.

Based on data obtained through the four previous steps, an increase of $20 \%$ of each metric was supposed to be achieved. The graph in Figure 6 depicts the analysis outcome.

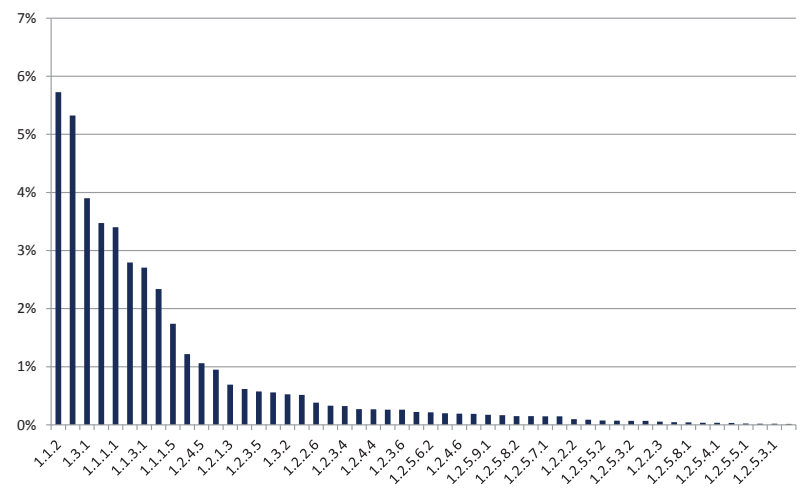

Fig. 6. Percentages of improvement of overall performance when each metric is supposed to be improved by $20 \%$

The graph clearly shows that objective reference 1.1 .2 presents the best return on management effort $(5.73 \%)$ followed by references 1.1.1.4 (5.32\%), 1.3.1 (3.90\%) and so on. If an investment is needed to allow future improvements, a 
cost-benefit analysis must be carried out before setting new targets.

\section{CONCLUSIONS}

A method combining three other popular methods in management (BSC, AHP and MMC) was applied to assess management performance on a timely basis of AVAC equipment allocated to a surgery room of a public Hospital.

Based on the second phase of BSC, a multilevel hierarchy of operational and technical objectives was designed to comply with strategic objectives of the Hospital. These objectives were weighted at each level of the hierarchy using the pairwise comparison advocated by AHP.

Metrics were chosen to enable the measurement of objectives in the most effective way possible. A minimum limit and a maximum limit of each metric, believed to be reached in the short run, were then negotiated with the people in charge.

For calculation purposes, metrics were then converted to a non-dimensional scale of arbitrary length depending on effort needed (or the merit that is supposed to reward it). In the exemplified case it was chosen to vary between 0 and 10 .

A multiplication of all these merit values by their correspondent weights through the hierarchy in ascending order allows reaching an overall merit value (also ranging from 0 to $10)$.

In the end, a sensitivity analysis allows tempering management effort by arranging in descendent order all the 52 metrics based on their actual gain contribution to the overall performance (or merit at the highest level of the hierarchy).
In short, a hierarchy of objectives were designed in such a way that the alignment with strategic objectives of the Organization is assured and a permanent negotiation of quantitative targets - made easy to monitor by practitioners themselves - actually encourages the development of a sense of responsibility and real commitment. Everyone knows where they are at any moment and where they are expected to be in the short run - this is exactly what we were aiming at.

The method can easily be used to reward performance with a pecuniary prize or any other form for that matter.

The method is intended to be replicated on two other services in the same hospital, in the context of the same project.

Scorecards built with the same methodology and applied to different services of the same organization, can be merged in order to provide management with a broader perspective on technical and operational maintenance performance of a health - or any other - facility.

\section{REFERENCES}

[1] Assis, Rui, Apoio à Decisão em Manutenção na Gestão de Activos Físicos, $2^{\text {nd }}$ edition, LIDEL, 2014

[2] Kaplan, Robert S. e David P. Norton, Balanced ScoreCard, Harvard Business School Press, Boston, 1996

[3] Saaty, Thomas L., Decision Making for Leaders: The Analytic Hierarchy Process for Decisions in a Complex World, RWS Publications, 2012

[4] Sink, Scott, e Thomas Tuttle, Planning and Measurement in your Organization of the Future, Industrial Engineering e Management Press, 1989 
(Página deixada propositadamente em branco) 


\title{
Lean Maintenance
}

\author{
Bruno Inácio \\ bruno.inacio@profitabilityengineers.pt \\ ProfitAbility Engineers, Lda. \\ Lisbon, Portugal
}

\begin{abstract}
Lean implementation requires full organizational involvement, and success often depends on the details. One of those details is, without a doubt, the "wellbeing" of process equipment.

In order to assure a levelled production flow, all key process elements, such as personnel, materials and machines, need to maintain high availability. Availability, performance and fabrication quality (which can all be traced back to the process equipment in direct or indirect ways) becomes essential for predictable and reliable adherence to scheduling and customer expectations.
\end{abstract}

Without adequate maintenance practices, such as TPM (Total Productive Maintenance), the process will most likely fall short of the overwhelming demands placed on it by JIT (Just In Time) and "zero stock" philosophies.

Methodologies such as SMED (Single Minute Exchange of Dies), Heijunka (levelled production scheduling) and Kanban (JIT pull-flow production) all depend on equipment uptime and performance. Deviations cause, as would be expected, wastes in the form of delays, defects and inventory.

Maintenance is therefore a cornerstone for achieving the so desired "perfect process" level. We can, of course, ask: What is a perfect process? It is a process without "muda" (Japanese word for "waste"), in which each step adds value, is perfectly capable, is available and is exactly adequate for the needs. All the steps are linked by continuous synchronous flow, pulled by customer demand and levelled.

Keywords - Lean, SMED, SMM, Waste Reduction, TPM.

\section{INTRODUCTION}

Lean Production - what is it?

- "A production philosophy which reduces the time between order and delivery, through the systematic reduction of waste (activities that do not add value)" [1].

- "A systematic approach to identify and eliminate waste, through continuous improvement, making products flow, whenever the customer requests, in the search for perfection" [2].

The goal is to promote competitiveness. This, in turn, can be defined as doing it better, cheaper and quicker than the competition.

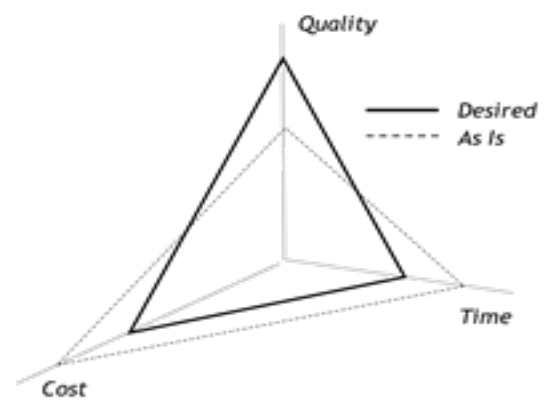

Fig. 1. The 3 vectors to improve in order to be competitive.

In this sense, the generalized objectives of Lean Production can be summarized as:

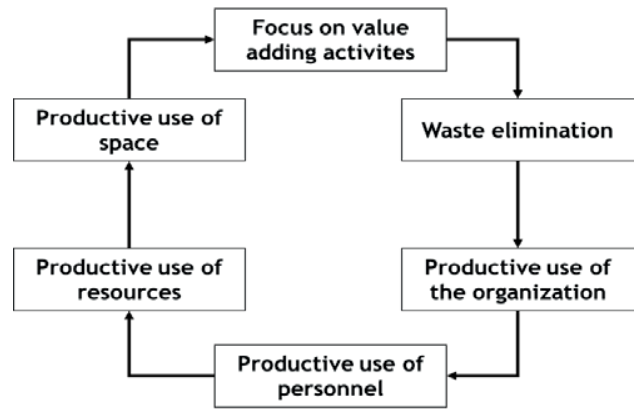

Fig. 2. The generalized Lean objectives.

It is precisely in the "productive use of resources" that the concept of Lean Maintenance finds it's framework, in other words, analyze and eliminate waste, improving continuously the maintenance activity.

But what of the waste? Any industrial activity can contain one or more of the following wastes:
1. Overproduction
2. Delays
3. Transport
4. Processing waste
5. Unnecessary inventory
6. Unnecessary movements
7. Product/service defects. ${ }^{[3]}$

Maintenance, an industrial activity, can naturally suffer from any of the abovementioned 7 wastes, but the Lean concept has 
gone further and references 8 specific wastes directly attributed to maintenance:

TABLE I. THE 8 WASTES IN MAINTENANCE [4]

\begin{tabular}{|c|c|c|}
\hline \multirow{2}{*}{$\mathbf{N}^{0}$} & \multicolumn{2}{|c|}{ The 8 wastes in maintenance } \\
\hline & Waste & Description \\
\hline 1 & $\begin{array}{l}\text { Equipment } \\
\text { malfunction }\end{array}$ & $\begin{array}{l}\text { Waste can occur due to loss of function or } \\
\text { deterioration of function (loss of } \\
\text { performance) }\end{array}$ \\
\hline 2 & Setups and tuning & $\begin{array}{l}\text { Downtime due to setups and process } \\
\text { adjustments, until the first conform } \\
\text { product is obtained. }\end{array}$ \\
\hline 3 & Component swap & $\begin{array}{l}\text { The need to stop the process to swap out a } \\
\text { cutting tool. }\end{array}$ \\
\hline 4 & Startup losses & $\begin{array}{l}\text { Waste generated when a process takes a } \\
\text { long time to stabilize, after a shutdown. }\end{array}$ \\
\hline 5 & Micro stoppages & $\begin{array}{l}\text { Short (often not recorded) downtime due } \\
\text { to a faulty sensor, a defective part that } \\
\text { blocks flow. }\end{array}$ \\
\hline 6 & Loss of speed & $\begin{array}{l}\text { Waste due to deviations between the } \\
\text { actual running speed and the planned } \\
\text { speed for the equipment. }\end{array}$ \\
\hline 7 & $\begin{array}{l}\text { Defects and } \\
\text { rework }\end{array}$ & $\begin{array}{l}\text { Delays and waste of resources due to } \\
\text { faulty product, which results from any } \\
\text { equipment deviation. }\end{array}$ \\
\hline 8 & Downtimes & $\begin{array}{l}\text { Losses associated with stopping } \\
\text { equipment in order to perform planned or } \\
\text { corrective maintenance. }\end{array}$ \\
\hline
\end{tabular}

II. LEAN MAINTENANCE

\section{A. The demands that Lean places on maintenance}

As stated in the abstract, a lean process requires process steps that add value, are capable and available. Bearing in mind that most process steps rely on equipment, the demands on the process are equally demands on the equipment. TPM has the objective of reducing breakdowns to zero, which improves the "bathtub" curve.

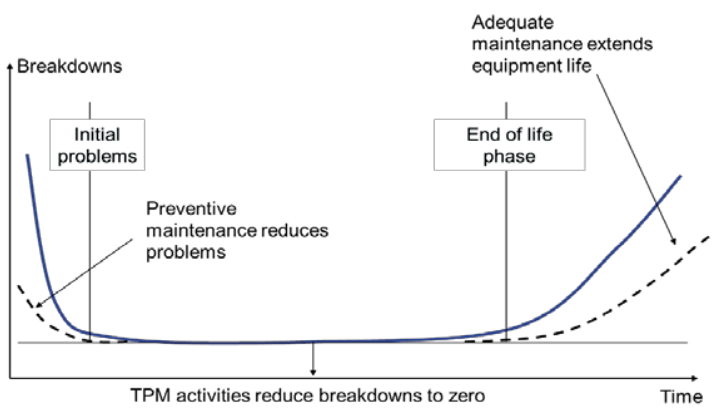

Fig. 3. The effect of TPM, [4]

\section{B. The 5 maintenances in Lean enterprises}

\section{Breakdown Maintenance (BM)}

The goal is to minimize the time wasted in stoppages due to breakdowns. Each simple breakdown should be solved in less than 10 minutes. This is often referred to as "Single Minute Maintenance".

\section{Preventive Maintenance (PM)}

Preventive maintenance refers to all tasks done to prevent breakdowns. Initial actions are based on the equipment manufacturer's recommendations, and as knowledge of the equipment and process needs improves, plans are adapted, with special attention not to "overservice" the equipment.

\section{Daily Maintenance (DM)}

Daily maintenance includes all the day-to-day maintenance activities, which are executed by the operators, such as cleaning, inspection, lubrication and tightening. In other words, this is TPM. Operators are obligated to request the aid of the maintenance personnel, whenever a symptom is detected which exceeds their training. Over time, maintenance personnel analyze the occurrences, and look for ways to simplify the repair work (based on the Single Minute Maintenance principle), so that it can be taught to the operator. The reason is simple: if the person who is already at the equipment can solve the problem, this is the best way to ensure that breakdown time will be minimal.

\section{Corrective Maintenance (CM)}

The need arises, from time to time, to take corrective actions on some equipment. After years of use, or due to some design flaw, a weakness in the equipment may arise, rendering it incapable or inadequate for the process needs. These weaknesses are therefore corrected, assuring that the equipment performs as needed. This is obviously done if the investment pays off, and as long as no compromise to product quality exists.

\section{Preventive Engineering (PE)}

The knowledge and experience of maintenance personnel is used, to specify equipment and/or tool needs prior to purchase. The goal is to prevent problems and the need for future corrections, in the equipment design phase. Also, clever changes to certain aspects of equipment design can make it much easier to swap parts in case of a breakdown, making it easier to reach the Single Minute Maintenance objective.

\section{The link between maintenance and productive mainteance} activities

TPM activities have a direct link with the planned maintenance, the core activity of the maintenance function. The image bellow shows the advantage of having TPM activities contribute to the various maintenance objectives.

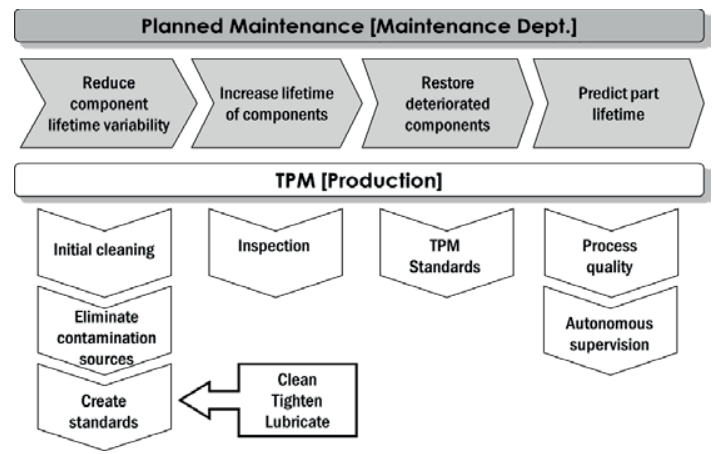

Fig. 4. TPM links to maintenance objectives, [4]

\section{A TPM standard example}

Figure 5 shows an example of a TPM plan template for a particular equipment, in this case, a plastic injection molding machine. It can be seen that visual aids have been created to assist the operator. These visual aids are physically placed on the equipment itself, making it very easy for the operator to identify what needs to be done, and with what frequency. Likewise, turning the TPM routine as simple and comprehensive as possible also facilitates the training of new personnel. 


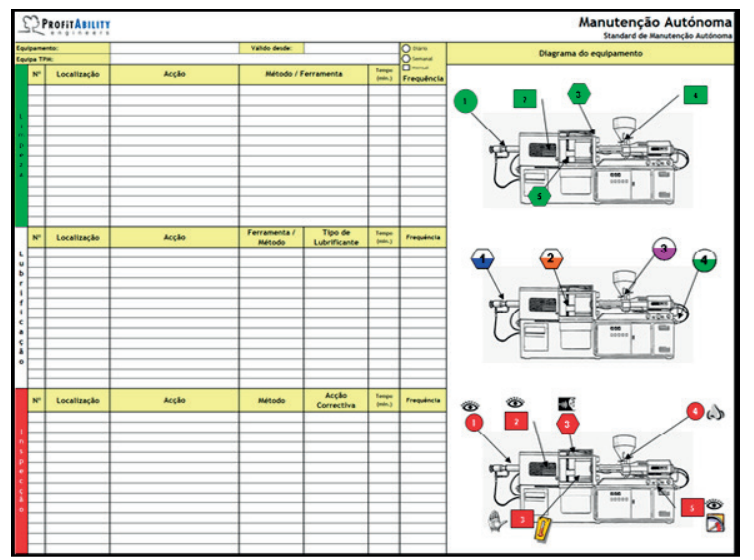

Fig. 5. Injection molding TPM template.

\section{E. Improving maintenance activities}

Many different lean tools can be applied to process improvement workgroups, but sometimes, keeping it simple makes the difference. A very simple 4 step method, adequate for involvement at the operator or technician level is the TWI "Job Methods" approach.[5]

The 4 step method can be summarized in Figure 6 .

\begin{tabular}{|c|c|}
\hline \multicolumn{2}{|c|}{$\begin{array}{c}\text { Step } 1 \text { : Operation Breakdown } \\
\text { List each and every detail }\end{array}$} \\
\hline $\begin{array}{l}\text { Step } 2 \\
\text { Question }\end{array}$ & $\begin{array}{l}\text { Step } 3 \\
\text { Improve }\end{array}$ \\
\hline $\begin{array}{l}\text { Why? } \\
\text { What? }\end{array}$ & Eliminate! \\
\hline $\begin{array}{l}\text { Where? } \\
\text { When? }\end{array}$ & Combine! \\
\hline Who? & Reorganize! \\
\hline How? & Simplify! \\
\hline
\end{tabular}

Fig. 6. Job Methods 4 steps [5]

Kaizen workshops/workgroups, using the 11-step method, are also very effective in analyzing and improving any activity, and are typically used to the reduction of waste at a process level, not at a specific operation. The Job Methods approach is typically preferential for shop floor workgroups.

\section{CASE STUDY - SMED APPLIED TO THE SUBSTITUTION OF AN ELECTRIC MOTOR}

\section{$F$. The SMED method in summary [6]}

The purpose of SMED (Single Minute Exchange of Dies) is to execute setup activities in processes such as stamping, injection molding or any other situation in which a process needs to be stopped to allow for setup of a different product. It is evident that it is of great interest to a process to minimize this time, with gains in terms of batch sizes, inventory and flexibility to customer changes. The improvement method is summarized in Figure 7, in which external activities refer to all activities that can be done while the process is still running (preparation) or after the process has initiated (cleanup, putting tools away) and internal activities refer to all activities that must be done with the equipment stopped.

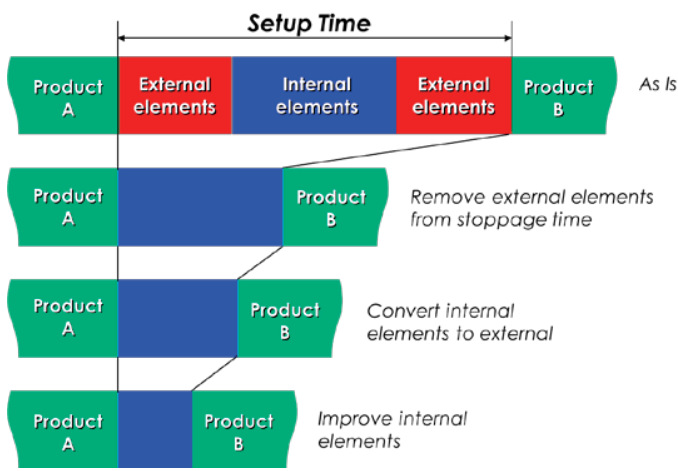

Fig. 7. SMED method summary.

\section{G. SMED to SMM application}

\section{Planned repair}

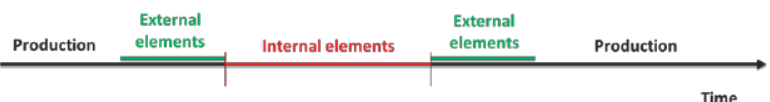

\section{Breakdown}

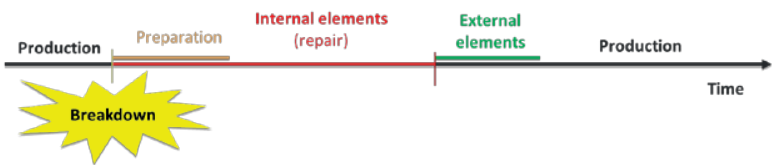

Fig. 8. SMM application logic

As Figure 8 shows, in the case of a maintenance activity, there is a direct analogy to the SMED method, when we are in the situation of a planned repair. But in the case of a breakdown, all preparation activities that would otherwise be done while the equipment is still running are now internal activities, since the equipment has broken down. In both of these situations, the SMED method can be applied, with obvious gains.

\section{H. Setup for documentation}

The chosen equipment was an electric motor, which needs to be removed, substituted, and the new motor aligned. Since these type of activities take some time and, fortunately, seldom happen, it is not practical to take notes about the process steps, especially when multiple operators are involved. In this case, two mechanical and one electrical maintenance technicians were involved. The best approach is to document the work with video, and in this case three cameras were set up, one of them with a wide angle of the operation, one of them filming close-ups from $180^{\circ}$, and the third was free to move around to capture hand details and accompany any one of the technicians that for some reason might need to walk away from the spot.

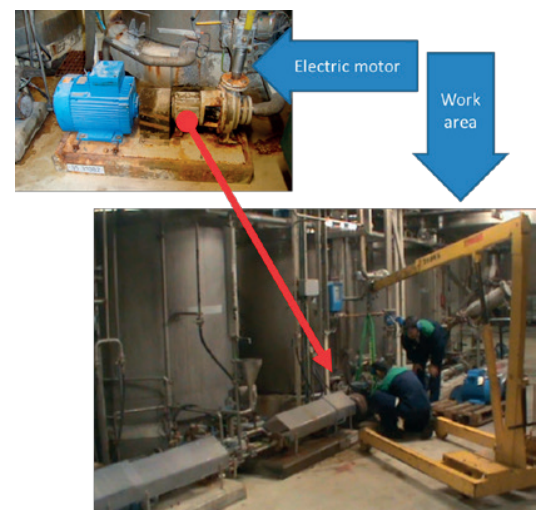

Fig. 9. Work area and equipment. 


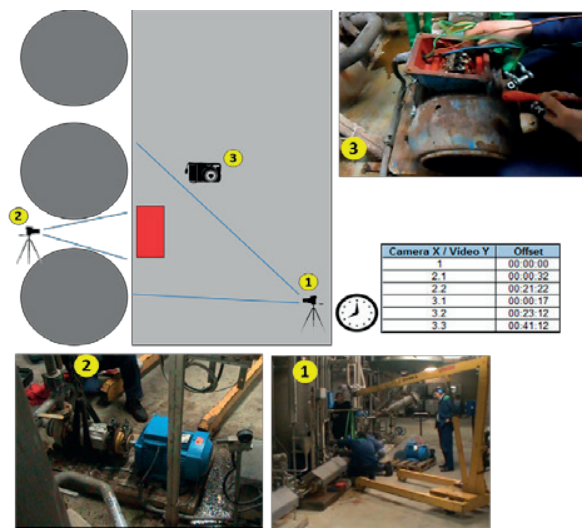

Fig. 10. Camera setup.

As shown in Figure 10, camera 1 was defined as the "master clock" and the other videos were then offset to assure that, referencing the appropriate camera, the correct time would be recorded for each detail.

After this, the technicians executed the setup as they would normally do.

\section{Analysis}

The team was then assembled in a meeting room to breakdown the various videos and to register the operation steps and times. This is the first analysis of this operation, therefore not every micro detail is recorded, the main steps are identified. It is of the utmost importance that the technicians filmed are also present in these work sessions, since they can clarify exactly what they are doing and why, and also to promote multi-level involvement and teamwork. It is also very important for the executers to be present during the discussion and brainstorming of improvements, since any decided change will directly impact on their work. They therefore have an important role in deciding what gets changed.

The work sessions yield a summary table with a quantitative indication of the times, and a Gantt chart, showing the critical path of the operation. The critical path, in this case, is identified as the sequence o activities which increment "stopwatch time". There are a number of activities which, regardless of the fact that they count as work time, occur simultaneously with critical path activities, therefore they are of second priority, since an improvement done on them will have no impact in the actual time that the equipment is stopped.
TABLE II. OPERATION ELEMENTS AND THEIR TIMES. RED BARS SHOW EXTERNAL ACTIVITIES, WHILE BLUE SHOW INTERNAL. THE REDDISH LINES SHOW STEPS THAT CAN BE ELIMINATED, REGARDLESS OF EXTERNAL OR INTERNAL.

\begin{tabular}{|c|c|c|c|c|c|c|}
\hline \begin{tabular}{l|l} 
No \\
Sea.
\end{tabular} & $\operatorname{sen} \mid=$ & $8 T^{7}$ & & 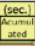 & $\%$ & Time chart \\
\hline 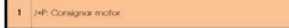 & $\cdots$ & $-\infty$ & - & -- & -1 & $\square$ \\
\hline 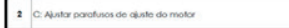 & $=-$. & - & - & $-\infty$ & $=1$ & $\square$ \\
\hline 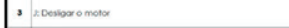 & $=-\infty$ & $\ldots$ & $=$ & $\cdots$ & $=1$ & $\square$ \\
\hline 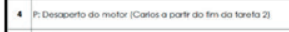 & $-\infty$ & $-\infty$ & $\cdots$ & $m-$ & $=$ & $\square$ \\
\hline 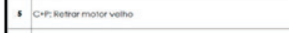 & $\cdots$ & --- & $-\infty$ & $=$ & -1 & I \\
\hline 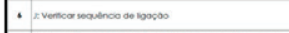 & $\ldots$ & - & - & - & -1 & 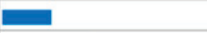 \\
\hline 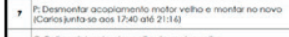 & $-\infty$ & - & - & - & -1 & 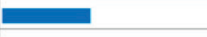 \\
\hline 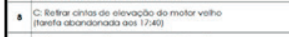 & $-\infty$ & $-\infty-$ & $=$ & $-\infty$ & $\cdot 1$ & 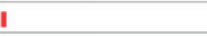 \\
\hline 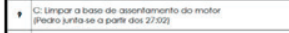 & $\ldots$ & -- & $\cdots$ & $-\infty$ & - & 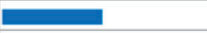 \\
\hline 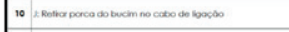 & $-\infty$ & $=-$ & $\cdots$ & $+a$ & $\cdot-1$ & $\mathbf{a}$ \\
\hline 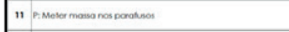 & $-\infty$. & $-\infty$ & $+\infty$ & $-m$ & $\cdot$ & $\square$ \\
\hline 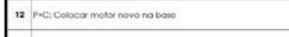 & $-\cdots$ & -- & $-\infty$ & -- & $\cdot 1$ & a \\
\hline 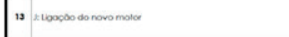 & $-\cdots$ & $-\infty$ & $\cdots$ & $-\infty+\infty$ & -1 & 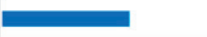 \\
\hline 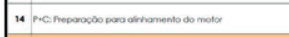 & 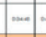 & $\ldots$ & $=$ & $=-\infty$ & -1 & 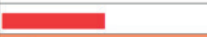 \\
\hline 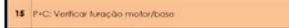 & - & $\ldots-\cdots$ & $-=$ & $-\infty$ & -1 & $\square$ \\
\hline 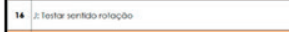 & $--\infty$ & $-\infty$ & $-\infty$ & $-\infty$ & -1 & 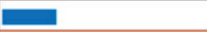 \\
\hline 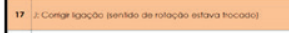 & $-\infty$ & -- & - & $-\infty$ & -1 & $\square$ \\
\hline 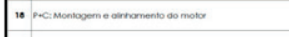 & $-\infty$ & - & $-\infty$ & -- & -1 & 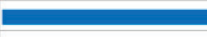 \\
\hline 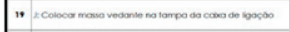 & $-\infty$ & $-\infty=$ & - & $\cdots$ & -1 & 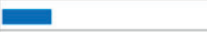 \\
\hline 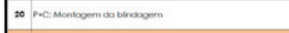 & $=$ & $=-$ & - & $\ldots$ & -1 & 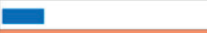 \\
\hline 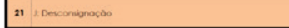 & $\cdots$ & $-\infty$ & -- & $\cdots$ & - & $\square$ \\
\hline
\end{tabular}

TABLE 3. GANTT CHART SHOWING CRITICAL PATH STEPS IN RED, AND SIMULTANEOUS STEPS IN BLUE.

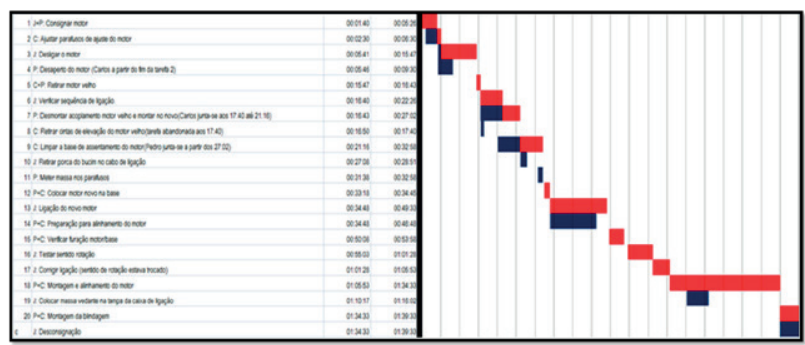

J. Results obtained

Based on the analysis mentioned above, the team decided upon actions and implemented the corresponding action plan. It is normal that, in the first iteration of these methods, simple aspects are optimized, such as:

- Work reorganization: Technicians wait for one to finish work before they start theirs, and when asked what could be be doing during this time, they tend to identify that they could prepare the following task, or prepare a later task

- Conversion to external tasks: The motor's coupling had to be removed and inserted into the new motor. With a second coupling, which is often available, this task can be converted to external.

- Improving tools: Simple hand wrenches were being used. These were substituted by a ratchet wrench, with significant reduction in time.

A new substitution was done, for the sake of validating the improvements, and new videos and analysis were done. A brief summary of the obtained results are shown in Table 4, where it is possible to see that $38 \%$ of "stopwatch time" reduction was obtained. This represents a reduction of approximately 38 minutes in downtime, with the first iteration of the SMM method on this operation. 
TABLE IV. SMM RESULTS SUMMARY.

\begin{tabular}{|l|l|l|c|c|}
\hline \multicolumn{5}{|c|}{ SMM summary table (first improvement iteration) } \\
\hline & Before & After & \multicolumn{1}{|c|}{ VARIATION } \\
\hline Time & [min] & [min] & Time (min.) & \% improved \\
\hline $\begin{array}{c}\text { Real stoppage } \\
\text { time }\end{array}$ & 99,55 & 61,5 & 38,05 & $38 \%$ \\
\hline $\begin{array}{c}\text { Work content } \\
\text { Activity } \\
\text { overlapping } \\
\text { (simultenous) }\end{array}$ & 141,48 & 77,53 & 63,95 & $45 \%$ \\
\hline
\end{tabular}

We can also see that there was a reduction of $45 \%$ in work content, which means that the improvements did eliminate a very significant part of the time spent doing work. This is important, because it means that the stoppage time was not reduced by $38 \%$ just by reorganization of external tasks, but there was significant elimination and simplification of work. It is possible to see a reduction of $9 \%$ in terms of work overlapping, which is not the best result, but it is primarily due to the elimination of some activities which were not in the critical path. However, this result is of lesser importance.

\section{CONCLUSIONS}

Maintenance is one of the fundamental pillars of Lean Production. It's importance is often neglected, but it becomes obvious that breakdowns and stoppages are against any logic of continuous flow, waste reduction and reduced inventory levels. Some final thoughts an highlights:

1) Maintain equipment efficiently. Do not overservice.

2) Train all personnel in the importance and execution of maintenance routines (TPM).

3) Standardize all maintenance operations, for production and maintenance personnel.
4) Eliminate problems at their root cause(s). Too often, maintenance is done at the symptom level, not the root.

5) Manter bases de dados e analisá-las. Só através de uma análise cuidada de dados dos equipamentos pode a manutenção desenvolver acções eficazes de manutenção preventiva.

6) Maintain and analyze data. Only through statistical and detailed analysis can it be possible to identify priorities and act in them.

7) Motivate and involve maintenance personnel in continuous improvement activities, in order to reduce time and cost.

8) Make sure all levels in the organization are taken into consideration when changes are decided upon, which affect the day-to-day work of shop floor personnel.

The application of the abovementioned guidelines to the substitution of an electric motor clearly shows the wide applicability of Lean methods to identify and eliminate waste, even in specific maintenance activities. Never compromising the quality of the maintenance service, it is important, in a globally competitive environment, that cost and time are minimized, through the continuous identification and reduction/ elimination of all non-value adding activities.

\section{REFERENCES}

[1] Taichii Ohno, Norman Bodek, "Toyota Production System”, Productivity Press, 1988.

[2] Taichii Ohno, “Gemba Keiei”, JMA Management Center Inc., 1982.

[3] J.P. Womack, D.T. Jones, "Lean Thinking", Free Press, 2003.

[4] K. Arai, K. Sekine, "TPM for the Lean Factory: Innovative Methods and Worksheets for Equipment Management", Productivity Press, 1998.

[5] "Job Methods - Sessions outline and reference manual", Training Within Industry Service, War Manpower Commission, 1943.

[6] [6] S. Shingo, "Quick Changeover for Operators: The SMED System", Productivity Inc. 1996. 
(Página deixada propositadamente em branco) 


\title{
CMMS - An integrated view from maintenance management to on-line condition monitoring
}

\author{
José Torres Farinha ${ }^{1}$; Inácio Fonseca ${ }^{2}$; Rúben Oliveira ${ }^{3}$; Hugo Raposo ${ }^{4}$ \\ ${ }^{1,2,3,4}$ Centre for Mechanical Engineering of the University of Coimbra - CEMUC \\ Coimbra, Portugal
}

\begin{abstract}
Nowadays, Enterprise Asset Management (EAM) systems or, more specifically, Computer Maintenance Management Systems (CMMS) need to fill requisites like the following ones: To work in all platforms, independently of operating system, being this cross-platform and multi operating system. However, CMMS also need to work in any language, being this native, where they were developed or any other, like English, Greek or Arabian.

Even the precedent challenges weren't big enough it is also necessary that CMMS receives and manages data from any type of sensors, independently where they are placed, locally or remotely, and the signals transmitted through wire or wireless.

In consequence, the on-condition predictive maintenance reached a new level to enlarge the availability.

Furthermore, it is also necessary to manage the configuration of the EAM itself to be able to communicate with the several existent platforms.

There are new technologies that represent new limits, not beyond tomorrow but for today. Such technologies like Augmented Reality, Artificial Vision and even holography have potential to increase maintenance performance.

The physical assets are each time more and more strategic to the organizations competitiveness then the EAM need to manage not only the maintenance of assets but also all their Life Cycle Cost, including investment, renewal and withdrawal aspects, and also resources optimization. This is a complex equation that increased in complexity along the time and, simultaneously, ought to be managed in a friendlier way by the final user and, yet more, its cost must be, each time, cheaper than before.

These are the main subjects that will be discussed in the paper and also the proposed solutions, both the software and hardware solutions in an integrated view, that represent not only a state-of-the-art but a step ahead in the physical asset management area, in general and in maintenance management, in particular.
\end{abstract}

Keywords-Maintenance; CMMS; EAM; Operating System; On-condition Maintenance.

\section{INTRODUCTION}

The Enterprise Asset Management (EAM) systems and or Computer Maintenance Management Systems (CMMS) are being entering in a new phase with a lot of challenges that are occurring simultaneously and are transforming the current systems into a new position that will put the present systems in a pre-historic position.

In fact these systems must work over Operating Systems (OS) like Linux, Windows, iOS, or others, and in any type of platforms, as a Personal Computer, a Tablet and a SmartPhone. Additionally, they must communicate with data acquisition systems even each one has its own specific protocol to transfer data to other devices.

The heterogeneity of the systems also implies an additional difficulty in the communication among them, namely in the relationship between maintenance companies and their customers, mainly when both have an EAM and the potential common data that must be shared.

Moreover the EAM also needs to incorporate components like Expert Fault Diagnosis Systems (ES), Augmented Reality (AR), Geographic Information Systems (GIS), among others.

These are the main subjects that are treated in this paper that is organized as follows:

- The chapter two makes the discussion of EAM versus CMMS;

- The chapter three deals with the problem of CMMS multiplatform;

- The chapter four deals with the On-Condition sensing and CMMS communication;

- The chapter five deals with the problems of Communication among different CMMS;

- The chapter six deals with questions referring to the incorporating new technologies in CMMS;

- The last chapter presents the conclusions and some tendencies for tomorrow.

\section{EAM VERSUS CMMS}

A Computer Maintenance Management System (CMMS) software package is an information system which main purpose is to support the management of maintenance activity. This information is intended to help technicians to do their work more effectively, to monitor the equipment performance and to aid the maintenance staff decision. CMMS data may also be used to verify regulatory compliance.

An Enterprise Asset Management (EAM) is an information system to manage the whole life of the Physical Assets of an organization. It covers such things as the acquisition, commissioning, operations, maintenance and decommissioning/replacement of plant, equipment and facilities. "Enterprise" refers to the management of the Physical Assets across departments, locations, facilities and, in some cases, business units. By managing assets across the facility, organizations can improve its utilization and performance, to reduce capital costs, and asset-related 
operating costs, extend Physical Assets life and subsequently helps to improve Return Of Investment (ROI).

As can be seen there are several differences between a CMMS and an EAM; however, they are commonly understood as the same.

Nowadays, because the enormous evolution of the maintenance sector, and by consequence their standards, the EAM tend to reach a widely field of application than CMMS. The following standards correspond to the most recent Physical Asset Management view:

- ISO 55000:2014 - Asset management - Overview, principles and terminology;

- ISO 55001:2014 - Asset management — Management systems - Requirements;

- ISO 55002:2014 - Asset management - Management systems - Guidelines for the application of ISO 55001 .

The NP 4492:2010 (Requirements for the provision of maintenance services) and associated standards, as will be seen in chapter four, corresponds to an approach within the CMMS systems that have their core in the maintenance activity.

However, this is an approach that has given its first step. It is necessary to wait before giving the next step in order to understand when the right time reaches to make the convergence and the synergy between them.

\section{CMMS MULTIPLATFORM}

Nowadays, some of the most important commercial OS in the world are Linux, Windows, iOS and Android, where the CMMS must work. Additionally, it must work in any type of platforms, as a Personal Computer, a Tablet or a Mobile Phone.

The main problem of the existing EAM/CMMS is their functioning that is mostly based on a Client-Server platformover a browser that directly connects to the server using a TCP-IP connection, among others. Usually they work with a relational database, based on a Structured Query Language (SQL), with a user interface developed in a specific tool.

The biggest challenges start from this point because it is necessary to "convert" old programs for new platforms with new tools.

Additionally, it is also necessary to consider the new challenge that arises from Cloud Computing, where both clients and suppliers can host their data and share or not them when customer and supplier establish a commercial maintenance contract.

Some of the challenges related to the creation of new platforms, namely the mobile devices, are the following ones,

- Generic Model for a Mobile Application

- Selecting a Template
This application can be separated in two big sides, the server side where all information is stored and processed and the mobile side where all information is accessed or entered.

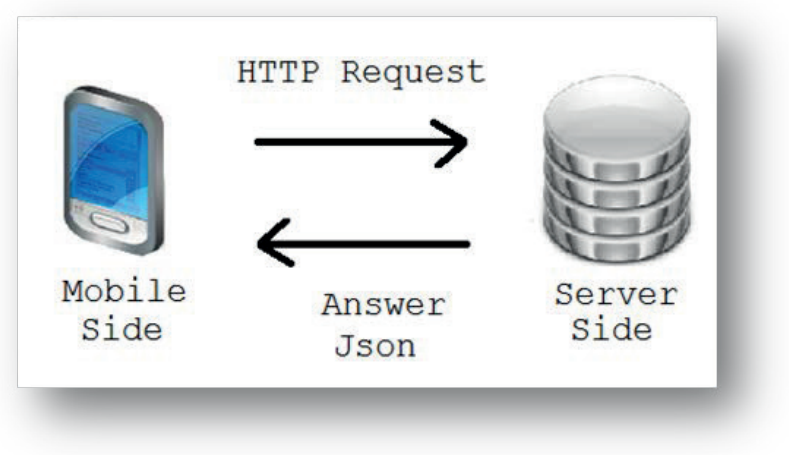

Fig. 1. Interaction between the server side and the Mobile side

The server side is running a Rest server (Fig. 1) which receives and manages all requests to the server. This Rest server is a PHP script, that is able to receive HTTP requests, either GET or POST requests, and it is able to respond in XML, HTML or JSON.

The Rest server is also used as a form of security, because it works between the database and all requests from outside, not allowing direct access to database. On the other hand the database should be SQL type, for easy development and integration with the Rest server (Fig. 2).

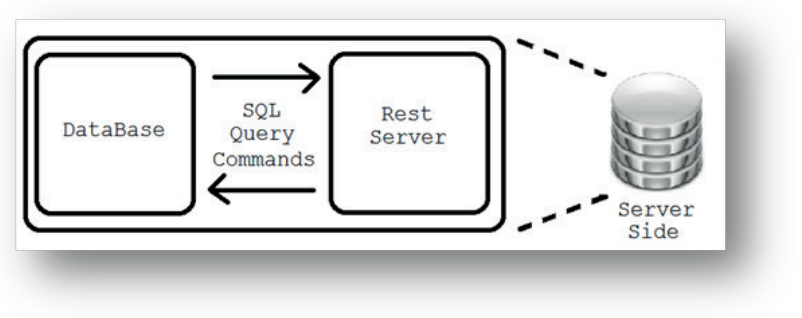

Fig. 2. Server Side Diagram

The mobile side must be able to communicate with the server in order to obtain all the required information, for this the device must be able to connect to the network via wireless or via General Packet Radio Service (GPRS). It is also necessary that the device is capable of reading barcodes; this can be achieved through image capture or scan which requires the mobile to have a camera or a laser scan. The device must also have in its hardware list a touch screen sensitive enough to capture signatures, a camera to take photos to store on the database and a Global Positioning System (GPS) system to gather the location of the device. Linking all this, the mobile device must also have to be able to run an internal database to implement an offline mode. For several years all these features could only be found in expensive industrial devices, such as the PDA Datalogic Lynx. But, nowadays, any Smartphone is capable to fulfill these requirements; because these reasons it was decided to use a Personal Digital Assistant (PDA) and a Smartphone for this work. 
At the beginning, the application should check if the device is connected to the network and that the server is functional before starting work. After this check, the application should ask the server to get the list of all types of perishable equipment and if all goes well displayed. After this the user needs to choose the type of item that he wants to catalog.

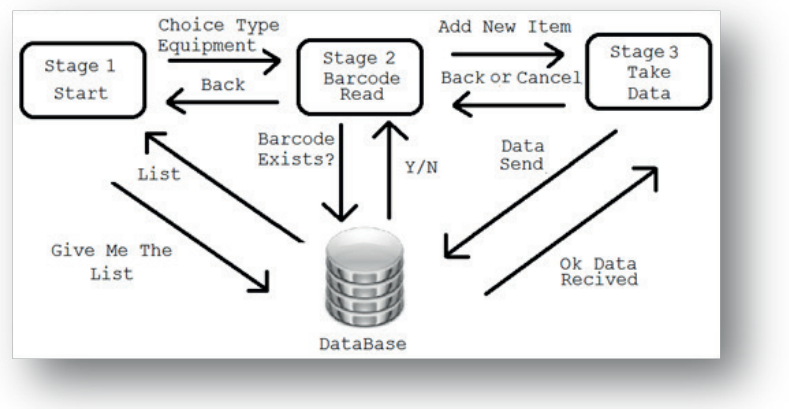

Fig. 3. Basic scheme of functioning of the application

On the next stage, the application will be allowed to scan barcodes, and after that, it should ask the database if the barcode was already been previously taken. If so, ask the user if he intends to overwrite the previous entry and if he says yes or is a new entry, the App should jump to its third stage.

In the third stage the user should collects photos, information about the location of equipment, comments about the equipment's state, and finally getting the signature of the user.

After all the information has been collected on the third stage it should be sent and processed by the server. The application should revert back to stage two and wait for a new barcode reading process. This behavior is illustrated in the flowchart of Fig. 3 .

This new and friendly access to CMMS is a step away to manage the maintenance interventions, work orders, maintenance auxiliary tools, and so on.

\section{ON-CONDITION SENSING AND CMMS COMMUNICATION}

Nowadays the EAM/CMMS have more and more modules associated to several data acquisition systems, being these ones aimed to control temperatures, vibrations, effluents, among others. However, these new capacities that are added to EAM have specific, proprietary, communication protocols, what difficult their $\mathrm{s}$ connection to other system beyond the proprietary; the proprietary systems predominate, but this situation tends to change progressively.

The standardization of the communications protocols is a big problem in order to put the EAM/CMMS in a new level of development, price and market generalization, what is an urgent step to give to reach the best availability and Life Cycle Cost (LCC) of physical assets.

The OSA-CBM (Open System Arquitecture for ConditionBased Maintenance) under the MIMOSA (Machinery Information Management Open Standards Alliance), that is a standards organization that manages open information standards for operation and maintenance, tries to define the architecture of an open system for maintenance conditioned with seven levels, [1] (Fig. 4):

1. Data Acquisition;

2. Data processing;

3. Monitoring the condition or state;

4. Evaluation of the operating state / fault detection and isolation;

5. Forecast / prediction of dysfunction;

6. Decision Support / recommended actions to correct the dysfunction;

7. Presentation - User interface.

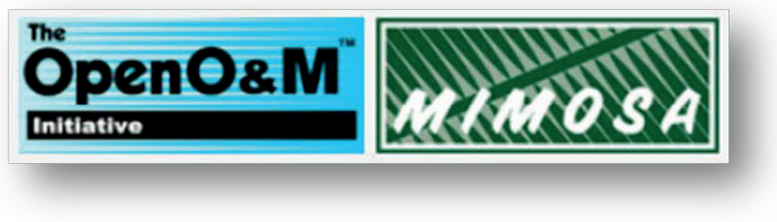

\section{Fig. 4. OSA-CBM / MIMOSA}

Under this context, the implementation and monitoring of the condition of physical assets, and interconnection with a CMMS that manages Working Orders (WO) is not dependent on any proprietary software vendor. This means that the end user (owner / operator) can select the data it deems appropriate without having to worry about integration problems or be forced to choose a single supplier to provide data in the format it need for integration and maintenance management of assets in your CMMS.

From this perspective, SMIT (Integrated Modular System for Terology) treats Physical Assets, integrating them in a modular information system that communicates with any database engine in a completely transparent and independently of the manufacturer and operating system involved [2].

\section{COMMUNICATION AMONG DIFFERENT CMMS}

Nowadays there is more and more necessity that each CMMS communicate among them and, particularly in the case of the providers certification, because the sharing of physical assets data in order to make possible the communication between client-supplier. About these problems it is particularly interesting to discuss the NP4492:2010 that is supported in the following standards:

- NP 4483:2009 - Guide to the implementation of a maintenance management system;

- NP EN 13269:2007 - Maintenance - Instructions for preparation of maintenance contracts;

- NP EN 13306:2007 - Maintenance Terminology;

- NP EN ISO 9000 - Quality management systems Fundamentals and vocabulary (ISO 9000:2005); 
- NP EN 13460:2009 - Maintenance - Documentation for maintenance;

- NP EN 15341:2009 - Maintenance - Key Performance Indicators (KPI);

- CEN/TR 15628:2007 - Maintenance - Maintenance Qualification of personnel.

One of the multiple requisites of NP4492:2010 is related to information systems, as is defined in chapter 5 - "5.1.1 Information management - The management of a company providing maintenance services requires the support of a management information system appropriate to the complexity of the activity carried".

And in item "(5.1.2 Documentation requirements) - The documentation of the maintenance provider shall include: Documented procedures and records required by this standard; Documents, including records, determined by it as necessary to ensure the planning and operation, as well as their effective control".

The above points, in many situations points out some difficult situations between client-provider, namely when both have a specific CMMS and these don't communicate. Then, the client has the information of their own assets and the provider must elaborate, again, new dossiers of those assets, what is a paradox.

The above problems make to emerge a new problem that is the necessity to have some standardization of the main data related to assets managed by any CMMS when the maintenance providers are certified and the customers require a supplier with this kind of profile.

In fact, it is nonsense to duplicate data when the client has a CMMS because it necessarily implies that, during the time the supplier manages the maintenance contract, he responds by the information, like WO, historic, KPI, and so on. If the CMMS client-provider do not communicate, at the end of the contract the provider data is not uploaded to the client CMMS. However, at this point the client can buy the provider's CMMS in order to access the data, but, if is true, the client will take two systems. But, if the client would have another contract with other supplier, the same problem potentially occurs. Then, probably it will have to buy a third system, and so on! It is a crazy situation that must be urgently solved.

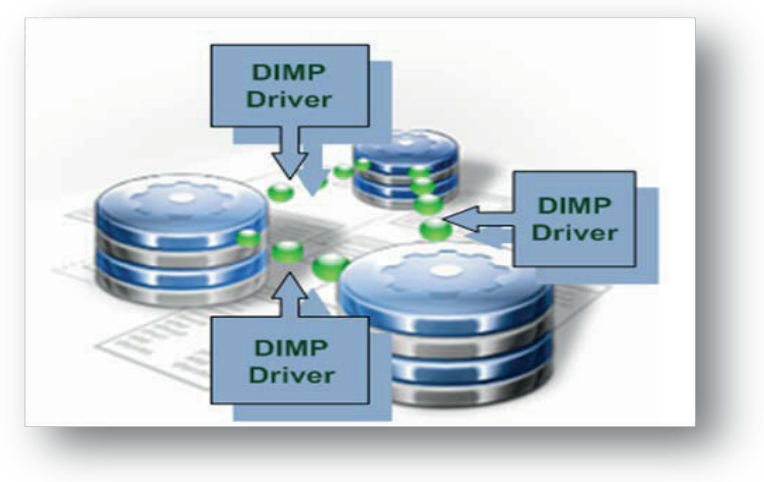

Fig. 5. Data Interchange among Multiple Platforms
It can be added other problems, as is the case of spare parts, because in some situations they are of the client responsibility and in other cases of the supplier. Then, if their CMMS are different and or do not communicate, the confusion is incremented.

The solution can be reached through a channel that obligatorily contains the main CMMS data fields, including the type of each field and its sequence, to share among the several maintenance players CMMS in order to optimize the role of each player. This solution can be called Data Interchange among Multiple Platforms (DIMP), as is illustrated in Fig. 5.

\section{INCORPORATING NEW TECHNOLOGIES IN CMMS}

One situation that can be more efficiently managed is during and after maintenance interventions, because, usually, the WO are printed to be used during interventions and its fulfillment is done after these. What happens is that there are several data that have the risk to be forgotten due to lack of time between intervention and WO fulfillment in office.

The above situation will be easily solved by the mobile solution referred in this paper (chapter 3), permitting to fill all WO data immediately after each maintenance action is done.

Other value-added can occur during the interventions itself, namely when these ones are not planned, because the technician can access on-line to a fault diagnosis tool, if it exists.

But the interest of the technology under discussion begins since the moment that equipment is purchased, because it permits to make its registration in site, including bar-code reading and so on. In fact, a correct registration of equipment dossier in database is determinant for a correct accompanying of its Life Cycle Cost (LCC), including WO, human resources, materials, and so on, as it was above referred.

When an intervention request reaches, namely the most urgent ones, and needs a quick response, a digital tool, like a tablet or a similar one, can immediately receive the information and the respective WO can be created; then, the technician, without loss of time, can, immediately treat it, make the interventions, and fulfill the WO.

Additionally, with the introduction of new technologies, like Augmented Reality (AR), 3D models, Expert Systems (ES), and so on, this new devices and applications create synergies in order to minimize intervention time, increase quality, minimize risks, and maximize availability. Fig. 6 shows an example of a flow chart of an inference operation of a CBR-ES [3-4].

In fact, if a technician use an integrated system with all these tools, AR, 3D and ES, the maintenance intervention time can be reduced, the errors minimized, and the efficiency incremented, [5]. But there are some additional benefits as is the fact that technicians less experienced can work like the fact that technicians less experienced can work like the most experienced ones, due to all the auxiliary tools that they have integrated to aid them (Fig. 7). 


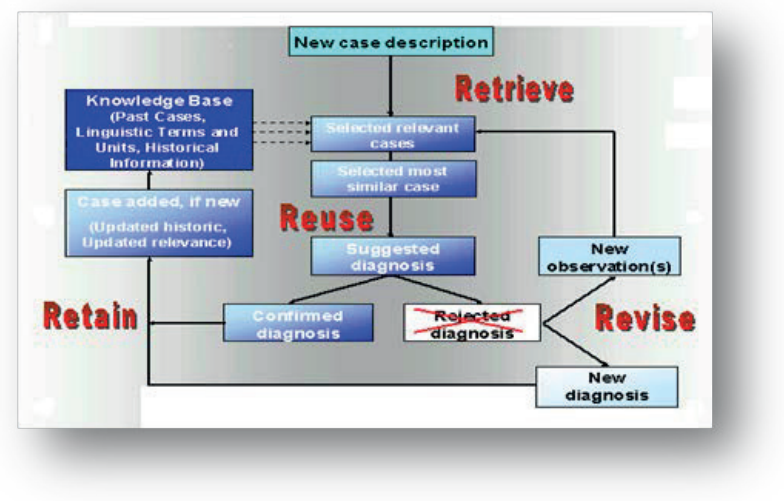

Fig. 6. The four phases of a CBR fault diagnosis system

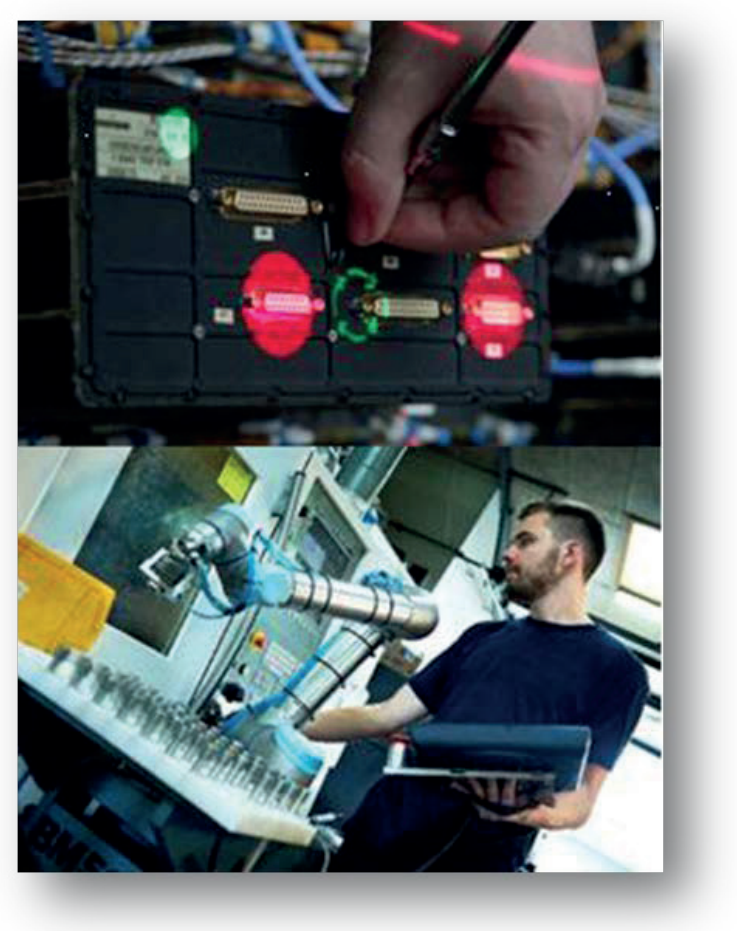

Fig. 7. Several Technologies converging to support maintenance interventions (upper) AR, AstroVAR project; (bottom) cooperative robots, Universal Robots.

\section{CONCLUSIONS}

The paper makes a short discussion of the CMMS in an integrated view from maintenance management to on-line condition monitoring, with emphasis to the communication among heterogeneous systems and multiple platforms.

It also discusses the relation between EAM and CMMS, in a time where everything is changing.

The communications among different systems, platforms and acquisition systems, where OPC/MIMOSA is trying to give a step ahead it is also proposed a Data Interchange among Multiple Platforms (DIMP) to make possible the data interchange among suppliers and clients, permitting a relation win-win.

Finally, the incorporation of new technologies in CMMS is also treated, namely the expert systems, that are not extensively used in this type of systems, even having very rich history files.

Additionally, 3D technologies, Augmented Reality, among others, are nowadays tools that have to be incorporated in EAM/CMMS to permit the maintenance activity be the key success to the organizations competiveness.

\section{REFERENCES}

[1] MIMOSA (2014): An Operations and Maintenance Information Open System Alliance. http://www.mimosa.org/?q=resources/specs/osa-cbm330, acedido em 2014.02.04.

[2] Farinha, J. M. T. (2011): Manutenção - A Terologia e as Novas Ferramentas de Gestão. MONITOR, Lisboa, Portugal. ISBN 978-9729413-82-7.

[3] Viriato Marques, Nelson Pincho, José Torres Farinha, António Brito (2004): "Health Equipment Maintenance Management and Knowledge Sharing ... In a Small World". Proceedings on CD of the 41st Annual Conference \& Technical Exhibition of the ASHE of the AHA. July 2529. Orlando, Florida; USA.

[4] Aamodt, A., Plaza,E., Case-Based Reasoning: Foundational Issues, Methodological Variations, and System Approaches, AI-Com Artificial Intelligence Communications, Vol.7, 1994.

[5] Oliveira, R., Farinha, J. T., Fonseca, I., Ferreira, L. A. and Armas, F (2012), Augmented reality as a new level for maintenance efficiency, in 'The 2nd international workshop and congress on eMaintenance', Luleå University of Technology, pp. 49-55 
(Página deixada propositadamente em branco) 


\title{
Practical challenges in determining periodic maintenance intervals on the Norwegian Continental Shelf (NCS): Some expert views and opinions
}

\author{
Nii Nortey Basil Lokko'; Jawad Raza ${ }^{2}$; Tore Markeset ${ }^{1}$; Sukhvir Singh Panesar ${ }^{1}$ \\ 1,2 nii,nortey.lokko@uis.no; 1,2 jawad.raza@,applysorco.no; ${ }^{1}$ tore.markeset@uis.no; ${ }^{1}$ sukpane@yahoo.com \\ ${ }^{1}$ University of Stavanger, N4012 Stavanger, Norway \\ ${ }^{2}$ Apply Sørco AS, N4012 Stavanger, Norway
}

\begin{abstract}
Maintenance is one of the key success factors for ensuring safe and reliable operations on the Norwegian continental shelf (NCS). Periodic maintenance is still a large part of the maintenance portfolio even if the ambition is to shift towards dynamic strategies. Therefore, one can conclude that, currently, the availability of offshore production facilities on the NCS is significantly influenced by maintenance programs that are based on predetermined periodic maintenance tasks.
\end{abstract}

This paper reviews current practices and experiences for determining intervals for performing maintenance tasks. The mapping is performed by comparing theoretical and practical industrial approaches to determine the preventive maintenance task intervals. The paper highlights some practical issues and challenges that maintenance engineers face in the determination of task frequencies/intervals on the NCS.

The study shows that the biggest challenge for the maintenance engineers is to determine the "optimal interval" for the maintenance tasks. A frequent task will increase the maintenance costs, whilst an extended interval could increase the risks related to unexpected failures. The maintenance engineers use their engineering judgment by combining manufacturer recommendations, regulatory requirements and operational needs to determine optimal intervals. The NCS, however, needs more dynamic maintenance strategies that are data driven but without the inhibiting computational and practical issues currently available in existing theoretical mathematical models.

\section{Keywords-Preventive maintenance, maintenance interval}

\section{INTRODUCTION AND BACKGROUND}

Predetermined periodic maintenance is a part of the broader concept of Preventive Maintenance (PM). Hence, drawing from standards such as EN 13306 [1], ISO 14224 [2], NORSOK Z-008 [3] and other literature, predetermined periodic maintenance may be defined as planned maintenance carried out on the basis of regular time intervals intended to reduce the probability of failure or the degradation of the function of an item ${ }^{1}$.

According to Mobley et al [4], predetermined periodic maintenance is based on the assumption that equipment will degrade and fail within a time frame (operational hours/calendar) that is typical of its particular classification. This assumption is accepted to be generally true. Experience, on the other hand, suggests that degradation and failure can occur outside this typical time frame, even for similarly classified equipment. Nonetheless, it is this assumption that forms the basis of why predetermined periodic maintenance is mathematically rooted in the concepts of statistics and probability. Three interpretations of probability are acknowledged in probability theory: classical, relativefrequency and subjective interpretations [5]. The relativefrequency interpretation of probability satisfies the scientific requirements of objectivity and repeatability. It also provides a probability interpretation that is closest to the assumption underlying predetermined periodic maintenance. This interpretation, understandably, forms the principal element of several models used for the determination of predetermined periodic maintenance intervals.

Maintenance activities and intervals are defined in a typical PM program. However, on the Norwegian continental shelf (NCS), developing a PM program also includes preparing PM task routines, specifying the requirement for spare parts, estimating the duration for executing each maintenance activity and assigning a discipline responsible for each maintenance activity. The study presented in the ensuing section will therefore be limited to determining the interval of maintenance tasks for a PM program on the NCS.

In this paper, we briefly review how predetermined periodic maintenance intervals are theoretically determined and compare these general concepts with practices on the NCS. We present two perspective views of the process of determining maintenance intervals on the NCS and also discuss some challenges in the PM program determination. The paper is primarily based on interviews with maintenance experts. Expert opinion from practicing engineers was sought in establishing the role that predetermined periodic maintenance plays in ensuring oil and gas $(\mathrm{O} \& \mathrm{G})$ asset availability. A brief literature survey was also undertaken, discussing general theoretical approaches to establishing predetermined periodic maintenance programs.

\footnotetext{
${ }^{1}$ An item is defined as, "any part, component, device, or an assembly of parts that is normally the lowest level in the hierarchy during maintenance" [3]
} 


\section{THEORETICAL ESTIMATION OF PREDETERMINED PERIODIC MAINTENANCE INTERVALS}

The determination of periodic maintenance intervals begins by finding the appropriate probability distribution to describe the equipment failure process. Establishing the probabilistic nature of the underlying failure process may be attained either by a parametric method or a non-parametric/empirical method [5]. Whichever method is chosen, a statistical analysis of equipment failure data is required. Most often though, real-life failure data fits the Weibull distribution [5] [6] [7]. The Weibull distribution is therefore considered the most appropriate probability distribution for inspection and preventive maintenance activities because of its possible application to a wide range of scenarios and its ability to approximate several other distributions.

The failure rate (number of failures per unit of time), often used to derive the statistical parameter known as he mean time to failure (MTTF), is a key reliability measure in the determination of periodic maintenance intervals. In addition to the failure rate, a description of the failure process requires the determination of the following: 1) the probability density function of the time to failure, 2) the cumulative density function, 3) the reliability function; and 4) the hazard function.

Once the probabilistic nature of the failure process has been defined, and the relevant parameters determined, any of the numerous theoretical models might be used to determine the most appropriate interval. These models suggest an optimal time for replacements [8] [9], inspections [6] [10] [11] [12] [13], and overhauls [14] [15] [16] [17]. Complex analysis techniques, such as Markov chains, Bayesian modeling, simulations, fuzzy logic, expert systems and genetic algorithms, form the basis for some of these models. Hence, they require a considerable amount of time, research and analysis to define a specific scenario. Furthermore, the analyst requires competence and skills in applying the methods and in assessing the assumptions to be applied to the system in question.

Models are developed with a specific target objective in mind. Either minimizing maintenance cost, reducing downtime, enhancing reliability, availability, maintainability or a combination of some or all of these objectives has been discussed and modeled in research works. The determination of periodic maintenance intervals thus transcends the intrinsic failure characteristics of the equipment. Applications of such models thus require the collection and storage of detailed information (both qualitative and quantitative). Such detailed information includes equipment failure, operation regimes, maintenance actions, modifications and related costs [18]. The intervals determined via these models are, therefore, a translation of specific corporate/business objectives and operating strategies.

\section{THE NORSOK GUIDELINES FOR PM INTERVAL DETERMINATION}

The maintenance management process defined in NORSOK Z-008 [3] also acknowledges the derived theoretical influence of specific corporate/business objectives and operating strategies on PM intervals and programs. Hence, the maintenance programs on the NCS are developed on the basis of the goals and requirements specific to each O\&G company but with a focus on:

- Reducing risks, increasing production and lowering cost

- Compliance with applicable regulatory requirements

- The technical condition of the facility (in particular the performance of safety systems and critical processes)

- Improvement of the overall maintenance process.

Consequence classification is the main foundation for the development of PM programs on the NCS. The classification is an analysis that determines the effects of potential equipment functional failures on HSE, production and costs by breaking down all the installation's functions into main and sub functions. Once the groupings and the classifications have been completed, maintenance activities and intervals are then determined.

For equipment classified as safety critical, testing intervals are determined on the basis of the performance requirements of their safety functions (OLF 070 [19] or IEC 61508). For nonsafety critical equipment, one of the following options is employed:

- Referring to standardized/ generalized strategies/ concepts. These standardized concepts are developed by performing detailed reliability-centered maintenance (RCM) analysis on equipment and documenting results such that they can be used for similar equipment of the same classification. Company-specific operational and maintenance experiences (best practices) as regards specific equipment are also used to enhance the RCM analysis results. Thus, within the framework of NORSOK Z-008, generalized strategies/concepts on the NCS are regarded as an efficient mode of capturing standardized company knowledge. The use of generalized maintenance strategies/concepts is considered an indirect RCM analysis on the specific equipment being examined.

- Performing detailed RCM analysis and risk-based inspection (RBI) methods to determine the specific maintenance activities, intervals and plans for execution for the equipment/system.

- $\quad$ Referring to original equipment manufacturers' (OEM) recommendations on maintaining the equipment/system.

- Deciding to run the equipment/system to failure.

Performing a cost/benefit analysis is one of the recommended steps to determine cost-effective maintenance activities for selected equipment. For low consequence class assets, however, an interpretation of the guidelines suggests that risk analysis and/or cost/benefit analysis may not always be a necessary activity. 


\section{THE EXISTING PRACTICAL APPROACH TO DETERMINING PM INTERVALS ON THE NCS}

On the NCS, there is a practical approach for identifying and developing an effective PM program, which mainly involves the consideration (among others) of:

- Regulatory and company requirements

- Company-specific best practices

- Generalized maintenance strategies/concepts
- Original equipment manufacturers' recommendations, and

- National and international standards and guidelines

Statutory regulations/requirements, as well as national (NORSOK) and international standards (ISO, IEC), are considered in the PM interval and activity determination process. Where there is a clearly defined statutory requirement, it supersedes any practice, concept, standard, recommendation or guideline.

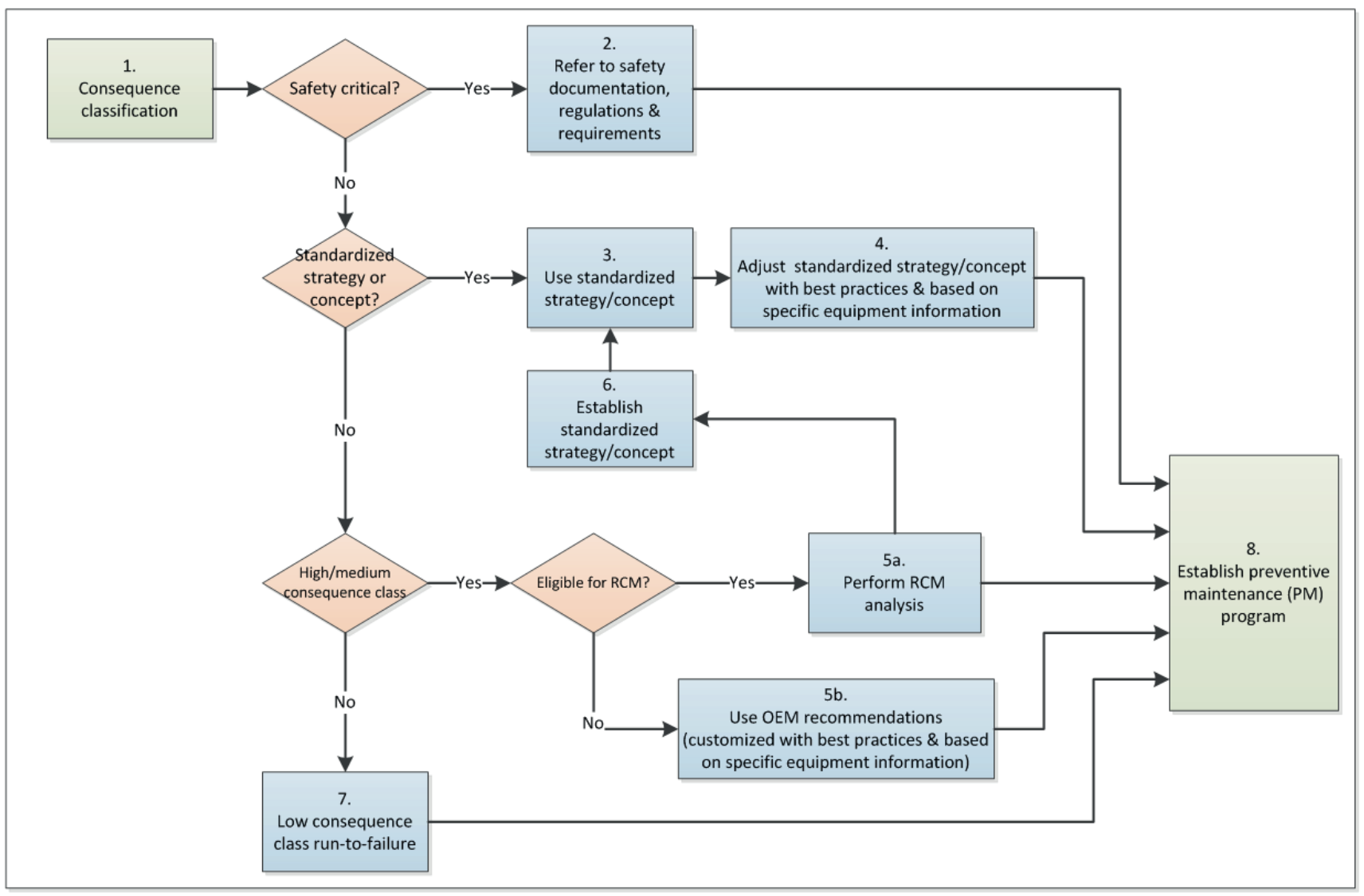

Fig. 1. Establishing a maintenance program: process description by Company A

Figure 1, therefore, captures an example of the process of establishing a maintenance program (as interpreted by a leading maintenance service provider on the NCS).

The work process in Figure 1 depicts a typical, simplified and relatively accurate interpretation of the maintenance guidelines on the $\mathrm{NCS}^{2}$. Keeping in mind that the standardized maintenance strategies/concepts are defined for a specific/generic group of items, the above process suggests that the time-consuming and capital-intensive RCM analysis will only be employed in certain special scenarios (refer to the

${ }^{2}$ This, however, is from the perspective of maintenance service providers (i.e. maintenance engineers who are often contracted by the operators to assist in developing a maintenance program). section on "some identified challenges in determining the optimum maintenance interval on the NCS").

Best practices and standardized concepts (if available) are therefore the primary sources of decision-making information with regard to PM interval determination on the NCS. According to some practicing maintenance engineers, these practices and concepts are significantly influenced by several years of personnel experience on the operation and maintenance of similar types of equipment. Inherent in these experiences are the corporate/business goals and objectives that govern all operations/activities. The generalized maintenance strategies/concepts can be considered as a maintenance representation of an operating company's corporate strategies. 
The OEM recommendation is also a major contributory factor in the PM interval determination process. Engineers on the NCS believe that, due to the constraints of contractual agreements pertaining to aftersales services, the OEM recommendations are increasingly becoming a major source for determining PM intervals. Opinions suggest that since OEMs prefer to avoid failures during the equipment warranty period, they often recommend conservative maintenance programs. Such programs, if not adjusted after the warranty period, can lead to a continued reliance on maintenance programs that may lead to more downtime and more spares in storage than necessary or simply over maintenance. This current trend may also have been compounded by the development and use of innovative technologies by operators on the NCS, for which little or no experience is available. This lack of experience (with regard to innovative technologies) has led to conservative and costly maintenance programs where too much maintenance is being done too often.

Figure 2 depicts a six-step process of establishing a maintenance program that is suggestive of a more operational interpretation of the NORSOK guidelines.

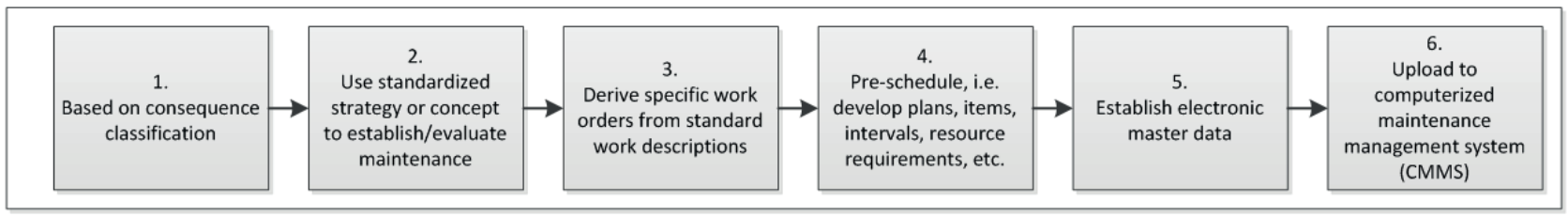

Fig. 2. Maintenance program development process by Company B.

The work process in Figure 2 is a view from the operating company's perspective. The operators themselves appear to be satisfied with being reliant on standardized maintenance strategies/concepts when available and wherever applicable. The figure seems to indicate that $O \& G$ operators consider plans for execution as part of the PM program. This is in contrast to the service providers' interpretation, which generally does not include such plans. Despite this contrast, good collaboration exists between maintenance service providers and O\&G operators. Both, however, seem to agree that, even when generalized maintenance strategies/concepts are available, the establishing of maintenance intervals and activities is a major issue to contend with on the NCS.

\section{SOME IDENTIFIED CHALLENGES IN DETERMINING THE OPTIMUM MAINTENANCE INTERVAL ON THE NCS}

\section{A. The challenge of using existing theoretical models}

Basic definitions for equipment reliability make reference to the probability of performing intended function(s) under certain prevailing conditions, and over a predefined time period [20]. Since predetermined periodic maintenance is a significant part of the PM on the NCS (according to several maintenance engineers), an equally significant part of improving reliability on the NCS can be suggested as a function of predetermined periodic maintenance. It is on this basis that theoretical approaches to establishing this time interval may be considered appropriate for establishing initial PM programs on the NCS. However, a major difficulty with these theoretical models is that not all the input (e.g. equipment failure history data, downtime and cost data) may be available to the maintenance engineer, especially in cases where the installations are new.

Some maintenance engineers on the NCS are of the opinion that, even when all such quantitative (and to some extent qualitative) data is available (as may be the case for some existing old installations), the reliability of the data itself maybe an inhibiting issue. These engineers also suggest that it is quite impractical to even consider the utilization of some of these models when they are faced with the task of determining the PM intervals for several thousands of tagged items. There are too many tags to be assessed individually, even if sufficient reliable data is made available. It would simply be computationally strenuous and time-consuming to perform such an assessment using most of the existing models.

\section{B. The challenge of using best practices and generalized maintenance strategies/concepts}

The assumption underlying theoretical mathematical models (i.e. equipment will degrade and fail within a fixed time frame typical of its particular classification) is also the basis for developing generalized maintenance strategies/concepts and using best practices. Consequently, the inherent limitation within mathematical models (i.e. the underlying assumption could be false), is also a limitation for relying on company best practices and generalized maintenance strategies/concepts for establishing PM programs.

The general nature of best practices and generalized maintenance strategies/concepts allows for some level of subjectivity if they are to be employed effectively for specific operating scenarios. Since generalized maintenance strategies/concepts are specifically defined for a group of equipment operating under similar conditions (i.e. particular classification), the judgment on similarity is often dependent on the responsible engineer(s). The adjustments that would be necessary in instances of deviations are also influenced by personal practical experiences and personal risk tolerance levels. An incorrect judgment (for example because of the responsible engineer's higher or lower personal risk tolerance) would likely result in costly, inefficient maintenance.

It was also suggested that, in the absence of generalized maintenance strategies/concepts (and specific company best practices), original equipment manufacturer (OEM) recommendations and/or other detailed reliability analyses such as RCM may be required. This, however, is dependent on the consequence classification groupings. Slight modifications to the OEM recommended PM activities with respect to 
functional and operational parameters would, in some cases, be sufficient. The available reliability standards [2] and databases (OREDA) which can provide useful information about critical failure modes and mechanisms etc. may be used for such adjustments. However, in principle OEM maintenance recommendations are either the specific best practices of that particular OEM or the generalized maintenance strategy/concept of the OEM for similar equipment types. Hence, the OEM recommendations may be limited in the same manner (if not more so) as earlier discussed in this section.

\section{The challenge of applying RCM analysis}

The study also indicated that there is an increasing request for RCM analysis on critical items on the NCS. Many engineers are in favor of performing RCM but are also quick to point to the time and resource (human and capital) intensive nature of the analysis as its major impediment. One engineer described an example where it took two fully dedicated engineers and a number of discipline experts more than three weeks to complete a full failure mode, effects and criticality analysis (FMECA). The FMECA was on two electro-plates (with no moving parts) for a subsea module. The engineer then emphasized that a complete FMECA is an integral part of any $\mathrm{RCM}$ analysis.

Some experts are of the view that another major challenge with RCM is that only a limited number of people actually who understand the process [21]. The opinion is that RCM takes time and requires an experienced facilitator who understands real failure modes. A thorough understanding of how functional failure is interconnected with how items work together, as well as the available actions and techniques to ensure equipment reliability, is a scarce expertise.

In principle, therefore, all items can benefit from RCM analysis. However, time and resource limitations indicate that priorities need to be defined. Hence, a detailed RCM analysis is only undertaken for some selected equipment.

\section{FURTHER DISCUSSIONS}

The discussion thus far indicates that the practical approach employed on the NCS relies largely on qualitative data/information (best practices, generalized maintenance strategies/concepts, OEM recommendations and standards/regulations) as against the quantitative data that is required for the existing mathematical models. Without the right experience and/or expertise, the subjectivity involved in interpreting (or deducing from) qualitative data can result in the development of PM programs with intervals that are ineffective. The challenges identified with regard to the use of theoretical mathematical models may have influenced the development of this qualitative approach on the NCS. There is, however, the need for the use of more quantitative data on the NCS.

Recent developments in technology have improved the ability to capture and store precise and accurate equipment data. Continuous technological advancement is thus providing the industry with innovative techniques with which to analyze the captured equipment data, and transform such data into decision-making information. Integrated Operations $(\mathrm{IO})^{3}$ is also a current operating regime on the NCS that provides the kind of collaborative environment that fosters the implementation of more dynamic strategies such as predictive maintenance. The challenge, however, is to develop innovative tools that readily and cost-effectively provide decision support regarding the health and condition of equipment (most preferably in real time). Such tools will provide the opportunity to relate the maintenance activities to condition rather than over-reliance on existing predetermined activities. Also, there is the ever-deepening challenge of developing competences that can effectively use any such tools and positively exploit the expertise made available in collaborative environments (such as IO).

The availability level of offshore assets is constantly under pressure. Expert opinion suggests that the know-how and practical experience required in establishing and continuously improving effective PM programs is wearing thin. Offshore operating regimes continue to increase in complexity (exemplified by recent Arctic operations). Consequently, despite the general feeling that predetermined periodic maintenance currently dominates offshore maintenance activities, this study expects predictive and dynamic maintenance strategies (which are data driven) to play a more significant role in improving the level of equipment availability in the near future.

\section{CONCLUDING REMARKS}

In summary, we have (on one hand) pure theoretical models based on reliability theory, whose applicability is somewhat in doubt by some maintenance engineers on the NCS. Some of these theoretical models lead to PM intervals that often result in either too little or too much maintenance. In addition, each of these models also has its related unwanted cost effects. On the other hand, we have a practical approach that is subjective, but which has been applied extensively for the determination of PM intervals and activities on the NCS. The overriding feature regarding the determination of task frequencies/intervals on the NCS is the art of combining equipment manufacturer recommendations, operating company's best practices, and the Norwegian O\&G regulatory framework with long-term operating experiences. Practical experiences, however, suggest that this practical approach often also results in either too little or too much maintenance.

The current approaches to determining PM intervals and activities on the NCS contribute to ensuring the availability and reliability of offshore equipment. There is, however, more room for improvement, especially in the area of maintenance effectiveness and efficiency with respect to the use of qualitative equipment data. There is a need for more dynamic maintenance strategies that are data driven but without the inhibiting computational and practical issues currently available in the existing theoretical mathematical models (as previously discussed). These dynamic strategies must be

3 IO is an initiative from the Norwegian Oil Industry Association (OLF), which emphasizes the need to use "ubiquitous real time data, collaborative techniques and multiple expertise across disciplines, organizations and geographical locations" to aid in taking smarter decisions [22]. 
sufficient to encapsulate those failures that are typical of specifically classified equipment types and those failures that make current maintenance strategies occasionally seem inadequate. Hence, these dynamic strategies must lay more emphasis on establishing the current condition of equipment (under prevailing operating and environmental circumstances) and incorporating methods for reassessment and adjustment of the maintenance strategy over time.

The need to pursue more dynamic concepts to optimize periodic maintenance on the NCS is widespread.

\section{ACKNOWLEDGMENT}

We would like to acknowledge all asset managers and maintenance engineers from the NCS who contributed to this study.

\section{REFERENCES}

[1] EN 13306, (2010), Maintenance - Maintenance terminology

[2] ISO 14224, (2006), Petroleum, petrochemical and natural gas industries - Collection and exchange of reliability and maintenance data for equipment

[3] NORSOK Z-008, (2011), Risk based maintenance and consequence classification

[4] Mobley, R.K., Higgins, L.R. and Wikoff, D.J., (2008), Maintenance Engineering Handbook, McGraw-Hill, New York

[5] Verma, A.K., Ajit, S. and Karanki, D.R., (2010a), Basic reliability mathematics, in: Reliability and Safety Engineering, Springer Series in Reliability Engineering. Springer London, pp. 15-70

[6] Hariga, M.A., (1996), A maintenance inspection model for a single machine with general failure distribution, Microelectronics Reliability: issue 36, pp. 353-358

[7] Verma, A.K., Ajit, S. and Karanki, D.R., (2010b), Mechanical reliability, in: Reliability and Safety Engineering, Springer Series in Reliability Engineering. Springer London, pp. 229-266

[8] Nakagawa, T. and Mizutani, S., (2009), A summary of maintenance policies for a finite interval, Reliability Engineering and Systems Safety: issue 94, pp. 89-96
[9] Young Yun, W. and Nakagawa, T., (2010), Replacement and inspection policies for products with random life cycle, Reliability Engineering and Systems Safety: issue 95, pp. 161-165

[10] Nakagawa, T. and Osaki, S., (1974), Optimum preventive maintenance policies maximizing the mean time to the first system failure for a twounit standby redundant system, Journal of Optimization Theory and Applications: issue 14, pp. 115-129

[11] Nakagawa, T., (1980), Replacement models with inspection and preventive maintenance, Microelectronics Reliability: issue 20, pp. 427433

[12] Lu, X., Wang, W., Yang, H., Zuo, M.J. and Zhou, D., (2012), Optimizing the periodic inspection interval for a 1-out-of-2 cold standby system using the delay-time concept, Quality and Reliability Engineering International: issue 28, pp. 648-662

[13] Wang, C.H. and Sheu, S.H., (2003), Determining the optimal production-maintenance policy with inspection errors: using a Markov chain, Computers \& Operations Research: issue 30, pp. 1-17

[14] Louit, D., Pascual, R. and Banjevic, D., (2009), Optimal interval for major maintenance actions in electricity distribution networks, International Journal of Electrical and Power Energy Systems: issue 31, pp. 396-401

[15] Mathew, J. and Rajendran, C., (1993), Scheduling of maintenance activities in a sugar industry using simulation, Computers in Industry: issue 21, pp. 331-334

[16] Seo, J. and Bai, D., (2004), An optimal maintenance policy for a system under periodic overhaul, Mathematical and Computer Modelling: issue 39 , pp. 373-380

[17] Srivastava, P.W. and Jain, N., (2011), Bayesian prediction of the overhaul effect on a repairable system with bounded failure intensity, Journal of Quality, Statistics and Reliability Engineering: vol. 2011

[18] Sharma, A., Yadava, G.S. and Deshmukh, S.G., (2011), A literature review and future perspectives on maintenance optimization, Journal of Quality in Maintenance Engineering: issue 17, pp. 5-25

[19] OLF 070, (2004), Application of IEC 61508 and IEC 61511 in the Norwegian Petroleum Industry

[20] Mishra, R.C., (2007), Reliability and Maintenance Engineering, New Age International Ltd., New Delhi

[21] Plucknette, D., (2014), Why are people afraid of RCM? [Online] Available from: http://www.maintworld.com/Asset-Management/Whyare-people-AFRAID-OF-RCM [Accessed: 24th July 2014]

[22] Liyanage, J., (2008), Integrated eOperations - eMaintenance: Applications in North Sea offshore assets. In Kobbacy, K.A.H. \& Murthy, D.N.P. (ed.), Complex System Maintenance Handbook (pp. 585-610). London: Springer-Verlag London Limited 


\title{
Hoshin kanri: a strategic approach to maintenance performance management
}

\author{
Peter Chemweno ${ }^{1}$, Liliane Pintelon ${ }^{1}$; Peter Muchiri $^{2}$ \\ ${ }^{1}$ peterkipruto.chemweno@kuleuven.be; ${ }^{1}$ liliane.pintelon@kuleuven.be; ${ }^{2}$ peter.muchiri@dkut.ac.ke \\ ${ }^{1}$ Centre for Industrial Management, KU Leuven, \\ Heverlee, Belgium \\ ${ }^{2}$ Dedan Kimathi University of Technology, \\ Nyeri, Kenya
}

\begin{abstract}
The Hoshin kanri is a popular methodology for strategic policy planning and deployment. The approach is widely used by firms as a tool for aligning organizational objectives at the strategic level with key performance measures at the tactical and operational levels. Moreover, the methodology presents a structured means for translating performance measures into specific performance indicators. Based on the performance indicators, decision makers are able to measure the performance of processes/systems and consequently, implement corrective actions. However, despite its successful implementation in diverse sectors such as finance, banking and quality management, not much work is mentioned regarding its use in maintenance performance management. Yet, recent literature underscores the strategic importance of performance measurement as a means of evaluating the effectiveness of implemented maintenance strategies. This paper adapts the Hoshin kanri technique for strategic maintenance performance management. The tool's applicability is demonstrated through the case study of an edible oil processing facility. The technique proposes a structure for; aligning strategic objectives to key performance indicators at the shop floor, setting performance targets and implementing improvement actions. Moreover, the technique is user intuitive and involves personnel at all levels in the organization.
\end{abstract}

Keywords-Hoshin kanri, policy deployment, asset maintenance.

\section{INTRODUCTION}

In recent years, research on asset maintenance has gained considerable attention. Indeed, for operable assets, the operation and maintenance costs often constitute as much as $70 \%$ of the total ownership cost [1]. For this reason, the maintenance function is no longer viewed as a 'necessary evil', but of strategic importance to the organizations' competitiveness. Often, the role of the maintenance function is to initiate and implement maintenance strategies that mitigate asset failures. Well-known maintenance strategies include; the Failure Based Maintenance (FBM), Time/Use Based Maintenance (UBM/TBM) and Condition Based Maintenance (CBM) [2]. Linked to these strategies are a set of maintenance interventions, e.g. corrective maintenance actions, in the event of failure, or preventive maintenance actions, prior to component failure.
However, evaluating the effectiveness of implemented strategies is often not straightforward. This informs the recent proliferation of literature on maintenance performance measurement [3]. According to Neely [4], performance measurement is the process of quantifying a purposeful action, where the process of quantification is measurement and the purposeful action equates to performance. Achieving a purposeful action requires a structured approach. One common approach is designing a maintenance performance reporting system. Ideally, the reporting system consists of defined set of maintenance performance indicators that assist practitioners evaluate the performance of past maintenance. Examples of such activities include evaluating the effectiveness of maintenance interventions undertaken or quality of repair actions. In this paper, the performance indicator is defined as $a$ variable that expresses quantitatively the effectiveness, efficiency or productivity of a system against a given norm or target [2].

Ideally, the maintenance performance indicators ought to cascade from the strategic goals/objectives defined by top management. This requires a methodological approach. However, this is often not the case in many organizations where generic list of indicators is often adopted [5]. In addition, performance indicators are derived from established standards, e.g. the EN 15341. As such, existing maintenance performance reporting models seldom link performance indicators to the strategic goals/objectives. Moreover, several limitations are noted with existing reporting models which include lack of structured approach for performance target setting, ad-hoc formulation of corrective actions and absence of systematic improvement actions, e.g. as proposed through the quality improvement cycle.

This article attempts to address the above concern by proposing the Hoshin kanri (H-K) methodology for policy deployment, performance measurement and implementing improvement actions. The remainder of this paper is organized as follows. In Section 2, introductory concepts in maintenance performance reporting is discussed. This is followed by a brief review of existing performance reporting models. The review highlights gaps in existing models. In Section 3, phases in the Hoshin kanri methodology are discussed. Section 4 describes adaptation of the Hoshin kanri for maintenance performance management where the methodology is demonstrated through the case study for edible oil - solvent extraction facility. 
Section 5 draws important conclusions and directions for future work.

\section{MAINTENANCE PERFORMANCE REPORTING}

\section{A. Overview on performance reporting}

Performance reporting is an integral aspect in asset management and by extension, maintenance decision making. Ideally, performance reporting strives towards excellence in maintenance and defines several aspects which include; defining a mission statement, setting goal and objectives, strategy development, performance measurement and finally, formulation of corrective actions [2].

In many organizations, the maintenance function is the responsibility of the maintenance department whose core task is formulating maintenance programs. Often, the programs detail the type of strategy, maintenance intervention or repair actions. As mentioned in the previous section, performance reporting provides an important structure for evaluating the effectiveness of the implemented programs. This is reflected by the maintenance performance indicators. In practice, maintenance performance measurement is characterized by diverse set of metrics and indicators e.g. see Kumar, Galar [3].

However, selecting appropriate indicators for the organization is often not straightforward. As a result, several authors propose multi-criteria decision making models (MCDM). For instance, Parida [6] propose a multi-criteria hierarchical framework for maintenance performance measurement. The framework proposes several performance indicators cascaded to the different organizational levels, i.e. strategic, tactical and operational levels. An analytic network process approach (ANP) is adopted by Van Horenbeek and Pintelon [7] where the maintenance performance indicators are prioritized and cascaded to all organizational levels. Recently, Gonçalves, Dias [8] propose a methodology for selecting key performance indicators for maintenance through the ELECTRE, a multi-criteria decision making approach.

The models discussed above propose an important structure that potentially guides practitioners towards selecting the right indicators. However, the models seldom address performance measurement aspects, e.g. performance target setting, performance measurement, and formulating maintenance improvement actions. These gaps are partially addressed by performance reporting models discussed in the next section.

\section{B. Performance reporting models}

Performance reporting models provide an important measurement tool that incorporates performance measurement aspects. The models aid in structuring performance measurement with a view of addressing the following concerns [2]:

- What is required for carrying out maintenance (input)?

- What is expected from the maintenance interventions (output)?
- What and how much maintenance is required (process)?

- What is being done to improve maintenance processes (continuous improvement)?

In literature, performance reporting models are discussed. Several of the models are based on the well-known balanced score card (BSC) [9]. Notable examples include Tsang [10] where the BSC approach is adopted for maintenance performance management. In the study, the corporate strategy is first translated to maintenance strategy, followed by maintenance objectives, and finally action plans. Moreover, the action plans are linked to performance measurement where periodic review against targets is implemented.

In other studies, Alsyouf [11] demonstrate how the BSC can be used by the organization to improve the return on investment (ROI) through adopting condition based maintenance strategy. Here, the overall equipment effectiveness (OEE) and cost measures are adapted as the key indicators of maintenance effectiveness. More recently, Galar, Parida [12] propose an approach based on the BSC where the maintenance performance indicators are derived from four BSC's perspectives, i.e. financial, customer satisfaction, internal processes and learning/growth. In the study, the authors demonstrate how the indicators are deployed to all levels in the organization. Using a different approach, Kutucuoglu, Hamali [13] propose a framework for maintenance performance management based on the quality function deployment (QFD) technique. In the study, the maintenance metrics/indicators are aligned to organizational goals via the QFD matrix.

The models described above form an important basis for developing performance reporting systems. Nevertheless, several important aspects that are central to performance reporting are insufficiently addressed. These include setting performance targets and formulating maintenance improvement actions.

\section{HOSHIN KANRI}

\section{A. Overview of the hoshin kanri}

The Hoshin kanri is a Japanese management term that loosely translates to policy deployment. The methodology traces its origin to early work in total quality control pioneered by the Japanese manufacturing industry. The methodology embraces four important steps $[14,15]$ :

1. Establish the organizational vision followed by translating the vision into goals, aims, and future scope;

2. Formulating strategy, objectives, key performance indicators (KPI's), performance benchmarks and targets;

3. Deploying the objectives, KPI's, benchmarks and targets to all levels in the organization; 
4. Performance evaluation, control and implementing continuous improvement actions with the aid of the Plan-Do-Check-Act (PDCA) cycle.

The Hoshin kanri forms an important pillar for Total Quality Management (TQM) by presenting a comprehensive methodology for quality management. This contrasts to standard practice where TQM is implemented using individual quality management tools, e.g. six-sigma or statistical process control [16]. As a result, the Hoshin kanri integrates core management aspects into one framework, right from strategic planning to control. Through the integration, decision makers are able to formulate long-term plans, translate the plans into short-term objectives, derive KPI's, set performance targets, and deploy the KPI's, benchmarks and targets. Moreover, the Hoshin kanri allows one to formulate and implement improvement actions in a structured way. Figure 1 depicts important elements of the Hoshin kanri.

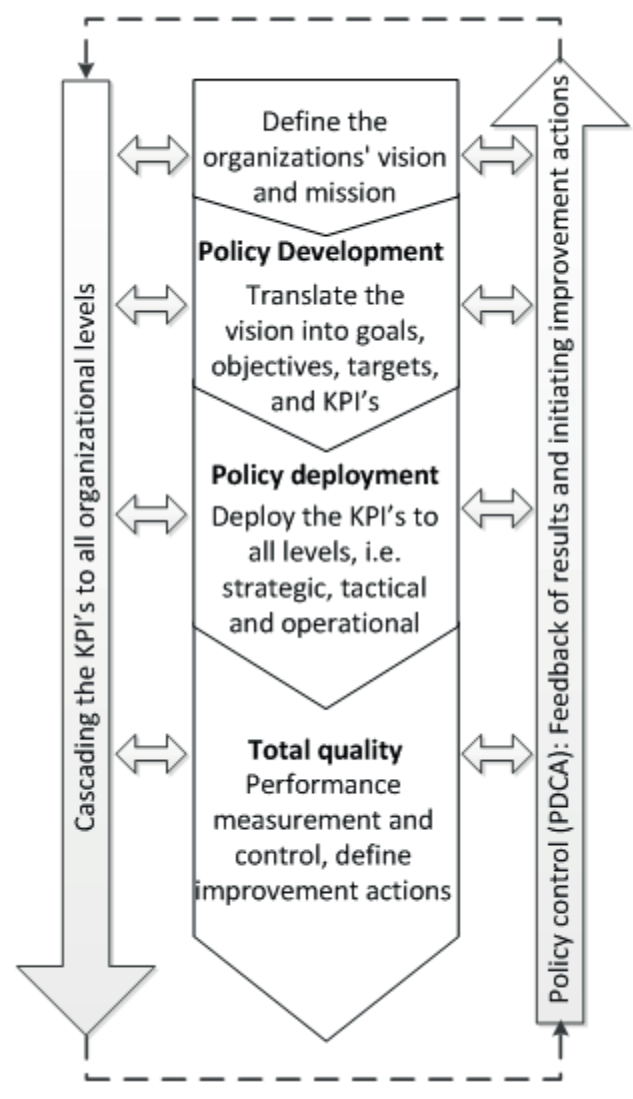

Fig. 1. Elements of the Hoshin kanri planning [16].

An important feature of the Hoshin kanri is the PDCA cycle for ensuring policy control. The cycle allows decision makers to measure the performance of the system against set targets. This is achieved through periodic review of the KPI's. Based on the performance, policy control activities are initiated. These may include implementing improvement actions, e.g. optimizing maintenance schedules for critical failure modes or improving spare parts order lead time through better inventory management. Such actions constitute the 'plan' and 'do' phase. Of course, to ensure that the implemented measures are achieving the desired results, the 'check' phase is undertaken through comparing the actual performance against desired targets. For out of spec measures, corrective actions become necessary. Here, the 'act' phase becomes rather important.

The cyclic PDCA approach is continuously repeated thus leading to improved management process. Indeed, the Hoshin kanri is a rather valuable tool in that it aligns employees at all levels of the organization to the organizational vision [16].

\section{B. Industrial application of Hoshin kanri}

One of the earliest industrial applications of the Hoshin kanri for quality control was the Bridgestone tire company in Japan [17]. Since then, its use in diverse industries, e.g. semiconductor manufacturing, automobile assembly and general engineering firms is reported [18-20]. In the aforementioned organizations, the Hoshin kanri is largely applied in quality improvement, productivity improvement and strategic policy deployment.

However, despite its wide application, not much work is reported regarding its use in maintenance performance management. Yet, performance measurement performs a critical role in maintenance decision making. This informs the reason for this article. In the following sections, the methodology for Hoshin kanri as adapted in this article is discussed. This is followed by a demonstration of its use in a case study.

\section{CASE STUDY}

\section{A. Case background}

This section discusses application of the Hoshin kanri methodology for performance management. The company considered in this study operates an edible oil processing facility. The production process entails extracting oil from oilseed through a solvent extraction process. The solvent used in this case is hexane. The extract, i.e. solvent-oil mixture, is directed to condenser units where the solute is separated from the solvent through an evaporation and condensation process. Afterwards, the extracted oil is channeled to a refining section, while the recovered solvent is re-circulated to the solvent chamber to facilitate further oil extraction.

The solvent extraction process is a controlled chemical process and requires the correct conditions for optimal extraction. Moreover, the solvent has low boiling point and highly flammable. This leads to important maintenance challenges should the extractor breakdown. Often, when a failure occurs, the extractor is stopped and allowed to cool down, until hexane fumes liquefy, a process that takes several hours. Moreover, both the extract and feed stock have to be flashed out of the system, leading to production and quality losses. In addition to production losses, any maintenance activity leading to sparking is avoided, e.g. striking one metal surface against another (hammering or arc welding). This is primarily due to the flammable nature of hexane. 
For the facility, periodic maintenance is undertaken. However, considering the rising demand for the company's products, the maintenance function is often constrained in terms of opportunity for carrying out maintenance. Moreover, in absence of a robust performance measurement tool, tracking the effectiveness of maintenance interventions is not straightforward. For these reasons, implementing performance management was considered necessary.

\section{B. Case methodology}

This section presents the proposed methodology for the Hoshin kanri planning applied in the context of the case study. Figure 2 depicts the methodological steps, where the cyclic relationships between the different steps are linked via the PDCA cycle. The steps are as follows:

1) Establish the organization vision and mission;

2) Translate the vision into both short term and longterm objectives;

3) For each objective, define key performance indicators (KPI's);

4) Establish the performance targets for each KPI's;

5) Deploy the KPI's to all organizational levels;

6) Formulate a structure for data collection relevant to the KPI's, e.g. failure data for computing reliability;

7) Depending on the KPI's, conduct periodic performance measurement. The review period may be short-term, e.g. daily/weekly/monthly or longterm, e.g. quarterly/yearly.

8) For out-of-spec KPI's, formulate corrective and improvement actions that enhance the effectiveness of implemented activities.

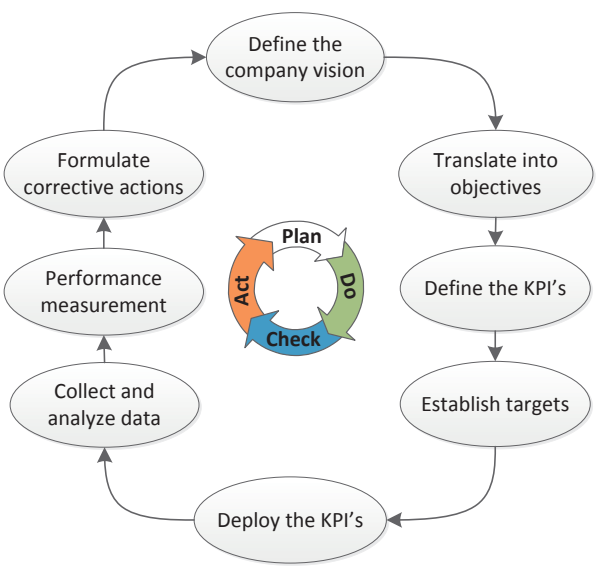

Fig.2. Methodology for implementing Hoshin kanri planning

(1) Establishing the vision of the organization

In this step, the top management defines a vision espousing the ideals of the company. The vision is often defined through the company mission statement. In addition to the company mission, each function within the organization translates the mission into specific statement(s) relevant to the unit. For the maintenance function, the specific statement is:

"Enhancing safety, quality and productivity"

The statement enumerates aspects the maintenance function considers as most important. Moreover, the three aspects are inter-linked to maintenance in that a faulty component within the solvent extraction plant may trigger maintenance actions. Depending on the failure mode, the repair action may expose the technician to explosion (safety) hazard, i.e. through hexane fumes. Moreover, the failure mode may result in plant shutdown thus adversely affecting the production throughput (productivity) and/or product quality, e.g. by having to remove the feed stock and extract.

\section{(2) Translating vision into maintenance objectives and performance indicators}

In this step, the vision is translated into maintenance objectives which specify how the goals/vision will be achieved. Table 1 depicts translation of the goal "maximize productivity through effective equipment utilization". Here, the goal is translated to five main objectives and further cascaded to several KPI's (see column 3).

The objectives described in column 2 represent recurrent maintenance problems as perceived by the maintenance engineers and technicians in the organization. Moreover, the objectives were arrived at through a rigorous brain storming session. Here, the Ishikawa approach is adopted as a tool for organizing ideas and suggestions elicited during the brain storming sessions.

TABLE I. TRANSLATING VISION INTO OBJECTIVES AND KPI'S

\begin{tabular}{|c|c|l|c|}
\hline Vision & & \multicolumn{1}{|c|}{ Maintenance objectives } & KPI's \\
\hline \multirow{2}{*}{$\begin{array}{c}\text { Maximize } \\
\text { productivity } \\
\text { through effective } \\
\text { equipment } \\
\text { maintenance }\end{array}$} & 1 & $\begin{array}{l}\text { Reduce hexane leaks through } \\
\text { periodic inspection of mechanical } \\
\text { seals and pipeline flanges }\end{array}$ & $\begin{array}{c}\text { Hexane loss } \\
\text { (kg/ton } \\
\text { throughput) }\end{array}$ \\
\cline { 2 - 5 } & 2 & $\begin{array}{l}\text { Reduce repair time through } \\
\text { effective maintenance planning } \\
\text { Adopt more time based } \\
\text { maintenance as compared to } \\
\text { failure based maintenance }\end{array}$ & $\begin{array}{c}\text { Mean time to } \\
\text { repair } \\
\text { (MTTR) }\end{array}$ \\
\cline { 2 - 5 } & 4 & $\begin{array}{c}\text { Percentage } \\
\text { scheduled } \\
\text { repair/ Total } \\
\text { repairs }\end{array}$ \\
\cline { 2 - 5 } & Redfective operational planning & $\begin{array}{c}\text { Percentage } \\
\text { response time } \\
\text { to initiate } \\
\text { shutdown }\end{array}$ \\
\hline
\end{tabular}

Once the critical maintenance objectives were agreed on, the next step was assigning appropriate KPI's to each

\footnotetext{
${ }^{1}$ Adapted from Muchiri and Pintelon [5]
} 
objective. It is important to mention that each objective may be represented by several alternative KPI's. However, in this article, the main criterion for selecting the KPI's was user intuitiveness. For instance, the maintenance objective "improve repair quality" may be represented by several quantitative KPI's, e.g. imperfect repair models [21]. However, such models may not be easily understood by maintenance practitioners. As such, a more meaningful indicator is "percentage of repair requiring rework"[5].

In total, the mission statement for the maintenance function is translated to a total of 26 maintenance objectives. It is worth mentioning that several of the aforementioned objectives are monitored across departments. For instance, the maintenance objective "improve the extractor's OEE" is monitored by the maintenance, production, and quality departments. This is because, the OEE is defined by the product of three metrics; availability (A), performance rate $(\mathrm{P})$ and quality rate $(\mathrm{Q})[22]$. The availability (A) is a maintenance function performance indicator measured by the following equation:

$$
\text { Availability }=\frac{M T B F}{M T B F+M T T R}
$$

Where MTBF is the mean time between failure and MTTR is the mean time to repair.

On the other hand, the quality rate $(\mathrm{Q})$ is viewed as an indicator for the quality department where the proportion of acceptable product is measured as a percentage of total production throughput. Lastly, the performance rate $(\mathrm{P})$ is an indicator of equipment utilization. An alternative way of representing $\mathrm{P}$ is through monitoring the production throughput. As such, the metric P measures the operational effectiveness, and for this reason, an indicator for the production department. For this reason, the metrics are deployed and monitored separately by the aforementioned departments. The OEE is afterwards aggregated.

\section{(3) Setting performance targets}

From literature, several approaches are suggested for setting performance benchmarks and targets. Examples include; target setting by maintenance managers, use of industry-wide benchmarks, and ad-hoc approaches [3]. However, the aforementioned approaches seldom take into account the operational and business context. For instance, setting target in an ad-hoc manner may yield unrealistic target(s), thus defeating the primary objective of performance management. On the other hand, relying on industry-wide benchmarks may lead to unrealistic expectations. This is often the case where the organizations vary in terms of the business context, e.g. petro-chemical facility and hospital equipment maintenance. For this reason, authors, e.g. Meekings [23] propose a systems approach for setting performance targets.

In the system approach, the maintenance function is viewed as a system consisting of: (i) a set of inputs, e.g. maintenance technicians, maintenance interventions; (ii) the maintenance process; (iii) and set of outputs, i.e. system performance. The maintenance process is often influenced by several dynamics that may include the type and age of the equipment, (un)availability of diagnostic equipment, or human factors, e.g. personnel expertise. For this reason, the system performance (i.e. output) is rather stochastic. This complicates the target setting exercise. For such complex processes, statistical process control (SPC) charts has been suggested in diverse fields, e.g. in quality management and process control. These charts vary in complexity and may be univariate or multivariate [24]. Univariate charts track a single process parameter, while multivariate chart tracks multiple process parameters.

The attractiveness of using SPC is that the charts provide a statistical basis for target setting, taking into consideration the process variability. Thus, upper and lower control limits (UCL and LCL) are computed based on performance variables collected from the system. Examples of such variables include the time to failure (TTF) or system availability.

In this article, a univariate SPC, i.e. the $X$ bar $-R$ chart is applied for setting targets for several performance measures. Here, $X_{b a r}$ represents the sample average, while the range (R) represents the system variability. Several out of spec values may indicate an unstable maintenance process, e.g. inappropriate maintenance schedule or low repair quality.

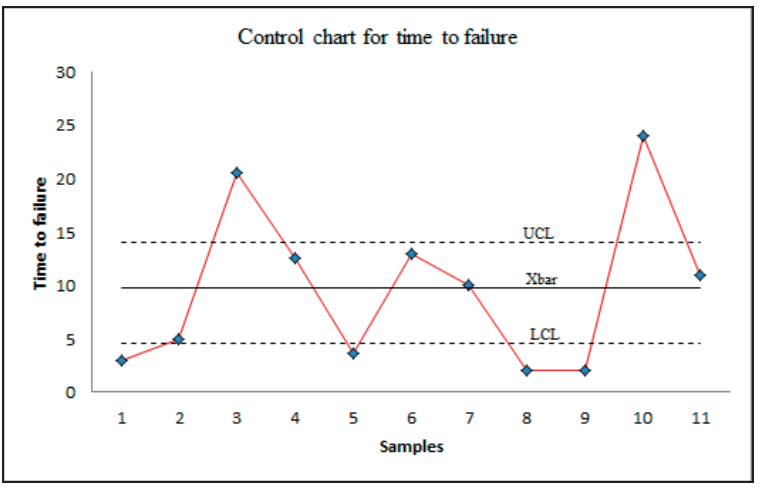

Fig. 3. Statistical control charts for time to failure.

Figure 3 depicts the $\mathrm{X}_{\text {bar }}$ process control for the time to fail of a solvent pump. From the figure, the trend represents eleven data points representing the TTF's for the solvent pump at different time instances. As clearly seen, the TTF varies from data point to data point. Based on the sample TTF's, the UCL and LCL are computed using the equations:

$$
\begin{aligned}
U C L & =\bar{x}+A_{2} R \\
L C L & =\bar{x}-A_{2} R
\end{aligned}
$$

Where the factor $\mathrm{A}_{2}$ depends on the sample size $n$ and read directly from SPC tables. From Figure 3, it is clear that several TTF's are outside the required thresholds, indicative of an unstable maintenance process. As such, one may conclude that there is the need to review the current maintenance interventions and undertake necessary corrective actions. Proposed actions may include shortening the maintenance schedule, e.g. from 4 to 3 months, reviewing the repair interventions, or re-training technicians on best repair practices specific to the type of solvent pump. 


\section{(4) Data collection and performance measurement}

In this phase, data relevant to the performance measurement exercise is collected and analyzed. Often, the data is linked to the KPI's and as such, should be appropriately structured. For instance, computing equipment availability, defined earlier in Equation 1 requires data on two performance metrics; time to failure and time to repair. As such, an appropriate data structure for the aforementioned metrics would include details such as; time the equipment failed, the repair time, and the time of commissioning the equipment after repair. For the case company, the information is captured from work orders generated from a computerized maintenance management system (CMMS).

Once the KPI's are derived, trend analysis, e.g. depicted in Figure 3 is performed with a view of tracking the performance of the individual indicators. However, it should be mentioned that not all KPI's are evaluated through the SPC's. Rather, target setting should be based on the criticality of the particular KPI. For instance, safety related KPI's, e.g. number of accidents should at all times be zero as per legislation. Other KPI's, e.g. operation or quality related may rely on targets established through the SPC charts. Nevertheless, the trend analysis is important given it maps the KPI's evolution with time, and as a result, trigger corrective/improvement actions.

\section{(5) Formulate corrective actions}

In this step, corrective actions are formulated for specific equipment. As previously mentioned, the actions are triggered by out of spec information derived from the trend analysis. To illustrate, consider the trend analysis for the hexane pump depicted in Figure 3. The TTF evolution indicates poor reliability due to several points that are out of spec. An indepth analysis indicates that the failures are linked to solvent leakage through the pump's mechanical seals. Often, the root cause of this problem relates to assembly process for the seals given the precise tolerances required. As a result, observing the installation procedure specified in the assembly manual is critical. Moreover, specialized tolerance gauges are necessary for successful assembly and dis-assembly.

However, following the assembly procedures and using the tolerance gauges requires a specific level of expertise, training and skills. Moreover, interpreting the technical manuals is often not straightforward, and as such influences the quality of the repair process. For the case company, scheduled maintenance is adopted where the seals are replaced every 6 months. For failures that occur in between the schedules, breakdown maintenance is performed. In addition, the repair action seldom follows the documented assembly procedures, but rather, relies on the experience of individual technician(s).

Table 2 describes the proposed improvement actions, Gantt chart planning, and responsibility assignment for implementing the action plans. The structured approach described in Table 2 ensures that the proposed actions are implemented and further, provides a means for follow-up. Moreover, the structure makes it possible to track the effectiveness of proposed actions once implemented. Here, effective action(s) will ideally translate to improved performance, reflected through fewer out of spec point on the SPC charts, or fewer accidents.

TABLE II. FORMULATING CORRECTIVE ACTIONS AND PLANNING

\begin{tabular}{|c|c|c|c|c|c|c|}
\hline & \multirow{2}{*}{ Actions } & \multicolumn{4}{|c|}{ Quarter } & \multirow{2}{*}{ Responsibility } \\
\hline & & 1 & 2 & 3 & 4 & \\
\hline 1 & $\begin{array}{l}\text { Formulate standard installation and repair } \\
\text { procedures }\end{array}$ & $\Rightarrow$ & & & & Maintenance department \\
\hline 2 & $\begin{array}{l}\text { Avail standard installation aids, e.g. finger } \\
\text { gauges, tolerance charts }\end{array}$ & & & & & Management \\
\hline 3 & \begin{tabular}{|l|} 
Re-train technicians on installation \\
procedures and use of installation aids
\end{tabular} & & & & & Original equipment manufacturer \\
\hline 4 & $\begin{array}{l}\text { Standardise the repair procedures and } \\
\text { verify the procedures are followed }\end{array}$ & & & & & Maintenance department \\
\hline
\end{tabular}

To conclude, the different phases of the Hoshin kanri methodology described previously are implemented in MS Excel. The MS Excel worksheet contains modules describing phases of the proposed methodology.

\section{CONCLUSIONS}

In this article, a methodology for maintenance performance management using the Hoshin kanri approach is proposed. The methodology is widely applied in the Japanese manufacturing industries as a tool for strategic policy deployment and total quality control. However, not much work is reported regarding its use in maintenance performance management. This inspite the strategic role of the maintenance function in enhancing the organizations' competitiveness.

In this article, the Hoshin kanri methodology is applied in the case study of an edible oil processor. In the study, we highlight how the organization can translate their vision into maintenance objectives and later, key performance indicators. An attractiveness with the methodology relates to personnel involvement at all levels in the organization, right from the top management to the shop floor where the KPI's are measured. Moreover, by achieving the right KPI's, the vision of the organization is implicitly attained. In conjunction with the Hoshin kanri, statistical process control charts are incorporated with a view of structuring the performance target setting exercise. This is achieved by viewing the maintenance process through the systems approach concept. Linked to the results of the SPC's are corrective and improvement actions and a structured plan that ensures continual improvement is attained systematically.

Future work will evaluate the effectiveness of linking the MS Excel based model to a structured data base, thus allow decision makers to pro-actively monitor the KPI's. Additional future work will look at the possibilities of introducing multivariate SPC's as a means for target setting where there is evidence of close correlation amongst the KPI's.

\section{REFERENCES}

[1] A. Koronios, D. Nastasie, V. Chanana and A. Haider, "Integration through standards-an overview of international standards for engineering asset management," Fourth International Conference on Condition Monitoring, Harrogate, United Kingdom. 2007.

[2] L. Pintelon, and V. Puyvelde, Asset management: the maintenance perspective. Acco, Leuven, 2013.

[3] U. Kumar, et.al., "Maintenance performance metrics: a state-of-the-art review," Journal of Quality in Maintenance Engineering, vol. 19, pp 233-277, 2013. 
4] A. Neely, "The performance measurement revolution: why now and what next?" International Journal of Operations \& Production Management, vol 19(2), pp. 205-228, 1999.

[5] P. Muchiri, L.Pintelon, L.Gelders, H. Martin, "Development of maintenance function performance measurement framework and indicators." International Journal of Production Economics, vol 131(1), pp. 295-302, 2011.

[6] A. Parida, "Development of a Multi-criteria Hierarchical Framework for Maintenance Performance Measurement," Doctoral Thesis. Division of Operation and Maintenance Engineering. Luleå University of Technology, 2006.

[7] A. Van Horenbeek and L. Pintelon, "Development of a maintenance performance measurement framework-using the analytic network process (ANP) for maintenance performance indicator selection." Omega, vol. 42(1), pp. 33-46, 2014.

[8] C. Gonçalves, J. Dias, and V. Cruz-Machado, "Decision Methodology for Maintenance KPI Selection: Based on ELECTRE I," Proceedings of the Eighth International Conference on Management Science and Engineering Management, pp. 1001-1012, Springer Berlin Heidelberg, 2014

[9] R.S. Kaplan, D.P. Norton, and P. Horv6th, "The balanced scorecard." Vol. 6, Harvard Business School Press, Boston, 1996.

[10] A.H. Tsang, "A strategic approach to managing maintenance performance." Journal of Quality in Maintenance Engineering, vol. 4(2), pp. 87-94, 1998

[11] I. Alsyouf, "Measuring maintenance performance using a balanced scorecard approach.” Journal of Quality in Maintenance Engineering, vol. 12(2), pp. 133-149, 2006.

[12] D. Galar, et al., "Maintenance metrics: a hierarchical model of balanced scorecard." IEEE International Conference on Quality and Reliability, 2011

[13] K. Kutucuoglu, et al., "A framework for managing maintenance using performance measurement systems." International Journal of Operations \& Production Management, vol. 21, pp. 173-195, 2001
[14] D. Hutchins, "Hoshin Kanri: The Strategic Approach to Continuous Improvement." Gower, 2012.

[15] Y. Akao, "Hoshin Kanri: Policy Deployment for Successful" Total Quality Management, Taylor \& Francis, 2004.

[16] C. Tennant, and P. Roberts, "Hoshin kanri: a tool for strategic policy deployment." Knowledge and Process Management, vol.8(4), pp.262269.

[17] M. Miyaji, "On promoting the Deming plan". Hinshitsu Kanri, vol. 20, pp. 21, 1969.

[18] C.G. Johannsen, "Strategic issues in quality management: I. Theoretical considerations." Journal of information science, vol. 22(3), pp. 155-164, 1996.

[19] B.J. Witcher, and R. Butterworth, "Hoshin Kanri: Policy Management In Japanese-Owned UK Subsidiaries." Journal of Management Studies, vol. 38(5), pp. 651-674, 2001.

[20] T. Yang, and C. Su, "Application of hoshin kanri for productivity improvement in a semiconductor manufacturing company." Journal of Manufacturing Technology Management, vol. 18(6), pp 761-775, 2007.

[21] P.N. Muchiri, et al., "Modelling maintenance effects on manufacturing equipment performance: results from simulation analysis." International Journal of Production Research, (ahead-of-print): pp. 1-16, 2013.

[22] P. Muchiri, and L. Pintelon, "Performance measurement using overall equipment effectiveness (OEE): literature review and practical application discussion." International Journal of Production Research, vol. 46(13), pp. 3517-3535. 2008.

[23] A. Meekings, "Unlocking the potential of performance measurement: A practical implementation guide." Public Money \& Management, vol. 15(4), pp. 5-12. 1995

[24] S. Bersimis, S. Psarakis, and J. Panaretos, "Multivariate statistical process control charts: an overview." Quality and Reliability Engineering International, vol. 23(5), pp. 517-543. 2007. 
(Página deixada propositadamente em branco) 


\title{
Aggregation of electric current consumption features for extraction of maintenance KPIs
}

\author{
Carl-Anders Johansson ${ }^{1}$, Victor Simon ${ }^{1}$, Diego Galar ${ }^{1}$ \\ carl-anders.johansson@1tu.se; ${ }^{2}$ victor.simon@1tu.se; ${ }^{3}$ diego.galar@1tu.se \\ ${ }^{1}$ Luleå University of Technology \\ Luleå, Sweden
}

\begin{abstract}
For all electric powered machines there is a possibility of extracting information and calculating Key Performance Indicators (KPIs) from the electric current signal. Depending on the time window, sampling frequency and type of analysis, different indicators from the micro to macro level can be calculated for such aspects as maintenance, production, energy consumption etc.
\end{abstract}

On the micro-level, the indicators are generally used for condition monitoring and diagnostics and are normally based on a short time window and a high sampling frequency. The macro indicators are normally based on a longer time window with a slower sampling frequency and are used as indicators for overall performance, cost or consumption.

The indicators can be calculated directly from the current signal but can also be based on a combination of information from the current signal and operational data like rpm, position etc.

One or several of those indicators can be used for prediction and prognostics of a machine's future behaviour.

This paper uses this technique to calculate indicators for maintenance and energy optimisation in electric powered machines and fleet of machines, especially machine tools.

Keywords - fingerprint, operational data, condition based maintenance (CBM), condition monitoring (CM), energy optimisation, machine tool

\section{INTRODUCTION}

Today's business environment sets ever-higher requirements on reliability, availability and economic performance of plants and equipment. Loss of production due to machine damage, especially if it occurs unexpectedly, diminishes the economic success of an enterprise and must be prevented. In recent years, the emphasis in maintenance has shifted to using emerging technology to measure machinery condition and predict maintenance requirements. Key words like preventive, predictive and condition-based maintenance reflect this tendency. If plant personnel can always make an accurate statement about the condition of their machines and plant assets, they are in the position to plan and introduce appropriate maintenance measures promptly, before larger and more serious damage and associated unplanned machine downtime occur. The bottom line benefits of such an approach, however, can include gaining experience and learning relevant mechanisms or correlations to better control production processes. The key component in this approach is achieving an accurate prediction of failure; therefore, an effective method of monitoring the status of an item or system is essential. Clearly the ideal technique is one in which the condition of the equipment is known at all times and which accurately predicts any potential failure on demand. Condition Monitoring (CM) attempts to fulfil these requirements.

The normal strategy to keep production systems in good condition is to apply preventive maintenance practices, with a supportive workforce being "reactive" in the case of obvious malfunctions, as these have an impact on quality, cost and productivity. The uncertainty of machine reliability at any given time also has an impact. For example, a worn-out mechanism can have higher energy consumption.

The use of intelligent predictive technologies could improve the situation, but these are not widely used in the production environment. Often sensors and monitors needed in the production environment are non-standard and require costly implementation.

Monitoring and profiling the electric current consumption in combination with operating data which describes the way the machine is used (the context) is an easy way to implement Green Condition Based Maintenance (Green CBM) to improve overall business effectiveness. Green CBM takes a triple perspective:

- Maintenance: Optimising maintenance strategies based on the prediction of potential failure, scheduling maintenance operations in convenient periods and avoiding unexpected breakdowns.

- Operation: Managing energy as a production resource and reducing its consumption.

- Product reliability: Providing the machine tool builder with real data about the behaviour of the product and its critical components.

This opens up the possibility of creating new business models for maintenance and service providers.

The Green CBM technique can be applied to many types of machines but we concentrate on machine tools.

This paper is part of the Power Consumption driven Reliability, Operation and Maintenance Optimisation (Power $\mathrm{OM}$ ) project (http://www.power-om.eu/) which is in the 
middle of collecting operating and fingerprint data. The paper is, therefore, mostly conceptual and will concentrate on possible techniques and methods to know and predict the condition of machine tools and fleets of machine tools, especially problems/faults in the spindle drive train and linear axis. The proposed method for Condition Based Maintenance $(\mathrm{CBM})$, based on fingerprint and operating data, gives information about both operating conditions and power consumption without increasing the complexity and can be seen as a Green Condition Based Maintenance platform (Green CBM) [1] for both CBM and energy optimisation.

\section{CONDITION MONITORING OF MACHINE TOOLS}

Knowing and predicting the condition of an asset is valuable. During the last 40 years, numerous diagnostic techniques have been developed, many based on signal analysis and statistical methods.

For stationary operating conditions, even prognostics of the failure work well, but the methods used often require costly installation of transducers and signal analysis equipment handled by skilled personnel.

For some time, there has been increasing interest in methods based on available operating data that do not require costly equipment or skilled personnel.

This is especially relevant for those with a fleet of similar equipment where methods and experience can be reused, for example, producers and owners of windmills, airplanes, ships, cars \& trucks, elevators, packing machines and machine tools.

Machine spindle defects are responsible for frequent and cost-intensive downtimes in machine-tools, so normally those are a focus of condition monitoring. But a machine tool consists of many subsystems that also can be supervised.

In the Power OM project, we have concentrated on the spindle and the linear axis.

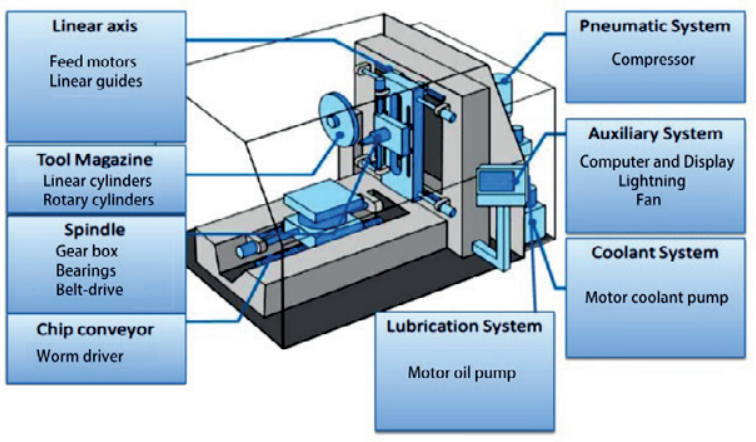

Figure I. Main sub system of a CNC Machine (source Siemens)

The main technique for detecting mechanical and electrical problems uses vibration analysis or Motor Current Signature Analysis (MCSA) in combination with context data. In the Power OM project, we use both, but in this paper we will concentrate on MCSA in combination with context data. MCSA uses the electric motor as a transducer, allowing the user to evaluate the electrical and mechanical condition of the motor control and, by extension, of the machine. The basic idea is that any load or speed variation within an electromechanical system produces correlated variations in current and voltage. The resulting time and frequency signatures reflect loads, stresses, and wear throughout the system, but seeing these requires a mapping process or pattern recognition. Comparing a reference, electric signature of equipment in good condition (the fingerprint), and equipment under monitoring supports fault identification.

There are a number of commercial products in this area, including the ARTESIS system (www.artesis.com). The methods described in this paper are similar to those used in other systems but are more focused on other context data than is available in current, voltage and vibration signals.

Power monitoring as torque sensor is evaluated in [2]. Other work uses power analysis to detect production machine failures using current signals [3,4] and machine internal signals [5].

As we can see in $[6,7]$ several failures can be detected using induction motor current analysis. The controlled values, for example of a gearbox failure, can be compared in the stator current spectrum, because there are several peaks related to shaft and gear speed. Characteristic gearbox frequencies can be detected in the stator current spectrum.
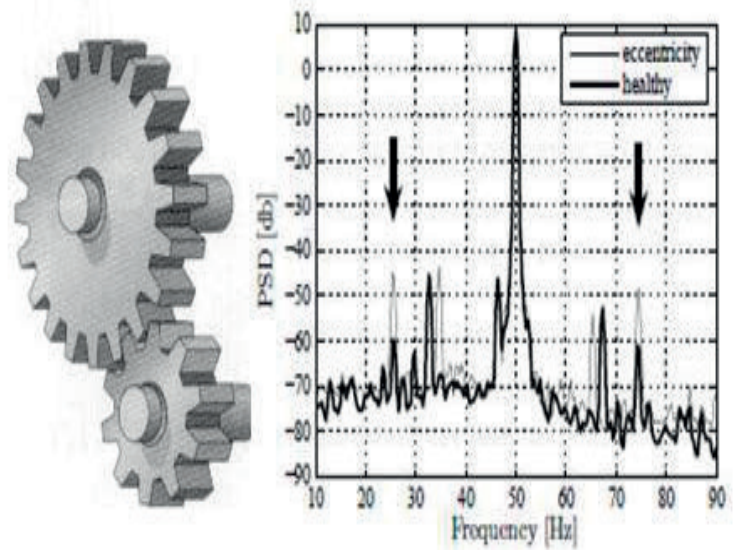

Figure II. Gear Failure detection with current signal

Current based diagnosis of mechanical faults such as unbalance and misalignment can be performed in the same way. It is possible to control the rotating movement of the machine; in addition, some work has been done on linear movement. For example, Electro Mechanical Actuators (EMA) are widely used in aeronautic systems; the use of Health Monitoring is also widespread [8, 9, 10]. Similar actuators are used in machine tools.

\section{A. Data collecting}

The proposed method uses two types of input data: fingerprint data and operating data.

\section{1) Fingerprint data}

Fingerprint data are collected in a standardised way every day/week/month using a test procedure. As part of this 
standardised procedure, the machine runs a special $\mathrm{CNC}$ programme every time the fingerprint is collected.

There is also a possibility of using standard sequences in ordinary production programmes like tool changing for part of the fingerprint collection.

The data are collected with a sampling frequency between $100 \mathrm{~Hz}$ and $50 \mathrm{kHz}$, depending on the type of data.

Typical data collected and synchronised in time are:

- Vibration

- Motor power for spindle and linear axis (current signal and motor current signature analysis)

- $\quad$ RPM and speed for spindle and linear axis and axis position

The data can be analysed in both time and frequency domains [11] and a number of features (Table II.1) can be calculated for each signal. In the frequency domain, the system follows the vibration levels on known frequencies like gear mesh frequencies, bearing frequencies, rotational speed etc. and their harmonics.

For faults/problems in the gear train, such as the bearing and gear problem, the most sensitive features have been chosen through the use of a test bench (see figure II.3) where different types of faults can be simulated and by using faulty components sent in by customers for repair (see figure II.4).

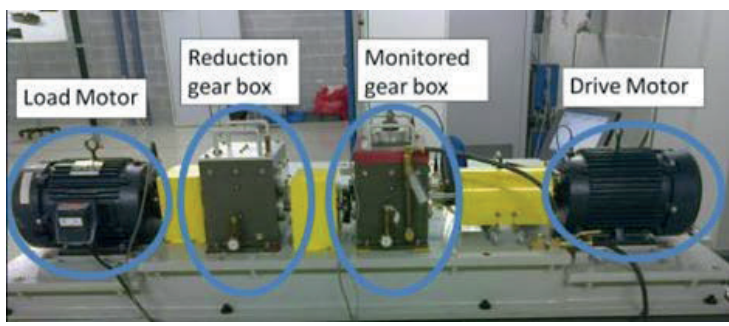

Figure III. Test bench for gear train

TABLE II.1 Time domain features

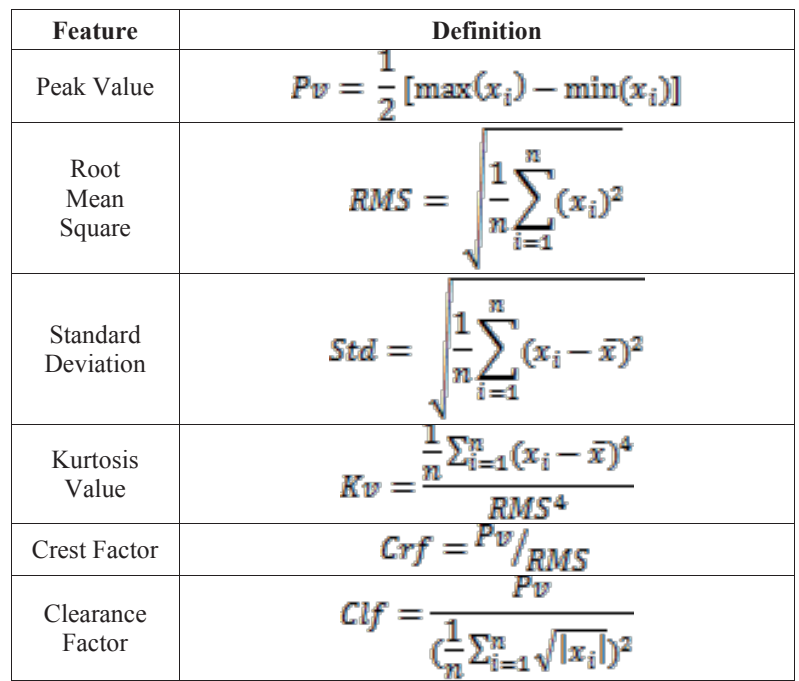

\begin{tabular}{|c|c|}
\hline $\begin{array}{c}\text { Impulse } \\
\text { Factor }\end{array}$ & $\operatorname{Im} f=\frac{P V}{\frac{1}{n} \sum_{i=1}^{n}\left|x_{i}\right|}$ \\
\hline $\begin{array}{c}\text { Shape } \\
\text { Factor }\end{array}$ & $S h f=\frac{R M S}{\frac{1}{n} \sum_{i=1}^{n}\left|x_{i}\right|}$ \\
\hline $\begin{array}{c}\text { Normal } \\
\text { Negative } \\
\text { value } \\
\text { valihood }\end{array}$ & $N N L=-\ln L_{p} L=\prod_{i=1}^{N} f\left(x_{i}, \mu, \sigma\right)$ \\
\hline
\end{tabular}

Normally, the spindle rotates clockwise. In some operations, like threading and some milling, it operates counter clockwise. The latter operation normally has less power/torque. Therefore, comparing the difference in feature values in different rotational directions gives valuable information.

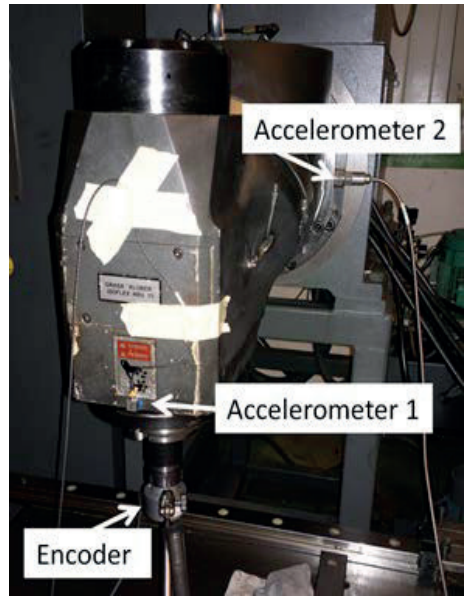

Figure IV. Spindle head in test bench

Table 2 shows the testing of a spindle head before and after repair in both rotational directions. As the table shows, the degradation was greater in the 'normal operation' direction (clockwise).

TABLE II.2 Motor Current Analysis of the Spindle Motor showing the difference in behaviour for a spindle head rotating in different directions. $\mathrm{CCW}$ is the normal rotating direction

\begin{tabular}{|c|c|c|c|}
\hline \multirow{2}{*}{ Feature } & Value & $\begin{array}{c}\text { Rotational } \\
\text { direction }\end{array}$ & Spindle Status \\
\hline \multirow{4}{*}{ Crest Factor } & 1,96 & Counter clockwise & Repaired \\
\cline { 2 - 4 } & 2,24 & Counter clockwise & Faulty \\
\cline { 2 - 4 } & 1,96 & Clockwise & Repaired \\
\cline { 2 - 4 } & 1,96 & Clockwise & Faulty \\
\hline \multirow{3}{*}{$\begin{array}{c}\text { Rotational } \\
\text { Frequency } \\
\text { sideband }\end{array}$} & 3,56 & Counter clockwise & Repaired \\
\cline { 2 - 4 } & 12,7 & Counter clockwise & Faulty \\
\cline { 2 - 4 } & 4,73 & Clockwise & Repaired \\
\cline { 2 - 4 } & 4,64 & Clockwise & Faulty \\
\hline
\end{tabular}

For the linear axis, there can be problems with the drive train (motor/gearbox/ball screw/nut/rack/pinion) and the linear bearings (see figure II.5). 


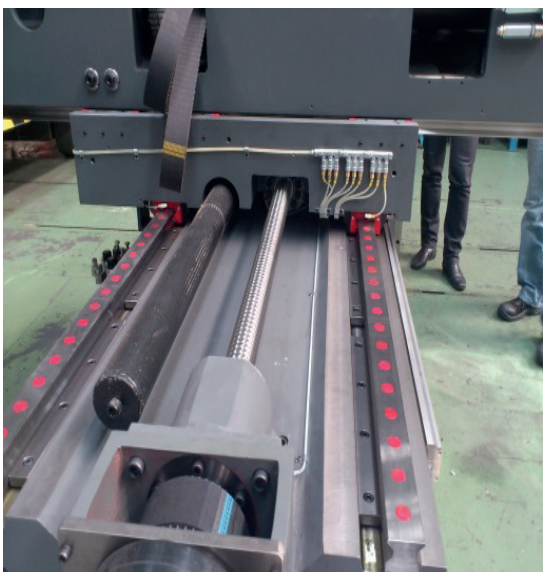

Figure V. Linear guides ball screw/nut

For the drive train, the machine tool axis dynamics is an important factor; it can be analysed by looking at the position/speed/acceleration and jerk values and by comparing differences in commanded and actual position [12].

With high resolution power or vibration measurements on the linear axis, it is possible to isolate problems in ball screw/nut, rack/pinion, hydraulic counter balance system, linear bearings [13].

\section{2) Operating data}

Operating data are collected with a sampling frequency between 1-100 Hz. The data are collected via interfacing with the Computer Numerical Control (CNC) controller of the Machine Tool (see figure II.6). In the case of the Power-OM project, the research toolbox GEM OA (Open Architecture) hardware from Artis is used for the data collection [14].

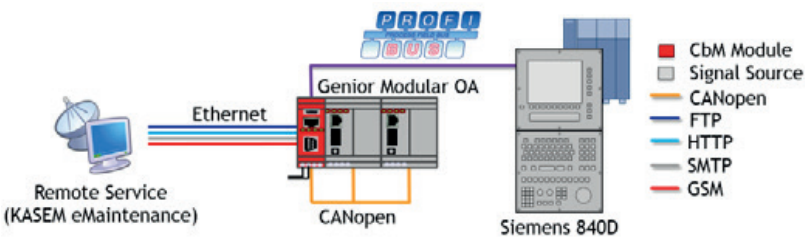

Figure VI. Local data collection unit GEM OA (Artis)

Typical data collected are:

- Spindle power and rpm

- Motor power and position for linear axis

- Difference between commanded and actual position

- Temperatures

- Programme number

- Tool number

- Alarms (sampled from the CNC or taken from the log file)

The operating data describe the way the machine has been used between the fingerprints.

3) KPI calculation
From the operating data, a number of KPIs can be calculated, for both condition monitoring and energy optimisation. Some examples are:

- Number of starts/stops/accelerations/retardations

- Total travelled length for linear axis and distribution over the axis or 'travelled load' calculated from power need during acceleration of the axis

- Mean power/torque for spindle and axis and distribution over the axis

- Difference in behaviour in different rotational directions for both spindle and linear axis

- $\quad$ Running time in different rpm, direction and power intervals

- Number of alarms per type/group

- Total energy used for a certain product/programme in a certain machine

- Total energy used for a certain tool

For each machine/component in the fleet, typical faults/problems are identified, and the most sensitive fingerprint features and KPIs are chosen for each. This means each machine/component has a number of faults, and each fault has a number of features and KPIs that can be traced in a multi-dimensional space to estimate the condition of the machine/component. The threshold for the estimation is based on the results of tests with known faults using a test bench, tests of faulty components (so far only for repaired and faulty spindle head) and the experience of this or similar machines in the fleet.

To begin, the estimation can be based on the history of the machine tool, including:

- Age of component/machine tool

- Designed lifetime of component/machine tool

- Type of production/use $(8 \mathrm{~h} / 24 \mathrm{~h} / 7 \mathrm{~d}$, heavy, medium, low)

- Maintenance history

- Experience of similar machines in the fleet

After a while, however, the estimation can be based on results from fingerprint and operating data.

The change in value of the different features between two fingerprints indicates the degradation of the component; it depends on both the previous condition and the way the machine has been used.

This means that the future condition, the feature value $F_{n}$, is a function of previous condition value $F_{n-1}$ and subsequent operating data.

$$
F_{\mathrm{n}}=f\left(F_{\mathrm{n}-1} \text {, Operational data }\right)
$$

\section{ENERGY OPTIMISATION}

A recent Directive of the European Parliament on Energy using Products [Directive 2009/125/EC] establishes a framework for the eco-design requirements of energy-using products. The European Commission has published a working plan [Working plan for 2009-2011 under the Eco design Directive] with a list of energy-using product groups which 
can be considered prioritised. Machine tools is included as one of ten product groups.

As a result, the machine tool sector is beginning to change. An example is the German Machine Tool Builder Association (VDW) which has developed the label Blue Competence.

In short, energy saving measures are increasingly relevant, especially in the machine tool sector for metal working production, as this sector requires $15 \%$ of the entire electric power consumption (German statistics).

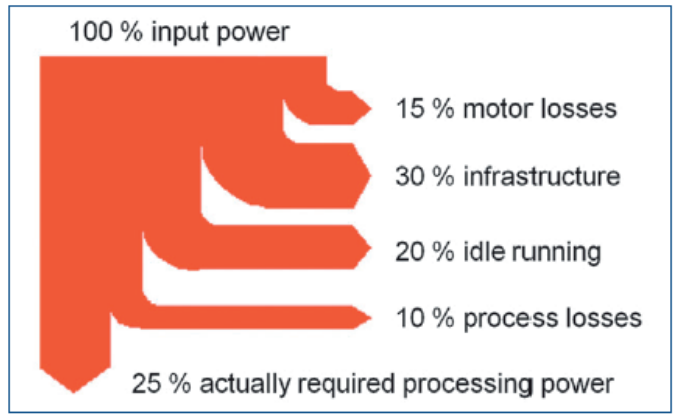

Figure VII. Machine tool power flow diagram (Translated from [15])

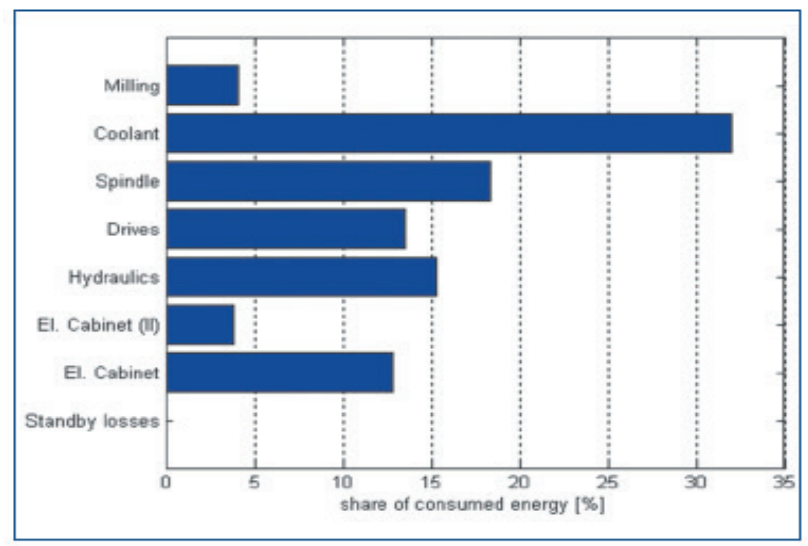

Figure VIII. Share of energy consumed by each Machine Tool component

Figures III.1 and Figure III.2, extracted from an ISW study [16] show with more detail where energy is lost in the use of a machine tool and the share of energy consumed by each main component of the machine tool. Motor losses and idle running comprise $35 \%$ of the energy loss, while spindle and drives consume more than $30 \%$.

Power optimisation in machine tools is normally in one of the following categories:

- Limiting power output by optimising production planning

- $\quad$ Minimising the use of energy by putting subsystems like cooling fluid, hydraulic pumps, cooling fans etc. into idle/sleep mode

- Minimising the use of energy by optimising cncprogrammes and processing paths.
- Reducing power consumption for deep whole machining with an adaptive pecking cycle, which executes pecking as needed by sensing cutting load.

- Reducing power consumption by synchronising the spindle acceleration/ deceleration with the feed system at rapid traverse stage.

- Minimising the use of energy by cutting parameters and optimising tool selection.

- Reducing power consumption for drilling and face/end milling by setting the cutting conditions high yet within a value range which does not compromise tool life and surface finish, thereby shortening machining time

- Minimising the cost for energy by optimising production planning based on different energy prices at different time of the day

The energy efficiency ( $n$ ) of a machine tool operation can be calculated in different ways.

$\frac{\text { Spindle used Energy }}{\text { Total Energy }} \quad$ (2) or as $\frac{\text { Total Energy }}{\text { RMV }}$

where RMV= Removed Material Volume [cm3]

\section{CONCLUSION}

The analysis of data from existing sensors and information about a machine's power consumption and operating conditions permits the use of a new, easy to implement, Green Condition based Maintenance platform (Green CBM).

For each machine/component in the fleet, typical faults/problems are identified, and the most sensitive fingerprint features and KPIs are calculated for each.

The calculation is based on data extracted from the electric current signal through MCSA in combination with context data.

Green CBM does not increase the complexity and can be used for many types of manufacturing machines.

By integrating all the information from machines, the fleet of machines and even between companies, the Green CBM platform can act as a hub of technology, providing the different user profiles (Machine Tool users, Maintenance Service Providers and Machine Tool Manufacturers) with services for Maintenance and Energy Optimisation and increased machine Reliability.

\section{ACKNOWLEDGMENT}

The research has received funding from the European Community's Framework Programme FP7-2012-NMP-ICTFoF.

Work programme: FoF.NMP.2012-2 "Methodologies and tools for the sustainable, predictive maintenance of production equipment" under grant agreement no. "314548 - Power-OM". The Consortium consists of TEKNIKER, ARTIS, FAGOR AOTEK, PREDICT, MONITION, GORATU and Luleå University of Technology (LTU). 


\section{REFERENCES}

[1] C-A. Johansson, D. Galar, R. Villarejo, M. Monnin, "Green Condition based Maintenance - an integrated system approach for health assessment and energy optimization of manufacturing machines", The Tenth International Conference on Condition Monitoring and Machinery Failure Prevention Technologies, Krakow, Poland, 18-20 June 2013.

[2] J.L. Stein, Wang and Churn-Hway, "Analysis of Power Monitoring on AC Induction Drive Systems", Journal of Dynamic Systems, Measurement, and Control - June - Volume 112, Issue 2, 239, 1990

[3] F. Zhao, X. Mei, T. Tao, G. Jiang, and Y. Zhou, "Fault diagnosis of a machine tool rotary axis based on a motor current test and the ensemble empirical mode decomposition method", Journal of Mechanical Engineering Science vol. 225, May 2011

[4] K. Chinmaya, A.R. Mohanty, "Vibration and current transient monitoring for gearbox fault detection using multiresolution Fourier transform", 2008

[5] M. Abu Ali, J. Lee, and W. Zhao, "Methods and Systems for Energy Prognosis", United States Patent Application Publication No US 2011/0066391 A1, Mar-17-2011

[6] E. L. Bonaldi, L. E. L. Oliveira, J. G. Borges da Silva, G. LambertTorres, and L. E. Borges da Silva, "Detecting Load Failures using the Induction Motor as a Transducer", 10 th International Conference on Control, Automation, Robotics and Vision; Hanoi, Vietnam 2008 pp 196-199. 2008

[7] H. B. Attia, "Détection et localisation de défauts mécaniques d'un entraînement électrique à vitesse variable" Ph.D. thesis, Institut National Polytechnique de Toulouse, Toulouse, France, Mar. 2003.

[8] S. Curran, T. E. Walters, and A. J. Chirico "Health monitoring and prognostics for electro mechanical actuation", Proceedings of the International Conference on Recent Advances in Aerospace Actuation Systems and Components, pp. 47-55. 2010
[9] C. S. Byington, M. Watson, and D. Edwards, "Data-driven neural network methodology to remaining life predictions for aircraft actuator components", Proc. IEEE Aerospace conference, 6, pp. 3581-3589, 2004.

[10] E. Balaban, P. Bansal, P. Stoelting, A. Saxena, K. F. Goebel, and S. Curran, "A diagnostic approach for electromechanical actuators in aerospace systems", Proc. IEEE Aerospace conference, pp. 113, 2009.

[11] D. Galar, U. Kumar, J. Lee \& W. Zhao,"Remaining Useful Life Estimation using Time Trajectory Tracking and Support Vector Machines", 25th International Congress on Condition Monitoring and Diagnostic Engineering, Conference Series 364 (2012) 012063, Huddersfield, United Kingdom, 18-20 June 2012. doi: 10.1088/1742-6596/364/1/012063

[12] J.J. Santiago-Pérez,R.A. Osornio-Rios \& R.J. Romero-Troncoso, G. Herrera-Ruiz \& M. Delgado-Rosas, "DSP algorithm for the extraction of dynamics parameters in $\mathrm{CNC}$ machine tool servomechanisms from an optical incremental encoder", International Journal of Machine Tools \& Manufacture 48 (2008) (1318-1334).

[13] B. Huang, H. Gao, X. Mingheng, X. Wu, M. Zhao \& L. Guo, "Life Prediction of CNC Linear Rolling Guide Based on DFNN Performance Degradation Model", Seventh International Conference on Fuzzy Systems and Knowledge Discovery (FSKD 2010), Yantai, China, 10-12 August 2010.

[14] A. Alzaga, E. Konde, I. Bravo, R. Arana, A. Prado, C. Yurre, M. Monnin, G. Medina-Oliva, "New technologies to optimize", EuroMaintenance conference, Helsinki, Finland, 5-8 May 2014.

[15] [http://www.energie.ch/themen/industrie/infel/druckluft.htm][2014 $-07-31]$

[16] B.V. Dasarathy, "Information Fusion. What, Where, Why, When, and How? Information Fusion”, 2, pp75-76, 2001 


\title{
(Legal) Maintenance Plan for building's energy performance
}

\author{
MARIMBA DA COSTA ${ }^{1}$, JOSÉ TORRES FARINHA ${ }^{2}$, INÁCIO FONSECA ${ }^{3}$, ANTÓNIO SIMÕES ${ }^{4}$ \\ joalmaco@gmail.com ${ }^{1} ;{ }^{2}$ torresfarinha@torresfarinha.com; ${ }^{3}$ inacio@isec.pt; ${ }^{4}$ assimoes@isec.pt \\ 1,2,4Departmento de Engenharia Mecânica, ${ }^{3}$ Departmento de Engenharia Eletrotécnica \\ ${ }_{1,2,3,4}$ Instituto Politécnico de Coimbra, ISEC ${ }^{5}$ \\ ${ }^{1,2,3}$ CEMUC - Centro de Engenharia Mecânica da Universidade de Coimbra ${ }^{6}$ \\ ${ }^{5}$ Rua Pedro Nunes - Quinta da Nora, 3030-199 Coimbra \\ ${ }^{6}$ Pinhal de Marrocos - 3030-788 Coimbra \\ $1,2,3,4$ PORTUGAL
}

\begin{abstract}
The EU Directive 2002/91/CE, regarding building's energy performance was transposed into national law in 2006, recently updated by Legislative Decree 118/2013 which substantiates: Energy Certification System of Buildings (SCE), Regulation of Energy Performance of Residential Buildings (SHR) and Regulation of Energy Performance of Commerce and Services Buildings (RECS).
\end{abstract}

This points to an evaluation of energy performance of buildings based on the thermal behavior and efficiency of the systems, and in the installation, operation and maintenance of technical systems. The TIM (Installation and Maintenance Technician) must perform several maintenance activities related to buildings and technical systems, including: maintenance management; planning; recording occurrences; details of tasks and operations; and other actions and documentation necessary for that purpose.

The RECS establishes rules to be observed in building's maintenance, to promote energy efficiency and indoor air quality. A maintenance plan must: be initiated at the design stage; be put in practice after the completion of the installation of building systems; and to be accomplished during the building's lifetime.

This paper proposes to present a working methodology, to be undertaken by TIM, leading to compliance with legal requirements for maintenance of Commerce and Services Buildings in assessment of the energy performance.

Keywords: Maintenance, Energy, Performance, Building, Technician

\section{INTRODUCTION}

The Directive No. 2002/91/EC [3] of the European Parliament and of the Council from 16 December 2002 regarding the energy performance of buildings, was transposed into Portuguese law by Decree No. 78/2006 [4] of April 4, which approved the National energy Certification System and Indoor Air Quality in buildings, Decree No. 79/2006 [5] of 4 April, which approved the Regulation of Energy in buildings and HVAC systems, and Decree No.
80/2006 [6] of 4 April, which approved the Regulation of characteristics of Thermal Behavior of Buildings.

More recently Directive No. 2010/31/EU [1] of the European Parliament and of the Council from 19 May 2010 regarding the energy performance of buildings, overhauled the system established by Directive No. 2002/91/EC [3], and clarified some principles of the original text and insert new provisions aimed at strengthening the framework of promotion of energy performance in buildings, aiming the goals and challenges agreed by the Member States for 2020.

Thus, the Member States of the EU, are doing the transposition of Directive No. 2010/31/EU [1] to the legal regime in each country. In the case of Portugal, was transposed into Portuguese law through Decree No. 118/2013 [2] of August 20, where it regulates:

- SCE - Energy Certification of Buildings;

- REH - Regulation of Energy Performance of Residential Buildings; and

- RECS - Regulation of Energy Performance of Buildings for Commerce and Services.

The requirements definition and assessment of energy performance of buildings shall be based on the following pillars:

- in the case of residential buildings a prominent position is assumed about:

$$
\begin{aligned}
& \circ \text { thermal behavior; and } \\
& \circ \text { efficiency of the systems; }
\end{aligned}
$$

- to which are added, in the case of buildings of commerce and services:

- Installation, handling and maintaining technical systems.

For each of these pillars are still defined general principles, embodied in specific requirements for:

- new buildings;

- buildings undergoing major intervention, and; 
- existing buildings.

The Directive No. 2010/31/EU [1] points to the main types of technical building systems:

- thermal quality requirements;

- energy efficiency requirements for various systems, including:

$$
\begin{array}{ll}
\circ & \text { air conditioning systems; } \\
\circ & \text { preparation systems for domestic hot } \\
\text { water; } \\
\circ \text { lighting systems; } \\
\circ \text { systems for using renewable energies, and; } \\
\circ \quad \text { energy management systems. }
\end{array}
$$

To put these requirements into practice, rules for installation, handling and maintenance of HVAC systems in buildings of commerce and services are defined, in order to promote optimal functioning in energy terms.

\section{TECHNICIANS OF THE ENERGY CERTIFICATION SYSTEM FOR BUILDINGS}

The energy performance of buildings is ensured by the intervention of two types of technicians:

- Qualified Experts (QE), and;

- Technicians for Installation and Maintenance (TIM).

\section{A. Duties of $Q E$}

- making energy assessment of buildings to be certified under the SCE, not compromising indoor air quality;

- identify and evaluate the buildings subject to certification, opportunities and recommendations for improvement of energy performance, registering them in pre-certificate or certificate and other accompanying documentation;

- send pre-certified and certified SCE;

- collaborate in the process of checking quality of SCE;

- check and submit to SCE's plan for energy rationalization.

\section{B. Duties of TIM}

The rules proposed for the installation, handling and maintenance of HVAC systems in buildings of commerce and services should be conducted by people with appropriate expertise designated by Technician for Installation and Maintenance (TIM).

Incumbent upon TIM coordinate or perform activities of planning, verification, management of energy use, installation and maintenance for buildings and technical systems and, in the case of large buildings of commerce and services (GES), the TIM shall develop and fulfill respective maintenance plan.

More specifically, in compliance with the provisions of paragraph 4 of article 13 of Decree No. 118/2013, of August
20 and without prejudice to the specific provision in the Rules of the Energy Performance of Buildings Trade and Services (RECS), the building's TIM, should:

- ensure proactive management building energy wich includes:

$\circ$ promote the installation of energy metering systems, which allow a more detailed assessment of consumption whenever possible;

- make the annual energy performance record, based on the best available information and according to the proposal of the managing body of the SCE for this purpose in buildings with a rated thermal input exceeding $250 \mathrm{~kW}$ for climate model;

○ use the computing platform provided by the managing entity, proceeding to fill the necessary information, as well as the submission of a report mentioned ahead.

- develop and/or maintain an updated Plan for Maintenance (PM) of the building and its technical systems;

- ensure compliance with the PM checking its proper implementation;

- inform the owner of the need for the energy certification of buildings;

- maintain the project and other technical documentation about the building and its technical systems upgraded, and advise the owner in the selection of new technical systems, exclusively with regard to compliance with the SCE, REH and RECS and other applicable laws;

- keep up to date register of occurrences;

- as it relates to the installation of new systems within their technical skills:

o integrating the team of system installation, directly and actively participating in the tasks;

○ monitor assays receipt of installations.

- as regards the maintenance of technical systems within its jurisdiction:

o integrating the maintenance team of systems, participating directly and actively in the tasks;

- ensuring the implementation of the actions envisaged in the PM, according to the procedures described therein;

- highlighting the execution of maintenance tasks. 


\section{BUILDINGS WITH ALMOST ZERO ENERGY NEEDS}

The Directive No. 2010/31/EU [1] cited above, indicates that buildings should progressively show almost zero energy needs. The buildings nearly zero energy needs are those that have a high energy performance and that meet the energy needs due in large measure of energy from renewable sources including that produced on site or nearby.

In terms of temporal gap it points that almost zero needs of energy for buildings should be obtained to license new buildings after December 31, 2020, or after December 31, 2018 in the case of new buildings on the property of a public entity and held by an entity public.

Buildings with almost zero energy must be provided with:

- efficient component compliant with the most demanding threshold levels of economic viability that may be obtained from the application of the methodology with cost, differentiated for new and existing buildings and different types; and

- forms of local capturing renewable energy covering much of the remaining energy needs planned, according to the REH models and RECS, according to the following forms of abstraction:

$\circ$ preferably, the building itself or the plot of land where it is built;

0 in addition to the in common use infrastructure as close as possible to the place where it is not possible to meet the needs of renewable energy with recourse to local funding provided specifically for this purpose.

\section{REH - REGULATION OF ENERGY PERFORMANCE OF} HOUSING BUILDINGS

The REH establishes requirements for residential buildings, new or subject to interventions, as well as the parameters and methodologies for characterizing the energy performance, in nominal terms, of all residential buildings and their technical systems in order to:

- to promote the improvement of the respective thermal behavior;

- the efficiency of their technical systems; and

- minimising the risk of surface condensation in the

\section{RECS - REGULATION OF ENERGY PERFORMANCE OF} BUILDINGS OF COMMERCE AND SERVICES

The RECS establishes rules to be observed in the design, construction, alteration, operation and maintenance of buildings of commerce and services and their technical systems, as well as requirements for the characterization of their performance in order to promote energy efficiency and the quality of indoor air.

The buildings covered by RECS should be evaluated and subject to requirements in order:
- promote the improvement of their thermal behavior;

- prevention of disease and the environment comfort focusing characteristics for this purpose in the glazed opaque envelope;

- promote efficiency and the rational use of energy, focusing, for this purpose, in components:

○ air conditionning;

○ preparation of hot water;

$\circ$ enlightenment;

○ power management systems, renewable energy, elevators and escalators.

- promote conditions of welfare and health of the occupants control of ventilation and indoor air quality;

- ensure that the technical building systems must be installed, maintained and conducted under conditions optimized for energy efficiency;

VI. INSTALLATION, HANDLING AND MAINTENANCE OF EQUIPMENT AND TECHNICAL SYSTEMS

In the implementation of energy performance regulations referred (REH and RECS), the operator TIM ensure the installation, handling and maintenance of equipment and technical systems appropriately.

In this task, the TIM should take into consideration:

- the requirements of the facility;

- the quality, organization and management of maintenance, including the respective planning, records of occurrences, the details of the tasks and operations and other actions and documentation necessary for that purpose;

- the operation of the facility through an optimized handling to ensure their operation in high energy efficiency schemes.

In new buildings the technical building systems must be designed, installed and maintained so as to be easily accessible for maintenance.

Manufacturers or installers of technical systems for new buildings of trade and services must:

- provide to the owner all technical documentation, including the make, model and features all the major constituents of technical systems installed in the building;

- ensure, where appropriate, that the equipment bearing installed in a clearly visible location after installation, the respective nameplate and technical characteristics.

\section{TESTING AND APPRAISAL OF INSTALLATIONS}

The test and appraisal are made after the completion of the facility and prior to the service phase, to demonstrate to various stakeholders in the design and installation process 
that the facilities meet the objectives for which they were designed and implemented. Testing should be performed working on the installation run, getting them registered in the implementation report.

\section{A. Implementation Report}

The implementation report should contain at least:

- date of completion and project managers of each test;

- identification of the entities or technicians present at the meeting;

- intended and achieved results;

- indication of possible follow-up measures in the event of the trial to be continued;

- indication of the need to make a new session and the term of start and finish must meet clearly defined.

\section{B. Actions prior to testing}

Prior to the completion of the tests or performance tests must:

- for each test must be specified in the design implementation of each specialty and be previously established procedures that includes:

- methodologies for the implementation;

- criteria for acceptance;

o indication of the regulations to be observed;

- local or form of testing (on site or in the laboratory, eg);

○ identifying the required stakeholders;

- the TIM of the building must get the proper training to testing;

\section{Tests to perform}

If they are installed, the respective components in building systems, the following tests shall be performed:

- testing the operational network condensate in order to verify the correct functioning and proper implementation of all siphoned areas;

- watertight to $100 \%$ of the pipe network, and the network must maintain a pressure of 1.5 times the rated working pressure for a period of twenty-four hours;

- sealing the ductwork, and the losses should be less than $1.51 / \mathrm{s} . \mathrm{m}^{2}$ area of conduct, when subjected to a pressure of $400 \mathrm{~Pa}$. First test $10 \%$ of the network indicated by the designer (in case repeat testing the failure of the network $20 \%$ and in case of failure the new repeat test network $100 \%$ );

- measurement of the flow of water in each major system component, eg producers equipment and air handling units, so accessories should be provided which enable their accurate measurement (indirect measurements will be accepted using differential pressure sensors in condition that they be calibrated by accredited bodies for this purpose);

- measurement of air flows in terminal units;

- measurement of temperature and relative humidity in the atmosphere in each independent functional area;

- measurement of electrical consumption in real working situations, all drivers of fluids, especially water and air, and refrigeration equipment including evaporators and condensing units;

- measurement of the combustion efficiency of all boilers or combustion and fuel consumption systems if they have their counters;

- check the electrical protections in situations of functioning of all thrusters fluids, specifically water and air, any existing boilers and refrigeration machines, with inclusion of evaporators and condensing units;

- checking the direction of rotation on all engines and propellers of fluids;

- verification of registration and respective good functioning of all monitoring points and control;

- confirmation of registration of cleaning of networks and components thereof, in compliance with the hygienic conditions of the facilities Heating, Ventilation and Air Conditioning (HVAC);

- test of light levels at sampling points representing the operation of the building;

- verification of the electricity consumption of lighting circuits, as follows:

○ the lighting apparatus operating at $100 \%$ light flux;

○ the lighting apparatus to function subject to the control functions.

\section{Information for conclusion of appraisal process}

The process of provisional acceptance is complete when the following information is available:

- manuals for operating the installation;

- final design plots of all facilities, containing the final elements of all facilities, including architecture;

- report to perform the tests;

- catalogs and technical certificates of conformity of the equipment;

- sheets indicative of the procedure to adopt for the maintenance of each equipment or system in order to be integrated into the Maintenance Plan. 


\section{MaINTENANCE Plan}

The MP should focus on the technical building systems, in order to maintain them in proper operating condition and operation optimized to achieve the intended goals of thermal comfort and energy efficiency.

The MP should include at least the following information duly updated:

- full identification of the building and its location;

- Identification and contact details of the owner and, if applicable, the tenant, lessee or user;

- identification and contact the TIM of the building, if applicable;

- description and summary description of the building and the respective compartments or different areas, including:

$\circ$ the area(s) and activity type(s) usually developed;

0 the average number of users, distinguishing, if possible, permanent occasional;

$\circ \quad$ the usual schedule of attendance of areas with permanent users.

- identification, location and brief characterization of the technical building systems, including HVAC, lighting, hot water preparation, renewable energy, technical management and elevator and escalator systems;

- detailed description of the procedures for preventive maintenance of technical systems, depending on the various types of equipment and the specific characteristics of its components and potential sources of indoor air pollutants;

- frequency of preventive maintenance and cleaning operations and the level of professional qualification of the technicians who must perform;

- register of preventive and corrective maintenance performed, with an indication of the technicians or technical performed, the results, and any other pertinent comments;

- definition of the quantities to be measured for subsequent formation of a history of facility operation.

The MP must include schematic diagrams of HVAC systems and other technical systems installed as well as a copy of the duly updated design and operation instructions and instructions about acting in case of an emergency.

The terminology used in the documentation and information that constitute the MP should be in accordance with the Standard EN 13306, as applicable to buildings.

\section{IX. (LEGAL) MAINTENANCE PLAN FOR BUILDING'S ENERGY PERFORMANCE}

Based on legal requirements set, the TIM can organize and implement a management system for building maintenance based on the following proposed work:

- characterization of building systems;

- counting energy systems;

- maintenance plan;

- other documentation.

In this paper it is proposed a set of items to be considered to accomplish with legal requirements concearning buildings maintenance.

By following the items proposed the TIM will fullfil all legal requirements pointed by Directive No. 2010/31/UE [1].

\section{A. Characterization of building systems}

Performance evaluation and maintenance of a building energy systems must be based on a thorough description of many existing systems. For this the following documentation must be available:

$\checkmark$ Support: Data identification and location of the building, indicating:

0 the names and contact details of the owners or users, as well as the TIM;

0 the description of the building, referring areas, activities, number of users, schedules;

$\checkmark$ Support: Listing or map of the installed technical systems indicating:

○ designation of equipment;

○ the make and model;

○ the main constituents;

$\checkmark \quad$ Supports: Picture of dog tags and specifications for each device;

$\checkmark$ Support: Listing of the various monitoring points and control;

$\checkmark$ Supports: operating and installation manuals;

$\checkmark$ Supports: Final blueprints of all facilities;

$\checkmark$ Supports: Catalogs and certificates of conformity of equipment;

The implementation report of the acceptance tests of the facilities that were conducted should be available. This report must be supported on the following media:

$\checkmark$ Support: Procedures for conducting the approval tests;

$\checkmark$ Supports: progress report for approval tests; 
This report should include information on the following:

$\checkmark$ Supports: Report of the tests of operating networks of condensates;

$\checkmark$ Support: Report of the tightness of pipes and pipelines;

Diagrams should still be available with the schematic representation of technical systems and action in case of emergency, by which the following must be available:

$\checkmark$ Supports: Schematics indicative of the operation of the facility;

$\checkmark$ Supports: Schematics indicative of action in case of an emergency;

\section{B. Counting Energy Systems}

The metering of energy must be registered and energy consumption of the building must be accessed. Some documentation can be used for this:

$\checkmark$ Support: Listing of energy metering systems;

$\checkmark$ Support: Registers of counting electricity;

$\checkmark$ Support: Registers of measuring water flow;

$\checkmark$ Support: Registers of measuring air flow;

$\checkmark$ Support: Registers of temperature and relative humidity;

$\checkmark$ Support: Registers of measuring combustion efficiency;

$\checkmark \quad$ Support: Registers of the electricity consumption of lighting circuits;

Following this registration, energy metering should be performed to analyze the energy performance (annually).

$\checkmark$ Support: Analysis of energy performance;

\section{Maintenance Plan}

The maintenance plan shall contain at least the following:

$\checkmark$ Support: Maintenance procedures for each equipment, technical system and installation;

$\checkmark$ Support: List and brief description of technical systems of the building grouped in:

○ air conditioning systems;

○ lighting systems;

○ systems of hot water preparation;

○ systems of renewable energies;

○ technical management systems;

- elevators and escalators.

$\checkmark$ Support: Maintenance schedule with indication of:

○ the frequency and / or expected dates of completion; o the indication of the technicians and / or levels of competence required;

The various maintenance activities should include the following brackets:

$\checkmark$ Support: Scan registry of installed electric protections;

$\checkmark$ Support: Registration check of the direction of rotation of motors and propellers;

$\checkmark$ Support: Scan registry of the various monitoring points and control;

$\checkmark$ Support: Scan registry cleaning of HVAC components and networks;

$\checkmark$ Support: Registration of testing the levels of lighting in the building;

$\checkmark$ Supports: Records of maintenance performed indicating:

○ dates;

- the technicians who performed the tasks;

- results of operations;

\section{Other documentation}

Adequate support to the event log must exist:

$\checkmark$ Support: Registration of occurrences; 


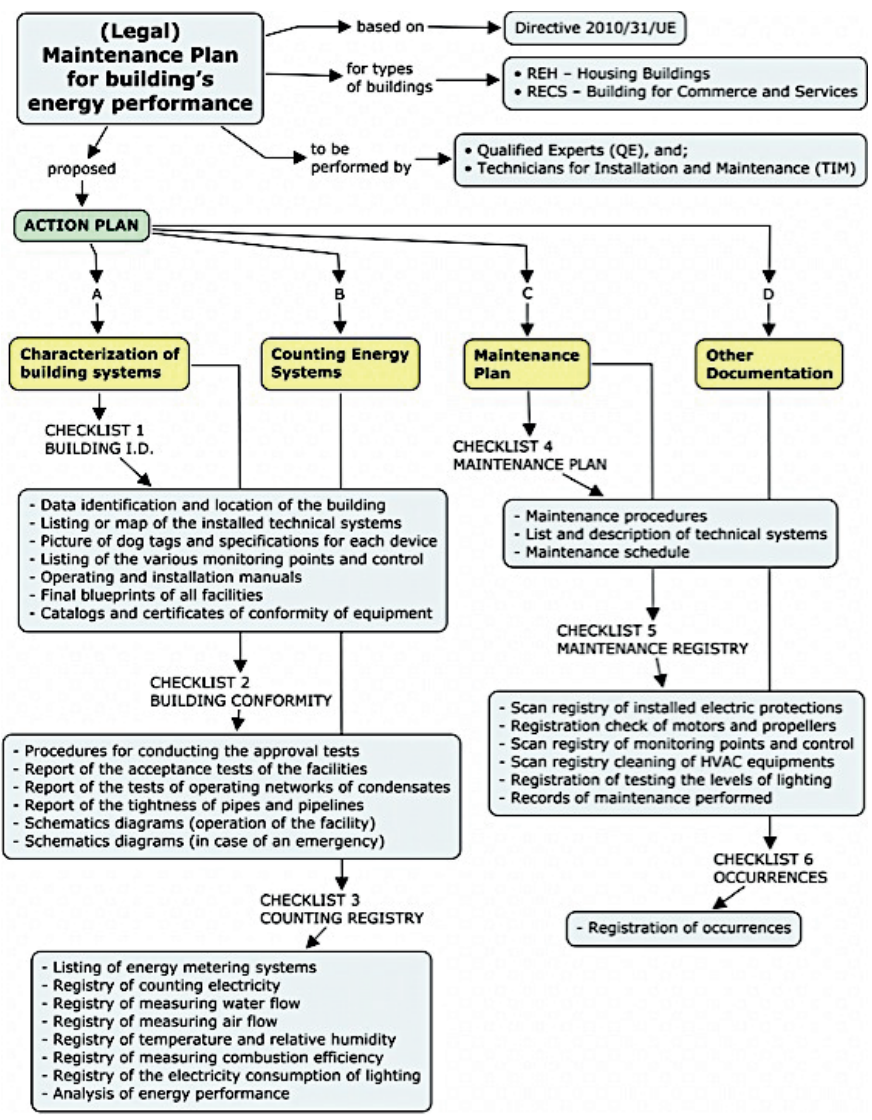

Fig. 1. Conceptual Map - (Legal) Maintenance Plan Content

\section{ACKNOWLEDGMENT}

The energy efficiency of buildings is close related with consumption reductions, replacement of existing equipment with others more efficient and by adopting appropriate measures to management and maintenance equipment. The European Union has in place concrete measures translated in Directive 2010/31 / EU [1] for an approach to the concept of "building with nearly zero energy needs" by 2020 .

To achieve this objective competes for skilled workers: the QE and the TIM, to develop correct design, installation, operation and proper maintenance.

The EU member states, to comply with the directive referred, issued legislation accordingly to introduce monitoring systems for energy performance.

Among the various activities of monitoring and evaluation of performance are included specific requirements for planning and execution of maintenance activities over the technical building systems.

With this paper is expected to have identified the main key requirements listed in various media and indicated in Fig. 1 that must be produced to comply with the legal requirements and obtain the consequent improvement of the energy performance of buildings, including large office buildings.

\section{REFERENCES}

[1] Directive No. 2010/31/UE, European Parliament and of the Council of May 19, 2010.

[2] Portuguese Decree No. 118/2013 of August 20

[3] Directive No. 2002/91 / EC of the European Parliament and of the Council of December 16, 2002.

[4] Portuguese Decree No. 78/2006, of April 4

[5] Portuguese Decree No. 79/2006, of April 4.

[6] Portuguese Decree No. 80/2006, of April 4. 
(Página deixada propositadamente em branco) 


\title{
Bottom to top approach for railway KPI generation
}

\author{
Roberto Villarejo ${ }^{1}$, Carl-Anders Johansson ${ }^{1}$, Urko Leturiondo, Victor Simon, Diego Galar ${ }^{1}$ \\ 1oberto.villarejo@ltu.se; ${ }^{1} \underline{\text { carl-anders.johansson@1tu.se; }}{ }^{1}$ urko.leturiondo@ltu.se ${ }^{1}$ victor.simon@1tu.se ${ }^{1}$ diego.galar@ltu.se \\ ${ }^{1}$ Luleå University of Technology \\ Luleå, Sweden
}

\begin{abstract}
Railway maintenance especially on infrastructure produces a vast amount of data. However, having data is not synonymous with having information; rather, data must be processed to extract information. In railway maintenance, the development of KPIs linked to punctuality or capacity can help plan and schedule maintenance, thus aligning the maintenance department with corporate objectives.

There is a need for an improved method to analyse railway data to find the relevant KPIs. The system should support maintainers, answering such questions as what maintenance should be done, where and when. The system should equip the user with the knowledge of the infrastructure's condition and configuration, and the traffic situation so maintenance resources can be targeted to only those areas needing work. The amount of information is vast, so it must be hierarchised and aggregated; users must filter out the useless indicators. Data are fused by compiling several individual indicators into a single index; the resulting composite indicators measure multidimensional concepts which cannot be captured by a single index.

The paper describes a method of monitoring a complex entity. In this scenario, a plurality of use indices and weighting values are used to create a composite and aggregated use index from a combination of lower level use indices and weighting values. The resulting composite and aggregated indicators can be a decisionmaking tool for asset managers at different hierarchical levels.
\end{abstract}

Keywords-maximum railway assets, fusion, hierarchy, granularity, aggregation, KPI, performance, DSS.

\section{INTRODUCTION}

The railway industry seeks maximum track availability at the lowest possible cost. Therefore, a proper asset management policy is essential. Such a policy requires that asset managers receive accurate information. This can be facilitated by the use of indicators, a popular decision-making support tool in asset management, especially in maintenance [1].

However, the recent flurry of indicator related activity has led some to argue there is a danger of information overload. Simply stated, asset managers need indices that give proper information to the right people. Yet even in the recently published standard [2] on maintenance performance indicators where 71 KPIs are proposed, the potential users of these indices are not identified.

Asset managers are a disparate group making decisions about operation and maintenance, and they have specific requirements of indicators $[1,3]$. Their duties span different disciplines of asset exploitation at different hierarchical levels. In summary, the following points need to be considered when selecting and using indicators:
- Only a limited number of indicators should be used to convey the performance of assets. Too many indicators can compromise the legibility of the information.

- Information should be presented in a format tailored to decision-making. This requires the construction of indicators that reduce the number of parameters needed to give precise account of a situation.

In the context of global business competition, decisionmakers are interested in the relationship between asset management and company profitability. Indicators should, therefore, concentrate on the interaction, rather than on asset management alone.

\section{THE NEED TO MEASURE MAINTENANCE PERFORMANCE}

Today's railways face increasing pressure from customers and owners to improve safety, capacity, and reliability of the rail system - while controlling expenses and tightening budget [4]. That is why, with fewer resources and shrinking budgets, having a proper maintenance management system in place to assist managers and engineers to get the most out of their existing infrastructure assets is essential. In this regard, the maintenance of large-investment equipment, once thought to be a necessary evil, is now considered key to improving cost effectiveness and creating additional value by delivering better and more innovative services to the customers.

With the change in the strategic thinking of organisations, it is crucial to measure, control and improve asset maintenance [5]. The main challenge is choosing efficient and effective strategies so organisations can enhance and continually improve their operational capabilities and reduce their maintenance costs. Therefore, in addition to formulating maintenance policies and strategies for asset maintenance, it is equally important to measure their performance.

Maintenance Performance Measurement (MPM) is defined as "the multidisciplinary process of measuring and justifying the value created by maintenance investment, and taking care of the organisation's stockholder's requirements viewed strategically from the overall business perspective" [6] . It is considered an important element for understanding the value created by maintenance, re-evaluating and revising maintenance policies and techniques, justifying investments in new trends and techniques in maintenance services, revising resource allocations, understanding the effect of maintenance on other functions and stakeholders as well as on health and safety etc. [7]. 
Unfortunately, these maintenance metrics have often been misinterpreted and many companies apply them incorrectly. The metrics should not be used to show workers they are not doing their jobs. They should not be used to satisfy the company's ego, i.e. to show the company is working excellently. Performance measurements, when used properly, should highlight opportunities for improvement, detect problems and, ultimately, help find solutions [8].

[9] provides an overview of the state of maintenance, its current problems and the need for adequate metrics to quantify it. The historical view of maintenance, mixed with traditional issues of performance measurement, creates problems developing and implementing a comprehensive package for measuring maintenance management performance [10]. For example, human factors affect the selection of the metric and its application, along with the subsequent use of the produced measurement. There is also a need to delineate responsibilities.

\section{A. Too much data and too little information}

Data acquisition has become relatively simple and cheap with the introduction of modern and powerful hardware systems and software. However, the enormous amount of data i.e. data overload, is a problem in itself. When collection is simple and inexpensive, many data can be gathered, but sophisticated data mining algorithms may be required to get useful information. When the data are more difficult to collect, an organisation needs to decide if their value to the company, usually to a single hierarchical level, is worth the effort and cost. This is accomplished by establishing what is important at different levels, i.e., determining the objectives at each organisational level and ensuring they emanate from the corporate ones. Once user needs are fully understood, it will be possible to determine the maintenance strategy and its required resources and systems.

\section{B. Time lag between action and monitoring results}

Sometimes there is a delay between policy change and the appearance of clear results associated with that change. A second delay occurs between the time the measurement is taken and the appearance of results. These problems must be treated individually against each objective, taking into account that technical levels can expect faster changes in their indicators than corporate levels; at these levels, the KPIs are measures of strategy and it can take longer to get visible results. Once a measure has been identified for a goal and level and is implemented, the method and frequency of data collection have to be specifically tailored to the factors involved: physical parameters, human factors, financial, organisational etc.

\section{SCORECARDS AND AGGREGATION OF PERFORMANCE INDICATORS}

It is essential to find the right indicators for the different organisational levels, indicators that match the objectives and strategy of the business. This is commonly done by starting from the business goal and working in a bottom-up manner.

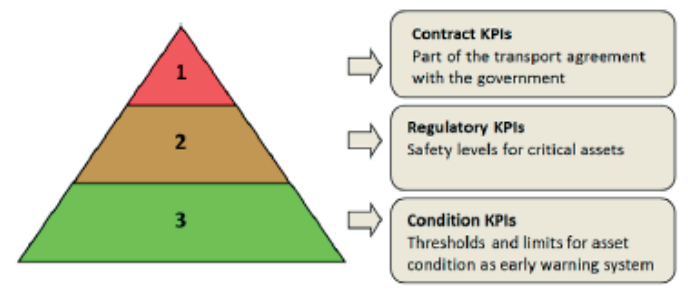

Fig. 1. KPI levels

The next step is to evaluate the available data and determine the appropriate indicators at each level. The data and the operational level indicators have to be aggregated up through the organisation. Hundreds of indicators can be spread throughout the various organisational units on the operational level, but the top management level may have only a few indicators, depending on the structure of the organisation, e.g. number of senior managers and organisational flatness.

The output of the development of a MPM-system is a framework, or scorecard, where indicators are grouped into categories, such as the following:

- Technical

- Functional

- Strategic level/top management

- Tactical/middle management

- Functional/supervisors and operators

- BSC perspectives (customer, processes, financial and innovation)

- Business areas

- Key result areas

- Quality

- Productivity

- Health

- Safety

- Environment

- Risk management

- Quantitative

- Qualitative

- Equipment performance

- Process performance

- Cost performance

- etc.

Campbell [11] classifies performance indicators into three categories: equipment, process and cost performance. Indicators of equipment performance are availability, reliability and OEE; indicators of process performance include the ratio of planned work and schedule compliance; cost performance indicators include maintenance labour and material cost.

Another way of grouping is into leading and lagging indicators which measure future events and events that already have occurred, respectively. Leading indicators are also called operational indicators, monitoring the inputs to a process, and lagging indicators are called financial measures, monitoring the outputs $[12,13]$. 


\section{DATA MANAGEMENT}

For a linear asset such as a railway, much information needs to be captured and analysed to assess the overall condition, maintenance, capital spending, and inspection of the railroad tracks.

Examples of information that can be collected include track availability, use of track time, track condition, performance history, and the work performed. Measurements of the condition of the track typically include continuous and spot measurements from automatic inspection vehicles, visual inspections from daily walking inspections, and records of inservices failures. Examples of conditions measured by automatic inspection vehicles include geometry car measurements (deviation from design curves, geometry exceptions to railroad standards, vehicle ride quality exceptions), rail measurements, gage restraint measurements, track deflection and stiffness measurements, clearance measurements, and substructure measurements.

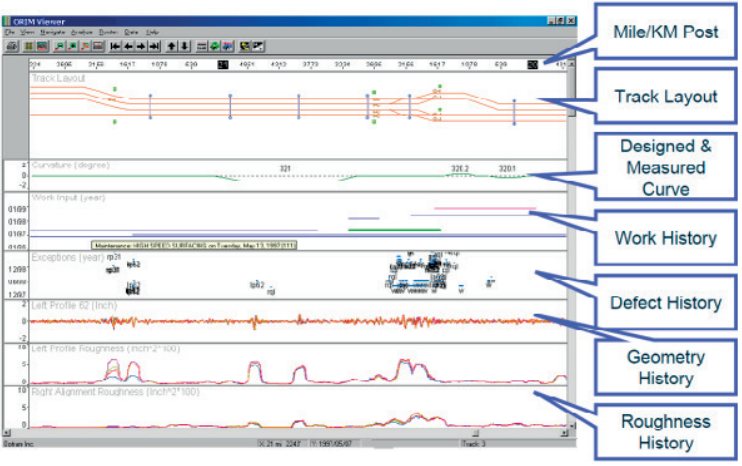

Fig. 2. Physical parameters monitored in linear assets by OPTRAM software

Information on a linear asset is usually collected and maintained, for example, in a set of track charts or line books (see figure 2). A track chart is the linear representation of all infrastructure assets along a linear asset based on a maker post and offset measurement system. Updating the track charts generally occurs on an ad hoc basis, so discrepancies, missing facilities, and incorrect location information are common. Even with an accurate map of the corridor, rail, ties, and other corridor assets do not have any physical characteristics that lead to easy identification. Furthermore, problem areas for targeted maintenance often do not obey discrete physical boundaries such as beginning and end of a rail section.

The development of a variety of track condition indicators such as geometry cars, rail defect detection equipment and gage restraint management systems has resulted in a significant amount of new and useful information for track maintenance [14]. However, a large amount of information provided over a large area quickly leads to information overload.

Accordingly, there is a need to create MPM indicators to analyse data on linear assets. Having a unified perspective on the relevant data within a single, accurate format would facilitate the analysis of these data. Accurate MPM indicators would help decision makers determine what should be worked on and why. Such indicators would support the user by providing knowledge of the infrastructure's condition and configuration, so maintenance resources could be targeted to only those areas needing work. The indicators would also help in the planning of such things as facility upgrades and expansions.

\section{MAPPING RAILWAY INFRASTRUCTURE INDICATORS}

Because the indicators used to manage railway infrastructure are comprehensive, in this work they are split into two large groups with a number of sub-groups. The two larger groups are managerial and infrastructure condition indicators. The former are extracted from various computer systems, e.g. enterprise resource planning (ERP), computerised maintenance management software (CMMS), etc., excluding condition monitoring (CdM) data. Therefore, the latter group includes all indicators extracted by sensors and various inspection methods in the railway network. Managerial indicators are at a higher level in the organisational hierarchy than the infrastructure CdM indicators; these are closer to the operational level (see figure $3)$.

Increased interoperability and the building of a transEuropean railway network require harmonisation and the standardisation of management across countries. This has led to the increased use of European standards. Consequently, the managerial KPIs identified here follow European standard EN 15341 , i.e. economic, technical and organisational KPIs. In the standard, the health, safety and environmental KPIs are in the technical group, but these indicators are considered to have such importance for railways that they have been put into a separate group. The managerial indicators consist, therefore, of four groups, or key result areas (KRAs) (see figure 3).

$\mathrm{CdM}$ indicators are grouped according to the common engineering sub-systems of railways: substructure, superstructure, rail yards, and electrification, signalling and information communication technologies (ICT). In this, we are following the grouping used by Swedish railway company Trafikverket.

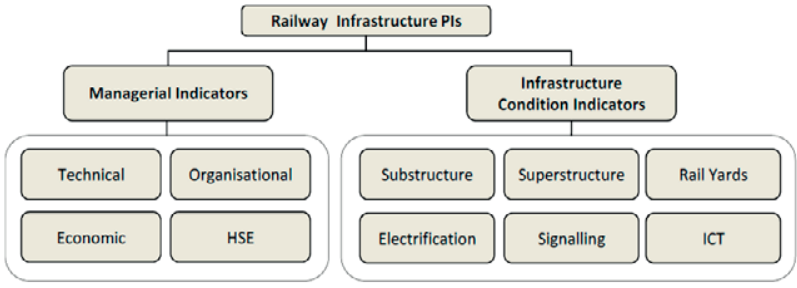

Fig. 3. Structure of railway infrastructure KPIs. ICT stands for information and communication technologies

\section{FUSION OF CONDITION INDICATORS AND HISTORICAL DATA: A NECESSARY INGREDIENT OF INFORMATION AGGREGATION}

Indicators must be mapped and grouped if an organisation is to make the right decisions at the right time for the right 
assets. However, data sources for the railway are so different and information is so disparate that decisions are not easy.

Moreover the information sources comprise two types of data: historical data contained in computerised maintenance management software or CMMS and condition data coming from the CM systems. CMMS data include information on preventive maintenance (PM) scheduling, automatic work order generation, maintenance inventory control, and data integrity. The CM systems feature multiple-method condition monitoring, trend tracking, and expert system diagnoses. These data must be integrated to contextualise decisions and produce aggregated indicators meaningful for the various actors who are managing railway assets and other linear assets. New methods must be developed to merge condition indicators with historical operation and maintenance data to form a solid base for the accurate assessment of the asset's current and future health [15].

The first step in integrating CMMS and CM is devising a way for the two systems to communicate using a common base of information. For example, all equipment monitored by the CM system must also exist in the CMMS database, and must be called by the same name in each. Next, there must be a system of data cross-referencing between the sensors, meter tags, or other measurement tools in a $\mathrm{CM}$ system and the appropriate module in the CMMS that associates readings in one system with readings in the other. Meter readings or alarm triggers that are out of the acceptable CMMS range should trigger a pre-defined work order. Any discrepancy in this cross-referencing for a piece of equipment will nullify the link for that piece of equipment, making the ability to predict problems much less comprehensive. In short, upfront planning of data entry rules and the database setup comprise a critical part of the pre-integration process. The third step in fully integrating a CMMS and CM package is to provide a direct link between the systems' data tables, usually called an "active exchange" of data. The best CMMS databases feature open architecture, such as SQL, Oracle and others. They can be read from and written to by CM programs with certain capabilities.

The most obvious obstacle in the integration of CMMS and $\mathrm{CM}$ data is the disparate nature of the data types; attempts to remedy this problem have encountered inconsistent implementation and limited scalability. For example, one possibility is to assign the mostly qualitative CMMS data with quantitative indexing, allowing $\mathrm{CM}$ data to be separated into discreet maintenance states. But it is the responsibility of the maintainer to correctly insert the appropriate fault or work code into the maintenance logs, and to date, this has not been done with sufficient accuracy or consistency to be deemed reliable.

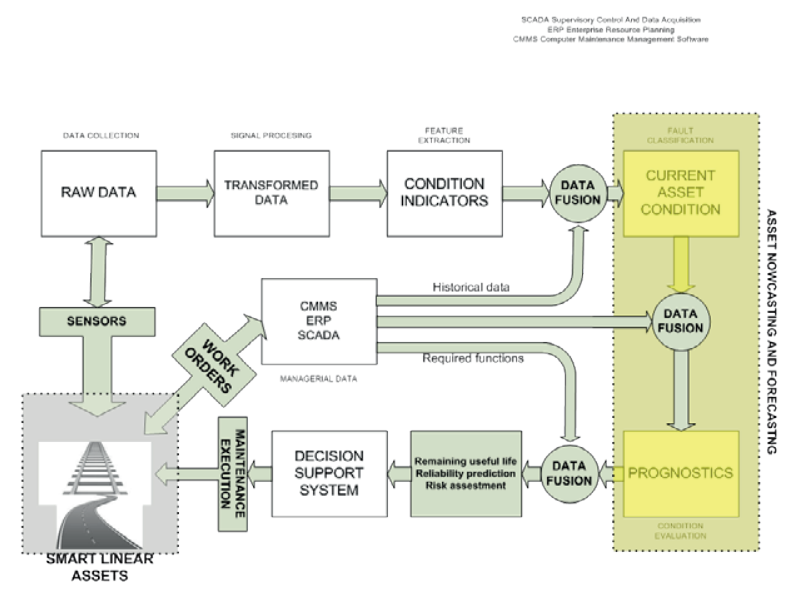

Fig. 4. Architecture for the asset condition assessment

Assessing the condition of linear assets requires communication systems that are reliable, flexible and, in most cases, wireless. These systems must also meet the energy constraints defined by the energy management system. The data, once communicated from the sensor systems, will be merged with historical data to assess the current health before being used for prognosis of the future health.

This is, however, not as simple as it may seem, since the condition monitoring data and the historical data are from completely different time frames. For example, control system data are real-time data measured in terms of seconds, whereas maintenance cycle data are generally measured in terms of calendar based maintenance (e.g., days, weeks, months, quarters, semi-annual, annual), and financial cycle data are measured in terms of fiscal periods. While using a good version of either technology can allow an organisation to meet its maintenance goals, combining the two into one seamless system can have exponentially more positive effects on the maintenance group's performance than either system alone might achieve. Ideally, combining the strengths of a top-notch CMMS with a leading-edge CM in such a way that work orders are generated automaticallywill allow the automatic generation of work orders based on information provided by CM's diagnostic and prognostic capabilities.

CMMS and $\mathrm{CM}$ systems are both indispensable to maintenance operation improvements [16]. But while CMMS is a great organisational tool, it cannot directly monitor equipment conditions. Meanwhile, a $\mathrm{CM}$ system excels at monitoring those equipment conditions, but is not suited to organising the overall maintenance operation. The logical conclusion is to combine the two technologies into a seamless system that provides aggregated indicators about the asset's condition for the different hierarchies in the organisation and avoids catastrophic breakdowns, but eliminates needless repairs to equipment that is running satisfactorily.

\section{DECISION MAKING BASED ON DATA FUSION}

Implementing condition-based maintenance requires the setting of an information system to meet the basic requirements of different audiences: 
- Collect and process a large quantity of information not previously available on the condition of each part of an asset.

- Initiate corrective maintenance actions within the leadtime (the period between the off-limits condition and an emergency shutdown). Two different situations which the examiner arise:

$>$ The condition of machine is not yet close to breakdown; in this case, the normal procedure of the maintenance planning section is followed.

$>$ The condition of the asset is already well within the lead-time (near to breakdown); the information must be directly passed on to the maintenance supervision to carry out emergency corrective maintenance actions.

To operate a condition based maintenance program correctly, the maintenance personnel should add the following information to the system:

- Condition of the asset

- Part of the asset probably defective

- Probable defect

- $\quad$ Time during which failure must be repaired

By scrutinising and correlating the diagnosis against actual findings during repair work, it will be possible:

- To control the examiner training

- To improve the correlation between parameters chosen for condition measurement and actual defects found

- To obtain severity curves specific to each machine

Turning the potential of condition monitoring into a reality requires large amounts of data to be collected, monitored, filtered and turned into actionable information. The cheaper and more ubiquitous the computerised monitoring hardware becomes, the greater the volume of data and the more challenging it becomes to manage and interpret. The vast amount of diagnostic data produced by today's smart field devices can be a very important source for accurate documentation of maintenance activities. But the sheer volume and complexity of such information can be daunting and difficult for maintenance personnel to manage. What is needed is an effective way to compile and organise the data for day-to-day use, while preserving and recording significant events for future reference data.

While this is starting to occur, in many cases, the data cannot be used; they may be of poor quality or may suffer from improper storage [17]:

- Project managers do not have sufficient time to analyse the computerised data so they don't care about proper storage

- The complexity of the data analysis process is beyond the capabilities of the relatively simple maintenance systems commonly used

- There is no well-defined automated mechanism to extract, pre-process and analyse the data and summarise the results

Maintenance personnel cope with large amounts of fieldgenerated data, turning that information to their advantage in a number of ways, depending on their level in the organisational hierarchy. For example, Real Time Condition Monitoring (RTCM) systems produce warnings, alarms and reports that can be used by maintenance people for many purposes. Such systems allow the most important issues to be identified and handled quickly.

The goal is to integrate these types of data with CMMS to generate work orders as needed. The process will be fully automated, linking the time a field device begins to show signs of reduced performance to printing a work order in the maintenance department and dispatching a technician to the scene. Figure 5 shows this automation of work order dispatching.

This level of integration of CMMS and CM is feasible, given the evolution of IT. With the development of open communication protocols, the information accumulated by smart field devices can be captured by asset management software. It is no longer necessary for technicians to carry handheld communicators or laptops into the plant to evaluate the condition of instruments, some of which are quite inaccessible or in hazardous areas, to be followed by manually documentation of test results and current device status.

Current applications compile databases of every smart instrument used for process control, including its design parameters, original configuration, maintenance history and present operating condition. With these online tools, technicians can obtain up-to-date information on any device; do not have to make manual entries into a system. Every event is recognised and recorded, whether initiated by a technician or caused by an external force such as an equipment breakdown or power failure. This process produces an immediate result for the shop floor level: work orders can be open and closed by devices that collect information automatically and send a warning if something goes wrong. Users can refer to recorded alerts to identify devices that have been problematic over time and to discover what corrective steps have been taken. Automated documentation provides a seamless record of events in a given area, including communication failures, device malfunctions and process variables that are out of range. Armed with this information, maintenance personnel are better equipped to understand and resolve nagging repetitive issues to improve the overall process. If there is an issue, or if maintenance personnel are experiencing a rash of issues, they can go back into the records and get a sense of what has been happening over time. They can search by a specific device or by location. 


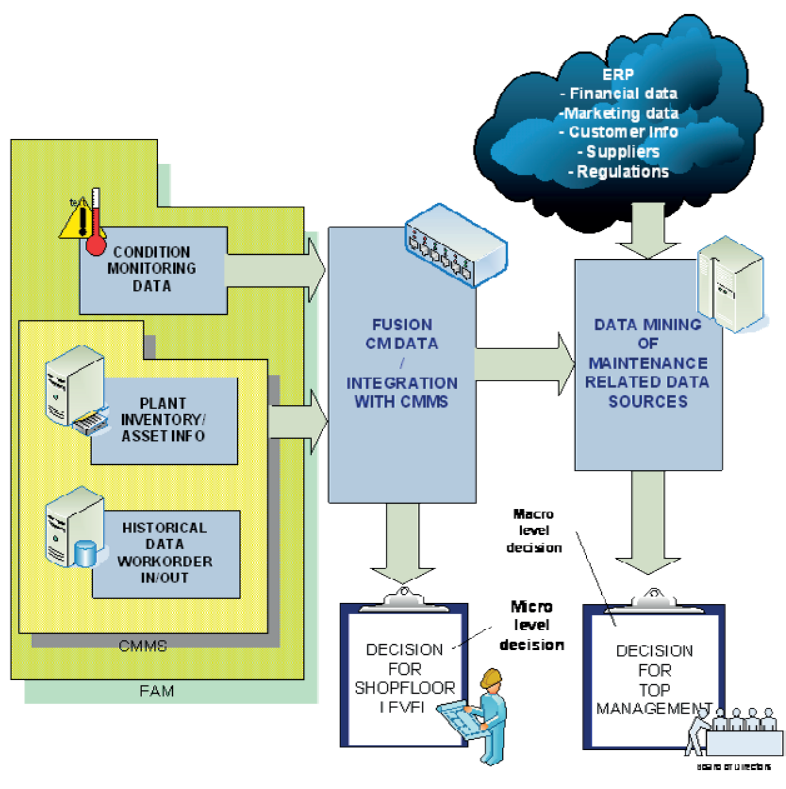

Fig. 5. Two step integration of RTCM and CMMS databases

Since all records are date and time stamped, users can easily determine when and by whom a particular device was changed or tested, including "as found/as left" notations. With this information stored in a database, it should never be necessary for technicians to spend time searching for historical information on a device. Since events can also be recorded manually, users can document unusual occurrences affecting the entire plant, such as a lightning strike or power outage, or individual events like device inspections

The integration of information has two steps. The first is the integration of technology; here, standards like MIMOSA are working to develop a common hardware and software platform for data storage. The second is related to the knowledge extraction required by the integration performed in the first step. In this case, data mining promised to be an effective tool.

Data mining has become useful over the past decade in maintenance to gain more information, to have a better understanding of the behaviour of running assets, and to find optimal maintenance policies derived from the new knowledge. Today, data mining is no longer thought of as a set of stand-alone techniques, far from the maintenance applications. Enterprises increasingly require the integration of data mining technology with relational CMMS and CM databases and their business-oriented applications. To support this move, data mining products are shifting from stand-alone technologies to integration in the relational databases.

A vast amount of available information can only produce new knowledge if it is properly exploited using the right tools. Modern CMMS information is stored in very large relational, or tabular, databases. This format is appropriate for integration, as there are many software tools available to query and investigate the tables. For historical analysis, only certain fields are required, thus allowing the previously mentioned sensitive data to be removed or filtered. The data subset still contains a full history of component faults and related actions, providing a comprehensive maintenance history profile while alleviating security concerns.

Importing $\mathrm{CM}$ data into this relational database is somewhat more challenging but possible, since each type of sensor generates different data classes, sampling rates, and number of compiled indicators. Furthermore, each manufacturer stores the collected information in unique proprietary formats, requiring platform-specific importation software to be written. However, most CM software allows the $\mathrm{CM}$ data to be exported from the original interface so they can be expanded and generalised.

Even when CMMS and CM data co-exist in a single database where they can be queried and explored, automating the discovery of linked events requires additional processing. Relating a given maintenance fault or action, which is textual, to sensor data, which is some arbitrary data class type, can only be accomplished through the compilation of overlapping metadata, [18]. The generated fields characterise the location and significance of events, creating a quantified set of parameters by which the disparate data can be compared. Metadata for CM records are generated differently depending on the data class involved. One-dimensional and dimensionless quantities can be assigned rarity parameters through statistical distribution analysis; higher dimensional data requires using neural networks to identify anomalies. Determining rarity is often accomplished through simple single variable statistical analysis, while severity is typically derived from developers' recommended threshold values. More complex domain types require more advanced, though typically well-understood analyses, such as neural networks which can isolate anomalous points from multidimensional data. It is predicted that through the integration process, more advanced metrics and indicators can be discovered to implement previously unexplored relationships in the data, such as multi-parameter trending. This new knowledge can help maintenance personnel determine the Remaining Useful Life of the system, allowing them to schedule operating and maintenance processes based on this information. This information affects replacement of assets, shutdown of the plant, overhauls etc., so it constitutes the second decision level displayed in figure 5, i.e., strongly related to business goals but useless for immediate interventions.

With the development of an easy-to-use interface and a tight integration with the existing environment, new and interesting patterns will emerge in the data; the derived knowledge will be invaluable in making maintenance decisions.

\section{CONCLUSIONS}

There is a real need for maintenance performance measurement in all sectors, but this need is particularly salient in transportation. In this sector, maintenance is critical, as it affects not just the bottom line financially but also safety. Many performance indicators (KPIs) have been developed to measure the quality of the maintenance in various railway assets, including rolling stock and all parts of the infrastructure. Several techniques of grouping indicators have also been developed. However, there is a real need to create 
composite indicators, aggregating information from bottom to top to serve all actors in maintenance decision making.

The maintenance function affects two different hierarchical levels. On the one hand, information collected in the field coming from sensors is used for condition monitoring purposes and fused for asset condition indicators that mostly serve the purpose of immediate interventions at the shop floor level, i.e. short term planning.

On the other hand, the information from the shop floor level may be fused with historical information and scaled it up to higher levels in the organisation for decisions related to long term planning, including overhauls or asset replacements. The information used in the lower levels may be merged and fused with managerial information to produce indicators adapted to the different levels of the organisation, facilitating the decision making process by avoiding the common mistake of having many indicators used in all levels without segregating them by user.

The methodology proposed here is consistent with the ISO 55000's establishment of mechanisms for continuous maintenance improvement; it also reflects the fact that huge amounts of data are collected on a daily basis and must be filtered to provide the right information to the right users.

\section{ACKNOWLEDGMENTS}

This research has been partially supported by OPTIRAIL, a project funded by the 7th Framework Programme of the European Commission. This project has received funding from the European Union's Seventh Programme for research, technological development and demonstration under grant agreement No 314031.

\section{REFERENCES}

[1] Kumar U, Galar D. Parida A., Stenstron C. Berges L. "Maintenance performance metrics: a state of the art review". Proceedings of International Conference on Maintenance Performance Measurement \& Management : $\mathrm{MPM}^{2}$ 13-12-11 - 15-12-11

[2] UNE-EN 15341:2008

[3] Boisevert, V., N. Holec, et al. "Economic and Environmental Information for Sustainability. Valuation for sustainable development: methods and policy indicators". S. Faucheux and M. O'Connor. Cheltenham, Edward Elgar Publishing 1998 Ltd: 99-119

[4] Wilmering, T. J., Ramesh, A. V., Mar. "Assessing the Impact of Health Management Approaches onSystem Total Cost of Ownership," IEEE Aerospace Conference, Big Sky, Montana. 2005

[5] Aditya Parida, Uday Kumar, "Handbook of Maintenance Management and Engineering”, Part I, 17-41. 2009

[6] Aditya Parida, Gopi Chattopadhyay, "Development of a multi-criteria hierarchical framework for maintenance performance measurement (MPM)", Journal of Quality in Maintenance Engineering, Vol. 13 Iss: 3 , pp. $241-258.2007$

[7] Aditya Parida, Uday Kumar, "Maintenance performance measurement (MPM): issues and challenges", Journal of Quality in Maintenance Engineering, Vol. 12 Iss: 3, pp.239 - 25. 2006

[8] Wireman, T. "Developing performance indicators for managing maintenance". Industrial Press (First edition): New York. USA. 1998

[9] Mata, D. \& Aller J. "Análisis Probabilístico del Mantenimiento Predictivo y Correctivo de Máquinas Eléctricas.Rotativas en una Planta Siderúrgica". Revista Universidad, Ciencia y Tecnología de la Universidad Nacional Experimental Politécnica Antonio José de Sucre 2008

[10] Woodhouse, J.. Asset Management - An Introduction. Institute of Asset Management, http://www.iamuk.org/iam_publications.htm. 2004

[11] Campbell, J.D. "Uptime: Strategies for Excellence in Maintenance Management".1st ed. Portland: Productivity Press. 1995

[12] Kaplan, R.S. and Norton, D.P.,. The Balanced Scorecard - Measures that Drive Performance. Harvard Business Review, vol. 70, no. 1, pp. 71-79. 1992

[13] Kaplan, R.S. and Norton, D.P.,. "The Balanced Scorecard: Translating Strategy into Action". 1st ed. Boston: Harvard Business Press, 09-01, ISBN 0875846513. 1996

[14] Parida, A. "Managing Information is the key to Maintenance Effectiveness", e-Proceedings of Intelligent Maintenance System, Arles, France, pp.15-17. 2004

[15] Galar, D et al. 'Maintenance decision making based on different types of data fusion', Eksploatacja i niezawodnosc - Maintenance and Reliability, Vol 14, No 2, pp 135-144. 2012

[16] Galar, D. et al. "Integration of disparate data sources to perform maintenance prognosis and optimal decision making". Insight: nonDestructive Testing and Condition Monitoring, 54 (8), 440-445. 2012

[17] Soibelman, L. \& Kim, H. "Data preparation process for construction knowledge generation through knowledge discovery in databases". Journal of Computing in Civil Engineering, 16 (1), 39-48. 2002

[18] Tianhao W, Khan F.M., Fisher T.A., Shuler L.A. \& Pottenger W.M. "Posting Act Tagging Using Transformation-Based Learning." ICDM'02Proceedings of the Workshop on Foundations of Data Mining and Discovery, IEEE International Conference on Data Mining. 1992 
(Página deixada propositadamente em branco) 


\title{
Creating an open-books -supported implementation framework for inter-organizational decision-making models in the industrial maintenance context
}

\author{
Antti Ylä-Kujala ${ }^{1}$; Salla Marttonen ${ }^{2}$; Tiina Sinkkonen ${ }^{3}$; Timo Kärri ${ }^{4}$ \\ 1'antti.yla-kujala@lut.fi; ${ }^{2}$ salla.marttonen@lut.fi; ${ }^{3}$ tiina.sinkkonen@lut.fi; ${ }^{4}$ timo.karri@lut.fi \\ 1,2,3,4 School of Industrial Engineering and Management, Lappeenranta University of Technology \\ Lappeenranta, Finland
}

\begin{abstract}
Rapid globalization has forced companies to outsource their intra-organizational activities and collaborate otherwise with previously unrelated partners. As the importance of networking and forming inter-organizational relationships is increasingly emphasized in industrial environments, there is also a need for inter-organizational methods, models and tools to manage network interdependencies. Especially in the industrial maintenance context, the interplay between a customer, a service provider and an equipment provider requires triadic and transparent collaboration.
\end{abstract}

An open-book accounting -supported implementation framework for inter-organizational decision-making models, featuring a relational dimension and a process dimension is created in the study. The theoretical framework is established through a literature review. Furthermore, the prerequisites and potential pitfalls of increasing real-life inter-organizational openness are studied framework-wise. The empirical data has been gathered in workshop events with companies acting in the field of industrial maintenance.

Firstly, the study reveals that the companies are not yet prepared to disclose intra-organizational information networkwide, rather a willingness to promote dyadic transparency and focal company -coordinated disclosure is highlighted. Secondly, the present state of companies' cost accounting systems seems to be relatively poor, which hinders the adoption of interorganizational models. Thirdly, a lack of systematic network infrastructure appears as well.

Keywords-inter-organizational relationships, networks, openbook accounting, industrial maintenance, model implementation, implementation framework.

\section{INTRODUCTION}

The modern-day world is highly globalized. This fairly rapid phenomenon has had direct and indirect effects on companies of very different sizes in the most traditional industries. Therefore, companies and other organizations are increasingly forced to concentrate on their core competencies to be able to thrive in worldwide competition. As a consequence, inter-organizational linkages between firms have multiplied, and networking has truly become a vital part in doing business. In industrial environments, companies' focus on their core competencies has resulted in outsourcing of equipment maintenance to external service providers, either completely or partially [1]-[9]. Outsourcing is an excellent example of vertical inter-organizational collaboration, i.e. networking, which conceptually takes place in a value chain between a company and its suppliers and/or customers [10]. Even though vertical collaboration is often reckoned as transactional by nature, maintenance networks that are in principle comprised of a maintenance customer, a maintenance service provider and an equipment provider [9], offer a fruitful platform for more partnership-like arrangements. Either way, the above-mentioned "maintenance triad" creates multiple interesting challenges for successful collaboration, such as how to implement, generally and as a process, a network model.

The benefits of establishing an inter-organizational infrastructure, e.g. network methods, models and tools, and developing suppliers' cost accounting systems in particular have been recognized in several research papers to promote better management and control of firm networks [11]-[17]. Despite their usefulness and a plausible demand, the current literature does not really take a stand on which matters should be considered when implementing collaborative models. As technological aspects in such implementation are, if not easier but in a way more straightforward to tackle, the challenges originating from inter-organizational interdependencies are definitely tricky to manage. Therefore, open-book accounting, which is probably the most predominant inter-organizational concept to date, has been chosen as the approach for the present study. So far, research papers in the area of open-book accounting have dealt for example with its successes and failures [15], [17] and [18], the variety of decision-making situations where disclosed data can be employed [19] and [20], profit-sharing incentives forwarding open-books utilization [21] and [22] and trust, as well as other relational factors in relation to the open-books phenomenon [23]-[25]. Nevertheless, the issues in implementing a network model is altogether a novel topic in the present literature.

The main objective of the study is to create a theoretical implementation framework for inter-organizational decisionmaking models from the open-book accounting perspective. The purpose of the framework is to help understand the relational dimensions and factors that have an influence on the model implementation process. Further, the supportive objective is to map the existing information disclosure potential in real-life maintenance networks from companies acting in this field. The chosen approach, studying the subject by creating a theoretical framework, has been adopted because the 
current understanding about inter-organizational model implementation is still rather scarce. Thus, some kind of theoretical basis is a very good starting point for further research, such as an extensive case study where the presented theories are comprehensively tested.

The research questions are as follows:

- Which open-book accounting theories, presented currently in the cost management literature, are essential from a model implementation standpoint?

- What do companies themselves in the field of industrial maintenance think about disclosing confidential information in practice?

- How could the implementation of an interorganizational decision-making model be theoretically illustrated from the open-books perspective?

The empirical data has been gathered in four workshop events arranged in Finland in February 2014. The participants, twelve individuals in total, came from eight Finnish companies, acting in the field of industrial maintenance, and were selected for collaboration because of their current linkage to an ongoing research project on maintenance services management. Thus, these companies and their representatives were already somewhat aware of inter-organizational matters and issues in relation to this specific industry. Moreover, the so-called maintenance network roles of the participating organizations are the following; three of them represent a maintenance customer, two firms are maintenance service providers and the remaining three are equipment providers. However, all these companies do not cooperate with each other directly, but form two separate networks, one acting in the mining industry and the other in the energy industry.

The overall structure of the paper is as follows. First, the concept of open-book accounting, together with its main content is studied in section II. Further in section III, the prerequisites and potential pitfalls for increasing interorganizational transparency are observed from the empirical point of view. The empirical data gathered in the workshops is analyzed in this particular section. The open-books -supported model implementation framework is presented and discussed in detail in section IV. Lastly, the paper is concluded in section V, where the main aspects are brought up once more. The potential need for further research is also acknowledged in the conclusions.

\section{OPEN-BOOK ACCOUNTING AS AN INTER- ORGANIZATIONAL PHENOMENON}

As cost data is probably the most sensitive piece of intraorganizational information, it has been traditionally kept hidden from firms' suppliers and customers. However, in the wake of network formation, in outsourcing in particular, disclosure of sensitive data has become a topical issue in management and control in industrial contexts. Conceptually, the practice of disclosing intra-organizational information inter-organizationally has been called open-book accounting, also known as OBA, see e.g. [11] and [15]. Alternatively, open-book costing, see e.g. [24] and [26], open-books policy, e.g. [19] and [20], open-book negotiations, e.g. [27] and [28], and open-books, e.g. [13] and [16], have also been employed in multiple references to the phenomenon. Moreover, cost transparency is sometimes understood as a synonym as well. However, for instance McIvor [26] distinguishes open-book costing and cost transparency from each other. By his standards, open-book costing, i.e. open-book accounting, is rather a negotiation method in contrast to cost transparency, which is, as a matter of fact, a technique of sharing cost information. In this paper, open-book accounting, open-books, as well as the abbreviation OBA are used. The phenomenon is also understood widely from preliminary negotiations as factual and realized disclosure of cost and other intraorganizational information between legally detached and independent companies.

Despite the obviously challenging nature of OBA terminology, its fundamental principle and potential benefits that directly ensue its purposes are fairly unambiguous. On the one hand, as Kajüter and Kulmala [15] state, open-book accounting is a means for revealing cost reduction opportunities through collaborative efforts, but on the other hand, a serious trust-building tool as well. Axelsson et al. [13] for example recognize the establishment of mutual trust as a key issue in utilizing the open-books technique. Kajüter and Kulmala [15] also mention that trust can be seen either as a prerequisite for opening the books or as an end result of the practice itself. In the end, however, the success of OBA is highly dependent on the existing motives, whether cooperative or opportunistic, of the participating organizations [29].

Inter-organizational cost management is very closely related to open-book accounting both in theory and in practice. As Cooper and Slagmulder [30] highlight, the objective of inter-organizational cost management (IOCM) is to identify opportunities for joint cost reductions through coordination of activities. Therefore, companies should be able to achieve lower total costs than acting independently. Agndal and Nilsson [16] underline specifically that IOCM practice focuses on costs that originate from overlapping inter-organizational activities, in other words reciprocal business transactions. Moreover, joint development of cost accounting systems can also occasionally take place in the context of interorganizational cost management [15]. Before anything, IOCM is an umbrella category that encompasses a variety of practices, such as performance measurement, target costing, activitybased costing and open-book accounting [31]. Evidently, these methods are similar to intra-organizational circumstances and thus IOCM and "regular" cost management should be understood analogically, as the only difference between them is really the organizational context. Open-book accounting, however, is a purely inter-organizational method and, in a sense, a platform that enables IOCM through proper cost accounting tools, such as target costing.

In order to get better understanding of the open-books phenomenon as a whole, its main content and features should be highlighted in closer detail. Windolph and Möller [18] have recognized three open-book accounting dimensions, which are the direction of information exchange, the degree and the quality of disclosure, and the existing boundaries to information openness. Also Angdal and Nilsson [32] have listed three open-books dimensions, but not entirely similarly. Their dimensions are the nature of data and the accounting data disclosure practices, the uses of disclosed accounting 
data, and the conditions of open-book accounting. As can be seen, the categorization of Angdal and Nilsson [32] is clearly more extensive, as it takes into account the decision-making situations where disclosed data is used, as well as the organizational attitudes towards information transparency in general. However, the above-mentioned definition of Windolph and Möller [18] is favored in this paper. For example, the uses of disclosed data are irrelevant because the preliminary decision-making situation, implementation of an inter-organizational decision-making model is already known. Moreover, also the open-book conditions, including the firms' past experiences and mutual trust between them are both entirely out of the researcher's hands.

The direction of information exchange can be either unilateral or bilateral in a dyadic, inter-organizational relationship. Unilateral, also known as one-way disclosure means that only one of the two collaborating companies "opens its books" to the other one in the relationship. Extremely often, the more powerful customer is tempted to demand one-way disclosure from its suppliers, which may ultimately lead to opportunistic behavior. In bilateral, a.k.a. two-way disclosure, both parties are willing to share information with joint goals and mutual benefits in mind. Occasionally, a third direction of information exchange, multilateral disclosure is also identified. Information is disclosed multilaterally when it is transparent to a third party outside a dyad as well. However, it is arguable whether such alternative even exists, according to this threedimensional view at least, because the boundaries to information openness conceptually encompass also multilateral disclosure.

The degree and the quality of disclosure comprises the type of transparent information and its level of detail. The type of information can be generally divided to actual cost data and other supporting information. Although the discussion in this context is naturally biased towards cost management, openbooks can also be seen as a method for disclosing cost-relevant information, such as budgets and forecasts. For example in the case "Leantech" of Mouritsen et al. [11] the focal company's sales forecasts were disclosed to its suppliers in exchange to actual cost accounting data. Furthermore, the level of detail can significantly differ case by case, ranging from inaccurate information to highly detailed and accurate internal cost accounting data. The boundaries to information openness can be drawn between dyadic and network-wide disclosure. When certain restrictions in transparency, whether natural or agreement-based, exist in a relationship between two companies, the disclosed data is never given to third parties. In proportion, information flow can be nothing short of unlimited in the network-wide disclosure, which of course is a situation in an ideal world. Therefore, the conditions to network-wide disclosure are realized always when the setting at hand is more extensive than dyadic.

Further, there are particular factors that have an effect on the implementation of open-book accounting in interorganizational settings, as Kajüter and Kulmala [15] have presented based on multiple case studies. Their framework consists of three factor categories, which are exogenous environmental factors, endogenous firm-specific factors and network-specific factors. According to Kajüter and Kulmala [15], the degree of competition and current economic trend are included in the exogenous environmental factors. Naturally, intense competition in any given industry puts pressure towards cost reductions, and thus more extensive transparency is expected from suppliers across the value chain. Moreover, the economic trend can also be seen as an important factor. In times of recession, suppliers are probably reluctant to "open their books". Customers may also be inclined to benchmark suppliers against each other and perform supplier selection while recession takes its toll on the focal firm.

The endogenous firm-specific factors comprise firm size, the state of cost accounting systems, and long-term interorganizational commitment. Kajüter and Kulmala [15] also list a firm's competitive policy, but depending on the perspective, it could also be seen as a part of the above-mentioned commitment. Angdal and Nilsson [32] refer to the same phenomenon as a company's purchasing strategy, which can be either transactional or relational by nature. If the volume of mutual business between organizations is high, a company probably wants to practice relational purchasing and is, for that reason, fully collaborating and perfectly committed to the network in a long term. Further, firm size influences openbooks implementation a lot, as the resources to adopt new accounting methods, models and tools is superior in bigger companies. The state of cost accounting systems is related to the firm size as well. In large companies, cost accounting systems are typically more advanced, and highly accurate accounting data is generally available. For instance Suomala et al. [17] have done an interventionist research in two Finnish manufacturing networks where the development of the supplier's cost management practices and cost accounting systems, i.e. achieving an IOCM structure, were an initial step before implementing open-book accounting.

Last, according to Kajüter and Kulmala [15], the networkspecific factors feature the network type, the selection of products and/or services produced, the supporting network infrastructure and inter-firm relations, which is basically a synonym for adequate mutual trust. Usually collaboration has a better opportunity for success if inter-organizational relationships are already well established, i.e. the network maturity is high. For example in the paper of Romano and Formentini [22], a case company called "A" had had an over 20 -year-long fruitful relationship with one of its customers. Thus the disclosure of information in joint product development was seen positively, and the gained benefits were also shared between the two organizations. In addition, openbooks are more advantageous in hierarchical networks than in short-term project-based cooperation. Further, products and services affect open-books practice, as possibilities for cost savings are easier to identify for functional products than for innovative service offerings. The OBA literature clearly supports this point of view, as case studies have been carried out mainly in manufacturing networks. Furthermore, the network infrastructure, composed of inter-organizational methods, models and tools, has a key role in supporting OBA implementation. However, the network infrastructure does not necessarily have to be extremely complex and sophisticated. Straightforward hand-on assistance offered by the customer in developing its suppliers' cost accounting systems that are often a major obstacle for open-books implementation belong to the infrastructure as well. Social relationships are the last but not 
least factor in this category, as they are very important for inter-organizational activities. Mutual trust cannot be highlighted enough. Also the balance of power in the network, whether symmetrical or asymmetrical, has a considerable effect on the open-books practice as well.

\section{EMPIRICAL FINDINGS OF PREREQUISITES FOR AND POTENTIAL PITFALLS IN INCREASING TRANSPARENCY}

In order to understand how companies perceive interorganizational openness and information disclosure in practice, collaborating companies acting in the field of industrial maintenance were asked ten questions related to open-book accounting. These questions are presented in table I below. As can be perceived, the questions cover the presented OBA dimensions as well as the enabling factors of open-books implementation. In addition, the companies were asked about the present state of inter-organizational openness and the premises for increasing openness in the future.

TABLE I. COMPANIES'REPLIES TO QUESTIONS ABOUT OPEN-BOOKS.

\begin{tabular}{|c|c|c|c|c|c|}
\hline $\boldsymbol{N}$ & Question & 1 & 2 & 3 & $\boldsymbol{R}$ \\
\hline 1 & $\begin{array}{l}\text { How ideal is the present state of } \\
\text { inter-organizational information } \\
\text { openness in the network? }\end{array}$ & 3 & 4 & 2 & 9 \\
\hline 2 & $\begin{array}{l}\text { How good are the premises for } \\
\text { increasing information openness } \\
\text { in the network? }\end{array}$ & 1 & 6 & 4 & 11 \\
\hline 3 & $\begin{array}{l}\text { Could the potential information } \\
\text { disclosure be network-wide in } \\
\text { the maintenance context? }\end{array}$ & 7 & $X$ & 4 & 11 \\
\hline 4 & $\begin{array}{l}\text { Should information disclosure be } \\
\text { bilateral so that both parties } \\
\text { "open their books" to each other? }\end{array}$ & 0 & $X$ & 11 & 11 \\
\hline 5 & $\begin{array}{l}\text { How extensively should actual } \\
\text { cost data be shared for the sake } \\
\text { of inter-firm openness? }\end{array}$ & 1 & 10 & 0 & 11 \\
\hline 6 & $\begin{array}{l}\text { How extensively should } \\
\text { supporting data be shared for the } \\
\text { sake of inter-firm openness? }\end{array}$ & 0 & 10 & 1 & 11 \\
\hline 7 & $\begin{array}{l}\text { How easily is sufficiently } \\
\text { detailed maintenance data } \\
\text { available in your cost accounting } \\
\text { systems? }\end{array}$ & 9 & $X$ & 3 & 12 \\
\hline 8 & $\begin{array}{l}\text { How strategically important do } \\
\text { you find your relationships to the } \\
\text { other players in the network? }\end{array}$ & 3 & 5 & 1 & 9 \\
\hline 9 & $\begin{array}{l}\text { Do you have any inter-firm } \\
\text { methods, models or tools in use } \\
\text { in maintenance? }\end{array}$ & 6 & $X$ & 2 & 8 \\
\hline 10 & $\begin{array}{l}\text { How significant is mutual trust } \\
\text { for inter-organizational openness } \\
\text { in the maintenance context? }\end{array}$ & 0 & 3 & 8 & 11 \\
\hline
\end{tabular}

Legend: $\mathrm{N}=$ question number, 1 = Negative or No (in X-questions), $2=$ Neutral, $3=$ Positive or Yes (in X-questions), $\mathrm{R}=$ the number of respondents for each question.

Questions 1 and 2 in the table are, in a sense, preliminary questions, the purpose of which was to map the present state of inter-organizational information openness and to reveal whether there was room for improvement. As can be seen, only two out of nine individuals were entirely satisfied with the way information currently flowed from one organization to another. Even though the responses were scattered, it seems obvious that the level of communication was far from ideal. As an interesting fact, two respondents from an equipment provider chose a bit astonishingly the two opposite extremes in the question. This only shows how differently inter-organizational matters can be experienced even inside the same company. Promisingly, the underlying potential was clearly seen more positively amongst the respondents than the present state of inter-organizational openness. As many as four individuals saw the potential as very good and six as fairly good. These results are altogether encouraging from the researcher's perspective, as there seems to be both a need as well as some potential for improving. Therefore, the replies to these questions really encourage developing tangible solutions to unleash the information openness potential in networked environments.

\section{A. How is the relational side of inter-organizational information disclosure experienced?}

The questions from 3 to 6 are connected to the open-book accounting dimensions. Basically the respondents were requested in question 3 to set a boundary to interorganizational information openness. As can be noticed, the majority of the respondents were of the opinion that information should not be disclosed network-wide, which indicates that they preferred dyadic transparency. However, it was slightly surprising that these replies did not have clear and unambiguous correspondence with the companies' predominant network roles. Based on this rather sparse empirical evidence, equipment providers seem to be the most skeptical ones towards network-wide disclosure. In addition, the OBA boundaries came up in the workshop discussions. The companies' outlook seemed to be that if collaboration were ever deepened, the focal company of the network, i.e. the maintenance customer should control the practice. Effectively, the two providers, the service provider and the equipment provider, would disclose information in a dyadic fashion to the maintenance customer, who would communicate with them separately. However, this kind of an arrangement could lead to opportunistic behavior from the customer side. Instead of pursuing mutual benefits and in-depth collaboration, the customer could make the providers compete with each other price-wise, especially if they had similar service offerings.

The respondents were asked about their opinions of the direction of information exchange in question 4. As can be seen, they were remarkably unanimous, as all of them thought that information should always be disclosed bilaterally in a relationship. As the literature-based preconception was that customers often demand unilateral disclosure from their smaller suppliers with a weaker negotiation status, this finding is extremely promising OBA-wise. However, it has to be acknowledged that there were no significant size differences between the organizations in question. Nevertheless, bilateral disclosure is certainly "fair play" for all the parties involved in information sharing processes, and thus the current attitudes are very adequate in this respect.

Last, questions 5 and 6 cover the third open-book accounting dimension, which is the degree and the quality of disclosure. However, it should be understood that the degree 
side, in other words the type of disclosed information, is mostly considered in this context. Since quality is an abstract concept that substantially depends on the situation at hand, it would require some kind of a reference point. Hence, the purpose of these questions was to find out whether there are mindsetrelated differences about information transparency. Rather expectedly, the respondents were of the opinion that the degree of disclosure should always be determined case-specifically. However, the consensus amongst the respondents is interesting, as the type of information, whether disclosed data is actual cost data or other supporting information, did not have an effect on the responses. All things considered, the companies are evidently open-minded about inter-firm transparency as they did not automatically turn down disclosure of a specific type of information beforehand. In practice, information transparency is not only case-specific but also heavily dependent on the made agreements as well.

\section{$B$. What is the current state of the networks in relation to the factors of open-book accounting implementation?}

The remaining four questions in the table are related to the factors of open-books implementation. It should be noted, however, that exogenous factors are not included, as they are unforeseen and uncontrollable from the model implementation perspective. In addition, the firm size of the endogenous firmspecific factors, and the type of network of the networkspecific factors, have been intentionally left out of the questions. The endogenous firm-specific factors are concerned in questions 7 and 8. The present state of companies' cost accounting systems is asked about in question 7, where the vast majority of the respondents reckoned that accurate and sufficiently detailed maintenance data was not readily available. Only three individuals were confident that their systems were elaborate enough to provide such data. As the accessibility of information and its details are altogether very important, the respondents were also given a chance to specify their replies. One of them mentioned that their factory-level maintenance data was currently quite accurate but on the other hand, item-level information did not even exist. Another respondent revealed that the level of detail might vary between specific and non-specific, depending on organizational unit. These findings are not surprising, because the state of cost accounting systems and the accuracy of data in particular have been many times recognized in cost management literature as one of the most troublesome factors in inter-organizational collaboration. It should also be highlighted that before a collaborative model can be implemented in a network, this factor should be considered.

In question 8 the respondents were inquired in maintenance-wise about the predominant purchasing strategy of their organization. As can be seen, only one respondent thought that a relational approach was distinctively favored. On the contrary and somewhat unexpectedly, as many as three individuals stated freely that their company operated from a purely transactional basis. As the ultimate goal is achieving an OBA practice in maintenance networks, these findings are more or less worrying because of the risk for opportunistic behavior. Therefore, the companies' mindsets should be directed towards the relational approach in order to ever promote implementation of network models. Nevertheless, this is mainly a question about choosing the right partners and agreeing on the conditions of cooperation, at least from the customer's viewpoint. It may sometimes be entirely impossible to have any influence on the deeply rooted organizational culture and thus selecting the partners can be far easier.

Last, the effect of the firm size factor should be considered briefly, although it was not directly inquired from the respondents. As the companies in question, apart from one firm that provides maintenance services to a specific customer, are equally sized, this factor has very little weight in this context. Hence, size-related matters, such as the state of cost accounting systems should largely be on a par with each other. However, if collaborative models are implemented, the smaller service provider should be given extra attention, assuming that its customer would wish to acquire the relevant data. The respondent representing the above-mentioned service provider revealed that the planning and follow-up of maintenance operations was currently based purely on accumulated experimental knowledge.

The network-specific factors are covered in questions 9 and 10. The existence of network infrastructure was asked about in question 9, as the respondents were inquired whether their companies had inter-organizational methods, models or tools in use or not. Not very astonishingly, the majority of the respondents admitted that no explicit network infrastructure existed currently. Even though two individuals claimed that their organizations had such practices, these infrastructures were not very elaborate. While the first respondent said that they had cooperative planning meetings for annual stoppages, the other one stated that they had certain key performance indicators (KPIs) for the follow-up of maintenance operations together with their customers. It is easy to comprehend that the role of network infrastructure is very important in interorganizational collaboration, as it supports information disclosure by creating a common ground that everybody is able to agree on. Thus infrastructure does not always have to be immensely complex but suitable for the case. The cooperative meeting above is an example of an inter-organizational method, and the KPIs an illustration of an actual tool. The significance of building a fully functioning network infrastructure should be emphasized more and more when collaboration is deepened.

Mutual trust, the importance of which for inter-firm openness was asked about in question 10, is a very significant factor in network environments. As can be perceived, a clear majority of the respondents found trust very important, and none of them saw mutual trust as totally meaningless. Disclosure-wise, these replies, and especially the attitudes they reflect, are naturally encouraging. On the other hand, some of the replies to the previous questions, such as the reluctance in network-wide disclosure, may indicate that there are trust issues among these organizations, even though they see the prerequisites for increasing openness rather positively. However, trust is a very hard factor to measure. 
Finally, the type of network is the last network-specific factor to be discussed. It was not inquired directly of the participating organizations, but it can be stated that their cooperation had not yet been long-term. Moreover, one indicator of low maturity is the lack of network infrastructure, which is the case here as well. However, this can also be seen positively. When there is not established infrastructure, neither functional nor a bit flimsy, the companies have a great chance to build inter-organizational factors, e.g. infrastructure and trust, from scratch. Altogether, high maturity undeniably helps in the implementation process, but even more important is the fact that the organizations work together for a common goal.

\section{THE INTER-ORGANIZATIONAL IMPLEMENTATION} FRAMEWORK SUPPORTED BY OPEN-BOOK ACCOUTING

The created model implementation framework is comprised of two separate parts. The first part is a relational illustration of inter-organizational relationships completed with the three open-book accounting dimensions of Windolph and Möller [18]. Therefore, it presents all the different possibilities to arrange inter-organizational information disclosure in a maintenance network, and the general interplay taking place in the context. The second part of the framework is a chronological illustration of a generalized model implementation process, added with the enabling factors of open-books implementation recognized by Kajüter and Kulmala [15]. Furthermore, the open-books factors have been connected to the different phases of a generalized model implementation process. This process view is based on a framework called enterprise system experience cycle originally presented by Markus and Tanis [33] and slightly modified later by Nah et al. [34]. It consists of four cognate process stages; the chartering phase, the project phase, the shakedown phase, and the onward and upward phase. All things considered, it has to be noted that the following bipartite model implementation framework is presented in a universal form. Therefore, the empirical findings that have been made earlier based on the workshops are discussed in relation to both parts of the framework but not illustrated separately in the figures. In addition, the open-book accounting -supported implementation framework is referred to as the OBAIF from now on.

\section{A. First part of the framework: the relational triangle}

The first part of the OBAIF, the so-called relational triangle is illustrated in figure 1. As can be seen, the maintenance network triad formed by a maintenance customer, a maintenance service provider and an equipment provider forms the body of the figure. Moreover, the open-book accounting dimensions are seamlessly integrated to the abovementioned setting. Firstly, the three arrow-headed lines, separating always two network actors from each other, picture the potential directions of information exchange. It can also be noticed that there are two dashed lines with an arrow head only at one end, and one continuous line with arrow heads at both ends. As the direction of information exchange in open-book accounting can be either unilateral or bilateral within a single dyadic relationship, there are the above-mentioned three possibilities. Unilateral, one-way disclosure is marked with the dashed lines in the figure, whereas the continuous line symbolizes bilateral, two-way disclosure, which should be seen as "the target state" in sound inter-organizational collaboration. This is also the reason why a continuous, solid line represents the bilateral alternative rather than a dashed, fragile line in this context.

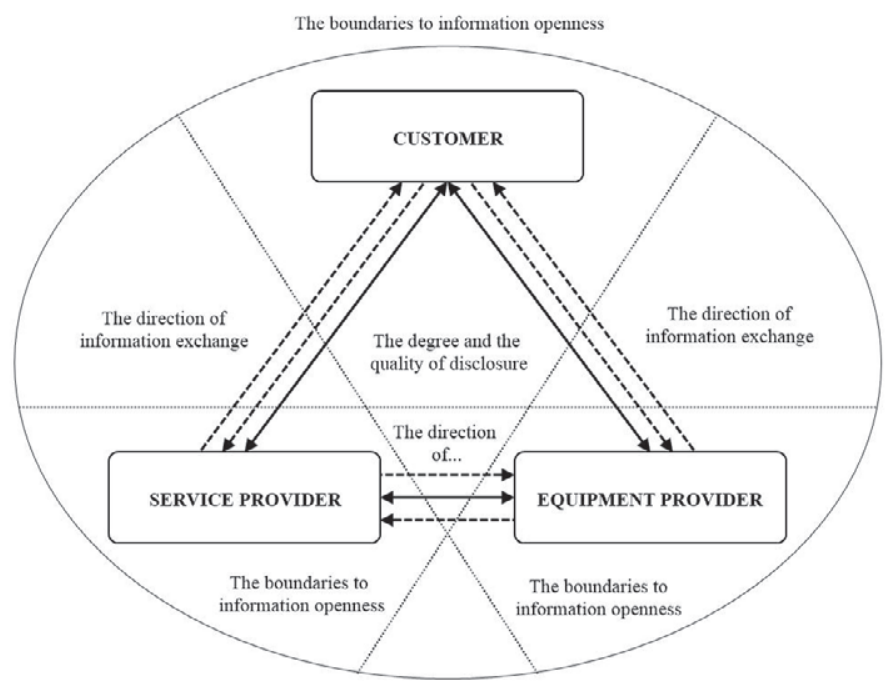

Fig. 1. Relational triangle: part $1 / 2$ of the OBAIF.

The degree and the quality of disclosure are positioned in the middle of the OBAIF by design. Placement like this highlights the importance of this specific open-books dimension. If the disclosed information is either flawed in general or unsuitable for the situation at hand, it might obliterate inter-organizational transparency once and for all. Therefore, it is a very important dimension, as it can make the other dimensions more or less insignificant. Additionally, both degree and quality are extremely case-specific concepts and thus simply impossible to present visually in a framework, such as the OBAIF.

The third open-books dimension is the boundaries to information openness, which four potential boundaries are underlined with the four limiting lines in the figure. The first boundary is the round-shaped exterior border that separates the maintenance network from "the outside world". Naturally, this boundary to openness, especially if confidential intraorganizational information is disclosed, exists basically in every network. Moreover, there are three thin dotted lines breaking the figure up to three recognizable segments in such a way that each segment is comprised of two network actors. These boundaries limit disclosure inside the network. For instance, both diagonal dotted lines separate a dyadic relationship, formed between a maintenance customer and one of the two providers, from the third player in the network. Hence, open-books are practiced only within this specific relationship. In proportion, the straight dotted line disassociates the relationship between the providers from the customer. As can be seen, the open-books dimensions create a noteworthy amount of options for collaboration. The first part of the OBAIF can, and should, be case-specifically adapted by removing the overlapping alternatives.

The "theoretical consequences" of the empirical findings should also be addressed briefly at this point. According to the 
workshop participants, the boundaries to information openness should be withdrawn as follows. Because there would not be a dialogical connection or direct transparency between the service provider and the equipment provider, all three arrowheaded dashed lines between the two should be completely removed from the figure. Consequently, the horizontally placed thin dotted line, otherwise a boundary to openness would also disappear, as there is full transparency towards the customer. Naturally, the exterior border would still exist. Despite of setting the above-mentioned boundaries, the respondents were unanimously of the opinion that bilateral disclosure should be favored. This would mean that the dashed lines with a single arrow head would be useless. This would not affect the situation between the two providers, however, as the customer would control the OBA in a concentrated fashion.

\section{B. Second part of the framework: the process timeline}

The second part of the OBAIF, also known as the process timeline is illustrated in figure 2. As mentioned above, the foundation of the figure is the enterprise system experience cycle. The enabling factors of open-books implementation, including the endogenous firm-specific factors, and the network-specific factors in particular, complete the OBAIF. The exogenous factors are also recognized in the OBAIF, but a real stand cannot be taken on how much and in which ways they might actually influence the implementation process for the reasons mentioned above. Therefore, they are separated from the other factors with the exterior border. In addition, it should be noted that the dashed lines in the figure, representing the duration of each factor in an implementation process, are highly preliminary as they are not based on actual empirical findings at this stage.

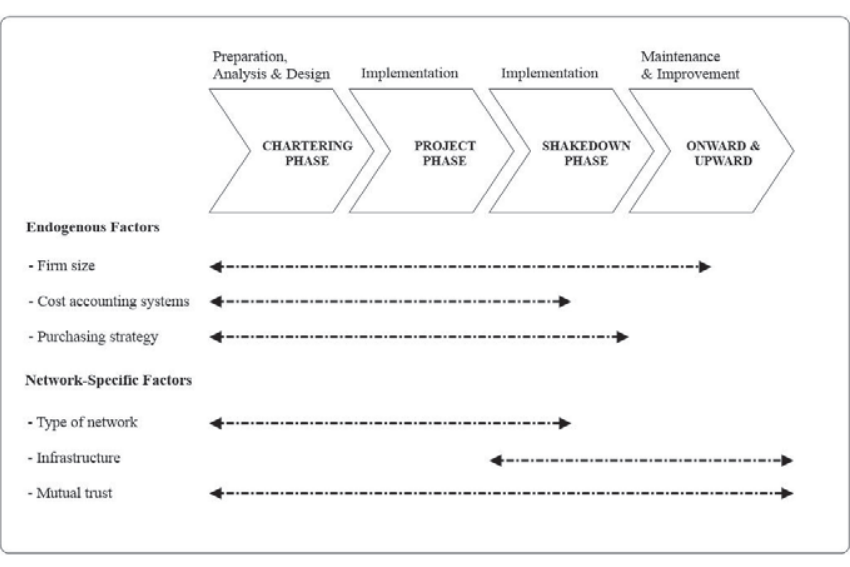

Exogenous Factors ( $=$ Degree of competition, Economic trend etc.)

Fig. 2. Process timeline: part $2 / 2$ of the OBAIF.

Before analyzing the figure more profoundly, the phases of the enterprise system experience cycle and their content should be addressed. Firstly, the chartering phase features initial and necessary actions, such as preparation, analysis and design, prior to actual model implementation. Therefore, general project planning, budgeting and scheduling take place in this phase, and the outcome can either be a decision to proceed with or alternatively abort the project for good. Moreover, "handson" implementation starts in the project phase, where the key activities are software configuration, system integration testing, data conversion, rollout, and training. In the project phase, it is crucial that everybody works closely and well together with others. The implemented model will be utilized for a first time in the shakedown phase, but routine use is not yet achieved. For example, bug fixing and system performance tuning are important tasks in this phase. Additionally, all accumulated system knowledge should be passed on from the project team to operational personnel at this point. Finally, the model has been successfully implemented and normal operation achieved in the onward and upward. This phase extends from the start of routine use all the way to eventual replacement in the future. Thus, it is characterized by on-going maintenance and system enhancement. Personnel skill building takes also place.

First, the endogenous firm-specific factors are discussed. As can be perceived, firm size is marked to have an impact on the implementation process of a model from the beginning of the chartering phase to the middle of the onward and upward phase. When an inter-organizational model is implemented in practice, there are usually a lot of very differently sized companies involved in the process. In the beginning of the process, notable size differences will most likely affect especially inter-organizational collaboration. There can be significant amounts of unwanted bureaucracy, general uncertainty about respective responsibilities, day-to-day breaks in communication, and so forth. Even though a huge size difference does not automatically create problems, the odds are higher because of the rather dissimilar organizational structure and policies. Nevertheless, all size-related challenges should be overcome in the onward and upward stage at the latest, where implemented model is utilized on a daily basis. Networks cannot bear these difficulties for long, as there will be far more important issues to tackle in the onward and upward phase.

Cost accounting systems is the second endogenous factor influencing OBA implementation, and an important one, as these systems are in charge of registering, storing and transferring cost accounting data, as well as creating divergent management reports. From the information disclosure perspective, the problem is often that the requisite data in companies' present systems is inaccurate and unavailable, as it can be scattered in parallel systems and storages. This issue was also seen in the companies' replies, as the majority of the respondents stated that sufficiently accurate maintenance data was not available. Therefore, improving the state of these systems is of high importance in the beginning of a model implementation process. In the OBAIF, the system upgrade stage has been marked to end in the middle of the shakedown phase, where the implemented model will be run at full scale for the first time. All in all, the focal company of the network, i.e. the customer, should assist the smaller companies, i.e. its suppliers, in improving their cost accounting systems when necessary in order to receive suitable information for interorganizational decision-making in years to come.

The remaining endogenous firm-specific factor is the company's purchasing strategy, as the purchasing strategy basically stands for the intra-organizational strategies and perceptions about inter-organizational relationships, e.g. how a firm deals with its relations and responds to them case by case. When the company's purchasing strategy is strongly based on the transactional alternative, they do not see extra benefits or 
additional value in investing in network relations. This kind of an attitude or intentionally chosen strategy is extremely difficult collaboration-wise. For a model implementation process to be successful, the transactional approach should definitely be backtracked more and more towards relational purchasing. Moreover, companies' purchasing strategies will have an effect on the process from the beginning to the end of the shakedown phase. The idea is that purely transactional views should be overcome before the implemented model is operated normally and inter-organizationally. However, there should not be any problems in this regard if each participant cooperates from a relational basis, as that approach already promotes potential success. Hands-on experience that accumulates throughout the implementation process should be an eye-opener for remaining critics about the mutual benefits. According to the empirical findings, the companies in question are currently not yet really poised to implement an interorganizational model.

Before discussing the network-specific factors in detail, it should be noted that one of the factors, the selection of products and services is not included in the framework. Even though this factor is undoubtedly an essential one from the perspective of open-book accounting, it really does not play any role in a model implementation process. However, the type of network, its maturity in particular, has a great influence on the process as well-established networks usually function better than new-found ones. Thus in the OBAIF, the type of network has an influence especially in the beginning of the process, where initially higher network maturity certainly helps. Once organizational learning takes place along the process in lower maturity networks, the difference tapers significantly, granted that maturity does not have boundaries in practice. In other words, the steepness of "the learning curve" is higher in the beginning, where the most sensitive steps, such as preparative measures and system design, are located.

The need for network infrastructure that is comprised of inter-organizational methods, models and tools does not become concrete until the shakedown phase. As the day-to-day operating of the implemented model starts at this point, mutually agreed network practices and other common protocols are certainly required. In addition, it has to be mentioned that the network infrastructure can, and should, be seen very broadly. The model in question is also in a way part of the infrastructure as it systematizes inter-organizational interactions. To consider the empirical findings briefly once more, it seems that networks today have clearly not properly invested in the network infrastructure. The importance of this factor should not be overlooked. Together with the state of companies' cost accounting systems, the network infrastructure is something tangible and thus easier to develop intentionally.

Finally, mutual trust has been perceived in OBAIF to have an influence on model implementation throughout the process. On one hand, there has to be a certain amount of prerequisite trust in the beginning, and on the other hand, the implementation process itself is an excellent trust-builder. Therefore, trust is always there but its nature will change from the prerequisite one in the chartering and the project phases to relationship-reinforcing trust in the shakedown phase, and especially in the onward and upward phase. Mutual trust was also seen important by the companies participating to the workshop events, although it should be improved in order to deepen inter-organizational collaboration in the future.

\section{CONCLUSIONS}

Despite of the recent proliferation of organizational interdependencies, i.e. networking, companies are struggling to capitalize on, or sometimes even understand, the opportunities that collaboration with other organizations can offer. The implementation of inter-organizational models, and in order to employ them, the disclosure of information are potential instruments that promote such cooperation. Even though companies are often reluctant to disclose sensitive information outside, lots of positive signals were received in this study from the participating companies acting in the field of industrial maintenance. It was revealed that extensive networkwide disclosure seemed to be a distant dream, but a customerled and dyadic transparency would still be an excellent initial step towards more complex arrangements in the future. At least, the companies, or their representatives to be exact, were able to agree that the exchange process should be bilateral.

The present state of firms' cost accounting systems was found relatively poor, and thus certain coordinated actions should be taken in order to generate accurate and adequately detailed maintenance data for an inter-organizational model. As the state of cost accounting systems is very essential from the perspective of successful model implementation, the data requirements and common standards should be mutually agreed on early in the process. Moreover, the establishment of a sound network infrastructure, e.g. collaborative methods, models and tools, is highly important for managing and controlling inter-organizational content. As was noted above, companies are lacking in this respect as well. To begin with, the implemented model can be sufficient, but supporting methods, such as network meetings or joint budgeting may become relevant in the long term, along with increasing network maturity.

Of course, even the most exclusive and comprehensive network infrastructure combined with state-of-the-art cost accounting systems is worthless if willingness to cooperate is missing. Any given organization that is still internally entangled to transactional purchasing strategy endangers the collaboration from the start. Based on the findings, the current way of thinking among these organizations evidently induces a serious risk for collaboration. However, pursuing relational purchasing is not by any means all about disclosing information companies are uncomfortable with. It is only important to work together for a common goal and keep the promises made. All things considered, mutual trust is the deciding factor in the end, which means that all existing trust issues should really be solved before commencing deeper relationships and agreements with other companies. As hard as relational matters, e.g. mutual trust, are to measure, they actually pose the biggest imaginable threat for a successful open-book accounting set-up in practice.

Finally, and regarding the bipartite framework OBAIF, especially the latter part of it, i.e. the process timeline, needs empirical testing in the future. Currently the illustrations of duration and location of each model implementation-affecting open-books factor are only the researcher's own advance 
impressions. However, the responses of the workshop participants left room for further speculation, as a real-life situation might significantly alter the opinions on the direction of information exchange, experienced surprisingly unanimously as bilateral by the organizations, for instance. Therefore, the next logical step would obviously be to conduct an extensive empirical study where an inter-organizational model is actually implemented. In addition, this kind of research setting might very well raise other important perspectives in regard to decision-making model implementation outside the OBA dimensions and factors.

\section{REFERENCES}

[1] J. D. Campbell, "Outsourcing in maintenance management: a valid alternative to self provision," Journal of Quality in Maintenance Engineering, vol. 1, pp. 18-24, iss. 3, 1995.

[2] H. H. Martin, "Contracting out maintenance and a plan for future research," Journal of Quality in Maintenance Engineering, vol. 3, pp. 81-90, iss. 2, 1997.

[3] M. Levery, "Outsourcing maintenance - a question of strategy," Engineering Management Journal, vol. 8, pp. 34-40, iss. 1, 1998.

[4] M. Bertolini, M. Bevilacqua, M. Braglia, and M. Frosolini, "An analytical method for maintenance outsourcing service selection," Journal of Quality \& Reliability Management, vol. 21, pp. 772-788, iss. 7,2004

[5] E. Y. Hui, A. H. Tsang, "The inter-organizational relationship in a multi-contractor business network," Journal of Quality in Maintenance Engineering, vol. 12, pp. 205-238, iss. 3, 2006

[6] A. Garg, and S. G. Deshmukh, "Maintenance management: literature review and directions," Journal of Quality in Maintenance Engineering, vol. 12, pp. 205-238, iss. 3, 2006.

[7] H. Al-kaabi, A. Potter, and M. Naim, "An outsourcing decision model for airlines' MRO activities," Journal of Quality in Maintenance Engineering, vol. 13, pp. 217-227, iss. 3, 2007.

[8] U. Al-Turki, "A framework for strategic planning in maintenance," Journal of Quality in Maintenance Engineering, vol. 17, pp. 150-162, iss. 2, 2011 .

[9] T. Sinkkonen, S. Marttonen, L. Tynninen, and T. Kärri, "Modelling costs in maintenance networks," Journal of Quality in Maintenance Engineering, vol. 19, pp. 330-344, iss. 3, 2013.

[10] J. Cullen, and J. Meira, "Inter-Organisational Accounting in Dyadic Settings," in H. Håkansson, K. Kraus, and J. Lind (ed.), Accounting in Networks. Madison Avenue, NY: Routledge, 2010.

[11] J. Mouritsen, A. Hansen, and C. Ø. Hansen, "Inter-organizational controls and organizational competencies: episodes around target cost management/functional analysis and open book accounting," Management Accounting Research: 12, pp. 221-244, 2001.

[12] H. I. Kulmala, J. Paranko, and E. Uusi-Rauva, " The role of cost management in network relationships," International Journal of Production Economics: 79, pp. 33-43, 2002.

[13] B. Axelsson, J. Laage-Hellman, and U. Nilsson, "Modern management accounting for modern purchasing," European Journal of Purchasing \& Supply Management: 8, pp. 53-62, 2002.

[14] H. I. Kulmala, "Developing cost management in customer-supplier relationships: three case studies," Journal of Purchasing \& Supply Management: 10, pp. 65-77, 2004.

[15] P. Kajüter, and H. I. Kulmala, "Open-book accounting in networks: potential achievements and reasons for failures," Management Accounting Research: 16, pp. 179-204, 2005.
[16] H. Angdal, and U. Nilsson, "Interorganizational cost management in the exchange process," Management Accounting Research: 20, pp. 85-101, 2009.

[17] P. Suomala, T. Lahikainen, J. Lyly-Yrjänäinen, and J. Paranko, "Open book accounting in practice - exploring the faces of openness," Qualitative Research in Accounting \& Management, vol. 7, pp. 71-96, iss. $1,2010$.

[18] M. Windolph, and K. Möller, "Open-book accounting: reason for failure of inter-firm cooperation?," Management Accounting Research: 23, pp. 47-60, 2012 .

[19] H. Angdal, and U. Nilsson, "Supply chain decision-making supported by an open books policy," International Journal of Production Economics: 116, pp. 154-167, 2008.

[20] R. Kumra, H. Angdal, and U. Nilsson, "Open book practices in buyersupplier relationships in India," Journal of Business \& Industrial Marketing, vol. 27, pp. 196-210, iss. 3, 2012.

[21] T. Jarimo, and H. I. Kulmala, "Incentive profit-sharing rules joined with open-book accounting in SME networks," Production Planning \& Control, vol. 19, pp. 508-517, iss. 5, 2008.

[22] P. Romano, and M. Formentini, "Designing and implementing open book accounting in buyer-supplier dyads: a framework for supplier selection and motivation," International Journal of Production Economics: 137, pp. 68-83, 2012.

[23] W. Seal, A. Berry, and J. Cullen, "Disembedding the supply chain: institutionalized reflexivity and inter-firm accounting," Accounting, Organizations and Society: 29, pp. 73-92, 2004.

[24] C. Free, "Walking the talk? Supply chain accounting and trust among UK supermarkets and suppliers," Accounting, Organizations and Society: 33, pp. 629-662, 2008.

[25] K. Möller, M. Windolph, and F. Isbruch, "The effect of relational factors on open-book accounting and inter-organizational cost management in buyer-supplier partnerships," Journal of Purchasing \& Supply Management: 17, pp. 121-131, 2011.

[26] R. McIvor, "Lean supply: the design and cost reduction dimensions," European Journal of Purchasing \& Supply Management: 7, pp. 227-242, 2001.

[27] R. C. Lamming, N. D. Caldwell, D. A. Harrison, and W. Phillips, "Transparency in supply relationships: concept and practice," The Journal of Supply Chain Management: A Global Review of Purchasing and Supply, 2001.

[28] R. C. Lamming, N. D. Caldwell, D. A. Harrison, and W. Phillips, "Sharing sensitive information in supply relationships: the flaws in oneway open-book negotiation and the need for transparency," European Management Journal, vol. 23, pp. 554-563, iss. 5, 2005.

[29] P. Kajüter, and H. I. Kulmala, "Open-book accounting in networks," in H. Håkansson, K. Kraus, and J. Lind (ed.), Accounting in Networks. Madison Avenue, NY: Routledge, 2010.

[30] R. Cooper, and R. Slagmulder, "Interorganizational cost management and relational context," Accounting, Organizations and Society: 29, pp. 1-26, 2004.

[31] A. F. Coad, and J. Cullen, "Inter-organisational cost management towards an evolutionary perspective," Management Accounting Research: 17, pp. 342-369, 2006

[32] H. Angdal, and U. Nilsson, "Different open book accounting practices for different purchasing strategies," Management Accounting Research: 21, pp. 147-166, 2010.

[33] M. L. Markus, and C. Tanis, "The enterprise system experience - from adoption to success," in R. W. Zmud (ed.), Framing the Domains of IT Management: Projecting the Future Through the Past. Cincinnati, OH: Pinnaflex Educational Resources, 2000.

[34] F. Nah, J. Lau, and J. Kuang, "Critical factors for successful implementation of enterprise systems," Business Process Management Journal, vol. 7, pp. 285-296, iss. 3, 2001. 
(Página deixada propositadamente em branco) 


\title{
Improving risk matrices using the MACBETH approach for multicriteria value measurement
}

\author{
Carlos A. Bana e Costa ${ }^{1}$; Diana F. Lopes ${ }^{2}$; Mónica D. Oliveira ${ }^{3}$ \\ 1'carlosbana@tecnico.ulisboa.pt; ${ }^{2}$ diana.lopes@tecnico.ulisboa.pt; ${ }^{3}$ monica.oliveira@tecnico.ulisboa.pt \\ CEG-IST, Centre for Management Studies of Instituto Superior Técnico, Universidade de Lisboa, \\ Avenida Rovisco Pais, 1049-001 Lisbon, Portugal
}

\begin{abstract}
Risk matrices (RMs) have been recommended by many organizations to evaluate and mitigate risks. This study aims at improving the design and the deployment of RMs, avoiding theoretical problems of traditional RMs and inconsistent risk ratings, following Multicriteria and Portfolio Decision Analysis. In particular, the MACBETH approach is used to build quantitative evaluation models from qualitative value judgments. A new RMs' modeling framework is proposed, which includes: (1) the construction of a multicriteria additive value model applying MACBETH to assess risk impacts; (2) the innovative use of MACBETH to derive subjective probabilities; (3) the transformation of a RM into a Value Risk Matrix (VRM); (4) the definition of multicriteria assignment procedures, applied to classify risks from the VRM by severity; (5) and the use of MACBETH's resource allocation to prioritize risk mitigation actions and analyze portfolios that offer the best value for money for different budgeting and contextual constraints.
\end{abstract}

Keywords- Risk evaluation, Multiple Criteria and Portfolio Decision Analysis, MACBETH.

\section{INTRODUCTION}

Organizations have been looking for processes to prevent risks that threaten the goals of their projects. In particular, risk managers are increasingly recognizing the need to determine the relative significance of different sources of risk, being this required to guide a cost effective management of risks (Chapman et al., 2007; Bertsch, 2008). This topic is even more critical in the context of tighter resource constraints (Dillon et al., 2003).

Risk matrices (i.e. tables mapping 'frequency' and 'severity' ratings to corresponding risk priority levels) have been recommended by international organizations - such as by the Project Management Institute (Project Management Institute, 2004) - to assess risk. Their use is rather appealing because they are easy to handle, demand for limited expertise, have a straightforward interpretation and allow for performing a quick analysis. Their incorporation in software packages has spread its use. Nevertheless, available studies indicate that the use of risk matrices (RMs) might generate inconsistencies in risk management and RMs do not respect important theoretical properties (Cox Jr., 2008). For example, RMs replicate non-compensatory decision rules that may not reflect the risk preferences of decision-makers (DM) across risk impacts in different criteria nor the multidimensional and compensatory nature of risk impacts. They do not respect the principle of translation invariance and, above all, RMs can lead to a suboptimal allocation of resources. Despite these problems, few studies have researched improvements to RMs.

This study proposes multiple criteria decision analysis (MCDA) methods, based on the Measuring Attractiveness by a Categorical Based Evaluation Technique (MACBETH) approach, to improve the design and the deployment of RMs to prioritize risks and interventions to reduce risk in the context of scarce resources. MCDA provides a set of methods with theoretical foundations and that can be used to overcome key weaknesses of RMs. In particular, MCDA methods and the MACBETH approach allow for accounting for the multiple dimensions of risk impacts (e.g. on budget, quality, delivery time, etc). Also they allow for accounting for quantitative and qualitative (objective) information of risks and for the subjective preferences of DMs while respecting the principle of translation invariance and promoting an optimal allocation of scarce resources

In this article we briefly describe how MCDA and MACBETH can improve the design of RMs, by following a modeling approach based on:

(1) a multi-criteria additive value model applying MACBETH to assess risk impacts;

(2) the modeling of probabilities using subjective and qualitative preference information and MACBETH;

(3) the use of multicriteria classification procedures to classify risks by severity;

(4) the transformation of a risk matrix into a Value Risk Matrix (VRM) that uses probabilities, multicriteria value and risk classifications from (1) to (3);

(5) the use of the recent portfolio decision analysis component of the M-MACBETH Decision Support System (DSS) that combined with VRM can derive the most effective set of interventions to reduce risk, while taking into account of costs and other constraints;

(6) modeling uncertainty in (1) to (2) so as to represent uncertainty in (4) and to perform robustness analysis in (5).

We are developing the proposed methods, as well as we are applying them to real case studies in risk management, including to the evaluation of health and safety risks. The proposed methods follow a socio-technical approach, with the technical component above described, and with the social component being defined by the use of participatory methods to build a compromise and confidence between stakeholders 
who participate in risk management. Nevertheless, in this paper we do not cover the social aspects related with the design and use of RMs (Phillips et al., 2007). The application of the proposed methods is supported by decision support systems including several components of the M-MACBETH DSS (Bana Consulting, 2005). We believe that the results of applying the proposed methods to improve RMs will correct existing problems in RMs and thus improve risk management procedures.

\section{LITERATURE REVIEW}

Risk management relates to all sources of risk that can affect an organization in terms of its goals and vision [1]. To compare and assess risks and to define risk management policies, RMs have been recommended by international organizations, such as United States Department of Defense and the National Patient Safety Agency from the United Kingdom, and are widely used as a framework for practical risk analysis. Appearing in literature under different designations - probability impact table [2], probability and impact matrix [3], probability impact diagram [4], probability impact grid [5] and risk maps [6] - risk matrices are tables (or plots) that have categories of 'probability', 'likelihood' or 'frequency' for its rows (or columns) and categories of 'severity', 'impact' or 'consequences' for its columns (or rows, respectively) [7]. Typically, in each RM, a recommended level of risk, urgency, priority or management action is presented in each row-column pair; risks categorized with higher priority are given a higher managerial attention for treatment and mitigation; and each RM can be used to describe the impact of a risk in a single dimension or in multiple dimensions (in this case a measure of global impact is represented in the matrix).

For example, the Health Service Executive of Ireland is using the matrix presented in table I and has defined three risk categories by applying that expected risk measure upon two 5level rating scales, as follows [8]: "The high risks are scored between 15 and 25 and are colored Red"; "Medium risks are scored between 6 and 12 and are colored Amber"; "Low risks are scored between 1 and 5 and are colored Green". In fact, the higher the 'risk rating', the more 'severe' the risk classified, having a higher score; and a type of traffic light system is used to break risks into groups requiring different response strategies. Similar systems have been used by organizations such as the US Department of Defense [9] and the Construction and Commission Department at ALSTOM [4].

TABLE I. EXAMPLE OF A QUANTITATIVE RISK MATRIX (ADAPTED FROM (QUALITY AND PATIENT SAFETY DIRECTORATE, 2011)), WITH THREE RISK CATEGORIES

\begin{tabular}{|c|c|c|c|c|c|}
\cline { 2 - 6 } \multicolumn{1}{c|}{} & Negligible (1) & Minor (2) & Moderate (3) & Major (4) & Dxtreme (5) \\
\hline Almost Certain (5) & $\mathbf{5}$ & $\mathbf{1 0}$ & 15 & 20 & 25 \\
\hline Likely (4) & $\mathbf{4}$ & $\mathbf{8}$ & $\mathbf{1 2}$ & 16 & 20 \\
\hline Possible (3) & $\mathbf{3}$ & $\mathbf{6}$ & $\mathbf{9}$ & $\mathbf{1 2}$ & 15 \\
\hline Unilikely (2) & $\mathbf{2}$ & 4 & 6 & 8 & 10 \\
\hline Rare/Remote (1) & $\mathbf{1}$ & $\mathbf{2}$ & $\mathbf{3}$ & $\mathbf{4}$ & $\mathbf{5}$ \\
\hline
\end{tabular}

The use of RMs is rather appealing because their use is intuitive and demands for limited expertise. RMs have a straightforward interpretation, are perceived as transparent tools and quickly provide a rough discrete (ordered categorical) approximation to a more detailed underlying quantitative relation [7]. Several software packages make use of RMs - for example the Active Risk Manager (ARM) [4], the MITRE's risk matrix tool [10] and the SAP software [11] for program risk management - enabling their use in different risk management contexts. By providing a clear framework for systematic review of risks, the use of RMs enables organizations to prepare convenient documentation for risk management and provides an opportunity for stakeholders participating in the process of building RMs [12].

Nevertheless, RMs should not be seen as a quantitative risk analysis method [2]. Their use should be aware that they do not respect important theoretical properties and their utilization might generate inconsistencies in risk management, namely:

a) RMs replicate non-compensatory decision rules that may not reflect the risk preferences of real DMs across risk impacts in different criteria [12];

b) RMs violate the principle of translation invariance [13];

c) RMs provide an approximation that can only be satisfactory if certain conditions are satisfied (e.g., in terms of preferences). However, as the risk attitudes of the RM builders are seldom documented, it can be impossible to determine how consequence severity classifications should be changed when someone else views or uses the matrix [Co09];

d) RMs use a discrete value function consisting on bands of impact and probability instead of a continuous value function. A discrete value function increases only by jump discontinuities and the border points where jumps occur are not always discussed. Also, RMs have often poor resolution, meaning that they can correctly and unambiguously compare only a small fraction of risks [Co09];

e) And above all, the use of RMs can lead to suboptimal resource allocation (for example, risks with high ratings typically receive higher priority for treatment and mitigation, which might be inadequate [Co08]), and there has been little rigorous empirical or theoretical study on how well RMs succeed in improving risk management decisions [Co09].

Other issues have been pointed out in literature, such as it is hard to dynamically use RMs, and difficult to incorporate and convey uncertainty in RMs.

Despite an increased interest from academia and organizations in risk management in recent years $[14,15]$ and some recent studies attempting to improve RMs, such as developing the fuzzy risk matrix [16], the RM with Borda method [9] and mathematical operations in inputs of RMs [9], major limitations of risks matrices are still unsolved [9] and further theoretical and applied research is needed [7]. 


\section{METHODOLOGICAL FRAMEWORK}

This study discusses how multiple criteria decision analysis (MCDA) methods, based on the MACBETH approach, can be used to improve the design and the deployment of RMs in risk management, and to build VRMs. We name this the IRIS approach. MCDA provides a set of methods with theoretical foundations [17-19] that can be used to evaluate and order risks and help to overcome the weaknesses of RMs identified in the literature. First of all, MCDA methods allow for accounting for the multidimensional impacts (for example, on budget, quality and delivery time - the triple constraint in project management). Secondly, MCDA methods allow for accounting for various levels of quantitative and qualitative information of risks, as well as for subjective preferences of DMs, which are key features in risk evaluation [7]. Thirdly, MCDA methods can be used to change RMs so as to respect the principle of translation invariance by assisting in the quantification of the impact of risks and of probabilities. Last, and above all, MCDA methods - in particular methods from portfolio decision analysis - can help to overcome the problem of suboptimal resource allocation through the use of multicriteria resource allocation models to select risk interventions. As mentioned above, we propose the use of MACBETH, that is an interactive multicriteria decision analysis approach used to build a quantitative (numerical) value model based on nonnumerical (qualitative) pairwise comparison judgments [2023]. MACBETH approach requires qualitative pairwise comparison judgments of difference in attractiveness (value), therefore involving only two elements in each judgment, to help an individual or group of decision makers to score options on each criterion and to weight criteria [24]. Previous studies have shown that MACBETH provides a simple and transparent approach in modelling complex multidimensional problems, and hence its wide applicability in MCDA (see for example $[23,25,26])$

The IRIS approach makes use of MACBETH in several of the activities presented in grey in Fig. 1, which defines our proposed modeling approach:

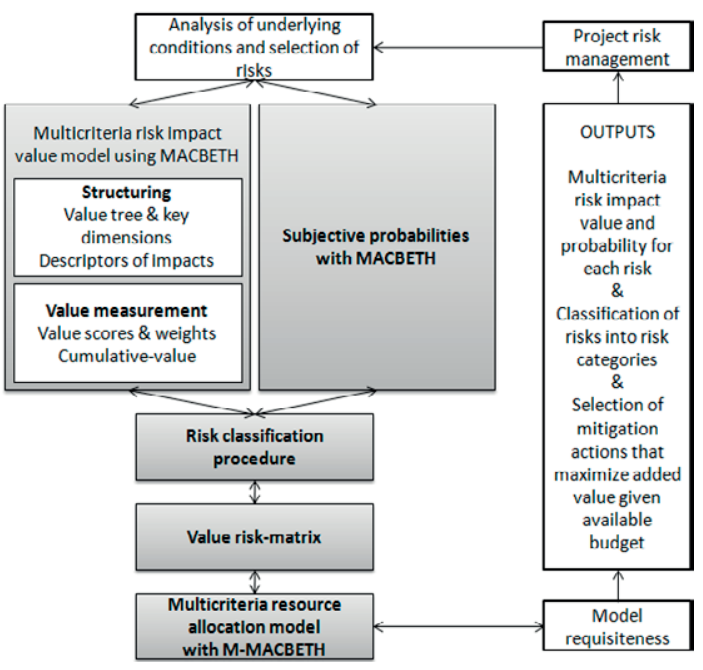

\section{IRIS ACTIVITIES}

\section{A. Multicriteria Risk Impact Value Model}

This section proposes the development of a multi-criteria additive value model applying the MACBETH approach [27] to measure risk impact value. Multicriteria value models allow for understanding how risk impacts are not important by themselves, but by the way they might contribute for creating or destroying value in an organization; and for analyzing impacts (and also probabilities) in a continuous scale (so as to avoid discontinuity problems), even if impacts might be qualitatively measured.

The development of a multi-criteria (hierarchical) additive value model applying MACBETH to measure risk impacts has already been tested in a real case study at ALSTOM Power (Switzerland) in the context of construction-related risks [4]. Results from this application have shown key advantages of using multicriteria value models to evaluate risk impacts in the context of RMs. We illustrate how to apply the proposed methods with application to the ALSTOM case.

Following Fig. 1, the development of multicriteria risk impact models involves structuring and evaluation activities [23]. Fig. 2 shows the value tree built in decision conferences at ALSTOM [4]. There are six evaluation criteria (in italics) considered to be exhaustive, non-redundant and additively independent. To appraise the extent to which different risk events can impact on the six criteria, an attribute or descriptor of impacts was associated to each of them [28] [29]. Table II shows the descriptor of impacts for the Schedule criterion.

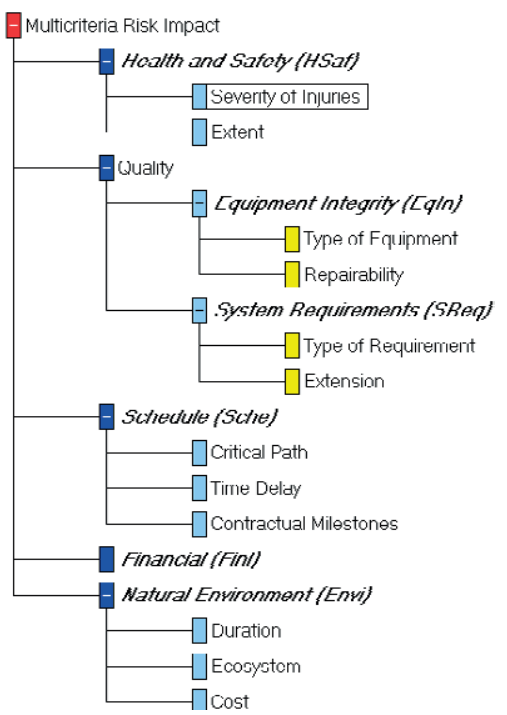

Fig. 2. A Value tree in the M-MACBETH DSS (adapted from (Figueiredo et al., 2009)), being all the criteria (key dimensions) in italics and their abbreviations in brackets.

Fig. 1. Activities and outputs. 
TABLE II. CONSTRUCTED DESCRIPTOR FOR THE SCHEDULE CRITERION (ADAPTED FROM (FIGUEIREDO, 2008))

\begin{tabular}{|c|l|}
\hline Impact levels & \multicolumn{1}{|c|}{ Description } \\
\hline No effect & $\begin{array}{l}\text { No impact on the schedule of the project (depicting no } \\
\text { changes to the Status Quo) }\end{array}$ \\
\hline Effect TD & $\begin{array}{l}\text { Impact on the schedule of the project, but not affecting } \\
\text { the internal critical path }\end{array}$ \\
\hline+ Small CP & $\begin{array}{l}\text { Impact on the internal critical path less than 10 days, } \\
\text { but no impact on contractual milestones }\end{array}$ \\
\hline+ High CP & $\begin{array}{l}\text { Impact on the critical path equal or higher than 10 } \\
\text { days, but no impact on contractual milestones }\end{array}$ \\
\hline+ CM & $\begin{array}{l}\text { Impact on critical path and on contractual milestones } \\
\text { (implying the payment of Late Deliveries) }\end{array}$ \\
\hline
\end{tabular}

Evaluation activities involve creating a model of intracriteria preferences that evaluate the impacts of different risks for each criterion, through the use of value scales or value functions (see Fig. 3), as well as the elicitation of relative weights for the criteria (see Fig. 4). These steps are required for assessing risk impacts on a common value scale. Value functions and weights require DM's judgments, being the subjective component of the multicriteria value model, and with the MACBETH approach assisting in this task. For building value functions, the MACBETH questioning protocol consists in asking the DM to qualitatively judge the difference in attractiveness between impact levels, two at a time, based on seven semantic categories: "is there no difference, or is the difference very weak, weak, moderate, strong, very strong, or extreme?" (Bana e Costa et al., 2012). During this questioning protocol, a matrix with the categorical judgments of the DM is populated (see Fig. 3 (left)). Each time a qualitative judgment is introduced in the matrix, the M-MACBETH DSS verifies its consistency and offers suggestions to solve eventual inconsistencies (Bana e Costa et al., 2008). After the consistency verification, the software derives, by mathematical programming, an interval numerical scale which has to be analyzed and validated by the DM (Bana e Costa et al., 2012) - see Fig. 3 (right). For details on the application of the MACBETH approach to build value functions and weights, consult (Bana e Costa et al., 1999; Carnero, 2006; Bana e Costa et al., 2008; Joerin et al., 2010; Barin et al., 2012).

It is worthwhile to note that the use of the recent version of M-MACBETH DSS makes available a hierarchical version of M-MACBETH, which allows for assigning weights hierarchically, as in Fig. 5. In this case, weighting is not only used to define weights at the criteria level, but also for areas which include criteria by type of concern - following Fig. 5, MACBETH allows (see green circles): (a) to weight all the criteria (similarly to Fig. 4); (b) to weight the children criteria of an area; and to weight criteria and area at same time by using (c) the information of all the criteria including all children criteria of the area or (d) the information of one children criterion of the area and all the remainder criteria.

\begin{tabular}{|c|c|c|c|c|c|c|c|c|}
\hline \multicolumn{6}{|c|}{ Schedule (Sche) } & \multicolumn{2}{|c|}{ W Schedule (Sche) } & \&S \\
\hline 四 & $+C M$ & + High CP & + Small CP & Effect TD & No effect & \multirow{3}{*}{58.99} & \multirow[t]{2}{*}{$+\mathrm{CM}$} & \multirow[t]{2}{*}{100} \\
\hline$+C M$ & no & extreme & extreme & extreme & extreme & & & \\
\hline + High CP & & no & mod-strg & strong & positive & & + High CP & 53 \\
\hline \begin{tabular}{|l|} 
+ Small CP \\
Effect TP
\end{tabular} & & & no & moderate & positive & & -+ Small CP & 35 \\
\hline $\begin{array}{l}\text { Effect ID } \\
\text { No effect }\end{array}$ & & & & no & $\begin{array}{l}\text { weak-extr } \\
\text { no }\end{array}$ & 35.01 & Effect TD & 18 \\
\hline \multicolumn{6}{|c|}{ Consistent judgements } & & No effect & 0 \\
\hline
\end{tabular}

Fig. 3. MACBETH matrix of judgments for the Schedule criterion (left) and the corresponding value scale (right) - adapted from (Figueiredo, 2008). The judgments "weak-ext" and "mod-strg" are abbreviations of "weak or extreme", "moderate or strong", respectively, and depict cases of differences in opinion or hesitation among ALSTOM risk managers (DM).

\begin{tabular}{|c|c|c|c|c|c|c|c|c|c|}
\hline \multicolumn{7}{|c|}{ Weighting (Multicriteria Risk Impact) } & $\mathbb{E}$ & Weighting (Multicri... & 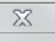 \\
\hline 圆 & [HSaf ] & [Envi] & [ Finl ] & [SReq] & [Sche ] & [Eqln ] & [all SQ] & [HSaf] & 1.00 \\
\hline [HSaf] & nn & strn-vstr & positive & positive & positive & positive & extreme & $-[$ Envi] & 0.81 \\
\hline [Envi] & & no & strong & positive & positive & positive & vstrq-extr & & \\
\hline [Finl] & & & no & strong & positive & positive & vstrg-extr & [Finl] & 0.62 \\
\hline [SReq] & & & & no & mod-strg & positive & strong & $-[$ SReq] & 0.43 \\
\hline [Sche] & & & & & no & mod-strg & strong & & \\
\hline [Eyln] & & & & & & no & moderate & [Sche ] & 0.28 \\
\hline [all SQ] & & & & & & & no & [Eqln] & 0.14 \\
\hline \multicolumn{8}{|c|}{ Consistent judgements } & [all SQ] & 0.00 \\
\hline
\end{tabular}

Fig. 4. MACBETH matrix of qualitative judgments (left) and the corresponding validated weighting scale (right). (Note: "mod-strg", "strg-vstrg" and "vstrgextr" are abbreviations of "moderate or strong", "strong or very strong" and "very strong or extreme", respectively).

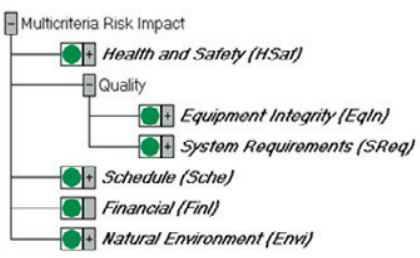

(a)

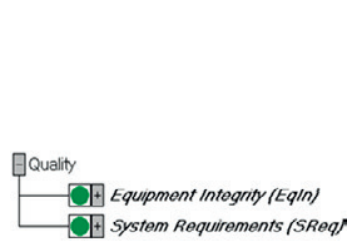

(b)

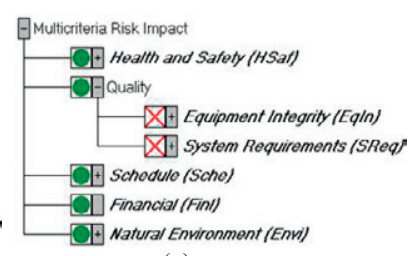

(c)

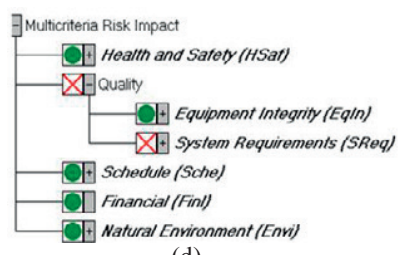

(d)

Fig. 5. Different possible ways for weighting criteria and area available in the recent hierarchical weighting component of the M-MACBETH DSS. 


\section{B. Subjective Probabilities}

Given the difficulties of organizations to elicit quantitative probabilities for risks when historical information is not available (or its use is not appropriate), RMs typically make use of qualitative scales (for example, low, medium, high) to probabilistically describe the likelihood of risk events. The use of probabilities in a discrete scale creates problems as it contributes for discontinuity jumps in the RM. MCDA methods can assist in building quantitative (subjective) probabilities using qualitative judgments from the DM following previous theoretical literature in the area using qualitative judgments to model probability [30] and using qualitative pairwise comparisons to model probabilities [3134], we will explore how MACBETH can be used to build a subjective probability scale. Naturally, MACBETH will be used in a different setting/logic in comparison to its common use in building multicriteria value models

\section{Risk Classification Procedure}

We propose exploring multicriteria classification procedures to classify risks from the VRM by severity. Building risk categories taking into account expected impacts and probabilities has been typically dealt in MCDA literature through the use of utilities (and lotteries) [19]. Given that the DM cannot choose between two risk events A and B, we propose developing alternative multicriteria procedures based on preference information over risk profiles to define the type of iso-risk lines that separate risk categories (i.e. isorisk thresholds that separate categories of risk are defined with the use of different colors of a traffic light system in a RM). In particular, procedures such as the ones used by Bana e Costa and Oliveira [35] will be further developed and adapted to the $\mathrm{RM}$ context.

\section{Value Risk-Matrix}

Using the methods proposed in A, B and C, a new RM can be designed, and we suggest creating a Value Risk Matrix (VRM). As an illustrative example, a preliminary design of VRM is shown in Fig. 6 (with multicriteria value scores in the $\mathrm{X}$-axis, probabilities in the $\mathrm{Y}$-axis, and risks classified into categories).

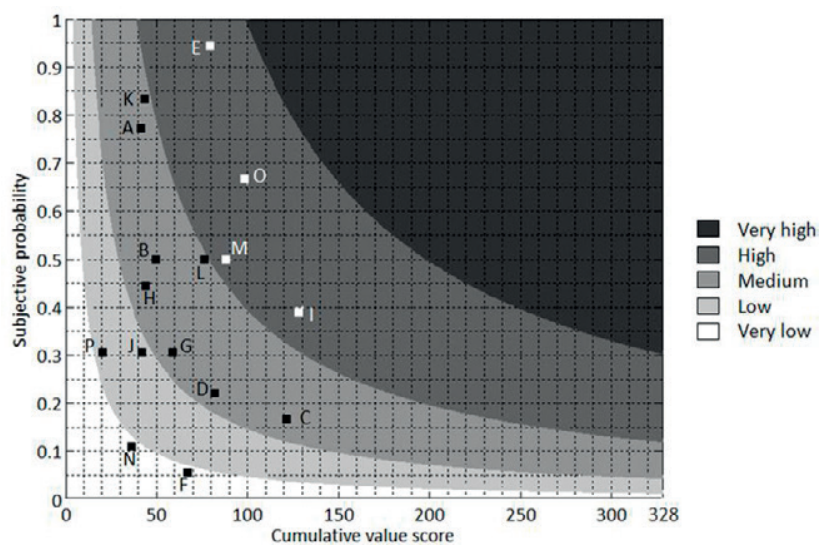

Fig. 6. Projecting the classification of risks into a VRM.

\section{E. Multicriteria Resource Allocation Model}

"Optimal" resource allocation demands for the quantitative information beyond the qualitative information that conventional RMs provide [7]. Combined with the VRM, the recent portfolio decision analysis component of the $\mathrm{M}$ MACBETH DSS can be built to assist the systematic analysis of the most effective set of interventions to reduce risk (i.e. which increase multicriteria impact value and/or decrease probabilities), while taking into account of cost and other constraints. Building multicriteria resource allocation models to assist the selection of interventions (and strategies) to reduce risks and that maximize value for money for the organization will help overcoming the problem of suboptimal allocations when using RMs.

It is worthwhile to note that the selection of the portfolio should be performed with the DM and the first step to find every efficient portfolio is to determine the added value (AV) of each mitigation action in relation to a baseline action. This AV can be calculated in two steps: a) first by calculating the adjusted value of a risk event (by multiplying the risk impact value by the probability of a risk event); and b) by measuring the difference between the value before and the adjusted value after adopting the mitigation action, which defined the AV of a mitigation action. A baseline mitigation action has null added value, i.e. if a mitigation action has negative added value, it should be regarded as globally unattractive and therefore excluded from the analysis. Then, it is necessary to determine the cost associated with each of the remaining mitigation action. Later, taking into account the available resources, the optimization approach, which solves the knapsack problem (for details see [36]). Fig. 7 shows all portfolios - i.e., combinations of mitigation actions - that can be formed with seven hypothetical mitigation actions and the efficient portfolio given a budget of $€ 39 \mathrm{~K}$. Note that the adopted Knapsack formulation covers other constraints than the mentioned budget constraints. These constraints can be translated as: inclusion and/or exclusion of certain actions in the portfolio; dependencies between actions; simultaneous integration of two actions; and exclusive integration of actions.

In practice, we propose using the M-MACBETH DSS since it allows, in an innovative way, to visualize the efficient frontier as well as take into account synergies and constraints between actions - a screen of the portfolio component of the M-MACBETH DSS is shown in Fig. 7.

\section{F. Modelling Uncertainty and Robustness Analysis}

Several types of uncertainty apply to the process of evaluating risks in VRMs, such as uncertainties regarding the measurement of risk impacts, regarding DM preferences and regarding the costs of risk mitigation actions (note that other types of uncertainties may also apply). When using the methods proposed in $\mathrm{A}$ to $\mathrm{D}$, the final question is how robust is the evaluation and classification of risks and of risk interventions. This requires the modeling of uncertainty sources and the availability of methods to carry out robustness analysis in an integrated form and to assist project risk management. 


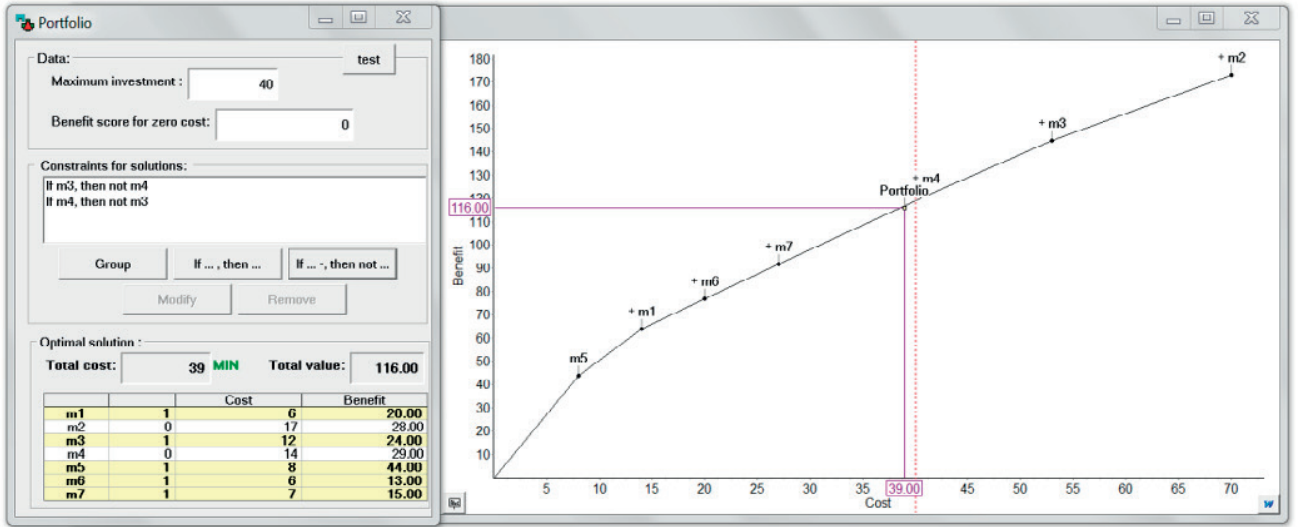

Fig. 7. Screen of the portfolio component of the M-MACBETH DSS, showing an optimization portfolio analysis of mitigation actions with several constraints.

Once the other methods within IRIS are developed and applied, uncertainty and robustness analyses will be built.

\section{CONCLUSIONS}

This study suggests methods and tools from multiple criteria and portfolio decision analysis tools, based on the MACBETH approach, to improve the design and the deployment of RMs in the context of prioritization of risks and of risk reductions. It shows how MACBETH method and software can be used within a social-technical process to build a VRM and to assist in the selection of mitigation actions. The social component includes the use of participatory methods to build preferences and a compromise and confidence between stakeholders who participate in risk management; and the technical component involves the modeling of the DM's preferences.

Within the IRIS project, the proposed methods are being developed and applied to several risk management case studies, including to the evaluation of health and safety risks and to the selection of risk mitigation actions in the Occupational Health and Safety Unit (OHSU) of the Regional Health Administration of Lisbon and Tagus Valley (RHA LVT). The aim is to build methods that are requisite (as defined in [37,38]) and can be used in risk management, as well as to build a new DSS to assist the use of VRM.

\section{ACKNOWLEDGMENT}

This work was funded by National Funds from the Portuguese Public Budget through FCT - Fundação para a Ciência e a Tecnologia, within the project PTDC/EGEGES/119230/2010.

\section{REFERENCES}

[1] T. Aven, Risk analysis: assessing uncertainties beyond expected values and probabilities, Wiley, 2008 ,

[2] D. Vose, Risk analysis: a quantitative guide, 3rd ed., Wiley, 2008,

[3] Project Management Institute, A guide to the project management body of knowledge: PMBOK guide, Project Management Institute, 2004,
[4] M.S.M. Figueiredo, M.D. Oliveira, Prioritizing risks based on multicriteria decision aid methodology: Development of methods applied to ALSTOM power, IEEE International Conference on Industrial Engineering and Engineering Management, Hong Kong, 2009, pp. $1568-1572$

[5] S.C. Ward, Assessing and managing important risks, International Journal of Project Management, 17, 1999, pp. 331-336.

[6] C. Alexander, Assessment of Operational Risk Capital, in: Risk Management: Challenge and Opportunity M. Frenkel, U. Hommel, M. Rudolf (Eds.)Springer, 2000, pp. 279-302.

[7] L.A. Cox Jr, Risk analysis of complex and uncertain systems, Springer, 2009 ,

[8] Quality and Patient Safety Directorate, Risk assessment tool and guidance (including guidance on application), Health Service Executive, 2011.

[9] H. Ni, Chen A., Chen N., Some extensions on risk matrix approach, Safety Science, 48, 2010, pp. 1269-1278.

[10] The MITRE Corporation, MITRE risk management toolkit, http:/www.mitre.org/work/sepo/toolkits/risk/ToolsTechniques/RiskMatr ix.html, 1999.

[11] SAP AG, Risk assessment with $\mathrm{SAP}{ }^{\circledR}$ EHS Management, SAP AG, 2012.

[12] L.A. Cox Jr., What's wrong with risk matrices?, Risk Analysis 28, 2008, pp. 497-512.

[13] P. Artzner, F. Delbaen, J.M. Eber, D. Heath, Coherent measures of risk, Mathematical Finance, 9, 1999, pp. 203-228.

[14] R.L. Dillon, E.M. Pate-Cornell, S.D. Guikema, Programmatic risk analysis for critical engineering systems under tight resource constraints, Operations Research, 51, 2003, pp. 354-370.

[15] Y.H. Kwak, F.T. Anbari, Analyzing project management research: Perspectives from top management journals, International Journal of Project Management, 27, 2009, pp. 435-446.

[16] A.S. Markowski, M.S. Mannan, Fuzzy risk matrix, Journal of Hazardous Materials, 159, 2008, pp. 152-157.

[17] R. Keeney, H. Raiffa, Decisions with multiple objectives: preferences and value tradeoffs, John Wiley \& Sons, 1976,

[18] D. Von Winterfeldt, W. Edwards, Decision analysis and behavioral research, Cambridge University Press, 1986,

[19] V. Belton, T.J. Stewart, Multiple criteria decision analysis: an integrated approach, Springer, 2002,

[20] C.A. Bana e Costa, J.-M. De Corte, V. J.-C., On the mathematical foundations of MACBETH, in: Multiple Criteria Decision Analysis: The State of the Art Surveys, 76, J. Figueira, Greco, S., Ehrgott, M. (Eds.), 2005, pp. 409-442. 
[21] C.A. Bana e Costa, J.C. Vansnick, MACBETH - An interactive path towards the construction of cardinal value functions, Internat Trans Oper Res 1, 1994, pp. 489-500.

[22] C.A. Bana e Costa, J.C. Vansnick, The MACBETH approach: Basic ideas, software and an application, in: Advances in Decision Analysis, N. Meskans, M. Roubens (Eds.),Dordrecht, Germany: Kluwer Academic Publishers, 1999, pp. 131-157.

[23] C.A. Bana e Costa, J.C. Lourenço, M.P. Chagas, J.C. Bana e Costa, Development of reusable bid evaluation models for the Portuguese Electric Transmission Company, Decision Analysis, 5, 2008, pp. 22-42.

[24] C.A. Bana e Costa, M.P. Chagas, A career choice problem: an example of how to use MACBETH to build a quantitative value model based on qualitative value judgments, European Journal of Operational Research, 103, 2004, pp. 323-331

[25] V. Clivillé, L. Berrah, G. Mauris, Quantitative expression and aggregation of performance measurements based on MACBETH multicriteria method, International Journal of Production Economics 105, 2007, pp. 171-189.

[26] F. Joerin, G. Cool, M.J. Rodriguez, M. Gignac, C. Bouchard, Using multi-criteria decision analysis to assess the vulnerability of drinking water utilities, Environmental Monitoring and Assessment 166, 2010, pp. 313-330.

[27] C.A. Bana e Costa, J.-M. De Corte, J.-C. Vansnick, MACBETH, International Journal of Information Technology and Decision Making, 11, 2012, pp. 359-387.

[28] R.L. Keeney, Value-focused thinking: a path to creative decisionmaking, Harvard University Press, 1992,

[29] C.A. Bana e Costa, L. Ensslin, E.C. Corrêa, J.-C. Vansnick, Decision Support Systems in action: Integrated application in a multicriteria decision aid process, European Journal of Operational Research, 113, 1999, pp. 315-335.

[30] K.-P. Schott, A model to support the assessment of subjective probabilities, Theory and Decision 12, 1980, pp. 173-183.

[31] S. Monti, G. Carenini, Dealing with the expert inconsistency in probability elicitation, IEEE Transactions on Knowledge and Data Engineering, 12, 2000, pp. 499-508.

[32] J.L. Riggs, S.B. Brown, R.P. Trueblood, Integration of technical, cost, and schedule risks in project management, Computers and Operations Research, 21, 1994, pp. 521-533.

[33] T.L. Saaty, Risk-its priority and probability: the analytic hierarchy process, Risk Analysis, 7, 1987, pp. 159-172.

[34] P. Szwed, J. Rene van Dorp, J.R.W. Merrick, T.A. Mazzuchi, A. Singh, A Bayesian paired comparison approach for relative accident probability assessment with covariate information, European Journal of Operational Research, 169, 2006, pp. 157-177.

[35] C.A. Bana e Costa, R.C. Oliveira, Assigning priorities for maintenance, repair and refurbishment in managing a municipal housing stock, European Journal of Operational Research, 138 2002, pp. 380-391.

[36] J.C. Lourenço, A. Morton, C.A. Bana e Costa, PROBE - a multicriteria decision support system for portfolio robustness evaluation, Decision Support Systems, 54, 2012, pp. 534-550.

[37] L.D. Phillips, A theory of requisite decision models, Acta Psychologica, 56, 1984, pp. 29-48.

[38] L.D. Phillips, C.A. Bana e Costa, Transparent prioritisation, budgeting and resource allocation with multi-criteria decision analysis and decision conferencing, Annals of Operations Research 154, 2007, pp. 51-68. 
(Página deixada propositadamente em branco) 


\title{
Risk-based Maintenance: Relationship between the risk and the environment of operation
}

\author{
J. F. D. Santos ${ }^{1}$; J. M. F. Calado ${ }^{2}$; A. A. Roque ${ }^{3}$ \\ 1940729@alunos.isel.pt; ${ }^{2}$ jcalado@dem.isel.ipl.pt; ${ }^{3}$ aroque@datanalise.pt \\ ${ }^{1,2,3}$ Mechanical Engineering Department, ISEL - Instituto Superior de Engenharia de Lisboa \\ IPL - Polytechnic Institute of Lisbon, Lisboa, Portugal \\ ${ }^{2}$ LAETA, IDMEC, Instituto Superior Técnico, Universidade de Lisboa, Lisboa, Portugal \\ ${ }^{3}$ DatAnálise Portugal, Rua Pé de Mouro - Centro Empresarial Lusoworld II - Armazém 31 - Linhó \\ Sintra, Portugal
}

\begin{abstract}
The risk-based maintenance is sustained in the mapping of the risk of the assets failure in an organization. The failure risk of an asset depends on the consequence of a specific failure and the probability of occurrence of such a failure. The maintenance tools based on risk assessment allow to reducing the risk of assets failure and contribute to the life cycle optimization. Being the failure risk of an asset affected by the environment of its operation, the corresponding maintenance management should be adapted to this specific environment to keep the failure below the pre-defined maximum risk criterion. Hence, the main goal of this paper is to demonstrate how the operating environment of an asset relates with its failure risk. Thus, the failure risk of a known system operating in normal conditions and in a hostile environment will be evaluated. In the end, it's expected to be known what criteria which contribute to the risk calculation we should be aware to recalculate the failure risk and review the maintenance plan.
\end{abstract}

Keywords- Risk-Based Maintenance; Risk; Life cycle costs optimization; Assets failure; Maintenance management.

\section{INTRODUCTION}

The risk-based maintenance has been a tool used in industry to reduce the risk of assets failure that have been growing in complexity and dimensions.

Since the seventy decade, one has been assisted to a growth of complexity and dimension in industrial plants. With the growth of industrial plants the list of hazard material has been increasing. The practice of learning by mistakes was no longer acceptable, and the risk analysis had gained a new importance. It started to identify the consequences of a failure by quantification methods.

There are many examples of industry disasters that have contributing for risk analysis development. The Flix borough disaster was an explosion at a chemical plant close to the village of Flixborough in England, on 1 June 1974. This disaster resulted in 28 deaths and 36 seriously injured. This accident had a lot of media coverage and had awakened the population for industry risks. Others accidents, continued occurring. Like the Seveso disaster in Italy on 10 July 1976 in a small chemical manufacturing plant that had affected the nearby populations.

Others more recent, like the Piper Alpha in the North Seal oil production platform on 6 July 1988.

After all this occurrences, the mentality had change and nowadays there are guidance and legislation that control the risk acceptance.

The risk can be variable since its factors are the probability and the consequence of occurrence. If for any reason, the failure consequence it's not the same, then the risk of failure has to be reevaluated.

Many developments have been taken to find the best methodology for risk-based maintenance. It will be done some review of the most significant methods.

In 1998, Harnly developed a procedure, which assigns priorities to repairs, based on risk of non-accordance that was identified in inspection procedures on chemical installations of Exxon. The procedure prioritizes the equipment's based on an index that is the relationship between the potential failure and the consequence. The general risk of the plant is reduced minimizing the risk index of the components that most contribute to the general risk level. [1]

In 2003, Kan and Haddara, developed a risk-based methodology for inspection and maintenance [2]. They applied the method in an HVAC system and developed a maintenance program. In this methodology the risk incorporates economic, safety and environment components [2]. Such a method has three steps: Risk Estimation; Risk Evaluation; and Maintenance Planning [2].

Wang et al. [3] defined the consequence of failure in three components: Personal security effect, environment threat, and economical lost. For the risk assessment the authors have been used the following strategy: 1. Identification of the scope; 2. Risk Assessment; 3. Risk evaluation; 4. Maintenance planning [3]. For this author, the risk of failure results from the product of the following three parcels: the personnel safety risk, the environmental impact and the economic losses [3]. In this article the authors used a FMEA methodology to quantify the severity of personnel injury and environment pollution. To 
prove their methodology they used a case study of a continuous catalytic reforming plant [3].

In this paper it will be analyzed the risk of failure of an air conditioned system installed on a frigate from the Portuguese Navy. After analyzed the risk of failure for each failure mode, it will be analyzed the risk of the same failure modes but in a hostile environment for the system.

To achieve the risk of each failure mode, will be used the FMEA methodology to decompose the system, analyze its failure modes and calculate the risk associated to each failure mode.

This paper is organized in three main parts, in the first is presented the risk-based maintenance methodologies, where will be explained how can be calculated the risk of each failure mode. The second part presents the case study, with a resume of the system and with the application of the chosen methodology to the case study. The third part analysis the results, where we have the comparison between the risk in normal working conditions and when the system is working in a hostile environment. The results are towards recommendations to reduce the risk of the chosen system when working on a considered hostile environment. The last section provides some concluding remarks.

\section{Risk-BASEd Methodology}

The FMEA (FMEA - Failure mode effects analysis) methodology helps the maintenance management people to identify the failure modes of complex systems as an entire plant, and use them to select the correct maintenance tasks, to avoid the failure of the plant. [4] The methodology consists of listing all components of a system, and finding the failure mode for each component. [5].

To do a correct risk assessment there is definitions that have to be clarified. The next definitions will be assumed for the entire paper.

Moubray [4] define failure as: "Failure is defined as the inability of any asset to do what their users want it to do." In this definition, Moubray centered the failure on the asset function.

An asset can have more than one function, then, it can have more than one failure. So, it's important to define what a functional failure is. Moubray [4] defined functional failure as: "A functional failure is defined as the inability of any asset to fulfill a function to a performance standard of that is acceptable to the user."

The use of FMEA analysis is important to define what a "failure mode" is. Moubray [4] defined failure mode as "A failure mode is any event which causes a functional failure".

Identifying the failure mode is the way to know what we can do to avoid the failure. Identifying the entire failure modes of a plant can be a hard work. But in the day-to-day basis, the maintenance team focuses in the failure mode, the team discusses about what have been failed, what caused them and what can be done to repair and avoided them.
A failure mode can has many levels of description. If it is known the failure function, like "pump set fails" we can advance in levels of description of the failure mode. We might stop in the level where is possible to identify an appropriate failure management task. On the other hand, we shouldn't stop in a level that is not possible to describe the failure mode enough that we can't find the appropriate task to cope with the corresponding failure.

Risk is the relationship between the probabilities of a failure occurrence versus its consequence. In maintenance, the occurrence is our failure probability.

When the risk-based maintenance is used in the maintenance optimization, the maintenance engineer pursues the answer to the following questions [2]:

- What event can happen to cause the system failure?

- How can this event happen?

- What is the probability of occurrence of this event?

- What would be the consequences for the organization from this event?

Then we'll want to know, how we can reduce the risk of failure, or to maintain a low risk and optimize the maintenance costs.

The methodology of risk-based maintenance, studies all equipment components failure modes and determines the risk associated to each failure mode.

Khan [2] present a risk-based maintenance based on three general steps that it will be explained as follows (risk estimation, risk evaluation and maintenance planning):

\section{A. Risk Estimation}

In this step is calculated the risk associated to each failure mode.

There are quantitative or qualitative methods for risk estimation. The quantitative approach is done by the estimation of each failure mode frequency and its consequences. This method is appropriate when is reasonable and practicable. The most common problem when we talk about quantifying the risk is the historical data surveys [6].

Qualitative risk assessment can be applied when the risk is small and well known [6]. In this methodology is quantified the parcels of risk-based on severity and occurrence matrix that are evaluated by the maintenance engineer.

\section{Identification of scope}

The first sub-step is to identify each failure mode associated with the equipment. There are many tools to find each failure mode related to a specific equipment. It can be used a fault tree analysis, which permit to identify the basic events and how to achieve the top event. The fault tree, with the necessary data, allows calculating the probability of a top event occurrence from the probability of basic events.

Other tool that can be used to decompose the system components it's the FMEA - failure mode and effects analysis. FMEA is a process that allows understanding how a 
component, from a complex system, contributes to the overall failure mode. The methodology consists of listing all components of a system, and finds the failure mode for each component [5].

The FMEA methodology has the following steps:

- It has to be identified all items of a system and defined how they can failure (the failure mode).

- It has to be evaluated the occurrence severity of those failure modes.

- It has to be evaluated the occurrence probability of the failure mentioned above.

- It has to be evaluated the corresponding detectability.

- Finally it's calculated the RPN - risk priority number.

In the end is possible to use the RPN as a quantification of the risk of each failure mode.

\section{Consequence analysis}

The consequence is evaluated as a failure severity classification. That provides a qualitative measure of the worst potential consequences resulting from the failure of a specific item.

In this paper will be used a matrix to quantify the severity of each failure mode. This matrix was pointed out by Khan [2] and gives a number between 1 and 10 that allows prioritizing equipments and their components. Usually the severity has three components: the system performance loss; the financial loss; and the human health loss [2]. However, the severity matrix determination could be simplified based on the criteria presented on Table I not including all the three severity components previously mentioned. This last approach has been followed in the studies described in this paper.

TABLE I : Quantification for severity index

\begin{tabular}{|c|l|}
\hline Classification & \multicolumn{1}{|c|}{ Description } \\
\hline 9 to 10 & $\begin{array}{l}\text { Very important for system operation. Failure would cause } \\
\text { system to stop functioning. }\end{array}$ \\
\hline 7 to 8 & $\begin{array}{l}\text { Important for good operation. Failure would cause impaired } \\
\text { performance and adverse consequences }\end{array}$ \\
\hline 5 to 6 & $\begin{array}{l}\text { Required for good operation. Failure may affect the } \\
\text { performance and may lead to subsequent failure of the } \\
\text { system. }\end{array}$ \\
\hline 3 to 4 & $\begin{array}{l}\text { Optional for good performance. Failure may not affect the } \\
\text { performance immediately but prolonged failure may cause } \\
\text { system to fail. }\end{array}$ \\
\hline 1 to 2 & $\begin{array}{l}\text { Optional for operation. Failure may not affect the system's } \\
\text { performance. }\end{array}$ \\
\hline
\end{tabular}

\section{Failure probability}

The failure probability can be calculated by using probability methods if exists sufficient historical data about the system performance [4].

However, for the sake of simplicity the work described below has been based on a matrix to quantify the probability of occurrence. Such a matrix was obtained using the information included in Table II. This approach induces a loss of accuracy but is based on the operators experience in working with the equipment and allows reaching some conclusions without having logged huge amounts of data corresponding to the operational variables of the system. This methodology is suitable to estimate the risk of new systems due to the lack of data about such a systems functioning. The probability is quantified as a number between 1 and 10 , as can be seen in Table II.

TABLE II: Quantification for probability index

\begin{tabular}{|c|c|l|}
\hline \multicolumn{2}{|c|}{ Classification } & \multicolumn{1}{c|}{ Description } \\
\hline 9 to 10 & Frequent & $\begin{array}{l}\text { A high probability of occurrence during the item } \\
\text { operation time interval. }\end{array}$ \\
\hline 7 to 8 & $\begin{array}{l}\text { Reasonably } \\
\text { probable }\end{array}$ & $\begin{array}{l}\text { A moderate probability of occurrence during the item } \\
\text { operating time interval. }\end{array}$ \\
\hline 5 to 6 & Occasional & $\begin{array}{l}\text { An occasional probability of occurrence during item } \\
\text { operating time interval. }\end{array}$ \\
\hline 3 to 4 & Remote & $\begin{array}{l}\text { An unlikely probability of occurrence during item } \\
\text { operating time interval. }\end{array}$ \\
\hline 1 to 2 & $\begin{array}{c}\text { Extremely } \\
\text { Unlikely }\end{array}$ & $\begin{array}{l}\text { A failure whose probability of occurrence is } \\
\text { essentially zero during item operating time interval. }\end{array}$ \\
\hline
\end{tabular}

\section{Detectability evaluation}

As defined in the military standard of USA Department of Defense [7], "Procedure for performing a failure mode, effects and criticality analysis", the detection mechanism, are methods by which a failure can be discovered by an operator under normal system operation or can be discovered by the maintenance crew by some diagnostic action.

To evaluate the detectability level, was used the matrix represented in the table III to quantify the possibility to identify the failure before the failure occurs.

TABLE III:Quantification for detectability index

\begin{tabular}{|c|c|c|}
\hline \multicolumn{2}{|c|}{ Classification } & Description \\
\hline 1 & $\begin{array}{c}\text { Easily } \\
\text { detectable }\end{array}$ & Automatic detection of the failure before it occurs \\
\hline 2 & $\begin{array}{c}\text { Moderately } \\
\text { detectable }\end{array}$ & Detection of failure by inspection \\
\hline 3 & $\begin{array}{c}\text { Hardly } \\
\text { detectable }\end{array}$ & Detection with advanced diagnosis methods \\
\hline 4 & $\begin{array}{c}\text { Impossible } \\
\text { to detect }\end{array}$ & $\begin{array}{c}\text { It's not possible to detect the failure mode before } \\
\text { the failure occurs }\end{array}$ \\
\hline
\end{tabular}

\section{Risk estimation}

Doing the product of the consequence with the probability of occurrence and the detectability we have the risk priority number, which represent the risk of failure for each failure mode. This number will allow making the risk evaluation and reaching the objective of the work described in this paper. Hence, the risk index could be achieved using the following equation:

$$
R=D * O * S
$$

The following nomenclature is used: R- Risk index; DDetectability; $\mathrm{O}$ - Occurrence, or failure probability; SSeverity. 


\section{B. Risk Evaluation}

In this step it will be defined the acceptance criteria, which will indicate the failure modes that have or not acceptable risk of failure.

The literature presents different methods for such criteria definition. The most known and used is the ALARP (As Low As Reasonable Practicable). The ALARP definition says that should be taken all the measures to reduce a risk, that are out of the tolerable zone, until the cost of risk reduction is disproportionate to the benefit [5].

In the case study described below, it has been assumed that the failure modes that have more or equal than $70 \%$ of the maximum risk possible will not be acceptable. This interval is called the "non-acceptable risk".

The failure modes between $70 \%$ and more or equal than $40 \%$ of the maximum risk possible will be within the "tolerable risk" criteria.

The failure modes with less than $40 \%$ of the maximum possible risk are in the "acceptable" interval.

\section{Maintenance Planning}

In this phase, maintenance techniques to reduce the risk of failures are applied to the failure modes that are within the "non-acceptable" risk criteria. To reduce the risk of a failure mode the risk index of (at minimum) one of the parameter should be reduced. There are three ways to achieve that:

- Reducing the occurrence probability by increasing the preventive maintenance tasks.

- Reducing the severity through the installations of redundant components.

- Or increasing the detectability before the failure occurs through the implementation of advanced condition monitoring techniques.

In the work carried out was not considered the detectability as influencing the risk index and the severity has been considered to be unchangeable, since it is considered that the equipment could be used in severity conditions without time to engineering modifications. So it will be analyzed how the risk can be controlled handling only the probability of a failure occur.

\section{CASE STUDY}

\section{A. System description}

The system chosen as test bed of the proposed methodology is an air conditioned chiller unit from a vessel. Its major function is to chill water to the ventilation system. Such a system includes a compressor, an electric motor, the chilled water system, the sea water system, the electronic unit for command and control and auxiliary components.

In Table IV it can be seen, as an example how was apply the FMEA methodology to one of the systems of the air conditioned chiller, the electrical motor. This table was extrapolated for the rest of the equipment systems and subsystems.
This system is always working since the vessel is on duty and can be used in situations not foreseen in its project.

In the last year, the chosen system worked during five months with sea water temperature around $32^{\circ} \mathrm{C}$. These working conditions are out of the corresponding maker specifications and it has been observed an increasing of operational temperatures and pressures by each hour of operation. The increased temperatures and pressures could induce premature failures and, hence, the maintenance program and the spares kits should preview such an abnormal situation.

The extreme working conditions mentioned above will be defined as hostile operation condition. From the experience observed for this work the number of failures in the hostile condition has raise in comparison with the normal working conditions.

\section{B. Risk estimation}

To achieve the aim claimed above by the author, the methodology previously described for risk-based maintenance assessment, has been adopted in the current work. Considering the normal equipment working conditions and for abnormal working situation mentioned above. The comparison will determine the maintenance plan that should be taken to preview premature failures.

Thus, to estimate the risk of each failure mode has been used the FMEA methodology.

The complete system was divided into 35 components. To each component was specified its function. For each function was defined the functional failure and for each functional failure was developed the failure modes. A failure mode should consist of a noun and a verb being the most consistent and precise as possible [4].

\section{Occurrence probability}

It was analyzed failures data recorded since 2009 , on a total of 40272 working hours. The existing data are from failures of the system that shutdown the system for more than 3 hours. In order to consider the other failures the qualitative method was used to evaluate the failure occurrence probability. In this methodology the expert opinion was used taking into consideration the most probable failures even without correct data recording.

The matrix used to evaluate the failure occurrence probability was the one represented in Table II. To determine the scale in the mentioned table was calculated the failure rate of each failure mode that had occurred during the observation time. With this failure rate, even if is 0 , was possible to achieve a scale index according to the one included in the mentioned Table. Furthermore, it was considered the expert opinion that has been considered very important to tune the index in accordance with his experience. Then, the quantification of the failure occurrence probability is a number in a scale from 1 to 10.

The results of this analysis can be seen in the column "O" on table 
TABLE IV : FMEA of electric motor

\begin{tabular}{|c|c|c|c|c|c|}
\hline NR & System/sub-system & Function & Functional Failure & Failure Mode & $\begin{array}{l}\text { Corrective } \\
\text { Maintenance }\end{array}$ \\
\hline \multicolumn{6}{|c|}{ Electric Motor } \\
\hline 1 & Motor (rotor and stator) & Produce rotation with electrical supply & Not run & Damaged cables & Replace cables \\
\hline 2 & Bearings & $\begin{array}{l}\text { Ensure the rotation of the shaft evenly } \\
\text { without adding stress to the electric motor }\end{array}$ & $\begin{array}{l}\text { The motor heats up, } \\
\text { makes noise and } \\
\text { increases consumption }\end{array}$ & Seized bearings & $\begin{array}{l}\text { Bearings } \\
\text { replacement }\end{array}$ \\
\hline 3 & Coupling & $\begin{array}{l}\text { Ensure equal rotation between the motor shaft } \\
\text { and compressor }\end{array}$ & $\begin{array}{l}\text { Only moves the electrical } \\
\text { motor }\end{array}$ & Damaged coupling & $\begin{array}{l}\text { Coupling } \\
\text { replacement }\end{array}$ \\
\hline
\end{tabular}

Based on the failures historical records, of this equipment working on the specific conditions described before as "hostile environment", was reviewed the level of occurrence probability to each failure mode, and was constructed a new FMEA with this specific data. The results can be seen in column " $\mathrm{O}$ "' on table VI.

\section{Severity analysis}

The analysis of the severity was performed according to Table I. It was based on the expert experience in working with the previously described equipment who have been accompanied this system since 2011, including the time that the system worked in the hostile environment.

The severity analysis took into consideration the scale of Table I, aiming to determine how each failure mode could contribute to the system unsatisfactory performance. Thus, the severity quantification is a number in a scale of 1 to 10 .

The severity level for the normal working conditions and for the abnormal working condition was considered constant. Once the severity index is function from the system arrangement, which is not changed in this case study. The results of severity analysis, can be seen in column "S" on tables V and VI.

\section{Detectability Evaluation}

The evaluation of detectability for each failure mode was performed according to the Table III. The detectability range is from 1 , to failures easily detectable, until 4, to failures impossible to detect before it happens.

The detectability index, is also independent of the operation conditions, so this index will be constant independently of the environment.

To determine the detectability value was taken into consideration the actual maintenance program. The results can be seen in column "D" on tables V and VI. The table VII shows how the risk can be reduced with the improvement of detectability index, this possibility will be analyzed later.

\section{Risk estimation}

The risk estimation is not more than the multiplication of the occurrence, severity and detectability indexes for each failure mode. The quantification of the risk of failure is a number in a scale taking the value 1 to the minimum possible risk and 400 to the maximum possible risk.
The "RPN" column on Table V shows the initial risk of failure for the failure modes out of the defined criteria. The "RPN" column on Table VI shows the failure modes that had increased the failure risk during the "hostile operation". The "RPN"" column shows the failure risk reduction obtained improving the detectability.

\section{Risk evaluation}

After the risk estimation, it should be defined the acceptable criteria. It was used the intervals defined in the section II. In accordance with the acceptance criteria defined, it will be used the next intervals:

\begin{tabular}{|c|c|}
\hline Less then $160(\mathrm{RPN})$ & Acceptable \\
\hline Equal or greater then 160 & Tolerable \\
\hline Equal or greater then 280 & Non-acceptable \\
\hline
\end{tabular}

Thus, in Table $\mathrm{V}$ is shown the failure modes that are out of the acceptance criteria.

In the Table VI is shown the failure modes that had increased risk index when the system was working in the hostile environment. There are two failure modes (the nr 23 and 24) that increased the risk value from a situation of "acceptable risk" to "tolerable risk".

Those two failure modes were acceptable, but with the failure historic analysis during hostile operation, the "occurrence" index had increased their values and the RPN had also increased to non-acceptable values.

\section{Maintenance planning}

After the risk index has been assessed for the normal working period and for the hostile working period, it is possible to know how the risk varies, if varies, and how can be accommodated the increasing risk to guaranty the most efficient system operation.

Analyzing the failure modes on Table VI, can be selected the failure modes that should be watchful. There are two situations:

- Failure modes that are already in those levels of concern, like the failure modes 6 and 12. In these cases, the risk is already worrying and the methodology to reduce risk should be taken independently of the working environment. 
TABLE V : Failure modes in the tolerable risk and non-acceptable risk index

\begin{tabular}{|c|c|c|c|c|c|c|c|c|}
\hline NR & System/sub-system & Function & Functional Failure & Failure Mode & $\mathbf{O}$ & $\mathbf{S}$ & D & RPN \\
\hline \multicolumn{9}{|c|}{ Compressor } \\
\hline 6 & $\begin{array}{l}\text { Suction and compression } \\
\text { valves }\end{array}$ & $\begin{array}{l}\text { Ensure the intake and exhaust the } \\
\text { FREON in correct timing }\end{array}$ & $\begin{array}{l}\text { Doesn't make the intake or } \\
\text { exhaust the FREON }\end{array}$ & Broken Valves & 9 & 10 & 4 & 360 \\
\hline 7 & Cylinders & $\begin{array}{l}\text { Ensure the compression and expansion } \\
\text { the FREON }\end{array}$ & $\begin{array}{l}\text { Doesn't make the compression } \\
\text { or expansion }\end{array}$ & Damaged cylinders & 6 & 10 & 4 & 240 \\
\hline \multicolumn{9}{|c|}{ Command and control automatism system } \\
\hline 12 & $\begin{array}{l}\text { Command and control } \\
\text { automatism (electronic } \\
\text { components) }\end{array}$ & $\begin{array}{l}\text { Receiving information from the sensors, } \\
\text { make an emergency stop of the } \\
\text { compressor and manage the phases of } \\
\text { compression of each compressor }\end{array}$ & System doesn't work & System has no command & 5 & 8 & 4 & 160 \\
\hline \multicolumn{9}{|c|}{ FREON circuits } \\
\hline 33 & Tubing & Ensure the tightness of the circuit & $\begin{array}{l}\text { Low suction pressure of the } \\
\text { FREON }\end{array}$ & FREON leakage & 6 & 8 & 4 & 192 \\
\hline
\end{tabular}

TABLE VI : Failure modes that had increased the risk In the hostile environment

\begin{tabular}{|c|c|c|c|c|c|c|c|c|}
\hline NR & System/sub-system & Function & Functional Failure & Failure Mode & $\mathbf{O}^{\prime}$ & $\mathbf{S}$ & $\mathbf{D}$ & $\mathbf{R P} \mathbf{N}^{\prime}$ \\
\hline \multicolumn{9}{|c|}{ Compressor } \\
\hline 6 & $\begin{array}{l}\text { Suction and compression } \\
\text { valves }\end{array}$ & $\begin{array}{l}\text { Ensure the intake and exhaust the } \\
\text { FREON in correct timing }\end{array}$ & $\begin{array}{l}\text { Doesn't make the intake or } \\
\text { exhaust the FREON }\end{array}$ & Broken Valves & 10 & 10 & 4 & 400 \\
\hline 7 & Cylinders & $\begin{array}{l}\text { Ensure the compression and expansion } \\
\text { the FREON }\end{array}$ & $\begin{array}{l}\text { Doesn't make the compression } \\
\text { or expansion }\end{array}$ & Damaged cylinders & 6 & 10 & 4 & 240 \\
\hline \multicolumn{9}{|c|}{ Command and control automatism system } \\
\hline 12 & $\begin{array}{l}\text { Command and control } \\
\text { automatism (electronic } \\
\text { components) }\end{array}$ & $\begin{array}{l}\text { Receiving information from the sensors, } \\
\text { make an emergency stop of the } \\
\text { compressor and manage the phases of } \\
\text { compression of each compressor }\end{array}$ & System doesn't work & System has no command & 6 & 8 & 4 & 192 \\
\hline \multicolumn{9}{|c|}{ Sea-Water cooling system } \\
\hline 23 & Bearings & Facilitate rotation & $\begin{array}{l}\text { The pump heats up, makes } \\
\text { noise and increases } \\
\text { consumption }\end{array}$ & Seized bearings & 6 & 7 & 4 & 168 \\
\hline 24 & Water retainer & Ensures the tightness of the pump & Water leakage from the shaft & Damaged retainer & 8 & 5 & 4 & 160 \\
\hline \multicolumn{9}{|c|}{ FREON circuits } \\
\hline 33 & Tubing & Ensure the tightness of the circuit & $\begin{array}{l}\text { Low suction pressure of the } \\
\text { FREON }\end{array}$ & FREON leakage & 7 & 8 & 4 & 224 \\
\hline
\end{tabular}

TABLE VII : Failure modes that had improved the detectability factor

\begin{tabular}{|c|c|c|c|c|c|c|c|c|}
\hline NR & System/sub-system & Function & Functional Failure & Failure Mode & $\mathbf{O}^{\prime}$ & $\mathbf{S}$ & $\mathbf{D}^{\prime}$ & $\mathbf{R P N}^{\prime}$ \\
\hline \multicolumn{9}{|c|}{ Sea-Water cooling system } \\
\hline 23 & Bearings & Facilitate rotation & $\begin{array}{l}\text { The pump heats up, makes noise and } \\
\text { increases consumption }\end{array}$ & Seized bearings & 6 & 7 & 3 & 126 \\
\hline
\end{tabular}


- There are two failure modes that rose from a situation of "acceptable risk" to "tolerable risk" when the equipment was working in the hostile environment. In those situations are recommended to implement maintenance management techniques to reduce the failure risk.

To demonstrate that the detectability improvement can reduce the failure risk, the Table VII quantifies the RPN in hostile environment with the appliance of advanced techniques of failure diagnosis. Applying this techniques, the detectability index reduces from 4 to 3 in the failure mode nr 23 and consequently the RPN reduces turning this failure mode as "acceptable".

\section{CONCLUSIONS}

The maintenance management can't be a static theory with closed methodologies. For each situation, for each system, the assets management requires a suiting policy that contributes to the most efficient exploitation of these assets.

The work carried out was based on well-known methodologies to advise a real case of an asset that have different necessities of maintenance during its period life cycle.

In the final analysis of the system considered were identified two failure modes that weren't failure modes of concern in normal working conditions but in a very specific environment they turn into failure modes of concern and, thus, it should be adopted suitable maintenance techniques for the components corresponding to those failures.

There were other two failure modes that were already case of concern with high level of failure risk, furthermore in the specific hostile environment considered, their risk increases. For the components corresponding to this failure modes, should be taken into consideration the adoption of monitoring techniques with a high frequency, due to the high severity of failures or high probability of occurrence.

With the failure modes out of acceptance criteria, was simulated the possibility of applying advanced techniques of diagnosis and one of the failure modes that as increased its RPN to non-acceptable has been reduced to acceptable.
For the future is important to validate these conclusions with data corresponding to more failures and like is quoted before, the analysis needs to evolve in time to guarantee a more reliable system.

\section{ACKNOWLEDGMENT}

Tthis work was partially supported by strategic project, PESTOE/EME/LA0022/2011, through FCT (under the unit IDMEC - pole IST, research group IDMEC/LAETA/CSI). authors are also very grateful for the financial support given by DATANÁLISE.

\section{REFERENCES}

[1] Krishnasamy, L et al. (2005). Development of a risk-based maintenance (RBM) strategy for a power-generating plant. Journal of Loss Prevention in the process industries.

[2] Khan and Haddara. (2003). Risk-based maintenance (RBM): a quantitative approach for maintenance/inspection scheduling and planning. Journal of Loss Prevention in the process industries.

[3] Wang, et al. (2012). Development of a risk-based maintenance strategy using FMEA for a continuous catalytic reforming plant. Journal of Loss Prevention in the process industries.

[4] Moubray, J. (1997). Reliability Centred Maintenance. $4^{\text {th }}$ ed., Industrial Press Inc. ISBN 0750633581

[5] Smith, D. (2001). Reliability, Maintability and Risk, $6^{\text {th }}$ ed., Butterworth Heinemann ISBN 0750651687

[6] Arunraj and Maiti. (2006). Risk-based maintenance- Techniques and applications. Journal of Hazardous Material.

[7] MIL-STD-1629A, "Military Standard - Procedures for performing a failure mode, effects and criticality anlyis" 1980

[8] Haijun $\mathrm{Hu}$ et al. (2009). Risk-based maintenance strategy and its applications in a petrochemical reforming reaction system. Journal of Loss Prevention in the process industries

[9] Diamantoulaki and Angelides. (2013). Risk-based maintenance scheduling using monitoring data for moored floating breakwaters. Structural safety 
(Página deixada propositadamente em branco) 


\title{
Risk Management based on the Assessment of Safety Barriers
}

\author{
${ }^{1}$ José Sobral; ${ }^{2}$ Carlos Guedes Soares \\ ${ }^{1}$ jsobral@dem.isel.ipl.pt; ${ }^{2}$ c.guedes.soares@,centec.tecnico.ulisboa.pt \\ ${ }^{1}$ Mechanical Engineering Department, ISEL - Instituto Superior de Engenharia de Lisboa \\ Lisboa, Portugal \\ ${ }^{1,2}$ Centre for Marine Technology and Engineering (CENTEC), Instituto Superior Técnico, Universidade de Lisboa, Av. Rovisco \\ Pais, 1049-001 Lisboa, Portugal
}

\begin{abstract}
The present paper deals with safety barriers, describing their characteristics and presenting a new classification for them based on their type and operating mode. While the assessment of safety barriers performance is often achieved by tests or inspections in order to determine the probability of failure on demand (PFD) and detect the so-called hidden failures, a new methodology to evaluate the adequacy of a safety barrier is proposed by linking the safety integrity level of an assessed safety barrier with the probability of occurrence of the hazardous event that it should protect. Based on the study of all possible safety function failures there is a selective approach to determine the ones classified as dangerous undetected in a way to use them on the determination of the PFD. Applying the methodology proposed it is also possible to estimate the probability of occurrence of a hazardous situation, once it depends on the simultaneity of happening the initiating event and the safety barrier fault, when a demand occurs. The impact of a specific safety barrier assessment on risk can thus be evaluated.
\end{abstract}

Keywords-safety barrier, probability of failure on demand, safety integrity level.

\section{INTRODUCTION}

In complex and technological industrial systems when some control variables go out of their natural range it can be a sign of failure of some equipment or process. To face this type of events and avoid the escalation of an incident or accident it is common to implement systems called safety barriers which function is to prevent the occurrence of such events or disable the evolution of their effects. If these functions are not accomplished it is considered a safety barrier's failure and then the consequences could be catastrophic in almost cases.

So, it is essential to assure that safety barriers have high availability and high reliability to keep risk under acceptable limits. The assessment of safety barriers availability and the reliability analysis of their functions are fundamental issues to take into account when, for example, someone wants to assure a high level of safety onsite or reduce the consequences of dangerous phenomenon or hazardous events on people, business or environment.

Most accidents result from a combination of an unexpected event and a dysfunctional or missing barrier. Usually, when an accident occurs the question is how could it happen if we had several safety features in place to face it? So it is essential to understand how those safety barriers failed in the course of an accident.

Several studies about safety barriers have been performed in a large range of industries and with different purposes.

Kecklund et al [1] presented a study with a general model for the reliability analysis of existing barrier functions in the refuelling process at the annual outage of a nuclear power plant (NPP) assuming on that study the technology-human interaction. Harms-Ringdahl [2] describes a method for accident investigation based on the concept of safety function, resulting on the proposal of some safety improvements. This author applied the referred method to five different incidents where around 40 safety functions were identified for each case and less than a half had worked when it was necessary. In this work the main attention is on common workplaces rather than major hazard installations. In other study safety barrier diagrams were developed as a tool for modelling safety of hydrogen applications just to document measures taken to prevent incidents and accidents in process industry [3]. Some works deal with operating situations and apply the notion of safety integrity level of a barrier at specific cases as the safety evaluation in complex guided transportation systems [4] or estimation of this parameter for safety related systems in high speed trains [5].

In this paper a deep reflection is done about safety barriers regarding different interpretations about some concepts and terminology in the existing literature. Based on this analysis a simple and coherent classification is made being possible to apply it to the majority of the safety barriers. A new methodology is also proposed in a way to evaluate the adequacy of a safety barrier for a specific hazard. This methodology is innovative since it links the safety integrity level of an assessed safety barrier with the probability of occurrence of the hazardous event that it should protect. Based on this relationship and using a risk acceptability matrix the adequacy of the safety barrier is evaluated.

The paper is structured in five Sections. The second focuses on the definition of safety barrier, safety function and safety barrier classification. Section III describes some safety integrity requirements and how to develop a safety barrier assessment. Section IV presents a methodology to assess safety barriers and illustrates it with a demonstrative example. Section V presents some conclusions and suggests future 
works that can be done on the field of safety regarding the management of safety barriers and the proposed methodology.

\section{SAFETY BARRIERS}

The definition of safety barrier is not unanimous and different interpretations can be seen on literature. Sometimes this kind of features and characteristics are called defences or energy models. Types and classification of safety barriers can also promote some discussion. For example, a division of hard and soft defences was made by Reason, where the former include physical barriers and alarms and the later refers to regulation, procedures and training [2]. For this reason, and according to the author, defence is a wider concept than barrier. The concept of "defence-in-depth" is also discussed meaning successive layers of protection.

Regarding an interesting work done by Sklet [6] about safety barriers definition, classification and performance, it has been concluded that either in literature or standards there are not universal definitions for terms like safety barrier, defence, layer of protection analysis (LOPA), safety function or other related terms.

\section{II.1. SAFETY BARRIER AND SAFETY FUNCTION}

In accordance to his review Sklet [6] defines safety barriers as physical and/or non-physical means planned to prevent, control or mitigate undesired events or accidents. It is distinct of a safety function that means a function planned to prevent, control or mitigate undesired events or accidents and so describes the purpose of safety barriers with a direct and significant effect. Usually, a safety function is described with a verb and a noun (e.g. "open valve"). A barrier system is a system designed and implemented to perform one or more barrier function. Hollnagel [7] distinguishes between what barriers "do" and what barriers "are", pointing out the first situation as the safety function and the last one as the way to achieve the referred function, meaning the barrier system by itself.

Duijm [8] defines in a simple way a safety barrier as a series of elements that implement a barrier function, where each element consists of a technical system or a human action.

In accordance to Dianous and Fiévez [9] safety barriers can be physical and engineered systems or human actions based on specific procedures or administrative controls. Sometimes these two types are interchangeable and work together to keep the effectiveness of the safety function. So, safety barrier is related to the way how the safety function is accomplished.

\section{II.2. SAFETY BARRIER CLASSIFICATION}

Concerning safety barrier classification, several interpretations can be seen when observing the literature available. There is not a consensus about safety barrier classification. Dianous and Fiévez [9] define four main categories for safety barriers:

- Active barriers - Barriers automated or activated manually and always require a sequence of detectiondiagnosis-action. This sequence can be performed using hardware, software and/or human actions;
- Passive barriers - Barriers with permanent functioning where there is no need for human actions and energy or information sources (e.g. firewall, corrosion prevention systems or inherent safe design);

- Human actions - Barriers which effectiveness is related with the knowledge of the operator. These human actions rely on the use of the human senses, effective communication, thinking, rules, guidelines and safety principles and may be part of the detection-diagnosisaction sequence;

- Symbolic barriers - Barriers that need an interpretation by a person in order to achieve their purpose (e.g. passive warnings).

Hollnagel [7] also presents four types of systems or barriers, but with a different notation:

- Physical (or material) barrier - Barrier that prevents the event occurrence or mitigates the effects by blocking the transportation of mass, energy or information from one place to another (e.g. walls, containers, fire curtains);

- Functional barrier - Barrier that creates one or more pre-conditions that have to be met before an action can be carried out (e.g. interlock system);

- Symbolic barrier - Barrier that works indirectly through their meaning, requiring an interpretation by someone (e.g. signals, warnings or alarms);

- Incorporeal barrier - Barrier that it is not a physical barrier, depends on the knowledge of the user and is often related to organisational barriers (e.g. rules for actions).

Independent of their classification, safety barriers can be represented in a bowtie diagram, where preventive and protective safety functions are included. Figure 1 shows those safety barriers on both sides of the diagram.

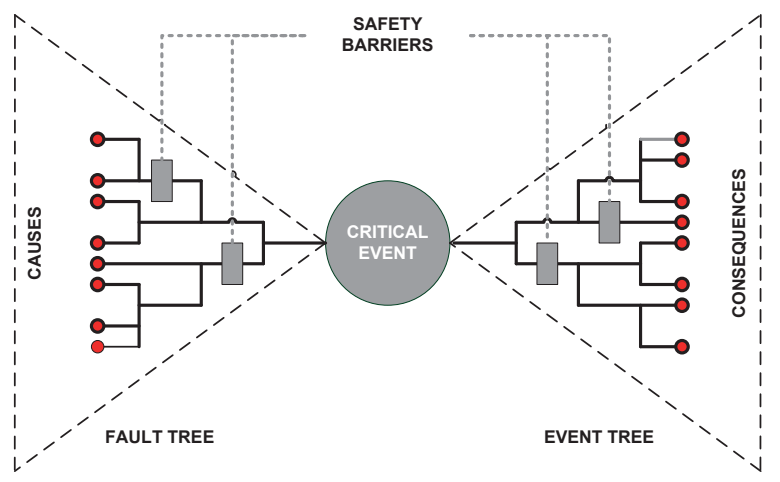

Fig. 1. Bowtie diagram for safety barriers

In this paper it was established and assumed a safety barrier classification based on two factors:

- Type of barrier - what barrier "is"; 
- Mode of operation of the barrier - how it "operates".

The different types and modes proposed on this paper are shown on Figure 2. This classification was used in the demonstrative example of Section IV.

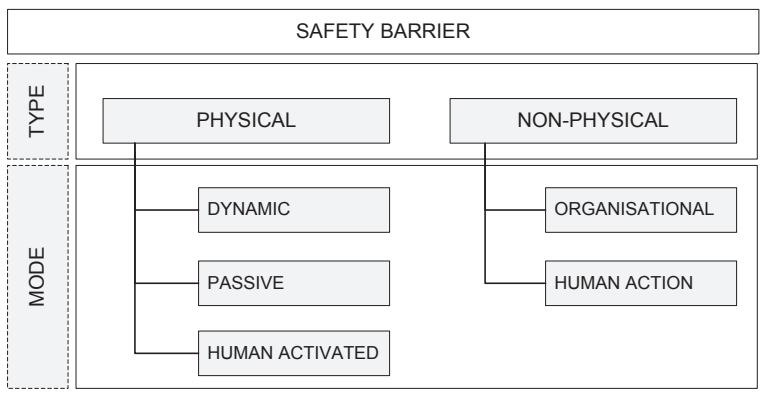

Fig. 2. Safety barrier classification

The "type" of safety barrier defines if it is a physical or a non-physical system. It means that a physical safety barrier is something that exists whether its function could be preventive or protective. The "mode" is related with the way how it acts when a demand happens.

A dynamic safety barrier corresponds to an automated system that is expected to operate changing from a dormant state to a living state and without human intervention (e.g. an automated sprinkler system or an automated shutdown valve).

A passive safety barrier is intended as static system that remains in the same state and usually is a design system with protective function (e.g. a fire wall).

A human activated safety barrier is a physical system that needs to be activated by someone. This is what differentiates a human activated safety barrier from a dynamic safety barrier.

By other side, an organisational safety barrier is related to training, safety procedures and internal rules and regulations established to avoid an accident or incident or to minimise the effects of the consequences (e.g. evacuation procedure).

At last, a human action safety barrier is any human actuation that not involves the use of physical systems (e.g. workplace cleaning).

\section{SAFETY INTEGRITY REQUIREMENTS}

IEC 61508 [10] standard represents a guide for design, validation and verification of a safety instrumented system (SIS) which fundamental purpose is to bring the plant or equipment to a safe state if an undesirable events occurs. The probability of a SIS satisfactory perform the required safety function under all the stated conditions within a specific time interval is called safety integrity. This standard defines four discrete levels for safety integrity named "safety integrity level" (SIL). In this scope a "SIL 4" corresponds to the higher level of safety integrity and "SIL 1" to the lowest one. The hardware safety integrity requirements include an estimation of the probability of failure on demand (PFD) or probability of failure per hour $(\mathrm{PFH})$, when a low or high demand (or even continuous) mode occurs, respectively [11].

Table I shows the safety integrity levels according IEC 61508 for the two situations above mentioned.

TABLE I. SAFETY INTEGRITY LEVELS (SIL)

\begin{tabular}{ccc}
\hline SIL & $\begin{array}{c}\text { Low demand mode } \\
\text { (average } \\
\text { probability of } \\
\text { failure on demand) }\end{array}$ & $\begin{array}{c}\text { High demand or } \\
\text { continuous mode } \\
\text { (probability of a } \\
\text { dangerous failure } \\
\text { per hour) }\end{array}$ \\
\hline 4 & $10^{-5}-10^{-4}$ & $10^{-9}-10^{-8}$ \\
3 & $10^{-4}-10^{-3}$ & $10^{-8}-10^{-7}$ \\
2 & $10^{-3}-10^{-2}$ & $10^{-7}-10^{-6}$ \\
1 & $10^{-2}-10^{-1}$ & $10^{-6}-10^{-5}$ \\
\hline
\end{tabular}

Jin et al [12] refer the IEC 61508 to define a low demand when the demand rate is less than once per year and less than twice the functional test frequency giving the example of emergency shutdown systems (ESD), fire and gas detection systems, process shutdown systems (PSD) and airbag systems installed in cars. For high demand systems the referred authors give the example of dynamic positioning (DP) systems for ships and offshore platforms, anti-lock braking systems (ABS) and railway signalling systems.

The IEC 61508 refers a "low demand mode" when the safety function is only performed on demand, in order to transfer the equipment under control (EUC) into a specified safe state, and when the frequency of demands is no greater than one per year. A high demand mode refers the situation where the safety function is only performed on demand, in order to transfer the EUC into a specified safe state, and where the frequency of demands is greater than one per year. Continuous mode is where the safety function retains the EUC in a safe state as part of normal operation.

The PFD is related to safety unavailability of the system and corresponds to the fraction of time that the system is unavailable to perform its function when the plant is operating. It can be modelled by several classical tools and methods such as Fault Tree Analysis (FTA), Markov Analysis (MA) and Reliability Block Diagrams (RBD), among others [13].

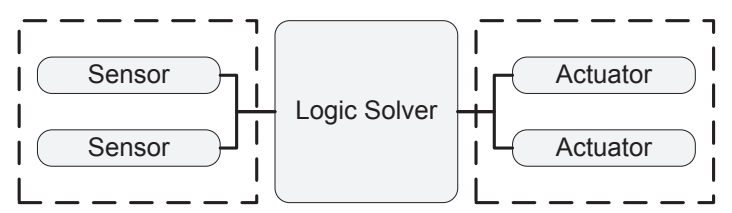

Fig. 3. Structure of a Safety Instrumented System (SIS)

Usually a SIS is presented as a structure with three main sub-systems, as shown in Figure 3. The first sub-system is related with the input elements present to detect the occurrence of a hazardous event such as sensors, switches, detectors, etc. The second sub-system concerns a logic solver 
or logic unit which is the element that will decide what to do (programmable logic devices, multi-agent structure, etc...). Finally, the last sub-system, including actuators (shutdown valves, cut-off energy devices, etc.) as the elements responsible for performing one or more safety instrumented functions (SIF), in accordance with the decision previously taken.

\section{III.1. SAFETY BARRIER PARAMETERS}

Risk control criteria are linked to the frequency and the severity of accident scenarios. The assessment of the frequency of occurrence of dangerous events is often based on statistical data. However, each analysis must be carried out with carefully because the available information is based on averaged data from different types of installation.

Usually, safety barriers are submitted to self-diagnostic and periodic tests or inspections. A dangerous failure puts the safety related system into a hazardous or failed condition. This happens, for example, due to existence of a hidden failure not detected by any kind of monitoring technique and only detected at the next test or inspection. A safe failure means a failure without the hazardous potential. When the dangerous failure is detected by some monitoring technique or self-tests, that is called as a dangerous detected failure. The following rates, assumed to be constant are then defined [14]:

- $\lambda_{\mathrm{DU}}=$ Dangerous undetected failure rate;

- $\lambda_{\mathrm{DD}}=$ Dangerous detected failure rate;

- $\lambda_{\mathrm{SU}}=$ Safe undetected failure rate;

- $\lambda_{\mathrm{SD}}=$ Safe detected failure rate;

- $\lambda_{\mathrm{S}}=$ Safe failure rate (detected + undetected);

- $\lambda_{\mathrm{D}}=$ Dangerous failure rate (detected + undetected $)$;

- $\mu_{\mathrm{DD}}=$ Repair rate (for dangerous detected failure).

Concerning the IEC 61508 some qualitative requirements can also be undertaken related to the architectural constraints that could limit the achievement of a determined SIL. These constraints could be the ability of a functional unit to continue to perform a function in the presence of faults or Fault Tolerance (FT) or the Safe Failure Fraction (SFF) which is a parameter that gives the fraction of overall hardware failure rate of the device considered as "safe", given by:

$$
S F F=\frac{\lambda_{S}+\lambda_{D D}}{\lambda_{S}+\lambda_{D}}
$$

The SFF value can be used to obtain a type of architecture for a given SIL (concerning the hardware fault tolerance) or can be applied to quantify the maximum expected SIL for a given architecture (type of SIS complexity) [14].

The ratio of the dangerous detected failure rate with respect to the total dangerous failure rate is called the "Diagnostic Coverage" (DC) and is an important parameter to be taken into account once dangerous failures early detected allows avoiding or mitigating undesirable situations.

$$
D C=\frac{\lambda_{D D}}{\lambda_{D}}
$$

Reference should also be made to a similar standard, known as ANSI/ISA-S84.01-1996, because it is still a guidance document in the United States (US), considered by the US Environmental Protection Agency (EPA) and the Occupational Safety and Health Administration (OSHA) as a generally accepted good industry practice. Based on this assumption it is mandatory that any US based instrumented system specified after march 1997 must be designed and developed in compliance with this standard [15] [16].

The dangerous undetected (DU) failure rate is due to failures related to non-safe situations and is influenced by the Diagnostic Cover factor.

$$
\lambda_{D U}=(1-D C) \cdot \lambda_{D}
$$

The periodic activity of safety barrier testing has the objective to find dangerous undetected failures or hidden failures and so achieve and improve the safety integrity level of the system.

The test interval $(\tau)$ should be, by one side the shortest one in a way to detect potential hidden failures, but by another side this kind of frequency brings higher cost and eventually increases the probability of human error induced during the referred tests. In general DU failures of the SIS are not detected immediately and are also referred to as dormant failures [17] [18].

After determining the PFD, a discrete SIL level is defined (Table I). Each SIL number represents a bounded interval for the probability of failure on demand (PFD). Some people assume the PFD as the average value of the unreliability function over an inspection period, but others interpret that as the steady state unavailability. In this later concept it is necessary to apply a Markovian approach just to observe the behaviour of the SIS in a continuous time, including the inherent repair rates.

Some studies introduce the concept of safety-related uncertainty when determining the safety integrity level (SIL). $\mathrm{Xu}$ et al. [19] state that the conventional global sensitivity analysis (GSA) is inappropriate to handle overall uncertainty when safety related uncertainty is of interest. The authors present and discuss four methods to measure it and compare with GSA. GSA is a useful technology to determine which parameters influence the output the most when uncertainty in the parameters is propagated through the model. It can identify critical parameters and rank them with respect to reliability and risk.

\section{III.2. LAYER OF PROTECTION ANALYSIS}

The layer of protection analysis (LOPA) is a method for determining the needed SIL of a SIS. This method can be applied after the HAZOP (Hazard and Operability) analysis where the identified consequences are classified for severity level. During the HAZOP analysis the various process deviations are analysed and the possible consequences are determined. To reduce or mitigate the effect of the consequences of the hazardous event some safeguards or barriers are designed. LOPA is a semi-quantitative methodology that can be used to identify safety barriers that 
meet the independent protection layer (IPL) criteria and work as extrinsic safety systems (active or passive systems). Summers [20] states some examples of IPL:

- Standard operating procedures;

- Basic process control systems;

- Alarms with defined operator response;

- Safety instrumented systems;

- Pressure relief devices;

- Blast walls and dikes;

- Fire and gas system;

- Deluge systems.

In accordance with the same author, LOPA provides specific criteria and restrictions for the evaluation of IPL, eliminating the subjectivity of qualitative methods and substantially less cost than fully quantitative techniques.

The IPL must meet the independence, specificity, dependability and auditability requirements. It means that the IPL must be completely independent of the initiating event. The probability of failure on demand (PFD) of an IPL is a measure of the risk reduction that can be obtained. For SIS the PFD is observed as the SIL level.

\section{III.3. SAFETY BARRIER ASSESSMENT}

Several methods related to barrier assessment and several variants can be found in literature. Methods such as the energy model, the Management Oversight and Risk Tree (MORT) method, the Accident Evolution and Barrier (AEB) analysis or the more classical Fault Tree Analysis (FTA) or Event Tree Analysis (ETA) are some of the methods used to study safety barriers.

The determination of the PFD of the safety functions are carried out according to the principles derived from the safety integrity level concept available in IEC 61508 [10] and IEC 61511 [21] standards knowing the reliability of the safety barrier. IEC 61508 is a generic standard common to several industries that states requirements for safety systems, while IEC 61511 was developed to the process industry.

In accordance with the regulations of Petroleum Safety Authority (PSA) in Norway, the performance of barriers can be seen as comprising three elements [22]:

- Functional requirements - Qualities such as capacity and efficiency related to the effect that the barrier has on the event/accident chain given that it functions;

- Integrity requirements - Qualities such as availability and reliability related to the barrier's ability to function when required and/or demanded;

- Vulnerability requirements - Qualities related to robustness and the barrier's ability to withstand relevant accidental loads.

Hollnagel [7] presents several different possible points to evaluate the quality of a safety barrier:

- Efficiency - how well the safety barrier meets its intended function;
- Resource needs - cost to design, develop and maintain a safety barrier;

- Robustness - related to reliability, measures how well a barrier can withstand the variability of the environment;

- Implementation delay - corresponding to time from safety barrier conception till its implementation;

- Availability - whether the barrier can fulfil its purpose when needed;

- Evaluation - how easy is the determination if the safety barrier works as expected;

- Independence - the safety barrier doesn't depend on human actuation to achieve its purpose.

The ARAMIS project presents three criteria for the assessment of the performance of safety barriers [9]:

- Effectiveness - is the ability of a safety barrier to perform a safety function during a determined period of time, in a non-degraded mode and in specified conditions. It is usual to present the effectiveness as a percentage or probability of the performance of the defined safety function;

- Response time - is related to the period between the straining of the safety barrier and the complete achievement of the safety function performed by the safety barrier;

- Level of confidence - is related to its reliability and is inversely proportional to the probability of failure on demand (PFD). It corresponds to the reliability of the barrier to perform properly the required safety function according to a specific effectiveness and response time under the stated conditions within a stated period of time.

The level of confidence of a safety barrier is based on some qualitative factors such as:

- The independence of the safety barrier (with causes and regulation systems);

- The architecture of the safety barrier (according to the complexity of the subsystems);

- The proven concept of the barrier (tested, experienced);

- The existence of periodic tests.

The level of confidence of a subsystem relies on two parameters:

- The Safe Failure Fraction (SFF) - Ratio between the frequency of failure corresponding to a safe failure and the frequency of failure of total failures;

- The Fault Tolerance (FT) - Linked to the capacity of the barrier to keep its safety function although the failure of one or more subsystems that belong to the safety barrier. It is usually kinked to the existence of redundancies. A Fault Tolerance of " 1 " means that if one component is defective, the safety function remains operational. 
In this case, the referred IEC 61508 and IEC 61511 standards divide the subsystems into two main classes or types:

- Type "A" - Simple Subsystem - If the failure modes of all safety barrier components are well defined;

- Type "B" - Complex Subsystem - If the failure mode of at last one component is not well defined.

The qualitative criteria for these two types of constraints are presented in Table II:

TABLE II. ARCHITECTURAL CONSTRAINTS

\begin{tabular}{ccccccc}
\hline & \multicolumn{5}{c}{ Fault Tolerance (FT) } \\
\cline { 2 - 7 } Safe Failure & \multicolumn{4}{c}{ Type "A” } & \multicolumn{3}{c}{ Type "B” } \\
\cline { 2 - 7 } & 0 & 1 & 2 & 0 & 1 & 2 \\
\hline SFF $<60 \%$ & LC 1 & LC 2 & LC 3 & na & LC 1 & LC 2 \\
$60 \%<$ SFF $<90 \%$ & LC 2 & LC 3 & LC 4 & LC 1 & LC 2 & LC 3 \\
$90 \%<$ SFF $<99 \%$ & LC 3 & LC 4 & LC 4 & LC 2 & LC 3 & LC 4 \\
SFF $\geq 99 \%$ & LC 4 & LC 4 & LC 4 & LC 3 & LC 4 & LC 4 \\
\hline na $=$ not applicable & & & & & &
\end{tabular}

For example:

- For a simple (type "A") SIS, with a 1002 architecture and a SFF of $75 \%$, it is expected a SIL 3 or LC 3 (maximum);

- For a complex (type "B") SIS, with a SFF of $80 \%$ and a desired SIL 2 or LC 2, it is recommended a FT of 1, with an architecture of 1002 .

The quantitative criteria are related to the probability of failure of the subsystems (type "A" or " $\mathrm{B}$ ") and depends on the mode of operation (low demand or high demand or continuous mode), as presented on Table I. On the level of confidence concept there is a correspondence between the LC and the SIL numbers.

The level of confidence of the safety barrier is then achieved assuming the lowest level of confidence of the analysed subsystems. Langeron et al. [14] and Guo and Yang [23] go a little bit further explaining how to determine the $\mathrm{SIL} / \mathrm{LC}$ for series and parallels arrangements of subsystems in a way to achieve the global SIL/LC for a system (safety barrier).

\section{METHODOLOGY PROPOSED}

Following the previous Sections and all the theoretical and practical issues analysed, a methodology to assess safety barriers is proposed in this Section. In simultaneous a demonstrative example is presented to show the applicability of the methodology to a real safety barrier.

The demonstrative example is based on a common safety system that is present in almost industrial facilities and commercial or residential buildings. This system acts in a protective mode, facing the undesirable consequences of a fire and so it is called "fire fighting system". The equipment under control (EUC) is assumed to be the facility or the building itself and the safety barrier is the "fire pumping system". Its safety function (SF) is to pressurize water to the fire extinguishing system. This equipment can be assessed assuming it as an independent protection layer (IPL) and applying the structure of a safety instrumented system (SIS) (see Figure 3).

In accordance with the classification proposed in this paper in Section II.2, this safety barrier is classified as:

- $\quad$ Type $=$ Physical;

- Mode = Dynamic

Based on these principles and regarding all the equipment design details and operating mode, the three subsystems of the SIS were defined as shown in Table III.

TABLE III. SAFETY BARRIER SUBSYSTEMS

\begin{tabular}{|c|c|c|}
\hline Subsystem & ID & Individual Function \\
\hline Sensor System & $\begin{array}{l}\text { Pressure } \\
\text { Switches }\end{array}$ & $\begin{array}{l}\text { Detect a pre-selected pressure } \\
\text { level and transmit an electric } \\
\text { signal to the Control System. It } \\
\text { includes two starter pressure } \\
\text { switches (one per pump) and } \\
\text { two security pressure switches } \\
\text { (one per pump). }\end{array}$ \\
\hline Logic System & $\begin{array}{l}\text { Control } \\
\text { System }\end{array}$ & $\begin{array}{l}\text { Receive the electric signal from } \\
\text { the Pressure Switches and give } \\
\text { order to activate the } \\
\text { Pressurization System (one } \\
\text { jockey pump and one of the } \\
\text { two main pumps). }\end{array}$ \\
\hline Actuator System & $\begin{array}{l}\text { Pressurization } \\
\text { System }\end{array}$ & $\begin{array}{l}\text { Receive the order from the } \\
\text { Control System and put a } \\
\text { determined flow of water at a } \\
\text { determined pressure (design } \\
\text { characteristics) on the } \\
\text { hydraulic fire fighting system } \\
\text { (extinguishing system). }\end{array}$ \\
\hline
\end{tabular}

The following step of the methodology is to describe all subsystem failure modes. At this stage a team work and a historic of failure analysis is fundamental once both potential and registered failures are essential to complete this part of the methodology. This is a kind of a partial failure mode and effects analysis (FMEA).

After this, the next step is to classify the safety function failure. To do so, it must be fulfilled for all identified failure modes the degree of severity as "safe" or "dangerous" and the degree of detectability as "yes" or "no". Based on the combination of these two factors the safety function failure could be classified as shown in Table IV.

TABLE IV. SAFETY FUNCTION FAILURE CLASSIFICATION

\begin{tabular}{lll}
\hline \multicolumn{1}{c}{ Severity } & Detectability & \multicolumn{1}{c}{ Safety Function Classification } \\
\hline Safe & Yes & SD - Safe Detected \\
Safe & No & SU - Safe Undetected \\
Dangerous & Yes & DD - Dangerous Detected \\
Dangerous & No & DU - Dangerous Undetected \\
\hline
\end{tabular}


From this classification all the dangerous undetected failure modes are selected and analysed at the next stage. For each one a dangerous undetected failure rate is achieved and based on the test interval $(\tau)$ of the subsystem an individual $\mathrm{PFD}_{\mathrm{i}}$ is determined.

$$
P F D_{i}=\frac{\lambda_{D U} \cdot \tau}{2}
$$

The PFD $_{\text {Ss }}$ of each subsystem is reached assuming the highest individual $\mathrm{PFD}_{\mathrm{i}}$.

$$
P F D_{S S}=\max \left(P F D_{i}\right)
$$

The safety barrier probability of failure on demand $\left(\mathrm{PFD}_{\mathrm{SB}}\right)$ is then determined by the sum of the subsystems probability of failure on demand ( $\mathrm{PFD}_{\mathrm{SS}}$ ) once the failure of the safety barrier could happen due to a failure on the Sensor System or on the Logic System or on the Actuator System.

$$
P F D_{S B}=\sum P F D_{S S}
$$

Based on the $\mathrm{PFD}_{\mathrm{SB}}$ and on Table I the safety integrity level (SIL) is determined.

The next step is to estimate the probability of occurrence of the initiating event (POIE). At the present example the initiating event is the existence of a "fire". The estimated probability value is then allocated into one of five levels according to Table $\mathrm{V}$.

TABLE V. Probability of ocCURRENCE of INTITIATING EVENT (POIE)

\begin{tabular}{lll}
\hline \multicolumn{1}{r}{ Level } & ID & Probability [occur./year] \\
\hline Very High & VH & $\mathrm{p}>1$ \\
High & $\mathrm{H}$ & $0,5<\mathrm{p}<1$ \\
Moderate & $\mathrm{M}$ & $0,1<\mathrm{p}<0,5$ \\
Low & $\mathrm{L}$ & $0,001<\mathrm{p}<0,1$ \\
Very Low & $\mathrm{VL}$ & $\mathrm{p}<0.001$ \\
\hline
\end{tabular}

Finally, the acceptance of the safety barrier is based on the determined SIL and on the POIE. If the result falls into a red zone of the matrix represented on Table VI it is not acceptable and something must be done (e.g. implement measures to reduce the POIE or increase the SIL value of the safety barrier). If it falls on the yellow zone it is acceptable but with remarks (meaning that an accurate analysis should be done on that cases). Obviously the green zone is the desirable one meaning that we have a safety barrier integrity level adequate to accomplish the safety function for the considered hazard.

It is also possible to determine the probability of a hazardous situation taking into account the POIE and the SIL corresponding to the PFD $\mathrm{SB}$.

$$
P H S=P F D_{S B} \cdot P O I E
$$

In accordance to the proposed methodology a simple tool was developed bringing automated and reliable results.
TABLE VI. ACCEPTABILITY MATRIX

\begin{tabular}{|l|c|c|c|c|}
\hline \multicolumn{1}{|c|}{ POIE } & \multicolumn{4}{c|}{ SIL } \\
\hline Very High & 4 & 3 & 2 & 1 \\
\cline { 2 - 5 } High & 4 & 3 & 2 & 1 \\
\cline { 2 - 5 } Moderate & 4 & 3 & 2 & 1 \\
\cline { 2 - 5 } Low & 4 & 3 & 2 & 1 \\
\cline { 2 - 5 } Very Low & 4 & 3 & 2 & 1 \\
\hline
\end{tabular}

\section{CONCLUSIONS AND FUTURE WORK}

This study illustrates how risk can be managed through safety barriers assessment. Some standards related to the assessment of safety barriers and safety functions were referred and some misunderstanding around concepts and their interpretation was clarified. It was proposed a classification for safety barriers according to their type and operation mode.

In the present work some requirements that must be fulfilled to achieve the necessary integrity level were mentioned and it was shown how to reach them.

Based on the theory and on previous works about safety barriers, safety instrumented systems and risk management a new methodology to assess safety barriers was proposed. In this methodology it is possible to identify dangerous undetected failure modes and determine the probabilities of those failures occur. Once determined such parameters it is possible to calculate the probability of failure on demand for the entire safety barrier.

Furthermore the study has shown that some innovation is brought with this methodology when the probability of occurrence of initiating event (POIE) is also considered and when the decision on acceptance of a safety barrier is based on both indicators, the SIL and the POIE.

Based on this work some studies can be developed in the future, including at the model the consideration of architectural constraints, repair rate times, self-diagnostic of failures (diagnostic coverage) and other methods to determine the probability of individual failures according to the period established to test the barrier as well as other influencing factors.

\section{REFERENCES}

[1] Kecklund, L, Edland, A., Wedin, P. and Svenson, O., "Safety barrier function analysis in a process industry: A nuclear power application", International Journal of Industrial Ergonomics, vol. 17, pp. 275-284, 1996.

[2] Harms-Ringdahl, L., "Analysis of safety functions and barriers in accidents", Safety Science, vol. 47, pp. 353-363, 2009.

[3] Duijm, N. and Markert, F., "Safety-barrier diagrams as a tool for modelling safety of hydrogen applications", International Journal of Hydrogen Energy, vol. 34, pp. 5862-5868, 2009.

[4] Beugin, J., Renaux, D. and Cauffriez, L., "A SIL quantification approach based on an operating situation model for safety evaluation in complex guided transportation systems", Reliability Engineering and System Safety, vol. 92, pp. 1686-1700, 2007.

[5] Wenjin, Z., Nan, L. and Xinwei, L., "Estimating Technology of Safety Integrity Level of Safety-Related Systems in High-speed Train”, IERI Procedia, vol. 1, pp. 172-177, 2012. 
[6] Sklet, S., "Safety barriers: Definition, classification, and performance", Journal of Loss Prevention in the Process Industries, vol. 19, pp. 494506, 2006

[7] Hollnagel, E., "Risk+barriers=safet?", Safety Science, vol. 46, pp. 221 229,2008

[8] Duijm, N., "Safety-barrier diagrams as a safety management tool", Reliability Engineering and System Safety, vol. 94, pp. 332-341, 2009.

[9] Dianous, V. and Fiéviez, C., "ARAMIS project: A more explicit demonstration of risk control through the use of bow-tie diagrams and the evaluation of safety barrier performance", Journal of Hazardous Materials, vol. 130, pp. 220-233, 2006.

[10] IEC, "IEC 61508: Functional safety of electrical, electronic and programmable electronic safety-related systems - Parts 1-7", International Electrotechnical Comission, Geneva, 2002.

[11] Catelani, M., Ciani, L. and Luongo, V., "The FMEDA approach to improve the safety assessment according to the IEC 61508", Microelectronics Reliability, vol. 50, pp. 1230-1235, 2010.

[12] Jin, H., Lundteigen, M. and Rausand, M., "Reliability performance of safety instrumented systems: A common approach for both low and high-demand mode of operation", Reliability Engineering and System Safety, vol. 96, pp. 365-373, 2011.

[13] Torres-Echeverría, A., Martorell, S. and Thompson, H., "Modelling and optimization of proof testing policies for safety instrumented systems", Reliability Engineering and System Safety, vol. 94, pp. 838-854, 2009.

[14] Langeron, Y., Barros, A., Grall, A. and Bérenguer, C., "Combination of safety integrity levels (SILs): A study of IEC 61508 merging rules",
Journal of Loss Prevention in the Process Industries, vol. 21, pp. 437449, 2008.

[15] Summers,A., "Viewpoint on ISA TR84.0.02 - simplified methods and fault tree analysis", ISA Transactions, vol. 39, pp. 125-131, 2000.

[16] Beckman, L., "Expanding the applicability of ISA TR84.02 in the field", ISA Transactions, vol. 39, pp. 357-361, 2000.

[17] Hokstad, P., "Demand rate and risk reduction for safety instrumented systems", Reliability Engineering and System Safety, vol. 127, pp. 1220, 2014.

[18] Sobral, J., "Utilização da metodologia RAMS na análise de barreiras de segurança de instalações industriais de risco elevado", Doctoral Thesis, FEUP - Faculdade de Engenharia da Universidade do Porto, 2010.

[19] Xu, M., Chen, T. and Yang, X., "The effect of parameter uncertainty on achieved safety integrity of safety system", Reliability Engineering and System Safety, vol. 99, pp. 15-23, 2012.

[20] Summers, A., "Introduction to layers of protection analysis", Journal of Hazardous Materials, vol. 104, pp. 163-168, 2003.

[21] IEC, "IEC 61511: Functional safety: Safety Instrumented Systems for the Process Sector", International Electrotechnical Comission, Geneva, 2003.

[22] Hauge, S., Krakenes, T., Habrekke, S., Johansen, G., Merz, M. and Onshus, T., "Barriers to prevent and limit acute releases to sea SINTEF A20727 Report", SINTEF, 2011.

[23] Guo, H. and Yang, X., "A simple reliability block diagram method for safety integrity verification", Reliability Engineering and System Safety, vol. 92 , pp. 1267-1273, 2007. 


\title{
Incorporating Carbon Penalties into Supplier Selection in the Supply Chain
}

\author{
Kanika Gandhi ${ }^{1}$; Diego Galar ${ }^{2}$; P. C. Jha ${ }^{3}$ \\ 1'gandhi.kanika@gmail.com; ${ }^{2}$ diego.galar@1tu.se; ${ }^{3}$ pcjha@yahoo.com \\ ${ }^{1,3}$ Department of Operational Research, University of Delhi \\ Delhi, India \\ ${ }^{2}$ Division of Operation and Maintenance Engineering, Lulea University of Technology, \\ Lulea, Sweden
}

\begin{abstract}
Supply chain management (SCM) practices have flourished since the 1990s. Enterprises realize that a large amount of direct and indirect cost can be managed from effective and efficient SCM practices. Supplier selection has great impact on integration of the supply chain relationship. Effective and accurate supplier selection decisions are significant components for procurement and distribution management in many firms to enhance their organizational performance. In this study a multiple sourcing procurement distribution optimization problem is considered. Three objective functions are minimization of costs, maximization of performance and minimization of carbon emission penalty cost respectively. In order to solve the problem, a fuzzy mathematical model and a fuzzy goal programming solution approach are proposed to satisfy the decision maker's aspirations for fuzzy goals. A real life case study is given to illustrate how the model is utilized.
\end{abstract}

Keywords-Carbon emission, Supplier selection, Carbon penalities, Supply cahin, Fuzzy goal programming, Deteriorating.

\section{INTRODUCTION}

In the current competition companies increasingly use their supply chain to compete and gain market share. Technology and process upgrades at companies clearly show that supply chain excellence is more widely accepted as an element of overall business strategy and that increasing value to customers is not just management's, but everyone's business. Today companies have understood that to make an important merger work, they would have to integrate its supply chain with their partners. In fact, the significant savings promised by the merger would not be possible without integrating activities in supply chain through all partners. The activities integrate in supply chain are procurement, manufacturing, inventory, distribution, logistics, retail store and end customer. Successful supply chain management, then, coordinates all these activities into a seamless process. It embraces and links all of the partners in the chain. To improve supply chain competitiveness, the companies must find and evaluate more efficient suppliers. Traditionally, supplier selection and evaluation methods focus on the requirements of single enterprises, and fail to consider the entire supply chain. Consequently, individual enterprises focus on developing their core capabilities and outsource non-core affairs to other partners or suppliers with different professional capabilities to upgrade their competitive advantage by applying these external and special sources and technology knowledge. In any supplier selection process, generally six main decision processes takes place viz: (1) make or buy, (2) supplier selection, (3) contract negotiation, (4) design collaboration, (5) procurement, and (6) sourcing analysis. Of these six decision process, supplier selection is one of the most vital and crucial decision and becomes more important when an organization has to select the supplier for more than one period and when the supplier's capacity, their quality level, lead time, and various cost parameters also vary. Therefore, the supplier selection for multi-period, multi-parts, and multi-source is a widely occurring phenomena in a large business organization while keeping the desired quality level. Hence, supplier selection is a multi-criteria problem which includes both tangible and intangible criteria, some of which may conflict.

On the other hand, finding coordination in procurement and distribution can be achieved by integrating means of coordination mechanisms as procurement, inventory, distribution, logistics and retail store in the optimization of the supply chain network. In a supply chain, if there is a single decision maker who tries to optimize the overall system, the structure is referred to as centralized. However, generally the various entities may have objectives' conflicts even when they belong to the same unit. For instance, procurement from supplier would be preferred in large lot sizes in order to reduce purchase costs. This would increase inventory amounts, and hence holding costs, which contradicts the objectives of the warehouses. On the other hand, a supply chain in which each entity tries to optimize its own system is referred to as decentralized. A centralized system leads to global optimization, whereas a decentralized system results in local optimization. Therefore, to achieve the global optimal solution in a decentralized supply chain, the conflicting objectives of the entities should be aligned through coordination issues. In the coordination, transportation of goods from one entity to another and inventory level at all the stages help in smooth integration. Proper inventory management has great influence on cost down and procurement stability for companies. In real world, the inventory of many products may face limitations as deterioration, deadlines of consumption (DOC), and vaporizing. That can be called as deteriorating inventory. 
When developing inventory model which have the traits of deterioration, it is very important to understand the traits and categories of deterioration by [1]. The deteriorating inventory has to be taken very seriously during coordination and may also be taken care with the help of return channels. This coordination can be adjoining in the above integration, as the transportation cost shall be associated in the return process. Finding out an optimum integration is important for understanding supply chain and its corresponding strategies and decisions as its members should be part of progression, which will be investigated in this paper.

\section{LITERATURE REVIEW}

In recent years, the studies of supply chain management focus on how to design the coordination schemes. Most work on coordinated supply chain scheduling focuses on coordinating the flows of supply and demand over a supply chain network to minimize the inventory, transportation and shortage costs. [2], [3] and [4] studied simplified models for integrated scheduling of production and distribution operations. The authors have analyzed computational complexity of various cases of the problem and have developed heuristics for NP-hard cases. [5] considered the problem of operations scheduling for capacitated multiechelon shipping network with delivery deadlines, where semi-finished goods are shipped from suppliers to customers through processing centers, with the objective of minimizing the shipping and penalty cost. The three polynomial-time solvable cases of this problem were reported: with identical order quantities; with designated suppliers; and with divisible customer order sizes. [6] developed a multi-objective mixed integer programming approach to address production, distribution and capacity planning of global supply chains considering cost, responsiveness and customer service level simultaneously.

A key component in developing a reliable supply chain is the selection of suppliers. Essentially, two types of supplier selection are prominent. In the first type (single sourcing), one supplier can satisfy the entire buyer's needs and the buyer needs to make only one decision: which supplier is the best. In the second and more common type (multiple sourcing), more than one supplier must be selected because no single supplier can satisfy all the buyer's orders. Hence, companies need to select both the best suppliers and how much quantity should be allocated among them for creating a constant environment of competitiveness [7]. Accordingly, multiple sourcing provides significant assurance of timely delivery and order flexibility due to the diversity of the firm's total orders [8]. Supplier selection is a multi criteria decision making (MCDM) problem containing both quantitative and qualitative criteria which, together, are in conflict. Goal programming (GP) is used widely for solving MCDM and multi-objective decision making (MODM) problems because of its simplicity and flexibility. Goal programming can handle relatively large numbers of decision variables, resource constraints, and objectives [9]. [10] proposed a multi-objective model for supplier quota allocation problem while demand was dependent on the offered price by suppliers. They solved their models using genetic algorithm and simulated annealing. [11] tried to construct a lot-sizing model with multi-suppliers and quantity discounts to minimize total cost over the planning horizon as a single-objective problem. The objective was to minimize total costs, where the costs include ordering cost, holding cost, purchase cost, and transportation cost.

[12] proposed a fuzzy multi-objective linear model for supplier selection in a supply chain by using an asymmetric fuzzy decision making technique to provide the decision maker to allocate different weights to various criteria. Bevilacqua et al. [13][5]* developed a fuzzy quality function deployment (QFD) approach for supplier selection problem. The quantitative techniques for supplier evaluation and selection can be categorized into three classes [14]: (1) multi-attribute decision making includes the linear weighting method and the analytical hierarchy process (AHP), (2) mathematical programming models include the linear programming models, mixed integer programming, multi-objective programming and data envelopment analysis, (3) intelligent approaches as for the last class include neural network based methods, expert systems, fuzzy decision making, hybrid approaches such as integrated AHP and linear programming, combined AHP, data envelopment analysis (DEA) and neural network has been applied for the supplier selection. Objective functions considered in the literature are minimizing the negative effect of vendor service rating, minimizing the negative effect of the economic environment [15], maximizing service and minimization of risk [16]. Objectives' aspiration levels are determined often by using ideal solutions. Other fuzzy parameters are buyer demand, vendors' quotas, and budget amount allocated to vendors, maximum capacity of vendors as right hand side constants. The parameters like consumption and performance parameters make the current study fuzzy. The paper shows a fuzzy multi-objective optimization model, conversion process of model in crisp process and the solution of the case discussed.

\section{PROBLEM DESCRIPTION}

The supply chain considered in this paper has three stages consisting of multiple independent suppliers with limited capacities, one intermediate point (warehouse), and one buyer (Retail store) along with return channel of deteriorated inventory. The model is a multi objective fuzzy optimization problem. The first objective of the model finds the optimum cost while ordering quantity from suppliers and procured at one warehouse. Further the inventory at warehouse is shipped to buyer as per requirement which incurs transportation cost and return channel cost of deteriorated inventory from retail store to warehouse. The transportation cost from supplier to warehouse is not discussed in the model as it is part of purchasing cost and supplier is taking care of it fully. The cost of transportation from warehouse to retail store uses transportation policies, who specify to take truckload (TL) policy, or truckload \& less than truckload (TL \& LTL) policy. The second objective chooses the best supplier on the bases of lot size 
acceptance and on-time delivery percentage. Third objective of the model find least carbon emission cost as per the distance travelled from supplier to warehouse, which is also one of the criteria to select a supplier.

Hence, the model discussed above integrates inventory, procurement and transportation mechanism to minimize all costs discussed above and also chooses the best supplier. The total cost of the model becomes fuzzy due to fuzzy holding cost and consumption. On the other hand, performance level is also fuzzy as percentage of on-time delivery and acceptances are fuzzy. So the model discussed above is fuzzy multi objective mixed integer non-linear model. In the solution process, the fuzzy model is converted into crisp and further fuzzy goal programming approach is employed where each objective could be assigned a different weight.

\section{MODEL FORMULATION}

The paper discussed a multi objective fuzzy optimization model, where first objective finds the optimum quantity; second objective find the best supplier and third objectives check carbon emission cost. The assumptions of the model says that demand at retail store is uncertain, supply of required quantity is instantaneous, available inventory at warehouse and retail store is positive at beginning of the planning horizon, which helps in managing ordered quantity from retail store and procurement from suppliers.

\section{A. Sets}

Product set with cardinality $P$ and indexed by $i$; Period set with cardinality $T$ and indexed by $t$; Supplier set with cardinality $J$ and indexed by $j$; Price break for carbon emission cost with cardinality $L$ and indexed by $l$.

\section{B. Parameters}

$C$ is fuzzy total cost; $C_{0} \& C_{0}^{*}$ are aspiration and tolerance

level of fuzzy cost respectively; $\tilde{P R}$ is total fuzzy the fuzzy performance of supplier; $P R_{0} \& P R_{0}^{*}$ are aspiration and tolerance level for fuzzy supplier's performance; $P C$ is cost of carbon emission; $\tilde{H S}_{i t} \& \overline{H S}_{i t}$ are fuzzy and defuzzified holding cost at warehouse; $\phi_{i j t}$ is unit purchase cost for $i^{\text {th }}$ product in $t^{\text {th }}$ period from $j^{\text {th }}$ supplier; $s$ is cost per weight of transportation in LTL policy; $\beta_{t}$ is fixed freight cost for each

truck load in period t; $\tilde{H D}_{i t} \& \overline{H D}_{i t}$ are fuzzy and defuzzified holding cost at retail store; $\lambda_{i t}$ is per unit inspection cost at retail store; $V h_{i t}$ is transportation cost of return channel from retail store to warehouse; $D C_{i t}$ is disposal cost of deteriorated quantity; $\widetilde{C R}_{i t} \& \overline{C R}_{i t}$ are fuzzy and defuzzified consumption at retail store respectively; $I S N_{i t} \& I D N_{i t}$ are inventory level at beginning of the planning horizon at warehouse and retail store; $\eta$ is constant deteriorating percentage at retail store; $w_{i}$ is per unit weight; $\omega$ is weight per full truck;
$\widetilde{D T}_{i j t} \& \overline{D T}_{i j t}$ are fuzzy and defuzzified on-time delivery percentage; $\tilde{A C}_{i j t} \& \overline{A C}_{i j t}$ fuzzy and defuzzified acceptance percentage; $C P_{i j}$ is the supplier's capacity; Dis ${ }_{j}$ is travelling distance from supplier $\mathrm{j}$ to warehouse; Amount $_{j t}$ is carbon emission threshold beyond which the higher emission cost incurs; Cost $P_{j t l}$ is cost of carbon emission; $D C_{a p}$ is disposal capacity at warehouse

\section{Decision Variables}

$I S_{i t} \& I D_{i t}$ are inventory levels at warehouse and retail house; $X_{i j t}$ is optimum ordered quantity of product i ordered in period $\mathrm{t}$ from supplier $\mathrm{j} ; X_{i t}$ is optimum ordered quantity of product $\mathrm{i}$ ordered in period $\mathrm{t}$ from all the suppliers; $L_{t}$ is total weighted quantity transported in stage I \& II respectively in period $t$ to retail store; $J_{t}$ is total number of truck loads in period $t ; y_{t}$ is weighted quantity in excess of truckload capacity; $u_{t}$ is usage of modes, either TL \& LTL mode (value is 1) or only TL mode (value is 0 ); $V_{i j t}$ is defined as, if ordered quantity is transported by supplier $j$ for product $i$ in period $t$ then the variable takes value 1 otherwise $0 ; D_{i t}$ is demand for product $i$ in period $t$ from retail store; $\mathrm{CO}_{i j t}$ is per unit carbon emission from supplier $\mathrm{j}$ to warehouse in period t; $P C_{j t l}$ is $l^{\text {th }}$ level of carbon emission cost activates as per the carbon emission threshold from supplier $j$ in period $t ; E X_{i t}$ is deteriorated inventory at retail store in period $t$ for product $i$.

\section{Formulation of Objective}

Fuzzy optimization is a flexible approach that permits adequate solutions of real problems when vague information is available, providing well defined mechanisms to quantify uncertainties directly. Therefore, we formulate fuzzy optimization model for vague aspiration levels on total cost, consumption, on-time delivery percentage and acceptance percentage where the decision maker may decide his aspiration levels on the basis of past experience and knowledge possessed by him.

Initially a bi-objective fuzzy model is formulated which discusses about fuzzy total cost and performance of the suppliers. The first objective of the model minimizes the total cost, including purchasing cost of goods from supplier, transportation cost from active supplier to warehouse, holding cost at warehouse for ordered quantity, transportation cost from warehouse to destination, cost of holding at retail store, inspection cost of the reached quantity at retail store, transportation cost of deteriorated quantity from retail store to warehouse and finally, disposal cost at warehouse.

$$
\begin{aligned}
& \operatorname{Min} \tilde{C}=\sum_{t=1}^{T} \sum_{j=1}^{J} \sum_{i=1}^{P} \phi_{i j t} X_{i j t} V_{i j t}+\sum_{t=1}^{T} \sum_{i=1}^{P} \tilde{H} S_{i t} X_{i t}+\sum_{t=1}^{T}\left[\left(s y_{t}+j_{t} \beta_{t}\right) u_{t}+\left(j_{t}+1\right) \beta_{t}\left(1-u_{t}\right)\right] \\
& +\sum_{t=1}^{T} \tilde{H} D_{i t} I D_{i t}+\sum_{i=1}^{P} \sum_{t=1}^{T} \lambda_{i t} X_{i t}+\sum_{t=1}^{T} \sum_{i=1}^{P} E X_{i t} V h_{i t}+\sum_{t=1}^{T} \sum_{i=1}^{P} E X_{i t} D C_{i t}
\end{aligned}
$$


The second objective discusses the performance of suppliers and maximizes the performance percentage of supplier as per delivery time percentage and acceptance percentage of ordered lot.

$$
\operatorname{Max} \tilde{P R}=\sum_{i=1}^{T} \sum_{j=1}^{J} \sum_{i=1}^{P}\left(\tilde{D} T_{i j t}+\tilde{A C}_{i j t}\right) V_{i j t}
$$

The third objective calculates carbon emission cost from active supplier to warehouse on the bases of carbon emission threshold. Carbon emission is calculated as per distance travelled.

$$
\operatorname{Min} P C=\sum_{t=1}^{T} \sum_{j=1}^{J} \sum_{i=1}^{P}\left(C o_{i j t} V_{i j t}\right) \sum_{l=1}^{L} \operatorname{Cos} t P_{j t l} P C_{j t l}
$$

\section{E. Constraints' Formulation}

The constraints in the model handle the capacity restrictions, shortages restrictions. The following constraint ensures that an activated supplier cannot supply more that capacity.

$$
X_{i j t} \leq C P_{i j} V_{i j t} \quad \forall i, j, t
$$

Xit calculates total quantity to be supplied from all active suppliers.

$$
X_{i t}=\sum_{j=1}^{J} X_{i j t} \quad \forall i, t
$$

In a period, for a particular product, only one supplier will be allowed to supply goods is assured by the constraint.

$$
\sum_{j=1}^{J} V_{i j t}=1 \quad \forall i, t
$$

Following three equations calculate inventory in period $t$ at warehouse and ensure no shortage at destination.

$$
\begin{gathered}
I S_{i t}=I S_{i t-1}+X_{i t}-D_{i t} \quad \forall i, t>1 \\
I S_{i t}=I S N_{i t}+X_{i t}-D_{i t} \quad \forall i, t=1 \\
\sum_{t=1}^{T} I S_{i t}+\sum_{t=1}^{T} X_{i j} \geq \sum_{t=1}^{T} D_{i t} \quad \forall i
\end{gathered}
$$

Next equation is an integrator and calculates the total weighted quantity to be transported from warehouse to retail store.

$$
L_{t}=\sum_{i=1}^{P} \omega_{i} X_{i t} \quad \forall t
$$

The constraint mentioned below checks the transportation policy as per the weighted quantity. It clearly specifies that, if the total weighted quantity is above the capacity of truck then LTL policy will get activated and otherwise only TL policy will be used.

$$
L_{t} \leq\left(y_{t}+j_{t} w\right) u_{t}+\left(j_{t}+1\right) w\left(1-u_{t}\right) \quad \forall t
$$

The equation measures the overhead weights from truckload capacity.

$$
L_{t}=y_{t}+j_{t} w \quad \forall t
$$

Next three constraints calculate inventory and optimum demand size at the destination, while considering deterioration percentage and ensuring no shortages.

$$
\begin{gathered}
I D_{i t}=I D N_{i t}+D_{i t}-\tilde{C R_{i t}} \quad \forall i, t=1 \\
I D_{i t}=I D_{i t-1}+D_{i t}-\tilde{C R_{i t}} \quad \forall i, t>1 \\
\sum_{t=1}^{T} I D_{i t}+\sum_{t=1}^{T} D_{i t} \geq \sum_{t=1}^{T} \tilde{C R_{i t}} \quad \forall i
\end{gathered}
$$

Following three equations evaluate carbon emission as per distance travelled and choose the level of cost as per emission threshold.

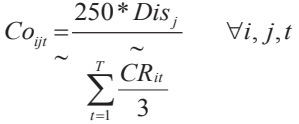

$$
\begin{aligned}
& C O_{i j t} \geq \sum_{l=1}^{L} \text { Amount }_{j t l} P C_{j t l} \quad \forall i, j, t \\
& \sum_{l=1}^{L} P C_{j t l}=1 \quad \forall j, t
\end{aligned}
$$

Following three equations calculate deteriorated inventory, and ensures that warehouse cannot dispose more than its capacity.

$$
\begin{gathered}
E X_{i t}=\eta I D_{i t-1} \quad \forall i, t>1 \\
E X_{i t}=0 \quad \forall i, t=1 \\
\sum_{i=1}^{P} E X_{i t} \leq \sum_{i=1}^{P} D^{P} \text { a }_{i t} \quad \forall t
\end{gathered}
$$

Finally constraint mentioned below enforces the binary and non-negativity restrictions on decision variables.

$X_{i j t}, X_{i t}, L_{t}, D_{i t}, C O_{i j t} \geq 0 ; V_{i j t}, u_{t}, P C_{j t l} \in[0,1] ; I S_{i t}, I D_{i t}, E X_{i t} y_{t}, j_{t}$ are integer

\section{F. Formulated Model}

$$
\begin{aligned}
& \operatorname{Min} \tilde{C}=\sum_{t=1}^{T} \sum_{j=1}^{J} \sum_{i=1}^{P} \phi_{i j t} X_{i j t} V_{i j t}+\sum_{t=1}^{T} \sum_{i=1}^{P} \tilde{H}{ }_{i t} X_{i t} \\
& +\sum_{t=1}^{T}\left[\left(s y_{t}+j_{t} \beta_{t}\right) u_{t}+\left(j_{t}+1\right) \beta_{t}\left(1-u_{t}\right)\right]+\sum_{t=1}^{T} \tilde{H} D_{i t} I D_{i t} \\
& +\sum_{i=1}^{P} \sum_{t=1}^{T} \lambda_{i t} X_{i t}+\sum_{t=1}^{T} \sum_{i=1}^{P} E X_{i t} V h_{i t}+\sum_{t=1}^{T} \sum_{i=1}^{P} E X_{i t} D C_{i t} \\
& \operatorname{Max} \tilde{\operatorname{PR}}=\sum_{t=1}^{T} \sum_{j=1}^{J} \sum_{i=1}^{P}\left(\tilde{D} T_{i j t}+\tilde{A C_{i j t}}\right) V_{i j t} \\
& \text { Min } P C=\sum_{t=1}^{T} \sum_{j=1}^{J} \sum_{i=1}^{P}\left(\tilde{\operatorname{CO}_{i j t}} V_{i j t}\right) \sum_{l=1}^{L} \operatorname{Cost} P_{j t l} P C_{j t l} \\
& \text { Subject to } X_{i j t} \leq C P_{i j} V_{i j t} \quad \forall i, j, t
\end{aligned}
$$




$$
\begin{aligned}
& X_{i t}=\sum_{j=1}^{J} X_{i j t} \quad \forall i, t \\
& \sum_{j=1}^{J} V_{i j t}=1 \quad \forall i, t \\
& I S_{i t}=I S_{i t-1}+X_{i t}-D_{i t} \quad \forall i, t>1 \\
& I S_{i t}=I S N_{i t}+X_{i t}-D_{i t} \quad \forall i, t=1 \\
& \sum_{t=1}^{T} I S_{i t}+\sum_{t=1}^{T} X_{i j} \geq \sum_{t=1}^{T} D_{i t} \quad \forall i \\
& L_{t}=\sum_{i=1}^{P} \omega_{i} X_{i t} \quad \forall t \\
& L_{t} \leq\left(y_{t}+j_{t} w\right) u_{t}+\left(j_{t}+1\right) w\left(1-u_{t}\right) \quad \forall t \\
& L_{t}=y_{t}+j_{t} w \quad \forall t \\
& I D_{i t}=I D_{i t-1}+D_{i t}-\tilde{C R_{i t}} \quad \forall i, t>1 \\
& I D_{i t}=I D N_{i t}+D_{i t}-\tilde{C R_{i t}} \quad \forall i, t=1 \\
& \sum_{t=1}^{T} I D_{i t}+\sum_{t=1}^{T} D_{i t} \geq \sum_{\sim}^{T} \tilde{C} \tilde{C R}_{i t} \quad \forall i \\
& C O_{i j t}=\frac{250 * \mathrm{Dis}_{j}}{\sim} \quad \forall i, j, t \\
& \sum_{t=1}^{T} \frac{C R_{i t}}{3} \\
& C O_{i j t} \geq \sum_{l=1}^{L} \text { Amount }_{j t l} P C_{j t l} \quad \forall i, j, t \\
& \sum_{l=1}^{L} P C_{j t l}=1 \quad \forall j, t \\
& E X_{i t}=\eta I D_{i t-1} \quad \forall i, t>1 \\
& E X_{i t}=0 \quad \forall i, t=1 \\
& \sum_{i=1}^{P} E X_{i t} \leq \sum_{i=1}^{P} D C a p_{i t} \quad \forall t \\
& X_{i j t}, X_{i t}, L_{t}, D_{i t}, C O_{i j t} \geq 0 ; V_{i j t}, u_{t}, P C_{j t l} \in[0,1] \\
& I S_{i t}, I D_{i t}, E X_{i t} y_{t}, j_{t} \text { are integer }
\end{aligned}
$$

\section{FUZZY SOLUTION ALGORITHM}

The following algorithm specifies the sequential steps to solve the fuzzy mathematical programming problems, discussed by [17].

Step1. Compute the crisp equivalent of the fuzzy parameters using a defuzzification function. Here, ranking technique is employed to defuzzify the parameters as $F(A)=\left(a_{l}+2 a_{m}+a_{u}\right) / 4$, where $a_{l}, a_{m}, a_{u}$ are the Triangular Fuzzy Numbers (TFN).

Step2. Since industry is highly volatile and customer demand changes in every short span, a precise estimation of cost and performance aspirations is a major area of discussion. Hence the better way to come out of such situation is to incorporate tolerance and aspiration level with the main objectives. So the model discussed in section $\operatorname{IV}(F)$ can be re-written as follows:

Find $X$

$$
\begin{aligned}
& X \in S ; \quad(1-\eta) \sum_{t=0}^{T} I D_{i t}+\sum_{t=0}^{T} D_{i t} \geq \sum_{\sim t=0}^{T} \overline{C R}_{i t} \quad \forall i \\
& C o_{i j t}=\frac{250 *{ }^{*} i_{j}}{\sim \sum_{t=1}^{T} \frac{\overline{C R}_{i t}}{3}} \quad \forall i, j, t \\
& C(X) \leq C_{0} \\
& P R \geq P R_{0} \\
& X_{i j t}, X_{i t}, L_{t}, D_{i t}, C O_{i j t} \geq 0 ; V_{i j t}, u_{t}, P C_{j t t} \in[0,1] ; I S_{i t}, I D_{i t}, E X_{i t} y_{t}, j_{t} \text { are integer }
\end{aligned}
$$

Step3. Define appropriate membership functions for each fuzzy inequalities as well as constraint corresponding to the objective functions.

$\mu_{C}(X)= \begin{cases}1 & ; \mathrm{C}(X) \leq C_{0} \\ \frac{C_{0}^{*}-C(X)}{C_{0}^{*}-C_{0}} & ; \mathrm{C}_{0} \leq C(X)<C_{0}^{*} ; \mu_{P R}(X)=\left\{\begin{array}{ll}1 & ; P R \geq P R_{0} \\ 0 & ; \mathrm{C}(X)>C_{0}^{*}\end{array} \frac{P R-P R_{0}^{*}}{P R_{0}-P R_{0}^{*}}\right. \\ 0 & ; P R_{0}^{*} \leq P R<P R_{0}\end{cases}$

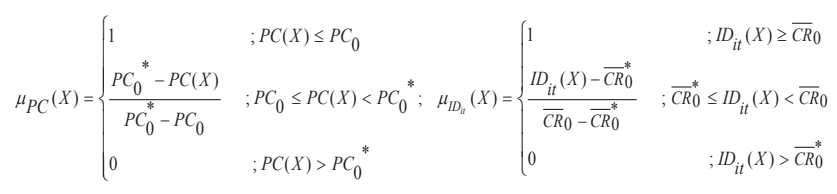

$\mu_{C O_{j i t}}(X)=\left\{\begin{array}{lc}1 & ; \mathrm{CO}_{i j t}(X) \geq \overline{C R}_{0} \\ \frac{C O_{i j t}(X)-\overline{C R}_{0}^{*}}{\overline{C R}_{0}-\overline{C R}_{0}^{*}} & ; \overline{C R}_{0}^{*} \leq C O_{i j t}(X)<\overline{C R}_{0}, \text { where } \overline{C R}_{0}=\sum_{t=1}^{T} \overline{C R}_{i t} \\ 0 & ; \mathrm{CO}_{i j t}(X)>\overline{C R}_{0}^{*}\end{array}\right.$

Step4. Employ extension principles to identify the fuzzy decision, which results in a crisp mathematical programming problem given by Maximize $\boldsymbol{\alpha}$

$$
\begin{gathered}
\text { s.t. } \mu_{c}(X) \geq w_{1} \alpha \\
\mu_{P R}(X) \geq w_{2} \alpha \\
\mu_{P C}(X) \geq w_{3} \alpha \\
\mu_{I D_{i t}}(X) \geq \alpha \\
\mu_{C O_{i j t}}(X) \geq \alpha \\
X \in S
\end{gathered}
$$$$
w_{1} \geq 0, w_{2} \geq 0, w_{3} \geq 0, w_{1}+w_{2}+w_{3}=1, \alpha \in[0,1]
$$

Where, $\alpha$ represents the degree to which the aspiration of the decision-maker is met. The above problem can be solved by the standard mathematical programming algorithms.

Step5. Following [18], while solving the problem by following steps 1-4, the objective of the problem is also treated as a constraint. Each constraint is considered to be an objective for the decision-maker and the problem is looked at as a fuzzy bi objective mathematical programming problem. Further, each objective can have a different level of importance and can be assigned weights to measure relative importance. The resulting problem can be solved by 
the weighted min max approach. On substituting values for $\mu_{P R}(\mathrm{x}), \mu_{P C}(\mathrm{x})$ and $\mu_{C}(\mathrm{x})$ the problem becomes as follows:

$$
\begin{gathered}
\text { Maximize } \boldsymbol{\alpha} \\
\text { s.t } \quad P R(\mathrm{X}) \geq P R_{0}-\left(1-w_{1} \alpha\right)\left(P R_{0}-P R_{0}^{*}\right) \\
C(\mathrm{X}) \leq C_{0}+\left(1-w_{2} \alpha\right)\left(C_{0}^{*}-C_{0}\right) \\
P C(\mathrm{X}) \leq P C_{0}+\left(1-w_{3} \alpha\right)\left(P C_{0}^{*}-P C_{0}\right) \\
\mu_{I D_{i t}}(X) \geq \alpha \\
\mu_{C O_{i j t}}(X) \geq \alpha \\
X \in S \\
w_{1} \geq 0, w_{2} \geq 0, w_{3} \geq 0, w_{1}+w_{2}+w_{3}=1, \alpha \in[0,1]
\end{gathered}
$$

Step6. If a feasible solution is not possible in Step 5, then fuzzy goal programming approach is resorted to obtain a compromised solution given by [19]. The method is discussed in detail in the next section.

\section{A. Fuzzy Goal ProgrammingMethod}

On solving the problem, we found that the problem (P1) is not feasible; hence the management goal cannot be achieved for a feasible value of $\alpha \in[0,1]$. We then apply the fuzzy goal programming technique to obtain a compromised solution. The approach is based on the goal programming technique to solve the crisp goal programming problem given by [14]. The maximum value of any membership function can be 1 ; maximization of $\alpha \in[0,1]$. This can be achieved by minimizing the negative deviational variables of goal programming (i.e., $\eta$ ) from 1. The fuzzy goal programming formulation for the given problem (P1) introducing the negative and positive deviational variables $\eta \mathrm{j}, \rho \mathrm{j}$ is given as

$$
\begin{aligned}
& \text { Minimize } \boldsymbol{u} \\
& \text { s.t. } \quad \mu_{P R}(X)+\eta_{1}-\rho_{1}=1 \\
& \mu_{C}(X)+\eta_{2}-\rho_{2}=1 \\
& \mu_{P C}(X)+\eta_{3}-\rho_{3}=1 \\
& u \geq w_{j} * \eta_{j}, j=1,2,3 \\
& \eta_{j} * \rho_{j}=0, \quad j=1,2,3 \\
& w_{1}+w_{2}+w_{3}=1 \\
& \alpha=1-u ; \eta_{j}, \rho_{j} \geq 0, \mathrm{X} \in \mathrm{S}, u \in[0,1] ; w_{1}, w_{2}, w_{3} \geq 0
\end{aligned}
$$

The above described model is coded into Lingo 11.0 to find the optimal solution.

\section{CASE STUDY}

In the scenario of multi brand stores like super market, big grocery retail stores are flourishing. These big store companies order in huge quantities from their suppliers and distribute the quantity to fulfill consumption of each retail store. The problem arises with these stores are generally, how to make floor plan, managing and optimally using the capacity, replenishment period and capacity to keep inventory. These problems emerge management terminologies and employ their technicalities to manage the issues.
Grocery items and packaged food \& snacks are easily available in these stores but the problem faced in keeping these products is their deteriorating nature, which makes demand of these products uncertain. Same is the problem of company discussed in this paper. Company wants to find out an optimum minimized cost comprising of procurement, transportation, holding, inspection and return channel, choosing suppliers with maximum performance and minimum carbon emission cost with respect to distance travelled from supplier to warehouse point. The problems faced by the company are uncertain consumption, uncertain performance parameters of the suppliers and they also have to adhere the aspiration and tolerance level of carbon emission.

Hence, a model has been developed to find an optimum plan of procurement \& distribution in forward supply chain and cost of transportation in return channel for deteriorated products. The process they follow as, they have multiple suppliers who can supply all types of products. The quantity procured from all suppliers is transported to a warehouse. From the warehouse, quantity is transported to retail stores as per the requirement. To validate the model proposed in this paper, we are showing a problem of multi supplier, one warehouse and one retail store. Four products namely Peanut Chikki (PC) (1000 gms.), Roasted Chana (RC) (500 gms.), Bajra Puff (BP) (1000 gms.), Oat wholemeal Biscuit (OWB) (500 gms.). The data for parameters is discussed as follows:

TABLE I. PURChASE COST PER UNIT (IN INR)

\begin{tabular}{|c|c|c|c|c|c|c|c|c|c|}
\hline & \multicolumn{3}{|c|}{ Supplier 1 } & \multicolumn{3}{c|}{ Supplier 2 } & \multicolumn{3}{c|}{ Supplier 3 } \\
\hline Product & $\boldsymbol{P 1}$ & $\boldsymbol{P 2}$ & $\boldsymbol{P 3}$ & $\boldsymbol{P 1}$ & $\boldsymbol{P 2}$ & $\boldsymbol{P 3}$ & $\boldsymbol{P 1}$ & $\boldsymbol{P 2}$ & $\boldsymbol{P 3}$ \\
\hline PC & 350 & 360 & 365 & 360 & 365 & 365 & 355 & 366 & 369 \\
\hline RC & 200 & 215 & 225 & 200 & 225 & 235 & 220 & 235 & 245 \\
\hline BP & 410 & 415 & 425 & 420 & 435 & 435 & 420 & 425 & 435 \\
\hline OWB & 225 & 235 & 240 & 200 & 215 & 225 & 235 & 245 & 250 \\
\hline
\end{tabular}

Where $\mathrm{P} 1=$ Period $1, \mathrm{P} 2=$ Period $2, \mathrm{P} 3=$ Period 3

TABLE II. HOLDING COST PER UNIT (IN INR)

\begin{tabular}{|c|c|c|c|c|c|c|}
\hline & \multicolumn{3}{|c|}{ WAREHOUSE } & \multicolumn{3}{c|}{ RETAIL STORE } \\
\hline Product & $\boldsymbol{P 1}$ & $\boldsymbol{P 2}$ & $\boldsymbol{P 3}$ & $\boldsymbol{P 1}$ & $\boldsymbol{P} 2$ & $\boldsymbol{P 3}$ \\
\hline PC & 2.5 & 2.8 & 2.3 & 3.2 & 3.1 & 3 \\
\hline RC & 2.3 & 3 & 2.5 & 2.8 & 2.9 & 2.6 \\
\hline BP & 3.4 & 2.7 & 2 & 3.5 & 2.9 & 2.5 \\
\hline OWB & 3.2 & 2.2 & 2.1 & 3.6 & 2.6 & 2.3 \\
\hline
\end{tabular}

TABLE III. INSPECTION, RETURN CHANNEL AND DISPOSAL COST PER UNIT (IN INR)

\begin{tabular}{|c|c|c|c|c|c|c|c|c|c|}
\hline & \multicolumn{3}{|c|}{ Inspection Cost } & \multicolumn{3}{c|}{ Vehicle return Cost } & \multicolumn{3}{c|}{ Disposal Cost } \\
\hline Product & $\boldsymbol{P 1}$ & $\boldsymbol{P} 2$ & $\boldsymbol{P 3}$ & $\boldsymbol{P 1}$ & $\boldsymbol{P} \mathbf{2}$ & $\boldsymbol{P} \mathbf{3}$ & $\boldsymbol{P 1}$ & $\boldsymbol{P 2}$ & $\boldsymbol{P 3}$ \\
\hline PC & 1 & 1 & 1 & 2 & 1.5 & 2 & 3 & 3 & 3 \\
\hline RC & 1.5 & 1.5 & 1.5 & 1.5 & 3 & 1.5 & 3.5 & 3.5 & 3.5 \\
\hline BP & 1 & 1 & 1 & 2 & 2 & 1.5 & 3 & 3 & 3 \\
\hline OWB & 1.5 & 1.5 & 1.5 & 3 & 2 & 2 & 4 & 4 & 4 \\
\hline
\end{tabular}

TABle IV. Performance Percentage

\begin{tabular}{|c|c|c|c|c|c|c|}
\hline & \multicolumn{3}{|c|}{ On-time Delivery } & \multicolumn{3}{c|}{ Lot Acceptance } \\
\hline Product & $\boldsymbol{S} \mathbf{1}$ & $\boldsymbol{S} \mathbf{2}$ & $\boldsymbol{S 3}$ & $\boldsymbol{S 1}$ & $\boldsymbol{S} \mathbf{2}$ & $\boldsymbol{S} \mathbf{3}$ \\
\hline PC & 0.88 & 0.87 & 0.81 & 0.84 & 0.84 & 0.84 \\
\hline $\mathrm{RC}$ & 0.85 & 0.83 & 0.8 & 0.87 & 0.8 & 0.8 \\
\hline BP & 0.95 & 0.9 & 0.95 & 0.9 & 0.81 & 0.94 \\
\hline OWB & 0.81 & 0.93 & 0.81 & 0.9 & 0.92 & 0.82 \\
\hline
\end{tabular}

Where S1=Supplier 1, S2=Supplier 2, S3=Supplier 3 
TABLE V. CARBON EMISSION PENALTy COST PER UNIT (IN INR)

\begin{tabular}{|c|c|c|c|c|c|c|}
\hline & \multicolumn{2}{|c|}{ Period 1 } & \multicolumn{2}{c|}{ Period2 } & \multicolumn{2}{c|}{ Period 3 } \\
\hline Penalty Breaks & Break 1 & Break 2 & Break 1 & Break 2 & Break 1 & Break 2 \\
\hline Supplier 1 & 4 & 8 & 3 & 7 & 5 & 10 \\
\hline Supplier 2 & 4 & 9 & 4 & 8 & 4 & 9 \\
\hline Supplier 3 & 5 & 10 & 4 & 9 & 4 & 8 \\
\hline
\end{tabular}

TABLE VI. CONSUMPTION AT RETAIL STORES (IN UNITS)

\begin{tabular}{|c|c|c|c|}
\hline Product & Period 1 & Period 2 & Period 3 \\
\hline PC & 169 & 138 & 185 \\
\hline RC & 135 & 176 & 182 \\
\hline BP & 167 & 184 & 169 \\
\hline OWB & 174 & 179 & 165 \\
\hline
\end{tabular}

TABLE VII. SUPPLIER's CAPACITY (IN UNITS)

\begin{tabular}{|c|c|c|c|}
\hline Product & Supplier 1 & Supplier 2 & Supplier 3 \\
\hline PC & 250 & 300 & 130 \\
\hline RC & 120 & 220 & 170 \\
\hline BP & 350 & 130 & 340 \\
\hline OWB & 230 & 120 & 240 \\
\hline
\end{tabular}

TABLE VIII. INITIAL INVENTORY (IN UNITS)

\begin{tabular}{|c|c|c|c|c|}
\hline Initial Inventory & PC & RC & BP & OWB \\
\hline Warehouse & 70 & 80 & 40 & 59 \\
\hline Retail store & 90 & 85 & 79 & 83 \\
\hline
\end{tabular}

In table $\mathrm{V}$, first break of penalty cost is applicable for less than $150 \mathrm{gm}$ carbon emission per kilometer, and afterwards second break is applied. The distance between first supplier to warehouse is $30 \mathrm{~km}$, second supplier to warehouse is $20 \mathrm{~km}$ and distance between third supplier to warehouse is $15 \mathrm{~km}$. Transportation from warehouse to retail store costs per truck as per truckload weight of $350 \mathrm{~kg}$. The cost per truck in three periods is Rs.950, Rs.1000 and Rs.1200. Weights which exceed truckload may also be transported per weight base. The cost of transportation per weight is Rs.5. It is observed that the deterioration percentage at retail store is $6 \%$. The deteriorated quantity returns back to warehouse for disposal. The disposal capacity is 100 units for PC, 80 units for RC, 90 units for $\mathrm{BP}$ and 95 units for OWB.

\section{A. Results and Managerial Implication}

The cost incurred to manage procurement and distribution is Rs.4,59,229.7, keeping fuzzy aspiration levels as Rs.3,80,000, Rs.4,00,000, Rs.4,20,000 and defuzzified aspiration cost is Rs.4,00,000 with tolerance of $4,80,000$. The performance of suppliers is quantified as 9.315400 with fuzzy aspiration levels as $11,13, \& 11$. Defuzzified aspiration and tolerance level are 12 and 9 respectively. Measuring carbon emission is not important to reduce the cost but it is our responsibility to improve environment condition for our future generations. The model is able choose the supplier as per minimum distance from supplier to warehouse. The Penalty cost because of carbon emission during travel between supplier and warehouse is Rs.4312.885. Fuzzy aspired costs carbon emission are Rs.3200, Rs.3400 \& Rs. 2000, defuzzified aspired cost is Rs.3000 with tolerance level of Rs. 4500 .
Nearby $73 \%$ of the aspiration level of cost, performance and carbon emission cost has been attained which makes the environment more certain and crisp for future discussions. The model tries to employ high performers to procure ordered quantity and ensure that only the best supplier shall fulfill the demand. Table IX shows the exact quantity procured from suppliers per product per period as per the performance.

TABLE IX. OPTIMUM ORDERED QUANTITY

\begin{tabular}{|c|c|c|c|c|c|c|c|c|c|}
\hline & \multicolumn{3}{|c|}{ Period 1 } & \multicolumn{3}{c|}{ Period 2 } & \multicolumn{3}{c|}{ Period 3 } \\
\hline Product & $\boldsymbol{S 1}$ & $\boldsymbol{S 2}$ & $\boldsymbol{S 3}$ & $\boldsymbol{S 1}$ & $\boldsymbol{S 2}$ & $\boldsymbol{S 3}$ & $\boldsymbol{S 1}$ & $\boldsymbol{S 2}$ & $\boldsymbol{S 3}$ \\
\hline PC & 0 & 292 & 0 & 0 & 40 & 0 & 0 & 0 & 0 \\
\hline RC & 120 & 0 & 0 & 120 & 0 & 0 & 0 & 0 & 88 \\
\hline BP & 0 & 0 & 210 & 0 & 0 & 191 & 0 & 0 & 0 \\
\hline OWB & 0 & 120 & 0 & 0 & 120 & 0 & 0 & 0 & 136 \\
\hline
\end{tabular}

The positive quantity in the table indicates that only the corresponding supplier is activated to supply goods as they have highest performance among the three. Some exceptions also exist, as in period 3 for PC and BP, supplier 3 is activated but no supply takes place.

Table $\mathrm{X}$ shows the ending inventory figures. It is observed that in almost all cases in the last periods, in-hand inventory is consumed and reaches zero or a small positive value.

TABLE $X . \quad$ INVENTORY LEVEL

\begin{tabular}{|c|c|c|c|c|c|c|}
\hline & \multicolumn{3}{|c|}{ Warehouse } & \multicolumn{3}{c|}{ Retail Store } \\
\hline Product & Period 1 & Period 2 & Period 3 & Period 1 & Period 2 & Period 3 \\
\hline PC & 279 & 185 & 0 & 4 & 0 & 0 \\
\hline RC & 128 & 92 & 0 & 22 & 2 & 0 \\
\hline BP & 162 & 130 & 0 & 0 & 39 & 0 \\
\hline OWB & 71 & 29 & 0 & 17 & 0 & 0 \\
\hline
\end{tabular}

The demand from retail store for supplier is shown in Table $\mathrm{XI}$ and depends on consumption at the retail store. The demand provides a basic idea to order.

TABLE XI. DEMAND FROM RETAIL STORE

\begin{tabular}{|c|c|c|c|}
\hline Product & Period 1 & Period 2 & Period 3 \\
\hline PC & 82.69113 & 134.3089 & 185 \\
\hline RC & 72 & 156 & 180 \\
\hline BP & 88.30887 & 222.6911 & 130 \\
\hline OWB & 108 & 162 & 165 \\
\hline
\end{tabular}

While transporting weighted quantity to retail store, policy type, number of trucks and overhead weights are to be checked as each of them incurs cost to the company. In Table XII, it is observed that in period 2 and 3 TL\&LTL policy is employed, as there is a positive overhead quantity. And in first period only TL policy as transporting overhead quantity the cost per unit is higher than full truck cost. In the case of TL\&LTL policy, if overhead weighted quantity is transported through full TL, the cost of transportation will become much higher than using LTL policy. 
TABLE XII. TRANSPORTED WEIGHTS, NO. OF TRUCKS, TRANSPORTATION MODE, OVERHEAD WEIGHT

\begin{tabular}{|c|c|c|c|}
\hline & Period 1 & Period 2 & Period 3 \\
\hline Transported Quantity (in kg) & 622 & 351 & 112 \\
\hline No. Of Trucks & 2 & 1 & 0 \\
\hline Transportation Mode & TL & TL \& LTL & TL \& LTL \\
\hline Overhead Quantity & 0 & 1 & 112 \\
\hline
\end{tabular}

As per the data provided, we receive negligible deteriorated quantity; hence cost of disposal is also near to zero.

Further, optimal carbon emission penalty cost was calculated on the basis of distance which is converted in per unit of each product. Table XIII shows the carbon emission (in gms) along with penalty cost per gram per unit.

TABLE XIII. CARBon EMISSION PENALTy COST

\begin{tabular}{|c|c|c|c|c|c|c|c|c|c|}
\hline & \multicolumn{4}{|c|}{ Period 1 } & \multicolumn{3}{c|}{ Period 2 } & \multicolumn{3}{c|}{ Period 3 } \\
\hline Product & S1 & $\boldsymbol{S 2}$ & $\boldsymbol{S 3}$ & $\boldsymbol{S 1}$ & $\boldsymbol{S 2}$ & $\boldsymbol{S 3}$ & $\boldsymbol{S 1}$ & $\boldsymbol{S 2}$ & $\boldsymbol{S 3}$ \\
\hline PC & 133 & 89 & 67 & 163 & 109 & 82 & 122 & 81 & 61 \\
\hline $\mathrm{RC}$ & 167 & 111 & 83 & 128 & 85 & 64 & 124 & 82 & 62 \\
\hline $\mathrm{BP}$ & 135 & 90 & 67 & 122 & 82 & 61 & 133 & 89 & 67 \\
\hline OWB & 129 & 86 & 65 & 126 & 84 & 63 & 136 & 90 & 68 \\
\hline
\end{tabular}

\section{CONCLUSION}

The supplier selection problem of multiple sourcing includes both selecting suppliers and allocating optimal order quantity among the selected suppliers, based on quality and delivery time criterion. In this study a multi sourcing procurement distribution problem is considered as a multi objective fuzzy optimization programming problem. A typical multi objective supplier selection model which considers three objective functions as minimization of costs, maximization of performance and minimization of carbon emission penalty cost with fuzzy aspiration levels repectively and fuzzy parameters are employed to construct fuzzy mathematical models. Each fuzzy parameter is represented mathematically by using an appropriate membership function. To solve the model, fuzzy goal programming with priority based is applied. The process provides balance among three objective functions and finds best supplier with optimal procurement distribution and penalty cost.

\section{REFERENCE}

[1] H. L. Yi, L. Chinho, and L. Binshan, "On conflict and cooperation in a two-echelon inventory model for deteriorating items," Computers and Industrial Engineering, Vol. 59, pp. 703-711, 2010.

[2] Z.L. Chen and G.L. Vairaktarakis, "Integrated scheduling of production and distribution operations," Management Science, Vol. 51, PP. 614-628, 2005.
[3] Z.L. Chen and G. Pundoor, "Order assignment and scheduling in a supply chain,” Operations Research, Vol. 54, pp. 555-572,2006.

[4] G. Pundoor, and Z.L. Chen, "Joint cyclic production and delivery scheduling in a two stage supply chain," International Journal of Production Economics, Vol. 119, PP. 55-74, 2009.

[5] G. Wang and L. Lei, "Polynomial-time solvable cases of the capacitated multi echelon shipping network scheduling problem with delivery deadlines," International Journal of Production Economics, Vol. 137, pp. 263-271, 2012.

[6] S. Liu, and L.G. Papageorgiou, "Multi objective optimization of production, distribution and capacity planning of global supply chains in the process industry," Omega: The International Journal of Management Science, Vol. 41, pp. 369-382, 2013.

[7] G. Alyanak and O. Armaneri, "An integrated supplier selection and order allocation approach in a battery company," Makine Mühendisleri Odasi, Vol. 19, pp. 2-19, 2009.

[8] F. Jolai, S.A. Yazdian, K. Shahanaghi, and M. AzariKhojasteh, "Integrating fuzzy TOPSIS and multi-period goal programming for purchasing multiple products from multiple suppliers," Journal of Purchasing and Supply Management, 2011, Vol. 17, pp. 42-53, 2011.

[9] O.P. Dubey, R.K. Dwivedi, S.N. Singh, "Goal programming: a survey (1960- 2000)," IUP Journal of Operations Management, Vol. 14, pp.29-53, 2012.

[10] N. Esfandiari and M. Seifbarghy, "Modeling a stochastic multiobjective supplier quota allocation problem with price-dependent ordering," Appl. Math. Modell., Vol. 37, pp.5790-5800, 2013.

[11] A.H.I. Lee, H.-Y. Kang, C.-M. Lai, and W.-Y. Hong, "An integrated model for lot sizing with supplier selection and quantity discounts," Appl. Math. Modell., Vol. 37, pp. 4733-4746, 2013.

[12] A. Amid, S.H. Ghodsypour and C. O'Brien, "Fuzzy multiobjective linear model for supplier selection in a supply chain," Int. J. Prod. Econ., Vol. 104, pp. 394-407, 2006.

[13] M. Bevilacqua, F.E. Ciarapica, and G. Giacchetta, "A fuzzy-QFD approach to supplier selection," J. Purch. Supply Manage., Vol. 12, pp. 14-27, 2006.

[14] T.Y. Wang and Y.H. Yang, "A fuzzy supplier selection in quantity discount environment," Expert System with Applications, Vol. 36, pp. 12179-12187, 2009.

[15] D.D. Wu, Y. Zhang, D. Wu, and D.L. Olson, "Fuzzy multi-objective programming for supplier selection and risk modeling: A possibility approach,” European Journal of Operations Research, Vol. 200, pp. 774-787, 2010.

[16] C.Y. Ku, C.T. Chang, and H.P. Ho, "Global supplier selection using fuzzy analytic Hierarchy process and fuzzy goal programming," Quality and Quantity, Vol. 44, pp. 623-640, 2010.

[17] H.J. Zimmermann, "Description and optimization of fuzzy systems," Int. J. Gen. Syst., Vol. 2, pp. 209-215, 1976.

[18] R.E. Bellman and L.A. Zadeh, "Decision-making in a fuzzy environment,” Manag. Sci., Vol. 17, pp. 141-164, 1970.

[19] R.H. Mohamed, "The relationship between goal programming and fuzzy programming,” Fuzzy Sets Syst., Vol. 89, pp. 215-222, 1997. 


\title{
Reliability Analysis on Crucial Subsystems of a Wind Turbine through FTA Approach
}

\author{
S. Katsavounis ${ }^{1}$;N. Patsianis ${ }^{2}$; E.I. Konstantinidis ${ }^{3}$; P.N. Botsaris ${ }^{4}$ \\ 1.skatsav@pme.duth.gr; ${ }^{2}$ nikopats@pme.duth.gr; ${ }^{3}$ ekonstan@pme.duth.gr; ${ }^{4}$ panmpots@.pme.duth.gr \\ ${ }^{1,2,3,4}$ Democritus University of Thrace
}

School of Engineering, Department of Production and Management Engineering

12 Vas.Sofias Str., Xanthi, Greece, 67100

\begin{abstract}
The wind turbine reliability is a crucial factor for the successful operation of a wind power plant, affecting its availability and efficiency. Operation and maintenance costs affect the performance of the whole system and reinforce the necessity of redesign of specific sub-assemblies achieving lower energy production costs.

At the first stage, field data make up Weibull sets in order to form the appropriate distribution-curve of the failure rate in each corresponding top event, are presented. These sets are limited to sub-systems having not only adequate data of the corresponding top events, producing more realistic results, but also having great risk priority, according to FMEA approach. These Weibull sets are linked with the corresponding top event of each subsystem and used to quantify the failure rates.
\end{abstract}

The validation of previous studies made on wind turbine reliability FMEA analysis through the FTA method is investigated in this paper, as well as the results from previous studies made on reliability of wind turbines using the FMEA method. Though, the reliability and importance results as derived from a quantitative analysis, seem to be following the same trend like previous studies from different and various approaches. As a result, Electrical and Control systems as far as the Hydraulic System need to be re-designed with better performance and reliability since they are crucial for the operation of each WT separately as well as for the whole wind farm.

Keywords: Wind Turbines, Reliability, Fault-Tree Analysis, Weibull Analysis, Isograph Reliability

\section{INTRODUCTION}

During the last decades many changes in the electricity demand and generation have taken place in a global scale, promoting renewable energy resources instead of fossil fuels which are starting degrading. Markets have started turning to alternative and renewable energy resources accompanied with increasing demand and production of electricity. A renewable energy source that is used for the production of electrical power is wind power. Wind power has become one of the world's fastest growing renewable energy resource making it more attractive to even more companies and enterprises around the globe for use as a main source of power for their facilities. By all means, wind energy should not perceived as a complete alternative to common means of electricity production but it turns out to be a competitive and sustainable energy source. Fig. 1 shows the globally installed wind power capacity from 1997 to 2011. As a result, Wind Turbines (WT) have become very popular among other renewable energy resources.

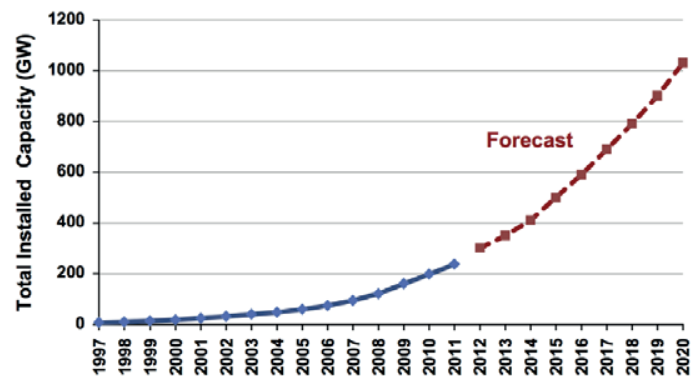

Fig.1. Wind energy: global capacity (blue) and forecast (red). [5]

Even though at a first glance, wind farms and the installation of wind turbines may seem simple, many factors must be considered such as the selection of the location of the wind farm, the layout of the wind turbines etc. All these operations and functions have proven quite costly. Operation and maintenance costs occupy a great share of the cost of a wind farm after its installation. Thus, the energy production of a wind farm depends on its reliability, meaning the reliability of each individual wind turbine as well as its subsystems. Fig.2 . [7] presents the main parts of a WT for the conversion of wind energy to electricity.

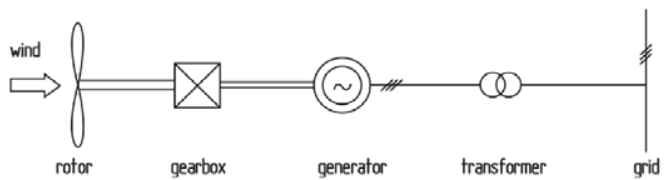

Fig.2.Mechanical-electrical functional chain in a wind turbine [7]

The reliability analysis methods used in the design stage of a WT are mostly qualitative while after some time of operation more evidence of components and sub-systems reliability are becoming available, providing engineers with adequate data to improve the design and the maintenance planning.

The fault tree analysis (FTA) has been widely used to measure and quantify the reliability of complex electromechanical systems, not only by identifying the most 
critical parts of the system, but also combining field data obtained from maintenance sheets and highlighting the most frequent top events. FTA is one of the most commonly used methods for reliability analysis along with Failure Modes and Effects Analysis (FMEA) [1] which supplement each other. FTA approach aims to quantify the reliability and availability of a complex system, in our case the Wind Turbine. The latter information provide useful data to engineers and end-users for maintenance planning reducing O\&M costs and finally leading to lower energy production costs. It is considered that wind turbines follow the bathtub curve illustrated in Fig. 3 which best describes the failure rates of a WT during its operational life considered between 20 to 25 years. At the first period, about 2 to 3 years of operation, it is clear that a high failure rate is presented which also is known as period of early failures. During the next period of useful life, there is a drop to the failure rates until the period of wearout comes after about 20 years of operation and the failure rates are starting increasing again, indicating the end of operational life of the WT.

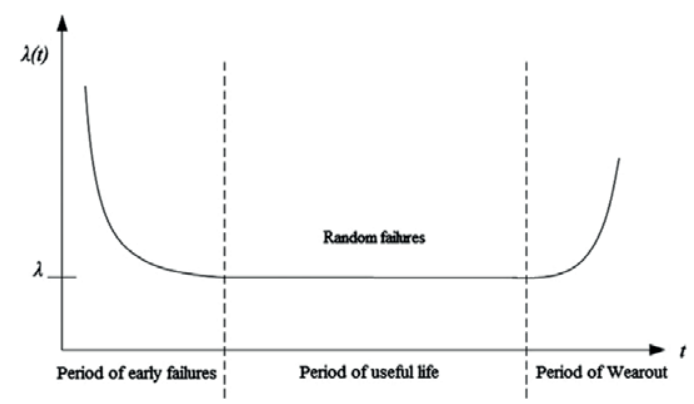

Fig. 3. Bathtub curve indicating the evolution of failure rate over the life cycle of a WT. [5]

The main objective of this paper is to apply FTA in a Wind Farm for reliability analysis of the most crucial sub-systems of its Wind Turbines.

\section{SYSTEM CHARACTERISTICS AND FAILURES}

The system analyzed in the current study is the WT. In Fig.4 a typical horizontal axis WT and its subsystems are illustrated. The main subsystems of a WT are:

\section{A. Rotor}

- Blades

- Hub

- Nose cone/spinner

- Pitch regulation systems

\section{B. Nacelle}

- Drive train

- Couplings

- Mechanical brake
- Generator

- Nacelle support frame

- Nacelle cover/enclosure

- Yaw systems

C. Tower

D. Foundation

E. Electrical and Control System

- Sensors

- Actuators

- Hardware/software

F. Hydraulic System

These subsystems together with failure data are further examined from the reliability point of view. The current Reliability Analysis and Data Failure Analysis regards a wind farm which consists of 10 horizontal axis wind turbines, located in a Greek island.

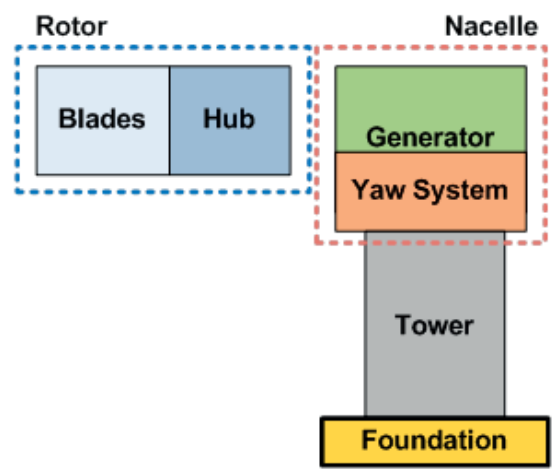

Fig. 4.Main Systems and Subsystems of a WT [ 4 ]

During the studied period, failures among all the subsystems took place with different failure rates and severities of failures. Some failures demanded the temporary shut down of the wind turbine for hours or even days. Such factors were not considered in the particular research, since our purpose is to propose a methodology for applying FTA using failure data of maintenance sheets which were provided by the personal record of the wind farm owner. During the development of the complete Fault Tree of the WT it was concluded that the main mechanisms that occur often and cause failures are the Corrosion, Mechanical overloads, Vibrations and Exposure to climatic extremes. According to a previous reliability analysis using the FMEA method [1] the above causes appear to be among the top 10 root causes. Table I shows the number of recorded failures that occurred during the 7.5-year studied period in all of the subsystems of the ten installed WTs of the wind farm. In Table II the failure rates from the subsystems were computed taking under 
consideration the examined period and the number of the WTs. From Tables I and II it is clear that the most crucial and important subsystems of the wind turbines of our studied wind farm are the Electrical and Control Systems and the Hydraulic System. The Gearbox is also considered to be a crucial wind turbine subsystem from Tables I and II, but it was not further analyzed with the proposed methodology since the wind farm owner did not provide detailed data for gearbox failures. So, the failure data from the gearbox failures were not able to be included in the proposed methodology.

TABLE I. SUMMARIZED NUMBER OF FAILURES IN THE WIND FARM

\begin{tabular}{|l|c|}
\hline \multicolumn{1}{|c|}{ Subsystem } & Number of failures \\
\hline Gearbox & 105 \\
\hline Brake system & 8 \\
\hline Hydraulic System & 97 \\
\hline Generator & 42 \\
\hline Yaw System & 44 \\
\hline Rotor & 19 \\
\hline Electrical \& Control Systems & 184 \\
\hline
\end{tabular}

TABLE II. SUBSYSTEMS FAILURE RATES

\begin{tabular}{|l|c|}
\hline \multicolumn{1}{|c|}{ Subsystem } & Failure rate, $\lambda(t)$ \\
\hline Gearbox & 1.4 \\
\hline Brake System & 0.1 \\
\hline Hydraulic System & 1.3 \\
\hline Generator & 0.6 \\
\hline Yaw System & 0.6 \\
\hline Rotor & 0.3 \\
\hline Electrical \& Control Systems & 2.5 \\
\hline
\end{tabular}

\section{RELIABILITY ANALYSIS}

Reliability, Availability and Maintainability and (RAM) are the most important factors that affect both the design and the life cycle of a machine, product or a system [9]. In order to perform reliability analysis using the Fault Tree Analysis approach of a system we need to have adequate data in order to construct its fault tree. At a prime stage the Tree will be more qualitative, determining the main events after analyzing the maintenance report sheets and deciding which gates should be used and defining main events interconnections. In the proposed study we used as failure data the times that each particular event (in hours) took place, having as a reference date the time that the farm owner started operating the farm. In our case this is the 1st of January 2005. In the next stage these failures were grouped into main events of the fault tree. After deciding which failure corresponds to each event, appropriate Weibull sets were developed using the Isograph Reliability Workbench [6] in order to estimate the Weibull set parameters which comply with each main event. The Weibull distribution is quite often used in reliability analysis applications rather than other distributions because it has the advantage to adapt its form depending on the samples values. So we can have as a result a variety of distribution shapes.

The 2-parameter Weibull distribution [6] probability density function as well as some reliability indicators in their mathematical form is described in eq. (1) to (4):

$$
f(t)=\frac{\beta t^{\beta-1}}{\eta} e^{-\left(\frac{t}{\eta}\right)^{\beta}}
$$

Where:

$\eta$ : characteristic life parameter

$\beta$ : shape parameter

Unreliability:

$$
F(t)=1-e^{-\left(\frac{t}{\eta}\right)^{\beta}}
$$

Failure rate:

$$
r(t)=\frac{\beta t^{\beta-1}}{\eta^{\beta}}
$$

Mean Time To Failure ( $M T T F)$ :

$$
M T T F=\eta \Gamma\left(\frac{1+\beta}{\beta}\right)
$$

Where:

$\Gamma=$ Gamma function

Availability:

$$
A=\frac{\text { uptime }}{\text { uptime }+ \text { downtime }}
$$

Isograph Reliability Workbench receives as inputs the failure times in hours for each main event and then estimates 
the parameters to form a unique distribution for each main event of our fault tree. Due to some inadequate data, to obtain more accurate parameter estimation and a whole perspective of the failures of the wind farm, the Weibull sets for each main event formed from failure data regarding the whole wind farm and not each wind turbine separately.

In the next stage, the Weibull sets with their parameters are linked with their corresponding Failure Model which indicates a specific main event in the Fault Tree. Due to the lack of information regarding the whole system and to make a simpler analysis approach, the Fault Trees of the Wind Turbine's Subsystems were constructed under the assumption that all gates are type 'OR'.

The fault tree of a Wind Turbine with its main subsystem as illustrated in Fig. 5 includes the following branches:

\section{A. Foundation}

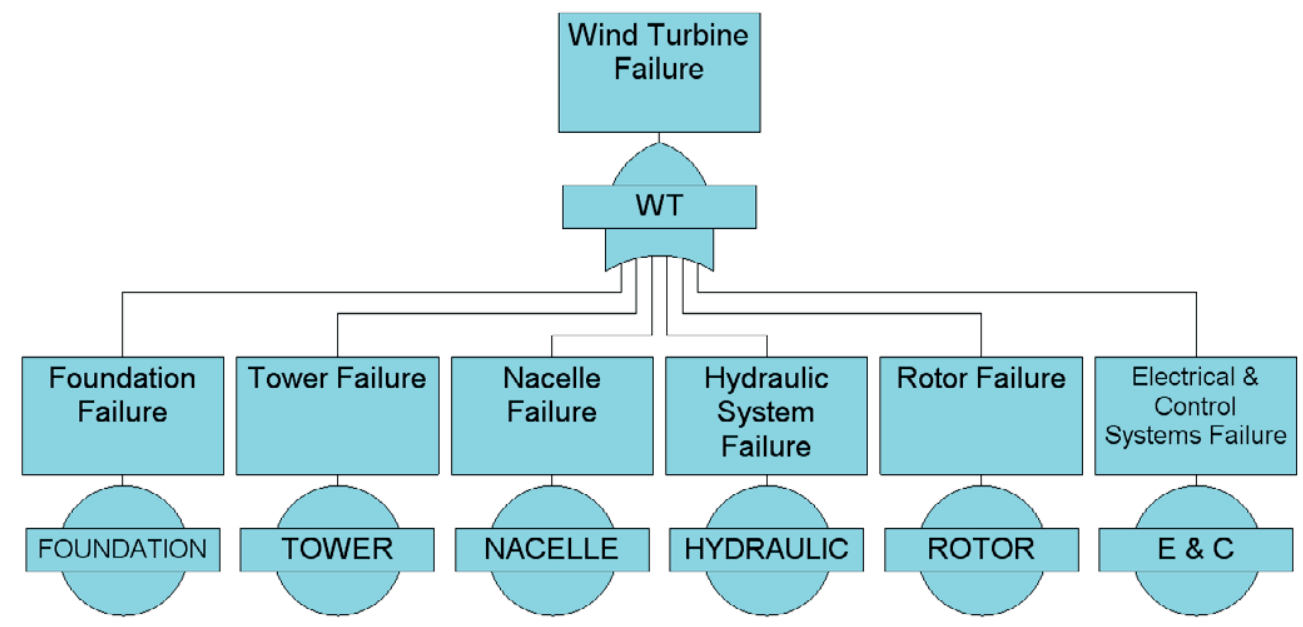

Fig. 5.Fault tree of a WT with its basic subsystems

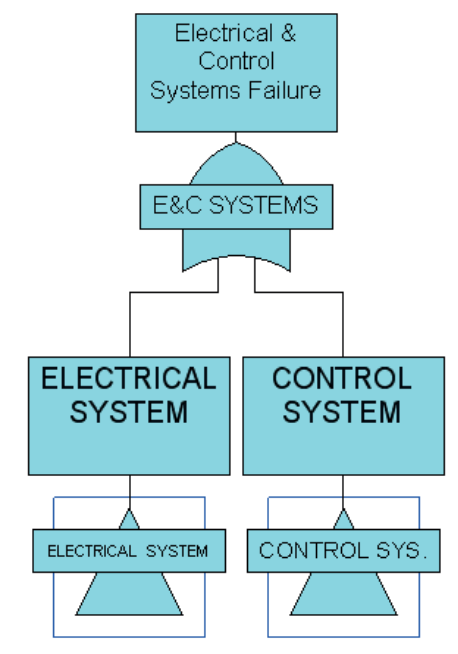

Fig. 6.Electrical \& Control Systems Fault Tree

B. Tower

C. Nacelle

D. Hydraulic System

E. Rotor(Blades \& Hub)

\section{F. Electrical \& Control Systems}

Fig. 6-9 illustrates the Fault Trees of the Electrical and Control System combined, the Electrical System, the Control System and the Hydraulic System, respectively.

Tables from III to VI present the analysis results for each discussed sub-system. Due to the lack of sufficient data, only certain reliability indicators are presented in the current study. In the reliability analysis is included the Availability, the Frequency of failures, the Reliability and the Mean Time To Failure among all components of the subsystems in hourly scale. 


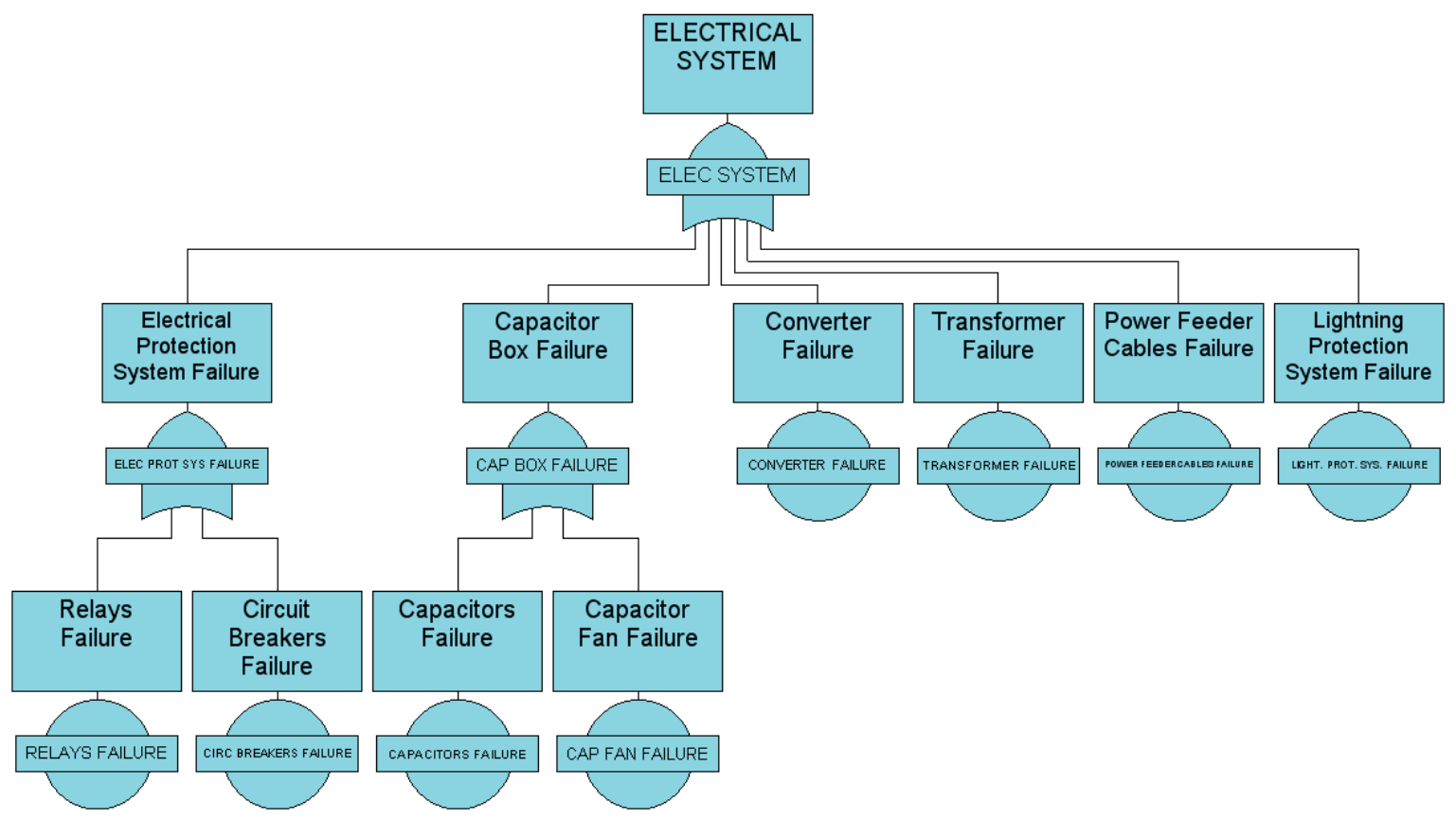

Fig. 7. Electrical System Fault Tree

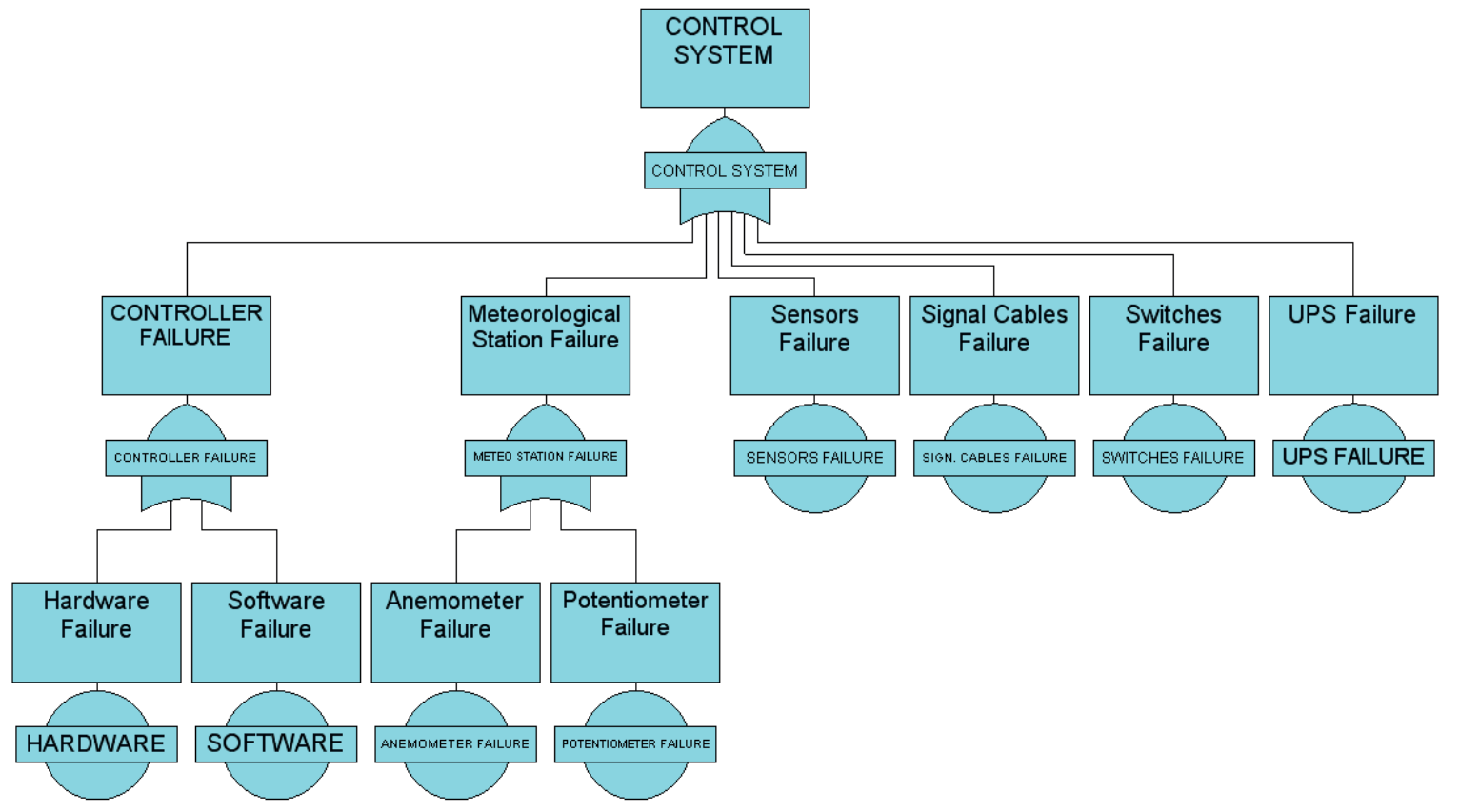

Fig. 8.Control System Fault Tree 


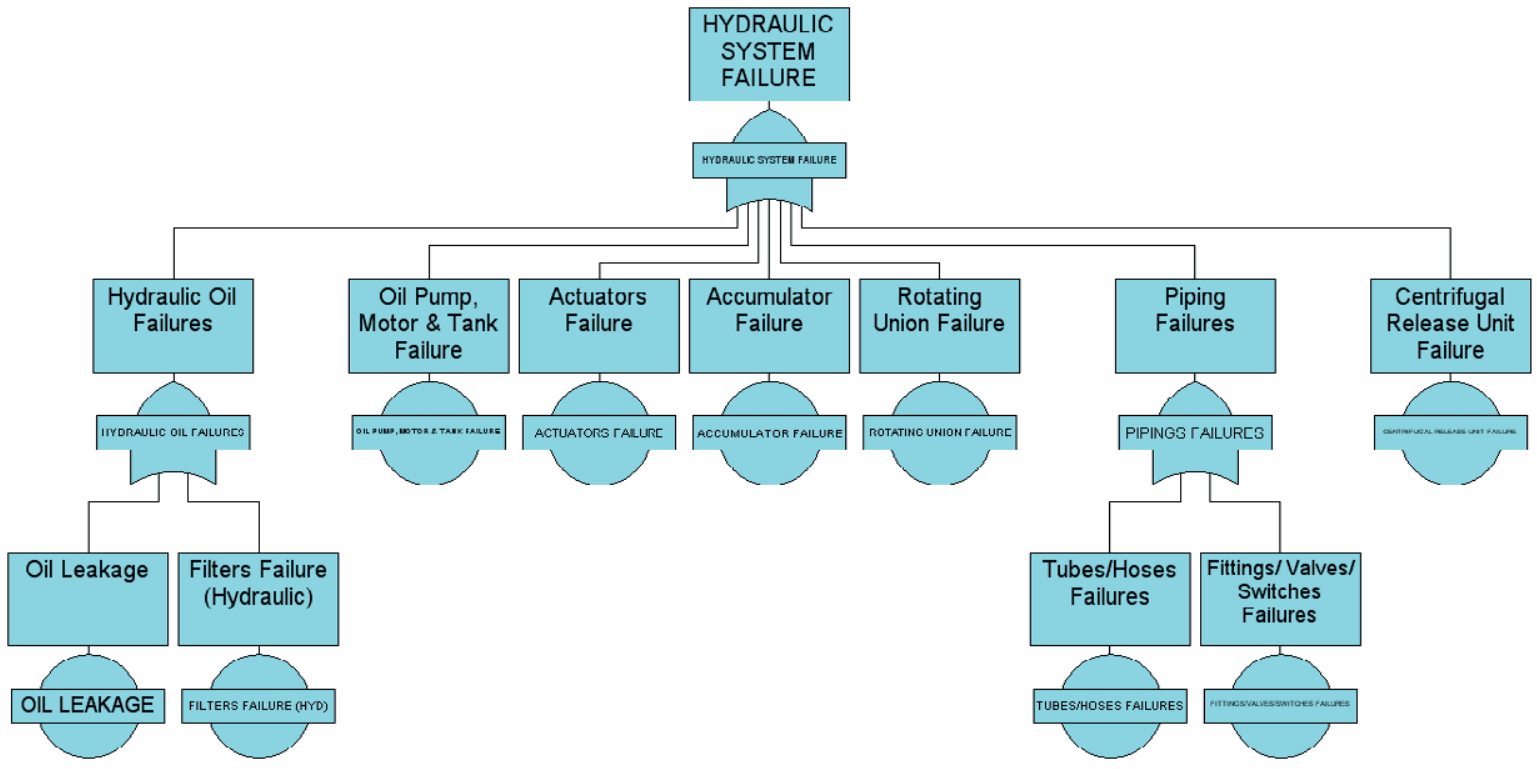

Fig. 9.Hydraulic System Fault Tree

TABLE III. ELECTRICAL AND CONTROL SYSTEM RELIABILITY INDICATORS

\begin{tabular}{|l|c|}
\hline \multicolumn{2}{|c|}{ Electrical \& Control Systems Failure } \\
\hline Availability & 0.9811 \\
\hline Frequency & 0.0091 \\
\hline Reliability & 0.9907 \\
\hline Mean Time To Failure (MTTF) & 1513 \\
\hline
\end{tabular}

TABLE IV. ELECTRICAL SYSTEM RELIABILITY INDICATORS

\begin{tabular}{|l|c|}
\hline \multicolumn{2}{|c|}{ Electrical System Failure } \\
\hline Availability & 0.9886 \\
\hline Frequency & 0.0052 \\
\hline Reliability & 0.9948 \\
\hline Mean Time To Failure (MTTF) & 3762 \\
\hline
\end{tabular}

TABLE V. CONTROL SYSTEM RELIABILITY INDICATORS

\begin{tabular}{|l|c|}
\hline \multicolumn{2}{|c|}{ Control System Failure } \\
\hline Availability & 0.9925 \\
\hline Frequency & 0.0040 \\
\hline Reliability & 0.9960 \\
\hline Mean Time To Failure (MTTF) & 3600 \\
\hline
\end{tabular}

TABLE VI. HYDRAULIC SYSTEM RELIABILITY INDICATORS

\begin{tabular}{|l|c|}
\hline \multicolumn{2}{|c|}{ Hydraulic System Failure } \\
\hline Availability & 0.9957 \\
\hline Frequency & 0.0023 \\
\hline Reliability & 0.9977 \\
\hline Mean Time To Failure (MTTF) & 6769 \\
\hline
\end{tabular}

Along with the reliability analysis it is useful to present the importance analysis of each component of each sub-system. Importance measures establish the significance for all the events in the Fault Tree in terms of their contributions to the top event probability. Both intermediate events (gate events) as well as basic events can be prioritized according to their importance [8]. The importance analysis is based on three basic Fault Tree Importance measures which include the Fussell-Vesely (FV) Importance, the Risk Achievement Worth (RAW) and the Risk Reduction Worth (RRW) [8]. The Fussell-Vesely importance indicates the relative contribution to the system failure probability from a component failure. Increasing the availability of components with high important values will have the most significant effect on system availability, consequence frequency or risk. The Risk Achievement Worth indicator represents the worth of the component associated with the Fault Tree event in achieving the present level of risk and indicates the importance of maintaining the present level of reliability for the component. The Risk Reduction Worth importance represents the maximum reduction in risk for an improvement to the component associated with the Fault Tree event.

Table VII summarizes the Electrical and Control Systems importance into one system, considering the Electrical System as one component and the Control System as the other. Table VII confirms that in the Electrical and Control System, the Electrical system has a more important role and is more critical than Control System. According to Table VIII, the more important components into the Electrical System include Power feeder cables and the Lightning protection system. According to Table IX, the most important component in the Control System, indicating a very high rate, appears to be the Controller. Table $\mathrm{X}$ regards the Hydraulic System and 
indicates Pipings as the most important component of the system.

TABLE VII. .ELECTRICAL \& CONTROL SySTEMS IMPORTANCE

\begin{tabular}{|l|c|c|c|}
\hline Components & $\begin{array}{c}\text { Fussell- } \\
\text { Vesely }\end{array}$ & $\begin{array}{c}\text { Risk } \\
\text { Achievement } \\
\text { Worth }\end{array}$ & $\begin{array}{c}\text { Risk } \\
\text { Reduction } \\
\text { Worth }\end{array}$ \\
\hline $\begin{array}{l}\text { Electrical } \\
\text { System }\end{array}$ & 0.6024 & 53.04 & 2.515 \\
\hline $\begin{array}{l}\text { Control } \\
\text { System }\end{array}$ & 0.3976 & 53.25 & 1.66 \\
\hline
\end{tabular}

TABLE VIII. ELECTRICAL SYSTEM IMPORTANCE

\begin{tabular}{|l|c|c|c|}
\hline Components & $\begin{array}{c}\text { Fussell- } \\
\text { Vesely }\end{array}$ & $\begin{array}{c}\text { Risk } \\
\text { Achievement } \\
\text { Worth }\end{array}$ & $\begin{array}{c}\text { Risk } \\
\text { Reduction } \\
\text { Worth }\end{array}$ \\
\hline $\begin{array}{l}\text { Power } \\
\text { feeder } \\
\text { cables }\end{array}$ & 0.8356 & 87.41 & 6.081 \\
\hline $\begin{array}{l}\text { Lightning } \\
\text { protection } \\
\text { system }\end{array}$ & 0.1580 & 88.08 & 1.188 \\
\hline $\begin{array}{l}\text { Electrical } \\
\text { protection } \\
\text { system }\end{array}$ & 0.0039 & 88.24 & 1.004 \\
\hline $\begin{array}{l}\text { Capacitor } \\
\text { box }\end{array}$ & 0.0013 & 88.24 & 1.001 \\
\hline Converter & 0.0011 & 88.24 & 1.001 \\
\hline Transformer & 0.0001 & 88.24 & 1 \\
\hline
\end{tabular}

TABLE IX. CONTROL SYSTEM IMPORTANCE

\begin{tabular}{|l|c|c|c|}
\hline Components & $\begin{array}{c}\text { Fussell- } \\
\text { Vesely }\end{array}$ & $\begin{array}{c}\text { Risk } \\
\text { Achievement } \\
\text { Worth }\end{array}$ & $\begin{array}{c}\text { Risk } \\
\text { Reduction } \\
\text { Worth }\end{array}$ \\
\hline Controller & 0.9329 & 132.4 & 14.91 \\
\hline $\begin{array}{l}\text { Meteorological } \\
\text { station }\end{array}$ & 0.0600 & 133.3 & 1.064 \\
\hline Switches & 0.0053 & 133.3 & 1.005 \\
\hline UPS & 0.0017 & 133.3 & 1.002 \\
\hline Sensors & 0.0007 & 133.3 & 1 \\
\hline Signal cables & 0.0005 & 133.3 & 1 \\
\hline
\end{tabular}

TABLE X. HydRAULIC SYSTEM IMPORTANCE

\begin{tabular}{|l|c|c|c|}
\hline Components & $\begin{array}{c}\text { Fussell- } \\
\text { Vesely }\end{array}$ & $\begin{array}{c}\text { Risk } \\
\text { Achievement } \\
\text { Worth }\end{array}$ & $\begin{array}{c}\text { Risk } \\
\text { Reduction } \\
\text { Worth }\end{array}$ \\
\hline Pipings & 0.8458 & 232 & 6.485 \\
\hline $\begin{array}{l}\text { Oil } \\
\text { pump,motor } \\
\& \text { tank }\end{array}$ & 0.1334 & 232.7 & 1.154 \\
\hline $\begin{array}{l}\text { Hydraulic } \\
\text { oil }\end{array}$ & 0.0208 & 232.8 & 1.021 \\
\hline $\begin{array}{l}\text { Rotating } \\
\text { union }\end{array}$ & 0.0001 & 232.9 & 1 \\
\hline Accumulator & 0.0001 & 232.9 & 1 \\
\hline $\begin{array}{l}\text { Centrifugal } \\
\text { release unit }\end{array}$ & 0 & 232.9 & 1 \\
\hline Actuators & 0 & 232.9 & 1 \\
\hline
\end{tabular}

\section{CONCLUSIONS AND FURTHER RESEARCH}

Performing a reliability analysis through FTA approach a sufficient amount of data is needed, along with information from maintenance sheets and diagrams indicating connections between all components of the systems. The reliability and importance results, as derived from a quantitative analysis, seem to be following the same trend like previous studies from different and various approaches [5]. Electrical and Control systems as far as the Hydraulic System need to be re-designed to demonstrate better performance and reliability, being crucial to the operation of the WTs and the total efficiency of the wind farm. Many failures appear to be of minor consideration, but when it comes to measure the reliability of the systems involved them, their importance seems to affect it. When more failure data are available from other subsystems, a relative research could illustrate a more holistic view of the reliability of a WT. The full fault tree of the studied WT is available from the authors upon request.

As an expansion from the current study, a sensitivity analysis on the parameter estimation of the Weibull sets using Monte Carlo simulations would indicate the variation of each system's reliability. Drawing directions for better maintenance planning and promote new and more reliable WT designs achieve high rates of reliability and availability, reduce failure rates of subsystems and components and improve the reliability of a whole wind farm.

\section{ACKNOWLEDGEMENT}

We would like to acknowledge the contribution and support of Isograph for providing us with an academic license of their products, Availability and Reliability Workbenches ver.11.1.

\section{REFERENCES}

[1] H. Arabian-Hoseynabadi, H. Oraee and P.J. Tavner "Failure modes and effects analysis (FMEA) for wind turbines", Electrical Power and Energy Systems, vol. 32,pp. 817-824, Elsevier, 2010.

[2] H.Guo, S.Watson, P.Tavner and J. Xiang "Reliability analysis for wind 
turbines with incomplete failure data collected from after the date of initial installation”, Reliability Engineering and System Safety, vol. 94, pp.1057-1063, Elsevier, 2009.

[3] F. Spinato, P.J. Tavner, G.J.W. van Bussel and E. Koutoulakos "Reliability of wind turbine subassemblies", IET, Renewable Power Generation, Vol. 3, Iss. 4, pp. 1-15, 2009.

[4] P. N. Botsaris, E.I. Konstantinidis and D. Pitsa "Systemic assessment and analysis of factors affect the reliability of a wind turbine", Journal of Applied Engineering Science, no. 10, vol.2, pp. 85-92, 2012.

[5] J.M.P. Pérez, F.P.G. Márquez, A. Tobias and M.Papaelias "Wind turbine reliability analysis", Renewable and Sustainable Energy Reviews, vol. 23, pp. 463-472, Elsevier, 2013.
[6] Isograph Reliability Workbench Version 11.1 User Guide, Isograph, 2011.

[7] E. Hau "Wind Turbines Fundamentals, Technologies, Application, Economics", $2^{\text {nd }}$ edition, Springer, 2006.

[8] Fault Tree Handbook with Aerospace Applications, NASA Headquarters, August 2002.

[9] B.S. Dhillon, Engineering Maintainability, Gulf Publising Company, 2006 


$$
\frac{\mathrm{I}}{\mathrm{U}}
$$

